\title{
Fundamentos de Derecho comunitario y comparado, europeo y norteamericano, del Trabajo y de la Seguridad Social
}

\section{Foundations on Community and Comparative, European and USA, Labor and Social Security Law}

Jesús Martínez Girón Catedrático de Derecho del Trabajo y de la Seguridad Social Universidad de A Coruña

Alberto Arufe Varela Profesor Titular de Derecho del Trabajo y de la Seguridad Social Universidad de A Coruña 


\section{FUNDAMENTOS DE DERECHO COMUNITARIO Y COMPARADO, EUROPEO Y NORTEAMERICANO, DEL TRABAJO Y DE LA SEGURIDAD SOCIAL}

No está permitida la reproducción total o parcial de este libro, ni su tratamiento informático, ni la transmisión de ninguna forma o por cualquier medio, ya sea electrónico, mecánico, por fotocopia, por registro u otros métodos, sin el permiso previo y por escrito de los titulares del Copyright.

\section{netbiglo}

www.netbiblo.com

DERECHOS RESERVADOS 2010, respecto a la segunda edición en español, por

(C) Netbiblo, S. L.

NETBIBLO, S. L.

C/. Rafael Alberti, 6 bajo izq.

Sta. Cristina 15172 Oleiros (La Coruña) - Spain

Tlf: +34 981915500 • Fax: +34 981915511

editorial@netbiblo.com

ISBN 978-84-9745-562-6

Depósito Legal: C-3249-2010

Directora Editorial: Cristina Seco López

Editora: Sheila Martínez Varela

Producción Editorial: Gesbiblo, S. L.

Impreso en España - Printed in Spain

Trabajo realizado con la cobertura económica de las "Ayudas para la consolidación y estructuración de unidades de investigación competitivas del sistema gallego de I+D+I del año 2009" (Orden de la Consellería de Economía e Industria de la Xunta de Galicia, de 2 junio 2009 [Diario Oficial de Galicia de 12 junio 2009]), referencia INCITE09ENA101006ES. 
PRÓLOGO A LA SEGUNDA EDICIÓN............................................................. xix

PRÓLOGO A LA PRIMERA EDICIÓN ............................................................ $\mathrm{xxi}$

\section{PARTE PRIMERA: FUENTES}

TEMA 1. EL DERECHO DEL CIUDADANO A CONOCER LAS FUENTES JURÍDICAS, TAMBIÉN LAS LABORALES Y DE SEGURIDAD SOCIAL, A TRAVÉS DE INTERNET

Sumario: §1.Laignoranciadelasleyesno excusa de sucumplimiento. §2. El modelo francés de difusión del Derecho a través de Internet. §3. Los otros modelos estatales europeos de difusión del Derecho a través de Internet. \$4. La Directiva 2003/98/CE, relativa a la reutilización de la información del sector público. §5. El modelo norteamericano de difusión del Derecho a través de Internet

TEMA 2. SITIOS DE INTERNET RELATIVOS A LOS CÓDIGOS EUROPEOS Y NORTEAMERICANOS DE TRABAJO Y SEGURIDAD SOCIAL

Sumario: §1. Internet y la codificación contemporánea. \$2. Los Códigos franceses del Trabajo y de la Seguridad Social. §3. El Código alemán de Seguridad Social. §4. El Código portugués del Trabajo. §5. El Código de los Estados Unidos de Norteamérica

TEMA 3. SITIOS DE INTERNET RELATIVOS A LA LEGISLACIÓN NO CODIFICADA, COMUNITARIA Y EUROPEA, DE TRABAJO Y SEGURIDAD SOCIAL

Sumario: §1. Para la localización de legislación laboral y de seguridad social de la Unión Europea. §2. Para la localización de la legislación laboral alemana. §3. Para la localización de la legislación de seguridad social portuguesa. §4. Para la localización de la legislación laboral y de seguridad social italiana (y también, española). §5. Para la localización de la legislación laboral y de seguridad social británica. 
TEMA 4. SITIOS DE INTERNET RELATIVOS A REGISTROS EUROPEOS, COMUNITARIOS Y NORTEAMERICANOS DE CONVENIOS COLECTIVOS

Sumario: §1. El modelo español. §2. Otros modelos estatales europeos (portugués y francés) basados en la publicación de convenios colectivos en periódicos oficiales. §3. Modelos estatales europeos (publicista italiano, confidencialista alemán y secretista británico) no basados en la publicación de convenios colectivos en periódicos oficiales. \$4. El modelo comunitario, integral ad extra y ocultista ad intra. \$5. El modelo publicista norteamericano ....

TEMA 5. SITIOS DE INTERNET RELATIVOS A REPERTORIOS COMUNITARIOS, EUROPEOS Y NORTEAMERICANOS PARA LA LOCALIZACIÓN DE JURISPRUDENCIA LABORAL Y DE SEGURIDAD SOCIAL

Sumario: §1. El modelo comunitario. §2. Los modelos continentales europeos de carácter integral. §3. Los modelos continentales europeos de carácter no integral. §4. El modelo anglo-irlandés. §5. El modelo norteamericano

\section{PARTE SEGUNDA: INSTITUCIONES}

TEMA 6. LOS SERVICIOS PÚBLICOS DE EMPLEO EN EUROPA Y EN LOS ESTADOS UNIDOS

Sumario: \$1. El Derecho de la Unión Europea regulador de la Oficina Europea de Selección de Personal y del «Servicio Europeo de Empleo». \$2. Los modelos de servicios públicos de empleo (alemán y británico) unitarios e integrales. \$3. Los modelos de servicios públicos de empleo (portugués y francés) unitarios, pero no integrales. $§ 4$. Los modelos de servicios públicos de empleo (italiano y español) ni unitarios ni integrales. §5. El Derecho federal norteamericano regulador de la Oficina de Gestión del Personal y del modelo norteamericano no unitario, pero sí integral, de servicios públicos de empleo

TEMA 7. LA INSPECCIÓN DE TRABAJO Y SEGURIDAD SOCIAL EN EUROPA Y EN LOS ESTADOS UNIDOS

Sumario: §1. El Comité de Altos Responsables de la Inspección de Trabajo de la Unión Europea. \$2. El carácter laboral o funcionarial de los Inspectores de Trabajo, a propósito del modelo 
laboral italiano de Inspección de Trabajo. §3. El carácter estatal o infraestatal de los funcionarios de la Inspección de Trabajo, a propósito del modelo alemán disgregado en dieciséis Inspecciones de Trabajo de los Estados federados. \$4. La formación jurídica o politécnica exigible a los funcionarios de la Inspección de Trabajo, a propósito del modelo politécnico británico de Inspección de Trabajo. §5. El carácter integral o no de la legislación estatal inspeccionada, a propósito del modelo portugués de Inspección de Trabajo (y también, de Seguridad Social). §6. La naturaleza de las funciones de campo o de despacho desarrolladas por los Inspectores de Trabajo, a propósito del modelo francés de Inspectores de Trabajo de despacho. §7. El modelo norteamericano (funcionarial, tendencialmente disgregado, politécnico, no integral y de campo) de Inspección de Trabajo.

TEMA 8. EL CONTENCIOSO LABORAL EN EUROPA Y EN LOS ESTADOS UNIDOS

Sumario: §1. El modelo alemán de contencioso laboral integral. \$2. Otros modelos europeos (francés, portugués e italiano) de contencioso laboral no integral. \$3. El modelo británico de contencioso laboral cuasi-jurisdiccional. $\$ 4$. El modelo norteamericano de pluralidad de contenciosos laborales cuasi-jurisdiccionales. §5. El contencioso laboral ante los tribunales de la Unión Europea

TEMA 9. LA GESTIÓN DE LA SEGURIDAD SOCIAL EN EUROPA Y EN LOS ESTADOS UNIDOS

Sumario: §1. El modelo español de gestión disgregada de la Seguridad Social. §2. Otros modelos europeos (alemán, italiano y francés) de gestión disgregada de la Seguridad Social. §3. Los modelos británico y portugués de gestión unificada de la Seguridad Social. §4. El reflejo en el Derecho de la Unión Europea de los modelos nacionales europeos de gestión de la Seguridad Social. §5. El modelo norteamericano de gestión unificada de la Seguridad Social

TEMA 10. EL CONTENCIOSO DE LA SEGURIDAD SOCIAL EN EUROPA Y EN LOS ESTADOS UNIDOS

Sumario: §1. El contencioso dual español de la Seguridad Social. \$2. El contencioso único británico y alemán de la Seguridad Social. \$3. Los contenciosos duales italianoy portugués de la Seguridad Social. §4. El contencioso disgregado francés de la Seguridad Social. §5. El contencioso único norteamericano de la Seguridad Social. 


\section{PARTE TERCERA: DERECHOS, LIBERTADES Y PRINCIPIOS}

TEMA 11. LA LIBERTAD SINDICAL EN EL ORDENAMIENTO COMUNITARIO, EN LAS LEGISLACIONES Y PRÁCTICAS NACIONALES EUROPEAS, Y EN LA LEGISLACIÓN DE LOS ESTADOS UNIDOS

Sumario: §1. La libertad sindical y el reconocimiento de sólo ciertos sindicatos como interlocutores sociales. \$2. Los modelos nacionales europeos (francés, español e italiano) de reconocimiento legal. §3. Los modelos nacionales europeos (alemán, portugués y británico) de reconocimiento empresarial. §4. El modelo de reconocimiento oficial del Derecho de la Unión Europea, ad extra y ad intra. \$5. El modelo norteamericano de reconocimiento empresarial.

TEMA 12. EL DERECHO DE PARTICIPACIÓN DE LOS

TRABAJADORES EN LA EMPRESA EN EL

ORDENAMIENTO COMUNITARIO, EN LAS

LEGISLACIONES Y PRÁCTICAS NACIONALES EUROPEAS, Y EN LA LEGISLACIÓN DE LOS ESTADOS UNIDOS

Sumario: §1. El Derecho de la Unión Europea sobre participación de los trabajadores en la empresa, ad extra y ad intra. \$2. Los modelos nacionales europeos (portugués y francés) de representación unitaria de los trabajadores carente de capacidad negociadora. §3. Los modelos nacionales europeos (español y alemán) de representación unitaria de los trabajadores dotada de capacidad negociadora. $\$ 4$. El modelo italiano de representación sindical unitaria de los trabajadores. \$5. Los modelos británico y norteamericano de participación de los trabajadores en la empresa a través de la negociación colectiva

TEMA 13. EL DERECHO DE NEGOCIACIÓN COLECTIVA EN

EL ORDENAMIENTO COMUNITARIO, EN LAS

LEGISLACIONES Y PRÁCTICAS NACIONALES EUROPEAS, Y EN LA LEGISLACIÓN DE LOS ESTADOS UNIDOS

Sumario: §1. El Derecho de la Unión Europea y el derecho de negociación colectiva, ad extra y ad intra. \$2. El modelo alemán (y su variante portuguesa) de convenio colectivo sectorial de eficacia normativa limitada basada en la doble afiliación. §3. El 
modelo francés (y su variante italiana provisional) de convenio colectivo sectorial de eficacia normativa limitada basada en la nuda afiliación empresarial. \$4. El modelo británico de convenio colectivo no normativo (o «acuerdo entre caballeros»). §5. El modelo norteamericano de convenio colectivo empresarial de eficacia normativa general

TEMA 14. EL DERECHO DE HUELGA EN EL ORDENAMIENTO COMUNITARIO, EN LAS LEGISLACIONES Y PRÁCTICAS NACIONALES EUROPEAS, Y EN LA LEGISLACIÓN DE LOS ESTADOS UNIDOS

Sumario: §1. El Derecho de la Unión Europea y el derecho de huelga, ad extra y ad intra. \$2. El modelo alemán de derecho de huelga. §3. El modelo francés (y sus variantes italiana, española y portuguesa) de derecho de huelga. $\$ 4$. El modelo británico de libertad de huelga. §5. El modelo norteamericano de derecho de huelga.

TEMA 15. EL PRINCIPIO DE ESTABILIDAD EN EL EMPLEO EN EL ORDENAMIENTO COMUNITARIO, EN LAS LEGISLACIONES Y PRÁCTICAS NACIONALES EUROPEAS, Y EN LA LEGISLACIÓN DE LOS ESTADOS UNIDOS

Sumario: §1. El principio de estabilidad en el empleo en el Derecho tradicional de la Unión Europea, ad intra y ad extra. \$2. La flexiguridad. §3. El modelo francés (y sus variantes portuguesa, alemana e italiana) de regulación del principio de estabilidad en el empleo. §4. El modelo británico de falta de estabilidad en el empleo. §5. El modelo norteamericano de falta de estabilidad en el empleo

TEMA 16. EL DERECHO A LA PROTECCIÓN DEL TRABAJADOR FRENTE A LOS RIESGOS DEL TRABAJO EN EL ORDENAMIENTO COMUNITARIO, EN LAS LEGISLACIONES Y PRÁCTICAS NACIONALES EUROPEAS, Y EN LA LEGISLACIÓN DE LOS ESTADOS UNIDOS

Sumario: §1. El Derecho de la Unión Europea sobre seguridad y salud laboral, ad extra. \$2. Los incumplimientos nacionales del Derecho de la Unión Europea sobre seguridad y salud laboral. §3. La legislación norteamericana sobre seguridad y salud laboral 
TEMA 17. EL PRINCIPIO DEL RESPETO A LAS CONDICIONES MÍNIMAS DE TRABAJO EN EL ORDENAMIENTO COMUNITARIO, EN LAS LEGISLACIONES Y PRÁCTICAS NACIONALES EUROPEAS, Y EN LA LEGISLACIÓN DE LOS ESTADOS UNIDOS

Sumario: §1. El Derecho de la Unión Europea sobre el principio del respeto a las condiciones mínimas de trabajo, ad extra. \$2. El Derecho de la Unión Europea sobre la jornada máxima, ad extra y ad intra. §3. La regulación de la jornada máxima en los ordenamientos nacionales europeos. $§ 4$. El inexistente Derecho de la Unión Europea sobre un salario mínimo europeo. §5. La jornada máxima y el salario mínimo en el Derecho de los Estados Unidos.

TEMA 18. EL DERECHO A LA PROTECCIÓN DEL TRABAJADOR ANTE LAS SITUACIONES CRÍTICAS DE LA EMPRESA EN EL ORDENAMIENTO COMUNITARIO, EN LAS LEGISLACIONES Y PRÁCTICAS NACIONALES EUROPEAS, Y EN LA LEGISLACIÓN DE LOS ESTADOS UNIDOS

Sumario: §1. El Derecho de la Unión Europea en materia de protección del trabajador ante las situaciones críticas de la empresa. §2. La Directiva comunitaria sobre despidos colectivos y su transposición a los ordenamientos nacionales europeos de referencia. §3. La Directiva comunitaria sobre traspasos de empresas y su transposición a los ordenamientos nacionales europeos de referencia. §4. La Directiva comunitaria sobre protección de los trabajadores en caso de insolvencia del empresario y su transposición a los ordenamientos nacionales europeos de referencia. §5. El reglamento comunitario sobre el Fondo Europeo de Adaptación a la Globalización. §6. El influjo de la legislación norteamericana en materia de protección del trabajador ante situaciones críticas de la empresa, sobre el Derecho de la Unión Europea. §7. El influjo del Derecho de la Unión Europea en materia de protección del trabajador ante situaciones críticas de la empresa, sobre la legislación norteamericana

TEMA 19. EL DERECHO A LA PROTECCIÓN DEL TRABAJADOR

FRENTE AL DESPIDO INJUSTIFICADO EN EL ORDENAMIENTO COMUNITARIO, EN LAS LEGISLACIONES Y PRÁCTICAS NACIONALES EUROPEAS, Y EN LA LEGISLACIÓN DE LOS ESTADOS UNIDOS

Sumario: §1. El modelo de despido libre con preaviso aplicado por la Unión Europea al personal laboral a su servicio. §2. La 
readmisión del trabajador, como regla, en el modelo alemán (y sus equivalentes italiano y portugués) de protección frente al despido injustificado. §3. La extinción indemnizada del contrato, como regla, en el modelo francés de protección frente al despido injustificado. §4. El modelo británico de despido libre con preaviso, como regla, y sus excepciones. \$5. El modelo norteamericano de despido libre, como regla, y sus excepciones

TEMA 20. LOS ACCIDENTES DE TRABAJO IN ITINERE EN EL ORDENAMIENTO COMUNITARIO, EN LAS LEGISLACIONES Y PRÁCTICAS NACIONALES EUROPEAS, Y EN LA LEGISLACIÓN DE LOS ESTADOS UNIDOS

Sumario: §1. En las legislaciones española y comunitaria. \$2. En las legislaciones continentales europeas. §3. En las legislaciones norteamericana y británica.

TEMA 21. EL PRINCIPIO DE AUTOMATICIDAD DE LAS PRESTACIONES DE SEGURIDAD SOCIAL EN EL ORDENAMIENTO COMUNITARIO, EN LAS LEGISLACIONES Y PRÁCTICAS NACIONALES EUROPEAS, Y EN LA LEGISLACIÓN DE LOS ESTADOS UNIDOS

Sumario: §1. La automaticidad de las prestaciones de seguridad social, desde el punto de vista del ordenamiento español. \$2. Los modelos continentales europeos (italiano y portugués) de automaticidad de las prestaciones de seguridad social, basada en el principio de responsabilidad empresarial. §3. Los modelos continentales europeos (francés y alemán) de automaticidad de las prestaciones de seguridad social, no basada en el principio de responsabilidad empresarial. §4. Los modelos británico y norteamericano de falta de automaticidad de las prestaciones de seguridad social, aun en caso de responsabilidad empresarial. §5. El Derecho de la Unión Europea sobre el tema, en sus vertientes ad extra y ad intra....

TEMA 22. EL PRINCIPIO DEL RESPETO A LOS DERECHOS ADQUIRIDOS EN MATERIA DE SEGURIDAD SOCIAL COMPLEMENTARIA EN EL ORDENAMIENTO COMUNITARIO, EN LAS LEGISLACIONES Y PRÁCTICAS NACIONALES EUROPEAS, Y EN LA LEGISLACIÓN DE LOS ESTADOS UNIDOS

Sumario: §1. La precariedad general de la protección de los derechos adquiridos en el ordenamiento español. \$2. La protección otorgada por el ordenamiento comunitario a los derechos adquiridos, 
dispersa y todavía insuficiente, en materia de seguridad social complementaria. §3. La antijurídica interpretación por la Sala de lo Social de nuestro Tribunal Supremo del precepto tradicionalmente protector, en España, de los derechos adquiridos en materia de seguridad social complementaria. $§ 4$. La jurisprudencia de la Sala de lo Social de la Corte de Casación francesa sobre libre disponibilidad por convenio colectivo de los derechos adquiridos en materia de seguridad social complementaria. §5. El respeto estricto a los derechos adquiridos en materia de seguridad social complementaria, según la jurisprudencia de la Sección Trabajo de la Corte de Casación italiana y del Tribunal Federal de Trabajo alemán. §6. La interpretación por la Corte Suprema de los Estados Unidos, protectora de los derechos adquiridos, de la «regla anti-recorte retroactivo» de pensiones complementarias de jubilación. §7. La Directiva 2003/41/CE, relativa a las actividades de supervisión de fondos de pensiones de empleo, y su defectuoso tratamiento de los derechos adquiridos. 
PREFACE TO THE SECOND EDITION xix PREFACE TO THE FIRST EDITION.

\section{FIRST PART: SOURCES}

THEME 1. THE CITIZEN'S RIGHT TO KNOW THE LEGAL SOURCES, ALSO THE LABOR AND SOCIAL SECURITY ONES, THROUGH INTERNET

Contents: §1. Ignorance of the Law is no excuse. \$2. The French model of diffusion of the Law through Internet. \$3. The other European state models of diffussion of the Law through Internet. \$4. The Directive 2003/98/EC, on the re-use of public sector information. \$5. The USA model of diffusion of the Law through Internet.

THEME 2. INTERNET SITES RELATING TO EUROPEAN AND USA LABOR AND SOCIAL SECURITY CODES

Contents: \$1. Internetand the contemporary codification. \$2. The French Labor and Social Security Codes. \$3. The German Social Security Code. \$4. The Portuguese Labor Code. \$5. The United States Code.

THEME 3. INTERNET SITES RELATING TO LABOR AND SOCIAL SECURITY, COMMUNITY AND EUROPEAN, NONCODIFIED LEGISLATION

Contents: \$1. To find labor and social security legislation of the European Union. \$2. To find German labor legislation. \$3. To find Portuguese social security legislation. \$4. To find Italian (and also, Spanish) labor and social security legislation. \$5. To find British labor and social security legislation. 
THEME 4. INTERNET SITES RELATING TO EUROPEAN, COMMUNITY AND USA FILES OF COLLECTIVE AGREEMENTS

Contents: \$1. The Spanishmodel.\$2. OtherEuropeanstatemodels (Portuguese and French) based on the publication of collective agreementsin officialjournals. §3. European statemodels (Italian publicist, German confidentialist and British secretist) not based on the publication of collective agreements in official journals. $\$ 4$. The Community, integral ad extra and occultist ad intra, model. \$5. The USA publicist model.

THEME 5. INTERNET SITES RELATING TO COMMUNITY, EUROPEAN AND USA REPERTORIES TO FIND LABOR AND SOCIAL SECURITY CASE LAW

Contents: \$1.The Communitymodel.\$2.TheEuropeancontinental models of integral nature. $\$ 3$. The European continental models of non-integral nature. $\$ 4$. The British-Irish model. $\$ 5$. The USA model.

\section{SECOND PART: INSTITUTIONS}

THEME 6. THE PUBLIC SERVICES OF EMPLOYMENT IN EUROPE AND IN THE UNITED STATES

Contents: \$1. The Law of the European Union regulating the European Personnel Selection Office and the «European Service of Employment». \$2. The (German and British) unitarian and integral models of public services of employment. \$3. The (Portuguese and French) unitarian but non-integral models of public services of employment. \$4. The (Italian and Spanish) neither unitarian nor integral models of public services of employment. \$5. The United States Law regulating the Office of Personnel Management and the USA non-unitarian but integral model of public services of employment......

THEME 7. THE LABOR AND SOCIAL SECURITY INSPECTION IN EUROPE AND IN THE UNITED STATES

Contents: \$1. The Committee of Senior Labour Inspectors of the European Union. \$2. The employment relationship or civil 
servant relationship of the Labor Inspectors, with regard to the Italian employment relationship model of Labor Inspection. \$3. The nationwide or undernationwide nature of the officers of the Labor Inspection, with regard to the German model, dispersed in sixteen Labor Inspections of the States. \$4. The legal or politechnical education required to the officers of the Labor Inspection, with regard to the British politechnical model of Labor Inspection. \$5. The integral nature or not of the enforced state legislation, with regard to the Portuguese model of Labor (and also, of Social Security) Inspection. \$6. The nature of the field or bureau functions developped by the officers of the Labor Inspection, with regard to the French model of bureau officers of the Labor Inspection. $\$$. The USA (civil servant relationship, tending to dispersion, politechnical, non-integral and field's) model of Labor Inspection

\section{THEME 8. THE LABOR LITIGATION IN EUROPE} AND IN THE UNITED STATES

Contents: \$1. The German integral model of labor litigation. $\$ 2$. Other European (French, Portuguese and Italian) non-integral models of labor litigation. \$3. The British model of quasijurisdictional labor litigation. $\$ 4$. The USA model of plurality of quasi-jurisdictional labor litigation. \$5. The labor litigation before the Courts of the European Union.

THEME 9. THE MANAGEMENT OF SOCIAL SECURITY IN EUROPE AND IN THE UNITED STATES

Contents: \$1. The Spanish model of dispersed management of Social Security. \$2. Other European models (German, Italian and French) of dispersed management of Social Security. \$3. The British and Portuguese models of unified management of Social Security. \$4. The reflex on the Law of the European Union of the European national models of management of Social Security. \$5. The USA model of unified management of Social Security.

THEME 10. SOCIAL SECURITY LITIGATION IN EUROPE AND IN THE UNITED STATES

Contents: \$1. The Spanish Social Security dual litigation. \$2. The British and German Social Security single litigation. 
\$3. The Italian and Portuguese Social Security dual litigation. \$4. The French Social Security dispersed litigation. \$5. The USA Social Security single litigation.....

\section{THIRD PART: RIGHTS, FREEDOMS AND PRINCIPLES}

THEME 11. THE UNION FREEDOM IN THE EUROPEAN LAW, IN THE NATIONAL EUROPEAN LEGISLATIONS AND PRACTICES, AND IN THE LEGISLATION OF THE UNITED STATES

Contents: $\$$ 1. The union freedom and the recognition of only certain unions as social partners. $\$ 2$. The national European models (French, Spanish and Italian) of statutory recognition. §3. The national European models (German, Portuguese and British) of employer recognition. \$4. The model of official recognition of the Law of the European Union, ad extra and ad intra. \$5. The USA model of employer recognition.

THEME 12. THE RIGHT OF PARTICIPATION OF THE EMPLOYEES IN

THE ENTERPRISE IN THE EUROPEAN LAW,

IN THE NATIONAL EUROPEAN LEGISLATIONS

AND PRACTICES, AND IN THE LEGISLATION

OF THE UNITED STATES

Contents: \$1. The Law of the European Union aboutparticipation of the employees in the enterprise, ad extra and ad intra. $\$ 2$. The national European (Portuguese and French) models of unitarian representation of the employees without negociating capacity. \$3. The national European (Spanish and German) models of unitarian representation of the employees with negociating capacity. \$4. The Italian model of union unitarian representation of the employees. \$5. The British and USA models of participation in the enterprise through collective bargaining....

THEME 13. THE RIGHT TO COLLECTIVE BARGAINING IN THE EUROPEAN LAW, IN THE NATIONAL EUROPEAN LEGISLATIONS AND PRACTICES, AND IN THE LEGISLATION OF THE UNITED STATES

Contents: \$1. The Law of the European Union and the right to collective bargaining, ad extra and ad intra. \$2. The German 
model (and its Portuguese variant) of industry level collective agreement with limited regulatory applicability founded on the double membership. \$3. The French model (and its provisional Italian variant) of industry level collective agreement with limited regulatory applicability founded on the single membership of the employer. \$4. The British model of non-regulatory collective agreement (or "gentlemen's agreement»). \$5. The USA model of company level collective agreement with general regulatory applicability.

THEME 14. THE RIGHT TO STRIKE IN THE EUROPEAN LAW, IN THE NATIONAL EUROPEAN LEGISLATIONS AND PRACTICES, AND IN THE LEGISLATION OF THE UNITED STATES

Contents: \$1. The Law of the European Union and the right to strike, ad extra and ad intra. $\$ 2$. The German model of right to strike. \$3. The French model (and its Italian, Spanish and Portuguese variants) of right to strike. \$4. The British model of freedom to strike. \$5. The USA model of right to strike.

THEME 15. THE PRINCIPLE OF EMPLOYMENT STABILITY IN

THE EUROPEAN LAW, IN THE NATIONAL EUROPEAN

LEGISLATIONS AND PRACTICES, AND IN THE LEGISLATION OF THE UNITED STATES

Contents: \$1. The principle of employment stability in the traditional Law of the European Union, ad intra and ad extra. \$2. The flexicurity. \$3. The French model (and its Portuguese, German and Italian variants) of regulation of the principle of employment stability. \$4. The British model of lacking of employment stability. \$5. The USA model of lacking of employment stability....

THEME 16. THE RIGHT OF THE EMPLOYEE TO PROTECTION BEFORE THE LABOR RISKS IN THE EUROPEAN LAW, IN THE NATIONAL EUROPEAN LEGISLATIONS AND PRACTICES, AND IN THE LEGISLATION OF THE UNITED STATES

Contents: \$1. The Law of the European Union about occupational safety and health, ad extra. $\$ 2$. The national violations of the Law of 
the European Union about occupational safety and health. \$3. The USA legislation about occupational safety and health.....

THEME 17. THE PRINCIPLE OF RESPECTING LABOR MINIMUM STANDARDS IN THE EUROPEAN LAW, IN THE NATIONAL EUROPEAN LEGISLATIONS AND PRACTICES, AND IN THE LEGISLATION OF THE UNITED STATES

Contents: \$1. The Law of the European Union about the principle of respecting labor minimum standards, ad extra. \$2. The Law of the European Union about maximum hours of work, ad extra and ad intra. \$3. The regulation of maximum hours of work in the European national legislations. $\$ 4$. The non-existent Law of the European Union about a European minimum wage. \$5. The maximum hours of work and the minimum wage in the Law of the United States

THEME 18. THE RIGHT TO PROTECTION OF THE EMPLOYEE BEFORE CRITICAL SITUATIONS OF THE ENTERPRISE IN THE EUROPEAN LAW, IN THE NATIONAL EUROPEAN LEGISLATIONS AND PRACTICES, AND IN THE LEGISLATION OF THE UNITED STATES

Contents: \$1. The Law of the European Union about protection of the employee before critical situations of the enterprise. $\$ 2$. The Community Directive about collective dismissals and its implementation by the European national reference legislations. \$3. The CommunityDirective about transferofundertakingsantits implementation by the European national reference legislations. $\$ 4$. The Community Directive about protection of the employees in the case of employer insolvency ant its implementation by the European national reference legislations. \$5. The Community Regulation about the European Globalization Adjustment Fund. \$6. The influence of the USA legislation about protection of the employee before critical situations of the enterprise, on the Law of the European Union. \$7. The influence of the Law of the European Union about protection of the employee before critical situations of the enterprise, on the USA legislation 
THEME 19. THE RIGHT TO PROTECTION OF THE EMPLOYEE BEFORE WRONGFUL DISMISSAL IN THE EUROPEAN LAW, IN THE NATIONAL EUROPEAN LEGISLATIONS AND PRACTICES, AND IN THE LEGISLATION OF THE UNITED SATATES

Contents: $\$ 1$. The free termination with notice model applied by the European Union to the employment relationship personnel in its service. $\$ 2$. The reinstatement of the employee, as a general rule, in the German model (andits Italian and Portuguese variants) of protection before wrongful dismissal. \$3. The severance pay, as a general rule, in the French model of protection before wrongful dismissal. $\$ 4$. The British model of termination with notice, as a general rule, and its exceptions. \$5. The USA model of free discharge, as a general rule, and its exceptions......

THEME 20. THE IN ITINERE ACCIDENTS AT WORK IN THE EUROPEAN LAW, IN THE NATIONAL EUROPEAN LEGISLATIONS AND PRACTICES, AND IN THE LEGISLATION OF THE UNITED STATES

Contents: \$1. In the Spanish and Community legislations. \$2. In the continental European legislations. $\$ 3$. In the USA and British legislations.

THEME 21. THE PRINCIPLE OF AUTOMATIC PAYMENT OF SOCIAL SECURITY BENEFITS IN THE EUROPEAN LAW, IN THE NATIONAL EUROPEAN LEGISLATIONS AND PRACTICES, AND IN THE LEGISLATION OF THE UNITED STATES

Contents: \$1. The automatic payment of social security benefits, from the viewpoint of the Spanish Law. \$2. The European continental (Italian and Portuguese) models of automatic payment of social security benefits, based on the principle of the employer liability. \$3. The European continental (French and German) models of automatic payment of social security benefits, not based on the principle of the employer liability. \$4. The British and USA models of lacking of automatic 
payment of social security benefits, even in the case of employer liability. \$5. The Law of the European Union about the subject-matter, in its ad extra and ad intra sides

THEME 22. THE PRINCIPLE OF RESPECTING TO VESTED RIGHTS

ON COMPLEMENTARY SOCIAL SECURITY IN THE

EUROPEAN LAW, IN THE NATIONAL EUROPEAN

LEGISLATIONS AND PRACTICES, AND IN THE

LEGISLATION OF THE UNITED STATES

Contents: \$1. The general precariousness of the protection of vested rights in Spanish Law. \$2. The dispersed and still short protection of vested rights by the European Law on the subjectmatter of complementary social security. \$3. The against Law interpretation by the Social Chamber of our Supreme Court of the traditionally protecting norm, in Spain, of the vested rights on the subject-matter of complementary social security. $\$ 4$. The decision of the Social Chamber of the French Court of Cassation about free disposal by collective agreement of vested rights on the subject-matter of complementary social security. $\$ 5$. The strict respecting to vested rights on the subject-matter of complementary social security, according to the decisions of the Labor Section of the Italian Court of Cassation and the German Federal Labor Court. \$6. The protective interpretation of vested rights, by the United States Supreme Court, of «the anti-cutback rule» of complementary retirement pensions. $\$ 7$. The Directive 2003/41/EC, on the activities and supervision of institutions for occupational retirement provision, and its faulty treatment of vested rights 


\section{PRÓLOGO A LA SEGUNDA EDICIÓN}

\section{PREFACE TO THE SECOND EDITION}

Agotada la primera edición de este Manual, nos hemos animado a realizar - contando con la experiencia de tres años de rodaje muy intensoesta segunda edición del mismo, acuciados por la necesidad de servir mejor nuestra docencia de postgrado en Derecho comparado del Trabajo y de la Seguridad Social, en la Facultad de Derecho de la Universidad de A Coruña, a la que ambos pertenecemos, y en Derecho comparado del Trabajo, en el Instituto Superior de Ciencias del Trabajo y de la Empresa (ISCTE)-Instituto Universitario de Lisboa, en el que hemos sido amistosamente acogidos por un par revisor externo de lo que hacemos, el Prof. Dr. Dr. h.c. António Monteiro Fernandes. Lógicamente, incorporamos ahora a esta segunda edición los resultados de nuestras investigaciones iuscomparatistas de esos tres últimos años, focalizados en publicaciones que coedita (con nuestro editor, Netbiblo) el Instituto de Investigación de la Asociación Coruñesa de Derecho Comparado del Trabajo y de la Seguridad Social, y también, en otras varias publicaciones realizadas al amparo de diversos proyectos de investigación de los que formamos parte; pero incorporando asimismo ideas concebidas sobre todo con ocasión de nuestras periódicas estancias de investigación, desde hace ya unos cuantos años, en Alemania. De entre todo este nuevo material, creemos que una sola obra es la que verdaderamente marca las distancias entre la primera edición (de 2007) y la edición presente (de 2010), elaborada con bastante calma, de este Manual nuestro.

Se trata de Los grandes casos judiciales del Derecho alemán del Trabajo, escrita junto con el Prof. Dr. Ulrich Zachert, que es - dando respuesta a una de las preguntas más difíciles que cabe plantear a todo verdadero Maestro universitario del Derecho positivo - a quien se debe la autoría de dicha lista de dieciocho grandes casos. Nos sirvió para consolidar nuestra visión del Derecho comparado como elemento de progreso, en el marco de una Universidad que queremos realmente europeísta; también, para abandonar definitivamente prejuicios dogmáticos acartonadores de lo 
que hacíamos, y en los que irremediablemente acaba cayéndose, si es que se miran única y exclusivamente las Leyes y la jurisprudencia que tenemos en casa; y por último, para confirmarnos en la creencia de que a los graves problemas que aquejan a nuestra disciplina (y en consecuencia, al trabajador asalariado), que parece amenazada incluso de disolución en las Facultades de Derecho de España, sólo cabía oponer soluciones eficaces testadas en los países de nuestro entorno más próximo, a metabolizar precisamente por la vía de la investigación paciente en Derecho comparado. Profundizando en esta misma vía - y sin perjuicio de otros varios proyectos investigadores más que tenemos, igualmente ilusionantes-, nos vamos a poner a trabajar ya, este próximo mes de octubre, en Los grandes casos judiciales del Derecho alemán de la Seguridad Social, cuya realización hemos convenido en la Universidad de Hamburgo con el Prof. Dr. Karl-Jürgen Bieback, Catedrático emérito de Derecho de la Seguridad Social en dicha Universidad alemana.

Supuesto que estructura es lo que dura, las líneas maestras de la primera edición de nuestros Fundamentos de Derecho comunitario y comparado, europeo y norteamericano, del Trabajo y de la Seguridad Social no pueden considerarse en absoluto ninguna coyuntura, dado que esta segunda edición mantiene los veintiún Temas de la primera (y sus sumarios respectivos), con sólo una novedad verdaderamente digna de ser reseñada. Ésta se refiere a la adición de un Tema nuevo - que hace que la obra, en vez de veintiuno, pase a contar ahora con veintidós Temas-, sobre «Los accidentes de trabajo in itinere en el ordenamiento comunitario, en las legislaciones y prácticas nacionales europeas, y en la legislación de los Estados Unidos». Formaba parte de lo que últimamente veníamos explicando en nuestra docencia de postgrado, y creemos que ejemplifica a la perfección, de un lado, todos los vicios que acaba generando la aburrida (y a la postre, injusta) endogamia nacional-positivista; y de otro lado - y por contraposición a ella-, todas las virtudes oxigenantes aportadas por el hecho de abrir la mirada jurídica a lo que ocurre del otro lado de nuestras fronteras (conciliación realista de la vida laboral y familiar, preocupación medioambiental vía «covoiturage», prevención eficaz y no sólo reparación de este concreto tipo de accidentes de trabajo, etc.).

Los Autores

A Coruña, septiembre de 2010 


\section{PRÓLOGO A LA PRIMERA EDICIÓN}

\section{PREFACE TO THE FIRST EDITION}

Aunque desde hace casi dos años vengamos dedicándonos prioritariamente al estudio del Derecho comparado — vía publicaciones (últimamente, nuestras Leyes laborales alemanas. Estudio comparado y traducción castellana, editadas por Netbiblo), vía informes y dictámenes-, el estímulo irresistible para haber acabado redactando este manual, animándonos a publicarlo, ha sido la necesidad de servir mejor los diez créditos ECTS sobre «Derecho comunitario y comparado del Trabajo y de la Seguridad Social», que impartimos en la Facultad de Derecho de nuestra Universidad de A Coruña, en el marco del Master Oficial sobre Estudios de la Unión Europea autorizado - el pasado curso académico 2005/2006 - por el Gobierno de nuestra Comunidad Autónoma (con una apuesta firme por el empleo de las nuevas tecnologías y por el uso docente de lenguas extranjeras, en especial el inglés), así como por las autoridades académicas competentes del Estado. En nuestro caso, se ha cumplido una vez más la inexorable interacción docencia-ciencia, de que hablamos - cuando contábamos la historia universitaria de nuestra disciplina - en la primera lección de nuestro manual de Derecho del Trabajo. Este condicionamiento, acentuado por la posibilidad de disponer sólo - lo que no es poco- de un cuatrimestre académico completo, explica que hayamos optado resueltamente, siguiendo algunas tradiciones universitarias europeas (por ejemplo, en Alemania, la de los Grundzüge), por titular «Fundamentos» a este nuevo manual universitario nuestro.

Ante todo, el género «Fundamentos» resulta ser sinónimo de selección. Y aquí la necesidad de selección se imponía por sí sola, vista la carga de tener que explicar a nuestros estudiantes de postgrado — buena parte de ellos, por cierto, de procedencia extranjera - precisamente «Derecho comunitario y comparado, europeo y norteamericano, del Trabajo y de la Seguridad Social». Esta necesidad de selección nos impuso, a su vez, tener que intentar acabar haciendo virtud pedagógica de ella, que proyectamos 
sobre los temas (procurando siempre elegir, con honestidad, los tópicos que nos parecieron más selectos), sobre los países a comparar y tratar (convencidos, como estamos, de que el Derecho comparado nada tiene que ver con ordenaciones alfabéticas de Estados, que empezasen en la «A», quizá con Afganistán, y concluyesen en la «Z», seguramente con Zimbabwe; e incluso, convencidos de que igualmente había países del llamado "primer mundo» que asimismo resultaban irrelevantes jurídicamente hablando, al menos al lado de otros que desde siempre figuraron en la vanguardia del progreso y del conocimiento jurídicos, también desde el punto de vista laboral y de la seguridad social), y por último, sobre la estructura expositiva (procurando aquí, aunque partiésemos de nuestro inesquivable condicionamiento de ser precisamente españoles, intentar conseguir siempre el que a operadores jurídicos del mundo que nos rodea pudiese resultarles cómoda, por familiar o razonable, la percha en que habíamos decidido colgar la selección de veintiún temas, sobre la que creíamos que nuestros estudiantes de postgrado, españoles y no españoles, tenían el deber de formarse).

La selección de temas es clara a todo lo largo y ancho de estos «Fundamentos», aunque resulte especialmente patente en el tratamiento que decidimos dar al Derecho comunitario del Trabajo y de la Seguridad Social. Sobre él, optamos resueltamente por renunciar a tratar los temas más tópicos y más manidos (y por tanto, los menos relevantes desde el punto de vista iuscomparatista) del que hemos denominado Derecho de la Unión Europea en su vertiente ad extra - esto es, la que sólo contempla dicha Unión como legislador o juzgador influyente en los Estados miembros-, para acentuar, en cambio, el tratamiento del Derecho de la Unión Europea en su vertiente ad intra - esto es, la que contempla la propia Unión Europea como empleador-, con resultados que nos han parecido iuscomparativamente sorprendentes. En efecto, puede causar un verdadero shock - desde luego nuestros estudiantes se han sentido abochornados e, incluso, escandalizados - explicar y comprobar que la Unión Europea predica ad extra la estabilidad en el empleo o la protección frente al despido injustificado, aunque practique luego ad intra la precariedad laboral y el despido libre (eso sí, con preaviso), que sólo reconoció - siempre en la citada vertiente ad intra - la libertad sindical tres lustros después de firmado el Tratado de Roma, o que resulta aparentemente imposible 
localizar en su portal jurídico (modelo de transparencia ad extra) los concretos acuerdos colectivos que negocia con los tres sindicatos a los que ha reconocido, siempre a sus efectos internos, la condición de interlocutores sociales representativos ante ella.

En cuanto a la selección de países, optamos resueltamente por los cuatro más «grandes» de Europa (esto es, Alemania, Francia, Italia y Gran Bretaña, pero no el Reino Unido, por considerar perfectamente prescindible el Derecho del Trabajo y de la Seguridad Social norirlandés), más Portugal — por evidentes razones transfronterizas, pues partíamos, recuérdese, de nuestro particular condicionamiento de ser precisamente españoles-, así como por los Estados Unidos de Norteamérica (estos últimos, en cuanto que única entidad nacional oponible, en términos iuscomparatistas eficaces, al conjunto de administraciones públicas de la Unión Europea). Tal reconducción cualitativa - supuesto que para nosotros el Derecho, también el comunitario y el comparado, se formula siempre por medio de «leyes» $\mathrm{y}$ «casos»— nos ha facilitado poder comparar a fondo algunas leyes positivas reguladoras de asuntos laborales cruciales, como las relativas a las condiciones mínimas de trabajo, y en especial el salario (en este sentido, por ejemplo, la existencia de un salario mínimo interprofesional federal norteamericano regulado en el Código de los Estados Unidos contrasta, e incluso canta, frente a la inexistencia de un salario mínimo interprofesional europeo, mucho más que el hecho de que también haya salarios mínimos interprofesionales californianos o neoyorkinos, regulados en sus respectivos Códigos de Leyes estatales, frente a la inexistencia de un salario mínimo interprofesional en Alemania o Italia). Pero nos ha permitido comparar, también creemos que a fondo, casos y doctrinas judiciales (para poner de relieve, por traer a colación otra vez sólo un ejemplo, frente a la jurisprudencia de conceptos manejada por nuestro Tribunal Supremo o por la Corte de Casación francesa en relación con el respeto que merezcan los derechos adquiridos en materia de seguridad social complementaria, que hay otras Cortes Supremas, en cambio, como la norteamericana o la italiana, o el Tribunal Federal de Trabajo alemán, que se guían por una jurisprudencia de intereses, al efecto de evitar el atropello consentido por los jueces españoles y franceses de personas indefensas y, por tanto, de las más elementales exigencias de decencia y de justicia material). 
En fin, en lo tocante a la percha o estructura en la que decidimos colgar los veintiún temas de nuestros «Fundamentos», optamos por engranarlo todo en tres grandes «partes» que nos hiciesen más fáciles las cosas, siempre desde el punto de vista docente. La primera trata de las «Fuentes», materializada en cinco temas, y se orienta en lo esencial al aprendizaje de la búsqueda y localización en Internet — respecto de los diversos ordenamientos que comparábamos - de toda clase de fuentes jurídico-positivas y jurisprudenciales laborales y de seguridad social. La segunda — titulada «Instituciones»—, destinada a exponer en otros cinco temas las que considerábamos infraestructuras primordiales del Derecho del Trabajo y de la Seguridad Social, tanto en Europa como en los Estados Unidos de Norteamérica (esto es, los servicios públicos de empleo, la Inspección de Trabajo, la gestión de la seguridad social y los contenciosos laboral y de la seguridad social). Y la tercera y última — articulada alrededor de los once temas restantes-, concebida como microcomparación jurídica de grandes «Derechos, Libertades y Principios» —expresión que tomamos del Derecho de la Unión Europea-, tanto jurídico-laborales (libertad sindical, negociación colectiva, huelga, estabilidad en el empleo, protección del trabajador frente a las situaciones críticas de la empresa, protección del trabajador frente al despido injustificado, etc.) como de seguridad social (habiéndonos parecido cardinal aquí, a pesar de todas las complicaciones del asunto, la regulación del principio de automaticidad de las prestaciones de seguridad social en los diversos ordenamientos que nos habíamos propuesto comparar). Evidentemente, no consideramos en absoluto cerrada esta lista, aunque la materialización de posibles ampliaciones de la misma (ya de nuevo con el concurso del profesor CARRIL VÁZQUEZ, ahora mismo ocupado en tareas del más alto servicio público universitario) parece que deberá esperar a la ampliación formal — que ya tenemos solicitada - de nuestros actuales diez créditos ECTS de postgrado, cuya metodología (incluida la utilización expansiva del inglés) pensamos incorporar este próximo curso académico 2007/2008, también a nuestra docencia ordinaria de grado. 


\section{PARTE PRIMERA}

\section{FUENTES}

FIRST PART

SOURCES 


\section{TEMA 1}

EL DERECHO DEL CIUDADANO A CONOCER LAS FUENTES JURÍDICAS, TAMBIÉN LAS LABORALES Y DE SEGURIDAD SOCIAL, A TRAVÉS DE INTERNET

Sumario: §1. La ignorancia de las leyes no excusa de su cumplimiento. §2. El modelo francés de difusión del Derecho a través de Internet. §3. Los otros modelos estatales europeos de difusión del Derecho a través de Internet. §4. La Directiva 2003/98/CE, relativa a la reutilización de la información del sector público. §5. El modelo norteamericano de difusión del Derecho a través de Internet.

THEME 1

THE CITIZEN'S RIGHT TO KNOW THE LEGAL SOURCES, ALSO THE LABOR AND SOCIAL SECURITY ONES, THROUGH INTERNET

Contents: \$1. Ignorance of the Law is no excuse. \$2. The French model of diffusion of the Law through Internet. \$3. The other European state models of diffussion of the Law through Internet. $\$ 4$. The Directive 2003/98/EC, on the re-use of public sector information. \$5. The USA model of diffusion of the Law through Internet.

§1. En España, el aforismo jurídico romano «la ignorancia de la ley no excusa [ignorantia legis non excusat]» ha estado siempre positivizado en nuestros textos normativos históricos ${ }^{1}$, apareciendo recogido en la actualidad en el artículo 6.1 del Código Civil, a cuyo tenor «la ignorancia de las leyes no excusa de su cumplimiento» ${ }^{2}$, respecto del cual nuestra jurisprudencia afirma que en las «leyes» aludidas por dicho precepto quedan comprendidas - como es lógico- las leyes laborales ${ }^{3}$, las leyes

1 En la ley 2 del título 2 del libro III de la Novísima Recopilación de 1805 (que reproduce una ley del Fuero Juzgo y dos del Fuero Real), se afirma literalmente lo siguiente: «La razón que nos movió a hacer leyes fue, porque por ellas la maldad de los hombres sea refrenada, y la vida de los buenos sea segura, y por miedo de la pena los malos se excusen de hacer mal. Y establecemos, que ninguno piense de mal hacer, porque diga que no sabe las leyes ni el Derecho; ca si hiciere contra ley, que no se pueda excusar de culpa por no la saber».

2 Párrafo primero. Originariamente, esta norma se ubicaba en el artículo 2 del propio Código.

3 Véase E. BORRAJO DACRUZ, «¿La ignorancia de la ley laboral excusa de su cumplimiento?», Actualidad Laboral, núm. 3 (1996), págs. 577 y ss. 
de seguridad social (a pesar de todo lo abigarrado y cambiante de las mismas) ${ }^{4}$ e, incluso, los convenios colectivos ${ }^{5}$. En su aplicación contemporánea en el mundo occidental, este viejo aforismo jurídico ha acabado adquiriendo progresivamente tres facetas principales, rigurosamente complementarias entre sí las tres, y que incluso - desde la perspectiva del ciudadano - podrían denominarse faceta neutra (normalmente no pasa nada, si el ciudadano ignora el contenido de la ley), faceta negativa (¿qué pasa si el ciudadano incumple una ley cuyo contenido ignoraba?) y faceta positiva (el ciudadano debe tener derecho a conocer el contenido de la ley). La primera — que constituyó la médula del aforismo durante todo el siglo XIX - se refiere jurídicamente hablando a la presunción de conocimiento de la ley por parte del ciudadano, a causa del mero hecho de la publicación de la misma en el periódico oficial correspondiente ${ }^{6}$, habiendo resultado pionero a este respecto el ordenamiento jurídico francés - tras la promulgación del Código Civil de Napoleón de 1804-, en cuyo artículo 1 estaba implícita la máxima de que «nadie está autorizado a ignorar la ley [nul n'est censé ignorer la loi]» ${ }^{7}$. La segunda faceta — que caracterizó la aplicación judicial del propio aforismo en la Europa continental, especialmente durante la segunda mitad del siglo $\mathrm{XX}$ - se refiere a la eventual eficacia jurídica de la prueba de falta de conocimiento de la ley, habiendo resultado sobre esto pionero en nuestro continente el ordenamiento jurídico alemán, tras declararse en una famosa resolución judicial alemana de 1952 que a la regla en cuestión (en alemán, «la ignorancia no protege ante la pena [Unwissenheit schützt vor Strafe nicht]») la hacía brillar en asuntos penales la excepción

4 Véase, por ejemplo, Sentencia del Tribunal Superior de Justicia (Sala de lo Social) de Galicia de 15 marzo 2004 (WESTLAW Aranzadi, referencia JUR 2004/140554).

5 Véase, por ejemplo, Sentencia del Tribunal Superior de Justicia (Sala de lo Social) de Madrid de 24 abril 2001 (WESTLAW Aranzadi, referencia JUR 2001/189274).

6 Aunque se trate de una publicación ocurrida mucho tiempo atrás, como ocurrió —a propósito de un pleito enjuiciado en 2004- en el caso del «Acta Adicional al Tratado [de Bayona], publicada en la Gaceta de Madrid, de fecha 22 de julio de 1866» (cfr., al respecto, Sentencia del Tribunal Superior de Justicia [Sala de lo Contencioso-administrativo] de Cataluña de 1 junio 2004 [WESTLAW Aranzadi, referencia JUR 2004/213548]).

El texto originario de dicho precepto afirmaba literalmente lo siguiente: «las leyes son ejecutorias en todo el territorio francés, en virtud de la promulgación que de ellas ha hecho el PRIMER CÓNSUL» (párrafo primero); «serán ejecutadas en cada parte de la República, desde el momento en que la promulgación de ellas pueda ser conocida [du moment où la promulgation en pourra être connue]» (párrafo segundo); y «la promulgación hecha por el PRIMER CÓNSUL se reputará conocida [sera reputée connue] en el departamento donde tenga su sede el Gobierno, un día después del de la promulgación; y en cada uno de los otros departamentos, tras la expiración del mismo plazo, aumentado tantos días cuantas veces haya diez miríadas [aproximadamente veinte leguas antiguas] entre la ciudad donde la promulgación ha sido hecha y la capital del departamento» (párrafo tercero). 
del «error de derecho». Y la tercera faceta, relativa a que el Estado debe facilitar al ciudadano, con realismo, el ejercicio del derecho subjetivo a poder conocer la ley, respecto de lo cual ha vuelto a resultar pionero otra vez - pero ya en este siglo XXI, en que nos encontramos_-, como ahora mismo se comprobará, el ordenamiento jurídico francés.

En relación con este tema, resulta obvio que los ordenamientos de Portugal y España deben adscribirse a una misma familia jurídica, pues en el Código Civil portugués también se afirma expresamente - con alcance general — que «la ignorancia o mala interpretación de la ley no justifica la falta de su cumplimiento ni libra a las personas de las sanciones en ella establecidas [a ignorância ou má interpretacão da lei não justifica a falta do seu cumprimento nem isenta as pessoas das sanções nela estabelecidas]» ${ }^{8}$.

La jurisprudencia alemana aludida, a propósito de la segunda faceta esencial de la máxima, arranca de un trascendental Auto de Sala General del Tribunal Federal Supremo alemán (Bundesgerichtshof) de 18 marzo 1952 ${ }^{\circ}$, en el que se declaró — sobre la base de que el Código Penal alemán por aquel entonces vigente «regula sólo el error de hecho [Tatbestandsirrtum]»—, a efectos de excusar al imputado, que «el error sobre la infracción jurídica es error de derecho [der Irrtum über die Rechtswidrigkeit ist Verbotsirrtum]».

El impacto de esta jurisprudencia alemana de 1952 resulta evidente sobre el ordenamiento jurídico español. En efecto, al aprobarse la reforma —en 1974- del Título Preliminar de nuestro Código Civil, la regla tradicional de la irrelevancia de la ignorancia de las leyes fue completada con un nuevo mandato, relativo a que «el error de derecho producirá únicamente aquellos efectos que las leyes determinen» ${ }^{10}$. Nuestra jurisprudencia ha confirmado luego - validando supuestos de ignorancia de la ley — que este nuevo mandato podía aplicarse en asuntos penales ${ }^{11} \mathrm{y}$ no penales ${ }^{12}$.

Resulta evidente asimismo el impacto de dicha jurisprudencia alemana en el ordenamiento jurídico de Italia, dado que el artículo 5 del Código Penal italiano (en el que se afirmaba, desde 1930, que «nadie puede invocar como excusa propia la ignorancia de la ley penal [nessuno può invocare a propria scusa l'ignoranza della legge penale]») fue declarado parcialmente inconstitucional en 1988, imponiéndosele por la Corte Constitucional italiana una interpretación correctora, al estar dicho precepto viciado de «ilegitimidad constitucional... en la parte en que no excluye de la inexcusabilidad de la ignorancia de la ley penal la ignorancia inevitable» ${ }^{13}$.

En fin, en los países anglosajones - donde la regla relativa a la ignorancia de la ley aparece incluso positivizada en algún Estado de los Estados Unidos de Norteamérica (así, en Arizona, «la ignorancia de la ley no libra a una persona de responsabilidad criminal

8 Artículo 6.

9 Referencia GSSt 2/51, localizable en www.servat.unibe.ch/verfassungsrecht/bs002194.html.

10 Artículo 6.1, párrafo segundo, del Código Civil.

11 Al respecto, véase Sentencia del Tribunal Supremo (Sala 2a) de 31 octubre 1992 (WESTLAW Aranzadi, referencia RJ 1992/8631).

12 Al respecto, véase Sentencia del Tribunal Superior de Justicia (Sala de lo Social) de La Rioja de 23 abril 1993 (WESTLAW Aranzadi, referencia AS 1993/1904).

13 Véase el fallo de la Sentencia de la Corte Constitucional núm. 364/1988, de 23-24 marzo 1988 (localizable a través de www.cortecostituzionale.it). 
[ignorance of the law does not relieve a person of criminal responsibility]»; en Georgia, «la ignorancia de la ley no excusa a nadie [ignorance of the law excuses no one]»; en Oklahoma, «la ignorancia de la ley no excusa del castigo por su incumplimiento [ignorance of the law does not excuse from punishment for its violation]»; etc.) -, el tema jurisprudencialmente más relevante en relación con ella ha sido también, durante el siglo pasado, el del error de derecho (mistake of law) ${ }^{14}$.

\$2. Alarmado — en 1999- el Gobierno francés por el hecho de que «en el momento actual, se cuenta con cerca de 8.000 leyes en vigor», y de que «en cuanto al número de textos reglamentarios en vigor, es difícil evaluarlo, aunque se estima que se aproxima a los 90.000» — por lo que también recordaba el Gobierno en cuestión, trayendo a colación el viejo aforismo sobre la ignorancia jurídica, que «los ciudadanos tienen cada vez peor conocer y comprender la ley que "nadie está autorizado a ignorar" [les citoyens ont de plus en plus de mal à connaître et comprendre la loi que "nul n'est censé ignorer"] ${ }^{15}$ —, se puso en marcha en Francia un proceso corrector de esta situación inadmisible sobre todo para el ciudadano corriente, que culminó con la promulgación del Decreto núm. 2002-1064, de 7 agosto 2002, «relativo al servicio público de difusión del Derecho por Internet» ${ }^{16}$. Según la versión original de este Decreto — que regula el modelo francés de difusión del Derecho a través de Inter net-, se trata de un servicio público que «tiene por objeto facilitar el acceso del público a los textos [normativos de eficacia general, incluidos los convenios colectivos] en vigor, así como a la jurisprudencia» ${ }^{17}$ - sobre la base de que el acceso en cuestión debe poder efectuarse por la ciudadanía siempre «gratuitamente» ${ }^{18}$ - , por lo que procedía a crear «un sitio denominado Légifrance (www.legifrance.gouv.fr), colocado bajo la responsabilidad del secretario general del Gobierno y explotado por la Dirección de los Diarios Oficiales» ${ }^{19}$. La gran ventaja de este servicio

14 Acerca de ello, fundamental, véase S.L. DAVIES, «The jurisprudente of willfulness: an evolving theory of excusable ignorance», 48 Duke L.J. 341 (manejable a través de www.law.duke.edu/shell/cite. pl?48+Duke+L.+J.+341).

15 Todas estas afirmaciones, en «Observaciones del Gobierno sobre el recurso [de inconstitucionalidad] planteado contra la ley concediendo habilitación al Gobierno para proceder por ordenanzas a la adopción de la parte Legislativa de ciertos códigos», publicadas en el Journal Officiel, núm. 296 de 22 diciembre 1999, págs. 19046 y ss.

16 Acerca de los orígenes y evolución de Internet, véase C. DELGADO KLOOS y C. GARCÍA RUBIO, «Historia de Internet», en J. CREMADES, M.A. FERNÁNDEZ-ORDÓÑEZ y R. ILLESCAS (Coordinadores), Régimen jurídico de Internet, La Ley (Madrid, 2002), págs. 87 y ss.

17 Artículo 1, párrafo segundo.

18 Artículo 1, párrafo tercero.

19 Artículo 2, párrafo primero. 
público francés, incluso para el ciudadano perito en leyes - e incluso para el ciudadano, como jueces y magistrados, legalmente obligado a conocer la ley («iura novit curia») ${ }^{20}$ - es que ofrece en todo caso la «versión consolidada» de los textos normativos que a través de él se difunden — esto es, con incorporación de todas las modificaciones que los mismos hayan podido padecer-, a cuyo efecto «la Dirección de los Diarios oficiales produce las bases de datos» ${ }^{21} \mathrm{y}$ 《realiza, en particular, una base que asegure la integración, en plazos breves, de las modificaciones ocurridas en los textos legislativos y reglamentarios» ${ }^{22}$.

Según el propio Decreto núm. 2002-1064 ${ }^{23}$, lo que se difunde a través de este sitio de Internet son «actos de carácter normativo» (esto es, «la Constitución, los códigos, las leyes y los actos de carácter reglamentario que emanan de las autoridades del Estado», y «los convenios colectivos que hayan sido objeto de una resolución de extensión»), los "aactos que resulten de compromisos internacionales de Francia» (esto es, «los tratados y acuerdos en los que Francia es parte», y «las directivas y reglamentos que emanen de las autoridades de la Unión Europea, tal y como son difundidos por estas autoridades»), la «jurisprudencia» (esto es, «las decisiones y sentencias del Consejo constitucional, del Consejo de Estado, de la Corte de casación y del tribunal de conflictos»; «las de las sentencias y fallos dados por el Tribunal de cuentas y las otras jurisdicciones administrativas, judiciales y financieras, que han sido seleccionadas según las modalidades propias de cada orden jurisdiccional», $\mathrm{y}$ «las decisiones del Tribunal de Justicia de las Comunidades Europeas y del Tribunal de Primera Instancia de las Comunidades Europeas»), y «un conjunto de publicaciones oficiales» (que incluye «la edición "Leyes y Decretos" del Diario Oficial de la República Francesa», «los Boletines Oficiales de los Ministerios» y el «Diario Oficial de las Comunidades Europeas») ${ }^{24}$.

El Decreto núm. 2004-459, de 28 mayo $2004^{25}$, fija «las categorías de actos individuales que no pueden ser objeto de publicación en forma electrónica en el Diario Oficial de la República Francesa» (Decretos sobre cambio de nombre, Decretos de adquisición de la nacionalidad, anuncios judiciales y legales que mencionen condenas penales, etc.).

Téngase en cuenta, según se advierte en este mismo sitio de Internet, que «la consolidación consiste en integrar en un acto único, sin valor oficial, las modificaciones y las correcciones sucesivas aportadas a un texto», y que «como toda forma de presentación de textos que necesita un trabajo de compilación pero también de interpretación, la consolidación no está al abrigo de errores e implica, en todo caso, un plazo de puesta al día precisado en las rúbricas de "Ayuda"». Por ello, «a pesar de todas las precauciones tomadas por los servicios de la dirección de los Diarios Oficiales, puede ser prudente, según el uso

20 Acerca de este principio, en relación con las fuentes normativas laborales (y especialmente, los convenios colectivos), véase J. MARTÍNEZ GIRÓN, A. ARUFE VARELA y X.M. CARRIL VÁZQUEZ, Derecho del Trabajo, $2^{\mathrm{a}}$ ed., Netbiblo (A Coruña, 2006), págs. 23 y 427.

21 Artículo 3, párrafo primero, inciso primero.

22 Ibidem, inciso segundo.

23 Modificado por el Decreto núm. 2010-31, de 11 enero 2010.

24 Cfr. artículo 1, párrafo tercero.

25 Siempre localizable a través de www.legifrance.gouv.fr. 
que quiera hacerse de la consulta de textos, verificar su estado dirigiéndose a los actos modificativos, accesibles a partir de la base "Diario Oficial" ${ }^{26}$.

§3. El resto de países europeos que consideramos de referencia nada tiene que ver todavía con este modelo francés, específicamente concebido - como acaba de decirse - para dar efectividad real al principio de que «nadie está autorizado a ignorar la ley» ${ }^{27}$. En efecto, estos otros países europeos se ajustan hoy a cinco modelos oficiales distintos en lo tocante a la difusión del Derecho a través de Internet, a saber: 1) el modelo italiano — gestionado por el poder legislativo y ubicado en www.normattiva.it-, de implantación progresiva, caracterizado porque también ofrece al público el acceso a «versiones consolidadas» (o en todo caso, «multivigencia») de normas estatales con buscadores útiles (especialmente, el de búsqueda avanzada), aunque sin el valor añadido de poder recorrer sincrónica y diacrónicamente todo el ordenamiento jurídico italiano, que caracteriza el modelo francés ${ }^{28}$; 2) el modelo alemán, que igualmente ofrece al público el acceso a «versiones consolidadas» de las leyes y reglamentos federales - a través del sitio oficial http://bundesrecht.juris.de, gestionado por el Ministerio federal de Justicia-, aunque carece de mecanismos de búsqueda libre (las normas almacenadas en él se encuentran clasificadas sólo alfabéticamente) ${ }^{29}$; 3) el modelo británico — gestionado a través del sitio www.statutelaw.gov.uk-, caracterizado por ofrecer sólo, en principio, «versiones consolidadas» parciales de las normas (de momento, desde su promulgación y generalmente hasta el año 2002), de manera que el ciudadano debe construirse artesanalmente por su cuenta la versión al día de las mismas, utilizando los materiales que se le indican en dicho sitio de Internet, respecto de cada concreta norma ${ }^{30}$; 4) el modelo español — gestionado a través del sitio www.boe.es, donde

26 Sobre todo ello, siempre en www.legifrance.gouv.fr, véase el epígrafe «À propos du droit».

27 Para la mejor comprensión de lo que sigue, y especialmente sobre el concepto de «base de datos», véase S. CÁMARA LAPUENTE, «Protección jurídica de las bases de datos en Internet (Un ensayo de explicación de Internet desde la normativa sobre la propiedad intelectual de las bases de datos)», en J. CREMADES, M.A. FERNÁNDEZ-ORDÓÑEZ y R. ILLESCAS (Coordinadores), Régimen jurídico de Internet, cit., págs. 1553 y ss.

28 La Gazzetta Ufficiale della Reppublica Italiana resulta electrónica y gratuitamente accesible a través de http://gazzettaufficiale.it.

29 El Boletín Oficial Federal (Bundesgesetzblatt) resulta electrónica y gratuitamente accesible a través de www.bundesgesetzblatt.de. El portal jurídico austriaco — denominado «Rechtsinformationssyst em», accesible a través de www.ris.bka.gv.at - está infinitamente más próximo al modelo francés que al modelo alemán.

30 En el Reino Unido, el sitio de Internet equivalente del de nuestro Boletín Oficial del Estado es www.opsi.gov.uk. 
se encuentra ubicada la base de datos «iberlex»—, que ni siquiera ofrece esas «versiones consolidadas» parciales (en consecuencia, en principio, sólo cabe acceder al texto histórico u originario de las normas), aunque - al igual que en el modelo británico - indique al ciudadano los materiales a utilizar para fabricarse artesanalmente los textos al día de leyes y reglamentos ${ }^{31}$; y 5) el modelo portugués — gestionado a través del sitio www.dre.pt-, que sólo permite acceder gratuitamente al texto histórico u originario de las normas, sin ayudas relativas a cómo poder reconstruir artesanalmente los textos vigentes (y además, a diferencia de lo que ocurre en los modelos británico y español, con el inconveniente de carecer de mecanismos de búsqueda libre de los textos normativos históricos que ofrece). Lógicamente, estos otros modelos estatales europeos de difusión del Derecho a través de Internet fomentan que empresas privadas (y en ocasiones, paradójicamente, también el propio Estado), con sus propias bases de datos jurídicos de pago — inaccesibles al ciudadano común y corriente, condenado de hecho por el Estado de que se trate a seguir ignorando todo o parte de la ley_-, cubran a su modo la distancia que media entre los mismos y el citado modelo francés.

En Alemania, esta distancia la cubre desde 1985 una sociedad de responsabilidad limitada — en la que el Estado alemán posee el 50’01 por ciento del capital social— denominada «Juris GmbH», encargada de la explotación lucrativa del sitio de Internet www.juris.de. Algo semejante ocurre en Italia, con la base de datos oficial de pago ubicada en www.italgiure. giustizia.it, fundamental para acceder a la jurisprudencia. Y en cuanto a Portugal, téngase en cuenta que el sitio oficial de Internet citado tiene un «servicio por suscripción [assinatura]».

En Francia, en cambio, no parece haber quedado mucho hueco libre para la actuación de este tipo de empresas privadas (ni siquiera multinacionales), resultando sintomático que el propio sitio de Internet del Consejo Nacional de Colegios de Abogados de Francia (Conseil National des Barreaux) recomiende a sus miembros la utilización del servicio público de difusión del Derecho por Internet, calificándolo como «l'essentiel du droit français» ${ }^{32}$.

Es sintomático, también, que el sitio de Internet www.top100-law.com, relativo a los cien sitios jurídicos de Internet más utilizados y citados, clasifique «Légifrance» por encima de la alemana «Juris» y, también, de otras conocidas multinacionales actuantes en este sector.

§4. La Unión Europea - consciente de la existencia de todos estos modelos nacionales tan diversos - ha pretendido poner un mínimo de orden

31 Utilizando, dentro de cada norma, el vínculo «Análisis jurídico». En este tema, nuestro país ha dado un evidente paso atrás. Lo prueba el progresivo desmantelamiento jurídico del portal del ciudadano (tradicionalmente útil, a efectos de localizar «versiones consolidadas» de toda nuestra legislación estatal básica), ubicado en www.060.es.

32 Al respecto, véase A. ARUFE VARELA, «¿Por qué no se encuentran ni siquiera mencionados en el Estatuto de los Trabajadores los contratos de trabajo comunes y especiales de más rabiosa actualidad?», Foro Galego, núm. 195 (2006), págs. 45-46. 
en el tema, mediante la promulgación de la Directiva 2003/98/CE del Parlamento Europeo y del Consejo, de 17 noviembre 2003, relativa a la reutilización de la información del sector público ${ }^{33}$. En ella se afirma, entre otras muchas cosas, que «la evolución hacia la sociedad de la información y del conocimiento afecta a la vida de todos los ciudadanos de la Comunidad, en particular al permitirles contar con nuevos medios para acceder y adquirir el conocimiento» ${ }^{34}$; también, que «existen considerables diferencias de un Estado miembro a otro en relación con las normas y prácticas de explotación de los recursos de información del sector público» ${ }^{35}$, y por ello mismo, que resultaba imprescindible «alcanzar una mínima armonización, evitando así que se acentúen las disparidades entre los Estados miembros» ${ }^{36}$, a cuyo efecto ordena: 1) sobre la base de que «reutilización» es «el uso de documentos que obran en poder de organismos del sector público por personas físicas o jurídicas con fines comerciales o no comerciales distintos del propósito inicial que tenían esos documentos en la misión de servicio público para la que se produjeron» ${ }^{37}$, que «en la medida de lo posible, los documentos se pondrán a disposición del público por medios electrónicos» ${ }^{38}$, con «dispositivos prácticos que faciliten la búsqueda» ${ }^{39}$; 2) supuesto que haya que tarifar al público por dicha «reutilización», que «cuando se aplique una tarifa, los ingresos totales obtenidos por la entrega y por permitir la reutilización de un documento no deberán superar el coste de recogida, producción, reproducción y difusión, incrementado por un margen de beneficio razonable de la inversión» ${ }^{40} ; \mathrm{y}$ 3) que «cuando sea necesario un derecho exclusivo [eventualmente otorgable a agentes que "exploten ya productos con valor añadido basados en estos documentos"], deberá reconsiderarse periódicamente, y en todo caso cada tres años, la validez del motivo que justificó la concesión del derecho exclusivo» ${ }^{41}$, teniendo en cuenta que «los acuerdos exclusivos establecidos tras la entrada en vigor de la presente Directiva deberán

\footnotetext{
33 Diario Oficial de la Unión Europea L 345, de 31 diciembre 2003.

34 Considerando 2.

Considerando 6.

36 Considerando 25

37 Artículo 2.4), inciso primero.

38 Artículo 3, inciso segundo.

39 Artículo 9.

40 Artículo 6, inciso primero.

41 Artículo 11.2, inciso primero.
} 
ser transparentes y ponerse en conocimiento del público» ${ }^{42}$. La Unión Europea - consciente asimismo del «derecho de todo ciudadano de la Unión y de toda persona física o jurídica que resida o tenga su domicilio social en un Estado miembro a tener acceso a los documentos del Parlamento Europeo, del Consejo y de la Comisión» ${ }^{43}$ — predica en este tema con hechos, pues cuenta en Internet con su propio portal jurídico integralmente plurilingüe denominado «EUR-lex» (accesible a través de http://eur-lex.europa.eu), de acceso totalmente libre y gratuito desde 1 julio 2004, que comprende todos los documentos oficiales de la Unión Europea (normativos y no normativos, como los jurisprudenciales), y que — al igual que sucede en el modelo francés - incluye un vínculo sobre «Búsqueda en la legislación consolidada», teniendo en cuenta que aquí también «la consolidación es la reunión de los textos básicos de la normativa comunitaria, con sus modificaciones y correcciones, en documentos únicos no oficiales», con la finalidad de «ofrecer mayor transparencia y facilitar el acceso al Derecho de la UE» ${ }^{44}$.

Más en concreto, lo que permite consultar este sitio de Internet es «el Diario Oficial de la Unión Europea» en veintitrés lenguas, «los Tratados» (constitutivos, de adhesión y otros), la «legislación» (reglamentos, directivas y decisiones; instrumentos adoptados en la política exterior y de seguridad común o en cooperación en justicia y asuntos de interior; estatuto y reglamento interno de las instituciones y órganos comunitarios, y dictámenes, recomendaciones y resoluciones del Consejo), la «legislación en preparación» (posiciones comunes del Consejo, dictámenes del Comité Económico y Social y del Comité de las Regiones, dictámenes e informes del Tribunal de Cuentas, etc.), la «jurisprudencia» (sentencias y autos del Tribunal de Justicia de la Unión Europea, del Tribunal de la Función Pública, conclusiones del Abogado General, etc.), las «preguntas parlamentarias» y otros «documentos de interés público» (libros blancos, libros verdes, documentos de trabajo de la Comisión, etc.).

Téngase en cuenta que el citado vínculo "Legislación consolidada» remite a un texto que no siempre ofrece la «versión consolidada» al día del documento de que se trate (reglamento, directiva, etc.), aunque esta última sí aparece consignada, en cambio, entre la información insertada en el lugar [usualmente bajo el rótulo «versiones consolidadas (pdf)»] donde se ubica dicho documento.

Por supuesto, la jurisprudencia del Tribunal de Justicia de las Comunidades Europeas, a instancia de la Comisión, afirma (en este concreto caso, en hasta once lenguas distintas) que «el principio general según el cual la ignorancia de la ley no excusa de su cumplimiento también se aplica a los Estados miembros» ${ }^{45}$.

42 Ibidem, inciso segundo.

43 Cfr. considerando 9 de la recién citada Directiva 2003/98/CE.

44 Al respecto, siempre en dicho portal, véase la entrada «¿Qué puedo hacer con los resultados de mi búsqueda?», dentro de «Sobre EUR-Lex».

45 Cfr. Sentencia del Tribunal de Justicia de la Comunidades Europeas de 21 enero 2003 (asunto C-512/99, República Federal de Alemania contra Comisión de las Comunidades Europeas), apartado 56. 
§5. Al menos en este tema de la difusión del Derecho a través de Internet, los Estados Unidos de Norteamérica van algo retrasados - siempre desde la perspectiva del ciudadano corriente - respecto de lo es ya una realidad tangible en la Unión Europea. En efecto, refiriéndonos sólo a la legislación federal norteamericana ${ }^{46}$, es cierto que el Gobierno de los Estados Unidos dispone de su propio portal jurídico público y de acceso gratuito en Internet - gestionado por la agencia federal denominada «Oficina de Imprenta del Gobierno [Government Printing Office]» y accesible a través de www.gpoaccess.gov—, aunque luego resulta: 1) que el texto refundido oficial del Código de los Estados Unidos (United States Code) — recopilación faraónica de todas las leyes federales - sólo se publica en soporte informático cada seis años (es la llamada «edition» del año correspondiente), desde 1994, anticipándose esa publicación por medio de apéndices anuales (denominados «annual cumulative supplements»), también publicados una vez al año electrónicamente ${ }^{47}$; y 2) que el texto refundido oficial del Código de Reglamentos Federales (Code of Federal Regulations) — todavía mucho más faraónico - sólo se publica en soporte informático una vez cada año, desde 1996, anticipándose esa publicación igualmente por medio de apéndices, en este otro caso de carácter trimestral (cada trimestre en relación sólo, sin embargo, con concretas partes del propio Código), que asimismo se publican electrónicamente. De ahí la existencia en Internet de sitios privados de pago, que cubren la necesidad de poder tener a mano una versión siempre al día (updated) de ambos importantísimos Códigos de normas federales.

El citado sitio oficial del Gobierno de los Estados Unidos ofrece información para que cada cual pueda reconstruirse artesanalmente su propia versión «al día» de las leyes y reglamentos recopilados en dichos Códigos, indicando - respecto del Código de los Estados Unidos- que «cuando un artículo [section] está afectado por una ley aprobada tras la fecha de revisión de un apéndice, el encabezado del artículo incluye una nota que identifica la ley pública que le afecta», de manera que «para conseguir una información al día, usted debe acudir a las bases de datos de leyes públicas con el número de la ley pública referenciado».

46 Acerca de la historia de la publicación de las leyes de los Estados Unidos, utilísimo, véase R.J. McKINNEY, «Basic overwiew on how federal laws are published, organized and cited», accesible a través de www.1lsdc.org/statutes-code.

47 Lógicamente, la ley de creación del sitio de Internet del Gobierno de los Estados Unidos que venimos mencionando, que fue la «Ley de Incremento del Acceso a la Información Electrónica de la Oficina de Imprenta del Gobierno [Government Printing Office Electronic Information Access Enhancement Act] de 1993», también aparece recopilada en el Código de los Estados Unidos; más en concreto, en el Capítulo 41 (rotulado «Acceso a la Información Electrónica Federal») de su Título 44 (rotulado «Imprenta y Documentos Públicos»), secciones 4101 a 4104. 
Con estas mismas limitaciones, también existen en Internet sitios privados de acceso gratuito, de carácter universitario, con valor añadido respecto de las prestaciones formales que ofrece dicho sitio oficial (por ejemplo, presentación, concordancias o calidad de impresión), como en el caso de www.law.cornell.edu/uscode, gestionado por el Instituto de Información Jurídica de la Universidad Cornell de Nueva York.

En cualquier caso, la magnitud de la información jurídica difundida a través del sitio oficial en cuestión abruma, apareciendo clasificada bajo el rótulo «GPO Access Online Resources: A-Z Resource List». 
TEMA 2

SITIOS DE INTERNET RELATIVOS A LOS CÓDIGOS EUROPEOS Y NORTEAMERICANOS DE TRABAJO Y SEGURIDAD SOCIAL

Sumario: §1. Internet y la codificación contemporánea. \$2. Los Códigos franceses del Trabajo y de la Seguridad Social. §3. El Código alemán de Seguridad Social. §4. El Código portugués del Trabajo. §5. El Código de los Estados Unidos de Norteamérica.

THEME 2

INTERNET SITES RELATING TO EUROPEAN AND USA LABOR AND

SOCIAL SECURITY CODES

Contents: \$1. Internet and the contemporary codification. \$2. The French Labor and Social Security Codes. \$3. The German Social Security Code. \$4. The Portuguese Labor Code. $\$ 5$. The United States Code

\$1. Evidentemente, el derecho de todo ciudadano a conocer las fuentes normativas (también, las jurídico-laborales y de seguridad social) queda asegurado de manera más satisfactoria si se procede a compilar y enlatar la legislación dispersa relativa a alguna concreta rama del Derecho en un único código ordenado sistemáticamente, y aun se puede asegurar más aquel derecho si después se trata de mantener permanentemente puesto al día el código en cuestión -ensamblando armoniosamente en él sus eventuales y más que previsibles modificaciones posteriores-, y mucho más todavía si se permite el acceso público, libre y gratuito a la consulta directa del propio código - en especial, a través de Internet-, pues esta serie de pasos marca una clara distinción entre los códigos más clásicos (tendentes siempre a fosilizarse) y los más c on te mp orán eos (siempre vivos, al requerir la existencia de versiones consolidadas oficiales, fácilmente manejables por el público en general, incluso desde casa). Históricamente en España, como se sabe, cabe dar cuenta de una experiencia codificadora en el primer cuarto del siglo 
pasado que cristalizó en el Código del Trabajo primorriverista de 1926, el cual constituía un claro ejemplo de código clásico, pues compilaba en sus cuatro libros - con vocación de perennidad- lo más esencial de la legislación obrera de la época ${ }^{1}$. Hoy, sin embargo, no existe en España ninguna muestra de codificación laboral o de seguridad social —ni clásica, ni mucho menos contemporánea—, sustentándose toda la estructura normativa jurídico-laboral y de seguridad social española sobre la base constituida fundamentalmente por cuatro normas ${ }^{2}$, que son todas ellas — a pesar de su juventud — normas apolilladas y llenas de costurones y remiendos, lo que se debe al hecho de que el instrumento en que formalmente se encarnan — esto es, el Real Decreto Legislativo aprobando un texto refundido de leyes, como en el caso del Estatuto de los Trabajadores - ha dejado de ser en las sociedades del siglo XXI un instrumento hábil para la regulación de los fenómenos laborales y de seguridad social, sujetos a un incesante proceso de evolución y cambio $^{3}$. Este previsible apolillamiento suyo lo había anticipado incluso la primera versión del propio Estatuto de los Trabajadores, puesto que lo que era en 1980 su disposición adicional $3^{\text {a }}$ (y es ahora la disposición adicional $8^{\text {a }}$ del texto refundido) ordenaba imperativamente al Gobierno que elaborase un «Código de Trabajo», aunque de éste no existe todavía rastro alguno en nuestro país. Pues bien, si en el futuro algún Gobierno español se animase a ejecutar el mandato estatutario, poniendo fin así a más de un cuarto de siglo de incumplimiento del mismo, podría tomar como ejemplo alguna de las experiencias codificadoras que desde hace algunos años se vienen desarrollando en otros países de referencia, tanto en Europa (es el caso de Francia, de Alemania y de Portugal) como en los Estados Unidos de Norteamérica.

Frente a las «Recopilaciones» del Antiguo Régimen - como las castellanas «Nueva Recopilación de las Leyes España» de 1567 ó la «Novísima Recopilación de las Leyes de España» de 1805-, la codificación clásica —iniciada, en realidad, por el Código Civil de Napoleón de 1804- se ajustaba al cumplimiento del triple objetivo de unidad de materia (carácter omnicomprensivo, respecto de la materia o rama del Derecho en cuestión), unidad

\footnotetext{
1 Sobre el Código primorriverista, véase J. MARTÍNEZ GIRÓN, A. ARUFE VARELA y X.M. CARRIL VÁZQUEZ, Derecho del Trabajo, 2a ed., Netbiblo (A Coruña, 2006), págs. 72-73.

2 Tres de contenido laboral (ibidem, págs. 18-19), y la cuarta de seguridad social (cfr. J. MARTÍNEZ GIRÓN, A. ARUFE VARELA y X.M. CARRIL VÁZQUEZ, Derecho de la Seguridad Social, 2a ed., Netbiblo [A Coruña, 2008], págs. 18 y ss.).

3 Véase A. ARUFE VARELA, «¿Por qué no se encuentran ni siquiera mencionados en el Estatuto de los Trabajadores los contratos de trabajo comunes y especiales de más rabiosa actualidad?», Foro Galego, núm. 195 (2006), págs. 43-44.
} 
de plan (carácter sistemático) y unidad de momento (carácter o vocación de perennidad) ${ }^{4}$. Esta última vocación la evidencia, por ejemplo, la disposición adicional tercera de nuestro Código Civil de 1889. Según ella, «en vista de estos datos, de los progresos realizados en otros países que sean utilizables en el nuestro, y de la jurisprudencia del Tribunal Supremo, la Comisión de codificación formulará y elevará al Gobierno cada diez años las reformas que convenga introducir» ${ }^{5}$.

Cuando el Gobierno español se anime a cumplirla, la citada disposición adicional octava del Estatuto de los Trabajadores precipitará en un verdadero «Código de Trabajo» contemporáneo — que incluiría también las Leyes Orgánicas de interés para un laboralista y sus enmiendas sucesivas, hoy de imposible refundición-, pues dicha disposición estatutaria extravagante afirma que «el Gobierno, a propuesta del Ministerio de Trabajo y Seguridad Social [hoy, como se sabe, Ministerio de Trabajo y Asuntos Sociales], recogerá en un texto único denominado Código de Trabajo, las distintas leyes orgánicas y ordinarias que, junto con la presente, regulan las materias laborales, ordenándolas en Títulos separados, uno por Ley, con numeración correlativa, respetando íntegramente su texto literal» (párrafo primero), y teniendo en cuenta que «asimismo se incorporarán sucesiva y periódicamente a dicho Código de Trabajo todas las disposiciones generales laborales mediante el procedimiento que se fije por el Gobierno en cuanto a la técnica de incorporación, según el rango de las normas incorporadas» (párrafo segundo) ${ }^{6}$.

En el ordenamiento portugués, como lenitivo, existe el mecanismo de la «republicación [republicação]» de las Leyes. Lo regula la Ley 74/1998, de 11 noviembre, «sobre la publicación, la identificación y el formulario de los textos legales», en la que se prevé la «republicación íntegra de los textos que revistan forma de Ley, en anexo», en todo caso, cuando «existan más de tres alteraciones al acto legislativo en vigor, salvo que se trate de alteraciones a Códigos» ${ }^{7}$. Esta misma institución se aplica en Portugal, también, a los convenios colectivos ${ }^{8}$.

§2. En Francia, sí se han tomado completamente en serio la tarea de facilitar al ciudadano el conocimiento de sus derechos y deberes, llevándose aquí a cabo la elaboración de códigos de legislación que son un paso adelante evidente sobre los códigos tradicionales o clásicos, puesto que se trata de auténticos códigos de Derecho constante, permanentemente puestos al día por el Estado con todas sus enmiendas, añadidos, supresiones, etc. Además, los códigos franceses resultan pública y gratuitamente manejables, en su última versión al día - en su versión consolidada, por tanto-, a través del portal en Internet de Legifrance (www.legifrance.gouv.fr) ${ }^{9}$ cuya entrada

4 Véase E. MONTANOS FERRÍN y J. SÁNCHEZ-ARCILLA, Historia del Derecho y de las Instituciones, Tomo III, Dykinson (Madrid, 1991), págs. 496 y ss.

5 Sobre los «riesgos de la codificación», véase M. ALONSO GARCÍA, La codificación del Derecho del Trabajo, CSIC (Madrid, 1957), págs. 77 y ss.

6 Véase J. SERRANO CARVAJAL, «La codificación del Derecho del Trabajo en España», Revista de Política Social, núm. 135 (1982), págs. 45 y ss.

7 Artículo 6, apartado 3, letra a).

8 Cfr. artículo 494, apartados 2 y 3, del vigente Código portugués del Trabajo, a que se alude infra, §4.

9 Véase supra, Tema 1, \$2. 
«los códigos [les codes]» da acceso a un total de hasta sesenta y uno de tales códigos, ordenados alfabéticamente en su lengua original. La propia entrada posibilita la consulta de casi una docena de ellos en lenguas inglesa $\mathrm{y}$ española ${ }^{10}$, aunque en versión original francesa sólo se encuentran disponibles los dos códigos que a un laboralista más le interesa conocer. En primer lugar, el "Código del Trabajo [Code du Travail]»" cuya parte principal o "parte legislativa» — también tiene una «parte reglamentaria»- se compone estructuralmente de ocho Partes, en las que no sólo se contiene la regulación sustantiva de las instituciones relativas al Derecho individual y al Derecho colectivo del Trabajo, sino que también incluyen aspectos de carácter propiamente adjetivo, penal y procesal, e incluso, de Seguridad Social ${ }^{12}$. Y en segundo lugar, el «Código de la Seguridad Social [Code de la Sécurité Sociale]» ${ }^{13}$, cuya parte principal o «parte legislativa» la conforman nueve Libros, en los que se contiene el conjunto de disposiciones reguladoras del sistema público francés de seguridad social, como lo concerniente a lo prestacional y lo instrumental, al régimen general y a los regímenes especiales, a lo contributivo y a lo no contributivo, etc. ${ }^{14}$.

En el Código del Trabajo, los preceptos incluidos en su parte principal o «parte legislativa» se componen siempre de un número de cuatro cifras, precedido por la letra mayúscula «L», y seguido por un guión y otro número más. Así, por ejemplo, en su artículo L. 1111-1, la letra mayúscula «L» indica que el precepto en cuestión se encuentra insertado precisamente en la «parte legislativa» del propio Código (en la que sólo se insertan preceptos con rango de Ley, pudiendo ser esta última una Ley en sentido propio [Loi], un Decreto-Ley [Décret-Loi] o una Ordenanza [Ordonnance]), mientras que las cuatro cifras del número central hacen referencia a la Parte (la cifra del millar), al Libro (la cifra de la centena), al Tïtulo (la de la decena) y al Capítulo (la de la unidad) en que se ubica el artículo L. en cuestión (por tanto, en el ejemplo citado, estaríamos hablando de un precepto perteneciente a su Parte I, Libro I, Título I, Capítulo I). El número que figura a continuación del guión constituye simplemente un número de orden.

10 Más en concreto, el Código Civil, el Código de Comercio, el Código Penal, el Código Procesal Penal, el Código de la Propiedad Intelectual, el Código del Consumo, el Código Monetario y Financiero, el Código de los Seguros, el Código de Proceso Civil, el Código de Medio Ambiente y el Código de Contratos Públicos.

11 Hipercríticos con él, para sorpresa de un laboralista español, véase J. PÉLISSIER, A. SUPIOT y A. JEAMMAUD, Droit du travail, 24a ed., Dalloz (Paris, 2008), pág. 78.

12 Más en concreto, el relativo al desempleo contributivo y no contributivo. Al respecto, véase infra, Tema 9, §1, y Tema 10, §4.

13 Véase A. ARUFE VARELA, «Dos modelos contrastantes de codificación de la legislación de seguridad social: el continental europeo y el norteamericano», Revista de Derecho Social, núm. 44 (2009), págs. 121 y ss.

14 Con esta misma estructura, también resulta de interés para el laboralista —aparte los códigos procesales comunes- el «Código de la Acción Social y de las Familias [Code de l'Action Sociale et des Familles]». Según F. KESSLER, Droit de la protection sociale, 2a ed., Dalloz (Paris, 2005), pág. 158, interesan al especialista en seguridad social hasta «8 códigos» franceses distintos. 
En el Código de la Seguridad Social, en cambio, los preceptos incluidos en su parte principal o «parte legislativa» se componen siempre de un número tres cifras, precedido asimismo por la letra mayúscula «L», y seguido por un guión y otro número más. Aquí las tres cifras del número central hacen referencia al Libro (la cifra de la centena), al Título (la de la decena) y al Capítulo (la de la unidad). Por eso, el artículo L. 111-1 indica aquí que se trata de un precepto correspondiente al Capítulo I del Título I del Libro I de dicho Código.

Esta «parte legislativa» es sólo una de las grandes partes de tales Códigos, a completar con la parte reglamentaria secundaria (en la que se recopilan preceptos de Decretos adoptados con intervención del Consejo de Estado [Décrets en Conseil d'Etat], a los que se asigna para su identificación la letra «R») y con la parte reglamentaria accesoria (en la que se recopilan preceptos de Decretos simples [Décrets simples], a los que se asigna para su identificación la letra «D»). La numeración de sus preceptos sigue las mismas pautas que en la «parte legislativa», aunque los preceptos de estas otras dos partes están precedidos por las letras «R»o «D», respectivamente. En el Código del Trabajo, ambas partes reglamentarias están fusionadas en una sola; en el Código de la Seguridad Social, en cambio, se encuentran formalmente diferenciadas.

La metodología a seguir para la creación o reelaboración de todos los códigos franceses contemporáneos aparece determinada, con una claridad que llama la atención, en una trascendental Circular de 30 mayo 1996, «relativa a la codificación de los textos legislativos y reglamentarios» ${ }^{15}$. De entre los principios a que se ajusta, destacan especialmente tres. El principio de la «codificación "en Derecho constante"», relativo a la inmediata inclusión en el Código de que se trate de todas las enmiendas por él padecidas, aportando — como regla - meras «modificaciones de forma para adaptar el texto a la necesidad de la comprensión o de la coherencia de los textos codificados»; el principio del «perímetro y relaciones con los otros códigos», asentado sobre las reglas «no "maxi-códigos" ni "mini-códigos"» y «no códigos de ministerios, sino códigos de materias»; y el de la programación con arreglo a un calendario razonable, a desarrollarse entre los años 1996-2000.

En esta programación no figuraban ni el Código del Trabajo ni el Código de la Seguridad Social, puesto que se trataba de Códigos existentes en Francia desde mucho antes. En efecto, el primer Código del Trabajo francés se remonta a los comienzos del pasado siglo XX, pues sus diversos Libros fueron promulgados entre 1910 y $1927^{16}$, habiendo sido el actualmente vigente Código francés del Trabajo promulgado en 2008, en sustitución del anterior de $1973{ }^{17}$. Por su parte, el Código francés de la Seguridad Social actualmente vigente fue promulgado en 1985, en sustitución del primer Código francés sobre el tema, que se remonta al año $1956^{18}$.

§3. En Ale mania, la legislación de contenido más estrictamente laboral no se encuentra codificada, pero sí existe en cambio un Código

15 Localizable en www.legifrance.gouv.fr.

16 Véase P. PIC, Traité élémentaire de législation industrielle. Les lois ouvrières, $6^{\mathrm{a}}$ ed., Rousseau \& Cie. (París, 1931), pág. 573.

17 Sobre las normas «recodificadoras» de 2008, legislativa y reglamentaria, véase J. PÉLISSIER, A. SUPIOT y A. JEAMMAUD, Droit du travail, 24a ed., cit., pág. 78.

18 Véase J.-P. CHAUCHARD, Droit de la Sécurité Sociale, $4^{\mathrm{a}}$ ed., LGDJ (Paris, 2005), pág. 90, nota 34. Acerca de su peculiar estructura, véase J.-J. DUPEYROUX, M. BORGETTO, R. LAFORE y R. RUELLAN, Droit de la sécurité sociale, $15^{\mathrm{a}}$ ed., Dalloz (Paris, 2005), pág. 385. Acerca del reparto constitucional de competencias legislativas y reglamentarias en materia de seguridad social, véase R. PELLET, Leçons de droit social, Dalloz (Paris, 2005), págs. 78 y ss. 
de Seguridad Social (Sozialgesetzbuch). Su texto completo resulta accesible de manera gratuita, y en versión consolidada en Internet -integrando todas las sucesivas e incesantes reformas que la materia de seguridad social, al igual que sucede en España, también padece en Alemania-, a través del repertorio legislativo genérico en la web del Ministerio federal de Justicia (el ya citado http://bundesrecht. juris.de) ${ }^{19}$. Aún resulta más útil la consulta del Código de Seguridad Social - siempre en su versión consolidada puesta al día, y de visita gratuita - a través del repertorio legislativo específico en la web del Ministerio federal de Trabajo y de Seguridad Social (Bundesministerium für Arbeit und Soziales) —en la dirección http://gesetze.bmas.bund.de—, que posee el valor añadido de facilitar en mayor medida el manejo de esta obra legislativa monumental, dado que permite visualizar el índice de cada uno de los doce Libros de que se compone, y además, da acceso directo desde el propio índice a todos y cada cada uno de los preceptos - que en Alemania no se denominan artículos (como en Francia [articles], Italia [articoli] o Portugal [artigos]), sino «parágrafos [Paragrafen]», representados en las leyes alemanas por el símbolo «§»— que integran el libro en cuestión. Son doce Libros de contenido eminentemente sustantivo, puesto que su núcleo duro viene conformado por la regulación al detalle del aseguramiento legal de los distintos riesgos y contingencias, aunque lógicamente también hay espacio para la regulación de los aspectos instrumentales de la protección. Lo que no aparece incluido de momento en el Código de Seguridad Social es la materia procesal — aun a pesar de existir en Alemania un contencioso específico de seguridad social—, dado que esta materia todavía se encuentra recogida en una Ley específica aparte, que quizá en el futuro llegue a constituir el decimotercer Libro del propio Código ${ }^{20}$.

Este Código alemán de Seguridad Social empezó a elaborarse en 1969 — con la finalidad de poner fin al caos legislativo existente en materia de seguridad social, regulada por aquel entonces en más de «800 leyes y reglamentos» ${ }^{21}$ - habiéndose promulgado en 2003 su Libro XII (y penúltimo, en principio) ${ }^{22}$.

19 Sobre él, véase supra, Tema $1, \$ 3$.

20 Al respecto, véase infra, Tema $10, \S 3$.

21 Véase K. WITTERSTÄTTER, Soziale Sicherung. Eine Einführung für Sozialarbeiter/ Sozialpädagogen mit Fallbeispielen, $6^{\mathrm{a}}$ ed., Luchterhand (Munich, 2003), págs. 27-28.

22 Véase B. SCHULIN, «Introducción», en el volumen Sozialgeseztbuch, 33 ed., Beck (Munich, 2006), págs. IX-LVIII. Acerca de su estructura, cfr. E. EICHENHOFER, Sozialrecht, 5 a ed., Mohr Siebeck (Tubinga, 2004), págs. 95-96. Acerca de su fundamentación constitucional, R. WALTERMAN, Sozialrecht, $5^{a}$ ed., C.F. Müller (Heidelberg, 2005), págs. 5 y ss. Y acerca de la legislación sustantiva alemana de seguridad social que todavía vaga fuera del Código, B. SCHULIN y G. IGL, Sozialrecht, $6^{\text {a }}$ ed., Werner Verlag (Düsseldorf, 1999), págs. 43 y ss,; y H. BLEY, R. KREIKEBOHM y A. MARSCHNER, Sozialrechr, 8ª ed., Luchterhand (Neuwied y Kriftel, 2001), pág. 9. 
Las rúbricas de los doce Libros en cuestión son las siguientes: la del Libro I, «Parte general [Allgemeiner Teil]»; la del Libro II, «Aseguramiento básico de los demandantes de empleo [Grundsicherung für Arbeitsuchende]»; la del Libro III, «Fomento del empleo [Arbeitsförderung]»; la del Libro IV, «Disposiciones comunes sobre el aseguramiento social [Gemeinsame Vorschriften für die Sozialversicherung]»; la del Libro V, «Aseguramiento legal de la enfermedad [Gesetzliche Krankenversicherung]»; la del Libro VI, «Aseguramiento legal de las pensiones [Gesetzliche Rentenversicherung]»; la del Libro VII, «Aseguramiento legal del accidente [Gesetzliche Unfallversicherung]»; la del Libro VIII, "Asistencia de niños y asistencia de jóvenes [Kinder- und Jugendhilfe]»; la del Libro IX, «Rehabilitación y discapacitados reconocidos [Rehabilitation und Teilhabe behinderter Menschen]» ${ }^{23}$; la del Libro X, «Procedimiento administrativo de seguridad social y protección de datos de seguridad social [Sozialverwaltungsverfahren und Sozialdatenschutz]»; la del Libro XI, «Aseguramiento social de la dependencia [Soziale Pflegeversicherung] ${ }^{24}$; y la del Libro XII, «Asistencia social [Sozialhilfe] ${ }^{25}$.

Téngase en cuenta que el Tratado de Unificación de Alemania de 1990 preveía la elaboración de un Código del Trabajo —en la República Democrática de Alemania existía ya un «Arbeitsgesetzbuch» desde 1961-, pero las diferencias entre la patronal y los sindicatos alemanes, a propósito de este tema, han provocado que dicho proyecto se encuentre actualmente en estado hibernación ${ }^{26}$.

§4. En Portugal, la legislación relativa a la materia de seguridad social se encuentra desperdigada, pero no sucede lo mismo con la propiamente laboral, que fue codificada en $2003^{27}$, apareciendo esta codificación actualmente encarnada en el Código del Trabajo (Código do Trabalho), publicado como Anexo a la Ley núm. 7/2009, de 12 febrero $^{28}$. Su contenido lo compone un total de más de seis centenares y medio de artículos, que se distribuyen entre dos grandes partes o Libros ${ }^{29}$,

23 Al respecto, véase K. LACHWITZ, W. SCHELLHORN y F. WELTI, HK-SGB IX. Handkommentar zum Sozialgesetzbuch IX. Rehabilitation und Teilhabe behinderter Menschen, $3^{\mathrm{a}}$ ed., Luchterhand (Colonia, 2010), págs. 516 y ss.

24 Al respecto, véase H. SCHELLHORN, SGB XI - Pflegeversicherung. Textausgabe des Sozialgesetzbuches -Elftes Buch -. Soziale Pflegeversicherung mit einer systematischen Einführung, $4^{\mathrm{a}}$ ed., Luchterhand (Munich, 2005), págs. 2 y ss.

25 Al respecto, véase W. SCHELLHORN, SGB XII - Sozialhilfe. Textausgabe des Sozialgesetzbuches -Zwölftes Buch - (SGB XII). Sozialhilfe mit einer systematischen Einführung, 12 a ed., Luchterhand (Munich, 2005), págs. 2 y ss.

26 Al respecto, véase U. ZACHERT, Lecciones de Derecho del Trabajo alemán (traducción castellana de F. MARTÍN RODRÍGUEZ y N. MENDOZA NAVAS), Ministerio de Trabajo y Asuntos Sociales (Madrid, 1998), pág. 31.

27 El primer Código portugués del Trabajo fue publicado como Anexo a la Ley núm. 99/2003, de 27 agosto. Sobre él, véase P. ROMANO MARTÍNEZ, L.M. MONTEIRO, J. VASCONCELOS, P. MADEIRA DE BRITO, G. DRAY y L. GONÇALVES DA SILVA, Código do Trabalho. Anotado, 4ª ed., Almedina (Coimbra, 2005), págs. 25 y ss.

28 Contextualizándolo magistralmente, véase A. MONTEIRO FERNANDES, Direito do Trabalho, $15^{\mathrm{a}}$ ed., Almedina (Coimbra, 2010), págs. 46 y ss.

29 Se trata de una estructura heredada del primer Código portugués del Trabajo. Sobre ella, véase B.G.L. XAVIER, Curso de Direito do Trabalho. I. Introdução, quadros organizacionais e fontes, $3^{\mathrm{a}}$ ed., Verbo (Lisboa, 2004), págs. 515 y ss. 
aunque en realidad el primero de estos dos Libros resulta ser muchísimo más grande que el segundo. Bajo la rúbrica genérica de «Parte general», el Libro primero se dedica a la regulación de lo individual - en un macrotítulo dedicado al "Contrato de trabajo [Contrato de trabalho]», conformado por casi cuatrocientos artículos - y de lo colectivo - en el título relativo al «Derecho colectivo [Direito colectivo]», menos extenso que el anterior, pero aun así con casi centenar y medio de preceptos-, aunque lo que más llama la atención a un laboralista español es que dentro de lo individual - y al lado del salario, de la jornada, de la extinción del contrato, etc. - se encuentre también la disciplina de los «accidentes de trabajo [acidentes de trabalho]» y la de las «enfermedades profesionales [doenças profissionais] ${ }^{30}$. Bajo la rúbrica «Responsabilidades penal y administrativa [Responsabilidades penal e contra-ordenacional]», el Libro segundo - mucho más breve que el anterior, puesto que sólo tiene dos decenas de preceptos - resulta ser el equivalente de nuestra Ley de Infracciones y Sanciones en el Orden Social de 2000, habida cuenta que el grueso de su contenido se dedica a la regulación general de las infracciones de carácter administrativo y a la de sus correspondientes sanciones. El Código portugués del Trabajo es más clásico que contemporáneo, aunque su texto íntegro pueda ser consultado a través del sitio público en Internet de localización genérica de la legislación lusa —recuérdese, en www.dre.pt ${ }^{31}$ — ya que aquí no podemos manejar un texto consolidado de la norma compiladora con sus reformas posteriores — que ya las ha habido—, sino sólo su texto originario; si bien este defecto queda paliado con el manejo del portal específico del Ministerio portugués del Trabajo y de la Solidaridad Social — sito en www.mtss.gov.pt—, donde consta una versión consolidada del Código ${ }^{32}$.

Dentro de este portal, se encuentra en la entrada de «Legislação», que permite acceder —vía «Emprego»— a la «Legislação Nacional». Aquí también se puede consultar el texto de la única norma que hasta el momento ha modificado el Código del Trabajo. Se trata de la Ley núm. 105/2009, de 14 septiembre.

El Código - a diferencia del primero de 2003 - no posee ninguna gigantesca norma de desarrollo ${ }^{33}$, aunque prevé la existencia de «legislación específica» a la que remite, y que va promulgándose progresivamente (como, por ejemplo, en materia de prevención y reparación de riesgos laborales).

30 Véase artículos 281 a 284. Justificando los porqués de esta peculiar regulación, véase B.G.L. XAVIER, Direito do Trabalho. Ensinar e investigar, Universidade Católica Editora (Lisboa, 2005), págs. 41-42.

31 Véase supra, Tema $1, \mathbf{\$ 3}$.

32 Véase infra, Tema 3, §3.

33 La del primer Código fue sorprendentemente aprobada por la Ley núm. 35/2004, de 29 julio, que «reglamenta la Ley núm. 99/2003, de 27 de agosto, que aprobó el Código del Trabajo». 
En Portugal, existe también un denominado «Código de Proceso del Trabajo [Código de Processo do Trabalho]», aprobado por Decreto-Ley núm. 480/99, de 9 noviembre. Pero se trata más bien de un equivalente de nuestra Ley de Procedimiento Laboral. Ha sido republicado como anexo del Decreto-Ley núm. 295/2009, de 13 octubre.

§5. Los Estados Unidos de Norteamérica son uno de los pocos países del mundo donde toda su legislación está codificada; y además, codificada en un solo código ${ }^{34}$, verdadera obra faraónica en la que aparece recogida toda la legislación federal, no sólo la relativa a las materias laboral y de seguridad social. En efecto, el Código de los Estados Unidos (United States Code) -accesible a través de Internet, como ya se dijo ${ }^{35}$-, que se remonta al año 1926, está estructurado en cincuenta grandes Títulos, ordenados alfabéticamente a partir del número 7 -que trata de la «Agricultura [Agriculture]» (los números 2 y 3 tratan de «El Congreso [The Congress]» y de «El Presidente [The President]», respectivamente)—, cabiendo manejar a su través legislación federal que con frecuencia se encuentra autónomamente codificada en Europa, como la legislación federal mercantil (en su Título 15, sobre «Comercio y profesión [Commerce and Trade]»), la legislación federal penal (en su Título 18, sobre «Delitos y Enjuiciamiento Criminal [Crimes and Criminal Procedure]»), la legislación federal jurisdiccional orgánica y procesal civil (en su Título 28, sobre «Organización Judicial y Enjuiciamiento Civil [Judiciary and Judicial Procedure]»), refiriéndose el último Tïtulo - el 50, recuérdese- de este Código faraónico a la «Guerra y la Defensa Nacional (War and National Defense)». A un laboralista, como es lógico, lo que más le interesan son dos concretos Títulos del Código, que tratan de las materias más íntimamente ligadas con los aspectos laborales y de seguridad social. En primer lugar, el Título 29 - rubricado «Trabajo [Labor]»—, que consta de más de tres decenas de Capítulos —resultando especialmente llamativos el Capítulo 7 (sobre «Relaciones entre el sindicato y la empresa [Labor-Management Relations]») ${ }^{36}$, el Capítulo 8 (sobre «Condiciones de Trabajo Mínimas

34 En la India - país emergente, pero con cada vez más intensas relaciones comerciales con el mundo occidental一, existe también un «Indiacode» electrónico, elaborado con la finalidad de sortear el obstáculo de que «las herramientas tradicionales de elaboración legislativa y de búsqueda parezcan ser tecnología de la Edad de Piedra». Al respecto, véase http://indiacode.nic.in.

35 Supra, Tema 1, §5.

36 Sobre el tema, véase R.A. GORMAN, Basic Text on Labor Law. Unionization and Collective Bargaining, West Publi. Co. (St.Paul-Minn, 1976), págs. 1 y ss.; B. TAYLOR y F. WITNEY, Labor

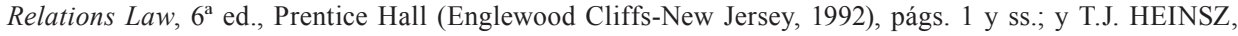
D.R. NOLAN y R.A. BALES, Labor Law. Collective Bargaining in a Free Society, 6 a ed., West Publ. Co. (St. Paul-Minn., 2009), págs. 2 y ss. 
[Fair Labor Standards]») ${ }^{37}$ y el Capítulo 15 (sobre «Seguridad y Salud Laboral [Occupational Safety and Health]») ${ }^{38}$-, casi siempre parcelados en Subcapítulos, que no constituyen ningún texto corrido, pues al igual que las leyes españolas también están divididos en artículos, que en el Código de los Estados Unidos - como en todas las leyes anglosajonas- se denominan «secciones (sections)» (y que, como los parágrafos alemanes, se representan en el Código con el símbolo «§»). Y en segundo lugar, el Título 42 -bajo la rúbrica «Salud pública y asistencia social [Public health and welfare]»-, parte gigantesca del Código compuesta por más de ciento cuarenta y siete Capítulos ${ }^{39}$, de los cuales el más decisivo a nuestros efectos es el Capítulo 7 (rotulado «Seguridad Social [Social Security]») ${ }^{40}$, que consta a su vez de veintiún Subcapítulos, resultando de entre ellos especialmente llamativos para un laboralista español el Subcapítulo II (rotulado «Prestaciones Federales del Seguro de Vejez, de Supervivientes y de Incapacidad [Federal Old-Age, Survivors, and Disability Insurance Benefits]») y el Subcapítulo VII (rotulado «Administración [Administration]»).

Los operadores jurídicos norteamericanos citan el Código de los Estados Unidos indicando sólo el número del precepto y el del Título, dado que cada uno de los cincuenta Títulos del mismo cuenta con su propia numeración independiente. Por eso, 42 U.S.C. $\S$ 405(g) significa sección (equivalente a artículo, recuérdese) 405(g) del Título 42 del Código de los Estados Unidos. Precisamente este precepto, de gran interés para un laboralista, trata del contencioso norteamericano de la seguridad social.

De acuerdo con la sección 204(a) de su Título 1, el Código de los Estados Unidos hace «prueba plena [legal evidence]» del Derecho en él contenido, pero sólo respecto de los Títulos «aprobados como derecho positivo [enacted into positive law]». Según esta misma sección, los Títulos 29 y 42 del Código no han sido aprobados como derecho positivo, y por esta razón el Código sólo constituye "prueba "iuris tantum" [prima facie evidence]» de su contenido. Ello explica que los operadores jurídicos norteamericanos deban seguir citando todavía el texto de las Leyes no codificadas, enlatadas en dichos Títulos, a través del repertorio oficial denominado «Leyes en extenso [Statutes at large]»—que sí hace prueba plena del Derecho en cuestión, según la sección 112 del Título 1 del Código de los Estados Unidos-, cuya consulta también resulta posible a través del portal jurídico del Gobierno de los Estados Unidos ${ }^{41}$.

37 Sobre la historia de esta legislación, véase S. ESTREICHER y M.C. HARPER, Cases and Materials on the Law governing the Employment Relationship, $2^{\mathrm{a}}$ ed., West Publi. Co. (St. Paul-Minn., 1992), págs. 1 y ss.

38 Sobre la historia de esta legislación, véase M.A. ROTHSTEIN, Occupational Safety and Health Law, $3^{\text {a }}$ ed., West Publ. (St. Paul-Minn., 1990), págs. 1 y ss.

39 Al respecto, véase J. MARTÍNEZ GIRÓN, «El modelo norteamericano de codificación de la legislación de Seguridad Social», en el vol. V Congreso Nacional de la Asociación Española de Salud y Seguridad Social. La Seguridad Social en el siglo XXI, Laborum-AESSS (Murcia, 2008), págs. 391 y ss.

40 Véase H.L. McCORMICK, Social Security. Claims and Procedures, $4^{\mathrm{a}}$ ed., West Publ. Co. (St. Paul-Minn., 1991), págs. 1 y ss.

41 Sobre él, véase supra, Tema 1, \$5. 
El Código de Reglamentos Federales (Code of Federal Regulations) — también accesible a través de Internet ${ }^{42}$ - resulta todavía más faraónico que el de Leyes federales. Por poner sólo un ejemplo, el Subcapítulo VII del Título 42 del Código de los Estados Unidos (relativo, como se dijo, a la Administración de Seguridad Social) aparece reglamentado en el Capítulo III del Título 20 del Código de Reglamentos Federales, que es un Título incluido en la rama del propio Código relativa a las «Agencias Ejecutivas», en la que aparecen reguladas Agencias federales como la CIA, la NASA, el Sistema de la Reserva Federal, el NLRB, o el Instituto Smithsoniano, entre otras muchísimas. Pues bien, da una idea tan solo aproximada de la complejidad de los Reglamentos federales relativos a la recién citada «Administración de Seguridad Social», el hecho de que el Capítulo III del Título 20 de este otro Código aparezca dividido, a su vez, en nada más y nada menos que cien Partes, numeradas del 400 al 499.

Algún concreto Estado federado norteamericano — no solamente la afrancesada Luisiana $^{43}$ - también posee codificada su propia legislación estatal. Es el caso, por ejemplo, de California - al parecer, sexta potencia industrial del mundo, por encima de Francia-, cuya legislación resulta accesible a través de www.leginfo.ca.gov. En este sitio oficial de Internet obran veintinueve códigos californianos (Civil, Penal, Comercial, etc.), incluido su «Código del Trabajo [Labor Code]».

La expresión «Código de Práctica [Code of Practice]» es, en la actualidad, más popular en la legislación británica que en la de los Estados Unidos. Se refiere a protocolos oficiales de actuación, que complementan - al modo de reglamentos - los preceptos de las leyes. Trascendentales son, por ejemplo, los «Códigos de Práctica emanados por el Secretario de Estado [Issue of Codes of Practice by the Secretary of State]» - esto es, por el Ministro galés e inglés, o escocés, de Industria y Comercio- a que se refiere el Capítulo III de la de la Ley (consolidada) de Sindicatos y Relaciones Laborales de $1992^{44}$.

42 Ibidem. En este otro Código, el «Federal Register» es el equivalente de las recién citadas «Leyes en extenso».

43 Su legislación resulta accesible a través de www.legis.state.la.us.

44 Estos Códigos resultan accesibles a través de www.bis.gov.uk (vía «employment matters»). 
TEMA 3

SITIOS DE INTERNET RELATIVOS A LA LEGISLACIÓN NO

CODIFICADA, COMUNITARIA Y EUROPEA, DE TRABAJO Y SEGURIDAD SOCIAL

Sumario: §1. Para la localización de legislación laboral y de seguridad social de la Unión Europea. \$2. Para la localización de la legislación laboral alemana. §3. Para la localización de la legislación de seguridad social portuguesa. §4. Para la localización de la legislación laboral y de seguridad social italiana (y también, española). §5. Para la localización de la legislación laboral y de seguridad social británica.

THEME 3

INTERNET SITES RELATING TO LABOR AND SOCIAL SECURITY, COMMUNITY AND EUROPEAN, NON-CODIFIED LEGISLATION

Contents: \$1. To find labor and social security legislation of the European Union. \$2. To find German labor legislation. \$3. To find Portuguese social security legislation. \$4. To find Italian (and also, Spanish) labor and social security legislation. \$5. To find British labor and social security legislation.

\$1. Lógicamente, el conocimiento por el ciudadano de las instituciones jurídico-laborales y de seguridad social, siempre a través de Internet, presenta dificultades adicionales cuando la legislación reguladora de dichas instituciones, en vez de estar toda sistematizada en Códigos (como ocurre, por ejemplo, en Francia o en los Estados Unidos de Norteamérica) ${ }^{1}$, se encuentra dispersa en una pluralidad de textos jurídicos distintos (que eventualmente pueden llegar a ser muchos $\mathrm{y}$, además, de muy diversos rangos). En los ordenamientos que poseen portales jurídicos de carácter multidisciplinar (civil, penal, administrativo, procesal, laboral, etc.), los problemas adicionales de conocimiento planteados por esta dispersión normativa pueden obviarse, sin necesidad de salir del sitio de Internet en cuestión, supuesto que aparezca en él clasificada — por grandes áreas temáticas — toda la variopinta legislación que resulte

$1 \quad$ Véase supra, Tema 2, \$2 y \$5. 
accesible a su través. Es lo que sucede, por ejemplo, en el ordenamiento jurídico de la Unión Europea — donde, como se sabe, su legislación no está en absoluto codificada-, dado que su portal jurídico plurilingüe «EUR-lex» ${ }^{2}$ permite acceder (vía «Colecciones») al «Repertorio de la legislación vigente de la Unión Europea», que ofrece una visión panorámica de la misma a través de veinte «capítulos», de los cuales el que a un laboralista le interesa más es el relativo a «Libre circulación de trabajadores y política social», cuyo subcapítulo «Política social» permite acceder directamente, a su vez, a la legislación comunitaria vigente sobre seis grandes tópicos laborales y de seguridad social («Disposiciones sociales generales», «Fondo Social Europeo», «Condiciones de Trabajo», «Desempleo y empleo», «Seguridad Social» y «Armonización de determinadas disposiciones en materia social»).

En «Eur-lex», tanto el mecanismo de búsqueda en la legislación como el de búsqueda simple permiten acceder a textos normativos comunitarios (por ejemplo, reglamentos o directivas) presentados con una utilísima documentación acompañante (trabajos preparatorios, relación con otros documentos, actos a los que afecta, sucesivas «versiones consolidadas», etc.).

Acerca del peculiar significado de la palabra «codificación» en la legislación comunitaria, resulta del todo revelador el Dictamen del Comité Económico y Social de la Unión Europea sobre la «Propuesta de Directiva del Consejo referente a la aproximación de las legislaciones de los Estados miembros que se refieren a los despidos colectivos (versión codificada)» ${ }^{3}$, en el que se afirma literalmente lo siguiente: 1) «es ésta la primera codificación de una Directiva en el ámbito de la legislación laboral y social»; 2) «con arreglo a su Decisión de 1 de abril de 1987, la Comisión debe proceder a la codificación constitutiva u oficial de los actos jurídicos como máximo tras su décima modificación»; y 3) «la Directiva sobre los despidos colectivos sólo se ha modificado en una ocasión», aunque «no obstante esto último, la codificación de los presentes actos jurídicos es conveniente y oportuna, dado que sus disposiciones afectan a un gran número de ciudadanos de la Unión Europea».

En el sitio en Internet de la Comisión Europea, resulta posible acceder — vía «Políticas y legislación»- a «Prelex», que es la base de datos de los procedimientos interinstitucionales, abriéndose así la posibilidad de manejar — entre otros muchos documentos - los textos de las «propuestas» y «comunicaciones» de la Comisión dirigidas al Consejo o al Parlamento Europeo.

§2. En el ordenamiento alemán, en cambio, no queda más remedio que salir del sitio de Internet relativo a su específico portal jurídico multidisciplinar — que posee, recuérdese, el valor añadido de ofrecer «versiones consolidadas» ${ }^{4}$ - , si es que pretende tenerse una visión panorámica de la legislación laboral allí vigente (la legislación de seguridad social, como

Sobre él, véase supra, Tema $1, \S 4$.

Localizable en el Diario Oficial de la Unión Europea Serie C 158, de 26 abril 1997, pág. 11.

4 Véase supra, Tema 1, \$3. 
se vio, está casi integralmente codificada en su «Código de Seguridad Social $\left[\right.$ Sozialgesetzbuch]») ${ }^{5}$. En efecto, en dicho portal jurídico multidisciplinar las normas legales y reglamentarias de la Federación (laborales y no laborales) aparecen todas entremezcladas, al estar clasificadas única y exclusivamente por orden alfabético. De ahí que existan otros sitios de Internet, de acceso libre, con el valor añadido de clasificar toda esa masa ingente de legislación por grandes áreas temáticas, entre los que destaca - a nuestros efectos - el sitio gestionado por el Ministerio Federal alemán de Trabajo y de Seguridad Social (Bundesministerium für Arbeit und Soziales) —ubicado en www. bmas.bund.de_- en el que todas las normas federales laborales, legales y reglamentarias, vigentes en Alemania (con su denominación completa y su correspondiente abreviatura) aparecen clasificadas (en el enlace «Gesetzte») por medio de sólo tres tópicos principales («Mercado de trabajo [Arbeitsmarkt]», «Derecho del Trabajo [Arbeitsrecht]» y «Protección [frente a los Riesgos] del Trabajo [Arbeitsschutz]») ${ }^{6}$.

Acerca del volumen de información jurídica acumulada en dichos tres tópicos principales - accesible utilizando el subenlace «Gesetze», dentro de cada tópico-, baste indicar que en «Mercado de Trabajo» se incluyen hasta cuarenta normas; en «Derecho del Trabajo», hasta setenta y cuatro (sustantivas y adjetivas); y en «Protección [frente a los Riesgos] del Trabajo», hasta treinta y cuatro.

Las versiones de todas estas normas son las mismas que constan alfabéticamente clasificadas en el portal jurídico multidisciplinar citado, pudiendo accederse a cada una de ellas desde el propio sitio en Internet de este Ministerio ${ }^{7}$.

La vitalidad del Código Civil alemán (Bürgerliches Gesetzbuch) de 1896, en la parte del mismo relativa a la regulación del «contrato de arrendamiento de servicios [Dienstvertrag]», parágrafos 611 a $630^{8}$ — que se aprovechan incluso para transponer Directivas laborales comunitarias-, puede explicar la resistencia de la legislación laboral alemana a codificarse, a diferencia de lo que ocurre con la de seguridad social ${ }^{9}$.

5 Véase supra, Tema 2, §4.

6 Tópicos secundarios, siempre de carácter exclusivamente laboral, son los relativos a «Aus- und Weiterbildung» y a «Teilhabe behinderter Menschen».

7 El más acreditado comentario al conjunto de la legislación laboral federal alemana es MÜLLERGLÖGE, R., PREIS, U. y SCHMIDT, I. (Editores), Erfurter Kommentar zum Arbeitsrecht, 10a ed., C.H. Beck (Múnich, 2010), XLI+2856 págs. Sobre él, véase J. MARTÍNEZ GIRÓN, «El género doctrinal "comentarios" en el Derecho alemán. A propósito del "Comentario Erfurtense" sobre Derecho alemán del Trabajo», Revista Española de Derecho del Trabajo, núm. 141 (2009), págs. 5 y ss.

8 Sobre el contexto en que se promulgaron estos parágrafos, véase G. BARREIRO GONZÁLEZ, G., «Análisis crítico», en O. VON GIERKE, Las raices del contrato de servicios (Traducción y comentario crítico del propio G. BARREIRO GONZÁLEZ), Civitas (Madrid, 1989), págs. 34 y ss. Nuestra traducción de los preceptos en cuestión, en J. MARTÍNEZ GIRÓN y A. ARUFE VARELA, Leyes laborales alemanas. Estudio comparado y traducción castellana, Netbiblo (A Coruña, 2007), págs. 107 y ss.

9 Sobre los parágrafos en cuestión del Código Civil y su vitalidad, véase J. MARTÍNEZ GIRÓN, «Las normas estructurales complementarias de la Ley actualmente vigente en Alemania en materia de protección contra el despido», Anuario da Facultade de Dereito da Universidade da Coruña. Revista Jurídica Interdisciplinar Internacional, vol. 10 (2006), págs. 718-719. Además, N. FOSTER y S. SULE, German Legal System and Laws, $3^{\mathrm{a}}$ ed., Oxford University Press (Oxford, 2002), págs. 364 y ss. 
§3. En el ordenamiento portugués, a la inversa de lo que ocurre en el ordenamiento alemán, lo que no está codificado es la legislación de seguridad social. Ahora bien, al igual que sucede en Alemania, el Ministerio portugués competente en materia de Trabajo y Seguridad Social (actualmente, el Ministério do Trabalho e da Solidariedade Social) ofrece información - a través de su sitio en Internet www.mtss.gov.pt, utilizando el enlace «Legislação»— acerca de la legislación de seguridad social vigente en dicho país ${ }^{10}$, aunque se trate de una información totalmente condicionada por el hecho de que — como se vio- el Estado portugués sólo posibilita el acceso a «versiones consolidadas» de la normas a través de una base de datos pública de pago ${ }^{11}$. Ello explica que este otro sitio de Internet, de acuerdo con el cual las áreas temáticas sobre las que incide la legislación portuguesa de seguridad social son cuatro («Regímenes [Regimes]», «Acción Social [Acção Social]», «Riesgos Profesionales [Riscos Profissionais]» y «CPO», esto es, «Centro Nacional de Pensiones [Centro Nacional de Pensões]»), sólo ofrezca herramientas al ciudadano para que pueda identificar, por años, cuáles resultan ser las normas en cuestión (y también, para que pueda construirse su propia «versión consolidada» de las mismas, artesanalmente) ${ }^{12}$.

En el portal específico de la Administración portuguesa de la Seguridad Social —que está ubicado en www.seg-social.pt—, resulta posible consultar la principal norma reguladora de la Seguridad social en dicho país, que es la Ley núm. 4/2007, de 16 enero, que «aprueba las bases generales del sistema de seguridad social [aprova as bases gerais do sistema de segurança social]» ${ }^{13}$.

§4. En el ordenamiento italiano, al igual que sucede en el ordenamiento español, tampoco está codificada ni la legislación laboral ${ }^{14}$ ni la legislación de seguridad social ${ }^{15}$, aunque en Italia — como se vio,

10 Sobre la estructura del Derecho de la Seguridad Social en Portugal, véase I. DAS NEVES, Lei de Bases da Segurança Social: Comentada e Anotada, Coimbra Editora (Coimbra, 2003), págs. 11 y ss. Desde una perspectiva histórica, I. DAS NEVES, Direito da Segurança Social: Principios Fundamentais numa Analise Prospectiva, Coimbra Editora (Coimbra, 1996), págs. 103 y ss.

11 Véase supra, Tema 1, §3.

12 Según el propio sitio, su página «legislación» tiene «como objetivo proporcionar el acceso a las referencias legislativas de los textos publicados», a cuyo efecto «se divulgan documentos que compilan, por años, el tratamiento legislativo de esos mismos textos».

13 Vía «A Segurança Social», y luego, «Organismos do sector», «ISS I.P.» y «Quem somos».

14 Desde una perspectiva histórica, véase L. MARIUCCI, Le fonti del Diritto del Lavoro. Quindici anni dopo, G. Giappichelli (Turín, 2003), págs. 19 y ss.; y G. SANTORO-PASSARELLI, Diritto dei Lavori, G. Giappichelli (Turín, 2004), págs. 23 y ss. Además, con perspectiva panorámica, L. GALANTINO, Diritto del Lavoro, $10^{a}$ ed., G. Giappichelli (Turín, 2000), págs. 43 y ss.

15 Véase M. CINELli, Diritto della Previdenza Sociale, 5a ed., G. Giappichelli (Turín, 2003), págs. 72 y ss.; R. PESSI, Lezioni di Diritto della Previdenza Sociale, $3^{\mathrm{a}}$ ed., CEDAM (Padua, 2004), págs. 35 y ss.; y M. PERSIANI, Diritto della Previdenza Sociale, 14ª ed., CEDAM (Padua, 2005), págs. 5 y ss. 
pero a diferencia de lo que ocurre en España y Portugal- existe la ventaja adicional de que el Estado ofrece el acceso gratuito a «versiones consolidadas» de las normas, aunque sin ningún tipo de clasificación de las mismas mediante criterios de carácter temático ${ }^{16}$. De ahí la utilidad del sitio en Internet del Ministerio italiano competente en materia de Trabajo y Seguridad Social (actualmente, el Ministero del Lavoro e delle Politiche Sociali) —ubicado en www.lavoro.gov.it—, porque menciona las normas que integran la mosaicista legislación italiana laboral y de seguridad social ${ }^{17}$, agrupándolas en seis áreas temáticas («Amortizadores sociales [Ammortizzatori sociali]», «Actividad inspectora [Attività ispettiva]», «Ocupación y mercado de trabajo [Occupazione e mercato del lavoro]», «Orientación y formación profesional [Orientamento e formazione professionale]», «Seguridad Social [Previdenza]» y «Tutela de las condiciones de trabajo [Tutela condizioni di lavoro]»). Estas áreas temáticas, a su vez, están divididas y subdivididas en fragmentos múltiples, que suelen contar con referencias normativas concretas a «leyes [leggi]», «decretos [decreti]» y «circulares [circolari]», localizables en «versión consolidada» — prescindiendo, por tanto, del buscador de normas incluido en este portal específico, que sólo las busca en su versión histórica u originaria- a través del citado portal público generalista.

El hecho de que el Código Civil italiano de 1942 dedique todo un Libro (el Quinto) a la regulación «Del Trabajo [Del Lavoro]»—en el que la Sección 3, del Capítulo I de su Título Segundo, artículos 2096 a 2129, trata «De la relación de trabajo [Del rapporto di lavoro]»- constituye indudablemente un obstáculo para la codificación de la legislación laboral italiana sustantiva ${ }^{18}$. Es, además, un Código — por paradójico que pueda resultar- que contiene importantísimas normas puras de seguridad social ${ }^{19}$. En cuanto a la legislación laboral adjetiva, téngase en cuenta que el Código italiano de Procedimiento Civil de 1940 contiene las «Normas para las controversias en materia de trabajo», artículos 409 a 473 - entre las que se incluye un Capítulo que trata «De las controversias en materia de previsión y de asistencia obligatorias» (esto es, en materia de seguridad social)—, que coexisten con diversas leyes procesales laborales posteriores, de carácter extravagante ${ }^{20}$.

Al igual que en Italia, el portal temático español más importante a nuestros efectos es el del Ministerio de Trabajo, ubicado en www.mtin.es. En él, a su vez, el enlace más útil resulta ser «Inspección de Trabajo y Seguridad Social», al que se accede vía «Legislación».

\footnotetext{
16 Véase supra, Tema 1, \$3.

17 Acerca del «mosaico» formado por esta última, véase R. PESSI, Lezioni di Diritto della Previdenza Sociale. II. Profili Storici, 4 a ed., CEDAM (Padua, 2005), pág. 57.

18 Véase A. VALLEBONA, Istituzioni di Diritto del Lavoro. II. Il rapporto di lavoro, $4^{\mathrm{a}}$ ed., CEDAM (Padua, 2004), págs. 61 y ss.; y G. FAVALLI (Coordinación), Codice di Diritto del Lavoro. Leggi, dottrina e giurisprudenza sul rapporto di lavoro subordinato, $2^{\mathrm{a}}$ ed., La Tribuna (Piacenza, 2004), págs. 37 y ss.

19 Así, por ejemplo, en materia de automaticidad de las prestaciones (cfr. infra, Tema 20, \$2).

20 Al respecto, véase infra, Tema $8, \$ 5$.
} 
Y ello, porque permite manejar en «versión consolidada» las normas laborales españolas de carácter más rigurosamente estructural.

Por su parte, el sitio en Internet de la Administración española de Seguridad Social, ubicado en www.seg-social.es, permite hacerse una idea cabal de la complejísima normativa española sobre el tema, utilizando precisamente el enlace «Normativa» (donde aparece almacenada en «versión consolidada» la vigente Ley General de la Seguridad Social de 1994).

§5. En fin, en el ordenamiento inglés —donde la legislación laboral y de seguridad social tampoco está codificada ${ }^{21}$, y donde ni siquiera existe una base de datos pública de pago que permita acceder a «versiones consolidadas» de todas las leyes y reglamentos-, el sitio de Internet del Ministerio competente en materia de Trabajo y Seguridad Social (actualmente, el Department for Work and Pensions) —ubicado en www.dwp. gov.uk - ofrece «versiones consolidadas» de las leyes y reglamentos de seguridad social vigentes en todo el Reino Unido, a través de la entrada «Asesor [Adviser]», que da acceso a «Los volúmenes de Derecho» ${ }^{22}$, uno de los cuales trata de «El Derecho Relativo a la Seguridad Social [The Law Relating to Social Security]». Por su parte, el sitio de Internet del Ministerio competente en materia de Comercio e Industria (actualmente, el Department for Business, Innovation \& Skills) —ubicado en www.bis. gov.uk - ofrece información clara y puesta al día, aunque ya no «versiones consolidadas», sobre identificación de la legislación laboral allí vigente (a través de una entrada rotulada «Materias de Empleo [Employment Matters]») ${ }^{23}$, aunque con exclusión de todo lo relativo a la legislación de prevención de riesgos laborales. Esta última puede localizarse, sin embargo, a través del sitio en Internet de la «Administración de Salud y Seguridad [Health and Safety Executive]» —ubicado en www.hse.gov. uk-, que de nuevo por excepción ofrece «versiones consolidadas» de la normas vigentes en Gran Bretaña sobre prevención de riesgos laborales.

21 Acerca de la primera, véase S. DEAKIN y G.S. MORRIS, Labour Law, $3^{\text {a }}$ ed., Butterworths (Londres, 2001), págs. 57 y ss.; R. UPEX, R. BENNY y S. HARDY, Labour Law, $1^{\mathrm{a}}$ ed., Oxford University Press (Oxford, 2004), págs. 20 y ss.; S. HONEYBALL y J. BOWERS, Textbook on Labour Law, $8^{\text {a }}$ ed., Oxford University Press (Oxford, 2004), págs. 11 y ss.; N.M. SELWYN, Law of Employment, 13 ed., LexisNexis-Butterworths (Londres, 2004), págs. 17 y ss.; y J. BOWERS, A practical approach to Employment Law, $7^{\mathrm{a}}$ ed., Oxford University Press (Oxford, 2005), págs. 1 y ss. En relación con la segunda, véase E. EAST, Social Security Law, McMillan (Londres, 1999), págs. 23 y ss.; N. HARRIS, «The Shape and Characteristics of Social Security Today (including Insurance, Pensions and Means-tests)», en N. HARRIS, Social Security Law in Context, Oxford University Press (Oxford, 2000), págs. 155 y ss.; y M. JENKINS, M. POORE, H. DOODS, A. BAIG, K. HAINSWORTH, K. BYERS, D. BRABBS, P. ABEYSEKERA y D. DON, Blackstone`s Guide to Pensions Act 2004, Oxford University Press (Oxford, 2005), págs. 9 y ss.

22 Vía «Specialist guidance and publications», y luego, «Law».

23 A la que se accede vía «Policies», y luego, «Policies by theme». 
Aparte el «volumen de Derecho» citado, el propio sitio del Ministerio competente en materia de Trabajo y Seguridad Social contiene otro «volumen» más, sobre «El Derecho Relativo al Apoyo a la Infancia [The Law Relating to Child Support]».

En cuanto a las «Materias de Empleo» citadas, el sitio de Internet del Ministerio competente en materia de Comercio e Industria ofrece - en el enlace «Employment rights»— información sobre las normas relativas, entre otras cuestiones, a «Festivos y período veraniego británico [Bank holidays and British summertime]», «Transmisiones y absorciones de negocios [Business transfers and takeovers]», «Información y consulta [Information and consultation]», «Salario Mínimo Nacional [National Minimum Wage]», «Sindicatos [Trade Unions]» y «Jornada [Working time]».

Entre estas mismas «Materias», se incluye por remisión igualmente detallada información sobre legislación procedimental y procesal laboral, a través del epígrafe «Resolución de conflictos [Dispute resolution]» ${ }^{24}$.

24 Entre los subepígrafes a que remite este último, entre otros, se cuentan los relativos a «Tribunales de Empleo [Employment Tribunals]» y a «Procedimientos disciplinarios [Disciplinary procedures]». 
Sumario: §1. El modelo español. §2. Otros modelos estatales europeos (portugués y francés) basados en la publicación de convenios colectivos en periódicos oficiales. §3. Modelos estatales europeos (publicista italiano, confidencialista alemán y secretista británico) no basados en la publicación de convenios colectivos en periódicos oficiales. §4. El modelo comunitario, integral ad extra y ocultista ad intra. §5. El modelo publicista norteamericano.

THEME 4

INTERNET SITES RELATING TO EUROPEAN, COMMUNITY AND USA FILES OF COLLECTIVE AGREEMENTS

Contents: \$1. The Spanish model. \$2. Other European state models (Portuguese and French) based on the publication of collective agreements in official journals. \$3. European state models (Italian publicist, German confidentialist and British secretist) not based on the publication of collective agreements in official journals. $\$ 4$. The Community, integral ad extra and occultist ad intra, model. \$5. The USA publicist model.

§1. Sobre la triple base de que los convenios colectivos negociados en España al amparo del Título III del Estatuto de los Trabajadores deben formalizarse por escrito, deben registrarse y deben publicarse en periódicos oficiales ${ }^{1}$, el modelo oficial español de difusión a través de Internet de dichos convenios colectivos puede considerarse de carácter integral, dado que existe un solo sitio - aunque parcialmente en construcción todavía, administrado por la Comisión Consultiva Nacional de Convenios Colectivos ${ }^{2}$ y ubicado en www.mtas.es/es/sec_trabajo/ccncc/ index.htm - en el que puede consultarse el texto de los mismos. En efecto,

1 Véase J. MARTÍNEZ GIRÓN, A. ARUFE VARELA y X.M. CARRIL VÁZQUEZ, Derecho del Trabajo, $2^{\mathrm{a}}$ ed., Netbiblo (A Coruña, 2006), págs. 426-427.

2 Sobre ella, ibidem, pág. 495. 
este sitio de Internet contiene un «Registro de datos sobre la negociación colectiva», que incluye una «Base de datos de convenios colectivos (a texto completo)», de los que los estatales (tanto de ámbito sectorial como de ámbito empresarial) pueden consultarse a través del Ministerio de Trabajo y Asuntos Sociales, y vía Boletín Oficial del Estado, desde 1995³; y los de ámbito infraestatal, por remisión a los sitios correspondientes de las diversas Comunidades Autónomas. De entre estos últimos sitios, merecen ser especialmente destacados — por la utilidad de la información que almacenan - los de las Comunidades Autónomas de Andalucía y de Galicia, gestionados por el Consejo Andaluz de Relaciones Laborales —a través de su sitio www.juntadeandalucia.es/empleo/carl- y por el Consello Galego de Relacións Laborais - a través de su sitio monolingüe http://cgrl.xunta.es_, respectivamente.

Estas dos bases autonómicas de datos poseen un importante valor añadido. La andaluza, porque contiene datos e informes relativos a «Negociación Colectiva en el Estado» y a «Negociación Colectiva en Andalucía», ofreciendo de cada convenio colectivo - aparte su texto íntegro - una ficha con documentación relativa al mismo (que eventualmente puede incluir, también, jurisprudencia relacionada). La gallega, porque - aparte el texto del convenio colectivo y su ficha- incorpora (siempre sólo en gallego) los informes sobre «Situación de la Negociación Colectiva en Galicia» (desde 2003).

El sitio citado de la Comisión Consultiva Nacional de Convenios Colectivos se estructura sobre la base de siete grandes áreas temáticas (algunas de ellas todavía hoy en construcción, recuérdese), a saber: «Información sobre la CCNCC», «Actuaciones de la CCNCC», «Registro de datos sobre la negociación colectiva», "Aspectos normativos y jurisprudenciales sobre la negociación colectiva», «Estudios e informes sobre la negociación colectiva de otras organizaciones», «Bibliografía sobre la negociación colectiva» y «Enlaces de interés».

El relanzamiento de este último sitio de Internet trae causa de la promulgación del Real Decreto-ley 5/2006, de 9 junio, según el cual «sin perjuicio del respeto a la autonomía colectiva de las partes, la Comisión Consultiva Nacional de Convenios Colectivos ... asumirá funciones de observatorio de la negociación colectiva que englobará la información, el estudio, la documentación y la difusión de la misma» ${ }^{4}$, de manera que «con el fin de garantizar el funcionamiento eficaz de la Comisión Consultiva Nacional de Convenios Colectivos, el Gobierno... le proporcionará el apoyo técnico y los medios que sean necesarios» ${ }^{5}$. Por ello, no se comprende bien la completa falta de mención a dicha Comisión en el Real Decreto 713/2010, de 28 mayo, sobre registro y depósito de convenios y acuerdos colectivos a través de medios electrónicos. Esta última norma posee

3 En consecuencia, se corresponde aparentemente con la base de datos de «convenios colectivos» estatales contenida en www.boe.es.

4 Disposición adicional $7^{\mathrm{a}}$, apartado 1.

5 Disposición adicional $7^{\mathrm{a}}$, apartado 2. 
un extraordinario interés doctrinal, al prever expresamente la posibilidad del «depósito de convenios y acuerdos de eficacia limitada y acuerdos de empresa» ${ }^{6}$.

§2. Integrales como el modelo español son los modelos portugués y francés, ambos basados asimismo - como el nuestro-en la publicación del texto de los convenios colectivos en periódicos oficiales. En efecto, visto que los convenios colectivos portugueses también deben formalizarse por escrito, registrarse y publicarse luego en el Boletín Oficial del Ministerio competente en materia de Trabajo (Boletim do Trabalho e Emprego) ${ }^{7}$, el sitio en Internet de este último Boletín —ubicado en http://bte.gep.mtss.gov.pt—, a través de su mecanismo de búsqueda avanzada, permite localizar el texto de los convenios colectivos que publica (ordenados según los nombres de las concretas partes que los estipularon, dada la regla general de que los convenios colectivos son, en Portugal, convenios de eficacia limitada). En Francia, en cambio, sólo se publican en el Boletín Oficial de Convenios Colectivos (Bulletin Officiel des Conventions Collectives) los convenios colectivos declarados de eficacia general (por haber sido objeto de una resolución administrativa de extensión o de ampliación, a su vez publicada en el Diario Oficial de la República Francesa [Journal Officiel de la République Française]) ${ }^{8}$, lo que explica que estos convenios colectivos sean los únicos que conformen una auténtica base de datos en «Légifrance» — recuérdese, el portal jurídico francés gubernamental, integral, multidisciplinar y de uso gratuito ${ }^{9}$-, pudiendo accederse a su texto íntegro precisamente a través del enlace «los convenios colectivos [les conventions collectives]».

6 Cfr. su disposición adicional segunda. Acerca de este tipo de convenios colectivos y su no siempre bien comprendida tipología, véase J. MARTÍNEZ GIRÓN, «La negociación colectiva extraestatutaria», Revista del Ministerio de Trabajo y Asuntos Sociales-Derecho del Trabajo, núm. 68 (2007), págs. 181 y ss. Acerca de los convenios colectivos «extraestatutarios» por antonomasia, véase A. ARUFE VARELA, «El convenio colectivo verbal. Comentario histórico, sistemático y posibilista del artículo 90.1 del Estatuto de los Trabajadores», Revista Española de Derecho del Trabajo, núm. 142 (2009), págs. 411 y ss.

7 Cfr. artículos 494 y 519 del Código del Trabajo de 2009. Sobre el tema, véase A. MONTEIRO FERNANDES, Direito do Trabalho, $15^{\mathrm{a}}$ ed., Almedina (Coimbra, 2010), págs. 798 y ss., y 849 y ss. Acerca de la regulación del tema en el primer Código del Trabajo de 2003, véase P. ROMANO MARTINEZ, L. MIGUEL MONTEIRO, J. VASCONCELOS, P. MADEIRA DE BRITO, G. DRAY y L. GONÇALVES DA SILVA, Código do Trabalho. Anotado, $4^{\mathrm{a}}$ ed., Almedina (Coimbra, 2005), págs. 823 y ss.

8 Véase artículo D. 2261-4 del Código francés del Trabajo de 2008. Los restantes convenios y acuerdos colectivos se depositan en los «servicios» del Ministerio competente en materia de Trabajo y, también, «en la secretaría-archivo del Consejo de Hombres Prudentes del lugar de conclusión», en donde todo interesado puede consultarlos y hacerse con una «copia a su cargo» (cfr. J. PÉLISSIER, A. SUPIOT y A. JEAMMAUD, Droit du Travail, 24ª ed., Dalloz [París, 2008], págs. 1324-1325).

9 Sobre él, véase supra, Tema 1, \$2. 
El mencionado mecanismo de búsqueda avanzada de convenios colectivos portugueses permite insertar cinco tipos distintos de datos. De cara a la búsqueda libre, los más fructuosos son «título» y «descritor», dado que ambos permiten buscar todo tipo de convenios colectivos, con sólo insertar una palabra indicativa del ámbito funcional del concreto convenio colectivo buscado (por ejemplo, «metal», «construcción [construção]» u «hostelería [hotelaria]»). Lo normal es que salgan muchos resultados, relacionados cronológicamente por orden descendente ${ }^{10}$.

Por su parte, la citada base de datos de «Légifrance» sólo almacena textos de convenios colectivos de eficacia general vigentes, aunque ofreciéndolos con toda la documentación convencional complementaria (anexos, acuerdos de revisión salarial, acuerdos complementarios, etc.), si publicada en el Boletín Oficial de Convenios Colectivos.

La versión electrónica de este último Boletín — accesible desde «Légifrance» ${ }^{11}$ — conforma otra base de datos informática de convenios colectivos franceses declarados de eficacia general, pero con una clamorosa falta de valor añadido — si comparada con la propia «Légifrance»—, por sus menores posibilidades de búsqueda y porque sólo permite localizar los convenios que almacena, desde el año 2005.

§3. La falta de publicación del texto de los convenios colectivos en periódicos oficiales manejables en versión electrónica no constituye ningún obstáculo insuperable para que puedan llegar a crearse registros de los mismos, que también resulten accesibles a través de Internet. Lo prueban los modelos italiano, alemán y británico, al estar bas ados los tres en la falta de publicación de los convenios colectivos en periódicos oficiales. El modelo italiano debe calificarse como p u bl i c is ta, pues el sitio en Internet del «Consejo Nacional de la Economía y del Trabajo [Consiglio Nazionale dell'Economia e del Lavoro]» —ubicado en www.portalecnel.it - permite acceder libremente al texto íntegro de los convenios colectivos italianos (incluso empresariales) del sector público y del sector privado, al amparo de lo dispuesto en la Ley núm. 936, de 30 diciembre 1986 - generosamente interpretada—, según la cual «se instituye en el CNEL el Archivo Nacional de los Contratos y de los Acuerdos Colectivos de Trabajo en el que se depositan en copia auténtica los acuerdos de renovación y los nuevos contratos en los 30 días siguientes a su estipulación y a su firma» ${ }^{12}$, teniendo en cuenta que la organización de este archivo de convenios colectivos «debe consentir su conservación

10 Menos interés, de cara siempre a la localización de convenios colectivos portugueses, tiene la base de datos denominada «REGTRAB», a la que se accede (vía «Digesto») a través de la versión electrónica del Diario de la República (ubicada, como se vio, en http://dre.pt), pues sólo tiene valor añadido para los usuarios abonados a la misma.

11 Utilizando su enlace «Les autres publications des Journaux Officiels en ligne».

12 Artículo 17, apartado 1. 
en el tiempo y la consulta pública» ${ }^{13}$. En cambio, el modelo alemán debe calificarse como modelo confidencialista ${ }^{14}$, dado que: 1) el «Registro Federal de Convenios Colectivos [Bundestarifregister]» sólo difunde a través de Internet —en el sitio, que se vio en su momento, del Ministerio Federal de Trabajo y de Seguridad Social ${ }^{15}$ - los datos mínimos para la identificación de cuáles sean los convenios colectivos de eficacia general vigentes en Alemania ${ }^{16}$; 2) el «Registro de Convenios Colectivos [de] R[enania del] N[orte]-W[estfalia] [Tarifregister NRW]» - de libre acceso en Internet a través de www.tarifregister.nrw.de, y creado mediante una interpretación voluntarista del parágrafo 6 de la Ley federal del Convenio Colectivo (Tarifvertragsgesetz) de $1949^{17}$ — sólo difunde el contenido despiezado (reconducido, por tanto, a una «ficha») de los convenios colectivos vigentes en este concreto Estado Federado; y 3) el «Archivo de Convenios Colectivos del Instituto de Ciencias Sociales y Económicas [WSI-Tarifarchiv]» gestionado por la «Fundación Hans Böckler [Hans Böckler Stiftung]» — también de acceso gratuito, y ubicado en el sitio www.boeckler.de ${ }^{18}$ _, cuya utilización recomienda incluso el registro del Estado Federado a que acaba de aludirse, difunde el contenido de convenios colectivos vigentes en toda Alemania, aunque empleando igualmente el sistema de disección de su contenido mediante «fichas» de lectura rápida. En fin, el modelo británico ${ }^{19}$ merece ser calificado como modelo secretista, pues los registros informáticos de convenios

13 Artículo 17, apartado 3. Según el apartado 2 de este mismo precepto, «el depósito es responsabilidad de los sujetos contratantes». Sobre la publicación en la Gaceta Oficial de la República de los convenios colectivos nacionales relativos al empleo público - al amparo ahora de lo dispuesto en el artículo 47 del Decreto Legislativo núm. 165, de 30 marzo 2001—, véase M. PERSIANI, Diritto Sindacale, $7^{\text {a }}$ ed., CEDAM (Padua, 2000), pág. 142; y F. DEL GIUDICE y F. MARIANI, Diritto Sindacale, $10^{\mathrm{a}}$ ed., Edizione Giuridiche Simone (Nápoles, 2001), pág. 266. En general, sobre la «forma» de los convenios colectivos italianos, véase L. GALANTINO, Diritto Sindacale, $4^{\text {a }}$ ed., G. Giappichelli (Turín, 1993), pág. 189.

14 Véase J. MARTÍNEZ GIRÓN, «La publicidad del convenio colectivo en el Derecho del Trabajo alemán», Revista de Derecho Social, núm. 42 (2008), págs. 183 y ss.

15 Véase supra, Tema 3, \$2.

16 Vía «Arbeitsrecht» (y luego, «Tarifverträge»). Estos mismos datos también se publican cuatrimestralmente en la Gaceta Federal de Anuncios (Bundesanzeiger), accesible electrónicamente desde 2002 a través de www.ebundesanzeiger.de.

17 Según este precepto (rotulado «Registro de Convenios Colectivos [Tarifregister]»), «en el Ministerio Federal de Trabajo y de Seguridad Social se llevará un registro de convenios colectivos, en el que constarán la celebración, la modificación y la revocación de los convenios colectivos, así como el comienzo y la terminación de la eficacia general».

18 También accesible a través de www.tarifvertrag.de.

19 Sobre la posibilidad general en Gran Bretaña de la existencia de convenios colectivos no escritos, y las peculiares resultas legales de este hecho, véase N.M. SELWYN, Law of Employment, $13^{\mathrm{a}}$ ed., LexisNexis-Butterworths (Londres, 2004), págs. 570-571; y R. UPEX, R. BENNY y S. HARDY, Labour Law, $1^{\text {a }}$ ed., Oxford University Press (Oxford, 2004), págs. 414 y ss. 
colectivos existentes en el Reino Unido son registros de pago, gestionados por entidades de carácter sindical y que sólo permiten una suscripción sindicalizada a los mismos.

Entre estos peculiares registros británicos, merece ser especialmente citado el gestionado por el linajudo (se constituyó en 1912, al amparo de la Sociedad Fabiana) «Departamento de Investigación Laboral [Labour Research Department]» —ubicado en www.lrd.org.uk-, que se autocalifica como «la organización de investigación independiente que publica noticias e información para sindicalistas». A través de su enlace «Payline»e introduciendo la palabra «guest» (como nombre de usuario y contraseña), permite acceder a los convenios colectivos por él registrados - a título de demostración-, en los que el nombre de la empresa empieza por la letra «A» (esto es, alrededor de ciento veinticinco convenios colectivos, tanto del sector privado como del sector público, siempre vigentes, sobre un total de más de dos mil). Pues bien, en la misma línea de los registros alemanes citados, únicamente ofrece el contenido despiezado en «fichas» de lectura rápida de los convenios colectivos que almacena.

La justificación dada por el Ministerio Federal alemán de Trabajo y de Seguridad Social, para eludir la publicación de los convenios colectivos registrados, se apoya —en lo esencial - en que «empresarios y trabajadores, así como los representantes encargados de sus intereses (por ejemplo, abogados y asesores fiscales), para que un convenio colectivo sea vinculante sobre la base de una declaración de eficacia general, pueden exigir de alguna de las partes del convenio una copia del convenio colectivo, al amparo del parágrafo 9, apartado 1, del Reglamento para la Ejecución de la Ley del Convenio Colectivo [Verordnung zur Durchführung des Tarifvertragsgesetzes]..., pagando los gastos correspondientes (que son los gastos de papel, los gastos de fotocopia o los gastos de impresión, así como los portes de envío)». Téngase en cuenta, además, que el «Archivo» de la Fundación alemana citada, con una finalidad meramente divulgativa o ilustrativa, recopila a texto completo el contenido de convenios colectivos supuestamente selectos, que todavía se encuentran vigentes ${ }^{20}$. La Ley federal del Convenio Colectivo, en relación con la publicación del contenido del convenio colectivo, lo que prevé es su publicidad meramente interna en las empresas, ordenando que «los empresarios están obligados a exponer los convenios colectivos que afecten a su centro de trabajo en un lugar adecuado del centro de trabajo» ${ }^{21}$.

Lo que se puede consultar en el citado «Archivo Nacional» italiano, a texto completo, es literalmente lo siguiente: «Acuerdos entre el Gobierno y las Partes Sociales», «Acuerdos Interconfederales», «Contratación Nacional» ${ }^{22}$, «Contratación Descentralizada» ${ }^{23} \mathrm{y}$ «Contratación Descentralizada por Regiones» ${ }^{24}$.

20 Localizables a través del enlace «Tarifdaten», que permite acceder a «Dokumente», permitiendo este otro enlace, a su vez, acceder ya a «Reglas convencionales en tenor literal [Tarifliche Regelungen im Wortlaut]».

21 Parágrafo 8. Sobre «publicación del convenio colectivo», véase O.E. KEMPEN y U. ZACHERT (Editores), Tarifvertragsgesetz, $4^{\mathrm{a}}$ ed., Bund-Verlag (Frankfurt am Maine, 2006), págs. 1114 y ss.

22 Relativa a convenios colectivos sectoriales de dicho ámbito, tanto vigentes (vía «Archivio Corrente») como caducados (vía «Archivio Storico»).

23 Relativa a convenios colectivos empresariales, tanto del «Empleo Público» como del «Sector Privado».

24 Veinte en total, accesibles en tres niveles (regional, interprovincial y provincial). 
§4. El modelo comunitario de difusión del Derecho a través de Internet vuelve a resultar casi ejemplar, también en relación con los convenios colectivos, pero sólo en lo que se refiere a la difusión de los resultados de una «negociación colectiva» ad extra, que permanece todavía casi en estado de embrión ${ }^{25}$. Se trata de un modelo gestionado por la Comisión Europea a través de un sitio específico de Internet —ubicado en http://ec.europa.eu/social/main.jsp?catId=329\&langId-, en el que resulta posible acceder al texto completo de dos tipos distintos de convenios colectivos «comunitarios» ${ }^{26}$, a saber: de un lado, los acuerdos aplicados por decisión del Consejo, cuyo texto aparece publicado en el Diario Oficial de la Unión Europea, como anexo de la norma comunitaria de que se trate (normalmente, una Directiva); y de otro lado, los denominados «acuerdos autónomos» que eventualmente hubiesen sido alcanzados por los interlocutores sociales europeos, cuyo texto se almacena por la Comisión en este sitio, aun cuando no aparezca publicado en el Diario Oficial de la Unión Europea. En cambio, por lo que se refiere a la negociación colectiva ad intra — esto es, la trabada entre la Administración de la Unión Europea y los sindicatos representantes del personal a su servicio-, sólo cabe hablar de la existencia de un modelo de carácter ocultista, dada la aparente imposibilidad de localizar el texto de los correspondientes acuerdos colectivos intracomunitarios en el portal jurídico de la Unión Europea ${ }^{27}$.

Respecto de la negociación ad extra, téngase en cuenta que el sitio de Internet citado sólo puede manejarse en inglés, francés y alemán. Pero no en las restantes lenguas oficiales de la Unión, incluido el castellano. Dentro de él, el enlace más útil es, sin duda, «base de datos de textos del diálogo social».

Entre los acuerdos colectivos aplicados por decisión del Consejo (con la vigilancia de la Comisión), entre otros, se recogen aquí el acuerdo marco sobre el permiso parental de 1995, el acuerdo marco sobre el trabajo a tiempo parcial de 1997 o el acuerdo sobre contratos de trabajo de duración determinada de 1999.

Entre los «acuerdos autónomos» no publicados en el Diario Oficial de la Unión Europea, cabe la cita del acuerdo marco sobre el teletrabajo de 2002, del acuerdo marco sobre el «stress» relacionado con el trabajo de 2004 o del acuerdo sobre acoso y violencia en el trabajo de 2007.

25 Véase F. PÉREZ DE LOS COBOS ORIHUEL, «Aporías de la negociación colectiva europea», en F. PÉREZ DE LOS COBOS y J.M.GOERLICH (Coordinadores), El régimen jurídico de la negociación colectiva en España, Tirant lo Blanch (Valencia, 2006), págs. 13 y ss.

26 Adoptados ambos con amparo en lo dispuesto en los artículos 154 y 155 del Tratado de Funcionamiento de la Unión Europea (cfr. infra, Tema 13, §1). Véase, asimismo, la base de datos de la Confederación Europea de Sindicatos, en su sitio de Internet www.etuc.org.

27 Véase infra, Tema 13, \$1. 
§5. En fin, el modelo norteamericano - en lo que concierne a los convenios colectivos regidos por el Derecho federal- presenta un notable parecido con el modelo italiano, que antes calificamos como modelo de signo publi c is t a ${ }^{28}$. En efecto, al igual que ocurre en Italia, la legislación federal laboral norteamericana también impone la llevanza de un «registro [file]» federal de convenios colectivos, del que se ocupa una «Oficina» del Ministerio competente en materia de Trabajo (Department of Labor) ${ }^{29}$. Y de modo análogo a lo que igualmente sucede en Italia, en el sitio de Internet correspondiente a este «registro» federal —ubicado en www.dol.gov/olms ${ }^{30}$-, se contienen «listados online de convenios del sector público y privado» (de empresas «que tengan 1.000 trabajadores o más», accesibles en formato electrónico, aunque algunos de ellos se remiten confidencialmente y «no están disponibles para el público general»), quedando «excluidos los convenios colectivos de ferrocarriles y de compañías aéreas». Estos últimos pueden consultarse libremente en el sitio de Internet de la «Oficina de Mediación Nacional [National Mediation Board]» — ubicado en www.nmb.gov— a texto completo, aunque lógicamente se trate de muchísimos menos convenios colectivos ${ }^{31}$. Lógicamente, existen sitios no oficiales de Internet, también de acceso gratuito, que intentan cubrir los vacíos dejados por el citado «registro» federal oficial de convenios colectivos ${ }^{32}$.

Entre estos otros sitios no oficiales, sobresale el del «Instituto de Relaciones Industriales [Institute of Industrial Relations]》 de la Universidad de California en Berkeley —ubicado en www.iir.berkeley.edu/library/contracts-, cuya base de datos de convenios colectivos a texto completo se nutre incluso de convenios colectivos «encontrados en la Web pública».

28 Acerca de que la negociación colectiva de buena fe implica «la formalización de un convenio escrito [written agreement] incorporando cualquier acuerdo alcanzado, si lo exige una de las partes», véase T.J. HEINSZ, D.R. NOLAN y R.A. BALES, Labor Law. Collective bargaining in a free society, $6^{\mathrm{a}}$ ed., Thomson-West (St.Paul-Minn., 2009), págs. 630 y ss.

29 La norma federal en cuestión es la sección 211(a) de la popularmente llamada Ley Taft-Hartley de 1947, relativa a lo siguiente: «Para guía e información de los representantes interesados de empresarios, trabajadores y del público en general, la Oficina de Estadísticas Laborales del Departamento de Trabajo [desde 2007, la Oficina de Condiciones Mínimas entre Empresarios y Sindicatos] mantendrá un registro de copias de todos los convenios colectivos disponibles y de otros acuerdos disponibles, y de acciones derivadas de los mismos para arreglar o ajustar conflictos laborales. Dicho registro estará abierto a inspección, bajo condiciones adecuadas prescritas por el Secretario de Trabajo, salvo que alguna información específica comunicada confidencialmente no deba ser revelada».

30 Vía «Union Reports and Collective Bargaining Agreements: On Line Public Disclosure Room».

31 En este sitio, resulta preciso utilizar sucesivamente los siguientes enlaces: «Documents \& Forms», «The NMB Knowledge Store» (pinchando en «Contracts/Agreements») y, por último, «Other NMB Public Information» (pinchando en «Air and Rail Contracts/Agreements»).

32 Al respecto, interesante e incluso divertido, véase J. BISSETT, «Reference from coast to coast. Finding U.S. Collective Bargaining Agreements», en www.1lrx.com/columns/reference24.htm. 
Los «listados online» del tan citado «registro» federal oficial de convenios colectivos, ordenados alfabéticamente, ofrecen - aparte, en su caso, el texto íntegro del convenio colectivo registrado - información sobre diez datos: «nombre del empresario», «formato» (indicando si es «copia electrónica» o «copia papel»), «localidad», «sindicato [union]», «delegación sindical [local]», «NAICS» (esto es, código del sector económico), «número de trabajadores», «fecha de expiración», «número de páginas» y «número de clave».

Los convenios colectivos ya no vigentes depositados en este «registro» federal oficial no se destruyen, sino que se transfieren al Centro Kheel de Documentación y Archivos Empresariales y Sindicales, de la Biblioteca Martin P. Catherwood, de la Universidad Cornell de Nueva York, aunque una vez consultado el sitio en Internet de esta biblioteca - ubicado en www.ilr.cornell.edu/library/kheel/collections/descriptions.html—, resulta que sólo ofrece electrónicamente meros «listados online» (pero que se remontan incluso a 1887). 


\section{TEMA 5 \\ SITIOS DE INTERNET RELATIVOS A REPERTORIOS COMUNITARIOS, EUROPEOS Y NORTEAMERICANOS PARA LA LOCALIZACIÓN DE JURISPRUDENCIA LABORAL Y DE SEGURIDAD SOCIAL}

Sumario: §1. El modelo comunitario. §2. Los modelos continentales europeos de carácter integral. §3. Los modelos continentales europeos de carácter no integral. §4. El modelo anglo-irlandés. §5. El modelo norteamericano.

THEME 5

INTERNET SITES RELATING TO COMMUNITY, EUROPEAN AND USA REPERTORIES TO FIND LABOR AND SOCIAL SECURITY CASE LAW

Contents: $\$ 1$. The Community model. $\$ 2$. The European continental models of integral nature. \$3. The European continental models of non-integral nature. $\$ 4$. The British-Irish model. $\$ 5$. The USA model.

§1. Sobre la base de que la jurisprudencia de los tribunales es siempre fuente principalísima de conocimiento del Derecho (y por tanto, también de conocimiento del Derecho del Trabajo y de la Seguridad Social) ${ }^{1}$, el portal jurídico plurilingüe «Eur-lex» de la Unión Europea debe ser calificado - desde el punto de vista de las posibilidades de acceder a su través al conocimiento de la jurisprudencia comunitaria - como verdadero portal jurídico de carácter integral ${ }^{2}$, por las siguientes razones. En primer lugar, porque este modelo comunitario permite conocer la jurisprudencia de todos los tribunales de la Unión Europea, que - como es sabido - son tres (el Tribunal de Justicia de la Unión Europea, el Tribunal General y el

1 Sobre el tema, véase J. MARTÍNEZ GIRÓN, A. ARUFE VARELA y X.M. CARRIL VÁZQUEZ, Derecho del Trabajo, $2^{\mathrm{a}}$ ed., Netbiblo (A Coruña, 2006), págs. 24-25.

2 Acerca de este portal, véase supra, Tema $1, \$ 4$. 
Tribunal de la Función Pública). En segundo lugar, porque permite acceder al texto íntegro de todas las resoluciones dictadas por esos tres tribunales - cualquiera que sea la fecha en que se dictaron-, aunque las posibilidades de acceso plurilingüe a las del Tribunal de Justicia de la Unión Europea se restrinjan a medida que se retrocede hacia atrás en el tiempo (las más antiguas, a partir de 1953 en adelante, siempre resulta posible manejarlas de todas formas en versión electrónica, al menos en francés). En tercer lugar, porque cuenta con múltiples dispositivos prácticos de búsqueda, tanto de búsqueda guiada (por ejemplo, mediante el número del asunto, la fecha de su pronunciamiento o el nombre de las partes) como de búsqueda libre (por ejemplo, mediante la utilización de expresiones en el texto o de la referencia al concreto ámbito temático de que se trate; en nuestro caso, recuérdese, «Fondo Social Europeo», «Condiciones de Trabajo», «Seguridad Social», etc., y sus subdivisiones respectivas) ${ }^{3}$. Por supuesto, todo esto se explica a causa del altísimo valor jurídico que posee la jurisprudencia comunitaria, expresamente reconocido en el frustrado «Tratado por el que se establece una Constitución para Europa» de $2004^{4}$, en el que se afirmaba que «la jurisprudencia del Tribunal de Justicia de las Comunidades Europeas y del Tribunal de Primera Instancia relativa a la interpretación y aplicación de los Tratados y actos derogados por el artículo IV-437, así como de los actos y convenios adoptados en aplicación de aquéllos, siguen siendo, mutatis mutandis, la fuente de interpretación del Derecho de la Unión y, en particular, de las disposiciones comparables de la Constitución» ${ }^{5}$.

Este mismo portal jurídico permite el acceso —aparte de a las conclusiones del abogado general—, también a la doctrina de la Dirección General de Competencia de la Comisión, a la jurisprudencia del Tribunal de la Asociación Europea de Libre Comercio y a la jurisprudencia de la Corte Europea de Derechos Humanos.

En él, la búsqueda libre genera una relación de resultados acompañados cada uno de ellos de su correspondiente ficha, lo que permite un rápido descarte - cuando los resultados son muchos- de lo que no interesa.

A través del enlace relativo al Tribunal de Justicia y vía «Jurisprudencia», también resulta posible acceder a un utilísimo listado de «Notas de la doctrina sobre la jurisprudencia»,

\footnotetext{
3 Véase supra, Tema 2, \$1.

4 Sobre él, véase J. MARTÍNEZ GIRÓN, A. ARUFE VARELA y X.M. CARRIL VÁZQUEZ, Derecho del Trabajo, $2^{\mathrm{a}}$ ed., cit., pág. 103.

5 Artículo IV-438 (rotulado «Sucesión y continuidad jurídica»), apartado 4. Sobre el tema, véase J. MARTÍNEZ GIRÓN, «El contenido social del Tratado por el que se instituye una Constitución para Europa», Actualidad Laboral, núm. 18 (2004), pág. 2142.
} 
que contiene «las referencias de publicación de los comentarios doctrinales relativos a las sentencias», dividido en tres Partes ${ }^{6}$.

§2. De algún modo parecidos a este modelo comunitario de acceso a la jurisprudencia a través de Internet son, también, ciertos modelos estatales europeos de carácter integral, como el modelo francés, el modelo portugués y el modelo español. En cuanto al modelo francés, porque el portal jurídico «Légifrance» ${ }^{7}$ permite — sin necesidad de tener que salir del mismo - acceder a las sentencias (arrêts) y demás decisiones del Consejo Constitucional ${ }^{8}$, a «la jurisprudencia de la Corte de Casación y las sentencias y fallos de las jurisdicciones de apelación y de las jurisdicción de primera instancia», y también, a «la jurisprudencia del Tribunal de Conflictos, del Consejo de Estado, de las Cortes Administrativas de Apelación y de los Tribunales Administrativos». En cuanto al modelo portugués, porque el sitio en Internet del «Instituto de las Tecnologías de Información en la Justicia [Instituto das Tecnologías de Informação na Justiça]» —-dependiente del Ministerio portugués de Justicia y cuyas bases de datos jurídicas están ubicadas en www.dgsi.pt - permite el acceso libre, entre otro material jurisprudencial, a las sentencias (acórdãos) del Supremo Tribunal de Justicia, del Tribunal Constitucional, del Supremo Tribunal Administrativo, del Tribunal de Conflictos, de las Audiencias Territoriales (Tribunais da Relação) de Lisboa, Oporto, Coimbra, Guimarães y Évora, y también, de los Tribunales Centrales Administrativos Norte y $\operatorname{Sur}^{9}$. Y en cuanto al modelo español, porque a través del denominado «Portal del Poder Judicial» —ubicado en www. poderjudicial.es - cabe acceder tanto a la jurisprudencia constitucional como a la de nuestros tribunales ordinarios. A la primera, por reenvío automático al portal del Tribunal Constitucional —ubicado en www.tribunalconstitucional.es—, mientras que a la segunda se accede directamente,

6 Según se sigue indicando en este enlace, «la primera Parte comprende las referencias de publicación de los comentarios doctrinales relativos a las sentencias del Tribunal de Justicia dictadas en los asuntos interpuestos antes del 1 de enero de 1989»; «la segunda Parte comprende las referencias de publicación de los comentarios doctrinales relativos a las sentencias del Tribunal de Justicia y del Tribunal General dictadas en los asuntos interpuestos entre el 1 de enero de 1989 y el 31 de diciembre de 2004»; «la tercera Parte comprende las referencias de publicación de los comentarios doctrinales relativos a las sentencias del Tribunal de Justicia, del Tribunal General y del Tribunal de la Función Pública dictadas en los asuntos interpuestos a partir del 1 de enero de 2005».

7 Sobre él, véase supra, Tema $1, \mathbf{\$ 2}$.

8 Sobre «control de constitucionalidad» y sobre «contencioso electoral y otras decisiones».

9 Recopila también sentencias de Juzgados (sentenças), como algunas selectas de Juzgados de Paz. 
cabiendo consultar en él sentencias y autos de todas las Salas del Tribunal Supremo y, también, de nuestros diecisiete Tribunales Superiores de Justicia autonómicos.

Este acceso directo puede efectuarse vía «Consejo General del Poder Judicial», marcando «jurisprudencia», y luego, según convenga, «Jurisprudencia del TS» o «Jurisprudencia de la AN, TSJ y AP».

La búsqueda libre de jurisprudencia en «Légifrance» — por ponerle alguna pegapresenta el inconveniente de que sólo ofrece, en principio, una relación meramente numérica de resultados encontrados (por orden cronológico descendente). Lo que lógicamente obliga a compulsar todos y cada uno de ellos, al efecto de descartar los que no interesen. Este inconveniente no existe, en cambio, en los buscadores de los modelos portugués y español.

La preocupación de los modelos francés y portugués por procurar el acceso al conocimiento de la jurisprudencia contrasta con lo episódico de las referencias normativas, en ambos países, a la propia jurisprudencia. En efecto, los grandes Códigos omiten aludir a ella en Francia - a pesar de la radical importancia forense que tiene ${ }^{10}$-, apareciendo nombrada como de pasada sólo cuatro veces en la parte reglamentaria del Código de la Organización Judicial ${ }^{11}$. En Portugal, en cambio, lo explica quizá el dato de que el artículo 2 del Código Civil portugués — que permitía fijar «doctrina con fuerza obligatoria general [doutrina com força obrigatória geral]» al Supremo Tribunal de Justicia, por medio de «máximas [assentos]»—- fuese declarado inconstitucional (por contrario a la separación de poderes) en 1993, e inmediatamente derogado - al igual que sus preceptos concordantes del Código del Proceso Civil— por un Decreto-ley de $1995^{12}$.

§3. En cambio, otros modelos continentales europeos, como el alemán o el italiano, deben considerarse de carácter no integral, aunque aparenten serlo. El modelo alemán, porque aunque el sitio de Internet del Tribunal Federal Constitucional — que está ubicado en www.bundesverfassungsgericht.de - permite acceder directamente a

10 Fundamental para entender sus peculiaridades (y en especial, su formulación mediante textos hiper-sucintos), sus formalismos y su valor, véase J.-F. WEBER, «Comprendre un arrêt de la Cour de Cassation rendu en matière civile», Bulletin d'Information de la Cour de Cassation, núm. 702 (2009), págs. 6 y ss., accesible en el sitio de Internet de la propia Corte, ubicado en www.courdecassation.fr.

11 Cfr. sus artículos R. 212-44, R. 222-26, R. 232-10 y R. 312-51, encomendando a ciertos órganos gubernativos de la magistratura el estudio de «la evolución de la jurisprudencia [l'évolution de la jurisprudence]». Sobre la jurisprudencia como fuente del Derecho francés del Trabajo, véase J. PÉLISSIER, A. SUPIOT y A. JEAMMAUD, Droit du Travail, 24a ed., Dalloz (París, 2008), págs. 84 y ss.; y J. PÉLISSIER, A. LYON-CAEN, A. JEAMMAUD y E. DOCKÈS, Les grands arrêts du Droit du Travail, $3^{\mathrm{a}}$ ed., Dalloz (París, 2004), págs. 1 y ss. En cuanto que fuente del Derecho francés de la Seguridad Social, véase F. KESSLER, Droit de la protection sociale, $2^{\mathrm{a}}$ ed., Dalloz (París, 2005), págs. 164-165; y X. PRÉTOT, Les grands arrêts du Droit de la Sécurité Sociale, $2^{a}$ ed., Dalloz (París, 1998), págs. 3 y ss.

12 Se trata del Decreto-ley 329-A/95, de 12 diciembre 1995, en cuya exposición de motivos - refiriéndose a las citadas «máximas»— se razona el porqué de la opción «por la revocación de dicha institución típica y exclusiva de nuestro ordenamiento jurídico». Sobre la jurisprudencia como fuente del Derecho del Trabajo en Portugal, véase P. ROMANO MARTÍNEZ, Direito do Trabalho, Almedina (Coimbra, 2002), págs. 179 y ss.; B.G.L. XAVIER, Curso de Direito do Trabalho. I. Introdução, quadros organizacionais e fontes, $3^{\mathrm{a}}$ ed., Verbo (Lisboa, 2004), págs. 522-523; y últimamente y sobre todo, A. MONTEIRO FERNANDES, «Notas sobre la jurisprudencia del trabajo en Portugal» (traducción castellana de J. MARTÍNEZ GIRÓN), Anuario Coruñés de Derecho Comparado del Trabajo-ACDCT, vol. II (2010), págs. 81 y ss. 
la jurisprudencia de dicho Tribunal y también, por reenvío, a la del resto de Tribunales «Supremos» de la Federación - esto es, la del Tribunal Federal Supremo, ubicado en www.bundesgerichtshof.de, que conoce de asuntos civiles y penales; la del Tribunal Federal de Trabajo, ubicado en www.bundesarbeitsgericht.de; la del Tribunal Federal de Seguridad Social, ubicado en www.bundessozialgericht.de; etc.- , resulta luego que en alguno de estos otros sitios cabe acceder a sentencias (Urteile) y autos (Beschlüsse) sólo muy recientes, del año corriente y de algunos años más, que son sólo los cuatro años inmediatamente anteriores precisamente en los dos casos que más nos interesan (esto es, el del Tribunal Federal de Trabajo y del Tribunal Federal de Seguridad Social) ${ }^{13}$. Y en el modelo que rige en Italia, porque de nuevo su integralidad lo es sólo puramente formal pero no de contenido, dado que el sitio de Internet de la Corte Suprema de Casación —ubicado en www.cortedicassazione.it — permite, sí, el acceso libre y gratuito a toda la jurisprudencia constitucional italiana - por reenvío, entre otros sitios de Internet, al de la Corte Constitucional, ubicado en www.cortecostituzionale.it ${ }^{14}$ — , pero no el acceso a la jurisprudencia de la propia Corte Suprema de Casación, que aparece recopilada en él, sólo si referida al concreto año corriente de que se trate.

Esto explica, respecto de Alemania, la aparición en Internet de sitios de acceso libre, como www.urteile.org, aparentemente montados sobre la base de recopilar sentencias y autos significativos correspondientes, también, a años ya «caducados» en los sitios oficiales citados, aunque sin el valor añadido de la base de datos (normativos, jurisprudenciales, doctrinales, etc.) de pago patronizada por el Gobierno Federal alemán ${ }^{15}$.

En cuanto a Italia, aparentemente sólo cabe acceder a sitios de acceso libre relativos a repertorios de extractos jurisprudenciales ${ }^{16}$.

Paradójicamente, a diferencia de lo que ocurre en Francia o en Portugal, las grandes leyes federales alemanas mencionan con naturalidad la «jurisprudencia [Rechtsprechung]» de los Tribunales Federales Supremos (así, por ejemplo, la Ley del Tribunal de Trabajo ${ }^{17} \mathrm{o}$ la Ley del Tribunal de Seguridad Social ${ }^{18}$ ), mientras que las «Disposiciones para la Aplicación

13 En cambio, en el caso del sitio del Tribunal Federal Constitucional, no existe «caducidad» ninguna, pues recopila decisiones desde 1 enero 1998.

14 También reenvía a www.giurcost.org.

15 Sobre «Juris», véase supra, Tema $1, \$ 3$.

16 Por ejemplo, http://coordinamentorsu.it.

17 Cfr. su parágrafo 45, apartado 4, a propósito precisamente de la «Sala General [Großer Senat]» del Tribunal Federal de Trabajo. Véase P. BADER, M. CREUTZFELDT y H.-F. FRIEDRICH, Kommentar zum Arbeitsgerichtsgesetz, 4 ${ }^{\mathrm{a}}$ ed., Luchterhand (Múnich, 2006), págs. 348 y ss.; y U. ZACHERT, «La jurisprudencia laboral en Alemania», Anuario Coruñés de Derecho Comparado del Trabajo-ACDCT, vol. I (2009), págs. 115 y ss.

18 Cfr. su parágrafo 41, apartado 4, también a propósito de la «Sala General», pero ahora del Tribunal Federal de Seguridad Social. Véase P. KUMMER, Das Sozialgerichtliche Verfahren, $2^{\text {a }}$ ed., Luchterhand (Munich, 2004), págs. 17 y ss. 
del Código del Procedimiento Civil» italiano obligan a los jueces a mencionar en sus sentencias, a título de motivación, los «precedentes favorables [precedenti conformi] ${ }^{19}$, aunque matizando - inmediatamente a continuación — que «en todo caso, debe omitirse toda cita de autores jurídicos [in ogni caso deve essere omessa ogni citazione di autori giuridici]» ${ }^{20}$.

\$4. El Reino Unido cuenta con un peculiar modelo de carácter integral de acceso a la jurisprudencia a través de Internet - a calificar como modelo anglo-irlandés-, puesto que permite la consulta gratuita no sólo de la jurisprudencia de las Cortes y Tribunales más significativos del Reino Unido y de los diversos «países» que lo integran ${ }^{21}$, sino también de la jurisprudencia de las Cortes más significativas y de ciertos Tribunales de la República de Irlanda. Patronizado por muy diversas entidades públicas, este modelo lo gestiona una entidad benéfica sin ánimo de lucro denominada «Instituto Británico e Irlandés de Información Jurídica [British and Irish Legal Information Institute]», radicado a la vez en Londres y en Cork ${ }^{22}$, y cuyo sitio en Internet es www.bailii. org. Refiriéndonos sólo al Reino Unido, este sitio permite acceder a las sentencias (decisions) de todas las principales Cortes de Derecho común de Inglaterra y Gales, de Escocia y de Irlanda del Norte (generalmente, a partir de 1996); a las sentencias de la Cámara de los Lores, en cuanto que antigua Suprema Corte en todo el Reino Unido (recopiladas desde 1838, aunque con vacíos hasta 1996); a las sentencias de la Corte Suprema del Reino Unido, operativa desde octubre 2009; y además, a la doctrina cuasijurisprudencial de ciertos tribunales administrativos -importantísimos, desde el punto de vista del Derecho individual del Trabajo y, también, desde el punto de vista del Derecho de la Seguridad Social-, como el Tribunal de Apelación de Empleo del Reino Unido (desde 1989) ${ }^{23}$ y el Tribunal Superior (desde noviembre 2008) ${ }^{24}$.

19 Cfr. artículo 118, párrafo primero.

20 Ibidem, párrafo tercero. Sobre la jurisprudencia como fuente del Derecho del Trabajo en Italia, véase L. GALANTINO, Diritto del Lavoro, $10^{a}$ ed., G. Giappichelli (Turín, 2000), págs. 44 y ss. Específicamente en relación con el Derecho del contrato de trabajo, véase A. TURSI y P.A. VARESI, Lineamenti di Diritto del Lavoro. Rapporti di lavoro e relazioni sindacali nel settore privato, $3^{\mathrm{a}}$ ed., KluwerIpsoa (s.1., 2004), págs. 28 y ss. Sobre el papel eminente de la jurisprudencia de la Corte Constitucional en materia de seguridad social, véase R. PESSI, Lezioni di Diritto della Previdenza Sociale. Parte Generale, $3^{\mathrm{a}}$ ed., CEDAM (Padua, 2004), págs. 306 y ss.

21 Sobre el «common law» como fuente «formal» del Derecho del Trabajo, interesante, véase S. DEAKIN y G.S. MORRIS, Labour Law, 3ª ed., Butterworths (Londres, 2001), págs. 59 y ss.

22 Más en concreto, en el Instituto de Estudios Jurídicos Avanzados de la Universidad de Londres y en la Facultad de Derecho del University College de Cork.

23 Acerca de este Tribunal, véase infra, Tema 8, §3.

24 Acerca de este Tribunal, véase infra, Tema 10, §2. 
Aparte la jurisprudencia de la República de Irlanda, a través de este mismo sitio cabe acceder (aunque por reenvío y, en bastantes casos, sólo respecto de los primeros años del siglo XXI), también, a la jurisprudencia de buena parte de los Estados integrantes de la Comunidad Británica de Naciones, como la jurisprudencia australiana, neozelandesa, canadiense, de Hong Kong, de las Islas del Pacífico, pakistaní, etc.

Lógicamente, las bases de datos jurisprudenciales de este sitio se nutren de la información suministrada por las correspondientes Cortes o Tribunales, indicándose respecto de la tradicionalmente más alta instancia jurisdiccional británica, por ejemplo, que «el material para esta [concreta] base de datos ha sido obtenido con autorización de la Cámara de los Lores».

El futuro de este sitio - que «suministra acceso al conjunto más completo de materiales jurídicos primarios británicos e irlandeses, que están disponibles gratis en un solo sitio de internet» ${ }^{25}$ - se orienta a la ampliación progresiva de sus fondos históricos, pues «profesores y abogados en ejercicio frecuentemente citan la vieja jurisprudencia [old case law] y los casos más viejos pueden ser una fuente fértil de datos sociales para investigadores de otras disciplinas» ${ }^{26}$.

§5. Respecto de la jurisprudencia federal de los Estados Unidos ${ }^{27}$, el modelo norteamericano de acceso a la misma a través de Internet también merece ser calificado como modelo de carácter integral. En efecto, el portal oficial de las Cortes federales, ubicado en www.uscourts.gov, permite ${ }^{28}: 1$ ) acceder a las resoluciones de las Cortes de Apelaciones de los trece circuitos federales - por reenvío automático a sus respectivos sitios en Internet—, aunque generalmente a partir de 1995; 2) acceder a las resoluciones de las Cortes de Distrito actuantes en cada uno de dichos circuitos - asimismo por reenvío automático a sus respectivos sitios de Internet-, aunque generalmente a partir de 2000; y 3) acceder a las resoluciones de la Corte Suprema de los Estados Unidos — por reenvío automático a su sitio www.supremecourt.gov—, pudiendo manejarse en este último a partir de octubre 1991. Por su parte, el portal jurídico del Gobierno de los Estados Unidos ${ }^{29}$ también permite acceder, siempre por reenvío automático —a través del enlace «Fuentes administrativas [Executive Resources] $\rangle^{30}$-, a los sitios de Internet de tres agencias federales muy significativas para un laboralista, a saber: 1) la Oficina Nacional de Relaciones Laborales (National Labor Relations Board) —ubicada en www.nlrb.gov—, cuyas

25 Véase, en el propio sitio, «What is BAILII?».

26 Véase, también en el propio sitio («BAILII in a Nutshell»), el documento «The British and Irish Legal Information Institute», apartado 6.

27 Sobre «Judges as Legislators», véase B.J. TAYLOR y F. WITNEY, Labor Relations Law, $6^{\mathrm{a}}$ ed., Prentice Hall (Englewood Cliffs-New Jersey, 1992), págs. 7-8. Infraestructural siempre, véase B.N. CARDOZO, The nature of the judicial process, Yale University Press (New Haven, 1949), págs. 9 y ss.

28 Utilizando el enlace «Federal Courts».

29 Acerca de él, véase supra, Tema 1, \$5.

30 Previo paso por «Web Sites Hosted by GPO Access» (obrante en «Publicaciones Administrativas») o, en su caso, por «Federal Agency Internet Sites» (obrante en «Fuentes Adicionales»). 
decisiones y órdenes (obrantes en el sitio desde 1936) crean cuasi-jurisprudencia en materias relativas al Derecho colectivo federal del Trabajo ${ }^{31}$; 2) la Comisión de Revisión de Seguridad y Salud Laboral de los Estados Unidos (United States Occupational Safety \& Health Review Commission) —ubicada en www.oshrc.gov-, cuyas decisiones obran recopiladas en este sitio desde 1972 (y las de sus jueces de Derecho Administrativo, desde 1993) ${ }^{32}$; y 3) la gigantesca Administración de Seguridad Social (Social Security Administration) —ubicada en www.socialsecurity.gov-, que ofrece información útil, entre otros muchos extremos, también sobre jurisprudencia de las Cortes federales en materia de seguridad social ${ }^{33}$.

El manejo del citado sitio de Internet relativo a la jurisprudencia de las Cortes federales de Apelaciones y de Distrito exige armarse de alguna paciencia, dada la relativa complejidad de los mapas e índices que sucesivamente resulta preceptivo utilizar en él, hasta llegar a la concreta Corte cuyas decisiones interese manejar. De ahí, una vez localizado su sitio de Internet, que lo más expeditivo sea - si es que hubiese que volver luego a él- acceder ya directamente al mismo. Por ejemplo, marcando www.ca9.uscourts. gov, si es que pretende manejarse la jurisprudencia de la Corte de Apelaciones del Noveno Circuito (que comprende Alaska, Arizona, California, Idaho, Montana, Nevada, Oregon, Washington, Guam y Hawaii); o marcando www.cacd.uscourts.gov, si es que pretende accederse a las sentencias y autos dictados por la Corte federal de Distrito del Distrito Central de California, que es el correspondiente al Condado de Los Angeles (y sus vecindades de Hollywood, Bel Air, Beverly Hills, etc.).

Complemento ideal del citado sitio de Internet relativo a la Corte Suprema de los Estados Unidos, donde constan los llamados «Volúmenes Vinculantes [Bound Volumes]» - que contienen, se supone que totalmente depurados de erratas, los textos definitivos (literalmente, la «generación cuarta y definitiva») de las resoluciones de dicha Corte-, desde el volumen «502» (correspondiente a los casos decididos por ella, entre 7 octubre 1991 y 24 febrero 1992), es el sitio privado www.justia.com, que permite la consulta gratuita de la totalidad de los volúmenes en cuestión ${ }^{34}$.

Para la búsqueda libre de jurisprudencia de la Corte Suprema de los Estados Unidos resulta siempre práctico el sitio de Internet — también de acceso gratuito- www.law. cornell.edu/supct/index.html, gestionado por el Instituto de Información Jurídica de la Universidad Cornell de Nueva York ${ }^{35}$. Téngase en cuenta asimismo la eventual necesidad de manejar jurisprudencia de las Cortes de los diversos Estados federados ${ }^{36}$. Esta última resulta accesible, por reenvío, a través del sitio www.findlaw.com/casecode.

31 Acerca de esta agencia federal, véase infra, Tema $8, \S 4$.

32 Acerca de esta agencia federal, véase infra, Temas 7, §5, y 16, §3.

33 Acerca de esta agencia federal, véase infra, Tema 9, §5.

34 Sobre la forma de citar estos volúmenes, cuyo acrónimo es «U.S.», véase A. ARUFE VARELA, «El voto particular del Juez Oliver Wendell Holmes, Jr. en el caso Coppage v. Kansas (1915). Un texto jurídico norteamericano clásico contra el despido libre», Anuario Coruñés de Derecho Comparado del Trabajo-ACDCT, vol. I (2009), pág. 14.

35 También acerca de este mismo Instituto, véase Tema $1, \$ 5$.

36 Sobre las relaciones entre las Cortes federales y estatales, véase C.A. WRIGHT, Law of Federal Courts, West Publ. Co. (St. Paul-Minn., 1983), págs. 268 y ss. 
PARTE SEGUNDA

INSTITUCIONES

SECOND PART

INSTITUTIONS 


\section{TEMA 6 \\ LOS SERVICIOS PÚBLICOS DE EMPLEO EN EUROPA Y EN LOS ESTADOS UNIDOS}

Sumario: §1. El Derecho de la Unión Europea regulador de la Oficina Europea de Selección de Personal y del «Servicio Europeo de Empleo». §2. Los modelos de servicios públicos de empleo (alemán y británico) unitarios e integrales. §3. Los modelos de servicios públicos de empleo (portugués y francés) unitarios, pero no integrales. §4. Los modelos de servicios públicos de empleo (italiano y español) ni unitarios ni integrales. §5. El Derecho federal norteamericano regulador de la Oficina de Gestión del Personal y del modelo norteamericano no unitario, pero sí integral, de servicios públicos de empleo.

THEME 6

THE PUBLIC SERVICES OF EMPLOYMENT IN EUROPE AND IN THE UNITED STATES

Contents: $\$ 1$. The Law of the European Union regulating the European Personnel Selection Office and the "European Service of Employment». \$2. The (German and British) unitarian and integral models of public services of employment. \$3. The (Portuguese and French) unitarian but non-integral models of public services of employment. \$4. The (Italian and Spanish) neither unitarian nor integral models of public services of employment. \$5. The United States Law regulating the Office of Personnel Management and the USA nonunitarian but integral model of public services of employment.

§1. El análisis de los servicios públicos de empleo desde la perspectiva del Derecho de la Unión Europea exige enfocar el tema en una doble vertiente. Una vertiente interna, puesto que la Unión Europea posee desde 1 enero 2003 un organismo encargado del reclutamiento del personal funcionario, contratado o becario al servicio de sus instituciones, que es la Oficina Europea de Selección de Personal (conocida por su acrónimo en inglés EPSO, esto es, European Personnel Selection Office $)^{1}$, a la que se puede acceder a través de su dirección en Internet

1 Esta Oficina fue creada por «Decisión de los Secretarios Generales del Parlamento Europeo, del Consejo y de la Comisión, del Secretario del Tribunal de Justicia, de los Secretarios Generales del Tribunal de Cuentas, del Comité Económico y Social y del Comité de las Regiones y del representante del Defensor del Pueblo Europeo, de 25 de julio de 2002, relativa a la organización y el funcionamiento de la Oficina de selección de personal de las Comunidades Europeas»». 
http://europa.eu/epso, cabiendo encontrar aquí — en lenguas inglesa, francesa y alemana - información detallada acerca de cómo es el trabajo en las instituciones de la Unión Europea, las oposiciones, las convocatorias para cubrir puestos contractuales y de becario, las listas de reserva o el curriculum vitae europeo ${ }^{2}$. Pero también una vertiente externa, dado que el Derecho de la Unión Europea pretende lograr un funcionamiento más eficaz de los servicios públicos de empleo de cada uno de los Estados miembros, fundamentalmente a través de las «Directrices para las políticas de empleo de los Estados miembros», que desde el año 2000 vienen insistiendo — por causa del protagonismo estelar de las políticas activas de empleo en el marco del Derecho de la Unión Europea- en la necesidad de modernizar los diversos servicios públicos nacionales de empleo $^{3}$. Asimismo en su vertiente externa, la Unión Europea igualmente se ha preocupado por conseguir una colaboración más intensa, así como un intercambio de información más eficaz, entre los respectivos servicios públicos de empleo de los Estados miembros, como acredita la denominada Red EURES (EURopean Employment Services) ${ }^{4}$, concebida como una red europea de servicios — aunque las fuentes europeas también se refieran a ella como «el Servicio Europeo de Empleo» ${ }^{5}$ - creada e integrada por los servicios de empleo de los Estados miembros, y que permite buscar ofertas de trabajo en toda la Europa unida - a fecha de 23 febrero 2010, aparecen 825.168 vacantes de empleo anunciadas-, a través de la dirección en Internet http://ec.europa.eu/eures. Todas estas preocupaciones tienen en cuenta, como es lógico, la evidencia de que en el seno de la Unión Europea coexisten diferentes modelos de organización de los servicios públicos de empleo, cuyas peculiaridades se explican

\footnotetext{
2 Sobre el personal al servicio de la Unión Europea, véase infra, Tema 15, §1.

3 Véase A. ARUFE VARELA, «El nuevo “compromiso de actividad”, de situación legal de desempleo, y de beneficiarios del subsidio por desempleo», Actualidad Laboral, núm. 33 (2002), págs. 719 a 721. Sobre la historia del tema, véase C. BARNARD, EC Employment Law, Oxford University Press (Oxford, 2000), págs. 42 y ss.

4 Acerca de la norma europea reguladora de la Red EURES, que es la Decisión 2003/8/CE, de 23 diciembre 2002, por la que se aplica el Reglamento (CEE) del Consejo núm. 1612/68, por lo que se refiere a la puesta en relación y la compensación de las ofertas y demandas de empleo, véase J. MARTÍNEZ GIRÓN, A. ARUFE VARELA y X.M. CARRIL VÁZQUEZ, Derecho del Trabajo, 2a ed., Netbiblo (A Coruña, 2006), págs. 111-112.

5 Cfr., por ejemplo, el «Acuerdo sobre la libre circulación de personas entre la Comunidad Europea y sus Estados miembros, por una parte, y la Confederación Suiza, por otra - Acta final—Declaraciones conjuntas - Información relativa a la entrada en vigor de los siete acuerdos con la confederación Suiza en los sectores siguientes: libre circulación de personas, transporte aéreo y por carretera, contratos públicos, cooperación científica, reconocimiento mutuo en materia de evaluación de la conformidad y agricultura», de 21 junio 1999 (artículo 11 de su Anexo I); y también, la Recomendación del Parlamento Europeo y del Consejo de 10 julio 2001, «relativa a la movilidad en la Comunidad de los estudiantes, las personas en formación, los voluntarios, los profesores y los formadores» [recomendación 1.f), último guión].
} 
—enseguida se verá- no sólo por causa del modo de configuración territorial de los mismos, sino también por el tipo de funciones o tareas principalmente asumidas por ellos.

El citado portal de EURES en Internet incluye cuatro entradas principales -denominadas «Solicitantes de empleo», «Vida y trabajo», «Empresas» y «Aprendizaje»—, de las cuales resultan especialmente atractivas para quien busca trabajo las dos primeras. La entrada «Solicitantes de empleo» permite gratuitamente al usuario, siempre a través de Internet, buscar y encontrar un empleo en otro país comunitario, y también, abrir una cuenta en el portal para introducir el currículo vital, posibilitando con ello que pueda ser consultado por potenciales empleadores europeos. La entrada «Vida y trabajo» facilita al usuario conocer las condiciones de vida (alojamiento, coste de la vida, sistema sanitario, etc.) y de trabajo (remuneración, tiempo de trabajo, vacaciones anuales, etc.) de los diversos Estados miembros.

Según el Tribunal de Luxemburgo, «las oficinas públicas de empleo están sometidas a la prohibición del artículo 86 del Tratado» — que va de las restricciones a la libre competencia-, por lo que «el Estado miembro que prohíbe toda actividad de mediación e interposición entre demandas y ofertas de trabajo cuando no la realizan dichas oficinas infringe el artículo 90, apartado 1, del Tratado si crea una situación en la que las oficinas públicas de empleo se ven necesariamente obligadas a infringir los términos del artículo 86 del Tratado» ${ }^{6}$.

Como es lógico, este tema cuenta en Europa con excelentes perspectivas de futuro, corroborándolo así el que la Carta de los Derechos Fundamentales de la Unión Europea afirme que «toda persona tiene derecho a acceder a un servicio gratuito de colocación» ${ }^{7}$, aclarando incluso las «explicaciones» relativas a la Carta, que «este artículo se basa en el apartado 3 del artículo 1 de la Carta Social Europea, así como en el punto 13 de la Carta Comunitaria de los Derechos Sociales Fundamentales de los Trabajadores» ${ }^{8}$.

§2. Desde un punto de vista organizativo, los servicios públicos de empleo de Alemania y Gran Bretaña se ajustan a un modelo u nitario e integral de servicio público de empleo, dado que el servicio en cuestión opera en todo el territorio del Estado de que se trate (de ahí su carácter «unitario»), ejecutando en todo ese ámbito territorial simultáneamente políticas activas de empleo y políticas pasivas de empleo (de ahí su carácter «integral») ${ }^{9}$. En efecto, en Alemania ${ }^{10}$, la Agencia

6 Cfr. Sentencia del Tribunal de Justicia de las Comunidades Europeas de 8 junio 2000 (asunto C-258/98). Sobre las ETTs en Europa, véase infra, Tema 15, §2.

7 Cfr. artículo 29 (rotulado «Derecho de acceso a los servicios de colocación»).

8 Véase la «explicación relativa al artículo 29».

9 Sobre la distinción entre ambos tipos de políticas, véase J. MARTÍNEZ GIRÓN, A. ARUFE VARELA y XOSÉ MANUEL CARRIL VÁZQUEZ, Derecho del Trabajo, 2a ed., cit., págs. 109-110.

10 Véase K. WITTERSTÄTTER, Soziale Sicherung. Eine Einführung für Sozialarbeiter/ Sozialpädagogen mit Fallbeispielen, $6^{\mathrm{a}}$ ed., Luchterhand (Munich, 2003), págs. 171 y ss.; E. EICHENHOFER, Sozialrecht, $5^{\mathrm{a}}$ ed., Mohr Siebeck (Tubinga, 2004), págs. 245 y ss.; y también, R. WALTERMANN, Sozialrecht, $5^{\text {a }}$ ed., C.F. Müller (Heidelberg, 2005), págs. 55 y ss. y 189 y ss. Desde el punto de vista del contencioso judicial relativo al tema, véase P. KUMMER, Das sozialgerichtliche Verfahren, $2^{\mathrm{a}}$ ed., Luchterhand (Munich, 2004), págs. 11 y ss. Y últimamente, véase A. ARUFE VARELA, «El modelo alemán de gestión de las políticas de empleo», en el volumen Estrategia europea, Estado autonómico y política de empleo. XVIII Congreso Nacional de Derecho del Trabajo y de la Seguridad Social, Ministerio de Trabajo e Inmigración (Madrid, 2008), págs. 383-391. 
Fe deral de Emple o (Bundesagentur für Arbeit) - cuya central radica en la ciudad de Nuremberg (Estado federado de Baviera), y que depende del «Ministerio Federal de Trabajo y de Seguridad Social [Bundesministerium für Arbeit und Soziales]»— se ocupa en todo el territorio de la República Federal, a través de sus oficinas de empleo (Geschäftsstellen), tanto de procurar un empleo a quienes se encuentran parados, como de pagar a quienes se encuentran jurídicamente desempleados las correspondientes prestaciones por desempleo. Y en Gran Bretaña ocurre algo similar ${ }^{11}$, puesto que 1 a agencia ejecutiva denominada Jobcentre Plus —dependiente del Ministerio inglés y galés, o escocés, de Trabajo y Pensiones (Department of Work and Pensions) -, a través de oficinas (legalmente denominadas «Jobcentre Plus Offices») integradas en su red, se ocupa de apoyar al demandante de empleo (jobseeker) y de pagar la prestación por desempleo (jobseeker's allowance).

Lógicamente, a través de Internet puede accederse a la información que ofrecen estas dos agencias a los parados y desempleados ${ }^{12}$. La agencia alemana se encuentra en el sitio www.arbeitsagentur.de, en el que resulta posible consultar no sólo muy interesante información práctica, sino también información relativa a la legislación aplicable al asunto. A la agencia inglesa se accede a través del sitio www.jobcentreplus.gov.uk, en el que sólo cabe hallar información práctica y muy de andar por casa.

Por debajo de su sede central, la Agencia Federal de Empleo alemana está estructurada en diez direcciones regionales - se superpone, por tanto, a la estructura de los Estados federados, que son dieciséis-, de las que dependen las «agencias de empleo» en las que se encuadran las citadas «oficinas de empleo». Esta estructura se encuentra regulada en el Libro Tercero del Código de Seguridad Social ${ }^{13}$, en el que también se trata todo lo relativo a las políticas activas y pasivas de empleo ligadas a la prestación contributiva de desempleo ${ }^{14}$. Además, la Agencia Federal de Empleo también se encarga de la administración del Libro Segundo del propio Código de Seguridad Social, dedicado a la regulación de las políticas activas y pasivas de empleo ligadas a las prestaciones no contributivas de desempleo ${ }^{15}$.

Las oficinas inglesas de empleo constituyen una red estructurada en ochenta y cinco distritos, a su vez agrupados en nueve regiones inglesas, Escocia y Gales, existiendo además una dirección central denominada Jobcentre Plus Direct. Esta red tiene encomendada la misión de gestionar y ejecutar las políticas activas y pasivas de empleo, contenidas en la

11 Véase R. EAST, Social Security Law, McMillan (Londres, 1999), págs. 69 y ss.; y J. BOWERS, $A$ practical approach to Employement Law, $7^{\text {a }}$ ed., Oxford University Press (Oxford, 2005), págs. 72-73. Desde una perspectiva estrictamente contractual, véase D. BRODIE, The employment contract. Legal principles, drafting and interpretation, Oxford University Press (Oxford, 2005), págs. 31 y ss.

12 Acerca de esta distinción crucial, véase J. MARTÍNEZ GIRÓN, A. ARUFE VARELA y XOSÉ MANUEL CARRIL VÁZQUEZ, Derecho de la Seguridad Social, $2^{\mathrm{a}}$ ed., Netbiblo (A Coruña, 2008), págs. 173-174.

13 Cfr. parágrafos 367 y ss.

14 Bajo el rótulo genérico «Fomento del empleo [Arbeitsförderung]».

15 Bajo el rótulo genérico «Aseguramiento básico de los demandantes de empleo [Grundsicherung für Arbeitsuchende]». Sobre otros entes que pueden intervenir en la gestión de este tipo de prestaciones, véase su parágrafo 6 . 
Ley de Demandantes de Empleo (Jobseeker's Act) de 1995, desarrollada por el gigantesco «Reglamento de la Prestación por Desempleo [The Jobseeker's Allowance Regulations]》 núm. 207 de 1996. En el aparato crítico de una de las múltiples disposiciones reglamentarias de la Ley, se aclara que «las oficinas designadas como Jobcentre Plus Offices se identifican en dos listas denominadas "Oficinas Rastreadoras [Pathfinder Offices] de Jobcentre Plus" y "Sitios de Extensión de Entrevistas enfocadas hacia el Trabajo [Work-focused Interview Extension Sites] de Jobcentre Plus", que están disponibles en el Ministerio de Trabajo y Pensiones, W2W1, 4S25, Quarry House, Quarry Hill, Leeds, LS2 7UA» ${ }^{16}$.

§3. En cambio, los servicios públicos de empleo existentes hoy en Portugal y Francia responden a los caracteres propios de un modelo unitario, pero no integral, de servicio público de empleo, dado que su actuación se extiende por todo el respectivo territorio continental de ambos Estados - en esto coincidente, por tanto, con el modelo alemán y británico-, pero sin gestionar el conjunto de políticas ligadas al empleo (de ahí su carácter «no integral»). En efecto, el servicio público de empleo portugués o «Instituto del Empleo y de la Formación Profesional, I.P. [Instituto do Emprego e da Formação Profissional, I.P.]» —incardinado en el «Ministerio portugués del Trabajo y de la Solidaridad Social [Ministério do Trabalho e da Solidariedade Social] ${ }^{17}$ — es un ente actuante a través de «centros de empleo [centros de emprego]» - territorialmente agrupados en seis grandes regiones peninsulares-, a los que pueden acudir todos aquellos parados que buscan un empleo, pero no los desempleados que pretendan el cobro de la «prestación de desempleo [prestação de desemprego»], puesto que la gestión de esta prestación está atribuida en Portugal al «Instituto de la Seguridad Social, I.P. [Instituto da Segurança Social, I.P.]» ${ }^{18}$. Por su parte, el servicio público de empleo francés está encarnado en el "Polo Empleo [Pôle Emploi]» —en la órbita del Ministerio competente en materia de Empleo ${ }^{19}$ - integrado por una extensa red de agencias locales repartidas por las veintidós regiones metropolitanas, resultando ser las mismas los «polos de empleo» a que los parados franceses deben acudir si desean beneficiarse de las

16 Cfr. «Reglamento de Seguridad Social (Entrevistas de Jobcentre Plus) [The Social Security (Jobcentre Plus Interviews) Regulations]», localizable como Statutory Instrument núm. 1703 de 2002, en www.statutelaw.gov.uk.

17 Desde una perspectiva estrictamente contractual, véase A. MONTEIRO FERNANDES, Direito do Trabalho, $15^{\mathrm{a}}$ ed., Almedina (Coimbra, 2010), págs. 303 y ss.

18 Sobre él, véase infra, Tema 9, §3.

19 Acerca de la «Agencia Nacional para el Empleo» o ANPE, antecedente del citado «Polo Empleo», véase J. PÉLISSIER, A. SUPIOT y A. JEAMMAUD, Droit du Travail, 24ª ed., Dalloz (París, 2008), págs. 357 y ss. 
políticas activas de empleo, pero no los que deben visitar los desempleados que pretendan cobrar el desempleo contributivo o «seguro de desempleo [assurance chômage]», dado que la gestión de este último está atribuida en Francia a otra entidade de Derecho privado, denominada UNÉDIC ${ }^{20}$.

Como en los casos alemán y británico, los servicios públicos de empleo portugués y francés resultan accesibles asimismo a través de Internet. El Instituto portugués -más conocido por su acrónimo, IEFP - se encuentra en el sitio www.iefp.pt, en el que cabe consultar una muy abundante información práctica, resultando especialmente útil el enlace a www.netemprego.gov.pt, que es un sistema de búsqueda de empleo en Portugal a través de la red. El ente francés aparece en www.pole-emploi.fr, donde también se contiene abundante información de ayuda para buscar empleo, en particular a través de su entrada «vous êtes candidat».

El IEFP portugués fue creado por el Decreto-Ley núm. 519-A2/79, de 29 diciembre, que contiene su «Ley Orgánica» ${ }^{21}$. En cuanto a la prestación portuguesa por desempleo, la regula actualmente el Decreto-Ley núm. 220/2006, de 3 noviembre, que entró en vigor el 1 enero $2007^{22}$. Como es lógico, esta última norma efectúa referencias a las «competencias de los centros de empleo» en relación con determinados actos instrumentales relativos a la prestación ${ }^{23}$, indicando que «las competencias asignadas en el presente decreto-ley al servicio público de empleo son ejercidas por el IEFP» ${ }^{24}$.

En cuanto a la regulación del ente francés, hay que consultar el Libro III de la Parte V del Código del Trabajo ${ }^{25}$, y principalmente sus artículos L. 5312-1 y ss. Su Libro IV contiene las notas básicas de la prestación de desempleo, indicando que su gestión compete «a un organismo de derecho privado» a elegir por «las partes firmantes del acuerdo previsto en el artículo L. 5422-20» ${ }^{26}$. Este acuerdo es, en la actualidad, el «Convenio de 19 febrero 2009 relativo a la indemnización del desempleo [Convention du 19 février 2009 relative à l'indemnisation du chômage]» ${ }^{27}$.

§4. A diferencia de Francia y Portugal —que son Estados-nación constituidos desde hace muchos siglos-, España e Italia todavía andan a vueltas con el tema de su estructuración territorial ${ }^{28}$, lo que explica que sus servicios públicos de empleo se ajusten a un modelo que

20 Sobre esta entidad, véase infra, Tema 9, §2.

21 Véase también el «Estatuto» del Instituto del Empleo y de la Formación Profesional, I.P. (aprobado por Decreto-Ley núm. 213/2007, de 29 mayo), y los «Estatutos del Instituto del Empleo y de la Formación Profesional, I.P.» (aprobados por Orden Ministerial [Portaria] núm. 637/2007, de 30 mayo).

22 Desarrollado por Orden Ministerial núm. 8-B/2007, de 3 enero, cuyo artículo 20.1 (sobre «Intercambio de información entre servicios») indica que «los servicios del empleo y los servicios de la seguridad social intercambian la información necesaria para el reconocimiento del derecho a la protección en el desempleo, al mantenimiento, suspensión y extinción de las respectivas prestaciones».

23 Cfr. artículo 70.

24 Cfr. artículo 68.2.

25 Libro rotulado «Servicio público del empleo y colocación [Service public de l'emploi et placement]».

26 Cfr. artículo L. 5427-1, párrafo primero.

27 Su texto puede localizarse en el sitio en Internet del UNÉDIC, ubicado en www.unedic.org.

28 Respecto de Italia, véase M. CINELLI y S. GIUBBONI, Il Diritto della sicurezza sociale in trasformazione, Giapichelli (Turín, 2005), págs. 69 y ss. 
no es integral -al igual que el modelo portugués y francés-, pero que - a diferencia de los modelos alemán, británico, portugués y francés- tampoco es un modelo unitario, al estar desagregado territorialmente. De ahí que en el caso de Italia -al igual que ocurre en España- no quepa hablar de un único servicio público de empleo, sino de una pluralidad de ellos, que en España son el «Servicio Público de Empleo Estatal»y los «Servicios Públicos de Empleo de las Comunidades Autónomas» ${ }^{29}$; y que son en Italia, en el plano estatal, la denominada «Agencia Técnica Italia Lavoro»-dependiente de los Ministerios competentes en materia de Trabajo y Seguridad Social一, $y$ en el plano regional, los "Servicios Regionales de Empleo [Servizi Regionali per l'Impiego]» —encarnados cada uno de ellos en su correspondiente «Agencia Regional [Agenzia Regionale]» (por ejemplo, la «Agenzia Regionale Lazio Lavoro», la «Agenzia Piemonte Lavoro», la "Agenzia regionale per l'instruzione, la formazione e il lavoro [de Lombardía]», etc. ${ }^{30}$ - , que coordinan las competencias que poseen en este tema las diversas provincias (por ejemplo, Milán y demás provincias de Lombardía, Turín y demás provincias de Piamonte, Roma y demás provincias de Lacio, etc.), y fundamentalmente la de crear y gestionar las oficinas de empleo, denominadas «centros de empleo [centri per l'impiego]». Esta pluralidad de servicios de empleo se ocupa únicamente de la gestión de las políticas activas (de ahí su carácter «no integral»), al estar confiada en Italia la gestión de las prestaciones contributivas de desempleo («indennità di disoccupazione ordinaria», «indennità di disoccupazione con requisiti ridotti») a una entidad gestora pública estatal específica, que es el Instituto Nacional de la Previsión Social (Istituto Nazionale della Previdenza Sociale) ${ }^{31}$.

La transferencia a las regiones italianas de las competencias relativas a las políticas activas de empleo fue operada por el Decreto Legislativo núm. 469, de 23 diciembre 1997, sobre «delegación a las regiones y a las entidades locales de funciones y competencias en materia de mercado del trabajo [conferimento alle regioni e agli enti locali di funzioni e compiti en materia di mercato del lavoro]», que confiaba «a las regiones las funciones y las

29 Véase J. MARTÍNEZ GIRÓN, A. ARUFE VARELA y X.M. CARRIL VÁZQUEZ, Derecho del Trabajo, $2^{a}$ ed., cit., págs. 109 y ss.; y de los mismos autores, Derecho de la Seguridad Social, $2^{\mathrm{a}}$ ed., cit., págs. 241-242.

30 Acerca de todo ello, véase G. SUPPIEJ, M. DE CRISTOFARO y C. CESTER, Diritto del Lavoro. Il rapporto individuale, $2^{\mathrm{a}}$ ed., CEDAM (Padua, 2003), págs. 140 y ss.

31 Sobre este Instituto, véase infra, Tema 9, \$2. 
competencias en materia de política activa del trabajo» ${ }^{32}$, y además, contenía los «criterios para la organización del sistema regional de empleo» ${ }^{33}$. En virtud de esta norma estatal, fueron aprobándose sucesivamente las diversas normas regionales sobre el tema. En este sentido, por ejemplo, la Ley Regional de Lacio núm. 38, de 7 agosto 1998, relativa a la «organización de las funciones regionales y locales en materia de políticas activas para el trabajo»; la Ley Regional de Piamonte núm. 41, de 14 diciembre 1998, acerca de la «organización de las funciones regionales y locales en materia de mercado del trabajo»; o también, la Ley Regional de Lombardía núm. 1, de 15 enero 1999, sobre «políticas regionales del trabajo y del servicio de empleo».

Todos los servicios públicos de empleo italianos citados, estatal y regionales, resultan accesibles a través de Internet. El estatal, a través de www.italialavoro.it; los regionales, a través de su respectivo sitio en Internet, como los casos de www.portalavoro.regione. lazio.it, www.agenziapiemontelavoro.net, o www.arifl.it. Los sitios de Internet de los respectivos Gobiernos regionales, a diferencia de lo que ocurre con los sitios de Internet de las Administraciones estatales, permiten en estos tres casos el acceso público y gratuito a versiones consolidadas de la legislación regional ${ }^{34}$.

Vista la desintegración del sistema derivada de la transferencia de competencias de finales de 1997, la «reforma Biagi» del mercado de trabajo - cuyo primer fruto fue la Ley núm. 30, de 14 febrero $2003^{35}$ - se planteó la necesidad de recuperar la unidad del sistema de colocación, cristalizando en la puesta en marcha de una red informática operante a través de Internet - la denominada «bolsa continua nacional del trabajo [borsa continua nazionale del lavoro]» ${ }^{36}$-, definida como un «sistema abierto y transparente de encuentro entre demanda y oferta de trabajo basado en una red de enlaces regionales ..., alimentado por toda la información útil a tal fin introducida en el sistema mismo ya por los operadores públicos y privados ..., ya directamente por los trabajadores y por las empresas» ${ }^{37}$. La citada «bolsa» resulta accesible en la web en www.borsalavoro.it. Lógicamente, todos los servicios públicos italianos de empleo, estatal y regionales, permiten acceder a ella desde sus propias páginas, a través del correspondiente enlace.

§5. Desde el punto de vista de la estructuración de los servicios públicos de empleo, el contrapunto real de los Estados Unidos de Norteamérica no son los diversos Estados europeos - Texas y Francia o California y Alemania sí resultarían, en cambio, magnitudes comparables a estos efectos-, sino el Derecho de la Unión Europea ${ }^{38}$. De un lado, porque la Unión Europea tiene su EPSO y los Estados Unidos de Norteamérica

32 Cfr. artículo 2.2.a).

33 Cfr. artículo 4.

34 Por ejemplo, en el caso del Gobierno regional de Lacio, www.regione.lazio.it.

35 Según ella, debería procederse al «desarrollo y simplificación de los procedimientos de encuentro entre demanda y oferta de trabajo» [artículo 1.2.a)]. Sobre dicha "reforma», véase A. ARUFE VARELA, «El cumplimiento por Italia de las recomendaciones europeas sobre el empleo, a través de la "Reforma Biagi"», Anuario da Facultade de Dereito da Universidad da Coruña. Revista Jurídica Interdisciplinar Internacional, vol. 10 (2006), págs. 61 y ss.

36 Cfr. Decreto Legislativo núm. 276, de 10 septiembre 2003, artículos 15 y 16.

37 Ibidem, artículo 15.1. El sistema informático se encuentra desarrollado normativamente en un Decreto de 13 octubre 2004.

38 Desde una perspectiva estrictamente contractual, véase M. A. ROTHSTEIN, C.B. CRAVER, E.P. SCHROEDER, E.W. SHOBEN y L.S. VABDERVELDE, Employment Law, West Publ. Co. (St. Paul-Minn., 1994), págs. 26 y ss. Desde el punto de vista del Derecho federal antidiscriminatorio, véase S. ESTREICHER y M.C. HARPER, Cases and Materials on the Law governing the Employment Relationship, $2^{\mathrm{a}}$ ed., West Publ. Co. (St. Paul-Minn., 1992), págs. 9 y ss. 
su OPM - acrónimo de "Oficina de Gestión del Personal [Office of Personnel Management]》-, que no son exactamente lo mismo - la OPM no recluta el personal al servicio de la Administración federal norteamericana-, pero que se parecen mucho, dado que la OPM actúa como agente de coordinación y apoyo de las Administraciones federales oferentes de empleos y, también, como agente de intermediación entre cada Administración federal oferente de empleos y el servicio federal norteamericano de empleo. De otro lado, porque existe este último, al igual que en la Unión Europea existe - como se vio- el «Servicio Europeo de Empleo». En efecto, el servicio federal norteamericano de empleo - legalmente denominado "Servicio de Empleo de los Estados Unidos [United States Employment Service]», y también conocido por el acrónimo USES - es una red integrada por los diversos servicios públicos de empleo de los Estados federados, con más competencias y mucho más evolucionada que la Red EURES, aunque al igual que esta última tampoco gestiona políticas de empleo. Estas políticas son gestionadas por cada Estado federado en su territorio propio, a través de su respectivo servicio estatal público de e mpleo - legalmente denominado «agencia estatal para el servicio de empleo [State job service agency]»-, competente para ejecutar tanto las políticas activas como las políticas pasivas de empleo, lo que explica que el modelo norteamericano de servicios públicos de empleo deba ser calificado de modelo no unitario (al estar desagregado territorialmente por Estados), pero sí integral (al corresponder en cada Estado a una misma agencia, actuante a través de «oficinas locales de empleo [local employment offices]》, la intermediación en el mercado de trabajo y el pago de las prestaciones por desempleo).

La OPM existe desde 1 enero 1979, y se ocupa —entre otras muchas cosas- de que las diversas agencias federales den efectividad real al principio de mérito y capacidad («merit system»). Se encuentra regulada en las secciones 1101 y ss. del Título 5 del Código de los Estados Unidos (rotulado «Organización del Gobierno y empleados [Government Organization and employees]») ${ }^{39}$. Posee su propio sitio en Internet, ubicado en www.opm. gov $^{40}$, donde se afirma que «Estados Unidos tiene la función pública más fina del mundo [The United States has the finest civil service in the world] ${ }^{41}$.

El USES fue creado en 1933 — por tanto, inmediatamente después del crack de 1929por la «Ley Wagner-Peyser [Wagner-Peyser Act]», luego sustancialmente modificada por la

39 Dichas secciones aparecen reglamentadas en el Capítulo I («Oficina de Gestión del Personal») del Título 5 («Personal administrativo») del Código de Reglamentos Federales.

40 Dentro de este sitio, el enlace más visitado es el que permite buscar empleos en las Administraciones federales, ubicado en www.usajobs.opm.gov.

41 Vía www.opm.gov/Strategic_Management_of_Human_Capital/documents/merit. 
«Ley de Inversión en la Fuerza de Trabajo [Workforce Investment Act]» de 1998. Esta Ley se encuentra actualmente recopilada en las secciones 49 y ss. del Título 29 del Código de los Estados Unidos ${ }^{42}$ — que no es, recuérdese, «Derecho positivo» de los Estados Unidos ${ }^{43}$ afirmándose en esta normativa que «para promover el establecimiento y mantenimiento de un sistema nacional de oficinas públicas de empleo, será establecido y mantenido el Servicio de Empleo de Estados Unidos en el Ministerio de Trabajo [Department of Labor]» ${ }^{44}$. Su consulta en Internet resulta accesible a través del sitio de la Administración federal de la que directamente depende dentro de esta Ministerio, que es la «Administración de Empleo y Formación [Employment \& Training Administration]», ubicado en www.doleta.gov.

La recién citada Ley Wagner-Peyser opera — respecto de las legislaciones de los Estados federados sobre servicios públicos de empleo- como una Ley de Bases, cuyo ajuste a las mismas (asumiendo, por ejemplo, la ejecución de las políticas activas y pasivas de empleo) permite a los Estados federados beneficiarse de sustanciosas ayudas federales. En el caso del Estado de California — siempre tan significativo—, su servicio público de empleo no aparece regulado en su Código Laboral ${ }^{45}$, sino en su «Código del Seguro de Desempleo [Unemployment Insurance Code]», donde se regulan las políticas activas y el régimen de las «prestaciones por desempleo [unemployment benefits]» del Estado federado en cuestión. Lógicamente, estos servicios estatales de empleo también cuentan con sus propios sitios en Internet, que en el caso del Estado de California es www.edd.ca.gov.

42 Desarrolladas por las «Partes» 651 a 658 del Capítulo V del Título 20 del Código de Reglamentos Federales.

43 Véase supra, Tema 2, §5.

44 Cfr. sección 1 de la Ley.

45 Véase supra, Tema 2, \$5 in fine. 
Sumario: §1. El Comité de Altos Responsables de la Inspección de Trabajo de la Unión Europea. \$2. El carácter laboral o funcionarial de los Inspectores de Trabajo, a propósito del modelo laboral italiano de Inspección de Trabajo. §3. El carácter estatal o infraestatal de los funcionarios de la Inspección de Trabajo, a propósito del modelo alemán disgregado en dieciséis Inspecciones de Trabajo de los Estados federados. §4. La formación jurídica o politécnica exigible a los funcionarios de la Inspección de Trabajo, a propósito del modelo politécnico británico de Inspección de Trabajo. §5. El carácter integral o no de la legislación estatal inspeccionada, a propósito del modelo portugués de Inspección de Trabajo (y también, de Seguridad Social). §6. La naturaleza de las funciones de campo o de despacho desarrolladas por los Inspectores de Trabajo, a propósito del modelo francés de Inspectores de Trabajo de despacho. \$7. El modelo norteamericano (funcionarial, tendencialmente disgregado, politécnico, no integral y de campo) de Inspección de Trabajo.

THEME 7

THE LABOR AND SOCIAL SECURITY INSPECTION IN EUROPE AND IN THE UNITED STATES

Contents: $\$ 1$. The Committee of Senior Labour Inspectors of the European Union. \$2. The employment relationship or civil servant relationship of the Labor Inspectors, with regard to the Italian employment relationship model of Labor Inspection. \$3. The nationwide or undernationwide nature of the officers of the Labor Inspection, with regard to the German model, dispersed in sixteen Labor Inspections of the States. \$4. The legal or politechnical education required to the officers of the Labor Inspection, with regard to the British politechnical model of Labor Inspection. \$5. The integral nature or not of the enforced state legislation, with regard to the Portuguese model of Labor (and also, of Social Security) Inspection. \$6. The nature of the field or bureau functions developped by the officers of the Labor Inspection, with regard to the French model of bureau officers of the Labor Inspection. \$7. The USA (civil servant relationship, tending to dispersion, politechnical, non-integral and field's) model of Labor Inspection.

§1. Aun siendo cierto que no existe en el seno de la Unión Europea ninguna Inspección comunitaria de Trabajo, sí existen, en cambio, en el seno de la misma intentos serios - y relativamente 
concretos, incluso- de avanzar por el camino de una futura armonización de las legislaciones y prácticas nacionales relativas a los servicios, asimismo nacionales, de Inspección de Trabajo de los diversos Estados miembros ${ }^{1}$. Lo prueba contundentemente la Decisión de la Comisión de 12 julio 1995, por la que se crea un "Comité de Altos Responsables de la Inspección de Trabajo», en la que - aunque al hilo del control de la aplicación del Derecho derivado comunitario en materia de seguridad y salud laboral ${ }^{2}$ - claramente se traza el propósito de «favorecer la aplicación efectiva y equivalente del Derecho comunitario en materia de salud y seguridad en el trabajo, gracias fundamentalmente a una cooperación más estrecha entre los sistemas nacionales de inspección del trabajo» ${ }^{3}$. Esta cooperación — «habida cuenta de la diversidad de competencias de los servicios nacionales de inspección del trabajo» ${ }^{4}$ - podría extenderse incluso a «cuestiones relativas a otros ámbitos de la legislación social comunitaria que tengan consecuencias para la salud y la seguridad en el trabajo» ${ }^{5}$; y todo ello, siempre a juicio de la Comisión, mediante la "promoción de un mejor conocimiento y comprensión mutua de los diferentes sistemas y prácticas nacionales de inspección de trabajo, de los métodos y de los marcos jurídicos de intervención» ${ }^{6}$.

Esta importante Decisión comunitaria de 1995 está montada sobre una tradición jurídica común, incluso universal, que resultaría temerario despreciar o desconocer. Dicha tradición jurídica de casi sesenta años, lo que no es poco en asuntos laborales, se refiere al Convenio núm. 81 de la OIT — ratificado por España, como se sabe, en 1960—, al que expresamente alude la Decisión comunitaria de 1995, afirmando que «la presente Decisión no es incompatible con las obligaciones de los Estados miembros derivadas del Convenio de la OIT, de 11 de julio de 1947, en materia de inspección de trabajo $\left(\mathrm{n}^{\circ} 81\right) »^{7}$.

1 Todo cuanto sigue - excluida la regulación de la Inspección de Trabajo en los Estados Unidos de Norteamérica- consta explicitado en A. ARUFE VARELA, Estudio comparado de la carrera administrativa de los funcionarios del sistema de Inspección de Trabajo y Seguridad Social en Europa, Ministerio de Trabajo y Asuntos Sociales (Madrid, 2007), págs. 15 y ss.

2 Sobre este Derecho derivado, véase infra, Tema 16 §1.

3 Artículo 2.3.

4 Artículo 2.2. Vista esa diversidad de competencias circula doctrinalmente la distinción entre sistemas «generalistas» y sistemas «especializados» de Inspección de Trabajo - popularizada en el mundo a través de publicaciones divulgativas de algún modo patrocinadas por la OIT (cfr. al respecto, W. VON RICHTHOFEN, Labour Inspection. A Guide to the Profession, OIT [Ginebra, 2002], pág. 37)-, a pesar de la intensa crítica a que la misma es sometida también doctrinalmente, al menos en España [cfr., por ejemplo, Ma.A. GARCÍA RUBIO, La inspección de trabajo y Seguridad Social (Doctrina y Jurisprudencia), Tirant lo blanch (Valencia, 1999), págs. 56 y ss.; y J. MINONDO SANZ, Fundamentos de la inspección de trabajo y seguridad social, Ministerio de Trabajo y Asuntos Sociales (Madrid, 2000), págs. 63-64].

Artículo 2.2.

6 Artículo 3, apartado 2).

7 Considerando noveno. 
Además, se sustenta sobre una larga experiencia de intercambio y puesta en común de prácticas inspectoras, puesto que la propia Decisión indica que «desde 1982 funciona, de manera informal, un "grupo de altos responsables de la inspección de trabajo"»", el cual «constituye, debido a su ya larga experiencia, el marco adecuado para asegurar, sobre la base de una colaboración estrecha entre sus miembros y la Comisión, la ejecución efectiva y equivalente del Derecho comunitario derivado en materia de salud y seguridad en el trabajo y para analizar de manera rigurosa las cuestiones prácticas planteadas por el control y la aplicación de la legislación en la materia» ${ }^{9}$.

Sobre el impacto de esta importante Decisión de la Comisión en nuestro Derecho interno, baste indicar que el recién citado «Comité de Altos Responsables de la Inspección de Trabajo» aparece expresa y repetidamente aludido por el Reglamento de organización y funcionamiento de la Inspección de Trabajo y Seguridad Social, aprobado por Real Decreto $138 / 2000$, de 4 febrero ${ }^{10}$.

\$2. Al igual que sucede en España ${ }^{11}$, los Inspectores de Trabajo son funcionarios —y además, verdaderos funcionarios de élite- en Alemania, Francia, Portugal y Gran Bretaña, pero no en el caso de Italia. La corrupción política generalizada existente en este último país hirió de muerte, a comienzos de la década de los años noventa del siglo pasado, la función pública italiana, con la consecuencia - tras la denominada «reforma Bassanini», en la misma década - de que se laboralizase allí la práctica totalidad de los funcionarios al servicio de las diversas Administraciones públicas italianas (es la gráficamente denominada, incluso por doctrina científica muy seria, "privatización» de la función pública), incluidos por supuesto los Inspectores de Trabajo (Ispettori del Lavoro). En efecto, dicha «reforma Bassanini» implicó, en sustancia,

8 Considerando primero.

9 Considerando octavo.

10 Cfr. artículos 29.2 («para el cumplimiento de objetivos establecidos por la Unión Europea a través de su Comité de Altos Responsables de la Inspección de Trabajo en materias regidas por Directivas europeas, se procederá en la misma forma establecida en el apartado anterior, cuando afecte al desarrollo general de la acción inspectora en España) y 47.8 («elaborar las estadísticas generales y comunes para todo el Estado, y los informes y memorias sobre la actuación general del sistema de la Inspección de Trabajo y Seguridad Social, así como la memoria anual y los informes periódicos exigidos por los Convenios y Recomendaciones de la Organización Internacional del Trabajo sobre la Inspección de Trabajo y Seguridad Social, y los relativos al Comité de Altos Responsables de la Inspección de Trabajo de la Unión Europea»). Doctrinalmente, véase $\mathrm{M}^{\mathrm{a}}$.A. GARCÍA RUBIO, La inspección de trabajo y Seguridad Social (Doctrina y Jurisprudencia), cit., págs. 61-62; e I. VÁZQUEZ GONZÁLEZ (Coordinador), La Inspección de Trabajo y Seguridad Social, Aranzadi (Pamplona, 1999), pág. 41. Acerca de cierto importantísimo acuerdo de este Comité, de 2003, sobre prevención de la siniestralidad laboral en una actividad de alto riesgo, véase $\mathrm{R}$. ARAGÓN BOMBÍN, «Campaña europea de inspecciones de trabajo sobre el riesgo de caída de altura en la construcción 2003», Prevención, trabajo y salud. Revista del Instituto Nacional de Seguridad e Higiene en el Trabajo, núm. 32 (2004), págs. 19 y ss.

11 Véase J. MARTÍNEZ GIRÓN, A. ARUFE VARELA y X.M. CARRIL VÁZQUEZ, Derecho del Trabajo, 2a ed., Netbiblo (A Coruña, 2006), pág. 489. 
todo lo siguiente ${ }^{12}:$ 1) la laboralización del antiguo personal funcionario al servicio «de las dependencias de las administraciones públicas»; 2) al igual que ocurre con los trabajadores del sector privado, que «las relaciones de trabajo de los dependientes de las administraciones públicas» se regulasen «por las disposiciones del capítulo I, título II, del libro V del código civil [esto es, sus artículos 2082 a 2134] y por las leyes sobre relaciones de trabajo subordinado en la empresa»; 3) que la regulación al detalle de las condiciones de trabajo y empleo de los antiguos funcionarios ahora laboralizados se llevase a cabo, como es lógico, a través de la negociación colectiva; 4) en consecuencia, la atribución de competencia a los tribunales civiles (equivalentes, en Italia, de nuestros tribunales laborales) ${ }^{13}$ para conocer de los pleitos laborales sustantivos entre las Administraciones públicas empleadoras y sus antiguos funcionarios ahora laboralizados; y 5) por último, la aplicación plena de todo cuanto acaba de decirse a los antiguos funcionarios de la Inspección de Trabajo (Ispezione del Lavoro), dada su plena laboralización actual en Italia.

Este proceso de laboralización de los Inspectores de Trabajo italianos resulta sorprendente, vista la ratificación sin reservas por Italia del ya citado Convenio núm. 81 de 1947 de la OIT, cuyo artículo 6 exige imperativamente - como garantía presunta de su plena independencia- que la Inspección de Trabajo se sirva precisamente de «funcionarios públicos».

Las fuentes reguladoras de la Inspección italiana de Trabajo se encuentran fundamentalmente en el Decreto Legislativo núm. 124, de 23 abril 2004, sobre «racionalización de las funciones inspectoras en materia de seguridad social y de trabajo». Esta norma constituye el fruto de la habilitación otorgada por la Ley «Biagi» núm. 30, de 14 febrero 2003, sobre «delegación al Gobierno en materia de ocupación y mercado de trabajo» ${ }^{14}$. Además, supuso una profunda enmienda de la Ley núm. 628, de 22 julio 1961, de «modificaciones de la ordenación del Ministerio del Trabajo y de la Seguridad Social», todavía hoy vigente.

De hecho, el Capítulo segundo de esta Ley de 1961 refleja un estado de cosas que al día de hoy se mantiene todavía - reforzando la impresión de caos en que se ve sumida la Inspección italiana de Trabajo ${ }^{15}$ - , relativo a la existencia de una pluralidad de entes distintos asimismo competentes para la vigilancia del cumplimiento, bien de la legislación sustantiva de seguridad social, bien de la legislación sustantiva de prevención de riesgos

12 Véase, A. ARUFE VARELA, Estudio comparado de la carrera administrativa de los funcionarios del sistema de Inspección de Trabajo y Seguridad Socia, en Europa, cit., págs. 97 y ss.

13 Sobre el contencioso laboral en Italia, véase infra, Tema 8, \$2.

14 Analizando el contenido de las normas delegante y delegada, véase A. ARUFE VARELA, «El cumplimiento por Italia de las recomendaciones europeas sobre el empleo, a través de la "Reforma Biagi"», Anuario da Facultade de Dereito da Universidad da Coruña, vol. 10 (2006), págs. 65 y ss.

15 Véase A. GASPARI y A. GUADAGNINO, Le ispezioni in azienda: obblighi, poteri e tutele dopo il D.Lgs. 124/2004. Ministeri del Lavoro ed Enti Previdenziali: due sistema ispettivi a confronto, Iuridica Editrice (Roma, 2005), págs. 17 y ss. 
laborales, bien incluso de toda la legislación sustantiva italiana laboral y de seguridad social. De entre esta pluralidad de entes competidores de la Inspección de Trabajo, el Capítulo en cuestión menciona — por razón de su fecha - solamente dos: 1) directamente, las diversas entidades gestoras de la Seguridad Social entonces existentes; y 2) indirectamente, los «militares del Arma de los guardias civiles [militari dell'Arma dei carabinieri]». A estos entes competidores de nuestra Inspección se les agregaron, en 1978, los servicios inspectores de las unidades sanitarias locales — dependientes del Ministerio de Sanidad ${ }^{16}$-, afirmando una Ley de dicho año que «a la unidad sanitaria local [unità sanitaria locale] se le atribuyen, con efectos de 1 enero 1980, las competencias actualmente desarrolladas por la inspección del trabajo en materia de prevención, de higiene y de control sobre el estado de salud de los trabajadores» ${ }^{17}$.

§3. El citado Convenio núm. 81 de 1947 de la OIT —que es una norma que tiene en cuenta que en el mundo no todos los Estados se organizan de igual manera - afirma que «la Inspección de Trabajo deberá estar bajo la vigilancia de una autoridad central» ${ }^{18}$, aunque matiza inmediatamente que «en el caso de un Estado federal, el término autoridad central podrá significar una autoridad federal o una autoridad central de una entidad confederada» ${ }^{19}$; y por esta razón, no cabe duda de que 1a estructura territorial del Estado puede resultar un condicionante potente de la definición de la estructura orgánica de la propia Inspección de Trabajo. Lógicamente, la federalización del Estado lleva aparejada el riesgo de disgregación del cuerpo de funcionarios - allí donde estos últimos lo son- de la Inspección de Trabajo. Prueba esto último el caso de la República Federal de Alemania, en donde la organización de la Inspección de Trabajo (Gewerbeaufsicht) no se caracteriza en absoluto por su carácter centrípeto, sino más bien por otro de signo marcadamente centrífugo. En efecto, el hecho - conforme a la Ordenanza Industrial alemana de 1869- de que la realización de las funciones propias de la Inspección de Trabajo haya que encomendarla «a funcionarios especiales a nombrar por los Gobiernos de los Estados Federados», determina que los Inspectores de Trabajo alemanes sean funcionarios públicos (denominados Gewerbeaufsichtsbeamten), sí, pero no de la Federación (Bund), sino de cada uno de los Estados Federados

16 Acerca de la organización de la sanidad pública en Italia, véase M. CINELLI, Diritto della previdenza sociale, Giappichelli (Turín, 2005), págs. 348 y ss.

17 Cfr. artículo 21, párrafo primero, de la Ley núm. 833, de 23 diciembre 1978, sobre «institución del servicio sanitario nacional». Comentando las competencias de dichas «unidades sanitarias locales», véase A. VALLEBONA, Istituzioni di Diritto del Lavoro. II. Il rapporto di lavoro, 4ª ed., Cedam (Padua, 2004), pág. 718.

18 Cfr. artículo 4.1.

19 Cfr. artículo 4.2. 
(Bundesländer) ${ }^{20}$. De aquí resulta, como es lógico, que en Alemania no exista una sola Inspección de Trabajo, sino dieciséis Inspecciones de Trabajo distintas $-\mathrm{y}$ por tanto, dieciséis cuerpos distintos de Inspectores de Trabajo-, una por cada uno de sus dieciséis Estados Federados.

Este hecho plantea en Alemania delicadísimos problemas operativos - por causa, fundamentalmente, de que la legislación que los Inspectores se ven obligados a aplicar no es legislación de cada concreto Estado Federado (Land), sino verdadera legislación de la Federación, en muchos casos dictada incluso para transponer Directivas comunitarias-, que pretenden paliarse mediante la estipulación de concretos «convenios [Vereinbarungen]», sujetos a evaluación tras el transcurso de un cierto período de tiempo, entre los diversos sujetos políticos alemanes territorialmente implicados.

Frente a lo que ocurre en Alemania, los modelos francés, portugués, italiano y británico - en lo que se refiere a la organización de sus respectivas Inspecciones de Trabajo- son modelos marcados por una clara tendencia centrípeta, evidenciada por el dato de que en los cuatro exista una única «autoridad central», y previéndose que sus funciones las pueda desempeñar bien directamente el Ministro competente en materia de Trabajo (por ejemplo, en el caso de Francia), bien otra autoridad distinta (por ejemplo, el «Inspector General del Trabajo», en Portugal).

En España, con una estructura territorial todavía por definir - aunque parece que inexorablemente tiende a la federalización-, nuestra Inspección de Trabajo sigue respondiendo a una «concepción única e integral», evidenciada por el hecho de que el Cuerpo Superior de Inspectores de Trabajo y Seguridad Social es un Cuerpo único, que —en palabras de la Ley 42/1997, de 14 noviembre- «tiene carácter de Cuerpo Nacional» ${ }^{21}$, y también, porque tengamos aquí una única «autoridad central» ${ }^{22}$. Ahora bien, esta concepción unitarista e integral podría cambiar radicalmente en el futuro ${ }^{23}$, puesto que la misma Ley 42/1997 considera que este modelo no puede «cerrarse a eventuales modificaciones posteriores ni impedir el ejercicio de las competencias autonómicas en la línea establecida por la jurisprudencia del Tribunal Constitucional» ${ }^{24}$. Pues bien, esta línea jurisprudencial posibilita incluso - como ya sucede en la República Federal de Alemania- que puedan coexistir diversas Inspecciones de Trabajo autonómicas con la Inspección estatal, vista la admonición contenida en la Sentencia del Tribunal Constitucional núm. 195/1996, de 28 noviembre, relativa a que una Comunidad Autónoma «se dote de su propio servicio de inspección» de Trabajo, de manera que «éste pueda actuar en el ámbito competencial que le corresponda» ${ }^{25}$; un concepturus constitucional, por cierto, que ya se ha traducido en un

20 Véase, A. ARUFE VARELA, Estudio comparado de la carrera administrativa de los funcionarios del sistema de Inspección de Trabajo y Seguridad Social en Europa, cit., págs. 31 y ss.

21 Artículo 2.1.

22 Según lo dispuesto en el Real Decreto 138/2000, «el Director general de la Inspección de Trabajo y Seguridad Social asumirá las funciones que el adjunto Reglamento establece para la autoridad central de dicha Inspección» (cfr. disposición transitoria tercera).

23 Al respecto, véase A. ARUFE VARELA, Estudio comparado de la carrera administrativa de los funcionarios del sistema de Inspección de Trabajo y Seguridad Social en Europa, cit., págs. 135 y ss.

24 Cfr. apartado II, párrafo tercero, in fine, de su exposición de motivos.

25 Fundamento jurídico $16^{\circ}$. 
nasciturus estatal — que, en realidad, son $\operatorname{dos}^{26}$ - e, incluso, en una criatura autonómica verdaderamente recién nacida, dado que por Real Decreto 689/2005, de 10 junio, se modifica el Reglamento aprobado por el citado Real Decreto 138/2000, creando los funcionarios autonómicos denominados «técnicos habilitados» - funcionarios que deben «pertenecer a cuerpos de los grupos $\mathrm{A}$ o $\mathrm{B} »{ }^{27}$ - , con funciones inspectoras «de campo» en materia de prevención de riesgos laborales.

§4. En todos los casos — supuesto que se trata de personal de élite al servicio de la Administración-, a quien aspira a acceder al cuerpo de Inspectores de Trabajo se le exige estar en posesión de la correspondiente titulación universitaria, lo que permite plantearse la existencia y eventual exigencia de un perfil, o jurídico o politécnico, a los propios aspirantes. En Francia, Portugal e Italia, el perfil recomendado es jurídico, vistas las titulaciones que permiten la participación en los correspondientes procesos de ingreso y, también, los concretos temarios de las oposiciones o concursos que los aspirantes se ven obligados a superar ${ }^{28}$. En Alemania y en Gran Bretaña, en cambio - por causa, sin duda, del carácter de la legislación que los correspondientes Inspectores de Trabajo se ven obligados a aplicar-, el perfil recomendado es politécnico ${ }^{29}$; razón por la cual, en Gran Bretaña, los anuncios sobre convocatorias de vacantes de «inspectores de la Administración de Salud y Seguridad [Health and Safety Executive Inspectors]»-desde luego, los anuncios más recientemente manejados - indican que los aspirantes deben estar en posesión de cualquier tipo de grado universitario, sí, pero reputando más aconsejables algunos de neto perfil politécnico, como los de «salud medioambiental» o «ingeniería».

Téngase en cuenta, además, que los Inspectores de Trabajo británicos en prácticas están obligados asimismo a estudiar, debiendo obtener a la finalización de dicho período

26 Al respecto, la Ley 42/1997 prevé que mediante acuerdo entre la Administración General del Estado y la de cada Comunidad Autónoma se pueda producir «la adscripción orgánica de funcionarios de la Inspección de Trabajo y Seguridad Social a la Administración autonómica» (artículo 17.3), de manera que si en estos mismos acuerdos «se dispusiera la transferencia de funcionarios de la Inspección de Trabajo y Seguridad Social, ésta se realizará por los procedimientos establecidos en el respectivo Estatuto de Autonomía para el traspaso de los servicios» (disposición adicional séptima). La propia Ley 42/1997 prevé, además, que «las Comunidades Autónomas con competencias legislativas plenas en materia de orden social podrán atribuir la función inspectora a funcionarios distintos de los enumerados en el artículo 2 [esto es, Inspectores y Subinspectores], en la Ley que regule cada materia y para el ámbito de la misma» (disposición adicional sexta).

27 Cfr. artículo 59.2.2 ${ }^{\circ}$ del Reglamento aprobado por el Real Decreto 138/2000.

28 Al respecto, véase A. ARUFE VARELA, Estudio comparado de la carrera administrativa de los funcionarios del sistema de Inspección de Trabajo y Seguridad Social en Europa, cit., págs. 141 y ss., y las remisiones allí contenidas.

29 Ibidem. 
formativo de dos años un Máster universitario (y existen conciertos al respecto, entre la «Administración de Salud y Seguridad [Health and Safety Executive]» y la Universidad Politécnica de Aston) precisamente en algo tan poco literario como la «salud ocupacional». El régimen jurídico básico se encuentra contenido en la Ley de Salud y Seguridad en el Trabajo, etc. (Health and Safety at Work, etc. Act) de $1974^{30}$.

En la misma línea, en las normas reguladoras del tema en los diversos Estados Federados alemanes, se especifica que para acceder a la posición del Inspector de Trabajo «supremo» se requiere estar en posesión de título otorgado por una «universidad técnica [Hochschule]», e incluso, que lo francamente preferido - como en los Estados de Baviera o de Hesse- son las titulaciones universitarias en construcción de máquinas, electrotécnica, física, química, ingeniería industrial, ingeniería técnica de medio ambiente, etc.

En cambio, en Francia, se exige estar en posesión de «uno de los títulos o diplomas exigidos para las oposiciones externas de entrada en la Escuela Nacional de Administración», marcando los mínimos la exigencia de «haber terminado con éxito el primer año del segundo ciclo de estudios superiores jurídicos o económicos». En Italia, lo que se requiere es estar en posesión de titulación universitaria — por este orden - en «Jurisprudencia, Ciencias políticas, Economía y comercio o equivalentes», indicándose asimismo que los temarios y las pruebas «se dirigirán a comprobar la posesión de una adecuada cultura jurídico-administrativa de base y a valorar la madurez de pensamiento, la capacidad de juicio y la actitud del candidato para desarrollar las funciones propias del perfil profesional [netamente jurídico, como se ve] de inspector del trabajo». Y en Portugal, en la misma línea, se prioriza la titulación universitaria en «Derecho» frente a otras varias (sólo en último lugar se mencionan «todas las carreras de Ingeniería que confieran grado»), teniendo en cuenta que para la preparación del concurso de acceso se recomienda no sólo la utilización de bibliografía única y exclusivamente jurídica, sino también el manejo solvente de una legislación que cuidadosamente se detalla, actualmente articulada alrededor del Código portugués del Trabajo de 2009.

§5. El perfil jurídico recomendado a quienes aspiran a ingresar en el cuerpo de Inspectores de Trabajo, que es el propio de los Inspectores italianos, franceses y portugueses, sólo tiene en cuenta que el Derecho del Trabajo y el Derecho de la Seguridad Social conforman una unidad inescindible, precisamente en Portugal. En efecto, al igual que sucede en España —donde el cuerpo se denomina, recuérdese, «Cuerpo Superior de Inspectores de Trabajo y Seguridad Social»-, los Inspectores de Trabajo portugueses - a pesar de su nombre (Inspectores do Trabalho) - también velan por el cumplimiento de la legislación laboral (en sentido amplio) y de la legislación de seguridad social. Al respecto, resulta inequívoco el Estatuto regulador de la Inspección portuguesa de Trabajo (actualmente denominada «Autoridad para las Condiciones de Trabajo [Autoridade para as Condições de Trabalho]», que «está dirigida por el Inspector-General del

30 Véase especialmente su sección 19, rotulada «nombramiento de inspectores». 
Trabajo [Inspector-geral do Trabalho]») ${ }^{31}$, allí donde atribuye competencia a los Inspectores de Trabajo para levantar actas de liquidación de cuotas, en caso de «falta de pago de las cuantías debidas a la seguridad social» ${ }^{32}$.

Aparte el caso italiano - que ya se vio $^{33}$-, en Gran Bretaña, la inspección de la legislación de seguridad social la regula la Parte VI (rotulada «Exigencia del Cumplimiento [Enforcement]») de la «Ley de la Administración de la Seguridad Social [Social Security Administration Act] de 1992», a cuyo tenor la concreta persona encargada de realizar dicha actividad no se conoce actualmente con el nombre de «inspector», sino con el de «funcionario autorizado [authorised officer] $\gg{ }^{34}$, cuya actividad se concreta - en lo esencial- en «investigar [ascertaining] si las disposiciones de la legislación sustantiva de seguridad social están siendo, han sido o van a ser probablemente incumplidas» ${ }^{35}$, y en «prevenir, detectar y hacerse con pruebas de la comisión ... de ilícitos sobre prestaciones [benefit offences]» ${ }^{36}$.

En Alemania, las Inspecciones de Trabajo de los dieciséis Länder no son verdaderas Inspecciones integrales de Seguridad Social, por causa de que las Mutuas patronales de accidentes de trabajo (genéricamente denominadas «Berufsgenossenschaften») también poseen competencias inspectoras en materia de prevención de riesgos laborales. En efecto, según el Libro Séptimo del Código alemán de Seguridad Social, estas «entidades gestoras del seguro de accidentes están obligadas a emplear personal de inspección [Aufsichtspersonen]» ${ }^{37}$. Y las competencias de este personal inspector propio de las Mutuas resultan indistinguibles de las que poseen los Inspectores de Trabajo al servicio de los Estados Federados - de ahí el denominado en Alemania problema del «dualismo [Dualismus]» inspector-, visto lo que dispone el larguísimo parágrafo 19 del propio Libro Séptimo del Código de Seguridad Social (rotulado «poderes del personal de inspección [Befugnisse der Aufsichtspersonen]») ${ }^{38}$.

En Francia, es claro que la Inspección de Trabajo no controla el cumplimiento por los empresarios y beneficiarios de la legislación de Seguridad Social - tampoco es, por tanto, Inspección de Seguridad Social-, lo que confirma el Código francés de la Seguridad Social, al indicar que «el control de la aplicación de las disposiciones del presente código por los empresarios, personas privadas o públicas, y por los trabajadores independientes, se confía a los organismos encargados de la recaudación de las cotizaciones del régimen general [organismes chargés du recouvrement des cotisations du régime général]» ${ }^{39}$ —esto es, a las propias entidades gestoras ${ }^{40}$-, que lo ejercen a través de funcionarios suyos

31 Cfr. artículo 5 del Decreto-Ley núm. 326-B/2007, de 28 septiembre.

32 Y especialmente, «si la infracción resultase de situaciones de falso trabajo independiente, de falta de comunicación obligatoria a la seguridad social o de prestación de trabajo no declarado». Al respecto, véase artículo 7, apartados 5 y 6, del Decreto-Ley núm. 102/2000, de 2 junio.

33 Supra, \$2.

34 Sección 121DA(2).

35 Sección 109A(2)(c).

36 Sección 109A(2)(d). Sobre los «delitos tipificados» en la «Ley de Pensiones de 2004», véase M. JENKINS, M. POORE, H. DOODS, A. BAIG, K. HAINSWORTH, K. BYERS, D. BRABBS, P. ABEYSEKERA y D. DON, Blackstone's Guide to the Pensions Act 2004, Oxford University Press (Oxford, 2005), pág. 71.

37 Parágrafo 18 (1).

38 Al respecto, véase A. ARUFE VARELA, Estudio comparado de la carrera administrativa de los funcionarios del sistema de Inspección de Trabajo y Seguridad Social en Europa, cit., págs. 42 y ss.

39 Artículo L. 243-7, párrafo primero, inciso primero.

40 Véase F. KESSLER, Droit de la protection sociale, $2^{\mathrm{a}}$ ed., Dalloz (París, 2005), págs. 301 y ss. 
(denominados «agentes encargados del control [agents chargés du contrôle]») ${ }^{41}$, nombrados «por orden del ministro competente en materia de seguridad social»» ${ }^{42}$.

§6. Cuando se analizan comparativamente las competencias, funciones y actividades desarrolladas por los Inspectores de Trabajo, resulta crucial la distinción entre Inspectores de Trabajo de campo e Inspectores de Trabajo de despacho ${ }^{43}$. Esta distinción se basa en la evidencia de que las actividades inspectoras de vigilancia del cumplimiento de la legislación - bien de la legislación laboral (y en especial, de la de seguridad y salud laboral), bien asimismo de la legislación de seguridad social - se desarrollan no sólo en las instalaciones, oficinas y despachos de la Inspección de Trabajo, sino también en las empresas, centros de trabajo y lugares de trabajo donde se aplica la legislación objeto de vigilancia. El más típico Inspector de despacho es el Inspector de Trabajo de referencia en Francia (allí denominado «inspecteur $d u$ travail»), cuyas actividades inspectoras se mencionan en casi un centenar de preceptos del Código francés del Trabajo. Su elevado estatus coexiste con una sorprendente cantidad y variedad de funcionarios habilitados, siempre en Francia, para ejercer también funciones inspectoras burocráticas (levantamiento de «actas [procès-verbaux]» de obstrucción, de infracción, etc.) y al aire libre -por ejemplo, los «controladores del trabajo [contrôleurs du travail]», y otros muchos más «funcionarios de control asimilados [fonctionnaires de contrôle assimilés]» ${ }^{44}$, y especialmente las «visitas», aunque jerárquicamente estén subordinados siempre a los Inspectores-referente (los «controladores», por ejemplo, «ejercen su competencia bajo la autoridad de los inspectores del trabajo») ${ }^{45}$. Ciertos trabajos delicados (incluso, políticamente muy delicados) de despacho se reservan en exclusiva sólo a estos Inspectores-referente franceses, como la tramitación y resolución de expedientes empresariales de despido de los representantes unitarios y sindicales de los trabajadores, pues en Francia el despido de este

\footnotetext{
41 Artículo L. 243-7, párrafo primero, inciso segundo.

42 Ibidem. El propio Código francés de la Seguridad Social prevé alguna excepción, que registra asimismo el Código francés del Trabajo (cfr., en este último, su artículo L. 8112-2, núm. $2^{\circ}$ ).

$43 \mathrm{Al}$ respecto, véase A. ARUFE VARELA, Estudio comparado de la carrera administrativa de los funcionarios del sistema de Inspección de Trabajo y Seguridad Social en Europa, cit., págs. 138 y ss.

44 Cfr., por ejemplo, artículo L. 8112-3.

45 Cfr. artículo L. 8115-5.
} 


\section{tipo de trabajadores requiere — so pena de nulidad- «autorización del inspector del trabajo» ${ }^{46}$.}

Desde luego, resultan ser mucho más Inspectores de campo, que meros Inspectores de despacho, los Inspectores de Trabajo italianos. En efecto, disponen de poderes de los que carecen otros Inspectores italianos distintos (como los que están al servicio de las entidades gestoras de la Seguridad Social), entre los que se cuenta el de actuar «también en calidad de oficial de policía judicial» (pudiendo efectuar, en consecuencia, interrogatorios de personas, registros domiciliarios, detenciones, etc.), aunque en Italia también existe el controlador del trabajo (accertatore del lavoro) ${ }^{47}$. Ahora bien, sin duda, es el Inspector de Trabajo portugués, que posee incluso el derecho de portar armas de fuego, el más prototípico Inspector de Trabajo de campo - también, de algún modo, el de Gran Bretaña, funcionalmente adscrito a una concreta «Dirección Operativa de Campo»—, lo que explica que no exista en dicho país ningún otro personal de control con derecho de realizar la «visita», en cuanto que actividad inspectora esencial desde siempre, por antonomasia.

En España, al haberse introducido dos nuevos elementos funcionariales de apoyo y colaboración (esto es, los Subinspectores de Empleo y Seguridad Social y los funcionarios «técnicos habilitados» por las autoridades autonómicas respectivas), que pasan a realizar - entre otras - funciones inspectoras de campo (en especial, las tradicionales visitas de inspección) ${ }^{48}$, se ha alterado el equilibrio tradicionalmente existente entre funciones burocráticas y no burocráticas de los Inspectores de Trabajo y Seguridad Social, con una clara potenciación de las primeras y detrimento de las segundas ${ }^{49}$, dado que: 1) las visitas que realizan los Subinspectores (y que, en consecuencia, dejan de realizar los Inspectores) se traducen ahora - como regla - en la actividad de despacho consistente en que «las actas de infracción practicadas por los Subinspectores serán visadas por el Inspector de Trabajo y Seguridad Social» ${ }^{50}$; y 2) las visitas que también realizan ahora los técnicos habilitados por las Comunidades Autónomas (y que, en consecuencia, dejan de nuevo de realizar los Inspectores) vuelven a traducirse en más actividad de despacho, pues «los informes de los técnicos habilitados, en los supuestos a que se refiere el artículo 9.3 de la Ley 31/1995, 8 de noviembre, de Prevención de Riesgos Laborales, cuando se constate el incumplimiento de un requerimiento previamente formulado por aquéllos, darán lugar a la práctica de actas de infracción, que serán extendidas por Inspectores de Trabajo y Seguridad Social, si resultara procedente» ${ }^{51}$.

El modelo español de Ley de Infracciones y Sanciones en el Orden Social —esto es, la reunión en una sola Ley de todas las infracciones y sanciones administrativas laborales ${ }^{52}$ sólo cabe encontrarlo en Portugal y Francia, aunque con variantes. Estas variantes son de fondo en el caso de Portugal, dado que el Libro II del Código del Trabajo regula no sólo

46 Cfr. artículo L. 2411-5, párrafo primero, para los delegados de personal; y artículo L. 2411-8, párrafo primero, para los miembros de comités de empresa y representantes sindicales.

47 Sobre él, véase A. ARUFE VARELA, Estudio comparado de la carrera administrativa de los funcionarios del sistema de Inspección de Trabajo y Seguridad Social en Europa, cit., pág. 105.

48 Cfr. artículo 8.3 de la Ley 42/1997, en relación con sus artículos 5.1 y 5.3.

49 Al respecto, A. ARUFE VARELA, Estudio comparado de la carrera administrativa de los funcionarios del sistema de Inspección de Trabajo y Seguridad Social en Europa, cit., págs. 139 y ss.

50 Cfr. artículo 8.4 de la Ley 42/1997.

51 Cfr. artículo 65.1 del Reglamento aprobado por el Real Decreto 138/2000.

52 Véase J. MARTÍNEZ GIRÓN, A. ARUFE VARELA y X.M. CARRIL VÁZQUEZ, Derecho del Trabajo, 2a ed., cit., págs. 497 y ss. 
las infracciones y sanciones administrativas, sino también los delitos sociales y sus penas (todo ello bajo el rótulo «responsabilidades penal y administrativa [responsabilidades penal e contra-ordenacional]»); y son de fondo y formales en el caso de Francia, dado que aquí la regla es que los diversos Títulos del Código francés del Trabajo contengan un Capítulo final (rotulado «Dispositions pénales», donde se tipifican las infracciones administrativas, delitos, sanciones administrativas y penas, correspondientes a la concreta materia regulada en el Título de que se trate ${ }^{53}$. En cambio, en Alemania, Italia y Gran Bretaña la dispersión del tema es clara, puesto que en estos otros tres países cada concreta Ley aplicada por la Inspección de Trabajo contiene su propio cuadro de infracciones y sanciones administrativas (en Alemania, bajo el rótulo «preceptos sobre multas administrativas y preceptos penales [Bußgeld- und Strafvorschriften] ${ }^{54}{ }^{54}$ en Italia, bajo el rótulo «Sanzioni» ${ }^{55}$; y en Gran Bretaña, bajo el rótulo «offences» ${ }^{56}$ ).

§7. En los Estados Unidos de Norteamérica, la Inspección equivalente de las diversas Inspecciones europeas de Trabajo aparece regulada en la "Ley de Seguridad y Salud laboral [Occupational Safety and Healt Act]» de $1970^{57}$, en cuyos reglamentos de desarrollo - contenidos, como es lógico, en el Código de Reglamentos Federales ${ }^{58}$ - se denomina a los concretos Inspectores que la sirven «funcionarios de cumplimiento de seguridad y salud laboral [Compliance Safety and Health Officers] ${ }^{59}$, y popularmente, $\mathrm{CO}^{\prime}{ }^{60}$. Según las convocatorias para cubrir vacantes de $\mathrm{CO}^{61}$, los aspirantes deben cumplir el procedimiento establecido para acceder a puestos integrados en la «función pública [civil service]» norteamericana, que está construido - tanto si pretende accederse por la vía de promoción interna, como por la más subsidiaria de turno libre- sobre el cumplimiento de

53 Por excepción, la materia puede estar tratada en todo un Título (como en el caso, por ejemplo, del Título IV del Libro VII de la Parte Cuarta) o, en el otro extremo, en una concreta sección de un Capítulo (cfr., por ejemplo, sección 3 del Capítulo II del Título II de la Parte Quinta).

54 Por ejemplo, en la «Ley para la lucha contra el trabajo negro y la ocupación ilegal [Gesetz zur Bekämpfung der Schwarzarbeit und illegalen Beschäftigung]» de 23 julio 2004.

55 Por ejemplo, en el Decreto Legislativo núm. 81, de 9 abril 2008, de «desarrollo del artículo 1 de la Ley núm. 123, de 3 agosto 2007, en materia de protección de la salud y de la seguridad en los lugares de trabajo».

56 Por ejemplo, en la citada Ley de Salud y Seguridad en el Trabajo, etc. de 1974.

57 Recopilada en las secciones 651 y ss. del Código de los Estados Unidos.

58 Y más en concreto, en el Capítulo XVII (rotulado «Administración de Seguridad y Salud Laboral, Ministerio de Trabajo [Occupational Safety and Health Administration, Department of Labor]») del Subtítulo B de su Título 29.

59 Cfr. la sección 3 (rotulada «Autoridad de inspección [Authority for inspection]») de la Parte 1903 (rotulada «Inspecciones, citaciones y penas propuestas [Inspections, citations and proposed penalties]»).

60 Sobre esta denominación popular, véase M.A. ROTHSTEIN, Occupational Safety and Health Law, $3^{\text {a }}$ ed., West Publishing Co. (St. Paul, Minn., 1990), pág. 248. En la línea de su peculiar idiosincrasia —que tanto le llama la atención a un laboralista europeo-, los Estados Unidos de Norteamérica no han ratificado el Convenio núm. 81 de 1947 de la OIT, al igual que otros muchos Convenios de la propia OIT, a pesar de ser el mayor contribuyente neto a la financiación de la misma.

61 Las últimas efectuadas pueden consultarse vía www.usajobs.gov. 
los principios de mérito y capacidad (merit system), a acreditar mediante entrevistas y exámenes. De acuerdo con estas convocatorias, el perfil de un $\mathrm{CO}$ es claramente politécnico, puesto que lo que se recomienda es poseer como mínimo dos años completos de la más alta formación graduada o un grado de master en un campo directamente relacionado con la seguridad y la salud laboral. Este perfil formativo se explica por causa de la legislación que un CO se ve obligado a interpretar y aplicar para poder cumplir su trabajo - consistente en «exigir el cumplimiento [enforcement]》 de dicha legislación ${ }^{62}$-, que es única y exclusivamente la hipertécnica legislación de prevención de riesgos laborales ${ }^{63}$-no la legislación de seguridad social, ni tampoco la legislación laboral sobre condiciones mínimas (jornada máxima, salario mínimo, trabajo infantil, etc.)-, de donde que la Inspección norteamericana de Trabajo no tiene un carácter integral. Sobre esta base, un CO es evidentemente un Inspector de Trabajo de campo, cuya misión se reconduce en lo esencial a la realización de visitas ${ }^{64}$ (las convocatorias de oposiciones insisten machaconamente en la exigencia de que el CO maneje un vehículo de motor para viajar a los sitios a inspeccionar $\mathrm{y}$, en consecuencia, que tenga un permiso de conducir válido), que eventualmente pongan en marcha el procedimiento administrativo sancionador ${ }^{65}$, en cuya tramitación el $\mathrm{CO}$ ya no interviene. En principio, los Inspectores norteamericanos de Trabajo son funcionarios federales al servicio de su correspondiente Administración federal empleadora (denominada, «Administración de Seguridad y Salud Laboral [Occupational Safety and Health Administration]», o simplemente OSHA), aunque el modelo norteamericano deba ser calificado - desde el punto de vista de su estructuración territorial- como un modelo tendencialmente disgregado, puesto que la recién citada Administración federal pretende animar a los diversos Estados y territorios que conforman la Unión, a que monten sus propios sistemas estatales de Inspección de Seguridad y Salud Laboral, servidos por sus propios funcionarios estatales ${ }^{66}$. Al día de hoy, sin embargo, sólo veintiséis Estados y territorios

62 Sobre el «procedimiento para la exigencia del cumplimiento [procedure for enforcement]», véase la sección 10 de la Ley federal.

63 Sobre ella, véase infra, Tema 16, \$3.

64 Reguladas en la sección 8 de la Ley federal.

65 Regulado en las secciones 9, 10 y 11 de la Ley federal.

66 Cfr. la sección 18 de la Ley federal (rotulada «Competencia estatal y planes estatales [State Jurisdiction and State Plans]»). 
de la Unión se han animado a crecer en este punto, montando sus propias Administraciones inspectoras estatales.

Según el utilísimo sitio en Internet de la citada Administración federal —ubicado en www.osha.gov, y entrando a través de «State Programs»- sólo veintiún Estados (Alaska, Arizona, California, Carolina del Norte, Carolina del Sur, Hawaii, Indiana, Iowa, Kentucky, Maryland, Michigan, Minnesota, Nevada, Nuevo México, Oregón, Tennessee, Utah, Vermont, Virginia, Washington y Wyoming) y el Estado libre asociado de Puerto Rico poseen Inspecciones de Trabajo equivalentes a la Inspección de Trabajo federal. En el caso de California, la materia aparece regulada en su propio Código Laboral ${ }^{67}$, y en especial, en los Capítulos 6 (rotulado «Oficina de Condiciones de Seguridad y Salud Laboral [Occupational Safety and Health Standards Board]》 y 7.5 (rotulado «División de Seguridad y Salud Laboral [Division of Occupational Safety and Health]») de su División 1 (rotulada, «Ministerio de Relaciones Industriales [Department of Industrial Relations]». Esta normativa californiana denomina incluso «ingenieros» a sus Inspectores de Trabajo, indicando que en California existe un «programa continuo de formación como ingenieros de seguridad [safety engineers] de la División de Seguridad y Salud Laboral» ${ }^{68}$.

La Administración federal de Seguridad y Salud Laboral anima a las empresas norteamericanas a asociarse a los denominados «Programas Voluntarios de Protección [Voluntary Protection Programs]》 —-más conocidos por su acrónimo en inglés VPP, cuya base legal genérica está contenida en la sección 2 de la Ley federal de Seguridad y Salud Laboral ${ }^{69}$-, teniendo en cuenta que los participantes en los VPP sirven como modelos de excelencia para otros en sus sectores y comunidades, y están exceptuados de «inspecciones programadas de la OSHA [programmed OSHA inspections]».

Al igual que en Alemania, Italia y Gran Bretaña, en los Estados Unidos de Norteamérica cada concreta Ley laboral federal va acompañada de su correspondiente cuadro de infracciones y sanciones administrativas y de delitos laborales y sus penas ${ }^{70}$.

67 Acerca de la accesibilidad a través de Internet de este Código, véase supra, Tema 2, \$5.

68 Cfr. sección 144.5(a)(3).

69 Rotulada «Consideraciones y objetivo del Congreso [Congressional findings and purpose]», apartado (b)(1).

70 Siempre en el plano del Derecho federal, es el caso de la sección 17 (rotulada «Penas [Penalties]») de la Ley de Seguridad y Salud Laboral; y también, el caso de la sección 16 (asimismo rotulada «Penalties») de la Ley de Condiciones de Trabajo Justas (Fair Labor Standards Act) de 1938. Sobre esta última Ley, véase infra, Tema 17, §5. 


\section{TEMA 8 \\ EL CONTENCIOSO LABORAL EN EUROPA Y EN LOS ESTADOS UNIDOS}

Sumario: §1. El modelo alemán de contencioso laboral integral. §2. Otros modelos europeos (francés, portugués e italiano) de contencioso laboral no integral. \$3. El modelo británico de contencioso laboral cuasi-jurisdiccional. $\$ 4$. El modelo norteamericano de pluralidad de contenciosos laborales cuasi-jurisdiccionales. §5. El contencioso laboral ante los tribunales de la Unión Europea.

THEME 8

THE LABOR LITIGATION IN EUROPE AND IN THE UNITED STATES

Contents: \$1. The German integral model of labor litigation. \$2. Other European (French, Portuguese and Italian) non-integral models of labor litigation. $\$ 3$. The British model of quasi-jurisdictional labor litigation. \$4. The USA model of plurality of quasi-jurisdictional labor litigation. \$5. The labor litigation before the Courts of the European Union.

§1. Desde el punto de vista del acoplamiento entre la materia contencioso-laboral y el enjuiciamiento de esta concreta materia contenciosa (esto es, de los pleitos laborales), el modelo europeo de referencia que lo consuma mejor es, sin ningún género de dudas al respecto, el modelo alemán ${ }^{1}$. En efecto, en él concurren los tres elementos que permiten calificar el modelo alemán de contencioso laboral como un verdadero contencioso integral. En primer lugar, porque todos los aspectos de ese contencioso aparecen regulados en una sola norma-que procede, en consecuencia, a su regulación integral一, la cual es en Alemania la «Ley del Tribunal

1 Véase K. DÖRNER, S. LUCZAK y M. WILDSCHÜTZ, Handbuch Arbeitsrecht, 4 ${ }^{\text {a }}$ ed., Luchterhand (Munich, 2004), págs. 2303 y ss.; P. HANAU y K. ADOMEIT, Arbeitsrecht, $13^{\mathrm{a}}$ ed., Luchterhand (Munich, 2005), págs. 306 y ss.; W. DÄUBLER, Arbeitsrecht. Ratgeber für Beruf, Praxis und Studium, $6^{\mathrm{a}}$ ed., Bund-Verlag (Frankfurt a.M., 2006), págs. 374 y ss.; y A. JUNKER, Grundkurs Arbeitsrecht, 5ª ed., C.H. Beck (Munich, 2006), págs. 457 y ss. 
de Trabajo [Arbeitsgerichtsgesetz]» de 1953, que es una Ley que regula todos los aspectos orgánicos y todos los aspectos procesales de todos los tribunales de trabajo alemanes ${ }^{2}$. En segundo lugar, porque en los diversos grados en que se plantean y resuelven pleitos laborales por «sentencia [Urteil] » - que en Alemania son tres grados-intervien e n siempre Tribunales de Trabajo, llamados así («Arbeitsgerichte»), en el primer grado jurisdiccional ${ }^{3}$; llamados Tribunales de Trabajo del Estado federado («Landesarbeitsgerichte») — que son diecinueve, uno por cada uno de los dieciséis Estados federados, salvo en Baviera (que tiene dos) y en Renania del Norte-Westfalia (que tiene tres) ${ }^{4}$-, en el segundo grado jurisdiccional o grado de «apelación [Berufung]» 5; y llamado Tribunal Federal de Trabajo («Bundesarbeitsgericht») — que es único para toda la federación y tiene su sede en la ciudad de Erfurt (Estado federado de Turingia)—, en el tercer grado jurisdiccional o grado de «casación [Revision] ${ }^{6}$. En tercer lugar, porque el escabinato rige la composición de todos los tribunales de trabajo en dichos tres grados jurisdiccionales, afirmando al respecto la Ley del Tribunal de Trabajo que «los tribunales para materias de trabajo se cubren con jueces profesionales» —llamados «Berufsrichter»— «y con jueces electivos» - llamados «ehrenamtliche Richter»— «de los sectores de los trabajadores y de los empresarios» ${ }^{7}$.

Los Tribunales de Trabajo alemanes son órganos jurisdiccionales colegiados, que actúan por medio de «Salas», denominadas «Cámaras [Kammern]» en los grados jurisdiccionales primero y segundo, y «Senados [Senate]» en el tercer grado. En el primer y segundo grados jurisdiccionales hacen Sala un juez profesional (que la preside) y dos jueces electivos (uno por el sector de los trabajadores y otro por el sector de los empresarios) ${ }^{8}$, mientras que en el Tribunal Federal de Trabajo hacen Sala cinco magistrados (tres profesionales y dos electivos) ${ }^{9}$. Como es lógico, los requisitos de edad, probidad, experiencia, etc., al efecto de poder ser elegido juez, aparecen minuciosamente pormenorizados en la Ley ${ }^{10}$.

2 Sobre ella, véase P. BADER, M. CREUTZFELDT y H.-F. FRIEDRICH, Kommentar zum Arbeitsgerichtsgesetz, $4^{\mathrm{a}}$ ed., Luchterhand (Munich, 2006), págs. 67 y ss. Nuestra traducción de la misma, en J. MARTÍNEZ GIRÓN y A. ARUFE VARELA, Leyes laborales alemanas. Estudio comparado y traducción castellana, Netbiblo (A Coruña, 2007), págs. 242 y ss.

3 Cfr. parágrafos 14 a 32 y 46 a 63.

4 Al respecto, véase P. BADER, M. CREUTZFELDT y H.-F. FRIEDRICH, Kommentar zum Arbeitsgerichtsgesetz, $4^{\mathrm{a}}$ ed., cit., págs. 326.

Cfr. parágrafos 33 a 39 y 64 a 71.

6 Cfr. parágrafos 40 a 45 y 72 a 77.

7 Cfr. parágrafo 6, apartado 1.

8 Cfr. parágrafos 16 y 35 , respectivamente.

9 Cfr. parágrafo 41.

10 Cfr. parágrafos 21 a 28 (en relación con los Tribunales de Trabajo), 37 (respecto de los Tribunales de Trabajo de los Estados federados) y 43 (a propósito del Tribunal Federal de Trabajo). 
Aparte los pleitos a resolverse y decidirse por «sentencia», los Tribunales de Trabajo alemanes también resuelven y deciden pleitos por «auto [Beschluss]». En estos otros casos, la Ley no habla de «apelación», sino de «segunda instancia [zweiter Rechtszug]», materializada en el recurso de «queja [Beschwerde]»; y tampoco habla de «casación», sino de «tercera instancia [dritter Rechtszug]», materializada en el recurso de «queja por razones de derecho [Rechtsbeschwerde]». Aparte sus Salas ordinarias, el Tribunal Federal de Trabajo también actúa por medio de «Sala General [Großer Senat] —que no es igual que el pleno-, al efecto de unificar la jurisprudencia, en cuyo caso decide por medio de «auto» ${ }^{11}$.

A través del citado proceso a resolverse por «sentencia», los Tribunales de Trabajo conocen de «pleitos jurídico-civiles [bürgerliche Rechtsstreitigkeiten]» relativos —entre otras cuestiones litigiosas- a «las partes de un convenio colectivo» ${ }^{12}$ y a los «derivados de la relación laboral» ${ }^{13}$. En cambio, a través del también citado proceso a resolverse por «auto», los Tribunales de Trabajo conocen sustancialmente de pleitos relativos a cuestiones de representación de los trabajadores en la empresa (esto es, reguladas en la Ley de Organización de la Empresa, en las Leyes de cogestión, en la Ley sobre el comité de empresa europeo, etc.) ${ }^{14}$. El carácter jurídico privado de los pleitos laborales en Alemania (recuérdese, pleitos «jurídico-civiles») explica las continuas remisiones de la Ley del Tribunal de Trabajo a la «Ley de Enjuiciamiento Civil [Zivilprozessordnung]» de 1950.

\$2. El modelo francés de contencioso laboral no es todo lo integral que resulta ser el modelo alemán ${ }^{15}$. En efecto, sobre la base de que aquí la integralidad viene marcada por la presencia de tres elementos, en el modelo francés uno de los tres elementos falla. Se trata del primer elemento (recuérdese, el relativo a las fuentes), dado que en Francia la regulación del contencioso laboral no está contenida en una única norma, sino dispersa en hasta tres normas distintas, que son el Código del Trabajo, el Código de la Organización Judicial (Code de l'Organisation Judiciaire) y el Código de Procedimiento Civil (Code de Procedure Civile). El segundo elemento (recuérdese, el relativo a la existencia de tribunales de trabajo en todos los grados jurisdiccionales) no falla, puesto que interviene, en el primer grado, siempre el «Consejo de Hombres Prudentes [Conseil de Prud'hommes]», cuyos aspectos orgánicos y procesales aparecen regulados en el Código del Trabajo ${ }^{16}$; en el segundo grado, la «Sala de

11 Cfr. parágrafo 45.

12 Cfr. parágrafo 2, apartado 1, núm. 1.

13 Cfr. parágrafo 2, apartado 1, núm. 3.a).

14 Cfr. parágrafo 2a.

15 Sobre él, véase J. VILLEBRUN y G.-P. QUÉTANT, Les jurisdictions du Travail en Europe, LGDJ (Paris, 1992), págs. 66 y ss.; J. VILLEBRUN y G.-P. QUÉTANT, Traité de la jurisdiction prud'homale, $3^{\mathrm{a}}$ ed., LGDJ (París, 1998), págs. 1 y ss.; S. GUÉRINOT, Aller et gagner aux Prud'hommes, $2^{\mathrm{a}}$ ed., DELMAS (Paris, 2004), págs. 10 y ss.; y J. PÉLISSIER, A. SUPIOT y A. JEAMMAUD, Droit du travail, $24^{\mathrm{a}}$ ed., Dalloz (París, 2008), págs. 145 y ss.

16 Cfr. artículo L. 1411-1 y ss. 
lo Social [Chambre Sociale]» de la «Corte de Apelación [Cour d'Appel]», regulada en lo orgánico en el Código de la Organización Judicial ${ }^{17}$, y en lo procesal en el Código de Procedimiento Civil ${ }^{18}$; y en el tercer grado, la Sala de lo Social de la «Corte de Casación [Cour de Cassation]», con sede en París - que conoce esencialmente del «recurso de casación [pourvoi en cassation]» frente a las «sentencias [arrêts]» de las Cortes de Apelación-, cuyos aspectos orgánicos y procesales regulan los mismos dos Códigos recién citados ${ }^{19}$. El tercer elemento (recuérdese, el relativo al escabinato) tampoco falla, puesto que — según el Código del Trabajo- los Consejos de Hombres Prudentes son una «jurisdicción electiva y paritaria» ${ }^{20}$, compuestos por «un número igual de trabajadores y de empresarios» ${ }^{21}$.

Sobre la base de que el Consejo de Hombres Prudentes se constituye allí donde existe Tribunal de Gran Instancia ${ }^{22}$, el propio Código del Trabajo regula pormenorizadamente su elección ${ }^{23}$, previendo que un juez del Tribunal de Instancia intervenga «en caso de empate [partage]» para deshacer la discordia existente entre los trabajadores y empresarios componentes del mismo ${ }^{24}$.

Los Consejos de Hombres Prudentes son competentes sólo en materia de lo que en España denominaríamos conflictos individuales de trabajo, puesto que «resuelven por vía de conciliación las diferencias que puedan ocurrir con ocasión de todo contrato de trabajo [les différends qui peuvent s'elever à l'occasion de tout contrat de travail] sometidas a las disposiciones del presente código entre los empresarios, o sus representantes, y los trabajadores que emplean», teniendo en cuenta que «enjuician los litigios cuando no se ha alcanzado la conciliación ${ }^{25}$.

El Título II del Libro V de la Parte Segunda del Código del Trabajo trata de los «conflictos colectivos [conflicts collectifs]», conteniendo «disposiciones generales» ${ }^{26}$ y reglas específicas sobre «conciliación» ${ }^{27}$, «mediación» ${ }^{28}$ y 《arbitraje» ${ }^{29}$, previéndose en estas últimas la emanación de «laudos arbitrales [sentences arbitrales]» y su posible impugnación ante la «Corte Superior de Arbitraje [Cour Supérieure d'Arbitrage]» ${ }^{30}$.

17 Cfr. artículo L. 311-1 y ss.

18 Cfr. artículo 542 y ss.

19 Cfr. artículo L. 411-1 y ss. del Código de la Organización Judicial (en relación con lo orgánico), y artículo 604 y ss. del Código de Procedimiento Civil (respecto de lo procesal).

20 Cfr. artículo L. 1421-1, párrafo primero.

21 Ibidem, párrafo segundo.

22 Cfr. artículo L. 1422-1, párrafo primero.

23 Cfr. artículo L. 1441-1 y ss.

24 Cfr. artículo L. 1454-2, párrafo primero.

25 Cfr. artículo L. 1411-1.

26 Cfr. artículo L. 2521-1 y ss.

27 Cfr. artículo L. 2522-1 y ss.

28 Cfr. artículo L. 2523-1 y ss.

29 Cfr. artículo L. 2524-1 y ss.

30 Cfr. artículo L. 2524-6. 
El modelo italiano de contencioso laboral tampoco es integral ${ }^{31}$, y aun resulta ser menos integral que el modelo francés, por causa de que en él - como de hecho sucede también en el modelo español de contencioso laboral- fallan dos de los elementos que permitían hablar de la integralidad del modelo alemán de contencioso laboral. En efecto, falla el primer elemento, por cuanto las fuentes reguladoras del contencioso laboral italiano se hallan dispersas fundamentalmente en tres normas, que son -en relación con las cuestiones orgánicas, aunque sorprenda- el «Real Decreto [Regio Decreto]» núm. 12, de 30 enero 1941, sobre «Ordenamiento Judicial [Ordinamento Giudiziario]», y además —en relación con las cuestiones procesales-, el «Código de Procedimiento Civil [Codigo di Procedura Civile]» de $1940^{32}$ — que es una norma «impura» ${ }^{33}$ —, y la Ley núm. 553, de 11 agosto 1973, sobre «regulación de las controversias individuales de trabajo y de las controversias en materia de previsión y de asistencia obligatorias» ${ }^{34}$; y asimismo falla el tercer elemento, dado que los jueces actuantes en los órganos correspondientes a los tres grados en que se diversifica la jurisdicción ordinaria italiana (que conoce de asuntos penales y civiles, incluyéndose dentro de estos últimos la materia contenciosa laboral y de seguridad social) son siempre jueces profesionales. Tales órganos - que son, en el primer grado jurisdiccional, el «Tribunal Ordinario [Tribunale Ordinario]», en el segundo grado jurisdiccional, la «Corte de Apelación [Corte di Apello]», y en el tercer grado jurisdiccional, la «Corte Suprema de Casación [Corte Suprema di Cassazione]», con sede en Roma- conocen de los asuntos laborales (y también, de los de seguridad social) a través de «secciones especializadas» —razón por la que no falla el segundo elemento-, las cuales dictan «sentencia [sentenza]» con un solo juez (y por tanto, «monocráticamente») en el primer grado ${ }^{35}, \mathrm{y}$ colegiadamente en el segundo y tercer grados jurisdiccionales (con tres y cinco magistrados «votantes», respectivamente) ${ }^{36}$.

31 Véase G. SUPPIEJ, M. DE CRISTOFARO y C. CESTER, Diritto del Lavoro. Il rapporto individuale, $2^{\mathrm{a}}$ ed., CEDAM (Padua, 2003), págs. 456 y ss.

32 Aprobado por Real Decreto núm. 1443, de 28 octubre 1940. Monográfico sobre él, véase A. GIUSSANI (Coordinador), Il processo del lavoro. Commentario di giurisprudenza, IPSOA (Milán, 2001), págs. 3 y ss.

33 Puesto que está reglamentada por el Real Decreto núm. 1328, de 18 diciembre 1941, sobre disposiciones para el desarrollo del Código de Procedimiento Civil, artículos 144-ter a 152.

34 Sobre esta Ley, véase L DE ANGELIS, Il processo del lavoro nella giurisprudenza e nella dottrina, $2^{\mathrm{a}}$ ed., CEDAM (Padua, 1986), págs. 13 y ss.

35 Cfr. artículo 48, párrafo segundo, del Real Decreto núm. 12 de 1941.

36 Cfr. artículo 56 del Real Decreto núm. 12 de 1941, y artículo 19 de la Ley núm. 553 de 1973, respectivamente. 
El Real Decreto núm. 12 de 1941 ordena que «las controversias en materia de trabajo y de previsión y de asistencia obligatorias se tratan exclusivamente en la sede principal del Tribunal» ${ }^{37}$, con la consecuencia de que sólo pueden tramitarse pleitos laborales en las veintiséis ciudades italianas declaradas sedes de dichos tribunales (ciudades que son, además, sede asimismo de las Cortes italianas de Apelación) ${ }^{38}$. El Real Decreto núm. 12 de 1941 es una norma plagada de anacronismos, en la que continuamente se alude todavía al «Imperio» y al «Rey Emperador» de Italia, afirmando incluso que «la Corte Suprema de Casación tiene sede en Roma y tiene jurisdicción sobre todo el territorio del reino, del imperio y sobre cualquier otro territorio sujeto a la soberanía del estado» ${ }^{39}$. En cualquier caso, se trata de una norma herida de muerte, pues la Ley núm. 150, de 25 julio 2005, autoriza al Gobierno italiano a elaborar un texto articulado regulador del ordenamiento judicial, en desarrollo de las bases contenidas en la misma, aunque este texto articulado sólo va promulgándose fragmentariamente.

El modelo portugués ${ }^{40}$ coincide con los modelos francés e italiano en que las fuentes reguladoras de su contencioso laboral también se hallan dispersas en normas diversas (una de ellas, incluso, exageradamente denominada «Código del Proceso de Trabajo [Código do Processo de Trabalho]»), aunque: 1) en el primer grado de la jurisdicción, cabe teóricamente la existencia de tribunales escabinos - al igual que en Francia-, pero en la práctica la regla general - al igual que en Italia - es que no lo sean; y 2) la materia contencioso laboral está claramente especializada en los grados jurisdiccionales segundo y tercero —en el segundo grado, actúan las «secciones sociales [secções sociais]» de las «Audiencias Territoriales [Tribunais da Relação]»; y en el tercer grado, la «sección social» del «Supremo Tribunal de Justicia [Supremo Tribunal de Justiça]», con sede en Lisboa, resolviendo por medio de «sentencia [acórdão]», al tratarse de un órgano judicial colegiado-, pero no necesariamente en el primer grado - a diferencia de lo que ocurren en Francia e Italia - , puesto que sólo en las comarcas donde el volumen de asuntos laborales lo requiera actuarán «Juzgados del Trabajo [Juízos do Trabalho]», resultando competentes en el resto los «Tribunales de Comarca [Tribunais de Comarca]».

Las fuentes reguladoras del tema son el citado Código del Proceso de Trabajo, aprobado por Decreto-Ley núm. 480/99, de 9 noviembre $^{41}$, y la Ley núm. 52/2008, de 28 agosto, que aprueba la «Ley de Organización y Funcionamiento de los Tribunales Judiciales [Lei de

37 Artículo 46.quater, párrafo segundo, inciso primero.

38 Las ciudades en cuestión aparecen detalladas en el Anexo A del Real Decreto núm. 12 de 1941.

39 Artículo 65, párrafo segundo.

40 Sobre sus estructuras tradicionales, véase P. ROMANO MARTÍNEZ, Direito do Trabalho, Almedina (Coimbra, 2002), págs. 1129 y ss.

41 Modificado, tras la entrada en vigor del actual Código portugués del Trabajo, por el Decreto-Ley núm. 295/2009, de 13 octubre. 
Organização e Funcionamiento dos Tribunais Judiciais]». El Código del Proceso de Trabajo viene a equivaler a nuestra Ley de Procedimiento Laboral, aunque la delimitación de la competencia material de los órganos jurisdiccionales laborales portugueses no se encuentra regulada en él, sino en la Ley de Organización y Funcionamiento de los Tribunales Judiciales, en la que las normas equivalentes del artículo 2 de nuestra Ley de Procedimiento Laboral resultan ser sus artículos 118 y $119^{42}$. Esta misma Ley orgánica regula la conexión escabinato-tribunal colectivo, teórica en asuntos laborales ${ }^{43}$.

§3. E1 modelo británico de contencioso laboral nada tiene que ver con los modelos continentales europeos recién citados, puesto que los pleitos laborales se resuelven con carácter previo por órganos cuasi-jurisdiccionales (denominados «Tribunales [Tribunals]»), que no forman parte como las «Cortes [Courts]» del poder judicial británico ${ }^{44}$. En efecto, del contencioso laboral en Gran Bretaña conocen los denominados "Tribunales de Empleo [Employment Tribunals]», en primera instancia ${ }^{45}$; y en apelación, los «Tribunales de Apelación de Empleo [Employment Appeal Tribunals]», con sedes en Londres y Edimburgo. Frente a las decisiones de estos últimos Tribunales - tras sortear obstáculos que le resultarían inverosímiles a cualquier jurista continental europeo-, cabe apelar ante verdaderas Cortes de Derecho común (no especializadas, por tanto, en el conocimiento de asuntos laborales), que son la «Corte de Apelación [Court of Appeal]», para asuntos relativos a Inglaterra o Gales, y la «Corte de Sesión [Court of Session]», para asuntos relativos a Escocia. Tras sortear parecidos obstáculos, cabría hipotéticamente apelar las decisiones de estas dos últimas Cortes ante la «Corte Suprema del Reino Unido [Supreme Court of the United Kingdom]». En efecto, en octubre de 2009 se cumplieron las previsiones de la «Ley de Reforma Constitucional [Constitutional Reform $A c t] \gg$ de 2005, a cuyo tenor dicha altísima Corte ha pasado a reemplazar a la «Cámara de los Lores [House of Lords]».

42 Este último precepto, rotulado «competencia en materia de infracciones administrativas», afirma que «compete a los juzgados del trabajo juzgar los recursos contra las decisiones de las autoridades administrativas en procesos de infracción administrativa en los ámbitos laboral y de seguridad social».

43 Al respecto, véase fundamentalmente su artículo 120.

44 Véase N.M. SELWYN, Law of Employment, 13 ${ }^{\mathrm{a}}$ ed., LexisNexis-Butterworths (Londres, 2004), págs. 9 y ss.; y S. HONEYBALL y J. BOWERS, Textbook on Labour Law, $8^{a}$ ed., Oxford University Press (Oxford, 2004), págs. 11 y ss.

45 Desgranando sus competencias, desde un punto de vista hiperpráctico, véase J. BOWERS, D. BROWN y D. MANSFIELD, Employment Tribunal. Practice \& Procedure, vol. 2, $4^{\mathrm{a}}$ ed., Sweet\&Maxwell (Londres, 2002), págs. 1 y ss.; e INNS OF COURT SCHOOL OF LAW (CITY UNIVERSITY, LONDON), Employment Law in Practice, $6^{\mathrm{a}}$ ed., Oxford University Press. (Oxford, 2004), págs. 16 y ss. Antes se denominaban Tribunales Industriales. Sobre estos últimos, véase R. GREENHALGH, Industrial Tribunals, Law and Employment Series (Londres, 1992), págs. 15 y ss. 
Las fuentes reguladoras de los Tribunales de Empleo y de los Tribunales de Apelación de Empleo son, desde un punto de vista orgánico, la «Ley de Tribunales de Empleo [Employment Tribunals Act]» de 1996; y desde un punto de vista procesal, el «Reglamento de los Tribunales de Empleo (Constitución y Reglas de Procedimiento) [The Employment Tribunals (Constitution and Rules of Procedure) Regulations]» de 2004, y las «Reglas del Tribunal de Apelación de Empleo [Employment Appeal Tribunal Rules]» de $1993^{46}$. En la recién citada Ley de Tribunales de Empleo de 1996, se afirma que «los Tribunales de Empleo ejercitarán la competencia conferida a ellos por o en virtud de esta Ley o de cualquier otra Ley, tanto si aprobada antes o después de esta Ley» ${ }^{47}$-resultando que las otras Leyes en cuestión son más de veinte Leyes distintas ${ }^{48}$ - y además, que el recurso frente a la decisión del Tribunal de Apelación de Empleo requiere «el permiso [leave] del Tribunal de Apelación o de la Corte de Apelación competente» ${ }^{49}$. Las complejísimas «Reglas de Procedimiento Civil [Civil Procedure Rules]», a que las Cortes británicas de Derecho común de instancia y de apelación ajustan su actuación — Cortes (incluida la Suprema) reguladas, desde un punto de vista orgánico, en la «Ley de Tribunales, Cortes y Exigencia del Cumplimiento [Tribunals, Courts and Enforcement Act]» de 2007-, resultan accesibles en «versión consolidada» a través de www.justice.gov.uk/civil/procrules_fin/index.htm.

\$4. El modelo norteamericano de contencioso laboral posee -en el plano federal - un parecido irresistible con el modelo británico, aunque no se identifica en absoluto con él. De un lado, porque en los Estados Unidos también resulta imprescindible distinguir entre contencioso laboral cuasi-jurisdiccional y contencioso laboral jurisdiccional, aunque - a diferencia de lo que ocurre en Gran Bretaña- el contencioso cuasi-jurisdiccional no es único, sino que aparece parcelado en una pluralidad de contenciosos laborales cuasi-jurisdiccionales, puesto que cada concreta gran Ley «laboral» federal (por ejemplo, la «Ley de Relaciones Laborales Nacionales [National Labor Relations Act]» o Ley Wagner de $1935^{50}$, el Título VII de la «Ley de Derechos Civiles [Civil Rights Act]» de 1964, o la «Ley de Seguridad y Salud Laboral [Occupational Safety and Health Act]》 de 1970) ${ }^{51}$ crea su propia Agencia (respecto de los tres ejemplos recién citados, la «Oficina Nacional de Relaciones Laborales [National Labor Relations Board]» o NLRB ${ }^{52}$, la «Comisión para la Oportunidad de un

46 Siempre útiles, a los efectos de manejar versiones consolidadas del «Procedimiento» de los Tribunales de Empleo y de las «Reglas» de actuación de los Tribunales de Apelación de Empleo, pueden consultarse los sitios de Internet www.employmenttribunals.gov.uk y www.employmentappeals.gov.uk, respectivamente.

47 Cfr. sección 2.

48 Cfr. sección 21.

49 Sección 37(1).

50 Sobre ella, véase infra, Tema 11, §5, y Tema 14, §5.

51 Sobre ella, véase supra, Tema 7, §7, e infra, Tema 16, §3.

52 Sobre ella y su sitio en Internet, véase supra, Tema 5, §5. Acerca de su contencioso cuasi-jurisdiccional, véase T.J. HEINSZ, D.R. NOLAN y R.A. BALES, Labor Law. Collective Bargaining in a Free Society, $6^{\text {a }}$ ed., Thomson-West (St. Paul-Minn., 2009), págs. 410 y ss. 
Empleo Igual [Equal Employment Opportunity Commission]» o EEOC ${ }^{53}$, y la «Comisión de Revisión de Seguridad y Salud Laboral [Occupational Safety and Health Review Commission]» u OSHRC ${ }^{54}$ ) e n c arg a d a de la «administración» de la concreta Ley federal de que se trate (esto es, de resolver cuasi-jurisdiccionalmente, con carácter previo, los litigios suscitados por su aplicación e interpretación) ${ }^{55}$. De otro lado, porque cabe recurrir las decisiones, acuerdos u órdenes de estas Agencias federales ante las Cortes federales de Derecho común —eso sí, sin las trabas para el acceso a la jurisdicción propiamente dicha características del modelo británico ${ }^{56}$, las cuales son: 1) las «Cortes federales de Distrito [United States District Courts]», competentes para el enjuiciamiento de los acuerdos de la recién citada EEOC; 2) las «Cortes de Apelaciones [Courts of Appeals]» de los «trece circuitos judiciales de los Estados Unidos», competentes para la «revisión judicial [judicial review]» directa de las decisiones u órdenes de las también recién citadas NLRB y OSHRC; y 3) la «Corte Suprema de los Estados Unidos [United States Supreme Court]》, competente para revisar las sentencias de las Cortes de Apelaciones - a través del mecanismo procesal denominado «orden de revisión [writ of certiorari]»-, aunque teniendo en cuenta que «la petición de una orden de revisión será concedida sólo por razones graves [compelling reasons]», y que entre las razones, «aunque ni decisivas ni completamente medidoras del arbitrio de la Corte [Suprema]» —al efecto de acceder a revisar un caso por esta vía, que nada tiene que ver con nuestro continental recurso de casación-, se cuenta la relativa a que «una Corte de Apelaciones de los Estados Unidos haya dictado sentencia en conflicto con las sentencias de otras Cortes de Apelaciones de los Estados Unidos sobre la misma materia importante [on the same important matter]».

Desde un punto de vista orgánico, todas las cortes federales norteamericanas aparecen reguladas en el Título 28 del Código de los Estados Unidos, que es derecho positivo ${ }^{57}$; y más

53 Cuyo sitio en Internet es www.eeoc.gov. Acerca de su contencioso cuasi-jurisdiccional, véase J.E. JONES JR., W.P. MURPHY y R. BELTON, Discrimination in employment, $5^{\text {a }}$ ed., West Publ. Co. (St. Paul-Minn., 1987), 462 y ss.; y M.A. PLAYER, Employment discrimination Law, West Publ. Co. (St. Paul-Minn., 1988), págs. 200 y ss.

54 Sobre ella y su sitio en Internet, véase supra, Tema 5, §5. Acerca de su contencioso cuasijurisdiccional, M.A. ROTHSTEIN, Occupational Safety and Health Law, $3^{\mathrm{a}}$ ed., West Publ. (St. Paul-Minn., 1990), págs. 368 y ss.

55 Sobre la OSHA, en cuanto que encargada de la actividad de «exigir el cumplimiento [enforcement]» de la citada Ley de Seguridad y Salud Laboral, véase supra, Tema 7, \$7.

56 Sobre el Derecho estructural aplicable a dichas Cortes federales, C.A. WRIGHT, Law of Federal Courts, West Publ. Co. (St. Paul-Minn., 1983), págs. 1 y ss.

57 Al respecto, véase supra, Tema 2, §5. 
en concreto, en sus secciones 81 a 144 (las Cortes de Distrito), en sus secciones 41 a 49 (las Cortes de Apelación) ${ }^{58}$ y en sus secciones 1 a 6 (la Corte Suprema).

Desde un punto de vista procesal, en el Apéndice del recién citado Título 28 del propio Código de los Estados Unidos - que asimismo es derecho positivo- aparecen contenidas las «Reglas federales de Procedimiento Civil [Federal Rules of Civil Procedure]», a las que se ajustan las Cortes de Distrito, y las «Reglas federales del Procedimiento de Apelación [Federal Rules of Appellate Procedure]», a las que se ajustan las Cortes de Circuito; en cambio, las «Reglas de la Corte Suprema de los Estados Unidos [Rules of the Supreme Court of the United States]» no figuran en dicho apéndice, aunque pueden consultarse en versión consolidada en el sitio en Internet de la propia Corte Suprema, ubicado en www.supremecourt.gov. En todas estas «Reglas» - elaboradas por la Corte Suprema y aprobadas por el Congreso ${ }^{59}$-, se contienen normas procesales de aplastante sentido común. Por ejemplo, a propósito de las apelaciones, las relativas a la posibilidad de presentar todo tipo de escritos ante las Cortes de Circuito utilizando «medios electrónicos» ${ }^{60}$, o las que tratan del tamaño y forma a que deben ajustarse los escritos de parte (siendo la regla general que el «escrito de interposición del recurso [principal appellant's brief]» no puede «exceder de 30 páginas» ${ }^{61}$, ni contener «más de 1.300 líneas» ${ }^{62}$, ni tampoco «más de 14.000 palabras» ${ }^{63}$ ).

Como es lógico, esta misma estructura de contencioso laboral (agencias cuasijurisdiccionales y cortes jurisdiccionales de derecho común) se reproduce en cada uno de los cincuenta Estados federados. Ciñéndonos sólo al contencioso laboral de California - sexta potencia industrial del mundo, recuérdese-, la organización y procedimiento de las Cortes estatales californianas (que son, las «Cortes Superiores [Superior Courts]», de los Condados; las «Cortes de Apelación [Courts of Appeal]», de los Distritos; y la «Corte Suprema [Supreme Court]») aparecen regulados en el «Código de Procedimiento Civil de California [Code of Civil Procedure of California]». Por su parte, la lista completa, y complejísima, de agencias cuasi-jurisdiccionales estatales californianas puede consultarse en www.ca.gov, a través de la entrada «State Agencies Directory».

§5. Como es lógico, el contencioso laboral ante los tribunales de la Unión Europea está regulado en el Tratado de Funcionamiento de la Unión Europea ${ }^{64}$ y, además, en el «Estatuto del

58 Según la sección 41 del Título 28, la composición y denominación de los «trece circuitos» mencionados es la siguiente: «Distrito de Columbia», que comprende el propio Distrito de Columbia; «Primero», que comprende Maine, Massachussets, New Hampshire, Puerto Rico y Rhode Island; «Segundo», que comprende Connecticut, Nueva York y Vermont; «Tercero», que comprende Delaware, New Jersey, Pensilvania e Islas Vírgenes; «Cuarto», que comprende Maryland, Carolina del Norte, Carolina del Sur, Virginia y Virginia Occidental; «Quinto», que comprende el Distrito de la Zona del Canal, Luisiana, Mississipi y Texas; «Sexto», que comprende Kentucky, Michigan, Ohio y Tennessee; «Séptimo», que comprende Illinois, Indiana y Wisconsin; «Octavo», que comprende Arkansas, Iowa, Minnesota, Missouri, Nebraska, Dakota del Norte y Dakota del Sur; «Noveno», que comprende Alaska, Arizona, California, Idaho, Montana, Nevada, Oregon, Washington, Guam y Hawaii; «Décimo», que comprende Colorado, Kansas, Nuevo México, Oklahoma, Utah y Wyoming; «Undécimo», que comprende Alabama, Florida y Georgia; y «Federal», que comprende «todos los distritos judiciales federales».

59 Al amparo de las autorizaciones concedidas en las secciones 2072 a 2075 del Título 28 del Código de los Estados Unidos.

60 Cfr. Regla 25(a)(2)(D).

61 Cfr. Regla 332(a)(7)(A).

62 Cfr. Regla 32(a)(7)(B)(i).

63 Ibidem.

64 Cfr. la Sección Quinta del Capítulo 1 del Título I de la Sexta Parte, artículos 251 y ss. 
Tribunal de Justicia de la Unión Europea» ${ }^{65}$. De acuerdo con estas fuentes, cabe hablar de Tribunal de Justicia de la Unión Europea en sentido amplio y en sentido estricto, teniendo en cuenta que en sentido amplio - a los efectos que aquí nos interesan- dicho Tribunal comprende el Tribunal de la Función Pública, el Tribunal General y el Tribunal de Justicia (o Tribunal de Luxemburgo) en sentido estricto. El Tribunal de la Función Pública a ${ }^{66}$ conoce del contencioso que es «laboral» desde un punto de vista formal y material, puesto que se trata del tribunal competente para conocer en primera instancia de los pleitos entre el personal funcionario y el personal laboral y su concreta administración pública empleadora de la Unión Europea. El Tribunal Ge neral —antiguo Tribunal de Primera Instancia- conoce de los «recursos de casación» interpuestos contra las sentencias de este Tribunal de la Función Pública ${ }^{67}$, pero también —en primera instancia - de asuntos encuadrables en el contencioso laboral sólo desde un punto de vista material, tales como recursos planteados por personas físicas o jurídicas (por ejemplo, confederaciones empresariales o sindicales) contra el Consejo o el Parlamento para que se anulen normas comunitarias emanadas con supuesto defecto de procedimiento (por ejemplo, por no haber consultado a quienes se consideran interlocutores sociales representativos ante la Unión Europea) ${ }^{68}$. En fin, el Tribunal de Luxemburgo conoce de los «recursos de casación» contra las sentencias falladas en primera instancia por el Tribunal General ${ }^{69}$, pero también en primera y única instancia de asuntos encuadrables en el contencioso laboral - de nuevo- sólo desde un punto de vista material, tales como cuestiones prejudiciales planteadas por los tribunales laborales de los diversos Estados miembros ${ }^{70}$ o recursos de incumplimiento planteados por

65 Sobre el «Estatuto» anterior al actualmente vigente, véase A. ARNULL, The European Union and its Court of Justice, Oxford University Press (Oxford, 1999), págs. 3 y ss.; G. DE BÚRCA y J.H.H. WEILER (Editores), The European Court of Justice, Oxford University Press (Oxford, 2001), págs. 9 y ss.; y H.G. SCHERMERS y D.F. WAELBROECK, Judicial Protection in the European Union, $6^{\text {a }}$ ed., Kluwer Law International (La Haya, 2001), págs. 309 y ss.

66 Creado por Decisión del Consejo de 2 noviembre 2004, para hacerse cargo de asuntos antes de competencia del Tribunal de Primera Instancia.

67 Cfr. artículos 256 y 257 del Tratado de Funcionamiento de la Unión Europea.

68 Hoy al amparo del artículo 263 del Tratado de Funcionamiento de la Unión Europea, según el cual «toda persona física o jurídica podrá interponer recurso ... contra los actos de que sea destinataria o que le afecten directa e individualmente». Al respecto, véase la Sentencia del Tribunal de Primera Instancia citada infra, Tema $11, \S 4$.

69 Cfr. artículo 256.1, párrafo segundo, del Tratado de Funcionamiento de la Unión Europea.

70 Cfr. artículo 267 del Tratado de Funcionamiento de la Unión Europea. Al respecto, véase la muy abundante jurisprudencia aludida infra, Tema $18, \S 3$. Todo ello, a la espera de que se concreten las reservas a favor del Tribunal General, relativas a «materias específicas», previstas por el propio Tratado (cfr. artículo 256, apartado 3). 


\section{la Comisión frente a concretos Estados miembros por falta de transposi- ción temporánea, o por transposición defectuosa, de concretas Directivas de contenido laboral ${ }^{71}$.}

Una prueba clarísima de los dos sentidos (amplio y estricto) con que debe manejarse la expresión «Tribunal de Justicia» del Tratado de Funcionamiento de la Unión Europea la suministra el artículo 270 del mismo, según el cual —refiriéndose, en principio, al Tribunal de la Función Pública - «el Tribunal de Justicia de la Unión Europea será competente para pronunciarse sobre cualquier litigio entre la Unión y sus agentes dentro de los límites y en las condiciones que establezca el Estatuto de los funcionarios de la Unión y el régimen aplicable a los otros agentes de la Unión».

Respecto de los funcionarios, la atribución de competencia la confirma el artículo 91 del «Estatuto de los funcionarios», aprobado por el Reglamento núm. 31(CEE) 11 (CEEA) de 1962 72; y respecto del personal laboral, el artículo 46 del «Régimen aplicable a los otros agentes de las Comunidades», aprobado por el mismo Reglamento.

Evidentemente, las sentencias del Tribunal de Luxemburgo gozan de plena santidad de cosa juzgada formal y material, resultando en consecuencia irrecurribles - a diferencia de lo que sucede, por ejemplo, con las de nuestro Tribunal Constitucional- ante la Corte Europea de Derechos Humanos (o Tribunal de Estrasburgo), cuyo sitio en Internet se encuentra en www.echr.coe.int, manejable únicamente en inglés y francés ${ }^{73}$.

71 Cfr. artículo 258 del Tratado de Funcionamiento de la Unión Europea. Al respecto, véase infra, Tema 16, §2. Acerca de la trascendencia de este tipo de fallos, a propósito del Derecho alemán del Trabajo, véase A. ARUFE VARELA, La igualdad de mujeres y hombres en Alemania. Estudio comparado de la legislación alemana con la legislación española, y traducción castellana, Netbiblo (A Coruña, 2009), págs. 13 y ss.; y J. MARTÍNEZ GIRÓN y A. ARUFE VARELA, El salario mínimo en Alemania. Un estudio comparado entre regímenes de salarios mínimos profesionales (alemanes) e interprofesionales legales (norteamericano y europeos), Netbiblo (A Coruña, 2009), págs. 29 y ss.

72 A cuyo tenor, «el Tribunal de Justicia de las Comunidades Europeas será competente para resolver sobre los litigios que se susciten entre las Comunidades y alguna de las personas a quienes se aplica el presente Estatuto».

73 Sobre el tema, véase V. BERGER, Jurisprudence de la Cour Européenne des Droits de l'Homme, $8^{\mathrm{a}}$ ed., Dalloz (París, 2002), págs. 1 y ss. 
TEMA 9

LA GESTIÓN DE LA SEGURIDAD SOCIAL

EN EUROPA Y EN LOS ESTADOS UNIDOS

Sumario: §1. El modelo español de gestión disgregada de la Seguridad Social. §2. Otros modelos europeos (alemán, italiano y francés) de gestión disgregada de la Seguridad Social. §3. Los modelos británico y portugués de gestión unificada de la Seguridad Social. §4. El reflejo en el Derecho de la Unión Europea de los modelos nacionales europeos de gestión de la Seguridad Social. §5. El modelo norteamericano de gestión unificada de la Seguridad Social.

THEME 9

THE MANAGEMENT OF SOCIAL SECURITY IN EUROPE AND IN THE UNITED STATES

Contents: $\$ 1$. The Spanish model of dispersed management of Social Security. \$2. Other European models (German, Italian and French) of dispersed management of Social Security. \$3. The British and Portuguese models of unified management of Social Security. \$4. The reflex on the Law of the European Union of the European national models of management of Social Security. \$5. The USA model of unified management of Social Security.

§1. Sobre la base de que la gestión de la Seguridad Social es la actuación administrativa orientada a hacer efectivos los derechos y deberes a que se refieren las fuentes normativas reguladoras de la Seguridad Social ${ }^{1}$, resulta claro que el modelo a que se ajusta la gestión de la Seguridad Social en España es un modelo de gestión disgreg a da. En efecto, de un lado, porque hay una separación neta entre gestión de prestaciones y gestión instrumental ${ }^{2}$; y de otro lado, porque aunque la gestión instrumental (esto es, afiliación, altas, bajas, cotización y recaudación) está encomendada (salvo en lo tocante a los regímenes especiales de funcionarios públicos) a un único ente administrativo - la Tesorería

1 Véase J. MARTÍNEZ GIRÓN, A. ARUFE VARELA y X.M. CARRIL VÁZQUEZ, Derecho de la Seguridad Social, $2^{\text {a }}$ ed., Netbiblo (A Coruña, 2008), pág. 237.

2 Acerca del contenido de ambas nociones, ibidem, págs. 239 ss. y 251 ss. 
General de la Seguridad Social-, la gestión de prestaciones (siempre con la salvedad de lo tocante a los regímenes especiales de funcionarios públicos) ${ }^{3}$ la realizan, en cambio, hasta cinco entidades gestoras distintas (el INSS o Instituto Nacional de la Seguridad Social, el SPEE o Servicio Público de Empleo Estatal, el ISM o Instituto Social de la Marina, el IMSERSO o Instituto de Mayores y Servicios Sociales y el INGESA o Instituto de Gestión Sanitaria), respecto de las que fenómenos de carácter político (por ejemplo, la transferencia a las Comunidades Autónomas de la gestión de la sanidad, de los servicios sociales o de ciertas prestaciones no contributivas) o condicionantes históricos (por ejemplo, la colaboración en la gestión de prestaciones por riesgos profesionales llevada a cabo por las Mutuas Patronales de Accidentes de Trabajo y Enfermedades Profesionales de la Seguridad Social) contribuyen a acentuar la naturaleza disgregada de nuestro sistema de gestión de prestaciones. Evidentemente, la disgregación de la gestión acarrea complicaciones administrativas e incrementa los costes financieros de la gestión; razón por la cual el Gobierno español se comprometió con los interlocutores sociales, en 2001, a enviar a las Cortes un proyecto de ley regulador de la denominada «Agencia de la Seguridad Social» — que unificaría la gestión de prestaciones-, aunque este compromiso haya resultado luego flagrantemente incumplido (quizá por causa de la ya imperiosa necesidad de puesta al día de nuestra envejecida Ley General de Seguridad Social, que ha padecido ya más de medio centenar de modificaciones desde que fue promulgada en 1994).

El plazo para remitir a las Cortes el proyecto de ley en cuestión remataba el 9 abril 2002, afirmándose en el compromiso incumplido que lo pretendido era que «la gestión y administración de la seguridad social se lleve a cabo con sujeción a los principios de simplificación, racionalización, economía de costes y eficacia social, además de descentralización funcional» ${ }^{4}$. Nuestra Administración de Seguridad Social cuenta con su propio sitio en Internet, ubicado en www.seg-social.es. Según la información estadística contenida en este sitio, el sistema español de Seguridad Social posee casi 18 millones de afiliados y más de 8 millones de pensionistas contributivos.

§2. Condicionados asimismo por sus peculiares antecedentes históricos, otros Estados europeos también aplican en sus respectivos sistemas de Seguridad Social — como ocurre en el caso español- un modelo de gestión disgregada. Se trata de grandes sistemas de Seguridad Social, implantados en Estados (como Alemania, Italia o

4 Ibidem, págs. 258-259. 
Francia) que cuentan con un activo de cotizantes y un pasivo de beneficiarios muy superiores (en millones de personas) a los de nuestro sistema de Seguridad Social. En el modelo a lemán, la gestión está disgregada por riesgos sociales (esto es, por ramos del aseguramiento social), de manera que la gestión de las prestaciones de cada uno de dichos ramos -que son cinco («seguro de desempleo» ${ }^{5}$, «seguro de enfermedad» común $^{6}$, «seguro de accidente» de trabajo ${ }^{7}$, «seguro de pensiones» derivadas de riesgos comunes ${ }^{8}$ y «seguro de dependencia» ${ }^{9}$ ), de donde «los cinco pilares [die fünf Säulen]» del sistema alemán contributivo de Seguridad Social ${ }^{10}$ — se encomienda a las respectivas entidades gestoras de los mismos (genéricamente denominadas «gestoras de prestaciones [Leistungsträger]») ${ }^{11}$, aunque luego resulta que de la gestión recaudatoria sólo se ocupan las gestoras de prestaciones del seguro de enfermedad común (encargadas de recaudar la legalmente denominada «cotización total de seguro social [Gesamtsozialversicherungsbeitrag]», comprensiva de la cotización por enfermedad común, dependencia, pensiones derivadas de riesgos comunes y desempleo) ${ }^{12}$ y las gestoras de prestaciones del seguro de accidente (encargadas de recaudar, por su parte, las primas de accidentes de trabajo que debe satisfacer el empresario) ${ }^{13}$. En el mo de lo italiano, los factores que condicionan la disgregación de la gestión son dos (los riesgos sociales y el tipo de trabajadores cubiertos), lo que explica la existencia de un verdadero mosaico de entidades gestoras

5 Regulado en los Libros Segundo (rotulado «Seguro básico de los demandantes de empleo [Gundsicherung für Arbeitsuchende]» y Tercero (rotulado «Promoción del Trabajo [Arbeitsförderung]») del Código de Seguridad Social.

6 Regulado en el Libro Quinto (rotulado «Seguro legal de enfermedad [Gesetzliche Krankenversicherung]») del Código de Seguridad Social.

7 Regulado en el Libro Séptimo (rotulado «Seguro de accidente [Unfallversicherung]») del Código de Seguridad Social.

8 Regulado en el Libro Sexto (rotulado «Seguro de pensiones [Rentenversicherung]») del Código de Seguridad Social.

9 Regulado en el Libro Undécimo (rotulado «Seguro de dependencia de la Seguridad Social [Soziale Pflegeversicherung]») del Código de Seguridad Social.

10 Triunfalista, pero preciso, claro y manejable en seis lenguas distintas, véase «Soziale Sicherung im Überblick», accesible a través de http://soziale-sicherung.bmas.bund.de.

11 Véase E. EICHENHOFER, E., Sozialrecht, 5a ed., Mohr Siebeck (Tubinga, 2004), págs. 128 ss.

12 Cfr. parágrafos 28d y 28i del Libro Cuarto del Código de Seguridad Social. Sobre el tema, véase B. SCHULIN y G. IGL, Sozialrecht, 6ª ed., Werner Verlag (Düsseldorf, 1999), págs. 107, 127 y 297 ; H. BLEY, R. KREIKEBOHM y A. MARSCHNER, Sozialrechr, $8^{\mathrm{a}}$ ed., Luchterhand (Neuwied y Kriftel, 2001), pág. 159; y R. WALTERMAN, Sozialrecht, $5^{\text {a }}$ ed., C.F. Müller (Heidelberg, 2005), pág. 173.

13 Cfr. parágrafo 150 del Libro Séptimo del Código de Seguridad Social. Sobre el tema, véase WITTERSTÄTTER, K., Soziale Sicherung. Eine Einführung für Sozialarbeiter/Sozialpädagogen mit Fallbeispielen, $6^{\mathrm{a}}$ ed., Luchterhand (Munich, 2003), pág. 186; y R. WALTERMAN, Sozialrecht, $5^{\mathrm{a}}$ ed., cit., págs. 130-131. 
grandes y pequeñas (genéricamente denominadas «institutos de previsión $\mathrm{y}$ asistenciales [istituti di previdenza e assistenziali]» ${ }^{14}$, de las cuales las más importantes son el INPS o «Instituto Nacional de la Previsión Social [Istituto Nazionale della Previdenza Soziale]» (competente en materia de gestión de los riesgos comunes, incluido el desempleo e incluida la gestión recaudatoria, del grueso de los trabajadores por cuenta ajena y por cuenta propia del sector privado) ${ }^{15}$, el INPDAP o «Instituto Nacional de Previsión para los Dependientes de la Administración Pública [Istituto Nazionale di Previdenza per i Dipendenti dell'Amministrazione Pubblica]» (competente en materia de gestión, incluso recaudatoria, de los riesgos comunes del grueso de los funcionarios y trabajadores al servicio de las diversas Administraciones públicas) ${ }^{16} \mathrm{y}$ el INAIL o «Instituto Nacional para el Aseguramiento contra los Riesgos del Trabajo [Istituto Nazionale per l'Assecurazione contro gli Infortuni sul Lavoro]» (entidad aseguradora de los accidentes de trabajo y enfermedades profesionales de los trabajadores tanto del sector privado como de la Administración pública, y recaudadora de las primas correspondientes) ${ }^{17}$. En fin, en el modelo francés, la disgregación de la gestión es todavía mucho mayor, al estar diversificada por riesgos, trabajadores cubiertos (o «regímenes») y concretas actividades de gestión ${ }^{18}$, bastando indicar al respecto que sólo en el «régimen general» existen cuatro grandes «ramas [branches]» de gestión («prestaciones familiares», «seguro de enfermedad», «seguro de vejez» y «recaudación», cuyo control se confía a otras tantas entidades gestoras de ámbito nacional) ${ }^{19}$, contribuyendo a exacerbar esta impresión de disgregación el hecho de que la gestión del aseguramiento del desempleo se confíe a un ente paritario de naturaleza jurídica privada y ámbito nacional, denominado en acrónimo UNEDIC.

14 Sobre el tema, véase M. CINELLI, Diritto della Previdenza Sociale, $5^{\text {a }}$ ed., G. Giappichelli (Turín, 2003), págs. 122 y ss.; R. PESSI, Lezioni di Diritto della Previdenza Sociale. Parte Generale, $3^{\mathrm{a}}$ ed., CEDAM (Padua, 2004), págs. 340 y ss.; y M. PERSIANI, Diritto della Previdenza Sociale, 14ª ed., CEDAM (Padua, 2005), págs. 68 y ss.

15 Cfr. artículo 1.1 de la Ley núm. 88 de 9 marzo 1989; también, Decreto Legislativo núm. 479 de 30 junio 1994, y Decretos de la Presidencia de la República núm. 639 de 30 abril 1970 y núm. 366 de 24 septiembre 1997.

16 Cfr. artículo 4.2 del Decreto Legislativo núm. 479 de 1994, citado; también, el Decreto de la Presidencia de la República núm. 368 de 24 septiembre 1997.

17 Cfr. artículo 55.1 de la Ley núm. 88 de 1989, citada; también, Decreto Legislativo núm. 479 de 1994, citado, y Decreto de la Presidencia de la República núm. 367 de 24 septiembre 1997.

18 Véase J.-J. DUPEYROUX, M. BORGETTO, R. LAFORE y R. RUELLAN, Droit de la sécurité sociale, $15^{\mathrm{a}}$ ed., Dalloz (París, 2005), págs. 252 y ss.; y F. KESSLER, Droit de la protection sociale, $2^{\mathrm{a}}$ ed., Dalloz (París, 2005), págs. 74 y ss.

19 El complejo «Organigrama» de toda la Administración francesa de Seguridad Social puede consultarse en el sitio www.securite-sociale.fr. También, desde un punto de vista histórico, véase F. NETTER, La Sécurité sociale et ses principes, Dalloz (París, 2005), págs. 313 y ss. 
Esta última anomalía es consecuencia del hecho de que el aseguramiento del desempleo no aparezca contenido en Francia en el Código de la Seguridad Social, sino en el Código del Trabajo (que remite su regulación a «los acuerdos concluidos entre organizaciones representativas de empresarios y de trabajadores») ${ }^{20}$. Según estos acuerdos interprofesionales colectivos de ámbito nacional, el ente nacional gestor del desempleo contributivo es la UNEDIC o «Unión Nacional Profesional para el Empleo en la Industria y el Comercio [Union Nationale Professionnelle pour l'Emploi dans l'Industrie et le Commerce]» ${ }^{21}$. Por su parte, las cuatro grandes entidades gestoras públicas del «régimen general» francés de Seguridad Social son la «Caja Nacional del Seguro de Enfermedad de los Trabajadores Asalariados [Caisse Nationale de l'Assurance Maladie des Travailleurs Salariés]» ${ }^{22}$, la "Caja Nacional de Prestaciones Familiares [Caisse Nationale d'Allocations Familiales]» ${ }^{23}$, la «Caja Nacional del Seguro de Vejez de los Trabajadores Asalariados [Caisse Nationale d'Assurance Vieillesse des Travailleurs Salariés]» ${ }^{24}$ y, en cuanto a la recaudación, la «Agencia Central de los Organismos de Seguridad Social [Agence Centrale des Organismes de Sécurité Sociale]» ${ }^{25}$.

En Italia, aparte las tres entidades gestoras gigantes citadas ${ }^{26}$, que cuentan incluso con sus propios servicios de inspección (separados de la Inspección de Trabajo) ${ }^{27}$, hay cuatro entidades gestoras públicas más de previsión obligatoria (el IPSEMA o «Instituto de Previsión para el Sector Marítimo [Istituto di Previdenza peri il Settore Marittimo]», el ENPALS o «Ente Nacional de Previsión y Asistencia para los Trabajadores del Espectáculo [Ente Nazionale di Previdenza e Assistenza per i Lavoratori dello Spettacolo]», el INPDAI o «Instituto Nacional de Previsión para los Dirigentes de Empresas Industriales [Istituto Nazionale di Previdenza per i Dirigenti di Aziende Industriali]» y el ENAPPS o «Ente Nacional de Asistencia para los Pintores y Escultores, Músicos, Escritores y Autores Dramáticos [Ente Nazionale di Assistenza per i Pittori e Scultori, Musicisti, Scrittori ed Autori Drammatici]»), que coexisten con más de una docena de entidades gestoras de previsión obligatoria «privatizada» ${ }^{28}$.

20 Cfr. artículo L. 5422-20.

21 El Código del Trabajo regula el tema muy genéricamente en sus artículos L. 5427-1 a L. 5427-6, bajo el rótulo «Gestión confiada a organismos de derecho privado por la vía de acuerdo o convenio [Gestion confiée à des organismes de droit privé par voie d'accord ou de convention]». Más detalles, supra, Tema 6, §3.

22 Regulada en los artículos L. 221-1 a L. 221-5 del Código de la Seguridad Social. Sobre las Cajas «Primarias»y «Regionales» del Seguro de Enfermedad, véanse artículos L. 211-1 a L. 211-7 y artículos L. 215-1 a 215-4 del propio Código, respectivamente.

23 Regulada en los artículos L. 223-1 a L. 223-4 del Código de la Seguridad Social. Sobre las Cajas de Prestaciones Familiares, de actuación departamental, véanse artículos L. 212-1 y L. 212-2 del propio Código.

24 Regulada en los artículos L. 222-1 a L. 222-7 del Código de la Seguridad Social.

25 Cfr. artículo L. 225-1 del Código de la Seguridad Social. Esta Agencia coordina y controla la actuación de las URSSAF o «Uniones para la Recaudación de las Cotizaciones de Seguridad Social y de Prestaciones Familiares [Unions pour le Recouvrement des Cotisations de Sécurité Sociale et d'Allocations Familiales]», reguladas en el artículo L. 213-1 del propio Código.

26 El INPS posee más de 19 millones de asegurados y más de 14 millones de pensionistas (cfr. www.inps.it); por su parte, el INPDAP cubre más de 3 millones de asegurados y aproximadamente 2.5 millones de pensionistas (cfr. www.inpdap.it); en fin, el INAIL (cfr. www.inail.it) asegura a más de 18 millones de trabajadores.

27 Al respecto, véase A. ARUFE VARELA, Estudio comparado de la carrera administrativa de los funcionarios del sistema de Inspección de Trabajo y Seguridad Social en Europa, Servicio de Publicaciones del Ministerio de Trabajo y Asuntos Sociales (Madrid, 2007), págs. 94 y 100-102.

28 Acerca de todo esto, véase «Vigilanza sugli Enti previdenziali pubblici e privati e sui patronati» (y más en concreto, «enti vigilati») del enlace «Previdenza», accesible a través de www.lavoro.gov.it. 
En fin, el Libro Primero del Código alemán de Seguridad Social contiene el régimen jurídico genérico de la gestión de la Seguridad Social, afirmándose en él que «son competentes sobre las prestaciones de Seguridad Social las corporaciones, Administraciones y autoridades mencionadas en los parágrafos 18 a 29 (gestoras de prestaciones)» del propio Libro Primero ${ }^{29}$, aunque «los límites de su competencia se establecen en partes especiales de este Código» ${ }^{30}$. Las «partes» en cuestión son los restantes Libros del propio Código de Seguridad Social. En ellos, aparecen reguladas la «Agencia Federal de Empleo [Bundesagentur für Arbeit]», que es la entidad gestora del seguro de desempleo ${ }^{31}$; las «Cajas Sanitarias [Krankenkassen]», de hasta seis tipos distintos, que son las entidades gestoras del seguro de enfermedad común ${ }^{32}$; las «gestoras del seguro legal de pensiones [Träger der gesetzlichen Rentenversicherung]», que pueden ser regionales y federales ${ }^{33}$; las «gestoras del seguro de accidente [Unfallversicherungsträger]», que pueden ser de hasta nueve tipos distintos, aunque las más importantes son las treinta y cinco «Mutuas patronales industriales [gewerblichen Berufsgenossenschaften]» de accidentes de trabajo y enfermedades profesionales ${ }^{34}$, que cuenta incluso con sus propios servicios inspectores separados de la Inspección de Trabajo ${ }^{35}$; y las "Cajas de Dependencia [Pflegekassen]», respecto de las que el Libro Undécimo del Código de Seguridad Social afirma que «en cada Caja Sanitaria... se constituirá una Caja de Dependencia» ${ }^{36}$, siendo unas y otras Cajas «corporaciones jurídicas de Derecho público con autonomía administrativa» ${ }^{37}$.

§3. Frente a la disgregación de la gestión — dominante en los grandes sistemas continentales europeos de Seguridad Social-, otros sistemas nacionales europeos se caracterizan por su tendencia a la gestión unificada, que es una tendencia creciente, en el caso de Portugal, y una tendencia menguante, en cambio, en el caso de Gran Bretaña. En efecto, tradicionalmente el modelo británico de gestión de la Seguridad Social siempre fue con claridad un modelo de gestión unificada, puesto que el Ministerio responsable en materia de Seguridad Social resultaba ser la única Administración pública competente en materia de gestión de prestaciones y de gestión instrumental, con amparo en lo dispuesto en la «Ley de la Administración de Seguridad Social [Social Security

29 Cfr. parágrafo 12 , inciso primero.

30 Ibidem, inciso segundo.

31 Cfr. parágrafo 367 del Libro Tercero del Código de Seguridad Social.

32 Cfr. parágrafo 4 del Libro Quinto del Código de Seguridad Social.

33 Cfr. parágrafo 125 del Libro Sexto del Código de Seguridad Social.

34 Cfr. parágrafo 114 del Libro Séptimo del Código de Seguridad Social. Sobre su naturaleza jurídico-pública y sus funciones, véase A. ARUFE VARELA, Estudio comparado de la carrera administrativa de los funcionarios del sistema de Inspección de Trabajo y Seguridad Social en Europa, cit., pág. 43; y J. MARTÍNEZ GIRÓN, «Las mutuas patronales alemanas de accidentes de trabajo y su gestión "especializada" de los riesgos profesionales», en el vol. La gestión del sistema de Seguridad Social, Laborum (Murcia, 2009), págs. 207 y ss.

35 Al respecto, véase A. ARUFE VARELA, Estudio comparado de la carrera administrativa de los funcionarios del sistema de Inspección de Trabajo y Seguridad Social en Europa, cit., págs. 44 y ss.

36 Parágrafo 46, apartado 1, inciso segundo.

37 Parágrafo 46, apartado 2, inciso primero. 
Administration Act]» de 1992, que personifica dicha gestión en lo que genéricamente denomina el «Ministro [Secretary of State]» ${ }^{38}$. Ahora bien, a partir de 1999 — con la promulgación de la «Ley de Cotizaciones de Seguridad Social (Transferencia de Funciones, etc.) [Social Security Contributions (Transfer of Functions, etc.) Act]» de ese año ${ }^{39}$-, dicha tendencia tradicional se invirtió, al pasar a atribuirse lo relativo a la gestión recaudatoria de la Seguridad Social a la Hacienda Pública británica - y por tanto, desde 2005, a un departamento no ministerial del Gobierno del Reino Unido, casi equivalente del todo a nuestra Agencia Tributaria, denominado «Los Comisionados de Renta y Aduanas de Su Majestad [The Commissioners for Her Majesty's Revenue and Customs]» ${ }^{40}$, aunque todavía puede seguir hablándose de gestión unificada, puesto que la gestión del grueso de las prestaciones permanece centralizada en el Ministerio competente en materia de Seguridad Social (que es en la actualidad, y desde 2001, el «Departamento de Trabajo y Pensiones [Department for Work and Pensions]» ${ }^{41}$. Por lo que respecta al modelo portugués, su tendencia creciente a la unificación de la gestión es clara, pues tanto la gestión de prestaciones como la gestión instrumental competen a una sola entidad gestora, que es el Instituto Público actualmente denominado «Instituto de Seguridad Social, I.P.[Instituto da Segurança Social, I.P.]». El caso portugués tampoco ejemplifica, sin embargo, una unificación perfecta o total de la gestión, puesto que la gestión financiera compete a otro Instituto Público distinto - el «Instituto de Gestión Financiera de la Seguridad Social, I.P. [Instituto de Gestão Financieira da Segurança Social, I.P.]»—, que es el ente en el que se materializa la «caja única» del sistema portugués de Seguridad Social.

Respecto de Portugal, en la actualidad la norma decisiva sobre el tema es el Decretoley núm. 211/2006, de 27 octubre, que aprueba la Ley Orgánica del Ministerio del Trabajo y de la Solidaridad Social. De acuerdo con él, corresponde al citado Instituto de Gestión Financiera de la Seguridad Social, entre otras atribuciones, «desempeñar las funciones de tesorería única del sistema de seguridad social, asegurando y controlando los pagos» ${ }^{42}$.

38 Véase E. EAST, Social Security Law, McMillan (Londres, 1999), págs. 24 y ss.

39 Como se indicó en su momento, la compulsa de «versiones consolidadas» de las normas reguladoras de la Seguridad Social británico puede efectuarse a través de «Los volúmenes de Derecho», obrantes en el sitio de Internet del Departamento de Trabajo y Pensiones del Gobierno del Reino Unido (cfr. supra, Tema 3, §5).

40 Al respecto, véase la «Ley de Comisionados de Renta y Aduanas [Commissioners for Revenue and Customs Act]» de 2005.

41 Téngase en cuenta que la sección 192(6) de la citada Ley de la Administración de la Seguridad Social de 1992 afirma que «excepto lo que se prevé en esta sección, esta Ley no se extiende a Irlanda del Norte».

42 Artículo 20.2.f). 
Siempre según esta misma norma, al Instituto de Seguridad Social — cuyo sitio en Internet es http://195.245.197.202 ${ }^{43}$ - le compete, por su parte, «gestionar las prestaciones [gerir as prestações] del sistema de seguridad social y de sus subsistemas» ${ }^{44}, \mathrm{y}$ «recaudar los recursos [arrecadar as receitas] del sistema de seguridad social, asegurando el cumplimiento de las obligaciones contributivas» ${ }^{45}$.

A la Administración británica de la Seguridad Social le compete, según la citada Ley de la Administración de Seguridad Social de 1992, no sólo la gestión de prestaciones (actividad técnicamente denominada «adjudication») ${ }^{46}$ — que comprende tres grandes ramas («pensiones», «apoyo a la infancia» y «desempleo») gestionadas por los servicios correspondientes de la misma ${ }^{47}$-, sino también la vigilancia del cumplimiento de la legislación sustantiva relativa a las prestaciones a su cargo (actividad técnicamente denominada «exigencia del cumplimiento [enforcement]») ${ }^{48}$, por medio de inspectores específicos, que conforman un cuerpo distinto y separado del de Inspectores de Trabajo en sentido estricto ${ }^{49}$.

Por lo demás, la separación entre gestión de prestaciones y gestión recaudatoria no es radical en Gran Bretaña, pues a los citados Comisionados de Renta y Aduanas - cuyo sitio en Internet es www.hmrc.gov.uk - también les compete la gestión de ciertas prestaciones sustantivamente reguladas, como la generalidad de prestaciones británicas de Seguridad Social, en la vigente «Ley de Cotizaciones y Prestaciones de Seguridad Social [Social Security Contributions and Benefits Act $] \gg$ de $1992^{50}$, muy enmendada por otras varias (por ejemplo, en materia de desempleo, enfermedad o incapacidad).

§4. El Derecho de la Unión Europea refleja todas las disparidades de los diversos modelos nacionales europeos de gestión de la Seguridad Social, en el Reglamento (CE) núm. 987/2009 del Parlamento Europeo y del Consejo de 16 septiembre 2009, por el que se adoptan las normas de aplicación del Reglamento (CE) núm. 883/2004, sobre la coordinación de los sistemas de Seguridad Social $^{51}$. Como se sabe, se trata de la norma que materializa las obligacio-

43 Este sitio, a través de su enlace «A Segurança Social» (dentro de él «Organismos do Sector», luego «ISS,IP», y luego, «Quem Somos»), permite acceder a un utilísimo elenco de normativa sobre gestión de la Seguridad Social portuguesa, ubicado en «Enquadramento Legal».

44 Artículo 18.2.a).

45 Artículo 18.2.f).

46 Actualmente regulada en la «Ley de Seguridad Social [Social Security Act]» de 1998, que procedió a derogar la Parte II (secciones 17 a 10), precisamente rotulada «adjudication», de la citada Ley de la Administración de Seguridad Social de 1992. Sobre el tema, véase R. SAINSBURY, «Social Security Decision Making and Appeals», en N. HARRIS, Social Security Law in Context, Oxford University Press (Oxford-Nueva York, 2000), págs. 207 y ss.

47 Sus sitios de Internet son www.dwp.gov.uk (vía «About DWP», y luego, «The Pension Service»), www.csa.gov.uk y www.jobcentreplus.gov.uk, respectivamente.

48 Ésta es justamente la rúbrica de su Parte VI (secciones 110 a 121).

49 Al respecto, véase A. ARUFE VARELA, Estudio comparado de la carrera administrativa de los funcionarios del sistema de Inspección de Trabajo y Seguridad Social en Europa, cit., pág. 112.

50 Cfr. sección 8(1)(f) de la citada Ley de Cotizaciones de Seguridad Social (Transferencia de Funciones, etc.) de 1999.

51 Acerca del Derecho de la Unión Europea sobre el tema, vigente hasta 1 mayo 2010, véase J. MARTÍNEZ GIRÓN, A. ARUFE VARELA y X.M. CARRIL VÁZQUEZ, Derecho de la Seguridad Social, $2^{\mathrm{a}}$ ed., cit., pág. 296. 
nes de colaboración instrumental entre las Administraciones de Seguridad Social de todos los Estados miembros, a los efectos fundamentales - entre otros - de certificar las cotizaciones realizadas en cualquier Estado miembro que resulten imprescindibles para causar derecho a prestaciones en otro Estado miembro distinto, de tramitar en cualquier Estado miembro la solicitud de prestaciones causadas en otro Estado miembro diferente y, también, de posibilitar la llamada «exportación de prestaciones» (esto es, el cobro en un Estado miembro de prestaciones ya reconocidas en cualquier otro Estado de la Unión) ${ }^{52}$. De ahí que este Reglamento se haya visto obligado a regular —en su Anexo $4^{53}$ — una «base de datos», administrada por la Comisión Europea (donde constan los nombres de los diversos «órganos» gestores nacionales, «su función» y «su competencia respecto a los diferentes riesgos, tipos de prestaciones, regímenes y cobertura geográfica»), pero que lamentablemente no resulta accesible al ciudadano.

En efecto, el citado Anexo 4 afirma que «la información utilizada a efectos operativos y administrativos no será accesible al público», y además, que «la lengua de uso general de la base de datos será el inglés». Por supuesto, la transparencia era mucho mayor mientras estuvo vigente el Reglamento (CEE) núm. 574/1972 del Consejo, de 21 marzo $1972^{54}$.

§5. Sobre la base de que para los norteamericanos la «Seguridad Social» no es ni el desempleo, ni los accidentes de trabajo ni los planes privados de pensiones, sino sólo la materia regulada en la «Ley de Seguridad Social [Social Security Act]» de $1935^{55}$, el modelo norteamericano de gestión de la Seguridad Social constituye un ejemplo perfecto de lo que debe ser un modelo de gestión unificada. En efecto, toda la gestión se confía a una sola agencia federal, denominada «Administración de Seguridad Social [Social Security Administration]» ${ }^{56}$, a cuyo frente se encuentra «un Comisionado de Seguridad Social [Social Security Commissioner]... que será designado por el Presidente, por y

52 Ibidem, págs. 306-307.

53 Elaborado en cumplimiento de lo dispuesto en el artículo 88, apartado 4, del propio Reglamento.

54 Pues los Anexos del mismo (en especial, los números 2 [«Instituciones competentes»], 4 [«Organismos de enlace»] y 10 [«Instituciones y organismos designados por las autoridades competentes»]), de compulsa libremente accesible a todos, trazaban una radiografía casi perfecta de los diversos modelos nacionales europeos de gestión de la Seguridad Social.

55 Actualmente recopilada en el Capítulo 7 del Título 42 del Código de los Estados Unidos. Con carácter general y fijando límites, véase J.W. LITTLE, T.A. EATON y G.R. SMITH, Workers' Compensation. Cases and materials, $3^{\mathrm{a}}$ ed., West Publ. Co. (St. Paul-Minn., 1993), págs. 1 y ss.

56 En lo esencial, regulada en el Subcapítulo VII del Capítulo 7 del Título 42 del Código de los Estados Unidos, secciones 901 a 913. Sobre el tema, véase McCORMICK, H.L., Social Security. Claims and Procedures, vol. I, $4^{\mathrm{a}}$ ed., West Publ. Co. (St. Paul-Minn., 1991), págs. 9 y ss. 
con el consentimiento del Senado» ${ }^{57}$, por «un período de 6 años» ${ }^{58}$, y que «será responsable de ejercitar todos los poderes y de cumplir todos los deberes de la Administración [de Seguridad Social], y tendrá poder y control sobre todo el personal y actividades de la misma» ${ }^{59}$. Para hacerse una idea de la magnitud de estos poderes y deberes suyos, baste indicar que la Administración norteamericana de Seguridad Social tiene asegurados a más de 163 millones de «trabajadores» — tanto del sector privado, incluso autónomos, como del sector público (estatal, federal y local), sean funcionarios o no ${ }^{60}$ - y que paga prestaciones a más de 54 millones de beneficiarios, a cuyo efecto el Comisionado en cuestión adopta dos grandes tipos de decisiones: 1) las relativas a la gestión de prestaciones (benefit decisions), que se corresponden en lo esencial con los dos grandes programas de prestaciones - uno contributivo (el de prestaciones de vejez [old-age], de supervivientes [survivors] y de incapacidad [disability]), y el otro no contributivo (llamado de la renta de seguridad complementaria [supplemental security income]) - asignados a la Administración norteamericana de Seguridad Social ${ }^{61}$; y 2) las relativas a la gestión instrumental (o decisiones relativas a la vida laboral, esto es, a los «registros salariales [wage records]» de todos los trabajadores asegurados, individualizados por el «número de cuenta de Seguridad Social [Social Security account number]» que se asigna a cada uno de ellos) ${ }^{62}$, afirmándose legalmente que «los registros del Comisionado harán prueba a los efectos de plantear procedimientos ante el Comisionado de Seguridad Social o ante cualquier tribunal sobre la cuantía de los salarios pagados a una persona, y sobre las rentas autónomas ingresadas por una persona, y sobre los períodos en los cuales esos salarios se pagaron o esas rentas se ingresaron ${ }^{63}$.

Para poder cubrir todo el territorio de los Estados Unidos, la Administración de Seguridad Social — que tiene su «oficina central» en Baltimore (Maryland)— actúa

57 Sección 902(a)(1) del Título 42 del Código de los Estados Unidos.

58 Sección 902(a)(3) del Título 42 del Código de los Estados Unidos.

59 Sección 902(a)(4) del Título 42 del Código de los Estados Unidos.

60 Esto último se explica, con prolijidad infinita, en las secciones 404.1001 y siguientes de la Parte 404 del Capítulo III del Título 20 del Código de Reglamentos Federales.

61 Cfr. sección 901(b) del Título 42 del Código de los Estados Unidos.

62 El tema aparece regulado en la indeciblemente prolija sección 405(c) del Título 42 del Código de los Estados Unidos. Según el apartado (2)(C)(i) de este precepto, «es política de los Estados Unidos que cualquier Estado (o subdivisión política del mismo), en la administración de las leyes sobre impuestos, asistencia pública general, permiso de conducir o derecho de registrar vehículos de motor dentro de su competencia, pueda utilizar los números de cuenta de Seguridad Social otorgados por el Comisionado de Seguridad Social con el propósito de establecer la identificación de las personas afectadas por tales leyes».

63 Sección 405(c)(3), inciso primero, del Título 42 del Código de los Estados Unidos. 
descentralizadamente, por medio de «oficinas de distrito y oficinas funcionales», territorialmente agrupadas en diez «oficinas regionales» (con sedes en las ciudades de Atlanta, Boston, Chicago, Dallas, Denver, Filadelfia, Kansas City, Nueva York, San Francisco y Seattle) ${ }^{64}$.

Por supuesto, el Comisionado no decide materialmente todo lo que formalmente hablando es decisión suya, sino que otros lo hacen por él, con amparo en la «delegación de poderes y deberes del Comisionado» contenida en el Código de los Estados Unidos ${ }^{65}$.

Esto sentado, el camino que conduce a una «decisión final» por parte del propio Comisionado suele iniciarse con la respuesta por escrito y motivada de la Administración de Seguridad Social a una solicitud del beneficiario (conocida con el nombre de «determinación inicial [initial determination]»), afirmando respecto de ella el Código de Reglamentos Federales que «las determinaciones iniciales son las determinaciones que hacemos y que están sujetas a revisión administrativa y judicial» ${ }^{66}$, y además, que «una determinación inicial es vinculante salvo que usted exija una reconsideración dentro del plazo establecido, o nosotros revisemos la determinación inicial» ${ }^{67}$.

64 Todos estos datos y los estadísticos antes citados, en www.socialsecurity.gov.

65 Cfr. sección 405(1) del Título 42.

66 Sección 404.902, párrafo primero, de la Parte 404 del Capítulo III del Título 20. La sección 404.902 de esta misma Parte especifica, ordenándolas por letras [de la (a) a la (x)], qué concretas actuaciones administrativas de Seguridad Social tienen la naturaleza de «determinaciones iniciales».

67 Sección 404.905 de la Parte 404 del Capítulo III del Título 20. 


\section{TEMA 10 \\ EL CONTENCIOSO DE LA SEGURIDAD SOCIAL EN EUROPA Y EN LOS ESTADOS UNIDOS}

Sumario: §1. El contencioso dual español de la Seguridad Social. §2. El contencioso único británico y alemán de la Seguridad Social. §3. Los contenciosos duales italiano y portugués de la Seguridad Social. §4. El contencioso disgregado francés de la Seguridad Social. §5. El contencioso único norteamericano de la Seguridad Social.

\section{THEME 10 \\ SOCIAL SECURITY LITIGATION \\ IN EUROPE AND IN THE UNITED STATES}

Contents: $\$ 1$. The Spanish Social Security dual litigation. \$2. The British and German Social Security single litigation. \$3. The Italian and Portuguese Social Security dual litigation. \$4. The French Social Security dispersed litigation. \$5. The USA Social Security single litigation.

§1. En España, el peculiar modelo de gestión disgregada a que se ajusta la gestión de nuestra Seguridad Social condiciona radicalmente el contencioso relativo a la misma ${ }^{1}$, dando lugar a la existencia de un c ontencioso dual de la Seguridad Social. En efecto, la distinción entre gestión instrumental - a cargo, como se vio, de la Tesorería General de la Seguridad Social - y gestión de prestaciones - a cargo, como también se vio, de una multiplicidad de entidades gestoras distintas - se proyecta sobre el contencioso de la Seguridad Social, provocando: 1) que los pleitos relativos a la gestión instrumental sean pleitos contencioso-administrativos, al estar atribuido su conocimiento a los tribunales de dicho orden jurisdiccional; y 2) en cambio, que los pleitos relativos a la gestión de prestaciones sean pleitos laborales, al estar atribuido su conocimiento a los tribunales laborales. Lo confirma nuestra vigente Ley de Procedimiento Laboral de 1995. De un lado, al

1 Sobre dicho modelo de gestión, véase supra, Tema 9, §1. 
declarar que «los órganos jurisdiccionales del orden social conocerán de las cuestiones litigiosas que se promuevan», entre un total de hasta dieciocho cuestiones litigiosas distintas, «en materia de Seguridad Social, incluida la protección por desempleo» ${ }^{2}$. De otro lado, al ordenar que «no conocerán los Órganos Jurisdiccionales del Orden Social» — sino los tribunales del orden jurisdiccional contencioso-administrativo-, entre otras varias cuestiones litigiosas, «de las resoluciones y actos dictados en materia de inscripción de empresas, formalización de la protección frente a riesgos profesionales, tarifación, cobertura de la prestación de incapacidad temporal, afiliación, alta, baja y variaciones de datos de trabajadores, así como en materia de liquidación y gestión recaudatoria» ${ }^{3}$, añadiendo que «asimismo, quedan excluidas de su conocimiento las resoluciones en materia de gestión recaudatoria dictadas por su respectiva entidad gestora en el supuesto de cuotas de recaudación conjunta con las cuotas de Seguridad Social, así como las relativas a actas de liquidación y de infracción» ${ }^{4}$.

La división en dos grandes porciones de nuestro contencioso de la Seguridad Social es reciente. Fue operada por la Ley 52/2003, de 10 diciembre, con efectos de 1 enero 2004 ${ }^{5}$, habiendo anunciado ya la Sala de lo Social de nuestro Tribunal Supremo que planteará en su momento cuestión de inconstitucionalidad contra la misma, al tratarse de una Ley ordinaria vulneradora de la atribución de competencia efectuada a la jurisdicción laboral por el artículo 9.5 de la Ley Orgánica 6/1985, de 1 julio, del Poder Judicial ${ }^{6}$, habiendo admitido a trámite el Tribunal Constitucional una cuestión de inconstitucionalidad sobre el tema, pero planteada en 2008 por la Sala de lo Contencioso-Administrativo de Sevilla del Tribunal Superior de Justicia de Andalucía ${ }^{7}$. Téngase en cuenta que el contencioso de la Seguridad Social de los funcionarios públicos (incluido el contencioso sobre gestión de prestaciones) es, en nuestro país, de competencia de los tribunales contencioso-administrativos ${ }^{8}$.

§2. A diferencia de lo que sucede en España, en Gran Bretaña su peculiar modelo de gestión dual de la Seguridad Social ${ }^{9}$ no se proyecta sobre el contencioso de esta última, dada la

\footnotetext{
2 Artículo 2.b).

3 Artículo 3.1.b), párrafo primero.

4 Ibidem, párrafo segundo.

5 Véase A. ARUFE VARELA «La posición procesal de la Tesorería General de la Seguridad Social en pleitos sobre gestión de prestaciones, tras la Ley 52/2003, de 10 de diciembre», Tribuna Social, núm. 178 (2005), págs. 16 y ss.

6 Véase Sentencia de la Sala de lo Social del Tribunal Supremo de 21 diciembre 2004 (Westlaw Aranzadi, referencia RJ 2005/1235).

7 Cfr. Providencia de 16 septiembre 2008 (Boletín Oficial del Estado de 30 septiembre 2008).

8 Véase J. MARTÍNEZ GIRÓN, A. ARUFE VARELA y X.M. CARRIL VÁZQUEZ, Derecho de la Seguridad Social, 2a ed., Netbiblo (A Coruña, 2008), págs. 311-312 y 320.

9 Véase supra, Tema $9, \S 2$.
} 
existencia allí de un contencioso único de la Seguridad Social. Este contencioso británico único —en consecuencia, común para la impugnación de decisiones sobre gestión instrumental y sobre gestión de prestaciones - está dividido en dos fases (cuasi-jurisdiccional y jurisdiccional), coincidiendo la jurisdiccional en todo con el contencioso laboral británico, regulado sustancialmente en la «Ley de Tribunales, Cortes y Exigencia del Cumplimiento [Tribunals, Courts and Enforcement Act]» de 2007, ya vista en su momento ${ }^{10}$. Y lo mismo sucede en Alemania, donde su modelo de gestión disgregada de la Seguridad Social ${ }^{11}$ tampoco se proyecta en absoluto sobre el contencioso de la Seguridad Social. Este último aparece regulado en la «Ley del Tribunal de Seguridad Social [Sozialgerichtsgesetz]» de 1953 — que es a la vez una ley orgánica y una ley procesal ${ }^{12}$ _, de acuerdo con la cual el contencioso alemán de la Seguridad Social es un contencioso único. De este contencioso conocen los tribunales de la «jurisdicción de Seguridad Social [Sozialgerichtsbarkeit]»" ${ }^{13}$, que son de tres tipos distintos: 1) los «Tribunales de Seguridad Social [Sozialgerichte]», competentes para decidir «en primera instancia todos los conflictos pertenecientes al contencioso de los tribunales de la jurisdicción de Seguridad Social» ${ }^{14}$; 2) los «Tribunales de Seguridad Social de Estado federado [Landessozialgerichte]» —uno por cada uno de los dieciséis Estados federados alemanes, salvo en los casos de Berlín-Brandeburgo y Baja Sajonia-Bremen, que comparten uno-, competentes para conocer del recurso de «apelación [Berufung]» frente a las resoluciones de los Tribunales de Seguridad Social de primera instancia $^{15}$; y 3) el «Tribunal Federal de Seguridad Social [Bundessozialgericht]» — con sede en la ciudad de Kassel (Estado Federado de Hesse)competente para conocer del recurso de «casación [Revision]» frente a las resoluciones dictadas en apelación por los Tribunales Estatales de Seguridad Social ${ }^{16}$.

10 Véase supra, Tema 8, §3.

11 Véase supra, Tema 9, \$2.

$12 \mathrm{Su}$ Parte Primera regula la «Organización de los Tribunales», parágrafos 1 a 59, mientras que su Parte Segunda regula el «Proceso», teniendo en cuenta que esta última regulación lo es de los procesos de Seguridad Social de cognición (bajo el rótulo «Preceptos procesales comunes [Gemeinsame Verfahrenvorschriften]», parágrafos 60 a 142a), de los procesos de Seguridad Social de impugnación (bajo el rótulo «Recurso [Rechtsmittel]», parágrafos 143 a 178a) y de los procesos de Seguridad Social de ejecución (bajo el rótulo «Costes y Ejecución [Kosten und Vollstreckung]», parágrafos 183 a 201).

13 Véase W. HENNIG y otros, Sozialgerichtsgesetz. Kommentar mit Nebenrecht, Tomo 1, Luchterhand (Neuwied, 2004), en relación con el comentario al parágrafo 1.

14 Cfr. parágrafo 8.

15 Cfr. parágrafo 143.

16 Cfr. parágrafo 39. 
Siempre según la Ley citada, todos estos Tribunales alemanes de Seguridad Social son órganos jurisdiccionales colegiados, integrados por una pluralidad de «salas» ordinarias ${ }^{17}$. Estas últimas se denominan «cámaras [Kammern]», en la hipótesis de los Tribunales de Seguridad Social de primera instancia ${ }^{18}$, y «senados [Senate]», en la hipótesis de los Tribunales de Seguridad Social de Estado federado ${ }^{19}$. Se trata de «salas» especializadas por razón de la materia, existiendo en cada Tribunal al menos cuatro, competentes para conocer de los litigios sobre protección por desempleo, incapacidades laborales, relaciones entre el personal facultativo y sus instituciones sanitarias empleadoras y, por último, del resto de pleitos sobre aseguramiento social. A su vez, todas estas «salas» están formadas por dos tipos distintos de jueces. De un lado, los «jueces profesionales [Berufsrichter]» o jueces de carrera, que presiden siempre la «Sala» ordinaria correspondiente ${ }^{20}$; y de otro lado, los «jueces electivos [ehrenamtliche Richter]», elegidos de entre ciudadanos incluidos en unas listas - cuya elaboración regula pormenorizadamente la Ley ${ }^{21}$ - y que deben cumplir, entre otros requisitos más ordinarios (edad, nacionalidad, probidad, etc.), también el específico de pertenecer al sector o "círculo [Kreis]» de los potencialmente afectados por la concreta materia litigiosa a enjuiciar por la «sala» de que se trate ${ }^{22}$.

Téngase en cuenta — por excepción - que ciertos pleitos de Seguridad Social no son de competencia de estos Tribunales, sino de los Tribunales contencioso-administrativos alemanes. Es el caso, por ejemplo, de los pleitos de Seguridad Social de los funcionarios públicos $^{23}$. La tendencia, sin embargo, es la de incrementar progresivamente el ámbito material del contencioso de los Tribunales de Seguridad Social — sobre todo a medida que va completándose la codificación del Derecho sustantivo de la Seguridad Social—, probándolo el dato de que la promulgación del Libro Décimosegundo (y penúltimo, en principio) del Código de Seguridad Social (rotulado «Asistencia Social [Sozialhilfe]») haya provocado - con fecha de efectos de 1 enero 2005 - la atribución de competencia a los Tribunales de Seguridad Social, en detrimento de la competencia de los Tribunales de lo contenciosoadministrativo, para conocer de «los asuntos de la asistencia social» ${ }^{24}$.

En Gran Bretaña, las decisiones de Los Comisionados de Renta y Aduanas de $\mathrm{Su}$ Majestad - competentes como regla, recuérdese, en materia de gestión instrumental ${ }^{25}$ - y las decisiones del Ministro de Trabajo y Pensiones - competente como regla, recuérdese también, en materia de gestión de prestaciones ${ }^{26}$ - pueden apelarse cuasi-jurisdiccionalmente, primero ante el denominado «Tribunal de Primer Nivel [First-Tier Tribunal]» ${ }^{27}$, y luego — si se obtiene permiso para apelar — ante el denominado «Tribunal Superior [Upper Tribunal $] \gg^{28}$. Agotada esta fase, se abre el contencioso propiamente jurisdiccional, idéntico

17 En el Tribunal Federal de Seguridad Social existe, además, una «Sala General [Großer Senat]», que resuelve por medio de «auto $[$ Beschluß]» y que garantiza la unificación de doctrina en las diversas «salas» ordinarias del mismo (cfr. parágrafo 41).

18 Cfr. parágrafos 10 y 12.

19 Cfr. parágrafos 31 y 33, y 40, respectivamente.

20 Cfr. parágrafos $9,30,33$ y 40 .

21 Cfr. parágrafos 14 y 46.

22 Cfr. parágrafos 16,35 y 47.

23 Cfr. parágrafo 126, apartado 1, de la «Ley Marco sobre la Unificación del Derecho de Funcionarios [Rahmengesetz zur Vereinheitlichung des Beamtenrechts]», o BRRG, de 1957.

24 Cfr. parágrafo 51, apartado 1, número 6a, de la Ley del Tribunal de Seguridad Social.

25 Véase supra, Tema 9, \$2.

26 Ibidem.

27 Cfr. secciones 11(2)(b) y 19 de la «Ley de Cotizaciones de Seguridad Social (Transferencia de funciones, etc.)» de 1999.

28 Cfr. «Ley de Tribunales, Cortes y Exigencia del Cumplimiento» de 2007, sección 11. 
al laboral, primero - supuesto que se haya obtenido permiso para recurrir lo decidido por el recién citado «Tribunal Superior»— ante la «Corte de Apelación [Court of Appeal]》, y luego - previa obtención del permiso de rigor-, ante la «Corte Suprema del Reino Unido [Supreme Court of the United Kingdom]». El caso Szoma (FC) v. Secretary of State for the Department of Work and Pensions, fallado el 27 octubre 2005, fue uno de los contadísimos casos decididos por la Cámara de los Lores (extinta en cuanto que órgano jurisdiccional supremo, en 2009, según se vio) ${ }^{29}$ en que se aborda frontalmente el tratamiento jurisdiccional de asuntos de Seguridad Social.

§3. Al igual que ocurre en España, otros dos países europeos también se ajustan a un modelo dual de contencioso de la Seguridad Social. Ahora bien, en estos otros casos se trata de una dualidad condicionada por razones distintas de la separación neta, existente en nuestro país, entre gestión de prestaciones y gestión instrumental. En el caso de Ita lia ${ }^{30}$, la dualidad está condicionada por el sector económico a que pertenezca el beneficiario, pues de los pleitos de Seguridad Social de los beneficiarios del sector privado (al igual que de los pleitos laborales) conocen los tribunales civiles ${ }^{31}$, mientras que de los pleitos de los beneficiarios al servicio de las Administraciones públicas conocen los tribunales de la jurisdicción contencioso-administrativa $^{32}$. En el caso de Portuga 1, dada la asimilación allí existente entre cotizaciones sociales e impuestos, la regla general es que de los pleitos sobre gestión recaudatoria conocen los tribunales tributarios, mientras que del resto de pleitos de Seguridad Social conocen los tribunales de la jurisdicción contencioso-administrativa ${ }^{33}$.

29 Véase supra, Tema $8, \mathbf{\$ 3}$.

30 Desde un punto de vista histórico, véase E. CATALDI, Studi di Diritto della Previdenza Sociale, Giuffrè (Milán, 1958), págs. 531 y ss.

31 Véase supra, Tema 8, \$2.

32 Téngase en cuenta, respecto de los pleitos sobre pensiones de los empleados públicos, que no son de competencia de los tribunales contencioso-administrativos en sentido estricto, sino del «Tribunal de Cuentas [Corte dei Conti]», que posee jurisdicciones descentralizadas (repartidas por toda Italia) y secciones jurisdiccionales centrales de apelación (con sede en Roma), las cuales conocen en última instancia de los recursos contra las «sentencias» de las secciones descentralizadas, ajustándose a las normas procesales contenidas en la Ley núm. 205, de 21 julio 2000, de disposiciones en materia de justicia administrativa (cfr., especialmente, sus artículos 5.1 y 5.2 ).

33 Al respecto, véase artículo 77 de la Ley núm. 4/2007, de 16 enero, que «aprueba las bases generales del sistema de seguridad social [bases gerais do sistema de segurança social]», a cuyo tenor «las acciones y omisiones de la Administración en el ámbito del sistema de seguridad social son susceptibles de reacción contenciosa en los términos del Código de Proceso en los Tribunales Administrativos [nos Tribunais Administrativos]», teniendo en cuenta que estos términos aparecen contenidos en las dos leyes siguientes: desde una perspectiva orgánica, la Ley núm. 13/2002, de 19 febrero, por la que se aprueba el «Estatuto de los Tribunales Administrativos y Fiscales»; y desde una perspectiva procesal, la Ley núm. 15/2002, de 22 febrero, por la que se aprueba el «Código de Proceso en los Tribunales Administrativos». La competencia de los tribunales tributarios para conocer del contencioso relativo a la gestión recaudatoria de la Seguridad Social viene siendo confirmada por reiterada jurisprudencia del Supremo Tribunal Administrativo portugués (cfr., por ejemplo, su Sentencia de 11 febrero 2004 [proceso 01927/03], o su Sentencia de 25 febrero 2009 [proceso 047/09]). 
En Portugal, téngase en cuenta — por excepción - que los pleitos sobre accidentes de trabajo y enfermedades profesionales no son de competencia de los tribunales contencioso-administrativos, sino de competencia de los Tribunales laborales ${ }^{34}$, lo que explica la regulación sustantiva del tema no en la legislación portuguesa de Seguridad Social, sino en su Código del Trabajo de 2009, artículos 281-284 ${ }^{35}$.

Respecto de Italia, a pesar de la confusión orgánica entre los contenciosos laboral y de Seguridad Social del sector privado (ambos, como se dijo, verdadero contencioso civil), el de la Seguridad Social del sector privado posee peculiaridades procesales, que lo singularizan frente al contencioso laboral ${ }^{36}$.

De entre estas peculiaridades, existen dos de cajón. En primer lugar, la necesidad de impugnación previa en vía administrativa de los actos administrativos dictados por las entidades gestoras ${ }^{37}$. En segundo lugar, la prohibición de recurrir a mecanismos extrajudiciales de solución de conflictos, pues «en las controversias en materia de previsión y de asistencia obligatorias carecen de toda eficacia vinculante, sustantiva y procesal, los arbitrajes rituales, los arbitrajes irrituales, los de colegios de médicos, cualquiera que sea su naturaleza jurídica, y las conciliaciones extrajudiciales ocurridas antes o después del ejercicio de la acción judicial» ${ }^{38}$.

§4. En cuanto a Francia, su modelo disgregado de gestión de la Seguridad Social condiciona, en parte, la existencia de un modelo asimismo disgregado de contencioso de la Seguridad Social ${ }^{39}$. En efecto, de un lado, existe allí un contencioso «general» de la Seguridad Social, del que conocen en primera instancia los denominados «Tribunales de Asuntos de Seguridad Social [Tribunaux des Affaires de Sécurité Sociale]», competentes para resolver la generalidad de pleitos suscitados por la interpretación y aplicación del Código de la

34 Al respecto, véase artículo 118.c) de la Ley núm. 52/2008, de 28 agosto, que aprueba la Ley de Organización y Funcionamiento de los Tribunales Judiciales.

35 Según B.G.L. XAVIER, Direito do Trabalho. Ensinar e Investigar, Universidade Católica Editora (Lisboa, 2005), págs. 41-42, «aunque de la Constitución y de las orientaciones generales de las Leyes de seguridad social parezca resultar que los accidentes tienen su lugar en la Seguridad Social, el riesgo relativo a "accidentes de trabajo" está configurado entre nosotros como perteneciendo al Derecho del Trabajo y está tratado pormenorizadamente en el Código del Trabajo».

36 De ahí la separación neta en el Código de Procedimiento Civil italiano de 1940, de un lado, de la regulación «De las controversias individuales de trabajo», artículos 409 a 441; y de otro lado, de la regulación «De las controversias en materia de previsión y de asistencia obligatorias [Delle controversie in materia di previdenza e di assistenza obligatorie]», artículos 442 a 473.

37 Cfr. artículo 443, párrafo primero, del Código de Procedimiento Civil.

38 Cfr. artículo 9 de la Ley núm. 533, de 11 agosto 1973, sobre «regulación de las controversias individuales de trabajo y de las controversias en materia de previsión y de asistencia obligatorias», en la parte relativa a la modificación que opera del artículo 147 de las disposiciones de desarrollo del Código de Procedimiento Civil, aprobadas por Real Decreto núm. 1368, de 18 diciembre 1941.

39 Esta fragmentación trae causa, además, de la regulación fragmentaria que también posee en Francia el Derecho sustantivo de la Seguridad Social, al aparecer regulado en hasta tres Códigos distintos, que son el Código de la Seguridad Social, el Código de la Acción Social y de las Familias y, respecto de la protección por desempleo, el Código del Trabajo. Sobre el tema, la doctrina francesa viene denunciando que aunque «la unificación de los regímenes de seguridad social no es sin duda realizable hoy», la «de los contenciosos no parece inconcebible ni irrealizable, aunque sólo fuera para permitir al justiciable saber a qué juez dirigirse» (cfr. J.-P. CHAUCHARD, Manuel de Droit de la Sécurité Sociale, 2a ed., LGDJ [París, 1998], pág. 227). 
Seguridad Social ${ }^{40}$. Pero junto a este contencioso «general» existen al menos otros tres contenciosos más, que son: 1) el contencioso «técnico» de la Seguridad Social, relativo en lo esencial a la determinación del grado de la incapacidad derivada de riesgos profesionales o comunes, del que conocen en primera instancia los «Tribunales del Contencioso de la Incapacidad [Tribunaux du Contentieux de l'Incapacité]» ${ }^{41}$; 2) el contencioso de la asistencia social, del que conocen en primera instancia los tribunales denominados «Comisiones Departamentales de Asistencia Social [Commissions Départamentales d'Aide Sociale]» ${ }^{42}$; y 3) el contencioso del desempleo, a su vez fragmentado en otros dos ${ }^{43}$, pues de los pleitos sobre desempleo contributivo ${ }^{44}$ conocen los tribunales civiles ${ }^{45}$, mientras que de los pleitos sobre desempleo no contributivo ${ }^{46}$ conocen los tribunales contencioso-administrativos ${ }^{47}$.

Al igual que ocurre en Alemania, los citados Tribunales de Asuntos de Seguridad Social son también tribunales escabinos, pues están formados por un magistrado — que preside el tribunal, en todo caso ${ }^{48}$ - y, como regla general, por dos vocales o «asesores [asseseurs]» (uno «en representación de los trabajadores asalariados», y el otro «en representación de los empresarios y trabajadores independientes») ${ }^{49}$ designados de entre las personas incluidas en una «lista», cabiendo que la propuesta de designación de los mismos sea realizada por «las organizaciones patronales y obreras más representativas» ${ }^{50}$.

Ahora bien, una vez agotada la primera instancia, el contencioso «general» de la Seguridad Social y el contencioso laboral se confunden orgánica y procesalmente, pues «la corte de apelación decide las apelaciones interpuestas contra las decisiones dadas por

40 Cfr. artículos L. 142-1 a L. 142-9, y R. 142-1 a R. 142-52, del Código de la Seguridad Social.

41 Cfr. artículos L. 143-1 a L. 143-10, y R. 143-1 a R. 143-42, del Código de la Seguridad Social.

42 Cfr. artículos L. 134-1 a L. 134-10, y R. 134-1 a R. 134-12, del Código de la Acción Social y de las Familias.

43 Véase J. SAVATIER, «Contentieux de l'assurance chômage», Droit Social, núm. 12 (2000), págs. $1130 \mathrm{y}$ ss.

44 Cuya prestación estelar es la llamada «prestación de seguro [allocation d'assurance]», financiada «por las contribuciones de los empresarios y de los trabajadores» (cfr. artículo L. 5422-9 del Código del Trabajo).

45 Al respecto, véase Sentencia de la Sala de lo Social de la Corte de Casación de 14 junio 2005 (recurso núm. 03-19136); también, negando al tiempo la competencia de la jurisdicción contencioso-administrativa, Sentencia de la Sala de lo Social de la Corte de Casación de 22 febrero 2005 (recurso núm. 03-13942).

46 Cuya prestación estelar es la llamada "prestación de solidaridad [allocation de solidarité]», a cargo del «fondo de solidaridad» mencionado por el artículo L. 5423-24 del Código del Trabajo.

47 Véanse, por ejemplo, Sentencia de la Corte Administrativa de Apelación de Burdeos de 14 mayo 1998 (contencioso núm. 95BX30182), Sentencia de la Corte Administrativa de Apelación de Nantes de 11 abril 2002 (contencioso núm. 98NT02142) y Sentencia de la Corte Administrativa de Apelación de Lyon de 14 octubre 2003 (contencioso núm. 03LY01007).

48 La regla general es que «el tribunal de asuntos de seguridad social está presidido por un magistrado de la sede del tribunal de gran instancia del distrito en que el tribunal de asuntos de seguridad social tiene su sede» (artículo L. 142-4, párrafo primero, del Código de la Seguridad Social).

49 Ibidem.

50 Cfr. artículo L. 142-5 del Código de la Seguridad Social. 
el tribunal de asuntos de seguridad social» ${ }^{51}$, teniendo en cuenta que «la apelación se lleva ante la sala de lo social de la corte de apelación [l'appel est portée devant la chambre sociale de la cour d'appel]» ${ }^{52}$, cuyas resoluciones —al igual que ocurre en el contencioso laboral- pueden luego «ser atacadas ante la Corte de Casación» ${ }^{53}$.

Además, en Francia es claro - a diferencia de lo que sucede en España o Alemaniaque el contencioso «general» de la Seguridad Social comprende, también, el contencioso de la Seguridad Social de los funcionarios públicos ${ }^{54}$.

§5. En los Estados Unidos de Norteamérica, al igual que sucede en Alemania, también existe un contencioso único de la S e guridad S o ci a l, aunque aquí dividido en dos fases sucesivas perfectamente diferenciadas. La primera fase se corresponde con el contencioso cuasi-jurisdiccional de la Seguridad Social, a través del cual se tramitan las reclamaciones contra las decisiones «iniciales» de la Administración norteamericana de Seguridad Social ${ }^{55}$, que son reclamaciones de las que sucesivamente conocen un «funcionario reconsiderador [reconsiderator official] ${ }^{56}$, un «Juez de Derecho Administrativo [Administrative Law Judge]» ${ }^{57}$ y, por último, el «Consejo de Apelaciones [Appeals Council]» de la propia Administración de Seguridad Social ${ }^{58}$. La segunda fase

51 Artículo L. 142-2, párrafo segundo, del Código de la Seguridad Social. Téngase en cuenta, sin embargo, que no cabe recurso de apelación si la cuantía de lo litigado no excede de 4.000 euros (cfr. artículo R. 142-25 del Código de la Seguridad Social.

52 Artículo R. 142-28, párrafo séptimo, del Código de la Seguridad Social.

53 Cfr. artículo L. 144-4 del Código de la Seguridad Social.

54 Cfr. artículo R. 711-20 del Código de la Seguridad Social. Por eso, afirma J.-P. CHAUCHARD, Manuel de Droit de la Sécurité Sociale, $2^{\mathrm{a}}$ ed., cit., pág. 215, nota 2, que la complejidad de este contencioso trae causa de la complejidad de la propia legislación a que se refiere, que es «compleja porque los textos son innumerables; compleja aún porque la influencia del derecho privado (derecho civil, derecho de los seguros, procedimiento civil) es permanente, sino inevitable hoy; compleja, en fin, en razón de la pluralidad de regímenes de seguridad social [funcionarios, trabajadores del mar, mineros, etc.] que obedecen, cada uno por su lado, a reglas propias, incluso si la influencia del régimen general de los trabajadores asalariados es en ellos preponderante».

55 Sobre estas «determinaciones iniciales», véase supra, Tema 9, §5.

56 La «reconsideración [reconsideration]» es, siempre en asuntos de Seguridad Social, un trámite expresamente mencionado por el Código de los Estados Unidos [cfr. sección 405(b)(2) de su Título 42] y prolijamente regulado en el Código de Reglamentos Federales (cfr., especialmente, secciones 404.909 a 404.921 de la Parte 404 del Capítulo III de su Título 20). No equivale del todo a nuestro recurso de reposición, pues se trata de una actividad realizada siempre por un funcionario distinto de la concreta persona que materialmente se encargó de adoptar la determinación inicial a reconsiderar.

$57 \mathrm{La}$ «audiencia [hearing]» ante él es, también, un trámite expresamente mencionado por el Código de los Estados Unidos [cfr. sección 405(b)(1) de su Título 42] e igualmente regulado con prolijidad agobiante por el Código de Reglamentos Federales (cfr., especialmente, las secciones 404.929 a 404.968 de la Parte 404 del Capítulo III de su Título 20). Este trámite permite hablar de la existencia de un verdadero contencioso cuasi-jurisdiccional de la Seguridad Social norteamericana, pues dicho «Juez de Derecho Administrativo» - así llamado porque se supone que actúa con toda independencia e imparcialidad, aunque se trate de un funcionario del Gobierno federal - no forma parte del personal al servicio de la Administración de Seguridad Social.

58 La intervención de este «Consejo» ya no es, sin embargo, un trámite que aparezca expresamente previsto en el Código de los Estados Unidos, lo que explica que la Administración de Seguridad Social se plantee la conveniencia de suprimirlo, indicando al respecto el Código de Reglamentos Federales que experimentalmente se está «probando [testing]» su «eliminación» en relación con los «procedimientos de determinación de la incapacidad» (cfr. sección 404.906 de la Parte 404 del Capítulo III de su Título 20). 
se corresponde, por su parte, con el contencioso jurisdiccional de la Seguridad Social, relativo a la posibilidad de impugnar las decisiones del citado «Consejo de Apelaciones» (en cuanto que «decisiones finales [final decisions]» de la Administración de Seguridad Social, formalmente adoptadas por el Comisionado que dirige la misma) ${ }^{59}$ ante las Cortes federales ordinarias de Derecho común, que son - como se vio- las Cortes federales de Distrito (United States District Courts), las Cortes de Apelaciones de los trece circuitos federales (United States Courts of Appeals) y, por último, la Corte Suprema de los Estados Unidos (United States Supreme Court) ${ }^{60}$.

El precepto clave sobre el contencioso norteamericano de la Seguridad Social es la larguísima sección 405(g) del Título 42 del Código de los Estados Unidos, de entre cuyos nueve incisos el más importante es el primero, en el que se afirma - compendiando la esencia del tema- que «toda persona, tras cualquier decisión final del Comisionado de Seguridad Social [any final decision of the Commissioner of Social Security] emanada tras una audiencia en la que haya sido parte, con independencia de la cuantía de lo litigado, puede obtener la revisión de tal decisión por medio de una acción civil [review of such decision by a civil action] ejercitada dentro de los sesenta días siguientes al envío por correo de la notificación de dicha decisión o dentro del tiempo posterior que pueda permitir el Comisionado de Seguridad Social» ${ }^{61}$.

Reflexionando sobre el citado contencioso cuasi-jurisdiccional (y más en concreto, sobre la reclamación del beneficiario ante el «Juez de Derecho Administrativo», que incluso puede enjuiciarla mediante comparecencia del propio beneficiario «en persona o por vídeo teleconferencia [by video teleconferencing]») ${ }^{62}$, la jurisprudencia federal norteamericana sostiene que la actuación de dicho «Juez» tiene una naturaleza «inquisitiva más que contenciosa [inquisitorial rather than adversarial]», pues su deber es «investigar los hechos y desarrollar los argumentos tanto a favor como en contra de la concesión de prestaciones», y porque «el Comisionado no tiene representante ante el Juez de Derecho Administrativo para oponerse a la reclamación de prestaciones» ${ }^{63}$.

Sobre la base de que el Código de los Estados Unidos regula minuciosamente el tema de los honorarios que los abogados pueden cobrar a los beneficiarios por la llevanza de asuntos jurisdiccionales de Seguridad Social - supuesto que ganen el pleito (en caso contrario, no cobran), nunca cabe que cobren «por encima del 25 por ciento del total de las prestaciones atrasadas y debidas [not in excess of 25 percent of the total past-due

59 Sobre este «Comisionado», véase supra, Tema 9, §5.

60 Sobre estas Cortes, véase supra, Tema $8, \S 4$.

61 A este mismo precepto remite - a propósito de las decisiones finales del Comisionado en materia de gestión instrumental - la sección 405(c)(3), inciso primero, del Título 42 del Código de los Estados Unidos.

62 Cfr. sección 404.929, inciso cuarto, de la Parte 404 del Capítulo III del Título 20 del Código de Reglamentos Federales.

63 Cfr. caso J. Sims v. K.S. Apfel, Commissioner of Social Security, fallado por la Corte Suprema de los Estados Unidos el 5 junio 2000 (referencia 530 US 103). 
benefits] ${ }^{64}$ - , la Corte Suprema de los Estados Unidos —en el caso Gary Gisbrecht et al. v. J.A.B. Barnhart, Commissioner of Social Security, fallado el 28 mayo $2002^{65}$ — ha declarado que «dentro del límite del 25 por ciento..., el abogado del demandante ganador debe mostrar que los honorarios que pretende son razonables por los servicios prestados», no siéndolo «si las prestaciones [de Seguridad Social reconocidas] son grandes en comparación con la cantidad de tiempo de asesoramiento empleado en el caso».

64 Cfr. sección 406(b)(1)(A) del Título 42. En la vía cuasi-jurisdiccional, la intervención de abogado no resulta preceptiva, aunque si interviene, debe presentar su minuta de honorarios al Comisionado de Seguridad Social antes de iniciarse las actuaciones cuasi-jurisdiccionales en cuestión, debiendo tenerse en cuenta que el cobro de la minuta requiere de «aprobación» por el propio Comisionado, una vez que el beneficiario-cliente obtiene una resolución administrativa favorable a sus intereses [cfr., acerca de esto último, sección 406(a)(2)(A) del Título 42 del Código de los Estados Unidos].

65 Referencia 535 US 789. 


\section{PARTE TERCERA}

\section{DERECHOS, LIBERTADES \\ Y PRINCIPIOS}

THIRD PART

\section{RIGHTS, FREEDOMS \\ AND PRINCIPLES}




\section{TEMA 11 \\ LA LIBERTAD SINDICAL EN EL ORDENAMIENTO COMUNITARIO, EN LAS LEGISLACIONES Y PRÁCTICAS NACIONALES EUROPEAS, Y EN LA LEGISLACIÓN DE LOS ESTADOS UNIDOS}

Sumario: §1. La libertad sindical y el reconocimiento de sólo ciertos sindicatos como interlocutores sociales. \$2. Los modelos nacionales europeos (francés, español e italiano) de reconocimiento legal. §3. Los modelos nacionales europeos (alemán, portugués y británico) de reconocimiento empresarial. \$4. El modelo de reconocimiento oficial del Derecho de la Unión Europea, ad extra y ad intra. §5. El modelo norteamericano de reconocimiento empresarial.

THEME 11

THE UNION FREEDOM IN THE EUROPEAN LAW, IN THE NATIONAL EUROPEAN LEGISLATIONS AND PRACTICES, AND IN THE LEGISLATION OF THE UNITED STATES

Contents: \$1. The union freedom and the recognition of only certain unions as social partners. \$2. The national European models (French, Spanish and Italian) of statutory recognition. \$3. The national European models (German, Portuguese and British) of employer recognition. \$4. The model of official recognition of the Law of the European Union, ad extra and ad intra. \$5. The USA model of employer recognition.

§1. La libertad sindical es un derecho proclamado y garanti za do en los países europeos que venimos comparando y en los Estados Unidos, por los más diversos instrumentos normativos, a saber: 1) ante todo, por los Convenios núm. 87 de 1948 y núm. 98 de 1949 de la OIT, ratificados por Alemania, España, Francia, Italia, Portugal y Gran Bretaña, aunque no por los Estados Unidos ${ }^{1}$; 2) por sus Constituciones respectivas, salvo en el caso de Gran Bretaña y nuevamente de los Estados

1 A pesar de ello, a propósito de este último país, véase D.L. GREGORY, «The Right to Unionize as a Fundamental Human and Civil Right», en D.L. GREGORY (Editor), Labour Law, Dartmouth (Aldershot, 1993), págs. 481 y ss. 
Unidos; y 3) por las legislaciones internas de dichos siete países, aunque entre los europeos sólo Francia, Portugal y Gran Bretaña posean normas equivalentes a nuestra omnicomprensiva y potente Ley Orgánica 11/1985, de 2 agosto, de Libertad Sindical ${ }^{2}$. Dicha proclamación y garantía abarcan desde luego la «faceta organizativa» de la libertad sindical — esto es, en lo más esencial, el derecho de crear libremente sindicatos-, provocando su ejercicio la existencia del fenómeno del pluralismo sindical, tan característico de los seis países europeos que venimos comparando y, también, de los Estados Unidos. Ahora bien, en lo tocante a la «faceta funcional» de la libertad sindical — cuyo núcleo duro está constituido, a su vez, por el derecho de negociar convenios colectivos-, las legislaciones y prácticas nacionales de todos y cada uno de esos siete países se han visto obligadas a efectuar una selección de los muchos sindicatos existentes en ellos, privilegiando a unos pocos — sin que ello suponga violación de la libertad sindical de los demás-, mediante la institución del «reconocimiento» legal o empresarial de sólo ciertos sindicatos como interlocutores sociales.

Nuestra jurisprudencia constitucional resulta muy explícita a este respecto, al haber sostenido que dicho trato privilegiado se apoya en el principio implícito en el artículo 7 de nuestra Constitución de la «promoción del hecho sindical», que pretende «garantizar la más eficaz defensa de los intereses de los trabajadores, que se vería perjudicada por una atomización sindical» ${ }^{3}$.

Según la Corte Constitucional francesa, la libertad sindical se encuentra constitucionalmente protegida en Francia por el párrafo sexto del Preámbulo de la Constitución de 27 octubre 1946, donde se afirma que «todo hombre puede defender sus derechos y sus intereses por la acción sindical y adherirse al sindicato de su elección» ${ }^{4}$.

A diferencia de Alemania - donde no existe ninguna legislación sindical específica distinta de las grandes leyes federales sobre las instituciones generales del Derecho Colectivo

2 Cfr., en lo esencial, respecto de Francia, los artículos L. 2111-1 a L. 2146-2 del «Código del Trabajo [Code du Travail]» de 2008; respecto de Portugal, los artículos 440 a 468 del «Código del Trabajo [Código do Trabalho]» de 2009; y respecto de Gran Bretaña, la Parte I, secciones 1 a 121, de la indescriptiblemente compleja «Ley (Consolidada) Sindical y de Relaciones Laborales [Trade Union and Labour Relations (Consolidation) Act]» de 1992. Sobre los precedentes de esta legislación de hoy en Gran Bretaña y Francia, siempre clarificadores, véase M. ALONSO OLEA, M., Leyes sindicales británicas. Estudio preliminar, traducción y notas, $2^{\mathrm{a}}$ ed., Instituto de Estudios Sindicales, Sociales y Cooperativos (Madrid, 1967), págs. 11 y ss.; y A. MONTOYA MELGAR, Leyes sindicales francesas. Estudio preliminar, traducción y notas, Instituto de Estudios Sindicales, Sociales y Cooperativos (Madrid, 1968), págs. 7 y ss.

3 Véase J. MARTÍNEZ GIRÓN, A. ARUFE VARELA y X.M. CARRIL VÁZQUEZ, Derecho del Trabajo, $2^{a}$ ed., Netbiblo (A Coruña, 2006), pág. 383.

4 Cfr. Decisión de 25 julio 1989 (núm. 89-257). Sobre el tema, véase F.-J. PANSIER, Droit du Travail, $2^{\text {a }}$ ed., Litec (Paris, 2000), pág. 29 ; también, J. PÉLISSIER, A. SUPIOT y A. JEAMMAUD, Droit du travail, $24^{\mathrm{a}}$ ed., Dalloz (Paris, 2008), págs. 1035 y ss. 
del Trabajo (convenios colectivos, comités de empresa, etc.) ${ }^{5}$ - en Italia sí cabe haber de un desarrollo parcial de lo dispuesto sobre la libertad sindical en la Constitución italiana ${ }^{6}$, que está representado por la Ley núm. 300, de 20 mayo 1970 (popularmente denominada «Estatuto de los trabajadores [Statuto dei lavoratori]») ${ }^{7}$.

§2. En tres países europeos (Francia, España e Italia) ese «reconocimiento»se efectúa por la ley, mediante la utilización del concepto jurídico «representatividad», Ahora bien, los sistemas de medición de la misma son distintos en los tres países, cabiendo hablar de la existencia de un método abstracto y de un método concreto de medición. En Francia — donde los sindicatos, a diferencia de lo que sucede en España, no «irradian» la «representatividad» que poseen a sus entes afiliados u órganos menores-, se utiliza el método concreto (o matemático) para su medición —al igual que ocurre en España ${ }^{8}$-, distinguiendo a estos efectos el Código francés del Trabajo tres tipos

5 De ahí la trascendencia de la jurisprudencia constitucional sobre «libertad sindical [Koalitionsfreiheit]», dictada en interpretación de las genéricas afirmaciones contenidas en el artículo 9 , apartado 3, de la Constitución Federal (cfr. W. DÄUBLER, Arbeitsrecht. Ratgeber für Beruf, Praxis und Studium, $6^{\text {a }}$ ed., Bund-Verlag [Frankfurt a.M., 2006], págs. 37 y ss). Este ultimo precepto constitucional se limita a afirmar lo siguiente: «el derecho a formar asociaciones para la preservación y promoción de las condiciones laborales y las condiciones económicas se garantiza a todo hombre y para toda profesión» (inciso primero); «los acuerdos que busquen restringir este derecho o dañarlo son nulos, y las decisiones judiciales basadas en ellos son ilegales» (inciso segundo); «las especificaciones de que tratan los artículos 12a y 35, apartados 2 y 3, el artículo 87a, apartado 4, y el artículo 91, no deben ser enjuiciadas contra los conflictos laborales que sean declarados para la preservación y promoción de las condiciones laborales y las condiciones económicas por las asociaciones a que se refiere el inciso 1» (inciso tercero). Véase, además, P. HANAU y K. ADOMEIT, Arbeitsrecht, 13 ed., Luchterhand (Munich, 2005), págs. 55 y ss.; H. REICHOLD, Arbeitsrecht, $2^{\text {a }}$ ed., C.H. Beck (Munich, 2006), págs. 271 y ss.; y A. JUNKER, Grundkurs Arbeitsrecht, $5^{\text {a }}$ ed., C.H. Beck (Munich, 2006), págs. 265 y ss. Decisiones judiciales trascendentales sobre el tema son un Auto del Tribunal Federal Constitucional de 14 noviembre 1995 (referencia 1 BVR 601/92) y una Sentencia del Tribunal Federal de Trabajo de 28 febrero 2006 (referencia 1 AZR 460/04). Nuestra traducción íntegra de ambas resoluciones, en U. ZACHERT, J. MARTÍNEZ GIRÓN y A. ARUFE VARELA, Los grandes casos judiciales del Derecho alemán del Trabajo. Estudio comparado con el Derecho español y traducción castellana, Netbiblo (A Coruña, 2008), págs. 258 y ss, y 264 y ss., respectivamente.

6 Cfr. su artículo 39.

7 Aunque referido a la acción sindical dentro de la empresa, su Título II trata «De la libertad sindical [Della libertà sindacale]», con prohibición expresa de los «sindicatos amarillos [sindacati di comodo]» (artículo 17); su Título III trata «De la actividad sindical [Dell'attività sindacale]», y el artículo 28 de su Título IV, de la «represión de la conducta antisindical [repressione della condotta antisindacale]». Sobre el tema, véase L. GALANTINO, Diritto Sindacale, 4 a ed., G. Giappichelli (Turín, 1993), págs. 75 y ss.; M. PERSIANI, Diritto Sindacale, $7^{\mathrm{a}}$ ed., CEDAM (Padua, 2000), págs. 17 y ss.; F. DEL GIUDICE y F. MARIANI, Diritto Sindacale, Simone (Nápoles, 2001), págs. 75 y ss.; A. TURSI y P.A. VARESI, Lineamenti di Diritto del Lavoro. Rapporti di lavoro e relazioni sindacali nel settore privato, $3^{\mathrm{a}}$ ed., Kluwer-Ipsoa (s.l., 2004), págs. 299 y ss.; y G. FAVALLI y F. ROTONDI, Manuale pratico di diritto del lavoro, $2^{\mathrm{a}}$ ed., CEDAM (Padua, 2005) págs. 519 y ss.

8 Acerca de nuestro país, véase J. MARTÍNEZ GIRÓN, A. ARUFE VARELA y X.M. CARRIL VÁZQUEZ, Derecho del Trabajo, $2^{\mathrm{a}}$ ed., cit., págs. 381 ss. Nuestro Estatuto de los Trabajadores menciona el «reconocimiento», a propósito de la regulación que efectúa de la negociación colectiva, afirmando que «en todos los casos será necesario que ambas partes se reconozcan como interlocutoras» (artículo 87.1, párrafo último). 
esenciales de «representatividad sindical [représentativité syndicale]»" 1) «a nivel de empresa y de centro de trabajo [au niveau de l'entreprise et de l'établissement]», teniendo en cuenta que en este concreto nivel «son representativas las organizaciones sindicales ... que han recogido al menos el 10\% de los sufragios emitidos en la primera vuelta de las últimas elecciones [a representantes unitarios de los trabajadores]»; 2) «a nivel de sector profesional [au niveau de branche professionnelle]», resultando aquí «representativas las organizaciones sindicales que ... han recogido al menos el $8 \%$ de los sufragios emitidos en la primera vuelta de las últimas elecciones [a representantes unitarios de los trabajadores] ... sumados a nivel de sector»; y 3) «a nivel nacional e interprofesional [au niveau national et interprofessionnel]», donde rige el mismo porcentaje aplicable a nivel de sector, pero teniendo en cuenta que aquí las organizaciones sindicales también han de ser «representativas a la vez en los sectores de la industria, de la construcción, del comercio y de los servicios». En It alia — donde los sindicatos monopolizan totalmente el ejercicio del derecho de negociación colectiva-, se utiliza un método abstracto y un método concreto de medición de la «representatividad», dado que: 1) si se trata de negociar con las Administraciones públicas, la legislación sólo admite «en la negociación colectiva nacional a las organizaciones sindicales que tengan en el sector o en el área una representatividad [rappresentatività] no inferior al 5 por ciento, considerando a tal fin la media entre el dato asociativo y el dato electoral» ${ }^{10}$; y 2) en cambio, si se trata de negociar en el ámbito supraempresarial privado ${ }^{11}$, la medición carece de todo tipo de concreción numérica, habiéndose visto incluso forzada la legislación italiana más reciente a introducir — pretendiendo reconducir de algún modo el creciente número de sindicatos que presuntivamente poseían la condición de «más representativos»— el nuevo concepto jurídico de

9 Cfr. artículos L. 2121-1 a L. 2122-12. Lógicamente, estos preceptos establecen un régimen propio para los sindicatos que no son «de clase», tan peculiares siempre (sobre el tema, véase R.P. RON LATAS, Los sindicatos horizontales, Comares [Granada, 2003], págs. 14 y ss.).

10 Art. 43, inciso primero, del Decreto Legislativo núm. 165 de 30 marzo 2001. Este mismo precepto continúa afirmando que «el dato asociativo está expresado por el porcentaje de delegaciones para el pago de las cotizaciones sindicales, respecto del total de delegaciones efectuadas en el ámbito correspondiente» (inciso segundo); y que «el dato electoral está expresado por el porcentaje de votos obtenidos en las elecciones a representaciones unitarias del personal, respecto de votos emitidos en el ámbito correspondiente» (inciso tercero).

11 Al respecto, véase A. TURSI y P.A. VARESI, Lineamenti di Diritto del Lavoro. Rapporti di lavoro e relazioni sindacali nel settore privato, $3^{\text {a }}$ ed., cit., págs. 305 y ss. También, M. PERSIANI, «Il problema della rappresentanza e della rappresentatività del sindacato in una democrazia neo-corporata», en su Diritto del Lavoro, CEDAM (Padua, 2004), págs. 195 y ss. 
«sindicatos comparativamente más representativos [sindacati comparativamente più rappresentativi] ${ }^{12}{ }^{12}$, que claramente favorece a las tres grandes confederaciones sindicales italianas ${ }^{13}$.

Se trata de la CGIL (Confederazione Generale Italiana del Lavoro) - cuyo sitio en Internet, ubicado en www.cgil.it, contiene interesantes materiales jurídicos, como una «versión consolidada» y parcialmente anotada del citado «Estatuto de los trabajadores»-, de la CSIL (Confederazione Italiana Sindacati dei Lavoratori) y de la UIL (Unione Italiana del Lavoro), que poseen 5'5 millones, 4,5 millones y 2,5 millones de afiliados, aproximada y respectivamente.

Siempre en Italia, si se trata de negociar convenios colectivos en el ámbito intraempresarial privado, están legitimadas — tras un referéndum popular de 1995, que suprimió en el artículo 19 del citado «Estatuto de los trabajadores» la referencia a los sindicatos «más representativos»— todas las representaciones sindicales empresariales pertenecientes a «asociaciones sindicales que hayan estipulado convenios colectivos (nacionales, locales o empresariales) aplicables en la unidad productiva» ${ }^{14}$.

En Francia, el Código del Trabajo afirma que «tras parecer del Alto Consejo del diálogo social, el Ministro encargado del Trabajo ordena la lista de las organizaciones sindicales reconocidas como representativas por sector profesional y de las organizaciones sindicales reconocidas como representativas a nivel nacional e interprofesional» ${ }^{15}$. Tradicionalmente, estas últimas eran la CGT (Confédération Générale du Travail), la CGT-FO (Confédération Générale du Travail-Force Ouvrière), la CFDT (Confédération Française Démocratique du Travail), la CFTC (Confédération Française des Travailleurs Chrétiens) y la CFE-CGC (Conféderation Générale des Cadres). Aunque de tamaño variable, ninguna de estas cinco confederaciones alcanza la cifra del millón de afiliados.

§3. Sin embargo, en Alemania, Portugal y Gran Bretaña el Estado se comporta con una neutralidad extraordinaria, absteniéndose - también al efecto esencial de fijar la legitimación para poder negociar convenios colectivos - de privilegiar a determinados sindicatos. En estos otros tres casos, se confía en que el empresario o las asociaciones de empresarios —en cuanto que interlocutores de los sindicatos - sean quienes efectúen la correspondiente criba, suponiéndose que el «reconocimiento»empresarial recaerá precisamente en aquellos sindicatos que cuenten con un mayor número

12 Por ejemplo, en las denominadas «leyes Biagi», sobre reforma del mercado italiano del trabajo. Acerca de estas leyes, véase A. ARUFE VARELA, «El cumplimiento por Italia de las recomendaciones europeas sobre el empleo, a través de la "Reforma Biagi"», Anuario da Facultade de Dereito da Universidade da Coruña. Revista jurídica interdisciplinar internacional, vol. 10 (2006), págs. 65 y ss.

13 Sobre ellas, véase F. DEL GIUDICE y F. MARIANI, Diritto Sindacale, cit., págs. 65 y ss.; y G. PERA y M. PAPALEONI, Diritto del Lavoro, $7^{\mathrm{a}}$ ed., CEDAM (Padua, 2003), págs. 89 y ss.

14 Al respecto, véase Sentencia de la Corte Constitucional núm. 244 de 10 julio 1996, rechazando el argumento de que la nueva redacción del citado artículo 19 «privaría al sindicato de la "autonomía del reconocimiento propio [autonomia del proprio riconoscimento]", sujetándolo a un poder de acreditación del empresario».

15 Artículo L. 2122-11, párrafo primero. 
de afiliados. En Alemania, este «reconocimiento» empresarial se produce al negociar el convenio colectivo ${ }^{16}$, puesto que la legislación se limita a afirmar - descartando deliberadamente efectuar cualquier tipo de gradación o clasificación sindical - que «las partes del convenio colectivo son los sindicatos [Gewerkschaften] y el empresario individual, así como las asociaciones de empresarios» ${ }^{17}$. Y lo mismo sucede en Portugal, puesto que allí el Código del Trabajo también afirma deliberadamente que todas «las asociaciones sindicales [associações sindicais] tienen, señaladamente, el derecho de... celebrar convenios colectivos de trabajo» ${ }^{18}$. En Gran Bretaña, en cambio, el «reconocimiento» empresarial puede ser no sólo voluntario, sino también resultar forzoso, dado que - a través del procedimiento administrativo de «reconocimiento sindical [trade union recognition]», tramitado ante el organismo público denominado «Comité Central de Arbitraje [Central Arbitration Committee]», a instancia del sindicato- cabe obligar al empresario (pero sólo si tiene 21 ó más trabajadores) a tener que aceptar la «declaración de que el sindicato está... reconocido como titular del derecho a llevar a cabo la negociación colectiva en nombre de los trabajadores que constituyen la unidad de negociación», especialmente cuando «la mayoría de los trabajadores que constituyen la unidad de negociación está afiliada al sindicato» ${ }^{19}$.

Este modelo británico aparece regulado en la infinitamente prolija Parte I de la disposición complementaria (Schedule) A1 de la Ley (Consolidada) Sindical y de Relaciones Laborales de $1992^{20}$. Los tradicionales «pactos de seguridad sindical [union security

16 Véase O.E. KEMPEN y U. ZACHERT (Editores), Tarifvertragsgesetz, $4^{\mathrm{a}}$ ed., Bund-Verlag (Frankfurt am Maine, 2006), págs. 580 y ss; P. HANAU y K. ADOMEIT, Arbeitsrecht, $13^{\text {a }}$ ed., cit., pág. 65;

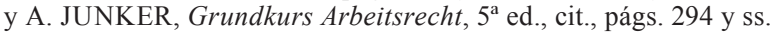

17 Parágrafo 2, apartado 1, de la «Ley del Convenio Colectivo [Tarifvertragsgesetz]» de 1949. Por excepción y a ciertos efectos de participación institucional, el parágrafo 12 de esta misma norma afirma que «organizaciones centrales [Spitzeorganisationen] a los efectos de esta Ley son — sin perjuicio de lo dispuesto en el parágrafo 2 - aquellas federaciones de sindicatos o de asociaciones empresariales que tengan relevancia esencial [wesentliche Bedeutung] para la representación de los intereses de los trabajadores o de los intereses de los empresarios en la vida laboral del territorio federal» (inciso primero). El caso decisivo sobre el tema es un Auto del Tribunal Federal de Trabajo de 28 marzo 2006 (referencia 1 ABR 58/04). Nuestra traducción íntegra del mismo, en U. ZACHERT, J. MARTÍNEZ GIRÓN y A. ARUFE VARELA, Los grandes casos judiciales del Derecho alemán del Trabajo. Estudio comparado con el Derecho español y traducción castellana, cit., págs. 237 y ss. Sólo por excepción, alguna norma alemana habla de «representatividad [Repräsentativität]», pero a propósito no de los sindicatos, sino de los convenios colectivos. Al respecto, véase J. MARTÍNEZ GIRÓN y A. ARUFE VARELA, El salario mínimo en Alemania. Un estudio comparado entre regímenes de salarios mínimos profesionales (alemanes) e interprofesionales legales (norteamericano y europeos), Netbiblo (A Coruña, 2009), pág. 32.

18 Artículo 443, apartado 1, letra a). Sobre el «"reconocimiento" de los interlocutores negociales [o "reconhecimento" dos interlocutores negociais]», véase A. MONTEIRO FERNANDES, Direito do Trabalho, $15^{\mathrm{a}}$ ed., Almedina (Coimbra, 2010), págs. 784 y ss.

19 Acerca de todo ello, véase N.M. SELWYN, Law of Employment, $13^{\mathrm{a}}$ ed., LexisNexis-Butterworths (Londres, 2004), págs. 550 y ss.

20 Cfr. especialmente los parágrafos $1,7,19 \mathrm{~F}$ y 22 de dicha Parte I. 
agreements]» ingleses ${ }^{21}$, dirigidos a forzar el incremento o mantenimiento de la afiliación sindical, aparecen ahora prohibidos en la Parte III de esta misma Ley (rotulada «Derechos en relación con las actividades y la afiliación sindical [Rights in relation to union membership and activities]») ${ }^{22}$. La principal central sindical existente en el Reino Unido, denominada TUC o «Congreso de los Sindicatos [Trades Union Congress]», posee aproximadamente 6,2 millones de afiliados.

En Alemania, la central sindical más potente es la DGB o «Federación Alemana de Sindicatos [Deutscher Gewerkschaftsbund] ${ }^{23}$, que cuenta con más de 6,2 millones de afiliados. Tras un proceso interno de concentración, posee actualmente sólo seis federaciones afiliadas - cuyos respectivos sitios de Internet resultan accesibles a través de www.dgb. de, verdadero modelo de transparencia, especialmente en lo tocante al punto sensible del número de afiliados que posee dicha central—, siendo las dos más importantes el «Sindicato Unido de Servicios» (Ver.di) y el «Sindicato Industrial del Metal» (o IG Metall). Los sindicatos alemanes no monopolizan la negociación colectiva empresarial, puesto que los comités de empresa están legitimados para negociar con el empresario «acuerdos de empresa [Betriebsvereinbarungen]», aunque estos últimos no pueden contradecir lo dispuesto en los convenios colectivos en sentido estricto (Tarifverträge), empresariales o sectoriales, negociados por los sindicatos ${ }^{24}$.

En Portugal, las dos principales centrales sindicales son la CGTP (Confederação Geral dos Trabalhadores Portugueses) y la UGT (União Geral de Trabalhadores), contando esta última con 260.000 afiliados. Según la doctrina portuguesa, resulta frecuente que en las grandes empresas el empresario tenga que negociar, incluso separadamente, con una pluralidad de sindicatos, que «pueden exceder el número de diez» ${ }^{25}$. En cualquier caso, prueba el valor que la legislación portuguesa otorga a la afiliación el hecho de que fije el número de «delegados sindicales» legalmente protegidos en atención no al censo de trabajadores que tenga la empresa - como ocurre en España o en Francia ${ }^{26}$ —, sino en atención precisamente al censo de «trabajadores sindicalizados» existente en la misma ${ }^{27}$.

§4. En el plano ad extra -esto es, el relativo al personal que no está al servicio de la Unión Eu ropea-, esta última parece haber renunciado - de momento - a poseer un Derecho común en materia de libertad sindical, puesto que el Tratado de Funcionamiento de la Unión Europea excluye la posibilidad de armonización, vía Directivas, de cuestiones relativas «a las remuneraciones, al derecho de asociación y sindicación,

21 Véase J. BOWERS, D. BROWN y S. GIBBONS, Trade Union Reform and Employment Rights Act 1993: A Practical Guide, Longman (Londres, 1993), págs. 10 y ss.

22 Cfr. secciones 137 y ss. Sobre una variante siempre vitalista de estos pactos, véase J. CABEZA PEREIRO, El descuento de la cuota sindical, Tirant lo blanch (Valencia, 2002), págs. 15 y ss.

23 Véase J. MARTÍNEZ GIRÓN, «Los estatutos de la Federación Alemana de Sindicatos (Deutscher Gewerkchaftsbund). Comparación contextualizadora con los estatutos confederales de Comisiones Obreras y de la Unión General de Trabajadores, y traducción castellana», Anuario Coruñés de Derecho Comparado del Trabajo-ACDCT, vol. I (2009), págs. 85 y ss.

24 Véase infra, Tema 12, §3.

25 Véase B.G.L. XAVIER, «Collective Bargaining in Portugal», en el vol. Collective Bargaining in Europe, Ministerio de Trabajo y Asuntos Sociales (Madrid, 2004), pág. 194.

26 Cfr. artículos L. 2143-3 a L. 2143-6 del Código del Trabajo.

27 Al respecto, véase artículo 463 del Código del Trabajo. 
al derecho de huelga» y «al derecho de cierre patronal» ${ }^{28}$. Ahora bien, para poder aplicar los preceptos del propio Tratado de Funcionamiento sobre el «diálogo social» ${ }^{29}$, la Comisión Europea se ha visto obligada a tener que discriminar entre los potencialmente muchos «interlocutores sociales» europeos (empresariales y sindicales), echando mano para ello del concepto «representatividad» - medida de una manera abstracta ${ }^{30}$, aplicando el cual el «reconocimiento» oficial de estos «interlocutores sociales» europeos «representativos» aparece actualmente contenido en una Comunicación de la Comisión de 12 agosto $2004^{31}$, en la que se afirma que ostentan dicha condición - entre las organizaciones «generales»— la Confederación Europea de Sindicatos (CES), del lado sindical, y la Unión de Confederaciones de Industriales y Empresarios de Europa (UNICE, denominada desde 2007 BUSINESSEUROPE), y el Centro Europeo de Empresas con Participación Pública y de Empresas de Interés Económico General (CEEP), por la parte empresarial ${ }^{32}$. En cambio, en

28 Cfr. artículo 153.5. Esta afirmación hay que completarla con lo dispuesto en el artículo 156 del propio Tratado de Funcionamiento de la Unión Europea, a cuyo tenor: 1) «la Comisión fomentará la colaboración entre los Estados miembros y facilitará la coordinación de sus acciones en los ámbitos de la política social tratados en el presente Capítulo, particularmente en las materias relacionadas con... el derecho de sindicación y las negociaciones colectivas entre empresarios y trabajadores»; 2) «a tal fin, la Comisión actuará en estrecho contacto con los Estados miembros mediante estudios, dictámenes y la organización de consultas, tanto para los problemas que se planteen a nivel nacional como para aquellos que interesen a las organizaciones internacionales»; y 3 ) «antes de emitir los dictámenes previstos en el presente artículo, la Comisión Consultará al Comité Económico y Social». Téngase en cuenta, además, que la Carta de los Derechos Fundamentales de la Unión Europea reconoce que «toda persona tiene derecho a la libertad de reunión pacífica y a la libertad de asociación en todos los niveles, especialmente en los ámbitos político, sindical y cívico, lo que supone el derecho de toda persona a fundar con otras sindicatos y a afiliarse a los mismos para la defensa de sus intereses» (artículo 12, apartado 1). Sobre concordancias de este último tema, véase U. ZACHERT, «Los derechos fundamentales de los trabajadores en la Carta Europea de Derechos Fundamentales», Temas Laborales, núm. 65 (2002), pág. 21.

29 Cfr. artículos 154 y 155. Sobre el tema, F. PÉREZ DE LOS COBOS ORIHUEL, «Aporías de la negociación colectiva europea», en F. PÉREZ DE LOS COBOS y J.M. GOERLICH (Coordinadores), El régimen jurídico de la negociación colectiva en España, Tirant lo Blanch (Valencia, 2006), págs. 13 y ss.

30 Como ha estudiado ejemplarmente X.M. CARRIL VÁZQUEZ, Asociaciones sindicales y empresariales de carácter internacional, Comares (Granada, 2003), pág. 188, organizaciones «representativas» a efectos comunitarios «son aquellas que cumplen los tres siguientes requisitos: 1) "ser interprofesionales, sectoriales o de una categoría de trabajadores, y estar organizadas a nivel europeo"; 2) "estar compuestas por organizaciones que, a su vez, formen parte integrante y reconocida de las estructuras de interlocutores sociales de los Estados miembros, tengan la capacidad de negociar acuerdos y sean, en lo posible, representativas de todos los países de la Unión Europea"; y 3) "disponer de las estructuras adecuadas que garanticen su participación efectiva en el proceso de consulta"».

31 Localizable, dada su falta de publicación en el Diario Oficial de la Unión Europea, a través de la referencia COM (2004) 557.

32 Cfr. su Anexo 5, apartado 1. En relación con el Derecho de la Unión Europea, tiene interés jurídico-sindical el que la Sentencia del Tribunal de Primera Instancia de 17 junio 1998 (asunto T 96/135), a propósito de un recurso planteado por cierta confederación empresarial europea distinta de las citadas UNICE y CEEP, recordase — manejando el concepto «representatividad acumulada suficiente»- «la importancia que tiene la obligación de la Comisión y del Consejo de comprobar la representatividad de los interlocutores sociales firmantes de un Acuerdo... cuya aplicación a escala comunitaria se solicita al Consejo» (sobre esta Sentencia, véase X.M. CARRIL VÁZQUEZ, Asociaciones sindicales y empresariales de carácter internacional, cit., págs. 188 y ss.). 
el plano ad intra, el método de «reconocimiento» oficial utilizado por la Comisión Europea -en consecuencia, en relación sólo con los sindicatos representantes del personal al servicio de las instituciones de la Unión Europea- es matemático, cabiendo indicar acerca de este otro «reconocimiento» lo siguiente: 1) como es lógico, presupone el reconocimiento ad intra de la libertad sindical, contenido - desde 1972- en el «Estatuto de los Funcionarios» aprobado por el Reglamento (CEE, EURATOM, CECA) núm. 259/68 del Consejo, de 29 febrero 1968, a cuyo tenor «los funcionarios gozarán del derecho de asociación» ${ }^{33}$, teniendo en cuenta que «podrán, en particular, ser miembros de organizaciones sindicales o profesionales de funcionarios europeos» ${ }^{34}$; 2) sobre esta base, la Comisión considera «representativas» de su propio personal las organizaciones sindicales y profesionales con una audiencia en las elecciones a representantes unitarios del $« 6 \%$ en el nivel central y $5 \%$ en el nivel local (sobre un lugar) del personal de la Comisión Europea», siempre y cuando cuenten con «un número de afiliados al menos igual a 400 miembros»; y 3) lógicamente, por aplicación de estos criterios tan mínimos — pero deliberadamente queridos de propósito por la Comisión Europea-, las organizaciones sindicales y profesionales representativas del personal funcionarial y laboral al servicio de la Unión Europea son muchas, figurando hasta doce de ellas como firmantes del vigente «acuerdo marco» de 18 diciembre 2008, regulador de todos estos extremos.

Este «acuerdo marco», oficialmente denominado «Acuerdo relativo a las relaciones entre la Comisión Europea y las organizaciones sindicales y profesionales», puede localizarse (en lengua francesa) en el sitio en Internet de la Federación de la Función Pública Europea o FPPE - uno de los doce sindicatos firmantes del mismo-, ubicado en www.ffpe-bxl.eu ${ }^{35}$.

En la citada Comunicación de 2004, también se afirma la necesidad de «ampliar y actualizar los estudios de representatividad», especialmente ante «la proliferación de comités de diálogo social sectorial y la ampliación de la UE». Al efecto, «la Comisión propone que el estudio de representatividad sea elaborado por el Observatorio Europeo de Relaciones Laborales de la Fundación de Dublín». Precisamente el sitio en Internet de este «Observatorio» - ubicado en www.eiro.eurofound.eu.int- contiene un estudio sobre «Trade union membership 1993-2003» ${ }^{36}$, con datos relativos a veintiséis países europeos, aunque — dada su falta de actualización — la fuente más fiable para consultar datos relativos

33 Cfr. artículo 24.ter.

34 Ibidem. El propio Reglamento declara aplicable el precepto al personal laboral, mediante la remisión que efectúan a él los artículos 11, 54 y 81 del «Régimen aplicable a los otros agentes de la Comunidad Económica Eueropea y de la Comunidad Europea de la Energía Atómica».

35 Yendo a «FFPE Commission Brussels \& Outside Union», luego a «Our tracks, our news, our events», y por último, a «6-2-2009».

36 Accesible vía «Comparative information» (y dentro de ella, vía «Comparative studies»). 
a la afiliación sindical en todos los países del mundo sea hoy el sitio en Internet de la Confederación Sindical Internacional, ubicado en www.ituc-csi.org ${ }^{37}$.

CCOO y UGT, que cuentan respectivamente con 1.200 .000 y 810.000 afiliados, pertenecen a la citada Confederación Europea de Sindicatos - cuyo sitio en Internet es www.etuc.org-, al igual que 79 confederaciones sindicales nacionales europeas más, entre las que figuran casi todas las ya mencionadas (esto es, las italianas CGIL, CSIL y UIL, las francesas CGT, CGT-FO, CFDT y CFTC, la DGB alemana, las portuguesas CGTP y UGT, y el TUC británico).

§5. En fin, en los Estados Unidos, rige — desde la promulgación de la llamada Ley Taft-Hartley de 1947-el «reconocimiento» e mpresarial del sindicato que actúa en el plano federal ${ }^{38}$, habiendo servido de inspiración este modelo norteamericano para la articulación muy posterior del relativamente parecido modelo británico. Se trata de un tema regulado en la sección 159 del Título 29 del Código de los Estados Unidos, bajo el rótulo genérico «Representantes y Elecciones [Representatives and Elections] ${ }^{39}$. Este precepto está construido alrededor de tres ideas principales: 1) si el empresario se niega a «reconocer» voluntariamente a un sindicato como interlocutor de sus trabajadores, cabe que el sindicato se dirija a la agencia federal denominada «Oficina Nacional de Relaciones Laborales [National Labor Relations Board]», alegando que «un número sustancial de trabajadores... desea ser representado a efectos de la negociación colectiva y que su empresario se niega a reconocer su representante [declines to recognize their representative]» ${ }^{40}$; 2) tras las comprobaciones pertinentes, dicha agencia federal «llevará a cabo una elección con votación secreta y certificará los resultados de la misma» ${ }^{41}$; y 3) el sindicato certificado como sindicato ganador pasa a convertirse en representante único ante el empresario de todos los trabajadores comprendidos en la correspondiente unidad de negociación —es el gráficamente denominado «gobierno de la mayoría [majority rule]», por paralelismo con el resultado de las elecciones norteamericanas puramente políticas, también ajustadas a un modelo electoral mayoritario ${ }^{42}$-, pues

37 Yendo a «List of Affiliates», dentro del enlace «About us».

38 Véase J. MARTÍNEZ GIRÓN, «Las elecciones sindicales en los Estados Unidos», Revista de Política Social, núm. 148 (1985), especialmente págs. 54 y ss.

39 Véase R.A. GORMAN, Basic Text on Labor Law. Unionization and Collective Bargaining, West Publ. Co. (St. Paul-Minn., 1976), págs. 40 y ss.; y T.J. HEINSZ, D.R. NOLAN y R.A. BALES, Labor Law. Collective Bargaining in a Free Society, $6^{\mathrm{a}}$ ed., Thomson-West (St. Paul-Minn., 2009), págs. 234 y ss.

40 Apartado (c)(1)(A)(i).

41 Apartado (c)(1)(B), inciso último.

42 Véase J. MARTÍNEZ GIRÓN, «Las elecciones sindicales en los Estados Unidos», cit., págs. 57 y ss. 
«los representantes designados o elegidos a los efectos de la negociación colectiva por la mayoría de los trabajadores en una unidad apropiada a tales efectos, serán los representantes exclusivos de todos los trabajadores en dicha unidad a los efectos de la negociación colectiva sobre escalas salariales, salarios, jornada y otras condiciones de empleo» ${ }^{43}$.

Aparte la citada Ley Taft-Hartley (o «Ley de Relaciones entre Empresarios y Sindicatos [Labor-Management Relations Act]»), también regulan otras cuestiones sindicales clave la Ley Wagner (o «Ley de Relaciones Laborales Nacionales [National Labor Relations Act]») de $1939^{44}$ y la Ley Landrum-Griffin (o «Ley de Revelación e Información de Empresarios y Sindicatos [Labor-Management Reporting and Disclosure Act]») de $1959^{45}$.

Quizá por causa de la crucialidad para los sindicatos norteamericanos del tema del mantenimiento e incremento de la afiliación ${ }^{46}$, la propia Ley Taft-Hartley — que pretendía recortar el poder de los sindicatos ${ }^{47}$ — prohibió los pactos duros de «seguridad sindical» (y especialmente, el de «fábrica cerrada [closed shop]» a los no afiliados al sindicato actuante en la empresa), posibilitando que los menos duros (como el pacto de «fábrica sindicada [union shop]», que otorgaba al trabajador un cierto plazo en que poder afiliarse) fuesen permitidos en los Estados federados, aunque la mayoría de estos últimos también procedió a prohibirlos, a su vez, mediante la promulgación de las llamadas «leyes de derecho al trabajo [right-to-work laws]» ${ }^{48}$.

La más poderosa central sindical norteamericana es la AFL-CIO o «Federación Americana del Trabajo-Congreso de Organizaciones Industriales [American Federation of Labor-Congress of Industrial Organizations]». Cuenta con 57 federaciones nacionales e «internacionales» (estas últimas así denominadas porque también actúan en Canadá) —sus organizaciones «estatales» y «locales» resultan accesibles en Internet a través del sitio www.aflcio.org-, y con casi 8,5 millones de afiliados. En contraste con la terminología británica, en los Estados Unidos no se consideran «sindicatos independientes [independent unions]» los sindicatos no dominados o controlados por el empresario ${ }^{49}$, sino aquellas «organizaciones de trabajadores... que no están afiliadas a ningún sindicato nacional o internacional» $\mathrm{y}$, por tanto, tampoco a la $\mathrm{AFL}-\mathrm{CIO}^{50}$.

43 Apartado (a), inciso primero.

44 Actualmente recopilada en las secciones 151 a 169 del Título 29 del Código de los Estados Unidos.

45 Actualmente recopilada en las secciones 401 a 531 del Título 29 del Código de los Estados Unidos. Sobre las circunstancias que hicieron necesaria la promulgación de esta Ley, véase M. ALONSO OLEA, La Ley sindical norteamericana de 1959. Traducción, introducción y notas, Consejo Social de la Organización Sindical Española (Madrid, 1960), págs. 11 y ss.

46 Al respecto, véase J. MARTÍNEZ GIRÓN y A. ARUFE VARELA, «The right to access of the nonemployee union organizers (das Zugangsrecht durch betriebsfremde Gewerkschaftsbeauftragte) to the premises of the enterprise. A comparative analysis of the German, Spanish and Federal North American case law», en T. DIETERICH, M. LE FRIANT, L. NOGLER y K. KEZUKA (Editores), Individuelle und kollektive Freiheit im Arbeitsrecht. Gedächtnisschrift für Ulrich Zachert, Nomos (Baden-Baden, 2010), págs. 627 y ss.

47 Calificándola de «vendetta» respecto de los sindicatos, véase A. ARUFE VARELA, «La problemática exigencia de responsabilidades laborales a los sindicatos por actividades huelguísticas de sus afiliados. Un análisis comparado de los ordenamientos español y norteamericano», Relaciones Laborales, núm. 9 (2006), pág. 18.

48 Véase R.A. GORMAN, Basic Text on Labor Law. Unionization and Collective Bargaining, cit., págs. 639 y ss.

49 Cfr. sección 6 de la citada Ley (Consolidada) Sindical y de Relaciones Laborales de 1992.

50 Véase J. MARTÍNEZ GIRÓN, «Las elecciones sindicales en los Estados Unidos», cit., pág. 53, nota 70 . 
TEMA 12

EL DERECHO DE PARTICIPACIÓN DE LOS TRABAJADORES EN LA EMPRESA EN EL ORDENAMIENTO COMUNITARIO, EN LAS LEGISLACIONES Y PRÁCTICAS NACIONALES EUROPEAS, Y EN LA LEGISLACIÓN DE LOS ESTADOS UNIDOS

Sumario: §1. El Derecho de la Unión Europea sobre participación de los trabajadores en la empresa, ad extra y ad intra. \$2. Los modelos nacionales europeos (portugués y francés) de representación unitaria de los trabajadores carente de capacidad negociadora. §3. Los modelos nacionales europeos (español y alemán) de representación unitaria de los trabajadores dotada de capacidad negociadora. \$4. El modelo italiano de representación sindical unitaria de los trabajadores. §5. Los modelos británico y norteamericano de participación de los trabajadores en la empresa a través de la negociación colectiva.

THEME 12

THE RIGHT OF PARTICIPATION OF THE EMPLOYEES IN THE ENTERPRISE IN THE EUROPEAN LAW, IN THE NATIONAL EUROPEAN LEGISLATIONS AND PRACTICES, AND IN THE LEGISLATION OF THE UNITED STATES

Contents: $\$ 1$. The Law of the European Union about participation of the employees in the enterprise, ad extra and ad intra. \$2. The national European (Portuguese and French) models of unitarian representation of the employees without negociating capacity. \$3. The national European (Spanish and German) models of unitarian representation of the employees with negociating capacity. \$4. The Italian model of union unitarian representation of the employees. \$5. The British and USA models of participation in the enterprise through collective bargaining.

§1. A diferencia de lo que ocurre en materia de libertad sindical ${ }^{1}$, el Derecho ad extra de la Unión Europea relativo a la participación de los trabajadores en la empresa-que ahora tiende a denominarse de «implicación de los trabajadores»- puede considerarse, en cambio, que sí resulta significativo. En primer lugar, por causa de su tradición de ya tres décadas, puesto que la primera norma

1 Véase supra, Tema 11, §4. 
comunitaria regulando la «información y consulta» por el empresario a los representantes de sus trabajadores - a propósito de los traspasos de empresas - se remonta al año 1977, y por tanto, casi a los albores mismos del ordenamiento laboral comunitario ${ }^{2}$. En segundo lugar, porque aparece positivizado en un coherente conjunto de cinco Directivas distintas, habiendo sido la última promulgada sobre el tema — que viene a operar, además, como una especie de norma de cierre - la Directiva 2002/14/CE del Parlamento Europeo y del Consejo, de 11 marzo 2002, por la que se establece un marco general relativo a la información y a la consulta de los trabajadores en la Comunidad Europea. En tercer lugar, por ser un Derecho posibilista, que actúa con diferente grado de intensidad creativa o innovadora, según que la participación de los trabajadores que procede a regular se refiera a empresas de dimensión comunitaria o, por el contrario, a empresas de dimensión meramente nacional. En efecto, en el plano transnacional europeo, su nivel de creatividad es muy grande, al obligar a los Estados miembros a tener que regular formas incluso extremas de participación de los trabajadores en la empresa, como en el caso - del todo asimilable a la «cogestión en la empresa [Mitbestimmung im Unternehmen]», típicamente alemana ${ }^{3}$, a no confundir con la «cogestión en el centro de trabajo [Mitbestimmung im Betrieb]», ya no tan típicamente alemana ${ }^{4}$ — de la participación de los

2 Sobre estos albores, véase J. MARTÍNEZ GIRÓN, A. ARUFE VARELA y X.M. CARRIL VÁZQUEZ, Derecho del Trabajo, 2a ed., Netbiblo (A Coruña, 2006), pág. 100.

3 Regulada en la Ley sobre la Cogestión de los Trabajadores en los Consejos de Vigilancia y Consejos de Dirección de las Empresas de la Minería y de la Industria Productora de Hierro y Acero (Gesetz über die Mitbestimmung der Arbeitnehmer in den Aufsichtsräten und Vorständen der Unternehmen des Bergbaus und der Eisen und Stahl erzeugenden Industrie) de 1951, en la Ley Complementaria de la Ley sobre la Cogestión de los Trabajadores en los Consejos de Vigilancia y Consejos de Dirección de las Empresas de la Minería y de la Industria Productora de Hierro y Acero (Gesetz zur Ergänzung des Gestzes über die Mitbestimmung der Arbeitnehmer in den Aufsichtsräten und Vorständen der Unternehmen des Bergbaus und der Eisen und Stahl erzeugenden Industrie) de 1956, en la Ley sobre la Cogestión de los Trabajadores (Gesetz über die Mitbestimmung der Arbeitnehmer) de 1976, y en la Ley de Participación de un Tercio de los Trabajadores en el Consejo de Vigilancia (Gestez über die Drittelbeteiligung der Arbeitnehmer im Aufsichtsrat) de 2004. Sobre el tema, véase K. FITTING, O. WLOTZKE y H. WIßMANN (Fundadores), Mitbestimmungsrecht. Mitbestimmungsgesetz, Drittelbeteiligungsgesetz, Wahlordnungen. Mitbestimmung auf europäischer Ebene. Kommentar, $3^{\mathrm{a}}$ ed., Franz Vahlen (Múnich, 2008), págs. 40 y ss.

4 Acerca de esta distinción, que permitiría hablar incluso de cogestión en sentido estricto y cogestión en sentido amplio, teniendo en cuenta que esta última es llevada a cabo por el «comité de empresa» de que se trata infra, \$3, véase P. HANAU. y K. ADOMEIT, Arbeitsrecht, 13ª ed., Luchterhand (Munich, 2005), págs. 102 y ss.; W. DÄUBLER, Arbeitsrecht. Ratgeber für Beruf, Praxis und Studium, 6 a ed., Bund-Verlag [Frankfurt a.M., 2006], págs. 135 y ss.; H. REICHOLD, Arbeitsrecht, 2a ed., C.H. Beck (Munich, 2006), págs. 321 y ss.; A. JUNKER, Grundkurs Arbeitsrecht, 5ª ed., C.H. Beck (Munich, 2006), págs. 358 y ss.; y R. RICHARDI (Editor), Betriebsverfassungsgesetz mit Wahlordnung, 11 a ed., C.H. Beck (Múnich, 2008), págs. 87 y ss. Además, véase la definición dada por A. KOKEMOOR y S. KREISSL, Arbeitsrecht, $3^{\mathrm{a}}$ ed., Boorberg (Stuttgart, 2006), pág. 130. También, en nuestra lengua, F. GAMILLSCHEG, «La cogestión de los trabajadores en el Derecho alemán. Balance a tenor de la Sentencia del Tribunal Constitucional Federal de 1 de marzo de 1979» (traducción castellana de C. MIÑAMBRES PUIG), Revista Española de Derecho del Trabajo, núm. 2 (1980), págs. 169 y ss. 
trabajadores en los órganos de administración y control de las llamadas «Sociedades Europeas». En cambio, en el plano meramente nacional, se trata más bien de un Derecho de mínimos — centrado sólo en las citadas «información y consulta», pero con exclusión de la verdadera negociación colectiva con el empresario-, por causa de los muy diversos modelos de representación unitaria de los trabajadores (esto es, de representación de «todos» los trabajadores ante el empresario, cualquiera que sea su afiliación sindical) existentes en los seis países europeos que venimos comparando - a uno de los cuales se ajusta incluso el propio Derecho ad intra de la Unión Europea, esto es, el relativo a la representación unitaria del personal funcionarial y laboral al servicio de las instituciones de la propia Unión Europea ${ }^{5}$ - y que se van a examinar seguidamente.

Sin duda por causa de estas divergencias, la citada Directiva 2002/14/CE define los «representantes de los trabajadores», limitándose a afirmar — en lo que resulta ser casi una cláusula de estilo en el Derecho laboral comunitario- que son tales «los representantes de los trabajadores con arreglo a lo dispuesto en las legislaciones y/o prácticas nacionales» ${ }^{6}$.

La Carta de Derechos Fundamentales de la Unión Europea proclama que «deberá garantizarse a los trabajadores o a sus representantes, en los niveles adecuados, la información y consulta con suficiente antelación, en los casos y condiciones previstos en el Derecho de la Unión y en las legislaciones y prácticas nacionales» ${ }^{7}$, aclarándose —en las «explicaciones» relativas a este concreto derecho- lo siguiente, en lo esencial: 1) que «este artículo figura en la Carta Social Europea revisada (artículo 21) y en la Carta Comunitaria de los Derechos Sociales Fundamentales de los Trabajadores (puntos 17 y 18)»; 2) que «la referencia a los niveles adecuados remite a los niveles previstos por el Derecho de la Unión o por el Derecho o las prácticas nacionales, lo que puede incluir el nivel europeo cuando la legislación de la Unión lo prevea»; y 3) que «el acervo de la Unión en este ámbito es importante: artículos 154 y 155 del Tratado de Funcionamiento de la Unión Europea y Directivas 2002/14/CE (marco general relativo a la información y a la consulta de los trabajadores), 98/59/CE (despidos colectivos), 2001/23/CE (traspasos de empresas) y 94/45/CE (comités de empresa europeos)».

A este conjunto de cuatro Directivas hay que agregar la Directiva 2001/86/CE del Consejo, de 8 octubre 2001, que completa el estatuto de la Sociedad Anónima Europea en lo que respecta a la implicación de los trabajadores ${ }^{8}$. Según ella, «implicación de los

5 Véase infra, \$2.

6 Artículo 2.e).

Artículo 27 (rotulado «Derecho a la información y consulta de los trabajadores en la empresa»).

8 Al respecto, véase M.E. CASAS BAAMONDE, «La implicación de los trabajadores en la Sociedad Anónima Europea (Procedimiento de negociación colectiva y diferentes modelos de implicación convenida)», Revista Española de Derecho del Trabajo, núm. 117 (2003), págs. 355 y ss.; J.L. MONEREO PÉREZ, J.A FERNÁNDEZ AVILÉS, Ma .D. GARCÍA VALVERDE y J.A. MALDONADO MOLINA, La Participación de los Trabajadores en las Sociedades Anónimas y Cooperativas Europeas. Estudio sistemático y crítico de la Ley 31/2006, de 18 de octubre, Thomson-Aranzadi (Cizur Menor-Navarra, 2007), págs. 15 y ss.; y A. ARUFE VARELA, «La implicación de los trabajadores en la sociedad anónima europea: puntos críticos sobre la Ley 31/2006, de 18 de octubre», Actualidad Laboral, núm. (2009), págs. 2572 y ss. 
trabajadores» es «la información, la consulta y la participación, y cualquier otro mecanismo mediante el cual los representantes de los trabajadores pueden influir en las decisiones que se adopten en la empresa» ${ }^{9}$. Además — siempre según esta Directiva-, «participación» (en sentido estricto) es «la influencia del órgano de representación de los trabajadores o los representantes de los trabajadores en una sociedad mediante», bien «el derecho de elegir o designar a determinados miembros del órgano de administración o de control de la sociedad», bien «el derecho de recomendar u oponerse a la designación de una parte o de todos los miembros del órgano de administración o de control de la sociedad» ${ }^{10}$.

§2. Desde un punto de vista orgánico, la estructura de la representación unitaria de los trabajadores es muy distinta en Portugal y en Francia. En efecto, la representación unitaria portuguesa es simple, al estar encarnada en un único tipo de órganos denominados «comisiones de trabajadores [comissões de trabalhadores]», de las que en principio existe una en cada empresa ${ }^{11}$; en cambio, la representación unitaria francesa es dual, al diversificarse en «delegados del personal [délégués du personnel]» ${ }^{12}$ y «comités de empresa [comités d'entreprise]» ${ }^{13}$, que en principio coexisten y actúan paralela e independientemente en cada centro de trabajo ${ }^{14}$. Ahora bien, a pesar de ello, cabe afirmar que Portugal y Francia se ajustan a un mismo modelo de representación unitaria ${ }^{15}$-que ha acabado influyendo sobre el modelo de representación unitaria del personal funcionarial y laboral al servicio de las instituciones de la Unión

9 Artículo 2.h). Téngase en cuenta que las Directivas 98/59/CE y 2001/23/CE matizan que la «consulta», aunque no se negocie, se realiza «con vistas a llegar a un acuerdo» o «con el fin de llegar a un acuerdo» (cfr. sus artículos 2.1 y 7.2 , respectivamente).

10 Artículo 2.k).

11 Cfr. artículo 415.1 del Código del Trabajo. Sobre la fundamentación constitucional de este tipo de representación, véase P. ROMANO MARTINEZ, L.M. MONTEIRO, J. VASCONCELOS, P. MADEIRA BRITO, G. DRAY y L. GONÇALVES DA SILVA, Código do Trabalho. Anotado, 4ª ed., Almedina (Coimbra, 2005), págs. 736 y ss.

12 Regulados en los artículos L. 2311-1 a L. 2316-1 del Código del Trabajo.

13 Regulados en los artículos L. 2321-1 a 2335-1 del Código del Trabajo.

14 Por eso, el artículo L. 2314-19 del Código del Trabajo afirma que «no hay incompatibilidad entre las funciones de delegado del personal y las de miembro del comité de empresa». Téngase en cuenta que «el personal elige delegados en todos los centros de trabajo de once trabajadores y más» (artículo L. 2312-1), y que el «comité de empresa se constituye en todas las empresas que empleen cincuenta trabajadores y más» (artículo L. 2322-1). Siempre según el Código del Trabajo, «en las empresas que tengan centros de trabajo distintos, se crean comités de centro [comités d'établissement] y un comité central de empresa [comité central d'entreprise]» (artículo L. 2327-1). Sobre el «comité de grupo de empresas [comité de groupe]», véanse artículos L. 2331-1 a L. 2335-1 del propio Código.

15 Aun teniendo en cuenta la peculiaridad superlativa representada por el hecho de que el «comité de empresa» francés sea de composición tripartita, pues «comprende el empresario» — que lo preside—, una «delegación del personal» - elegida directamente por los trabajadores del centro- y un representante de cada organización sindical de trabajadores representativa en la empresa, aunque este representante sindical «asiste a las sesiones con voz pero sin voto [avec voix consultive]» (cfr. artículos L. 2324-1 y L. 2324-2 del Código del Trabajo). Por ello, el artículo L. 2325-18 del propio Código se ve obligado a matizar que «el presidente del comité no participa en la votación cuando consulta a los miembros electos del comité en tanto que delegación del personal» (párrafo segundo). 
Europea ${ }^{16}$ - fundamentalmente por dos razones. En primer lugar, porque en ambos países - frente a lo que ocurre en algún otro país europeo de referencia - pueden resultar elegidos como representantes unitarios sujetos independientes (esto es, sujetos no afiliados a ningún sindicato) ${ }^{17}$. En segundo lugar, porque los órganos en cuestión carecen de capacidad negociadora frente al empresario ${ }^{18}$, pues — como ya se vio ${ }^{19}$ — la negociación colectiva sectorial y empresarial está monopolizada en Portugal y en Francia, del lado de los trabajadores, por los sindicatos.

En Francia, la elección de los «delegados del personal» y de los miembros de los «comités de empresa» se efectúa por el sistema «de dos vueltas [à deux tours $] »{ }^{20}$. Sobre esta base, sólo en la segunda vuelta cabe elegir candidatos independientes, supuesto que en la primera vuelta los presentados por los sindicatos no hubiesen obtenido al menos la mitad de los votos de los trabajadores electores ${ }^{21}$. Al parecer, este hecho empieza a resultar infrecuente, pues «las competencias económicas ... difícilmente pueden ser ejercidas por los elegidos privados de los recursos y de la experiencia de una organización sindical» ${ }^{22}$.

Desde 1993, el empresario francés puede - si quiere - evitar que en sus centros de trabajo coexistan «delegados del personal» y «comités de empresa», apelando a la denominada «delegación única». En este caso, los «delegados del personal» asumen las competencias del «comité de empresa». Pero sólo resulta posible en empresas medianas y pequeñas, pues «en las empresas de menos de doscientos trabajadores, el empresario puede decidir que los delegados del personal constituyan la delegación del personal en el comité de empresa» ${ }^{23}$, aunque «no puede tomar esta decisión más que después de haber consultado a los delegados del personal y, si existe, al comité de empresa» ${ }^{24}$.

Aunque en Portugal la regla sea la existencia de una sola «comisión de trabajadores» por empresa, también «pueden crearse subcomisiones de trabajadores [subcomissões de trabalhadores] en centros de trabajo de la empresa geográficamente dispersos» ${ }^{25}$, e incluso, «comisiones coordinadoras [comissões coordenadoras] ${ }^{26}$.

16 Esta representación unitaria intracomunitaria está encarnada en el denominado «comité de personal», regulado en el artículo 9.1.a) y en el Anexo II del «Estatuto de los Funcionarios», aprobado por el Reglamento núm. 31 (CEE), núm. 11 (CEEA) de 1962. Según este mismo Estatuto, es claro que dicho «comité de personal» carece de capacidad convencional, que monopolizan las organizaciones sindicales o profesionales «representativas» ante las instituciones de la Unión Europea (cfr. artículos 10.ter y 10.quater).

17 Para el caso de Portugal, véase artículo 415.3 del Código del Trabajo.

18 Téngase en cuenta, respecto de Francia, que ésta es la regla si se trata de «empresas provistas de uno o varios delegados sindicales [entreprises pourvues d'un ou plusieurs délégués syndicaux]» (cfr. artículos L. 2232-12 a L. 2232-20), previendo el Código del Trabajo la posibilidad de convenios empresariales negociados «por uno o varios trabajadores apoderados», cuando ni siquiera exista representación unitaria del personal (cfr. artículos L. 2232-24 a L. 2232-27). Respecto de los «derechos» de las «comisiones de trabajadores», véanse el artículo 423 del Código del Trabajo, y A. MONTEIRO FERNANDES, Direito do Trabalho, $15^{\text {a }}$ ed., Almedina (Coimbra, 2010), págs. 758 y ss.

19 Supra, Tema 11, \$2 y \$3.

20 Cfr. artículos L. 2314-24 y L. 2324-22 del Código del Trabajo.

21 Ibidem.

22 Véase J. PÉLISSIER, A. SUPIOT y A. JEAMMAUD, Droit du Travail, 24ª ed., Dalloz (París, 2008), pág. 1138 .

23 Artículo L. 2326-1, párrafo primero, inciso primero, del Código del Trabajo.

24 Ibidem, inciso segundo.

25 Artículo 415.2 del Código del Trabajo.

26 Cfr. artículo 415.4 del Código del Trabajo. 
§3. También España y Alemania poseen un sistema de representación unitaria de los trabajadores estructuralmente diferente, que se confía en nuestro país a los «delegados de personal» (en centros de trabajo de entre 6 y 49 trabajadores) y a los "comités de empresa» (en centros de trabajo de 50 ó más trabajadores) ${ }^{27}$, mientras que en Alemania la asume el "comité de empresa [Betriebsrat]» (existente en centros de trabajo que tengan 5 ó más trabajadores) ${ }^{28}$. Además, al igual que ocurre en Portugal y en Francia, cabe también que en estos otros dos países puedan resultan elegidos sujetos independientes como representantes unitarios ${ }^{29}$. Ahora bien, a pesar de ello, España y Alemania conforman un modelo propio de representación unitaria -inasimilable al modelo portugués y francés-, puesto que los representantes unitarios españoles y alemanes -al igual que los sindicatos en ambos países-tienen capacidad para negociar convenios colectivos con el empresario ${ }^{30}$.

En Alemania, los convenios colectivos estipulados por el «comité de empresa» y el empresario se denominan legalmente «acuerdos de empresa [Betriebsvereinbarungen] ${ }^{31}$. Aunque similares a los «convenios colectivos [Tarifverträge]» en sentido estricto - negociados por los sindicatos con el empresario o las asociaciones de empresarios ${ }^{32}$-, no pueden contradecir lo dispuesto en estos últimos. De ahí que la legislación alemana afirme que «los salarios y demás condiciones de trabajo que estén o sean principalmente reguladas por convenio colectivo no pueden ser objeto de un acuerdo de empresa» ${ }^{33}$, aunque «esto no se

27 Acerca de todo ello, véase J. MARTÍNEZ GIRÓN, A. ARUFE VARELA y X.M. CARRIL VÁZQUEZ, Derecho del Trabajo, $2^{\mathrm{a}}$ ed., cit., págs. 361 y ss. Sobre las disfunciones del sistema, clarificador y ordenador, véase A. ARUFE VARELA, «Los representantes legales o unitarios "extraestatutarios" de los trabajadores», Revista Española de Derecho del Trabajo, núm. 127 (2005), págs. 297 y ss.

28 Al respecto, véase parágrafo 1 de la Ley de Organización de la Empresa (Betriebsverfassungsge setz) de 1972. Según la propia Ley, «si existen en una empresa varios comités de empresa, entonces hay que crear un comité de empresa conjunto [Gesamtbetriebsrat]» (parágrafo 47, apartado 1). Aparte «comités de empresa» especiales (de de grupos de sociedades, de flota, de transporte aéreo, etc.), esta misma Ley regula la «representación de jóvenes y la representación de aprendices [Jugend- und Auszubildendenvertretung]» (cfr. parágrafos 60 y ss.), que ejerce sus derechos «frente al comité de empresa, no frente al empresario» (cfr. W. DÄUBLER, Arbeitsrecht. Ratgeber für Beruf, Praxis und Studium, $6^{a}$ ed., cit., pág. 130). Nuestra traducción de la gigantesca Ley de Organización de la Empresa, en J. MARTÍNEZ GIRÓN y A. ARUFE VARELA, Leyes laborales alemanas. Estudio comparado y traducción castellana, Netbiblo (A Coruña, 2007), págs. 179 y ss.

29 Para el caso de Alemania, véase el parágrafo 14, apartado 3, de la Ley de Organización de la Empresa, según el cual «para la elección del comité de empresa pueden hacer listas electorales [Wahlvorschläge] los trabajadores electores y los sindicatos representados en el centro de trabajo»; y W. DÄUBLER, Arbeitsrecht. Ratgeber für Beruf, Praxis und Studium, $6^{\mathrm{a}}$ ed., cit., págs. 76 y ss.

30 Sobre el tema en nuestro Derecho, véase J. MARTÍNEZ GIRÓN, A. ARUFE VARELA y X.M. CARRIL VÁZQUEZ, Derecho del Trabajo, $2^{\text {a }}$ ed., cit., págs. 370-371.

31 Ésta es justamente, en parte, la rúbrica del parágrafo 77 de la Ley de Organización de la Empresa.

32 Por eso, los «acuerdos de empresa... hay que redactarlos por escrito» (ibidem, apartado 2, inciso primero). Más precisiones, infra, Tema 13, §2.

33 Parágrafo 77 , apartado 3 , inciso primero. 
aplica cuando un convenio colectivo admite expresamente la celebración de acuerdos de empresa complementarios» ${ }^{34}$.

También a diferencia de lo que ocurre en España, los «comités de empresa» alemanes carecen del derecho de declarar huelgas u otras medidas de presión colectiva frente al empresario, pues «las medidas de lucha laboral entre el empresario y el comité de empresa son inadmisibles», debiendo ambos «abstenerse de acciones a través de las que sean perjudicadas la actividad laboral o la paz del centro de trabajo» ${ }^{35}$.

Siempre en Alemania, la regla es que los miembros de los "comités de empresa» alemanes estén afiliados en su inmensa mayoría a algún sindicato ${ }^{36}$, afirmando la norma reguladora del asunto que «los trabajadores que desarrollen funciones en el marco de esta Ley no serán perjudicados a causa de ello por la actividad para su sindicato también en el centro de trabajo» ${ }^{37}$.

§4. Al igual que sucede en España y Alemania, la representación unitaria de los trabajadores también tiene en Italia capacidad para negociar convenios colectivos empresariales, aunque el modelo italiano resulta inasimilable al de dichos dos países, por causa de que en los correspondientes procesos electorales italianos las listas de candidatos son elaboradas única y exclusivamente por los sindicato ${ }^{38}$. De ahí que en Italia se denomine a esta institución «representación sindical unitaria [rappresentanza sindacale unitaria]» de los trabajadores en la empresa, apareciendo regulada en un acuerdo Gobierno-Sindicatos de 23 julio $1993^{39}$, desarrollado por el «Acuerdo interconfederal para la constitución de las representaciones sindicales unitarias» de 1 diciembre $1993^{40}$. Según este último pacto, en las correspondientes elecciones (que

34 Ibidem, inciso segundo. Al respecto, véase O.E. KEMPEN y U. ZACHERT (Editores), Tarifvertragsgesetz, $4^{\mathrm{a}}$ ed., Bund-Verlag (Frankfurt am Maine, 2006), págs. 231 y ss.

35 Cfr. parágrafo 74, apartado 2, inciso primero, de la Ley de Organización de la Empresa. También, véase infra, Tema $14, \$ 2$.

36 Según la doctrina, «aproximadamente el 80 por ciento de los miembros de comités de empresa están organizados sindicalmente» (cfr. W. DÄUBLER, Arbeitsrecht. Ratgeber für Beruf, Praxis und

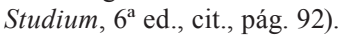

37 Cfr. parágrafo 74, apartado 3, de la Ley de Organización de la Empresa. Sobre el tema, véase A. JUNKER, Grundkurs Arbeitsrecht, $5^{\mathrm{a}}$ ed., cit., págs. 364 y ss.

38 Véase A. TURSI y P.A. VARESI, Lineamenti di Diritto del Lavoro. Rapporti di lavoro e relazioni sindacali nel settore privato, $3^{\mathrm{a}}$ ed., Kluwer-Ipsoa (s.1., 2004), págs. 305 y ss.

39 Oficialmente denominado «Protocolo sobre la política de rentas y de la ocupación, sobre especificaciones convencionales, sobre políticas del trabajo y sobre el apoyo al sistema productivo [Protocollo sulla politica dei redditi e dell'occupazione, sugli assetti contrattuali, sulle politiche del lavoro e sul sostegno al sistema produttivo]».

40 El texto íntegro de estos dos acuerdos, además de en el «Archivo Nacional» mencionado supra (Tema 5, §3), también puede localizarse - junto con otros muchos materiales de interés sobre el tema, incluso jurisprudenciales - en el sitio de Internet www.coordinamentorsu.it. Acerca de la sustitución de las estructuras representativas reguladas por el artículo 19 de la Ley núm. 300, de 20 mayo 1970 —-denominadas «representaciones sindicales empresariales [rappresentanze sindacali aziendali]» o RSA-, por estas otras estructuras representativas convencionales, véase A. TURSI y P.A. VARESI, Lineamenti di Diritto del Lavoro. Rapporti di lavoro e relazioni sindacali nel settore privato, $3^{\mathrm{a}}$ ed., cit., págs. 306 y ss. 
aquí, con claridad, sí son verdaderas «elecciones sindicales») sólo pueden concurrir listas electorales que sean presentadas: 1) por «las asociaciones sindicales firmantes del presente acuerdo y del convenio colectivo nacional de trabajo aplicado en la unidad productiva» ${ }^{41}$; y 2) también, por «asociaciones sindicales formalmente constituidas», a condición de que «acepten expresamente y formalmente la presente regulación», y siempre y cuando su «lista sea apoyada por un número de firmas de trabajadores dependientes de la unidad productiva igual al 5\% de los que tengan derecho de voto» ${ }^{42}$.

Los dos acuerdos citados confirman la naturaleza de representación «unitaria» de este peculiar tipo de órganos, al afirmar que su «composición... deriva en $2 / 3$ de la elección por parte de todos los trabajadores y para $1 / 3$ de la designación o elección por parte de las organizaciones estipulantes del CCNL [convenio colectivo nacional de trabajo], que han presentado listas, en proporción a los votos obtenidos» ${ }^{43}$.

Los propios acuerdos reconocen asimismo su capacidad negociadora, dado que «la RSU [representación sindical unitaria] y las estructuras territoriales competentes de las asociaciones sindicales firmantes del convenio colectivo nacional de trabajo, pueden estipular el convenio colectivo empresarial en las materias, con el procedimiento, modalidad y dentro de los límites establecidos por el convenio colectivo nacional aplicado en la unidad productiva» ${ }^{44}$.

Este mismo sistema de representación unitaria ha sido extendido a las Administraciones públicas italianas por el Decreto Legislativo núm. 396 de 4 noviembre 1997, según el cual «en toda Administración, ente o estructura administrativa..., a iniciativa de las organizaciones sindicales..., se constituye asimismo... un organismo de representación unitaria del personal mediante elecciones en las que se garantice la participación de todos los trabajadores» ${ }^{45}$.

§5. En Gran Bretaña y, también, en los Estados Unidos de Norteamérica, desde siempre vino considerándose que la participación de los trabajadores en la empresa se desarrolla a través de la negociación colectiva-consumándose, en consecuencia, con la celebración de convenios colectivos empresariales ${ }^{46}$-, lo que explica que la representación unitaria de los trabajadores fuese tradicionalmente asumida en estos dos países por el

41 Parte Segunda, apartado 4, letra a.

42 Ibidem, letra b.

43 Cfr. Acuerdo Gobierno-Sindicatos de 23 julio 1993, núm. 2, apartado 5, letra a), párrafo segundo; además, en el citado Acuerdo Interconfederal, su Parte Primera, apartado 2, párrafo primero.

44 Cfr. Acuerdo Interconfederal citado, Parte Primera, apartado 5, párrafo segundo; además, en el citado acuerdo Gobierno-Sindicatos, su núm. 2, apartado 5, letra e).

45 Cfr. su artículo 6. Al respecto, véase F. DEL GIUDICE y F. MARIANI, Diritto Sindacale, Simone (Nápoles, 2001), págs. 133 y ss.

46 Véase L.S. MERRIFIELD, «La participación del trabajador en las decisiones de las empresas» (traducción castellana de J. MARTÍNEZ GIRÓN), Revista Española de Derecho del Trabajo, núm. 12 (1982), págs. 501 y ss. 
sindicato «reconocido» - a los efectos de la negociación colectiva- por el empresario ${ }^{47}$; sindicato actuante en las fábricas, normalmente, por medio de uno o varios «enlaces sindicales [shop stewards]》 ${ }^{48}$. Ahora bien, el Tribunal de Justicia de las Comunidades Europeas declaró en 1994 incompatible este modelo británico con la legislación comunitaria sobre participación de los trabajadores en la empresa, supuesto que dicho modelo toleraba que en un buen número de empresas - de todos los tamaños - no hubiese ningún tipo de representación de los trabajadores, que debiese ser informada o consultada por el empresario, por falta de «reconocimiento» empresarial como interlocutor de algún sindicato ${ }^{49}$. Por ello, la legislación sindical británica tuvo que ser enmendada, al efecto de posibilitar la existencia en las empresas de algún tipo de representación unitaria de los trabajadores afectados — cuando no haya representación sindical «reconocida» por el empresario-, aunque se trate de una representación unitaria ad hoc y meramente contingente.

En lo esencial, este tema aparece actualmente regulado en las secciones 188 y $188 \mathrm{~A}$ de la Ley (Consolidada) Sindical y de Relaciones Laborales [Trade Union and Labour Relations (Consolidation) Act] de $1992^{50}$. Según esta normativa, el empresario - para que la representación unitaria exista - debe organizar una elección «limpia [fair]» ${ }^{51}$, determinando «el número de los representantes a elegir, en tanto sean representantes suficientes como para representar los intereses de todos los trabajadores afectados» ${ }^{52}$. Incluso, «antes de la elección, el empresario determinará la duración del mandato [term of office] como representantes de los trabajadores, en tanto sea de extensión suficiente como para permitir la información a ser dada y las consultas... a ser completadas» ${ }^{53}$.

La Sentencia comunitaria citada rechazó el argumento relativo, literalmente, a que «el Gobierno del Reino Unido reconoce que en el Reino Unido la representación de los trabajadores en la empresa se basa tradicionalmente en el reconocimiento voluntario de los sindicatos por parte del empresario y que, en consecuencia, el empresario que no reconoce

47 Véase supra, Tema 11, §4 (para Gran Bretaña) y \$5 (para los Estados Unidos).

48 Véase, para Gran Bretaña, S. HONEYBALL y J. BOWERS, Textbook on Labour Law, $8^{\mathrm{a}}$ ed., Oxford University Press (Oxford, 2004), pág. 367; y para los Estados Unidos, con recopilación de jurisprudencia pertinente, T.J. HEINSZ, D.R. NOLAN y R.A. BALES, Labor Law. Collective bargaining in a free society, $6^{\mathrm{a}}$ ed., West Group-Thomson (St. Paul-Minn., 2009), págs. 364 y ss.

49 Cfr. Fallo de la Sentencia del Tribunal de Justicia de las Comunidades Europeas de 8 junio 1994 (asunto C-382/92), en el caso «Comisión de las Comunidades Europeas contra Reino Unido de Gran Bretaña e Irlanda del Norte», en proceso sobre incumplimiento de ciertas disposiciones de la citada Directiva 77/187/CEE, sobre traspasos de empresas.

50 Véase, además, el «voluntarista» Reglamento de Información y Consulta de los Trabajadores (Information and Consultation of Employees Regulations), aprobado por Statutory Instrument núm. 3426 de 2004 (y promulgado para transponer la Directiva 2002/14/CE), aplicable sólo en empresas que tengan 50 ó más trabajadores; y el Reglamento (Protección del Empleo) de Traspaso de Empresas [Transfer of Undertakings (Protection of Employment) Regulations] de 2006, aprobado por Statutory Instrument núm. 246 de 2006.

51 Cfr. sección 188A(1)(a).

52 Cfr. sección $188 \mathrm{~A}(1)(\mathrm{b})$.

53 Cfr. sección $188 \mathrm{~A}(1)(\mathrm{d})$. 
al sindicato no está sometido a las obligaciones de información y consulta previstas [por el Derecho comunitario]..., pero sostiene que [el Derecho comunitario]... no ha querido modificar las normas o las prácticas nacionales de designación de los representantes de los trabajadores» ${ }^{54}$.

En los Estados Unidos, las representaciones unitarias de los trabajadores con meras competencias de información y consulta sobre las condiciones de trabajo — genéricamente denominadas «programas de participación del trabajador [employee participation progra$m s] »-$, aun en ausencia de sindicato «reconocido» por el empresario como representante exclusivo de sus trabajadores, se consideran «práctica laboral sucia del empresario [employer unfair labor practice]», dada la aparente imposibilidad de distinguirlas - siempre desde el punto de vista norteamericano- de los sindicatos espurios, dominados o controlados por el propio empresario ${ }^{55}$.

54 Cfr. «Motivación de la Sentencia», apartado 13.

55 Al respecto, con cita de reiterada jurisprudencia de la Oficina Nacional de Relaciones Laborales (National Labor Relations Board), véase T.J. HEINSZ, D.R. NOLAN y R.A. BALES, Labor Law. Collective bargaining in a free society, $6^{\mathrm{a}}$ ed., cit., págs. 364 y ss. 


\section{TEMA 13 \\ EL DERECHO DE NEGOCIACIÓN COLECTIVA EN EL ORDENAMIENTO COMUNITARIO, EN LAS LEGISLACIONES Y PRÁCTICAS NACIONALES EUROPEAS, Y EN LA LEGISLACIÓN DE LOS ESTADOS UNIDOS}

Sumario: §1. El Derecho de la Unión Europea y el derecho de negociación colectiva, ad extra y ad intra. \$2. El modelo alemán (y su variante portuguesa) de convenio colectivo sectorial de eficacia normativa limitada basada en la doble afiliación. §3. El modelo francés (y su variante italiana provisional) de convenio colectivo sectorial de eficacia normativa limitada basada en la nuda afiliación empresarial. §4. El modelo británico de convenio colectivo no normativo (o «acuerdo entre caballeros»). §5. El modelo norteamericano de convenio colectivo empresarial de eficacia normativa general.

THEME 13

THE RIGHT TO COLLECTIVE BARGAINING IN THE EUROPEAN LAW, IN THE NATIONAL EUROPEAN LEGISLATIONS AND PRACTICES, AND IN THE LEGISLATION OF THE UNITED STATES

Contents: $\$ 1$. The Law of the European Union and the right to collective bargaining, ad extra and ad intra. \$2. The German model (and its Portuguese variant) of industry level collective agreement with limited regulatory applicability founded on the double membership. \$3. The French model (and its provisional Italian variant) of industry level collective agreement with limited regulatory applicability founded on the single membership of the employer. $\$ 4$. The British model of non-regulatory collective agreement (or "gentlemen's agreement»). \$5. The USA model of company level collective agreement with general regulatory applicability.

§1. E1 Derecho de la Unión Europea regulador del derecho de negociación colectiva, si observado con frialdad y desapasionamiento, debe ser calificado como un Derecho hipócrita. Enefecto, en el plano de la negociación colectiva ad extra - esto es, la que tiene lugar extramuros de la Administración pública de la Unión Europea-, las fuentes reguladoras de la misma, originarias (contenidas en los artículos 154 y 155 del Tratado 
de Funcionamiento de la Unión Europea) y derivadas ${ }^{1}$, conforman un Derecho políticamente correcto, cuyas líneas maestras son tres: 1) la negociación colectiva que regulan (denominada «diálogo social») equivale a lo que en España se conoce genéricamente con el nombre de «concertación social» ${ }^{2}$; 2) este «diálogo social» puede ser interprofesional (también denominado «general») y profesional (también denominado «sectorial»); y 3) el «diálogo social» en su vertiente «general», supuesto que sea bipartito o sólo entre los interlocutores sociales europeos asimismo «generales» ${ }^{3}$, se materializa en dos grandes tipos de acuerdos, que son: a) los acuerdos aplicados «sobre la base de una decisión del Consejo adoptada a propuesta de la Comisión» (decisión que suele ser una Directiva), cuyo texto se publica en el Diario Oficial de la Unión Europea; y b) los acuerdos aplicados «según los procedimientos y prácticas propios de los interlocutores sociales y de los Estados miembros» (popularmente denominados acuerdos «autónomos»), cuyo texto -al tratarse de meros convenios para convenir luego en el plano nacional- no se publica en el Diario Oficial de la Unión Europea. En cambio, en el plano ad intra, todo son resistencias a reconocer el derecho de negociación colectiva de los representantes del personal al servicio de la Administración pública de la Unión Europea, habiéndose enmendado últimamente -en 2004- el «Estatuto de los funcionarios», aprobado por el Reglamento núm. 31 (CEE) 11 (CEEA) de 1962, para limitarse a indicar — haciéndose un eco lejano, más que del modelo alemán, del modelo francés de negociación colectiva- que «cada institución podrá celebrar acuerdos relativos a su personal con sus organizaciones sindicales y profesionales representativas» ${ }^{4}$. Refuerza esta impresión de hipocresía, supuesto que la Administración pública de la Unión Europea no emplea sólo funcionarios, lo que la Carta de los Derechos Fundamentales de la Unión Europea proclama respecto del derecho de negociación colectiva. Y es que, de acuerdo con su artículo 28, «los trabajadores y los empresarios, o sus

1 Acerca de algunas de ellas, en conexión con lo sindical, véase supra, Tema 11, §4. También, F. PÉREZ DE LOS COBOS ORIHUEL, «Aporías de la negociación colectiva europea», en F. PÉREZ DE LOS COBOS y J.M. GOERLICH (Coordinadores), El régimen jurídico de la negociación colectiva en España, Tirant lo Blanch (Valencia, 2006), págs. 13 y ss.; y M.-L. MORIN, Le droit des salariés à la négociation collective principe général du droit, LGDJ (Paris, 1994), págs. 167 y ss.

2 Al respecto, véase J. MARTÍNEZ GIRÓN, A. ARUFE VARELA y X.M. CARRIL VÁZQUEZ, Derecho del Trabajo, $2^{\mathrm{a}}$ ed., Netbiblo (A Coruña, 2006), págs. 399-400.

3 Sobre el tripartito y al más alto nivel, ibidem, págs. 495-496.

4 Cfr. artículo 10.quater, inciso primero. 
organizaciones respectivas, de conformidad con el Derecho de la Unión y con las legislaciones y prácticas nacionales, tienen derecho a negociar y celebrar convenios colectivos», pudiendo reconducirse tales legislaciones y prácticas nacionales en esencia a los tres modelos siguientes.

Asimismo, se aclara — en la «explicación» correspondiente — que dicho precepto «se basa en el artículo 6 de la Carta Social Europea, así como en la Carta Comunitaria de los Derechos Sociales Fundamentales de los Trabajadores (puntos 12 a 14)».

La negociación colectiva ad intra (también llamada «concertación») existe, al menos, desde 1974. Sus fuentes reguladoras principales parecen ser, desde un punto de vista orgánico, una Decisión del Consejo de 23 junio 1981, creando la denominada «Comisión de Concertación»; y desde un punto de vista sustantivo, el denominado «acuerdo marco» de 2008, estipulado entre la Comisión y las «organizaciones sindicales y profesionales» que la propia Comisión considera representativas, regulador de los derechos colectivos de tales organizaciones ${ }^{5}$. Estas fuentes reguladoras resultan, sin embargo, ilocalizables en el, en todo lo demás eficacísimo, utilísimo y tan políticamente correcto, portal jurídico de la Unión Europea ${ }^{6}$.

En el plano ad extra no existe problema alguno de localización ${ }^{7}$. Entre los acuerdos colectivos de carácter «general» aplicados por Directiva del Consejo, cabe citar el acuerdo marco sobre el permiso parental de 1996, el acuerdo marco sobre el trabajo a tiempo parcial de 1997, o el acuerdo marco sobre el trabajo con contrato de duración determinada de 1999. Entre los «acuerdos autónomos» de carácter «general» no publicados en el Diario Oficial de la Unión Europea, cabe la cita del acuerdo marco sobre el teletrabajo de 2002, del acuerdo marco sobre el «stress» relacionado con el trabajo de 2004 o del acuerdo sobre acoso y violencia en el trabajo de 2007.

\$2. Alemania posee un modelo propio de negociación colectiva, que se encuentra regulado en la «Ley del Convenio Colectivo [Tarifvertragsgesetz]» de $1949^{8}$. En lo esencial, siempre según esta Ley —que posee su propio Reglamento de desarrollo ${ }^{9}$-, el modelo alemán aparece caracterizado por tres notas: 1) el convenio colectivo

5 Véase supra, Tema $11, \$ 4$.

6 Véase J. MARTÍNEZ GIRÓN, «Tipología y eficacia de los acuerdos marco negociados entre la Comisión Europea y las organizaciones sindicales y profesionales representativas de su personal», Aranzadi Social, núm. 6 (2009), págs. 11 y ss.

7 Al respecto, véase supra, Tema $4, \$ 4$.

8 Véase O.E. KEMPEN y U. ZACHERT (Editores), Tarifvertragsgesetz, $4^{\mathrm{a}}$ ed., Bund-Verlag (Frankfurt am Maine, 2006), págs. 275 y ss.; y H. WIEDEMANN, Tarifvertragsgesetz mit Durchfürungs- und Nebenvorschriften, $7^{\text {a }}$ ed., C.H. Beck (Múnich, 2007), págs. 1 y ss. También, U. ZACHERT, «Collective bargaining in Germany», en el volumen Collective bargaining in Europe, Ministerio de Trabajo y Asuntos Sociales (Madrid, 2004), págs. 27 y ss. Nuestra traducción íntegra de la misma, en J. MARTÍNEZ GIRÓN y A. ARUFE VARELA, Leyes laborales alemanas. Estudio comparado y traducción castellana, Netbiblo (A Coruña, 2007), págs. 234 y ss.

9 Se trata del «Reglamento para la ejecución de la Ley del Convenio Colectivo [Verordnung zur Durchführung des Tarifvertragsgesetzes]» de 20 febrero 1970. Nuestra traducción íntegra del mismo, en J. MARTÍNEZ GIRÓN y A. ARUFE VARELA, Leyes laborales alemanas. Estudio comparado y traducción castellana, cit., págs. 239 y ss. 
más social y económicamente relevante es el convenio colectivo sectorial(Flächentarifvertrag o Verbandstarifvertrag) ${ }^{10}$, entendiendo por tal aquél en que las partes son «los sindicatos y ... las asociaciones de empresarios» ${ }^{11}$; 2) este convenio colectivo posee incuestionable eficacia normativa, dado que «las normas jurídicas [Rechtsnormen] del convenio colectivo ... rigen directamente e imperativamente entre ambas partes obligadas por el convenio colectivo que estén incluidas en el ámbito de aplicación del convenio colectivo» ${ }^{12}$; y 3) sin embargo, la eficacia normativa que posee es una eficacia normativa limitada basada en el principio de la doble afiliación -esto es, el convenio colectivo sólo despliega su eficacia sobre los empresarios afiliados a la asociación empresarial pactante y sobre los trabajadores asimismo afiliados al sindicato pactante ${ }^{13}$-, dado que «están obligados [Tarifgebunden] por el convenio colectivo los afiliados a las partes del convenio colectivo» ${ }^{14}$. El modelo portugués resulta ser sólo una variante de este modelo alemán, puesto que — según el Código del Trabajo- «el convenio colectivo de trabajo obliga a los empleadores que lo suscriben y a los afiliados a las asociaciones de empleadores signatarias, así como a los trabajadores a su servicio que sean miembros de las asociaciones sindicales otorgantes» ${ }^{15}$.

Esto es lo que la más reciente jurisprudencia del Supremo Tribunal de Justicia portugués denomina «principio de doble afiliación [princípio de dupla filiação]»—que es, a su vez, lo que nuestra jurisprudencia (a propósito de la negociación colectiva extraestatutaria) denomina principio de la «doble pertenencia» ${ }^{16}$ - en virtud del cual «para la aplicación de

10 Acerca de esta terminología, que no utiliza la Ley del Convenio Colectivo, véase O.E. KEMPEN y U. ZACHERT (Editores), Tarifvertragsgesetz, $4^{\mathrm{a}}$ ed., cit., págs. 282 y ss. Sobre «Tarifkonkurrenz und Tarifpluralität», véase F.J. SÄCKER (Editor), Kollektives Arbeitsrechr. Case by case, Recht und Wirtschaft (Frankfurt am Maine, 2006), págs. 81 y ss.

11 Cfr. parágrafo 2, apartado 1.

12 Cfr. parágrafo 4 (rotulado «Eficacia de las normas jurídicas [Wirkung der Rechtsnormen]»), apartado 1, inciso primero.

13 Desde un punto de vista procesal, véase E. KOCHER, «Requisitos de la demanda y objeto del litigio en el ejercicio de una pretensión de conflicto colectivo sobre cesación de negociaciones individuales en masa violadoras del convenio colectivo» (traducción al castellano de A. ARUFE VARELA), Anuario da Facultade de Dereito da Universidade da Coruña. Revista Jurídica Interdisciplinar Internacional, vol. 10 (2006), págs. 599 y ss.

14 Cfr. parágrafo 3 (rotulado «Obligatoriedad del convenio colectivo [Tarifgebundenheit]»), apartado 1. Al respecto, véase U. ZACHERT, «La eficacia de los convenios colectivos en Alemania» (traducción castellana de A. ARUFE VARELA), Anuario Coruñés de Derecho Comparado del Trabajo-ACDCT, vol. II (2010), págs. 129 y ss.

15 Cfr. artículo 496 (rotulado «Principio de afiliación [Princípio da filiação]»), apartado 1; y A. MONTEIRO FERNANDES, Direito do Trabalho, 15a ed., Almedina (Coimbra, 2010), págs. 833 y ss.

16 Cfr. J. MARTÍNEZ GIRÓN, A. ARUFE VARELA y X.M. CARRIL VÁZQUEZ, Derecho del Trabajo, 2a ed., cit., pág. 447. 
un convenio colectivo, habrá que verificarse, simultáneamente, la afiliación del empleador y del trabajador a la respectiva entidad otorgante» ${ }^{17}$.

En Alemania, a diferencia de los convenios colectivos (Tarifverträge) de empresa, los legalmente denominados «acuerdos de empresa [Betriebsvereinbarungen]» —regulados en la Ley de Organización de la Empresa de 1972 - poseen eficacia normativa general, pero por causa del hecho de que no son negociados por los sindicatos, sino por el comité de empresa (Betriebsrat) ${ }^{18}$. En el ámbito de las administraciones públicas, estos mismos acuerdos se conocen con el nombre de «acuerdos de empresa pública [Dienstvereinbarungen]» ${ }^{19}$.

Siempre en Alemania, los convenios colectivos sectoriales pueden llegar a alcanzar eficacia normativa general — previa resolución administrativa de extensión de los mismos-, afirmando al respecto el parágrafo 5 de la citada Ley del Convenio Colectivo (rotulado «Eficacia general [Allgemeinverbindlichkeit]») ${ }^{20}$ que «el Ministerio federal de Trabajo y de Seguridad Social puede declarar la eficacia general de un convenio colectivo» ${ }^{21}$, cuando «los empresarios obligados por el convenio colectivo ocupen no menos del 50 por ciento de los trabajadores incluidos en el ámbito de aplicación del convenio colectivo» ${ }^{22}$, teniendo en cuenta que «con la declaración de eficacia general, las normas jurídicas del convenio colectivo comprenden también en su ámbito de aplicación a los empresarios y trabajadores no obligados por el convenio colectivo hasta ese momento» ${ }^{23}$.

17 Cfr. Sentencia de 24 enero 2007 (proceso núm. 06S2447).

18 Sobre el tema, el precepto fundamental es el parágrafo 77 de la Ley en cuestión, a cuyo tenor: 1) «los acuerdos de empresa hay que celebrarlos conjuntamente por el comité de empresa y el empresario y redactarlos por escrito» (apartado 2, inciso primero); 2) «los salarios y demás condiciones de trabajo que estén o sean principalmente regulados por convenio colectivo no pueden ser objeto de un acuerdo de empresa» (apartado 3, inciso primero); y 3) «los acuerdos de empresa vinculan directamente y obligatoriamente» (apartado 4, inciso primero).

19 Véase A. JUNKER, Grundkurs Arbeitsrecht, $5^{\text {a }}$ ed., C.H. Beck (Munich, 2006), pág. 435.

20 De los dieciocho parágrafos de que consta el citado Reglamento de 1970, nueve (parágrafos 4 a 12) tratan justamente este mismo tema. Sobre el tema, véase O.E. KEMPEN y U. ZACHERT (Editores), Tarifvertragsgesetz, $4^{\mathrm{a}}$ ed., cit., págs. 1075 y ss. La constitucionalidad del citado precepto de la Ley del Convenio Colectivo fue confirmada por un trascendental Auto del Tribunal Federal Constitucional de 24 mayo 1977 (referencia 2 BVL 11/74). Nuestra traducción íntegra del mismo, en U. ZACHERT, J. MARTÍNEZ GIRÓN y A. ARUFE VARELA, Los grandes casos judiciales del Derecho alemán del Trabajo. Estudio comparado con el Derecho español y traducción castellana, Netbiblo (A Coruña, 2008), págs. 318 y ss.

21 Cfr. su apartado 1, inciso primero.

22 Cfr. su apartado 1, inciso primero, número 1.

23 Cfr. su apartado 4. Acerca de nuevas vías para la existencia en Alemania de convenios colectivos - sobre salarios mínimos - declarados de eficacia general, véase J. MARTÍNEZ GIRÓN y A. ARUFE VARELA, El salario mínimo en Alemania. Un estudio comparado entre regímenes de salarios minimos profesionales (alemanes) e interprofesionales legales (norteamericano y europeos), Netbiblo (A Coruña, 2009), págs. 30 y ss. 
§3. Francia también posee su propio modelo de negociación colectiva, que se encuentra regulado en el Libro II (rotulado «La negociación colectiva - Los convenios y acuerdos colectivos de trabajo [La négociation collective - Les conventions et accords collectifs de travail]») de la Parte Segunda del Código del Trabajo, artículos L. 2211-1 a L. 2283-2. En lo esencial, este modelo francés también aparece caracterizado por tres notas, a saber: 1) aunque existan muy distintos tipos de convenios colectivos en Francia, cada uno de ellos con su denominación legal peculiar, el convenio colectivo más social y económicamente relevante es -al igual que en Alemania- el convenio colectivo «de sector [de branche]» ${ }^{24}, 2$ ) en principio, este convenio colectivo sectorial posee - también al igual que en Alemania- eficacia normativa limitada, afirmando al respecto el Código del Trabajo que «la aplicación de los convenios y acuerdos es obligatoria para todos los firmantes o miembros de las organizaciones o grupos firmantes» ${ }^{25}$; y 3 ) ahora bien, a diferencia de lo que ocurre en Alemania, la eficacia normativa limitada que dicho convenio posee no está basada en Francia en el principio de la doble afiliación, sino sólo en la nuda afiliación empresarial a la asociación patronal pactante del mismo, pues - siempre según el Código del Trabajo- «cuando un empresario está vinculado por las cláusulas de un convenio o de un acuerdo, estas cláusulas se aplican a los contratos de trabajo concluidos con él, salvo disposiciones más favorables» ${ }^{26}$. Acerca de la capacidad de influencia de este modelo - sobre todo por la vía doctrinal-, cabe indicar que aunque la Constitución italiana preveía un modelo de negociación colectiva de eficacia general $^{27}$, el modelo italiano provisionalmente vigente de negociación

24 Véase, J. PÉLISSIER, A. SUPIOT y A. JEAMMAUD, Droit du travail, 24ª ed., Dalloz (París, 2008), págs. 1347 y ss.

25 Cfr. artículo L. 2262-1.

26 Cfr. artículo L. 2254-1. Sobre el tema, véase J. PÉLISSIER, A. SUPIOT y A. JEAMMAUD, Droit du travail, $24^{\mathrm{a}}$ ed., cit., págs. 1351 y ss.

27 Según el artículo 39, y supuesto que no se ha promulgado en Italia la normativa prevista en el párrafo segundo de ese precepto («a los sindicatos no se les puede imponer más obligación que su registro en las oficinas locales o centrales, según las normas legales»), el párrafo cuarto del propio precepto continúa afirmando que «los sindicatos registrados tienen personalidad jurídica», teniendo en cuenta que «pueden, representados unitariamente en proporción a sus afiliados, estipular convenios colectivos con eficacia obligatoria para todos los pertenecientes a los sectores a los que el convenio se refiere». Sobre la base de este precepto, el último intento de dotar de eficacia normativa general a los convenios colectivos entonces existentes fue llevado a cabo por la Ley núm. 1027, de 1 octubre 1960, pero esta Ley fue inmediatamente declarada inconstitucional por la Sentencia de la Corte Constitucional núm. 106, de 19 diciembre 1962. Al respecto, véase C. SANTORO, I Contratti “Erga Omnes", Gruppo Cooperativistico Editoriale (Salerno, 1994), págs. 14 y ss.; y F. GÓMEZ ABELLEIRA, La adhesión al convenio colectivo, Escola Galega de Administración Pública (Santiago de Compostela, 1997), págs. 476 y ss. 
colectiva - cuyo régimen jurídico se encuentra desperdigado en normas múltiples, enmendadas o promulgadas a partir de 1970 - resulta de todo asimilable al modelo francés, y más teniendo en cuenta que el «convenio colectivo nacional de trabajo [contratto collettivo nazionale di lavoro]»-que es un convenio «de sector [di categoria $] »^{28}$-, al regular el correspondiente salario profesional —mejorable y, por tanto, mínimo-, cubre de algún modo el vacío creado en Italia por la falta de un salario mínimo interprofesional ${ }^{29}$.

Entre las normas italianas más señeras reguladoras de este modelo provisional — doctrinalmente denominado de negociación colectiva «de Derecho común»-, se cuentan el Statuto dei Lavoratori de $1970^{30}$ y la Ley núm. 533, de 11 agosto 1973, que procedió - al efecto de regular aspectos cardinales de la negociación colectiva no prevista por la Constitución- a modificar, entre otras normas, el Código de Procedimiento Civil de 1940 y el Código Civil de 1942. Este último Código, en su nuevo artículo 2113, confirma la eficacia normativa de los convenios colectivos italianos (sin prejuzgar su eficacia limitada o no), al disponer que «las renuncias y las transacciones ..., que tienen por objeto derechos del prestador del trabajo derivados de las disposiciones inderogables de la ley y de los convenios o acuerdos colectivos [contratti o accordi collettivi] concernientes a los contratos a que se refiere el art. 409 del Código de Procedimiento Civil [definidor de la materia contenciosa laboral], no son válidas» ${ }^{31}$. Los convenios colectivos italianos «de empresa [di azienda]» pueden poseer eficacia normativa general, y más teniendo en cuenta la posibilidad de que los negocien las «representaciones sindicales unitarias» existentes en las empresas ${ }^{32}$.

El modelo francés de negociación colectiva es tendencialmente más «dinámico» que «estático», probándolo —-según el Código del Trabajo - el hecho de que quepa en Francia la celebración de convenios colectivos de duración indefinida («el convenio o el acuerdo se concluye por una duración determinada o indeterminada») ${ }^{33}$, y también, el que el propio Código del Trabajo prevea la obligación de negociar con periodicidad diversa sobre materias concretas, que es una periodicidad anual en el caso de los salarios, tanto a nivel de sector ${ }^{34}$ como a nivel de empresa (y en este último caso, recayendo la iniciativa negociadora sobre el empresario, lo que quizá explica que la normativa al respecto hable de «negociación obligatoria [négociation obligatoire]») ${ }^{35}$.

Los convenios colectivos franceses «de sector» de eficacia limitada pueden llegar a alcanzar eficacia normativa general ${ }^{36}$, a través de dos mecanismos regulados en el Código

28 Véase A. TURSI y P.A. VARESI, Lineamenti di Diritto del Lavoro. Rapporti di lavoro e relazioni sindacali nel settore privato, $3^{\mathrm{a}}$ ed., Kluwer-Ipsoa (s.1., 2004), págs. 317 y ss.

29 Sobre el tema, véase infra, Tema $17, \S 4$.

30 Cfr. artículos 7, 11, 18, 20, 21, 23, 35, 36 y 40. Los artículos 20 y 21 se refieren expresamente a los convenios colectivos de empresa, y el artículo 36 menciona los convenios colectivos de sector.

31 Cfr. artículo 2113, párrafo primero.

32 Sobre ello, véase supra, Tema $12, \S 4$.

33 Cfr. artículo L. 2222-4, párrafo primero. Sobre la denuncia no extintiva de los convenios colectivos franceses, cualquiera que sea su duración, véase A. ARUFE VARELA, La denuncia del convenio colectivo, Civitas (Madrid, 2000), págs. 31-32.

34 Cfr. artículo L. 2241-1, párrafo primero.

35 Cfr. artículo L. 2242-1.

36 Véase J. PÉLISSIER, A. SUPIOT y A. JEAMMAUD, Droit du travail, 24a ed., cit., págs. 1391 y ss. 
del Trabajo. En primer lugar, la «extensión [extension]» —equivalente de la «Allgemein verbindlichkeit» alemana-, pues «las disposiciones de un convenio de sector ... pueden convertirse en obligatorias para todos los trabajadores y empresarios comprendidos en el campo de aplicación de dicho convenio ..., por orden del ministro competente en materia de trabajo, tras parecer motivado de la comisión nacional de la negociación colectiva» ${ }^{37}$. En segundo lugar, la «ampliación [élargissement]» —equivalente de la extensión española de convenios colectivos ${ }^{38}$-, dado que, como regla general, «en caso de ausencia o de carencia de organizaciones de trabajadores o de empresarios que se traduzca en una imposibilidad persistente de concluir un convenio o un acuerdo en un sector de actividad o un sector territorial determinado, el ministro competente en materia de trabajo puede, a petición de una de las organizaciones representativas interesadas o a iniciativa propia ..., convertir en obligatorio en el sector territorial considerado un convenio o un acuerdo de sector ya extendido a un sector territorial diferente» ${ }^{39}$.

\$4. Por su parte, Gran Bretaña posee su propio y muy peculiar modelo de negociación colectiva, apareciendo actualmente regulado este mod elo británico en el Capítulo I (rotulado «negociación colectiva [collective bargaining]») de la Parte IV de la Ley (Consolidada) Sindical y de Relaciones Labores [Trade Union and Labour Relations (Consolidation) $A c t$ de 1992, secciones 178 y ss $^{40}$. La peculiaridad de este modelo es clara, en primer lugar, por causa de que el convenio colectivo ni siquiera llega a ser un contrato entre las partes que lo concertaron - sólo es entre ellas un «compromiso honorable [honourable understanding]» o mero «a cu erdo entre caballeros [gentlemen's agreement]»-, afirmando al respecto la Ley que «se presumirá concluyentemente que no ha sido intención de las partes que un convenio colectivo sea un contrato de cumplimiento judicialmente exigible [a legally enforceable contract], salvo» ${ }^{41}$ que el convenio colectivo en cuestión "conste por escrito» ${ }^{42}$, y además -y esta salvedad es de ocurrencia casi impensable-, que «contenga una cláusula (en todo caso, expresa) que establezca la intención de las partes de que el convenio será un contrato de cumplimiento judicialmente exigible» ${ }^{43}$. En segundo lugar, porque el convenio colectivo británico ni siquiera posee eficacia normativa propia, alcanzado eficacia jurídica sólo

37 Cfr. artículo L. 2261-15, párrafo primero.

38 Al respecto, véase J. MARTÍNEZ GIRÓN, A. ARUFE VARELA y X.M. CARRIL VÁZQUEZ, Derecho del Trabajo, $2^{\text {a }}$ ed., cit., págs. 403-404.

39 Cfr. artículo L. 2261-17.

40 Véase N.M. SELWYN, Law of Employment, $13^{\mathrm{a}}$ ed., LexisNexis-Butterworths (Londres, 2004), págs. 552 y ss.; y S. HONEYBALL y J. BOWERS, Textbook on Labour Law, 8 a ed., Oxford University Press (Oxford, 2004), págs. 365 y ss.

41 Cfr. sección 179(1).

42 Ibidem, apartado (a).

43 Ibidem, apartado (b). 
si su contenido se incorpora (expresa o implícitamente) al contenido del contrato individual de trabajo, indicando al respecto la Ley que las cláusulas convencionales «no formarán parte del contrato entre el trabajador y la persona para quien trabaje, salvo» ${ }^{44}$ —aunque esta salvedad sí es, en cambio, de ocurrencia frecuente- que «el contrato con el trabajador incorpore expresa o implícitamente esas cláusulas al contrato [the contract with the worker expressly or impliedly incorporates those terms in the contract]» ${ }^{45}$.

La legislación laboral británica —ya desde 1978— pretende facilitar al trabajador la prueba de la incorporación «expresa» del convenio colectivo a su contrato individual de trabajo, ordenando que «el empresario ... vendrá obligado a entregar al trabajador [que comienza su trabajo] una declaración escrita», que «deberá contener las indicaciones ... relativas a» sus «condiciones de empleo», consignándolas bien directamente o - y esto es lo importante- por remisión a un «documento [document]》 que «el trabajador tenga oportunidades razonables de leer en el curso de su empleo», o al que «se haga acceso razonable al trabajador por cualquier otro medio» ${ }^{46}$; documento, como es lógico, que puede ser perfectamente el convenio colectivo vigente en la empresa.

A falta de incorporación expresa, «la incorporación implícita puede acreditarse probando: 1) la existencia de "anteriores modificaciones en el contrato del trabajador en línea con las [sucesivas] modificaciones del convenio colectivo", ó 2) "el hecho de que los términos y condiciones [del convenio] son uniformemente observados por el grupo de trabajadores al que pertenece el trabajador [que estipuló el contrato]"» ${ }^{47}$.

$\mathrm{La}$ «falta de intención contractual [lack of contractual intent]》 entre quienes estipulan convenios colectivos obedece a una serie concatenada de razones, a saber: 1) tradicionalmente, los sindicatos ingleses sienten una profunda desconfianza hacia los jueces, que serían los órganos naturalmente competentes para conocer de pleitos sobre incumplimientos de convenios colectivos, si estos fuesen verdaderos contratos; 2) esta desconfianza forzó a los sindicatos a idear remedios alternativos — que les permitiesen no sólo garantizar la observancia de los convenios que concertaban, sino también excluir la indeseable intervención de los jueces-, concretados en la creación de órganos de composición paritaria (patronal-obrera) y de carácter permanente (usualmente llamados joint industrial councils,

44 Cfr. sección 180(1).

45 Cfr. sección $180(2)(b)$.

46 Cfr. secciones 1, 2 y 6 de la «Ley de Derechos de Empleo [Employment Rights Act]» de 1996.

47 Véase, con cita jurisprudencial y doctrinal, J. MARTÍNEZ GIRÓN, «La negociación colectiva en Inglaterra y en los Estados Unidos», Documentación Laboral, núm. 31 (1990), pág. 27. Ahora bien, la prueba de estos dos hechos suele resultar, por regla general, de una facilidad sorprendente, y ello - como en su día puso de relieve KAHN-FREUND-, porque en el Reino Unido existe la costumbre (técnicamente llamada «custom and practice»), pacíficamente observada por el empresario y cuyo cumplimiento garantiza, en última instancia, la libertad de huelga, de incorporar automáticamente el contenido sustantivo del convenio colectivo a los contratos individuales de trabajo comprendidos en su ámbito, de manera que «salvo que haya sido "acordado" (en sentido jurídico) lo contrario entre empresario y trabajador, los salarios, la jornada y horario, las vacaciones, etc., establecidos en el convenio colectivo se convierten, así, en términos de los contratos de trabajo y pueden, como tales, llegar a ser interpretados por el Juez o tribunal llamados a exigir el cumplimiento de ese contrato» (véase O. KAHN-FREUND, Labour and the law, $2^{\mathrm{a}}$ ed., Stevens \& Sons [Londres, 1977], págs. 133-134). 
conciliation boards, joint committees, etc.), sobre los cuales se ha edificado un sistema «dinámico» o de negociación colectiva permanente; 3) en este sistema resulta inútil distinguir entre conflictos jurídicos y de intereses, dado que el convenio colectivo - carente de todo período mínimo de vigencia- se reduce a un mero «acuerdo provisional [provisional arrangement $]$ regulador de la relación entre las partes sólo hasta que cualquiera de ellas sienta necesidad de renegociarlo»; 4) lógicamente, el buen funcionamiento de un sistema tan peculiar - basado en la negociación continua- presupone la existencia de agentes negociadores «fuertes», teniendo en cuenta que la fortaleza de los sindicatos ingleses está basada en el elevado número de afiliados que poseen (lo que explica la tradicional querencia sindical británica por los pactos, ahora virtualmente prohibidos, «de seguridad sindical»); y 5) en fin, el poder negociador de los sindicatos ingleses carecería de toda «credibilidad», si no estuviese amparado en última instancia por la libertad de huelga ${ }^{48}$.

§5. Como es sabido, el Derecho laboral colectivo en los Estados Unidos comparte un origen común con el Derecho inglés, aunque en la actualidad el modelo norteamericano de negociación colectiva - regulado, en lo esencial, en las Leyes Wagner de 1935 y Taft-Hartley de 1947- nada tenga que ver con el modelo británico ${ }^{49}$. En efecto, el convenio colectivo más relevante en los Estados Unidos es hoy el convenio de empresa, que posee —al igual que sucede en España, y a diferencia de lo que ocurre en toda Europa- efic a cia normativa general, desprendiéndose esta resulta de los tres siguientes preceptos legales: 1) la sección 9 de la Ley Wagner, a cuyo tenor el sindicato negociador del convenio colectivo con el empresario actúa en representación de todos los trabajadores de la empresa (literalmente, «los representantes designados o elegidos a efectos de la negociación colectiva por la mayoría de los trabajadores en una unidad apropiada a tales efectos, serán los representantes exclusivos de todos los trabajadores [shall be the exclusive representatives of all the employees] en dicha unidad a los efectos de la negociación colectiva») ${ }^{50}$; 2) la sección 8 de la propia Ley Wagner, según la cual el empresario tiene el deber legal de negociar de buena fe con el sindicato representante de todos sus trabajadores, dado que - según este precepto- «negociar colectivamente es el cumplimiento de la obligación mutua del empresario y del representante de los trabajadores de encontrarse en períodos razonables y conferenciar de buena fe [to meet

48 Acerca de todo esto, véase J. MARTÍNEZ GIRÓN, «La negociación colectiva en Inglaterra y en los Estados Unidos», cit., págs. 18 y ss.

49 Véase R.A. GORMAN, Basic Text on Labor Law. Unionization and Collective Bargaining, West Publ. Co. (St. Paul-Minn., 1976), págs. 93 y ss.; B.J. TAYLOR y F. WITNEY, Labor Relations Law, $6{ }^{a}$ ed., Prentice Hall (Englewood Cliffs-New Jersey, 1992), págs. 37 y ss.; D.L. LESLIE, Labor Law. In a nutshell, $4^{\mathrm{a}}$ ed., West Group (St. Paul-Minn., 2000), págs. 181 y ss.; y T.J. HEINSZ, D.R. NOLAN y R.A. BALES, Labor Law. Collective Bargaining in a Free Society, 6a ed., Thomson-West. (St. Paul-Minn., 2009), págs. 630 y ss.

50 Cfr. su apartado (a). 
at reasonable times and confer in good faith] en relación con los salarios, jornada y otros términos y condiciones de empleo, o la negociación de un convenio o de cualquier cuestión que se derive del mismo, y la ejecución de un contrato escrito que incorpore cualquier acuerdo alcanzado si así lo exige alguna de las partes, aunque dicho deber no obliga a ninguna de las partes a llegar a aceptar una propuesta o exigir que se haga una concesión» ${ }^{51}$; y 3) la sección 301 de la Ley Taft-Hartley, a cuyo tenor el convenio colectivo resulta ser un contrato de cumplimiento judicialmente exigible, puesto que este precepto indica que «las demandas por violación de contratos [suits for violation of contracts] entre un empresario y un sindicato ... se pueden deducir en cualquier Corte de Distrito de los Estados Unidos [may be brought in any district court of the United States] que tenga competencia sobre las partes, con independencia de la cuantía de lo litigado o de la ciudadanía de las partes ${ }^{52}$. Esta eficacia normativa general del convenio colectivo fue contundentemente reconocida por la Corte Suprema de los Estados Unidos en 1944, afirmando que «los contratos individuales no pueden sustraerse a los colectivos [individual contracts cannot subtract from collective ones]» ${ }^{53}$, y sorprendiéndose del hecho de que - siempre según la Corte Suprema de los Estados Unidos - en algunos países europeos fuese preciso, para conseguir esa misma eficacia, someter a controles gubernamentales el contenido del convenio colectivo.

En este leading case de 1944 se afirma literalmente lo siguiente: «verdaderamente, en algunos países europeos, en contra de la práctica americana, los términos de un convenio colectivo negociado se someten a un ministerio del gobierno y, si se aprueban, se convierten en una normativa gubernamental que regula el trabajo en la unidad [indeed, in some European countries, contrary to American practice, the terms of a collective negotiated trade agreement are submitted to a government department and if approved become a governmental regulation ruling employment in the unit]».

La casuística judicial generada por la citada sección 301 de la Ley Taft-Hartley posee un interés doctrinal superlativo, especialmente desde la perspectiva del Derecho de la negociación colectiva europeo. En efecto, al amparo de dicho precepto, cabe que las partes del convenio colectivo se demanden entre sí por incumplimiento de convenio, ejercitando pretensiones de dar (por ejemplo, cantidades en concepto de indemnizaciones de daños y perjuicios), pretensiones de hacer (por ejemplo, someterse al arbitraje pactado en convenio

51 Cfr. su apartado (d). Las secciones 8(a)(5) y 8(b)(3) consideran «práctica laboral sucia [unfair labor practice]» del empresario y del sindicato, respectivamente, negarse a negociar de buena fe con su contraparte, con todas las graves consecuencias jurídicas que acarrea la realización de este tipo de prácticas. Sobre el tema, con utilísimo estudio de jurisprudencia federal, véase J. CABEZA PEREIRO, La buena fe en la negociación colectiva, Escola Galega de Administración Pública (Santiago de Compostela, 1995), págs. 44 y ss.

52 Cfr. su apartado (a).

53 Se trata del caso J.I. Case Co. v. NLRB (referencia 321 US 332). 
colectivo) y pretensiones de no hacer (por ejemplo, las encaminadas a paralizar huelgas en violación del convenio colectivo, mediante «interdictos [injunctions]»). También cabe que los trabajadores individuales demanden al propio empresario por incumplimiento de convenio colectivo, pues «los trabajadores pueden deducir demanda al amparo de la sección 301, aunque no sean formalmente parte del convenio colectivo, para exigir el cumplimiento de sus términos», dado que «la palabra "entre" de la sección 301 se refiere a "contratos" y no a "demandas" ${ }^{54}$.

Al hilo del tratamiento judicial de la «defensa de "leyes extranjeras"» — que es una institución procesal vinculada al carácter extraterritorial de las grandes leyes laborales antidiscriminatorias norteamericanas ${ }^{55}$-, la jurisprudencia federal norteamericana ha confirmado no sólo que el convenio colectivo norteamericano es verdadera «ley [law]» o Derecho objetivo (como las leyes y reglamentos federales), sino también que asimismo en los Estados Unidos son verdaderas «leyes» los convenios colectivos extranjeros, aunque se trate de convenios colectivos de eficacia normativa limitada (como en el caso, por ejemplo, de los convenios colectivos alemanes) ${ }^{56}$.

54 Acerca de todo cuanto acaba de decirse, véase J. MARTÍNEZ GIRÓN, «El incumplimiento del convenio colectivo en la jurisprudencia federal norteamericana», Revista Española de Derecho del Trabajo, núm. 16 (1983), págs. 577 y ss. Sobre los límites de la exigencia por el empresario norteamericano de responsabilidades por daños y perjuicios a los sindicatos, véase A. ARUFE VARELA, «La problemática exigencia de responsabilidades laborales a los sindicatos por actividades huelguísticas de sus afiliados. Un estudio comparado de los ordenamientos español y norteamericano», Relaciones Laborales, núm. 9 (2006), págs. 11 y ss.

55 Véase J. MARTÍNEZ GIRÓN, «La regulación de la “defensa de 'leyes extranjeras'” en la legislación laboral antidiscriminatoria de los Estados Unidos», Actualidad Laboral, núm. 10 (2007), págs. 1190 y ss.

56 Véase A. ARUFE VARELA, «La aplicación judicial de la "defensa de 'leyes extranjeras'" regulada en la legislación laboral antidiscriminatoria de los Estados Unidos», Actualidad Laboral, núm. 9 (2007), págs. 1075 y ss. 


\section{TEMA 14 \\ EL DERECHO DE HUELGA EN EL ORDENAMIENTO COMUNITARIO, EN LAS LEGISLACIONES Y PRÁCTICAS NACIONALES EUROPEAS, Y EN LA LEGISLACIÓN DE LOS ESTADOS UNIDOS}

Sumario: §1. El Derecho de la Unión Europea y el derecho de huelga, ad extra y ad intra. §2. El modelo alemán de derecho de huelga. §3. El modelo francés (y sus variantes italiana, española y portuguesa) de derecho de huelga. \$4. El modelo británico de libertad de huelga. §5. El modelo norteamericano de derecho de huelga.

THEME 14

THE RIGHT TO STRIKE IN THE EUROPEAN LAW, IN THE NATIONAL EUROPEAN LEGISLATIONS AND PRACTICES, AND IN THE LEGISLATION OF THE UNITED STATES

Contents: $\$ 1$. The Law of the European Union and the right to strike, ad extra and ad intra. \$2. The German model of right to strike. \$3. The French model (and its Italian, Spanish and Portuguese variants) of right to strike. $\$ 4$. The British model of freedom to strike. $\$ 5$. The USA model of right to strike.

§1. Al igual que ocurre en materia de libertad sindical, la Unión Eu rop e a -hipócrita casi siempre, si se analiza su vertiente ad intratambién ha renunciado a poseer en el plano ad extra un Derecho común en materia de actos colectivos de fuerza, dado que el Tratado de Funcionamiento de la Unión Europea - como se vio- excluye la posibilidad de armonizar, vía Directivas, todo lo relativo a la huelga y al lock-out (literalmente, «al derecho de huelga ni al derecho de cierre patronal») ${ }^{1}$. La explicación del fenómeno ha de buscarse y encontrarse, una vez más, en las disparidades existentes en el seno de los países de la Unión Europea en punto a la regulación del tema. Estas disparidades — que permiten hablar, en los seis países europeos que

1 Cfr. artículo 153.5. 
consideramos de referencia, de hasta tres modelos distintos de regulación de la huelga - aparecen implícitamente reconocidas en la Carta de los Derechos Fundamentales de la Unión Europea, dado que en las «explicaciones» relativas a su artículo 28 -que es el precepto que proclama el derecho de «acción colectiva» ${ }^{2}$ - se afirma que «las modalidades y límites en el ejercicio de acciones colectivas, incluida la huelga, entran dentro del ámbito de las legislaciones y prácticas nacionales, incluida la cuestión de si pueden llevarse a cabo de forma paralela en varios Estados miembros» ${ }^{3}$.

En el plano ad intra del Derecho de la Unión, no deja de sorprender que el Reglamento núm. 31(CEE), 11 (CEEA) de 1962, por el que se establece el «Estatuto de los funcionarios de las Comunidades Europeas y el régimen aplicable a los otros agentes de estas Comunidades», omita mencionar el derecho de huelga de los diversos tipos de empleados al servicio de la Unión Europea.

El Tribunal de Luxemburgo, tras constatar este hecho - «aunque ciertos Estados miembros niegan a sus empleados públicos o a ciertas categorías de empleados públicos el derecho de huelga, mientras que otros Estados miembros lo permiten, el Estatuto de funcionarios de las Comunidades Europeas guarda silencio sobre el tema»-, ha declarado que «de acuerdo con un principio reconocido en el Derecho laboral de los Estados miembros, los salarios y otros beneficios correspondientes a los días de huelga no se deben a las personas que hayan tomado parte en esa huelga», pero teniendo en cuenta que "esta declaración en modo alguno implica una decisión en relación con la existencia del derecho de huelga de los funcionarios [de las Comunidades Europeas] o en relación con las reglas concretas que puedan gobernar el ejercicio de tal derecho» ${ }^{4}$.

La renuncia a poseer - en el plano ad extra - una regulación propia del derecho de huelga, a pesar de todo el escándalo doctrinal suscitado, propicia que el Tribunal de Luxemburgo haya considerado que el derecho de huelga se encuentra subordinado al ejercicio de otras libertades comunitarias de carácter estructural, como la libertad de establecimiento (caso Viking) ${ }^{5}$ o la libertad de prestación de servicios (caso Laval) ${ }^{6}$.

2 Según este precepto (rotulado «Derecho de negociación y de acción colectiva»), «los trabajadores y los empresarios o sus organizaciones respectivas, de conformidad con el Derecho de la Unión y con las legislaciones y prácticas nacionales, tienen derecho a negociar y celebrar convenios colectivos, en los niveles adecuados, y a emprender, en caso de conflicto de intereses, acciones colectivas para la defensa de sus intereses, incluida la huelga».

3 En las «explicaciones» en cuestión, se indica asimismo que «este artículo se basa en el artículo 6 de la Carta Social Europea, así como en la Carta Comunitaria de los Derechos Sociales Fundamentales de los Trabajadores (puntos 12 a 14)», y que «el Tribunal Europeo de Derechos Humanos reconoció el derecho a la acción colectiva como uno de los elementos del derecho de sindicación establecido en el artículo 11 del CEDH».

4 Cfr. Sentencia del Tribunal de Justicia de las Comunidades Europeas de 18 marzo 1975 (asuntos acumulados 44, 46 y 49/74), en el caso «Marie-Louise Acton y otros contra Comisión de las Comunidades Europeas». El vigente «acuerdo marco» de 2008, estipulado entre la Comisión Europea y las organizaciones sindicales y profesionales que considera representativas ante ella, regula el derecho de huelga del persona funcionarial y laboral al servicio de la Unión Europea en su Título 5, bajo el rótulo genérico «De los paros de trabajo», artículos 35 a 45. Se trata de un acuerdo sólo localizable extramuros el portal jurídico de la Unión Europea (cfr. supra, Tema 11, §4).

5 Sentencia del Tribunal de Justicia de las Comunidades Europeas de 11 diciembre 2007 (asunto C-438/05). C-341-05).

6 Sentencia del Tribunal de Justicia de las Comunidades Europeas de 18 diciembre 2007 (asunto 
\$2. Uno de esos tres modelos europeos diferenciados — que nuestra jurisprudencia constitucional calificaría como modelo «contractual» puro de derecho de huelga ${ }^{7}$ - es el modelo alemán ${ }^{8}$. Teniendo en cuenta que la regulación del mismo aparece contenida en reiterada jurisprudencia del Tribunal Federal de Trabajo — dictada en interpretación y aplicación del artículo 9.3 de la Constitución Federal, que se refiere a la «huelga [Streik]» utilizando la expresión genérica «luchas laborales [Arbeitskämpfen] ${ }^{9}$ - , se trata de un modelo caracterizado en lo esencial por las cinco notas siguientes ${ }^{10}$. En primer lugar, porque los titulares del derecho de huelga no son los trabajadores ni tampoco sus representantes unitarios ${ }^{11}$, sino única y exclusivamente los sindicatos ${ }^{12}$. En segundo lugar, porque los sindicatos sólo pueden declarar huelgas —una vez transcurrido el período de vigencia originaria del convenio colectivo, durante el que juega el denominado «deber de paz [Friedenspflicht]》» ${ }^{13}$ - para reforzar su posición negociadora, con ocasión de la renegociación (o negociación ex novo) del propio convenio colectivo con el empresario o las asociaciones de empresarios (de ahí la «contractualidad» estricta del modelo) ${ }^{14}$. En tercer lugar, porque la huelga es siempre un recurso subsidiario, al que los sindicatos sólo pueden acudir tras haber agotado todas las posibilidades razonables de negociación con el empresario o las

7 Acerca de los modelos teóricos de regulación de la huelga, y su análisis en la Sentencia del Tribunal Constitucional 11/1981, de 8 abril, véase J. MARTÍNEZ GIRÓN, A. ARUFE VARELA y X.M. CARRIL VÁZQUEZ, Derecho del Trabajo, $2^{\mathrm{a}}$ ed., Netbiblo (A Coruña, 2006), págs. 453 y ss.

8 Véase P. HANAU y K. ADOMEIT, Arbeitsrecht, $13^{\mathrm{a}}$ ed., Luchterhand (Múnich, 2005), págs. 81 y ss.; W. DÄUBLER, Arbeitsrecht. Ratgeber für Beruf, Praxis und Studium, 6 a ed., Bund-Verlag (Frankfurt a.M., 2006), págs. 61 y ss.; y A. JUNKER, Grundkurs Arbeitsrecht, 5a ed., C.H. Beck (Múnich, 2006), págs. 330 y ss. Además, A. MONTOYA MELGAR, «Introducción», Revista de la Facultad de Derecho de la Universidad Complutense, núm. 17 [monográfico sobre «El derecho de huelga. Seminario HispanoAlemán en honor de los Profesores Manuel Alonso Olea y Franz Gamillscheg»] (1993), págs. 10 y ss.

9 Según el inciso 3 de este precepto, «las especificaciones de que tratan los artículos 12a y 35, apartados 2 y 3, el artículo 87a, apartado 4, y el artículo 91, no deben ser enjuiciadas contra las luchas laborales que sean declaradas para la preservación y promoción de las condiciones laborales y las condiciones económicas por las asociaciones a que se refiere el inciso 1», indicando este inciso, por su parte, que «el derecho a formar asociaciones para la preservación y promoción de las condiciones laborales y las condiciones económicas se garantiza a todo hombre y para toda profesión».

10 Esta jurisprudencia arranca de una resolución decisiva, que fue un Auto (Sala General) del Tribunal Federal de Trabajo de 28 enero 1955 (referencia GS 1/54).

11 Véase supra, Tema 12, \$3.

12 Véase Sentencia del Tribunal Federal de Trabajo de 20 diciembre 1963 (1 AZR 428/62). Nuestra traducción íntegra de la misma, en U. ZACHERT, J. MARTÍNEZ GIRÓN y A. ARUFE VARELA, Los grandes casos judiciales del Derecho alemán del Trabajo. Estudio comparado con el Derecho español y traducción castellana, Netbiblo (A Coruña, 2008), págs. 389 y ss.

13 Véase Sentencia del Tribunal Federal de Trabajo de 31 octubre 1958 (referencia 1 AZR 632/57).

14 Véase Sentencia del Tribunal Federal de Trabajo de 10 diciembre 2002 (referencia 1 AZR 96/02). Sobre la huelga de apoyo, véase U. ZACHERT, J. MARTÍNEZ GIRÓN y A. ARUFE VARELA, Los grandes casos judiciales del Derecho alemán del Trabajo. Estudio comparado con el Derecho español y traducción castellana, cit., págs. 151 y ss. 
asociaciones de empresarios (en cumplimiento del principio denominado de la «ultima ratio») ${ }^{15}$. En cuarto lugar, porque el empresario o las asociaciones de empresarios (en virtud, a su vez, del principio de la «paridad en la lucha [Kampfparität]») disponen de su propia medida de lucha opuesta a la huelga, que es el «cierre patronal [Aussperrung]» ${ }^{16}$. Y en quinto lugar, porque las huelgas en servicios públicos no plantean ninguna problemática especial que merezca ser reseñada, dado que los funcionarios públicos alemanes carecen del derecho de huelga ${ }^{17}$.

El legislador alemán, como regla, nunca ha pretendido interferir la labor reguladora del Tribunal Federal de Trabajo en materia de huelgas y cierres patronales, probándolo contundentemente, por ejemplo, la trascendental Ley de Protección contra el Despido (Kündigungsschutzgesetz) de 1951, en la que se afirma que «los preceptos de esta Ley no se aplican en las extinciones y despidos que sean adoptados solamente como consecuencia de los conflictos económicos [wirtschaflichen Kämpfen] entre empresarios y trabajadores» ${ }^{18}$.

Los sindicatos alemanes regulan sistemáticamente en sus estatutos el abono a sus afiliados huelguistas — cuyo contrato de trabajo está, lógicamente, suspendido- de un subsidio de resistencia, denominado «apoyo de huelga [Streikunterstützung]». Según la doctrina, este subsidio oscila «entre $2 / 3$ y el 90 por ciento del salario neto» ${ }^{19}$. Y así, por ejemplo, en el caso del poderoso «Sindicato Industrial del Metal» (o IG Metall), sus estatutos - accesibles en Internet a través del sitio www.igmetall.de ${ }^{20}$ — prevén "por una cotización [al sindicato] de 3 a 12 meses» la percepción semanal de «doce veces la cotización media» mensual ${ }^{21}$, teniendo en cuenta que «las cotizaciones ascienden a un uno por ciento de las ganancias mensuales brutas» ${ }^{22}$.

Supuesto que el empresario decida no cerrar, la jurisprudencia del Tribunal Federal del Trabajo obliga a los huelguistas a garantizar la prestación de «servicios de mantenimiento

15 Véase Sentencia del Tribunal Federal de Trabajo de 18 febrero 2003 (referencia 1 AZR 142/02). Sobre la huelga de advertencia, véase U. ZACHERT, J. MARTÍNEZ GIRÓN y A. ARUFE VARELA, Los grandes casos judiciales del Derecho alemán del Trabajo. Estudio comparado con el Derecho español y traducción castellana, cit., págs. 145 y ss.

16 Véase Sentencia del Tribunal Federal de Trabajo de 10 junio 1980 (referencia 1 AZR 168/79). Nuestra traducción íntegra de la misma, en U. ZACHERT, J. MARTÍNEZ GIRÓN y A. ARUFE VARELA, Los grandes casos judiciales del Derecho alemán del Trabajo. Estudio comparado con el Derecho español y traducción castellana, cit., págs. 353 y ss.

17 Sobre el tema, aplicando la genérica previsión contenida en el artículo 33, apartado 5, de la Constitución Federal («el régimen jurídico de la función pública se regulará dentro del respeto a los principios fundamentales tradicionales del funcionariado de carrera»), véase Auto del Tribunal Federal Constitucional de 2 marzo 1993 (referencia 1 BVR 1213/85). Más precisiones, en A. JUNKER, Grundkurs Arbeitsrecht, $5^{\text {a }}$ ed., cit., pág. 345.

18 Parágrafo 25 (rotulado «Despido en conflictos laborales [Kündigung in Arbeitskämpfen]». Sobre despido por participación en «huelga ilícita [rechtswidrige Streik]», véase Sentencia del Tribunal Federal de Trabajo de 14 febrero 1978 (1 AZR 76/76); y también, A. MARTÍN VALVERDE, «Huelga ilícita y despido en el Derecho del Trabajo alemán», Revista de Politica Social, núm. 96 (1972), págs. 34-35.

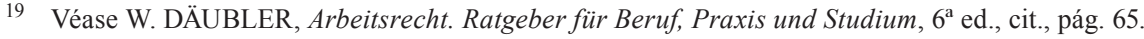

20 Vía «Die IG Metall» (y luego, «zur vollständigen Satzung der IG Metall»).

21 Cfr. parágrafo 23.

22 Cfr. parágrafo 5. Los parágrafos 24 a 30 regulan otros muchos subsidios sindicales (en caso de cierre patronal, de despidos u otras sanciones disciplinarias a los afiliados, de accidente no laboral, etc.). Sobre el tema, véase W. DÄUBLER, Arbeitsrecht. Ratgeber für Beruf, Praxis und Studium, 6 a ed., cit., pág. 65. 
[Erhaltungsarbeiten]» y, en su caso — para prevenir daños a la vida o la salud de terceros-, de «servicios de emergencia [Notstandsarbeiten] ${ }^{23}$.

§3. Frente al modelo «contractual» alemán, el modelo francés de derecho de huelga se caracteriza, en cambio, por su desconexión del derecho de negociación colectiva; y ello, hasta el punto de poder afirmarse que en Francia las resultas jurídicas derivadas de la protección constitucional del «derecho de huelga [droit de grève]» ${ }^{24}$-explicitadas por reiterada jurisprudencia de la Sala de lo Social de la Corte de Casación ${ }^{25}$ _ contrastan radicalmente, punto por punto, con las del modelo alemán que acaba de verse ${ }^{26}$. En primer lugar, porque en Francia la huelga es un derecho de titularidad individual — que posee todo trabajador — , pero en modo alguno un derecho (como ocurre en Alemania) de titularidad sólo sindical ${ }^{27}$. En segundo lugar, porque cabe declarar huelgas para la consecución de objetivos inalcanzables mediante la estipulación de un convenio colectivo, como en el caso claro de las huelgas para protestar por la política económica o social del Gobierno (que en Alemania serían consideradas, en cambio, huelgas ilícitas) ${ }^{28}$. En tercer lugar, porque la huelga — dada su desconexión de la negociación colectiva - no constituye ninguna «ultima ratio» o recurso extremo y subsidiario, cabiendo incluso en el sector privado francés su declaración por sorpresa (esto es, sin necesidad de que

23 Véase Sentencia del Tribunal Federal de Trabajo de 31 enero 1995 (referencia 1 AZR 622/93). Sobre el tema, véase W. DÄUBLER, Arbeitsrecht. Ratgeber für Beruf, Praxis und Studium, $6^{\text {a }}$ ed., cit., pág. 63.

24 Dicha protección aparece contenida en el párrafo 7 del Preámbulo de la Constitución de 1946, según el cual «el derecho de huelga se ejerce en el marco de las leyes que lo reglamentan».

25 En realidad, si se hace abstracción del tema de los servicios públicos, la regulación legal ordinaria del derecho de huelga se reconduce en Francia a lo dispuesto en el artículo L. 2511-1 del Código del Trabajo, de acuerdo con el cual «el ejercicio del derecho de huelga no puede justificar la ruptura del contrato de trabajo, salvo falta grave [faute lourde] imputable al trabajador» (párrafo primero); «su ejercicio no puede dar lugar a ninguna medida discriminatoria ... especialmente en materia de remuneraciones y de ventajas sociales» (párrafo segundo), y «todo despido pronunciado en ausencia de falta grave es nulo de pleno derecho» (párrafo tercero).

26 Véase J. PÉLISSIER, A. SUPIOT y A. JEAMMAUD, Droit du Travail, 24a ed., Dalloz (París, 2008), págs. 1411 y ss.

27 Como regla, se trata de un derecho de titularidad individual pero de ejercicio colectivo, de manera que «siendo la huelga un cese colectivo y concertado del trabajo con la finalidad de apoyar reivindicaciones profesionales, un trabajador, salvo en el caso en que obedezca a una convocatoria formulada en el plano nacional, no puede pretender ejercer aisladamente el derecho de huelga» (Sentencia de la Sala de lo Social de la Corte de Casación de 29 marzo 1995 [recurso núm. 93-41863]). A pesar de ello, sin embargo, «en las empresas que no tengan más que un trabajador, éste, que es el único que puede por sí mismo presentar y defender sus reivindicaciones profesionales, puede ejercer este derecho constitucionalmente reconocido» (Sentencia de la Sala de lo Social de la Corte de Casación de 13 noviembre 1996 [recurso núm. 93-42247]). Comentando esta última decisión, véase J. GARCÍA MURCIA, «¿Huelga de un solo trabajador? A propósito de una Sentencia de la Sala de lo Social del Tribunal francés de Casación de 13 de noviembre de 1996», Anuario Coruñés de Derecho Comparado del Trabajo, vol. I (2009), págs. 71 y ss.

28 Cfr., por ejemplo, Sentencia de la Sala de lo Social de la Corte de Casación de 15 febrero 2006 (recurso núm. 04-45738), a propósito de una huelga que «tenía como objetivo obtener la renegociación del proyecto gubernamental de reforma de la jubilación». 
medie ningún tipo de preaviso) ${ }^{29}$. En cuarto lugar, porque el empresario francés carece del derecho de cierre patronal o de lock-out ${ }^{30}$, aunque se le reconozca - frente a la huelga — un derecho limitado de reorganizar el trabajo en la empresa (sobre todo apelando a lo que en España llamaríamos «esquirolaje interno») ${ }^{31}$. Y en quinto lugar, supuesto que los funcionarios públicos también son titulares en Francia del derecho de huelga, porque las huelgas en el sector público (y señaladamente, en los servicios públicos) han acabado siendo objeto de una regulación especial limitadora de su ejercicio lícito — avalada por el Consejo Constitucional—, sobre todo mediante la imposición del llamado "servicio mínimo [service minimum]»» ${ }^{32}$. En fin, aunque con variantes y especificidades, los modelos italiano, español y portugués se ajustan sustancialmente a los parámetros del modelo francés de derecho de huelga (titularidad individual del derecho, admisibilidad de las huelgas económico-políticas, restricción del derecho cuando su ejercicio afecta a los servicios esenciales de la comunidad, etc. $)^{33}$.

En Italia — donde la Constitución afirma que «el derecho de huelga [diritto di sciopero] se ejercita en el ámbito de las leyes que lo regulan ${ }^{34}$-, las únicas leyes reguladoras del mismo son las relativas a su ejercicio en "servicios públicos esenciales [servizi pubblici essenziali]». Se trata de la Ley núm. 146, de 12 junio 1990, modificada y completada por la Ley núm. 83, de 11 abril 2000, que confían en que sean los instrumentos de la autonomía colectiva (por ejemplo, convenios colectivos, códigos de autorreglamentación sindical o reglamentos de servicio empresariales) quienes garanticen en caso de huelga el disfrute de otros derechos constitucionalmente protegidos (a la vida, a la salud, a la seguridad social, a la libertad de circulación y comunicación, etc.). Para administrarla, fue creada por esta normativa la denominada «comisión de garantía [commissione di garanzia]», en cuyo sitio

29 Ni siquiera aunque se imponga por convenio colectivo, pues «un convenio colectivo no puede tener por efecto limitar o reglamentar para los trabajadores el ejercicio del derecho de huelga constitucionalmente reconocido», dado que «sólo la ley puede crear un plazo de preaviso de huelga que se les imponga» (Sentencia de la Sala de lo Social de la Corte de Casación de 12 marzo 1996 [recurso núm. 93-41670]).

30 Véase J. PÉLISSIER, A. SUPIOT y A. JEAMMAUD, Droit du Travail, $24^{a}$ ed., cit., págs. 1492 y ss.

31 La regla general es que «sin perjuicio de las prohibiciones [legalmente] previstas ... no está prohibido al empresario, en caso de huelga, organizar la empresa para asegurar la continuidad de su actividad» (Sentencia de la Sala de lo Social de la Corte de Casación de 11 enero 2000 [recurso núm. 97-22025]).

32 Esta regulación aparece contenida, en parte, en los artículos L. 2512-1 a L. 2512-5 del Código del Trabajo. Al respecto, además, véanse Decisiones del Consejo Constitucional de 25 julio 1979 (núm. 79-105), de 18 septiembre 1986 (núm. 86-217) y de 28 julio 1987 (núm. 87-230).

33 Sobre el modelo italiano, véase M. PERSIANI, Diritto Sindacale, $7^{\mathrm{a}}$ ed., CEDAM (Padua, 2000), págs. 149 y ss.; y A. TURSI y P.A. VARESI, Lineamenti di Diritto del Lavoro. Rapporti di lavoro e relazioni sindacali nel settore privato, $3^{\mathrm{a}}$ ed., Kluwer Ipsoa (s.1., 2004), págs. 331 y ss. Sobre el modelo español, véase J. MARTÍNEZ GIRÓN, A. ARUFE VARELA y X.M. CARRIL VÁZQUEZ, Derecho del Trabajo, $2^{\mathrm{a}}$ ed., cit., págs. 453 y ss. Y sobre el modelo portugués, P. ROMANO MARTINEZ, L.M. MONTEIRO, J. VASCONCELOS, P. MADEIRA BRITO, G. DRAY y L. GONÇALVES DA SILVA, Código do Trabalho. Anotado, $4^{a}$ ed., Almedina (Coimbra, 2005), págs. 929 y ss.; y A. MONTEIRO FERNANDES, Direito do Trabalho, 15a ed., Almedina (Coimbra, 2010), págs. 924 y ss.

34 Artículo 40. 
en Internet - ubicado en www.commissionegaranziasciopero.it - resultan accesibles todas las fuentes legales (en «versión consolidada») y no legales relativas al asunto.

En cambio, en Portugal — donde el artículo 57 de la Constitución proclama que «se garantiza el derecho a la huelga [direito à greve]» ${ }^{35}$, que «compete a los trabajadores definir el ámbito de intereses a defender a través de la huelga, no pudiendo la ley limitar ese ámbito» ${ }^{36}$, que «la ley define las condiciones de prestación, durante la huelga, de los servicios necesarios para la seguridad y el mantenimiento [serviços necessários à segurança e manutençao] de equipos e instalaciones, así como de servicios mínimos indispensables [serviços mínimos indispensáveis] para permitir la satisfacción de necesidades sociales impreteribles» ${ }^{37}$, y por último, que «se prohíbe el lock-out» ${ }^{38}$-, existe una completísima regulación legal del tema, contenida en el Código del Trabajo ${ }^{39}$.

A diferencia de España y Portugal $-\mathrm{y}$ al igual que ocurre en Francia-, la jurisprudencia ordinaria italiana le reconoce al empresario - también carente de un verdadero derecho de «cierre patronal [serrata] $\rangle^{40}$ - el derecho a reorganizar la actividad productiva durante la huelga, recurriendo al denominado «esquirolaje interno [crumiraggio interno]», que ampara implícitamente el tenor del artículo 2103 del Código Civil ${ }^{41}$.

§4. Por su parte, el modelo británico resulta inasimilable a los modelos continentales europeos de derecho de huelga, por causa de que en Gran Bretaña la huelga ni siquiera se considera un «derecho», sino sólo una mera «libertad» (la llamada «libertad de huelga [freedom to strike]») ${ }^{42}$, actualmente regulada —en lo esencial — en la Parte V de la Ley Sindical y de Relaciones Laborales (Consolidada) [Trade Union and Labour Relations (Consolidation) Act] de $1992^{43}$. Se trata de una regulación cuyo objetivo es garantizar a los sindicatos - cuando declaran una huelga - inmunidad jurisdiccional o defensas frente a acciones de indemnización de daños y perjuicios extracontractuales (o acciones in tort) — deducidas por los empresarios_-, que impedirían a los jueces entrar a conocer del fondo de las mismas ${ }^{44}$. Pero esta inmunidad jurisdiccional sólo juega cuando se cumplen cumulativamente dos requisitos. En primer

35 Apartado 1.

36 Apartado 2.

37 Apartado 3.

38 Apartado 4.

39 Artículos 530 a 545.

40 véase M. PERSIANI, Diritto Sindacale, $7^{\mathrm{a}}$ ed., cit., págs. 181 y ss.; y G. PERA y M. PAPALEONI, Diritto del Lavoro, $7^{\text {a }}$ ed., CEDAM (Padua, 2003), págs. 211 y ss.

41 Al respecto, véase G. DIÉGUEZ, «"Esquirolaje” interno y otras cuestiones (Comentario a la Sentencia de la Cassazione italiana n. 20164, de 26 septiembre 2007)», Anuario Coruñés de Derecho Comparado del Trabajo, vol. I (2009), págs. 43 y ss.

42 Véase J. MARTÍNEZ GIRÓN, «La huelga laboral: experiencias inglesa y norteamericana», Actualidad Laboral, núm. 39 (1992), pág. 695.

43 Véanse S. HONEYBALL y J. BOWERS, Textbook on Labour Law, $8^{\text {a }}$ ed., Oxford University Press (Oxford, 2004), págs. 388 y ss.; y N.M. SELWYN, Law of Employment, 13 $3^{\mathrm{a}}$ ed., Lexis Nexis UK (Londres, 2004), págs. 549 y ss.

44 Acerca del carácter tradicional de este planteamiento, véase J. MARTÍNEZ GIRÓN, «La huelga laboral: experiencias inglesa y norteamericana», cit., pág. 695. 
lugar, que la huelga pueda considerarse un acto realizado «en previsión o como consecuencia de un conflicto laboral [in contemplation or furtherance of a trade dispute] ${ }^{45}$, teniendo en cuenta que no se consideran tales - por no encajar en el concepto de "conflicto laboral»" ${ }^{46}$ - las huelgas para forzar la estipulación de un pacto de seguridad sindical, las huelgas de solidaridad o las huelgas políticas, entre otras varias ${ }^{47}$. En segundo lugar, que se hubiera respetado el procedimiento legalmente establecido para la realización de la huelga, que exige — desde los tiempos de la Sra. THATCHER - cumplir cumulativamente, a su vez, tres condiciones: 1) «si el sindicato hubiese celebrado una votación [ballot] con respecto» a la huelga ${ }^{48}$, teniendo en cuenta - como regla general - que «deberá celebrarse para cada centro de trabajo una votación separada» ${ }^{49}$; 2) «si la mayoría de las personas participantes en la votación hubiese respondido con un "sí" a la pregunta pertinente»" ${ }^{50}$, teniendo en cuenta - de nuevo como regla general - que sólo tienen derecho a votar los afiliados al sindicato a quienes éste vaya a pedir que se declaren en huelga ${ }^{51}$; y 3 ) supuesto que el sindicato haya dado publicidad adecuada a los resultados de la votación, si la huelga tiene lugar dentro del «período, a contar desde la fecha de la votación,... de cuatro semanas» ${ }^{52}$.

Siempre según dicha Ley, «un trabajador no tiene derecho a reclamar por despido ilegal [unfair dismissal] si en el momento del despido tomó parte en una huelga no controlada sindicalmente [unofficial strike] o en otra acción industrial no controlada sindicalmente» ${ }^{53}$; en cambio, «un trabajador que sea despedido será considerado a los efectos de la Parte X de la Ley de Derechos de Empleo [Employment Rights Act] de 1996 (despido ilegal) como ilegalmente despedido [unfairly dismissed] si... la razón (o, si hay más de una, la principal razón) del despido es que el trabajador realizó una acción industrial protegida» ${ }^{54}$.

La propia Ley afirma — sobre la base de que en Gran Bretaña el lock-out puede ser incluso extintivo del contrato de trabajo ${ }^{55}$, y supuesto que «el empresario esté realizando o

45 Sección 219(1).

46 Sobre este concepto, sección 244.

47 Acerca de todo esto, véase J. MARTÍNEZ GIRÓN, «La huelga laboral: experiencias inglesa y norteamericana», cit., págs. 696-697.

48 Sección 226(2)(a).

49 Sección 228(3).

50 Sección 226(2)(a)(iii).

51 Cfr. sección 227(1).

52 Sección 234(1)(a).

53 Sección 237(1).

54 Sección 238A(2)(a).

55 Según la Ley de Derechos de Empleo (Employment Rights Act) de 1996, «lock-out significa (a) el cierre de un lugar de empleo, (b) la suspensión de trabajo, o (c) la negativa de un empresario a continuar empleando cualquier número de personas empleadas por él, como consecuencia de un conflicto planteado con el propósito de obligar a personas empleadas por el empresario, o ayudar a otro empresario a obligar a personas empleadas por él, a aceptar términos y condiciones de empleo o que afecten al empleo» [sección 235(4)]. 
creando un lock-out»— que «en tal caso un tribunal de empleo no resolverá si el despido fue legal o ilegal, salvo que se demuestre... que uno o más trabajadores relevantes del mismo empresario no ha sido despedido, o... que a un trabajador relevante le ha sido ofrecida la readmisión antes de la expiración del período de tres meses a contar desde la fecha del despido, y que al demandante no le ha sido ofrecida la readmisión» ${ }^{56}$.

La norma británica equivalente de las leyes continentales europeas sobre servicios esenciales es, en la actualidad, la Ley de Contingencias Civiles (Civil Contingencies Act) de 2004, construida sobre la base del concepto de «emergencia [emergency]» ${ }^{57}$.

§5. Aunque comparta unos orígenes similares a los del modelo británico, el modelo norteamericano es, en cambio, un verdadero modelo de «derecho de huelga [right to strike]» ${ }^{58}$, regulado —aunque mínimamente - en la Ley de Relaciones Laborales Nacionales (National Labor Relations Act) o Ley Wagner de $1935^{59}$. La constitucionalidad de esta regulación legal mínima fue confirmada en 1937 por la Corte Suprema de los Estados Unidos en un caso famoso, en el que se declaró que el empresario - a pesar de que la regla general era y sigue siendo todavía, en los Estados Unidos, la del despido libre - no podía despedir al trabajador por causa de su participación en «actividades concertadas [concerted activities]» ${ }^{60}$. Evidentemente, las actividades en cuestión - entre las que se «incluye el derecho de huelga» ${ }^{61}$ _ pueden ser lícitas o ilícitas, habiendo aclarado la propia Corte Suprema de los Estados Unidos que el empresario tiene derecho a despedir a quienes «participaron en huelgas desarrolladas de manera ilícita [unlawful manner] o para un objetivo ilícito [unlawful objective]», únicas dos «"limitaciones o cualificaciones" del derecho de huelga» ${ }^{62}$. El modelo norteamericano resulta inasimilable, sin embargo, a los modelos continentales europeos —incluido el alemán, que es el modelo con el que guarda un parecido más claro (por ejemplo, en materia de permisividad del lock-out o de prohibición de la huelga a

56 Sección 238(2)(a) y (b). Extrayendo consecuencias del tratamiento jurídico del lock-out en Gran Bretaña, véase G. DIÉGUEZ, «Huelga y cierre patronal: una recapitulación», Revista del Ministerio de Trabajo y Asuntos Sociales. Derecho del Trabajo, núm. 13 (1998), págs. 141 y ss.

57 Cfr. su sección 1.

58 Véase J. MARTÍNEZ GIRÓN, «La huelga laboral: experiencias inglesa y norteamericana», cit., págs. 693-694.

59 Su sección 13 (recopilada en la sección 163 del Título 29 del Código de los Estados Unidos) afirma que «nada contenido en esta Ley, excepto si se prevé específicamente, se interpretará ya para interferir o disminuir o impedir en cualquier modo el derecho de huelga, o para afectar a las limitaciones o cualificaciones de ese derecho». Sobre el tema, véase W.E. OBERER, T.J. HEINSZ y D.R. NOLAN, Labor Law. Collective bargaining in a free society, $5^{\text {a }}$ ed., West Group (St. Paul-Minn., 2002), págs. 352 y ss.

60 Se trata del caso NLRB v. Jones and Laughlin Steel Corporation (referencia 301 US 1).

61 Cfr. caso NLRB v. Erie Resistor Corp., fallado por la Corte Suprema de los Estados Unidos en 1963 (referencia 373 US 221). 632 US 274).

62 Caso NLRB v. Drivers, Chauffeurs, Helpers, Local Union No. 639, fallado en 1969 (referencia 
los empleados públicos)—, dado que desde 1938 el empresario goza frente a la huelga lícita del derecho de reemplazar, permanentemente incluso, a los huelguistas por otros trabajadores («esquiroles», por tanto, en sentido estricto) ${ }^{63}$. En efecto, según la Corte Suprema de los Estados Unidos, el empresario puede negarse a readmitir a los huelguistas, probando que «su acción fue debida a "legítimas y sustanciales justificaciones económicas"》, existentes «cuando los puestos de trabajo reclamados por los huelguistas están ocupados por trabajadores contratados como sustitutos permanentes [permanent replacements]», aunque en este caso el huelguista no readmitido tampoco pueda considerarse un trabajador despedido - su situación, con terminología española, podría calificarse como de excedencia voluntaria-, pues «cuando esté vacante un puesto de trabajo... tiene derecho [preferente] a una oferta de readmisión ${ }^{64}$.

La Corte Suprema de los Estados Unidos reconoció sin ambages al empresario, en 1965, el derecho de lock-out, negando que «el derecho de huelga "lleve aparejado" el derecho de determinar en exclusiva el calendario y duración de todos los paros de trabajo», y además, que el «uso de este instrumento concedería al empresario "demasiado poder"» ${ }^{65}$.

En cambio, el empresario no puede exigir a los huelguistas la prestación de servicios de mantenimiento, que deberán ser prestados por los trabajadores que hubiese contratado como «guardas [guards]», afirmando respecto de estos últimos la Ley de Relaciones entre Empresario y Sindicato (Labor-Management Relations Act) o Ley Taft-Hartley de 1947, que una unidad de negociación colectiva no es apropiada «si incluye, junto a otros trabajadores, a cualquier individuo empleado como guarda para exigir el cumplimiento frente a los trabajadores u otras personas de las normas para proteger el patrimonio del empresario o para proteger la seguridad de las personas en las instalaciones del empresario» ${ }^{66}$.

La prohibición de la huelga de «empleados públicos [public employees]», tradicionalmente contenida en la recién citada Ley Taft-Hartley de $1947^{67}$, fue derogada y reformulada en $1955^{68}$, apareciendo actualmente contenida en la legislación recopilada en el Código de los Estados Unidos, en los siguientes términos: 1) bajo el rótulo «Lealtad y hacer huelga [Loyalty and striking]», indicando que «una persona no puede aceptar o mantener un puesto en el Gobierno de los Estados Unidos o en el Gobierno del Distrito de Columbia si... participa en una huelga, o defiende el derecho de huelga, contra el Gobierno de los Estados Unidos

63 El precedente judicial fue el caso NLRB v. Mackay Radio and Telegraph Co., fallado por la Corte Suprema de los Estados Unidos en dicho año (referencia 304 US 333).

64 Acerca de todo ello, véase caso NLRB v. Fleetwood Traiter Co., fallado en 1967 (referencia 389 US 375).

65 Cfr. caso American Shipbuilding Co. v. NLRB, fallado en 1965 (referencia 380 US 300). Sobre el tema, véase F.J. GÓMEZ ABELLEIRA, El "Lockout" en el Derecho de los EE.UU. Su Contraste con el Cierre Patronal en el Derecho Español, Cedecs (Barcelona, 1998), págs. 13 y ss.

66 Sección 9(b)(3) del Título I [recopilada en la sección 159(b)(3) del Título 29 del Código de los Estados Unidos].

67 Cfr. sección 188 del Título 29 del Código de los Estados Unidos.

68 Véase D.H. WOLLET, J.R. GRODIN y J.M. WEISBERGER, Collective bargaining in public employment, West Publ. Co. (St. Paul-Minn., 1993), págs. 252 y ss. 
o el Gobierno del Distrito de Columbia» ${ }^{69}$, ni tampoco si «está afiliada a una organización de empleados del Gobierno de los Estados Unidos o de personas empleadas por el Gobierno del Distrito de Columbia, que sabe que defiende el derecho de huelga contra el Gobierno de los Estados Unidos o el Gobierno del Distrito de Columbia» "70; y 2) bajo el rótulo «Deslealtad $\mathrm{y}$ defensa del derecho de huelga contra el Gobierno [Disloyalty and asserting the right to strike against the Government]», imponiendo que quien viole estas prohibiciones «será multado ... o encarcelado no más de un año y un día, o ambas cosas» ${ }^{71}$. 
TEMA 15

EL PRINCIPIO DE ESTABILIDAD EN EL EMPLEO EN EL ORDENAMIENTO COMUNITARIO, EN LAS LEGISLACIONES Y PRÁCTICAS NACIONALES EUROPEAS, Y EN LA LEGISLACIÓN DE LOS ESTADOS UNIDOS

Sumario: §1. El principio de estabilidad en el empleo en el Derecho tradicional de la Unión Europea, ad intra y ad extra. \$2. La flexiguridad. \$3. El modelo francés (y sus variantes portuguesa, alemana e italiana) de regulación del principio de estabilidad en el empleo. §4. El modelo británico de falta de estabilidad en el empleo. §5. El modelo norteamericano de falta de estabilidad en el empleo.

THEME 15

THE PRINCIPLE OF EMPLOYMENT STABILITY IN THE EUROPEAN LAW, IN THE NATIONAL EUROPEAN LEGISLATIONS AND PRACTICES, AND IN THE LEGISLATION OF THE UNITED STATES

Contents: $\$ 1$. The principle of employment stability in the traditional Law of the European Union, ad intra and ad extra. \$2. The flexicurity. \$3. The French model (and its Portuguese, German and Italian variants) of regulation of the principle of employment stability. \$4. The British model of lacking of employment stability. \$5. The USA model of lacking of employment stability.

§1. Al igual que ocurre en materia de negociación colectiva ${ }^{1}$, también cabe calificar como un Derecho hipócrita el Derecho tradicional de la Unión Europea, pero ahora en lo tocante al principio de estabilidad en el empleo. En efecto, en el plano ad intra - esto es, el relativo al personal laboral al servicio de la Unión Europea, tal y como obra regulado en el confuso, y quizá deliberadamente equívoco, Anexo del Reglamento núm. 31 (CEE), 11 (CEEA) de 1962, sobre el «Régimen aplicable a los otros agentes de las Comunidades»- resulta que el principio de estabilidad en el

1 Véase supra, Tema 13, §1. 
empleo no se respeta en absoluto, dado que: 1) los «agentes temporales» —que vienen a ser los contratados laborales más próximos (por razón de las funciones que desempeñan) a los funcionarios de la Unión Europea, clasificados en cuatro tipos distintos [tipo a), tipo b), tipo c) y tipo d)] por su precepto definidor ${ }^{2}-$ son todos trabajadores precarios (de ahí su denominación "agentes temporales», recuérdese), visto: a) que los agentes tipo b) y tipo d) - que necesariamente ocupan un «puesto de trabajo permanente ${ }^{3}$ - son empleados mediante un contrato con una duración máxima de cuatro más dos años, de manera que «una vez extinguido el contrato, el agente no podrá ocupar un puesto de trabajo permanente de la institución, salvo que sea nombrado funcionario» ${ }^{4} ; \mathrm{y}$ b) que los agentes tipo a) y tipo c) - que necesariamente desempeñan funciones de «carácter temporal»- pueden ser contratados «por tiempo indefinido» ${ }^{5}$, pero teniendo en cuenta que esta última expresión equivale simplemente a poseer un contrato de trabajo sin plazo - en absoluto, un contrato de trabajo fijo-, supuesto que se trata de trabajadores sujetos a despido libre mediante preaviso ${ }^{6}$; 2) los «agentes contractuales»-que desempeñan, por ejemplo, «tareas manuales o de apoyo administrativo» ${ }^{7}$ - se contratan inicialmente siempre como trabajadores precarios y al cabo de cinco más cinco años de precariedad pueden convertirse en agentes con un contrato «por tiempo indefinido» ${ }^{8}$, pero teniendo en cuenta -al igual que sucede con los «agentes temporales»— que su contrato de trabajo está siempre sujeto a despido libre con preaviso ${ }^{9}$; y 3) los «agentes locales» —que ya no tienen por qué ser necesariamente nacionales de la Unión Europea- pueden llegar a tener estabilidad en el empleo, si así lo establece la legislación del Estado tercero (por ejemplo, Bolivia, Nigeria o Arabia Saudita) donde sean contratados por la propia Unión Europea para efectuar «tareas manuales o de servicios» ${ }^{10}$, pues el tema de sus «formas de contratación» se determinará «por cada institución sobre la base de la reglamentación y de las costumbres existentes en el lugar donde el agente

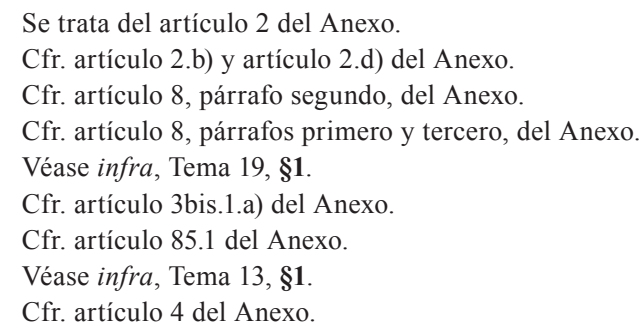


sea nombrado para ejercer sus funciones» ${ }^{11}$. En cambio, en el plano ad extra más tradicional —esto es, el relativo a lo que debería o currir en los Estados miembros de la Unión Europea-, la Directiva 1999/70/CE del Consejo, de 28 junio 1999, relativa al Acuerdo marco de la CES, la UNICE y el CEEP sobre el trabajo de duración determinada, afirma que «los contratos de trabajo de duración indefinida son la forma más común de relación laboral, y que contribuyen a la calidad de vida de los trabajadores afectados y a mejorar su rendimiento», y que «la utilización de contratos de trabajo de duración determinada basados en razones objetivas es una forma de evitar abusos», por lo que resulta ser «objeto» políticamente correcto e irreprochable de la propia Directiva, a cumplir por todos los Estados miembros a más tardar el 10 julio 2001, «mejorar la calidad del trabajo de duración determinada»y «establecer un marco para evitar los abusos derivados de la utilización de sucesivos contratos o relaciones laborales de duración determinada» ${ }^{12}$.

Interpretando esta Directiva al hilo de una cuestión prejudicial, la jurisprudencia del Tribunal de Luxemburgo afirma que «el Acuerdo marco concibe la estabilidad en el empleo como un componente primordial de la protección de los trabajadores», por lo que «aceptar que una disposición nacional pueda justificar, de pleno derecho y sin mayores precisiones, la utilización sucesiva de contratos de trabajo de duración determinada equivaldría a ignorar voluntariamente la finalidad del Acuerdo marco, que consiste en proteger a los trabajadores contra la inestabilidad en el empleo, y a vaciar de contenido el principio que establece que los contratos de trabajo de duración indefinida constituyen la forma general de relación laboral» ${ }^{13}$.

Todas las confusiones y equivocidades del citado Reglamento, sobre el «Régimen aplicable a los otros agentes de las Comunidades», se derivan del hecho de que en esta norma no se habla por ningún lado ni de personal laboral, ni de contrato de trabajo, ni de despido, ni de negociación colectiva, ni de huelga, ni de absolutamente nada que ponga de relieve que esos «otros agentes de las Comunidades» — distintos de los funcionarios- son personal laboral al servicio de la Unión Europea. Tales equívocos y eufemismos han sido contundentemente desmentidos por una Sentencia del Tribunal de la Función Pública de la Unión Europea (pleno) de 26 octubre 2006, apelando - a propósito del despido nulo de una «agente temporal» decretado por cierta agencia de la Unión Europea- al Convenio núm. 158 de 1982 de la OIT y, también, al artículo 24.a) de la Carta Social Europea (sobre «el derecho de todos los trabajadores a no ser despedidos sin que existan razones válidas para ello relacionadas con sus actitudes o su conducta, o basadas en las necesidades de funcionamiento de la empresa, del establecimiento o del servicio»). A nuestro juicio, sin

11 Cfr. artículo 120 del Anexo.

12 Desde la perspectiva del Derecho español, véase I. GONZÁLEZ DEL REY RODRÍGUEZ, «Los contratos de trabajo de duración determinada (Directiva 1999/70/CE)», en J. GARCÍA MURCIA (Director), La transposición del Derecho social comunitario al ordenamiento español, Ministerio de Trabajo y Asuntos Sociales (Madrid, 2005), págs. 285 y ss.

13 Al respecto, véase Sentencia del Tribunal de Justicia de las Comunidades Europeas de 4 julio 2006 (asunto C-212/04). 
embargo, esta sentencia viene a concluir - seguramente, porque la hipócrita normativa interna de la propia Unión Europea no da pie para más- que los «agentes temporales» se encuentran permanentemente, en realidad, en una situación análoga a la de los trabajadores sujetos a período de prueba ${ }^{14}$.

Siempre según el hipócrita Reglamento comunitario citado, sólo los «agentes temporales» figuran ocupando puestos de trabajo consignados en las relaciones de puestos de trabajo de las muy diversas agencias e instituciones de la Unión Europea. En cambio, los «agentes contractuales» y los «agentes locales» no figuran reflejados en estas relaciones de puestos de trabajo ${ }^{15}$, lo que explica que tampoco figuren reflejados en la información estadística —aparentemente obsesionada sólo por la perspectiva de género-, obrante en http://ec.europa.eu/civil_service/about/figures/index_en.htm. Acerca de las posibilidades de utilización casi ad libitum de este otro personal laboral precario no obrante en tales relaciones de puestos de trabajo, téngase en cuenta que el Reglamento comunitario regulador de su estatus afirma también que «basándose en la información que habrán de facilitarle todas las instituciones, la Comisión presentará cada año a la autoridad presupuestaria un informe sobre el empleo de agentes contractuales, indicando si el número total de dichos agentes se sitúa dentro del límite del $75 \%$ de los efectivos totales de, respectivamente, las agencias, otros organismos situados en la Unión Europea, las representaciones y delegaciones de las instituciones comunitarias y otros organismos situados fuera de la Unión Europea» ${ }^{16}$.

§2. El Derecho ad extra de la Unión Europea apuesta ahora decididamente, frente a su Derecho ad extra tradicional - que acabamos de ver- contra el principio de estabilidad en el empleo, al haber adoptado como guía de su política de empleo — desde el año 2006- el modelo danés de «flexiguridad [flexicurity]». El modelo de este pequeño país nórdico está basado en las tres ideas siguientes: 1) la continua rotación de un trabajador entre empleos distintos, con objeto de lograr la mayor empleabilidad posible a lo largo de su vida laboral; 2) el reforzamiento de la protección por desempleo, para así asegurar al trabajador ingresos económicos equiparables a los salariales, mientras carezca de empleo; y 3) el reforzamiento de la formación profesional, al efecto de facilitar las transiciones entre períodos de desempleo y períodos de acceso por el trabajador a un nuevo empleo ${ }^{17}$. El espaldarazo comunitario a este modelo

14 Acerca de esto último, véase infra, Tema 19, §1.

15 Tampoco, como es lógico, los «consejeros especiales» (cfr. artículos 123 y 124 del Anexo) y los «asistentes parlamentarios acreditados» (cfr. artículos 125 a 139 del Anexo), puesto que se trata de personal de confianza de los políticos comunitarios.

16 Cfr. artículo 3bis.2 del citado Anexo.

17 Acerca del tema en la Comunicación de las Comunidades Europeas al Consejo Europeo de Primavera, fechada en Bruselas el 12 noviembre 2006, sobre ejecución de la estrategia de Lisboa renovada para el crecimiento y el empleo [COM (2006) 816 final], véase J. MARTÍNEZ GIRÓN, «Mercado de trabajo y protección social. Su consideración desde la perspectiva del Derecho de la Unión Europea y de las principales reformas legislativas operadas en España, en el bienio 2006-2007», Anuario da Facultade de Dereito da Universidade da Coruña. Revista jurídica interdisciplinar internacional, vol. 12 (2008), págs. 619-620. 
de política de empleo — que no sólo dinamita el principio de estabilidad en el empleo, sino también el principio de especialización profesional- se lo da, por ejemplo, la Decisión del Consejo de la Unión Europea 2008/618/CE, de 15 julio, aprobando las orientaciones para las políticas de empleo de los Estados miembros durante el período 2008-2010 ${ }^{18}$, pues una de estas orientaciones se refiere precisamente a «promover la flexibilidad combinada con la seguridad del empleo..., prestando la debida atención al papel de los interlocutores sociales, mediante» - entre otras varias cosas - «la facilitación de las transiciones en materia de categoría profesional» ${ }^{19}$.

En materia de «flexiguridad», la Unión Europea empezó exigiéndosela sólo a algunos Estados miembros ${ }^{20}$, aunque luego ha acabado extendiéndola - como una mancha de aceite - a todos los Estados miembros, salvo el Reino Unido y los Países Nórdicos.

No deja de resultar sintomático que la Directiva 2008/104/CE del Parlamento Europeo y del Consejo, de 19 noviembre 2008, relativa al trabajo a través de empresas de trabajo temporal, aluda también entusiásticamente a la «flexiguridad», afirmando que «además, el Consejo Europeo de diciembre de 2007 dio su respaldo a los principios comunes acordados en materia de flexiguridad que mantienen un equilibrio entre la flexibilidad y la seguridad en el mercado de trabajo y que contribuyen a que tanto los trabajadores como los empresarios aprovechen las oportunidades que ofrece la globalización» ${ }^{21}$.

Esta última Directiva — que colma el vacío que no cubría la Directiva 91/383/CEE, del Consejo, de 25 junio 1991, por la que se completan las medidas tendentes a promover la mejora de la seguridad y de la salud en el trabajo de los trabajadores con una relación laboral de duración determinada o de empresas de trabajo temporal ${ }^{22}$ - contribuirá decisivamente a armonizar los diversos Derechos nacionales en materia de empresas de trabajo temporal, actualmente muy divergentes ${ }^{23}$, aunque su plazo de transposición vence el 5 diciembre 2011.

§3. En la Europa continental, el modelo que mejor refleja lo que teóricamente debe ser el principio de

18 Diario Oficial de la Unión Europea Serie L, núm. 198, de 26 julio 2008.

19 Cfr. Orientación núm. 21.

20 Véase A. ARUFE VARELA, «"Flexiguridad" laboral danesa y "rigiseguridad" laboral alemana (La sesgada exigencia del cumplimiento de la directriz de la Unión Europea sobre "flexiguridad" laboral sólo a algunos Estados miembros)», Aranzadi Social, núm. 7-8 (2008), págs. 97 y ss.

21 Considerando 9.

22 Véase I. GONZÁLEZ DEL REY RODRÍGUEZ, «Trabajo temporal y prevención de riesgos laborales (Directiva 91/383/CEE)», en J. GARCÍA MURCIA (Director), La transposición del Derecho social comunitario al ordenamiento español, cit., págs. 301 y ss. Evidentemente, tampoco cubría el vacío la Directiva 96/71/CE del Parlamento Europeo y del Consejo, de 16 diciembre, sobre el desplazamiento de trabajadores efectuado en el marco de una prestación de servicios, allí donde se refiere a trabajadores desplazados al servicio de empresas de trabajo temporal. Acerca de su transposición en España, véase J. MARTÍNEZ GIRÓN, A. ARUFE VARELA y X.M. CARRIL VÁZQUEZ, Derecho del Trabajo, 2ª ed., Netbiblo (A Coruña, 2006), pág. 118.

23 Respecto de Italia, véase A. ARUFE VARELA, «El cumplimiento por Italia de las recomendaciones europeas sobre el empleo, a través de la "Reforma Biagi"», cit., págs. 68-69. Lógicamente, la crítica doctrinal del asunto viene de antiguo. Al respecto, véase R. BLANPAIN, «Temporary Work and the Law: the EC Directive and Proposals», en R. BLANPAIN (Editor), Temporary Work and Labour Law of the European Community and Member States, Kluwer (Deventer, 1993), págs. 25 y ss. 
estabilidad en el empleo es el modelo francés ${ }^{24}$. En efecto, según el Código del Trabajo, se trata de un modelo articulado alrededor de tres ideas principales: 1) no existe libertad entre las partes del contrato de trabajo para acordar la duración de un término resolutorio, de manera que - sobre la base de que en Francia no existe, por supuesto, despido libre- todo contrato de trabajo se entiende concertado por tiempo indefinido («El contrato de trabajo de duración indeterminada es la forma normal y general de la relación de trabajo [Le contrat de travail à durée indeterminée est la forme normale et générale de la relation de travail]») ${ }^{25}$, pudiendo pactarse el término resolutorio sólo en los supuestos expresamente permitidos por la ley ( «Sin embargo, el contrato de trabajo puede conllevar un termino fijado con precisión desde su conclusión o resultante de la realización del objto para el que ha sido concluido en los casos y en las condiciones mencionadas en el Título IV relativo al contrato de trabajo de duración determinada [«Toutefois, le contrat de travail peut comporter un terme fixé avec précision dès sa conclusion ou résultant de la réalisation de l'objet pour lequel il est conclu dans les cas et dans les conditions mentionnés au titre IV relatif au contrat de travail à durée déterminée]») ${ }^{26}$; 2) estos casos se refieren a necesidades ocasionales, transitorias o temporales de la actividad empresarial, pues «un contrato de trabajo de duración determinada, cualquiera que sea su motivo, no puede tener ni por objeto ni por efecto atender duraderamente un empleo ligado a la actividad normal y permanente de la empresa [un contrat de travail à durée determinée, quel que soit son motif, ne peut avoir ni pour objet ni pour effet de pourvoir durablement un emploi lié à l'activité normale et permanente de l'entreprise]» ${ }^{27}$; y 3) la sanción contractual que lleva aparejada el incumplimiento por el empresario de esta normativa limitadora de la libertad contractual es la conversión del contrato precario en un contrato por tiempo indefinido («se reputa de duración indeterminada todo contrato de trabajo concluido en inobservancia de las disposiciones de los artículos [est réputé à durée indeterminée tout contrat de travail conclu

24 Sobre él, véase J. PÉLISSIER, A. SUPIOT y A. JEAMMAUD, Droit du travail, 24a ed., Dalloz (París, 2008), págs. 405 y ss.; F.-J. PANSIER, Droit du travail. Relations individuelles et collectives, Litec (París, 2005), págs. 70 y ss. ; y A. MARTINON, Essai sur la stabilité du contrat de travail à durée indéterminée, Dalloz (París, 2005), págs. 31 y ss.

25 Cfr. artículo L. 1221-2, párrafo primero.

26 Ibidem, párrafo segundo.

27 Cfr. artículo L. 1242-1. Téngase en cuenta, sin embargo, lo dispuesto en el artículo L. 1242-3, acerca de que en otros dos supuestos también «un contrato de trabajo de duración determinada puede ser concluido». 
en méconnaissance des dispositions des articles L. 1242-1 a L. 1242-4, L. 1242-6 a L. 1242-8, L. 1242-12, párrafo primero, L. 1243-11, párrafo primero, L. 1243-13, L. 1244-3 y L. 1244-4]») ${ }^{28}$. Los demás modelos continentales europeos son meras variantes imperfectas de este modelo francés, visto: 1) en Portugal —donde la Constitución menciona expresamente la «seguridad en el empleo [segurança no emprego]» ${ }^{29}$-, que el Código del Trabajo excepciona la regla general de que «el contrato de trabajo a término resolutorio [contrato de trabalho a termo resolutivo] sólo puede ser celebrado para satisfacción de necesidad temporal de la empresa y por el período estrictamente necesario para la satisfacción de esa necesidad ${ }^{30}$, admitiendo dos excepciones muy genéricas a e s a re gla («lanzamiento de nueva actividad de duración incierta, así como el inicio de actividad de una empresa o centro de trabajo» $\mathrm{y}$ 《contratación de trabajador en busca de primer empleo, en situación de desempleo de larga duración») $)^{31}$; 2) en A lemania, que la norma reguladora del tema -que es la «Ley sobre trabajo a tiempo parcial y contratos de trabajo a plazo [Gesetz über Teilzeitarbeit und befristete Arbeitsverträge]», o TzBfG, de 21 diciembre $2000^{32}$ - , frente a la regla general de que el contrato de trabajo a plazo sólo cabe estipularlo «si está justificado por una razón objetiva [durch einen sachlichen Grund] » ${ }^{33}$, también autoriza su celebración -con mayor laxitud que en Portugal- si la duración del contrato en cuestión no excede de dos años («el plazo cierto de un contrato de trabajo sin la existencia de una razón objetiva es admisible por una duración de hasta dos años [bis zur Dauer von zwei Jahren]») ${ }^{34}$; y 3) en It a li a ${ }^{35}$, que

28 Cfr. artículo L. 1245-1.

29 Cfr. su artículo 53.

30 Cfr. artículo 140.1.

31 Cfr. artículo 140.4, letras a) y b), respectivamente. Acerca de todo ello, en términos prácticamente idénticos en el Código de Trabajo de 2003, véase J. MARTíNEZ GIRÓN, «Estudo Comparativo do Projecto Português de Código do Trabalho de 2002 e da Legislação Laboral Espanhola Vigente - Restrições à Celebração de Contratos de Trabalho a Termo», en el volumen Código do Trabalho. Alguns aspectos cruciais, Principia (Cascais, 2003), págs. 63 y ss.; P. ROMANO MARTÍNEZ, L.M. MONTEIRO, J. VASCONCELOS, P. MADEIRA DE BRITO, G. DRAY y L. GONÇALVES DA SILVA, Código do Trabalho. Anotado, $4^{\mathrm{a}}$ ed., Almedina (Coimbra, 2005), págs. 276 y ss.; y A. MONTEIRO FERNANDES, Direito do Trabalho, $15^{\mathrm{a}}$ ed., Almedina (Coimbra, 2010), págs. 327 y ss.

32 Sobre ella, véase W. BOECKEN y J. JOUSSEN, Teilzeit- und Befristungsgesetz. Handkommentar, $2^{\mathrm{a}}$ ed., Nomos (Baden-Baden, 2010), págs. 124 y ss. Nuestra traducción de la misma, en J. MARTÍNEZ GIRÓN y A. ARUFE VARELA, Leyes laborales alemanas. Estudio comparado y traducción castellana, Netbiblo (A Coruña, 2007), págs. 113 y ss.

33 Cfr. parágrafo 14 , apartado 1.

34 Cfr. parágrafo 14, apartado 2, inciso primero.

35 Véase C. ENRICO, Diritto del Lavoro, $2^{\text {a }}$ ed., Giapichelli (Turín, 2004), págs. 89 y ss.; A. TURSI y P.A. VARESI, Lineamenti di Diritto del Lavoro. Rapporti di lavoro e relazioni sindacali nel settore privato, $3^{\mathrm{a}}$ ed., Kluwer-Ipsoa (s.1., 2004), págs. 109 y ss.; y G. FAVALLI y F. ROTONDI, Manuale pratico di diritto del lavoro, $2^{\mathrm{a}}$ ed., CEDAM (Padua, 2005), págs. 30 y ss. 
la norma de transposición de la Directiva comunitaria —esto es, el Decreto Legislativo núm. 368, de 6 septiembre 2001- se limita a afirmar genéricamente, aunque parezca increíble - tras declarar que «el contrato de trabajo subordinado se estipula como regla por tiempo indeterminado» ${ }^{36}$-, que «se consiente el establecimiento de un término a la duración del contrato de trabajo subordinado frente a razones de carácter técnico, productivo, organizativo o su st it ut ivo [un termine alla durata del contratto di lavoro subordinato a fronte di ragioni di carattere tecnico, produttivo, organizzativo o sostitutivo], aunque se refiera a la actividad ordinaria del empresario» ${ }^{36}$.

Esta norma fue desarrollada por el Decreto Legislativo núm. 276, de 10 septiembre 2003, a través del cual «el Gobierno italiano elaboró un surtido menú — bien creando figuras contractuales nuevas, bien remozando alguna otra ya existente-, al que dedica por completo su Título V, en el que se trata del "trabajo intermitente [lavoro intermittente]", del "trabajo repartido [di lavoro ripartito]" y del "trabajo a tiempo parcial [lavoro a tempo parziale]" (todos bajo la rúbrica común "Tipologías contractuales de horario reducido, modulado o flexible [tipologie contrattuali a orario ridotto, modulato o flessibile]"); también su Título VI, que se ocupa del "aprendizaje [apprendistato]" y del "contrato de inserción [contratto di inserimento]"; y además, su Título VII — bajo la rúbrica "Tipologías contractuales a proyecto y ocasionales [Tipologie contrattuali a progetto e occasionali]"- en el que se halla la regulación del "contrato de trabajo a proyecto [contratto di lavoro a progetto]", se hace referencia a las denominadas "prestaciones ocasionales [prestazioni occasionali]", a secas, y se trata de las "prestaciones ocasionales de tipo accesorio rendidas por sujetos particulares [prestazioni occasionali di tipo accessorio rese da particolari soggeti]" ${ }^{37}$.

A diferencia de lo que ocurre en España — donde el contrato de trabajo de lanzamiento de nueva actividad feneció en 1997- y al igual que sucede en Portugal, la Ley alemana citada admite la licitud de esta concreta modalidad contractual precaria, afirmando que «en los primeros cuatro años subsiguientes a la creación de una empresa es admisible el plazo cierto [kalendermäßige Befristung] de un contrato de trabajo sin existencia de una razón objetiva, por un período de cuatro años ${ }^{38}$, teniendo en cuenta que «lo determinante para precisar el momento de la creación de la empresa es el comienzo de la actividad empresarial, que hay que comunicar al Ayuntamiento o a la oficina tributaria» ${ }^{39}$.

Que la precariedad es una expresión jurídica y que, además, constituye un mal jurídico, lo prueba el artículo L. 1243-8 del Código francés del Trabajo, a cuyo tenor «cuando, a la finalización de un contrato de trabajo de duración determinada, las relaciones contractuales de trabajo no se prosiguen por un contrato de trabajo de duración indeterminada, el trabajador tiene derecho, a título de complemento de salario, a una indemnización de fin de contrato

36 Cfr. artículo 1.1.

37 Sobre todo esto, véase A. ARUFE VARELA, «El cumplimiento por Italia de las recomendaciones europeas sobre el empleo, a través de la "Reforma Biagi"», Anuario da Facultade de Dereito da Universidade da Coruña. Revista Jurídica Interdisciplinar Internacional, núm. 10 (2006), págs. 69-70.

38 Cfr. parágrafo 14 , apartado $2 \mathrm{a}$, medio inciso primero.

39 Ibidem, inciso tercero. 
destinada a compensar la precariedad [précarité] de su situación» ${ }^{40}$, teniendo en cuenta que «esta indemnización es igual al $10 \%$ de la remuneración total bruta debida al trabajador» ${ }^{41 .}$

§4. El modelo británico de regulación de los contratos de trabajo de duración determinada nada tiene que ver con los modelos continentales europeos que acaban de describirse, puesto que es un modelo caracterizado por su falta de respeto al principio de estabilidad en el empleo ${ }^{42}$. El régimen jurídico vigente del mismo aparece contenido en el «Reglamento de trabajadores a plazo fijo (Prevención de trato menos favorable) [Fixed-term Employees (Prevention of Less Favourable Treatment) Regulations]» de 2002, supuestamente promulgado para transponer al Derecho interno británico la citada Directiva 1999/70/CE, aunque resulta evidente que tal Reglamento y la Directiva absolutamente nada tienen que ver en materia de estabilidad en el empleo - lo que no extraña, visto que en Gran Bretaña continúa todavía rigiendo un modelo de despido libre con preaviso ${ }^{43}$ - , fundamentalmente por tres razones. En primer lugar, porque el trabajador y el empresario tienen completa libertad para acordar la duración del contrato de trabajo, siempre y cuando el término resolutorio acordado no exceda de cuatro años, según viene a afirmarse crípticamente en los apartados (1) a (3) de la sección 8 del Reglamento en cuestión (rotulada «Contratos a plazo fijo sucesivos [Successive fixed-term contracts]»). En segundo lugar, porque esta libertad de estipulación del término resolutorio puede incluso ser ampliada por convenio colectivo, afirmando al respecto la propia sección 8 del Reglamento que «un convenio colectivo o un acuerdo de franja pueden modificar la aplicación de los apartados (1) a (3) ... mediante $\ldots$ disposiciones diferentes que ... especifiquen $\ldots$ el período máximo total por el cual el trabajador ... puede ser continuamente empleado mediante un contrato a plazo fijo» ${ }^{44}$. En tercer lugar, siempre según esta misma sección 8 , porque «a los efectos de este Reglamento se aplicará el Capítulo 1 de la Parte 14 de la Ley [de Derechos de Empleo]

40 Párrafo primero.

41 Párrafo segundo. Sobre la «notion de precarité», véase P.-Y. VERKINDT, Le Droit du Travail, Dalloz (París, 2005), págs. 135 y ss.

42 Véase N.M. SELWYN, Law of Employment, 13ª ed., LexisNexis-Butterworths (Londres, 2004), págs. 64 y ss.; J. BOWERS, A practical approach to Employment Law, $7^{\mathrm{a}}$ ed., Oxford University Press (Oxford, 2005), pag. 276; y J. HOLLAND y S. BURNETT, Employment Law, Oxford University Press (Oxford, 2005), pág. 28.

43 Al respecto, infra, Tema 19, §4.

44 Cfr. apartado (5). 
de 1996 para determinar si un trabajador ha sido continuadamente empleado» ${ }^{45}$, lo que significa que si hay solución de continuidad entre contrato de trabajo precario y contrato de trabajo precario, cabe volver a emplear otra vez al trabajador mediante un nuevo contrato de trabajo de duración determinada de incluso hasta cuatro años (si no la hubiese, el trabajador pasaría entonces, supuesto que no hubiese razón objetiva que justificase la estipulación del nuevo contrato precario, a convertirse en un «trabajador permanente [permanent employee]»).

Acerca del carácter críptico de los citados apartados (1) a (3) de la sección 8 del Reglamento, basta poner de relieve que en los mismos se afirma literalmente lo siguiente: «esta norma reglamentaria se aplica donde (a) un trabajador es empleado con un contrato que pretende ser un contrato a plazo fijo, y (b) el contrato mencionado en el subapartado (a) ha sido previamente renovado, o el trabajador ha sido previamente empleado con un contrato a plazo fijo antes del comienzo del contrato mencionado en el subapartado (a)» ${ }^{46}$; «donde esta norma reglamentaria se aplica entonces, con efecto desde la fecha especificada en el apartado (3), la cláusula del contrato mencionada en el apartado (1)(a) que restrinja la duración del contrato no tendrá efecto, y el trabajador será un trabajador permanente, si (a) el trabajador ha sido continuadamente empleado mediante el contrato mencionado en el apartado 1(a), o mediante aquel contrato tomado con un previo contrato a plazo fijo, para un período de cuatro años o más, y (b) el empleo del trabajador mediante un contrato a plazo fijo no estaba justificado por motivos objetivos, (i) donde el contrato mencionado en el parágrafo (1)(a) ha sido renovado, al tiempo en que fue últimamente renovado, (ii) donde el contrato no ha sido renovado, al tiempo en que estipulado» ${ }^{47}$; «la fecha referida en el apartado (2) es cualquiera que sea la última de, (a) la fecha en que el contrato mencionado en el apartado (1)(a) fue estipulado o últimamente renovado, y (b) la fecha en que el trabajador adquirió cuatro años de empleo continuado» ${ }^{48}$.

El citado Capítulo 1 de la Parte 14 de la Ley de 1996, fundamental para determinar los períodos que «no rompen la continuidad del empleo [do not break continuity of employment]», comprende las secciones 210 a 219 de la propia Ley, resultando claves de entre éstas las relativas a «semanas que cuentan en el período de cómputo» ${ }^{49}$, a «intervalos en el empleo» ${ }^{50} \mathrm{y}$ a «disposiciones especiales sobre pagos a personal sobrante» ${ }^{51}$.

Desde un punto de vista jurídico continental, este Reglamento británico ni siquiera garantiza integralmente el principio de trato igual de los trabajadores británicos precarios, puesto que su sección 4 -aplicando la técnica de la comparación conjunta- afirma que existe justificación objetiva para tratar a un trabajador a plazo fijo de manera «menos favorable que ... a un trabajador permanente comparable», cuando «los términos del contrato de trabajo del trabajador a plazo fijo, tomados en conjunto, son al menos tan favorables como los términos del contrato de trabajo del trabajador permanente comparable» ${ }^{52}$.

\footnotetext{
45 Cfr. apartado (4).

46 Cfr. apartado (1).

47 Cfr. apartado (2).

48 Cfr. apartado (3).

49 Cfr. sección 212.

50 Cfr. sección 213.

51 Cfr. sección 214.

52 Cfr. apartado (1).
} 
§5. La comparación entre lo que ocurre en Europa continental y lo que sucede en los Estados Unidos, a propósito siempre de la duración del contrato de trabajo, exige tener en cuenta que se trata de dos mundos con culturas jurídicas muy diferentes ${ }^{53}$. En la Europa continental, el contrato de trabajo de duración determinada es mirado con aversión por trabajadores y sindicatos (el mote contratos «precarios» habla por sí solo), lo que explica la protección que merece el principio de estabilidad en el empleo. En cambio, en los Estados Unidos, el término resolutorio del contrato de trabajo es una institución protectora del trabajador, dado que un trabajador contratado sin término (y por tanto, mediante un contrato de trabajo de «duración indefinida [indefinite duration]») $\mathrm{se}$ encuentra en situación de despido libre (técnicamente, de contrato de trabajo «a voluntad [at will]》 de ambas partes), $\mathrm{m}$ i e $\mathrm{n} \mathrm{t} \mathrm{r}$ a s que un trabajador contratado a plazo (esto es, con un contrato de trabajo de duración determinada o a «término [term]») s ó $1 \mathrm{o}$ puede ser despedido por el empresario mediante la invocación de una justa causa ${ }^{54}$. De ahí, del otrolado del Atlántico, la existencia de una regulación de los contratos de trabajo de duración determinada, que aquí —en Europa continental— resultaría de un liberalismo monstruoso, y que aparece contenida —en términos más o menos uniformes, salvo en Montana ${ }^{55}$ - en el Derecho de los diversos Estados federados. Según este Derecho estatal, más o menos uniforme: 1) el término puede convenirse oralmente o por escrito, al concluirse el contrato o después de comenzada su ejecución, y expresa o implícitamente ${ }^{56}$; 2) la periodicidad de pago del salario no hace prueba de que existe dicho término, pues «el hecho de que la compensación se mida a tanto por día, por mes o por año no hace necesariamente del contrato un contrato por un día, por un mes o por un año, de manera que en todos esos casos el contrato puede ser extinguido en cualquier momento por cualquiera de las partes, salvo que se haya fijado [de otro modo] su duración» ${ }^{57}$; y 3) existe siempre término implícito en los supuestos de tácita reconducción, pues

53 Descarnadamente desde su peculiar punto de vista, M.A. ROTHSTEIN, C.B. CRAVER, E.P. SCHROEDER, E.W. SHOBEN y L.S. VANDERVELDE, Employment Law, West Publ. Co. (St. Paul-Minn., 1994), págs. 9 y ss.

54 Véase J. MARTÍNEZ GIRÓN, El despido en el Derecho de los Estados Unidos, Civitas (Madrid, 1988), págs. 127 y ss.

55 Véase infra, Tema 19, §5.

56 Véase J. MARTÍNEZ GIRÓN, El despido en el Derecho de los Estados Unidos, cit., pág. 52.

57 Ibidem, pág. 53. 
«si una persona es empleada por tiempo cierto ... y continúa en el mismo empleo después de la expiración del término, se presume que su empleo fue renovado por otro término de idéntica extensión que el original» ${ }^{58}$.

Al proceder a regular el tema, las leyes de los diversos Estados federados enlatan asimismo reglas de cajón; y así, por ejemplo, el Código Laboral de California — que codifica la regla «at will» en su sección 2922- afirma que «un trabajador no empleado por un plazo especificado y que es despedido por su empresario, tiene derecho al pago de los servicios prestados hasta el momento de dicho despido» ${ }^{59}$.

Esta regulación estatal también se aplica a nivel federal (esto es, a las empresas implicadas en el «comercio interestatal»), al haberla aceptado la Corte Suprema de los Estados Unidos en los años 1908 y 1915, antes incluso de que comenzase la promulgación de la legislación federal «laboral» norteamericana en sentido estricto ${ }^{60}$. La propia Corte Suprema ha vuelto a refrendarla en 2008, en el contexto del empleo público ${ }^{61}$. Modalidad típicamente yanqui del contrato de trabajo de duración determinada es el «contrato de trabajo de por vida [contract for life employment]», que no es inválido o ineficaz siempre y cuando esté apoyado en una «causa [consideration]» distinta de la promesa del trabajador de prestar servicios, de manera que si existe, la empresa tampoco puede despedir al trabajador si no posee una justa causa ${ }^{62}$.

En los Estados Unidos, la figura del prestamista de mano de obra se admite con plena naturalidad, aunque se distinga entre «empresa de trabajo temporal [temporary employment agency]», "servicio de envío de trabajo [employment referral service]» y "contratista de trabajo [labor contractor]». Respecto de estas figuras, el Código Laboral de California les impone la responsabilidad por accidentes de trabajo (workmen's compensation) ${ }^{63}$. Por su parte, la «Ley de Protección del Trabajador Agrícola Migrante y Estacional [Migrant and Seasonal Agricultural Worker Protection Act]» de 1983 —-Ley federal cuya intención es «complementar el Derecho estatal»- afirma que «contratista de trabajo de granja [farm labor contractor]» significa «cualquier persona, distinta de un empresario agrícola, una

58 Ibidem, pág. 54.

59 Cfr. sección 2926.

60 Véase J. MARTÍNEZ GIRÓN, El despido en el Derecho de los Estados Unidos, cit., pág. 132.

61 Véase J. MARTÍNEZ GIRÓN, «El caso Engquist v. Oregon Department of Agriculture et al. (2008). La última palabra de la Corte Suprema de los Estados Unidos en favor del despido libre», Anuario Coruñés de Derecho Comparado del Trabajo-ACDCT, vol. II (2010), págs. 59 y ss.

62 Sobre el tema, J. MARTÍNEZ GIRÓN, El despido en el Derecho de los Estados Unidos, cit., págs. 56-58, poniendo de relieve que «esa consideration distinta ... existe: 1) "cuando el trabajador compra (purchases) el puesto de trabajo", mediante la cesión de algo — negocios, dinero derechos, ideas- económicamente valioso para el empresario; 2) también cuando el trabajador "renuncia a demandar [al empresario promitente]", pues dicha renuncia "es consideration suficiente ... si la parte renunciante tenía la intención honesta de pleitear", como ha reconocido reiteradísima jurisprudencia a propósito de renuncias a demandar por accidente de trabajo, y 3) por último, "el sufrimiento de un perjuicio por el trabajador" —al aceptar la promesa- resulta igualmente suficiente consideration de la misma si, por ejemplo, "el empresario sabía al tiempo de la contratación que el trabajador nunca habría dejado su antiguo empleo excepto por la oferta de un puesto permanente" o, también, si la oferta se hizo a un funcionario del gobierno, a un trabajador ya contratado de por vida en otra empresa, a quien hacía competencia al empresario como trabajador autónomo o a un huelguista que al aceptarla abandonó la huelga». Acerca del contexto en que se promulgó la hoy anacrónica prohibición contenida en el artículo 1583 de nuestro Codigo Civil, véase J. MARTÍNEZ GIRÓN, Los pleitos de Derecho privado sobre esclavitud ultramarina en la jurisprudencia del Tribunal Supremo (1857-1891), Civitas (Madrid, 2002), págs. 11 y ss.

63 Véase sección 3302. 
asociación agrícola, o un trabajador de un empresario agrícola o asociación agrícola, que, mediante dinero $u$ otra causa evaluable pagada o que se prometa pagar, realiza cualquier actividad de contratista de trabajo de granja» ${ }^{64}$, teniendo en cuenta que «actividad de contratista de trabajo de granja [farm labor contracting activity]» significa, a su vez, «reclutar, solicitar, contratar, emplear, suministrar o transportar trabajadores agrícolas migrantes o estacionales» ${ }^{65}$; y teniendo en cuenta, además, que lo que este contratista realiza es la actividad denominada «operación de acarreo del día [day-haul operation]», que consiste en «la reunión de trabajadores en un punto de recogida esperando a ser contratados y empleados, transporte de tales trabajadores al empleo agrícola, y el retorno de tales trabajadores a un punto de dejada en el mismo día» ${ }^{66}$. 
TEMA 16

EL DERECHO A LA PROTECCIÓN DEL TRABAJADOR FRENTE A LOS RIESGOS DEL TRABAJO EN EL ORDENAMIENTO COMUNITARIO, EN LAS LEGISLACIONES Y PRÁCTICAS NACIONALES EUROPEAS, Y EN LA LEGISLACIÓN DE LOS ESTADOS UNIDOS

Sumario: §1. El Derecho de la Unión Europea sobre seguridad y salud laboral, ad extra. §2. Los incumplimientos nacionales del Derecho de la Unión Europea sobre seguridad y salud laboral. §3. La legislación norteamericana sobre seguridad y salud laboral.

THEME 16

THE RIGHT OF THE EMPLOYEE TO PROTECTION BEFORE THE LABOR RISKS IN THE EUROPEAN LAW, IN THE NATIONAL EUROPEAN LEGISLATIONS AND PRACTICES, AND IN THE LEGISLATION OF THE UNITED STATES

Contents: $\$ 1$. The Law of the European Union about occupational safety and health, ad extra. \$2. The national violations of the Law of the European Union about occupational safety and health. \$3. The USA legislation about occupational safety and health.

§1. El Derecho de la Unión Europea relativo a la seguridad y salud laboral —en su vertiente ad extra ${ }^{l}$-, que es el equivalente contemporáneo de lo que tradicionalmente se llamaba en España y en la Europa continental «seguridad e higiene en el trabajo» ${ }^{2}$, resulta extraordinariamente

1 En su vertiente ad intra (la relativa, recuérdese, al personal al servicio de las instituciones de la propia Unión Europea), el «Estatuto de los Funcionarios» contenido en el Reglamento núm. 31 (CEE), núm. 11 (CEEA) de 1962, afirma que «a los funcionarios en activo se les concederán condiciones de trabajo que se ajusten a normas sanitarias y de seguridad apropiadas y, como mínimo, equivalentes a los requisitos mínimos aplicables con arreglo a las medidas adoptadas en estos ámbitos en virtud de los Tratados» (artículo 1 sexto, apartado 2).

2 Recuérdese que esta expresión es la que todavía utiliza nuestra Constitución y, también, el Estatuto de los Trabajadores. Al respecto, véase J. MARTÍNEZ GIRÓN, A. ARUFE VARELA y X.M. CARRIL VÁZQUEZ, Derecho del Trabajo, 2ª ed., Netbiblo (A Coruña, 2006), pág. 225. 
influyente y significativo ${ }^{3}$. Desde 1986 — con la promulgación del Acta Única Europea, que fue la primera gran reforma de los Tratados fundacionales-, se encuentra sólidamente asentado en el Derecho originario de la Unión. En lo esencial, este D e r e cho orig in ario sobre el tema aparece actualmente contenido en el artículo 153 del Tratado de Funcionamiento de la Unión Europea, a cuyo tenor: 1) «la Comunidad apoyará y completará la acción de los Estados miembros en... la mejora, en concreto, del entorno de trabajo, para proteger la salud y la seguridad de los trab aja d or e $s{ }^{4}$; 2) en lo relativo a la puesta en práctica de estas acciones, «el Parlamento Europeo y el Consejo decidirán, con arreglo al procedimiento legislativo ordinario [esto es, mediante Directivas adoptadas por mayoría cualificada] y previa consulta al Comité Económico Social y al Comité de las Regiones» ${ }^{5}$; y 3) «todo Estado miembro podrá confiar a los interlocutores sociales, a petición conjunta de estos últimos, la aplicación de las directivas adoptadas» ${ }^{6}$, asegurándose «de que, a más tardar en la fecha en que deba estar transpuesta o aplicada una directiva..., los interlocutores sociales hayan establecido, mediante acuerdo, las disposiciones necesarias» ${ }^{7}$.

A pesar de que el carácter hipertécnico del Derecho relativo a la seguridad y la salud laboral parece requerir necesariamente de la intervención normativa del Estado, cabe registrar algún ejemplo concreto en Italia de transposición, aunque parcial, de una Directiva comunitaria sobre seguridad y salud laboral a través de un convenio colectivo, como el «convenio colectivo marco [contratto collettivo quadro]» de 7 mayo 1996 suscrito entre la ARAN, del lado de la Administración pública, y las confederaciones sindicales CGIL, CISL, UIL, CISAL, CISNAL, CONFEDIR, USPPI y UNIONQUADRI, en materia de «representantes de seguridad».

La Carta de los Derechos Fundamentales de la Unión Europea reconoce que «todo trabajador tiene derecho a trabajar en condiciones que respeten su salud, seguridad y dignidad» ${ }^{8}$.

Recuérdese que el Acta Única Europea de 1986, que entró en vigor el 1 julio 1987, añadió al Tratado CEE un nuevo artículo 100A, que excluía la regla de la «mayoría cualificada» para poder legislar en materia de «derechos e intereses de los trabajadores por cuenta ajena» ${ }^{9}$; y también, que le añadía un nuevo artículo 118A, imponiendo dicha regla, en cambio, para aprobar Directivas orientadas a proteger «la seguridad y la salud de los trabajadores» ${ }^{10}$.

3 Véase M.A. CASTRO ARGÜELLES, «Seguridad y salud en el trabajo (Directiva 89/391/CEE y Directivas complementarias)», en J. GARCÍA MURCIA (Director), La transposición del Derecho social comunitario al ordenamiento español, Ministerio de Trabajo y Asuntos Sociales (Madrid, 2005), págs. 394 y ss.

4 Apartado 1.a).

Apartado 2, párrafo segundo.

6 Apartado 3, párrafo primero. Acerca de la precariedad del tema en España, véase J.M. MIRANDA BOTO, «El papel de la autonomía colectiva en la transposición de directivas», Aranzadi Social, núm. 21 (2003), págs. 49 y ss.

7 Artículo 2, apartado 3, párrafo segundo.

8 Artículo 31 (rotulado «Condiciones de trabajo justas y equitativas»), apartado 1.

9 Cfr. su artículo 18.

10 Cfr. su artículo 21. 
Como era previsible — dada la posibilidad de decidir por mayoría cualificada, sin que hiciese falta unanimidad-, el Derecho derivado de la Unión Europea en materia de seguridad y salud laboral ha acabado convirtiéndose en un Derecho denso y abigarrado, integrado por multitud de Directivas. Dentro de este conjunto, la norma estelar es la Directiva 89/391/CEE del Consejo, de 12 junio 1989, o Directiva marco para promover la mejora de la seguridad y de la salud de los trabajadores en el trabajo, promulgada — sobre la constatación de que «en los Estados miembros, los sistemas legislativos en materia de seguridad y de salud sobre el lugar de trabajo son muy diferentes y que deben ser mejorados» ${ }^{11}$, y de que en Europa «hay que lamentar todavía demasiados accidentes de trabajo y enfermedades profesionales» ${ }^{12}$ - con el objetivo de regular «principios generales relativos a la prevención de los riesgos profesionales y la protección de la seguridad y de la salud, la eliminación de los factores de riesgo y accidente, la información, la consulta, la participación equilibrada de conformidad con las legislaciones y/o los usos nacionales, la formación de los trabajadores y de sus representantes, así como las líneas generales para la aplicación de dichos principios» ${ }^{13}$. Estas líneas generales fueron luego concretadas en casi dos docenas de Directivas más — progresivamente promulgadas, también a partir de 1989—, de las cuales la mayoría se adjetivan y numeran ordinalmente como Directivas «específicas» de la citada Directiva marco [por ejemplo, Directiva 89/654/CEE del Consejo, de 30 noviembre 1989, «relativa a las disposiciones mínimas de seguridad y salud en los lugares de trabajo (primera Directiva específica con arreglo al apartado 1 del artículo 16 de la Directiva 89/391/CEE)»; o Directiva 2006/25/CE del Parlamento Europeo y del Consejo, de 5 abril 2006, «sobre las disposiciones mínimas de seguridad y salud relativas a la exposición de los trabajadores a riesgos derivados de los agentes físicos (radiaciones ópticas artificiales) (decimonovena Directiva específica con arreglo al artículo 16.1 de la Directiva 89/391/CEE)»].

Entre las no específicas se incluye muy forzadamente alguna — como, por ejemplo, la de protección de los trabajadores con contratos de duración determinada y de empresas de trabajo temporal ${ }^{14}$, la de ordenación del tiempo de trabajo ${ }^{15} \mathrm{o}$ la de protección de los jóvenes

11 Cfr. considerando $9^{\circ}$.

12 Cfr. considerando $10^{\circ}$.

13 Artículo 1.2.

14 Sobre ella, supra, Tema 15, §2. Además, J. MARTÍNEZ GIRÓN, «La Directiva comunitaria sobre seguridad e higiene en el trabajo en las empresas de trabajo temporal», en el vol. IV Xornadas Galegas sobre Condicións de Traballo e Saúde, Fundación Caixa Galicia (Ferrol, 1994), págs. 18 y ss.

15 Véase infra, Tema 17, \$2. 
en el trabajo, significativamente carentes de la citada numeración ordinal, y que claramente tienen más que ver con los derechos e intereses de los trabajadores que con la seguridad y salud laboral-, por causa de todos los desajustes de la política social comunitaria derivados del veto (en 9 diciembre 1989) de la Sra. THATCHER a la Carta Comunitaria de los Derechos Sociales Fundamentales de los Trabajadores, que no concluyeron formalmente hasta la promulgación del Tratado de Amsterdam de $1997^{16}$.

Las citadas Directivas «específicas» padecen continuas enmiendas — por causa de la necesidad de adaptarlas al progreso de la técnica-, que obligan a publicar «versiones codificadas» de las mismas, con el consiguiente trastoque de fechas en la serie [por ejemplo, la segunda Directiva específica de 1989 ha pasado a convertirse, en la actualidad, en la Directiva 2009/104/CE del Parlamento Europeo y del Consejo, de 16 septiembre 2009, «relativa a las disposiciones mínimas de seguridad y de salud para la utilización por los trabajadores en el trabajo de los equipos de trabajo (segunda Directiva específica con arreglo al apartado 1 del artículo 16 de la Directiva 89/391/CEE)»].

Téngase en cuenta que existen Directivas materialmente indistinguibles de las promulgadas en desarrollo de la citada Directiva marco — anteriores y posteriores a ella-, cuya vitalidad queda acreditada por el dato de que todavía continúen poniéndose al día y adaptándose al progreso de la técnica (así, las relativas a máquinas, productos e instalaciones, a sustancias y preparados peligrosos, a la protección de trabajadores, consumidores y población en general, etc.).

Desde un punto de vista orgánico y por pura necesidad, esta normativa precipitó en la creación, a su vez, de la Agencia Europea para la Seguridad y la Salud en el Trabajo, regulada en el Reglamento (CE) núm. 2062/94 del Consejo, de 18 julio 1994. Tiene su sede en Bilbao ${ }^{17}$. Y se ocupa, en lo esencial, de «facilitar... a la Comisión las informaciones técnicas, científicas y económicas que necesite para llevar a buen término sus tareas de identificación, preparación y evaluación de la legislación y de las medidas en el ámbito de la protección de la seguridad y la salud de los trabajadores ${ }^{18}$.

El sitio en Internet de esta Agencia — ubicado en http://osha.europa.eu - contiene una utilísima base de datos normativos comunitarios (vía «About us», y luego, «Legislation»), aunque incomprensiblemente toda la información de interés contenida en él sólo está disponible en inglés.

A través de este mismo sitio de Internet (vía «European network») resulta posible acceder a las fuentes normativas sobre seguridad y salud laboral de todos y cada uno de los Estados miembros, en sus lenguas respectivas.

16 Sobre el tema, véase J. MARTÍNEZ GIRÓN, A. ARUFE VARELA y X.M. CARRIL VÁZQUEZ, Derecho del Trabajo, $2^{\mathrm{a}}$ ed., cit., págs. 101-102.

17 En el citado Reglamento se afirma que «la Decisión adoptada de común acuerdo por los representantes de los Gobiernos de los Estados miembros reunidos a nivel de Jefes de Estado o de Gobierno, de 29 de octubre de 1993, relativa a la fijación de las sedes de determinados organismos y servicios de las Comunidades Europeas y de Europol, fijó en España la sede de la Agencia de salud y seguridad en el trabajo, en una ciudad que designaría el Gobierno español» (considerando $11^{\circ}$ ), y además, que «el Gobierno español ha designado a tal fin la ciudad [sic; rectius, "villa"] de Bilbao» (ibidem).

18 Cfr. artículo 3.1.e). 
Las «estadísticas» sobre siniestralidad laboral asimismo ofrecidas por este sitio de Internet (vía «statistics») reproducen las estadísticas sobre el propio tema publicadas por Eurostat, cuyo sitio en Internet —ubicado en http://epp.eurostat.ec.europa.eu- presenta la ventaja adicional de resultar accesible en inglés, francés y alemán.

\$2. Centrándonos en los seis países europeos que consideramos de referencia, parece claro que la transposición al Derecho interno de todo ese cúmulo de normas comunitarias exigía la promulgación de una norma general — como se sabe, en España fue la Ley 31/1995, de 8 noviembre, de prevención de riesgos laborales-, que transpusiese la Directiva marco, y además y como regla (con sus excepciones), la promulgación de multitud de normas de menor rango - en el caso de España, siempre como regla, Reales Decretos-, que procediesen cada una de ellas a transponer el resto de Directivas implicadas, a medida que las mismas se promulgaban o se iban enmendando ${ }^{19}$. Pues bien, sobre esta base, una singularidad reseñable del Derecho de la Unión Europea sobre seguridad y salud laboral se refiere a la notable cantidad de casos del Tribunal de Luxemburgo que viene suscitando su aplicación, y en los que se declara el incumplimiento por muy diversos Estados miembros de las obligaciones que les incumben en relación con la transposición de las Di rectivas mencionadas, acreditándose así — una vez más — la falta de ejemplaridad del Estado, que siempre predica aunque no siempre da trigo sobre el tema ${ }^{20}$. En cuanto al número de Directivas incumplidas, el récord relativo - esto es, dentro de los seis países que venimos comparando - lo ostentan de momento ex aequo Italia y España, ambas condenadas por falta de transposición temporánea o por transposición defectuosa de la Directiva marco y de cinco Directivas «específicas». En cuanto al número de condenas acumuladas, Italia ostenta de nuevo el récord relativo, dado que fue condenada en seis ocasiones (en $1999^{21}$, en $2000^{22}$, en $2001^{23}$,

19 Al respecto, para el caso de España, véase J. MARTÍNEZ GIRÓN, A. ARUFE VARELA y X.M. CARRIL VÁZQUEZ, Derecho del Trabajo, $2^{\mathrm{a}}$ ed., cit., pág. 227. Para el caso de otros ordenamientos nacionales comunitarios, véase A.V. SEMPERE NAVARRO y M. CARDENAL CARRO, Transposición de la Directiva Marco de Seguridad Laboral en diferentes países de Europa, Fundación Mapfre (Madrid, 2000), págs. 11 y ss.

20 Fundamental para todo lo que sigue, véase A. ARUFE VARELA, «La jurisprudencia del Tribunal de Justicia de las Comunidades Europeas sobre incumplimientos por los Estados miembros de sus deberes de transposición de las Directivas marco y "específicas" en materia de seguridad y salud laboral», Tribuna Social, núm. 221 (2009), págs. 8 y ss.

21 Sentencia del Tribunal de Justicia de las Comunidades Europeas de 21 septiembre 1999 (asunto C-362/98)

22 Sentencia del Tribunal de Justicia de las Comunidades Europeas de 16 marzo 2000 (asunto C-439/98). C-49/00).

23 Sentencia del Tribunal de Justicia de las Comunidades Europeas de 15 noviembre 2001 (asunto 
en $2002^{24}$, en $2003^{25}$ y en $2008^{26}$ ), ostentando aquí España la segunda posición, al haber sido condenada tres veces (en $1996^{27}$, en $2004^{28}$ y en $2006^{29}$ ). Otros varios Estados miembros, diversos de los dos citados, también acumulan condenas por incumplimiento de sus obligaciones de transponer esta concreta parcela del ordenamiento laboral comunitario, como Austria (ocho condenas) — récord absoluto en la Unión Europea-, el Gran Ducado de Luxemburgo (dos condenas), Alemania (dos condenas), Francia (una condena) e Irlanda (también una condena).

La República Portuguesa, el Reino de Suecia y el Reino Unido también fueron denunciados por la Comisión, pero resultaron absueltos por el Tribunal de Luxemburgo en 2003, 2006 y 2007 , respectivamente.

Las normas legales de transposición de la Directiva marco, en los países europeos que consideramos de referencia, son «la Ley sobre la Ejecución de Medidas de Protección [frente a los Riesgos] del Trabajo para la Mejora de la Seguridad y de la Protección de la Salud de los Trabajadores en el Trabajo [Gesetz über die Durchführung von Maßnahmen des Arbeitsschutzes zur Verbesserung der Sicherheit und des Gesundheitsschutzes der Beschäftigen bei der Arbeit]》 de 1996, en Alemania ${ }^{30}$; la Parte Cuarta del Código del Trabajo (rotulada «Salud y Seguridad en el Trabajo [Santé et Sécurité au Travail]»), artículos L. 4111-1 y ss., en Francia ${ }^{31}$; la «Ley de Seguridad y Salud en el Trabajo, etc. [Health and Safety at Work etc. Act]» de 1974, en Gran Bretaña ${ }^{32}$; el Decreto Legislativo núm. 81 de 9 abril 2008 «de aplicación del artículo 1 de la Ley núm. 123 de 3 agosto 2007, en materia

24 Sentencia del Tribunal de Justicia de las Comunidades Europeas de 24 octubre 2002 (asunto C-455/00).

25 Sentencia del Tribunal de Justicia de las Comunidades Europeas de 10 abril 2003 (asunto C-65/01)

26 Sentencia del Tribunal de Justicia de las Comunidades Europeas de 25 julio 2008 (asunto C-504/06).

27 Sentencia del Tribunal de Justicia de las Comunidades Europeas de 26 septiembre 1996 (asunto C-79/95)

28 Sentencia del Tribunal de Justicia de las Comunidades Europeas de 14 septiembre 2004 (asunto C-168/03).

29 Sentencia del Tribunal de Justicia de las Comunidades Europeas de 12 enero 2006 (asunto C-132/04).

30 Téngase en cuenta, y desde una óptica contractualista, que el Derecho de Prevención de Riesgos Laborales aparece tratado muy sintéticamente en la manualística alemana sobre Derecho del Trabajo. Por ejemplo, bajo el rótulo «Deberes de protección de la vida y la salud del trabajador», en K. DÖRNER, S. LUCZAK y M. WILDSCHÜTZ, Handbuch Arbeitsrecht, 4a ed., Luchterhand (Munich, 2004), págs. 670 y ss.; o como «Protección de la vida y la salud en el puesto de trabajo», en W. DÄUBLER, Arbeitsrecht. Ratgeber für Beruf, Praxis und Studium, 6 a ed., Bund-Verlag (Frankfurt am Main, 2006), págs. 175 y ss.; o como «otros deberes del trabajador» y «otros deberes del empresario», en A. JUNKER, Grundkurs Arbeitsrecht, $5^{\mathrm{a}}$ ed., C.H. Beck (Munich, 2006), págs. 128 y 143. Por supuesto, existen comentarios específicos sobre la Ley en cuestión, como el de R. PIEPER, ArbSchR. Arbeitsschutzrecht. Arbeitsschutzgesetz, Arbeitssicherheitsgesetz und andere Arbeitsschutzvorschriften, $4^{\mathrm{a}}$ ed., Bund Verlag (Frankfurt a.M., 2009), págs. 142 y ss. Nuestra traducción de dicha Ley, en J. MARTÍNEZ GIRÓN y A. ARUFE VARELA, Leyes laborales alemanas. Estudio comparado y traducción castellana, Netbiblo (A Coruña, 2007), págs. 157 y ss.

31 Véase J. PÉLISSIER, A. SUPIOT y A. JEAMMAUD, Droit du travail, 24 ed., Dalloz (París, 2008), págs. 829 y ss.

32 Véase N.M. SELWYN, Law of Employment, 13 ${ }^{\mathrm{a}}$ ed., LexisNexis-Butterworths (Londres, 2004), págs. 273 y ss. 
de protección de la salud y de la seguridad en los lugares de trabajo [tutela della salute e de la sicurezza nei luoghi di lavoro]», en Italia ${ }^{33}$; y el Capítulo IV (rotulado «Prevención y reparación de accidentes de trabajo y enfermedades profesionales [Prevenção e reparação de acidentes de trabalho e doenças profissionais]») del Título II del Libro I del Código del Trabajo, artículos 281 a 284 — este último precepto desarrollado por la Ley 102/2009, de 10 septiembre, de «régimen jurídico de la promoción de la seguridad y salud en el trabajo [promoção da segurança e saúde no trabalho]»—, en Portugal ${ }^{34}$.

Las normas de transposición más específicas suelen adoptar la forma de reglamentos (Verordnungen), en Alemania ${ }^{35}$; Decretos Legislativos (Statutory Instruments), en Gran Bretaña $^{36}$; y de Decretos (Decreti) y Circulares (Circolari), en Italia ${ }^{37}$. En Francia, el artículo L. 4111-6 del Código del Trabajo remite a lo que denomina «Decretos con intervención del Consejo de Estado [Décrets en Conseil d'État]», actualmente contenidos en la Parte Cuarta de la parte reglamentaria del propio Código, los cuales «remiten, a su vez, a "Órdenes Ministeriales [Arrêtés]" de desarrollo de los mismos, que lógicamente vagan fuera del Código del Trabajo (de ahí su carácter de reglamentación "no codificada")» ${ }^{38}$. Y en Portugal, por su parte, el artículo 284 del Código del Trabajo afirma que «lo dispuesto en el presente Capítulo [IV del Título II del Libro I] se regula en legislación específica» ${ }^{39}$.

§3. En los Estados Unidos de Norteamérica, la norma equivalente de la citada Directiva marco comunitaria y de las diversas leyes nacionales de transposición de la misma es la Ley de Seguridad y Salud en el Trabajo (Occupational Safety and Health Act) de 1970 ${ }^{40}$. Según ella, se encarga de velar por su cumplimiento un complejo conjunto de órganos administrativos — genéricamente denominado "Administración de Seguridad y Salud en el Trabajo [Occupational Safety and Health Administration]» u OSHA, con sede central en Washington D.C. ${ }^{41}$ - , cuya cabeza ejecutiva es el Ministro de Trabajo (Secretary of the Department of Labor) del Gobierno federal norteamericano ${ }^{42}$. Entre otras muchas competencias relacionadas con el tema, este Ministro posee la de promulgar los

33 Véase A. TURSI y P.A. VARESI, Lineamenti di Diritto del Lavoro. Rapporti di lavoro e relazioni sindacali nel settore privato, $3^{\mathrm{a}}$ ed., Kluwer-Ipsoa (s.1., 2004), págs. 208 y ss.

34 Véase, además, A. MONTEIRO FERNANDES, Direito do Trabalho, 15 a ed., Almedina (Coimbra, 2010), pág. 297.

35 La lista completa de estas y otras normas sobre el tema, con inclusión de hasta cuarenta de ellas, en www.bmas.bund.de (vía «Gesetze», y luego, «Arbeitsschutz»).

36 La lista completa de los mismos, exhaustiva y agobiante, en www.hse.gov.uk (vía «Legislation»).

37 Cfr. www.ispesl.it.

38 Véase A. ARUFE VARELA, Estudio comparado de la carrera administrativa de los funcionarios del sistema de Inspección de Trabajo y Seguridad Social en Europa, Ministerio de Trabajo y Asuntos Sociales (Madrid, 2007), pág. 62.

39 Cfr. www.ipq.pt.

40 Recopilada en las secciones 651 a 678 del Título 29 del Código de los Estados Unidos. Con un completo análisis de historia legislativa, véase M.A. ROTHSTEIN, Occupational Safety and Health Law, $3^{\mathrm{a}}$ ed., West Publ. (St. Paul-Minn., 1990), págs. 5 y ss.

41 Cfr. sección 7 (rotulada «Comités Consultivos; Administración [Advisory Committees; Administration]»).

42 Cfr. la definición de «Secretary» contenida en su sección 3(1). 
concretos reglamentos de prevención de los más diversos riesgos laborales —denominados por la propia Ley «condiciones [standards]» de seguridad y salud laboral ${ }^{43}$ - , bastando indicar acerca de la complejidad de los mismos que su contenido ocupa casi medio centenar de «partes» del Título 29 del Código de Reglamentos Federales. En principio, esta normativa federal legal y reglamentaria se aplica en todo el territorio de los Estados Unidos, aunque la Ley autoriza a los Estados federados a promulgar y elaborar sus propias normas y planes preventivos, a condición de que sean «al menos tan efectivos» como las normas y planes federales ${ }^{44}$. Sólo veintiséis Estados y Territorios de la Unión poseen, sin embargo, su propia normativa específica de seguridad y salud laboral.

Se trata de Alaska, Arizona, California, Carolina del Norte, Carolina del Sur, Connecticut, Hawaii, Indiana, Iowa, Kentucky, Maryland, Michigan, Minnesota, Nevada, Nueva Jersey, Nueva York, Nuevo México, Oregón, Puerto Rico, Tennessee, Utah, Vermont, Virginia, Washington, Wyoming y las Islas Vírgenes ${ }^{45}$. El sitio en Internet de la Administración federal de Seguridad y Salud Laboral —ubicado en www.osha. gov - contiene enlaces a toda esta legislación estatal ${ }^{46}$, y además, el texto al día de la Ley de Seguridad y Salud Laboral, y de sus reglamentos de desarrollo recopilados en el Código de Reglamentos Federales ${ }^{47}$.

A través de este mismo sitio de Internet también resulta posible acceder a las estadísticas norteamericanas de siniestralidad laboral, por reenvío directo (a través del enlace «Statistics») a las que elabora la Oficina federal de Estadísticas Laborales (Bureau of Labor Statistics) ${ }^{48}$.

La Ley norteamericana de Seguridad y Salud Laboral también afirma que «nada en esta Ley se interpretará para derogar o afectar de cualquier modo a cualquier ley de accidentes de trabajo [de los Estados federados], o para extender o disminuir o afectar de cualquier otro modo al Derecho común [common law] o a los derechos normativos, deberes o responsabilidades de empresarios y trabajadores, al amparo de cualquier ley, en relación con lesiones, enfermedades o muerte de trabajadores con ocasión o por consecuencia del trabajo [arising out of, or in the course of, employment] $\gg^{49}$.

43 Cfr. su sección 6 (rotulada «Condiciones de seguridad y salud laboral [Occupational Safety and Health Standards]».

44 Cfr. su sección 18 (rotulada «Competencia estatal y planes estatales [State Jurisdiction and State Plans]»). Al respecto, véase J. MARTÍNEZ GIRÓN y A. ARUFE VARELA, «Federalismo y distribución de competencias normativas en materia de Prevención de Riesgos Laborales: los modelos Norteamericano, Alemán y Español», Aranzadi Social, núm. 21 (2010), págs. 65 y ss.

45 Téngase en cuenta que en este último territorio, al igual que en los Estados de Connecticut, Illinois, Nueva Jersey y Nueva York, los planes en cuestión sólo se refieren a los empleados de las Administraciones públicas estatales y locales.

46 Vía «State Programs».

47 Vía «Laws and Rulemaking».

48 Sobre este tema, véase la sección 24 de la citada Ley de Seguridad y Salud Laboral.

49 Cfr. su sección 4 (rotulada "Aplicabilidad de esta Ley [Applicability of this Act]»), apartado (b)(4). Acerca del «Derecho común» citado, véase J.W. LITTLE, T.A. EATON y G.R. SMITH, Workers' Compensation. Cases and materials, $3^{\mathrm{a}}$ ed., West Publ. Co. (St. Paul-Minn., 1993), págs. 125 y ss. 


\section{TEMA 17 \\ EL PRINCIPIO DEL RESPETO A LAS CONDICIONES \\ MÍNIMAS DE TRABAJO EN EL ORDENAMIENTO \\ COMUNITARIO, EN LAS LEGISLACIONES Y \\ PRÁCTICAS NACIONALES EUROPEAS, Y EN LA LEGISLACIÓN DE LOS ESTADOS UNIDOS}

Sumario: §1. El Derecho de la Unión Europea sobre el principio del respeto a las condiciones mínimas de trabajo, ad extra. §2. El Derecho de la Unión Europea sobre la jornada máxima, ad extra y ad intra. §3. La regulación de la jornada máxima en los ordenamientos nacionales europeos. §4. El inexistente Derecho de la Unión Europea sobre un salario mínimo europeo. §5. La jornada máxima y el salario mínimo en el Derecho de los Estados Unidos.

THEME 17

THE PRINCIPLE OF RESPECTING LABOR MINIMUM STANDARDS IN THE EUROPEAN LAW, IN THE NATIONAL EUROPEAN LEGISLATIONS AND PRACTICES, AND IN THE LEGISLATION OF THE UNITED STATES

Contents: \$1. The Law of the European Union about the principle of respecting labor minimum standards, ad extra. \$2. The Law of the European Union about maximum hours of work, ad extra and ad intra. \$3. The regulation of maximum hours of work in the European national legislations. $\$ 4$. The non-existent Law of the European Union about a European minimum wage. \$5. The maximum hours of work and the minimum wage in the Law of the United States.

§1. Como es sabido, sin la existencia de condiciones de trabajo mínimas - que el empresario deba cumplir, a las que el trabajador no pueda renunciar, y que (precisamente por su carácter de condiciones «mínimas») puedan ser reemplazadas por otras mejores para el trabajador (normalmente, mediante pacto con el propio empresario) - no cabría hablar de que 
existe Derecho del Trabajo ${ }^{1}$. Se explica, por ello, que el orde namiento laboral comunitario también imponga el respeto a las condiciones de trabajo mínimas, en los dos planos a d extra en que dicho ordenamiento tiene capacidad de influencia ${ }^{2}$. De un lado, en el plano de las condiciones de trabajo meramente "nacionales», exigiendo - mediante la Directiva 96/71/CE del Parlamento Europeo y del Consejo, de 16 diciembre $1996^{3}$ - que el empresario que desplaza trabajadores suyos a otro Estado miembro para prestar servicios garantice «a los trabajadores desplazados... las condiciones de trabajo y empleo... que, en el Estado miembro donde se efectúe el trabajo, estén establecidas» ${ }^{4}$, supuesto siempre que se trate de condiciones mínimas (por ejemplo, «los períodos máximos de trabajo así como los períodos mínimos de descanso», o «las cuantías de salario mínimo, incluidas las incrementadas por las horas extraordinarias») $)^{5}$ y supuesto, también, que sean condiciones mejores que las correspondientes a la ley de celebración del contrato de trabajo, pues el desplazamiento «no impedirá la aplicación de condiciones de empleo y trabajo más favorables para los trabajadores» ${ }^{6}$. De otro lado, en el plano de las condiciones de trabajo propiamente «e u rope as», regulando - mediante Directivas - condiciones de trabajo aplicables en toda Europa que los Estados miembros pueden asimismo mejorar (esto último a través de una cláusula de estilo, tan característica de algunas Directivas clásicas de contenido laboral, a cuyo tenor «la presente Directiva no afectará a la facultad de los Estados miembros de aplicar o de introducir disposiciones legales, reglamentarias o administrativas más favorables para los trabajadores o de permitir o de fomentar la aplicación de disposiciones convencionales más favorables para los trabajadores») ${ }^{7}$.

1 Sobre los «principios» de nuestra disciplina, y en especial el de la norma más favorable para el trabajador (que presupone el de respeto a los mínimos), véase J. MARTÍNEZ GIRÓN, A. ARUFE VARELA y X.M. CARRIL VÁZQUEZ, Derecho del Trabajo, 2ª ed., Netbiblo (A Coruña, 2006), págs. 31 y ss.

2 Sobre el plano ad intra, respecto de la jornada máxima, véase infra, §2. Sobre todos los teóricamente posibles planos de "presión» del Derecho laboral comunitario sobre los Derechos nacionales y sus diversas variables, véase J. GARCÍA MURCIA, «Introducción», en J. GARCÍA MURCIA (Director), $L a$ transposición del Derecho social comunitario al ordenamiento español, Ministerio de Trabajo y Asuntos Sociales (Madrid, 2005), págs. 25 y ss.

3 Véase $\mathrm{M}^{\mathrm{a}}$.E. CASAS BAAMONDE, Los desplazamientos temporales de trabajadores en la Unión Europea y en el Espacio Económico Europeo, Civitas (Madrid, 2001), págs. 13 y ss.

4 Artículo 3.1, párrafo primero.

5 Sobre estas condiciones, ibidem, guión segundo.

6 Artículo 3.7.

7 Cfr., por ejemplo, artículo 5 de la Directiva 98/59/CE del Consejo, de 20 julio 1998, sobre despidos colectivos; y artículo 8 de la Directiva 2001/23/CE del Consejo, de 12 marzo 2001, sobre traspasos de empresas. 
Como enseguida se comprobará, en lo tocante a las dos condiciones de trabajo más señeras e importantes para el trabajador — jornada y salario_- este segundo plano de posible intervención del Derecho de la Unión Europea todavía deja bastante que desear.

Aunque la citada Directiva 96/71/CE sea materialmente hablando una Directiva «laboral», desde un punto de vista formal se trata de una norma basada en la libertad comunitaria de circulación de los servicios, que toma en consideración el hecho de que «la realización del mercado interior ofrece un entorno dinámico para la prestación de servicios transnacionales al invitar a un número cada vez mayor de empresas a desplazar a sus trabajadores temporalmente para trabajar en el territorio de un Estado miembro distinto del Estado en que trabajan habitualmente» ${ }^{8}$.

Pretendió alterar su esencia -imponiendo, respecto de las condiciones de trabajo, la cláusula del país de origen - la denominada «Propuesta de Directiva Bolkestein» de 2004, aunque las protestas sindicales habidas en toda Europa determinaron la enmienda radical de la «Propuesta» en cuestión, cuyo trámite legislativo ha concluido ya sin sobresaltos con la promulgación de la Directiva 2006/123/CE del Parlamento Europeo y del Consejo, de 12 diciembre 2006, relativa a los servicios en el mercado interior.

En los países europeos que consideramos de referencia ${ }^{9}$, las normas nacionales de transposición de dicha Directiva 96/71/CE son la «Ley sobre condiciones de trabajo obligatorias para los trabajadores y trabajadoras desplazados transnacionalmente y empleados ordinariamente dentro del país (Ley de desplazamiento del trabajador) [Gesetz über zwigende Arbeitsbedingungen für grenzüberschreitend entsandte und für regelmäßig im Inland beschäftigte Arbeitnehmer und Arbeitnehmerinnen]» de 2009, en Alemania ${ }^{10}$; los artículos L. 1261-1 a L. 1263-2 del Código del Trabajo de 2008, en Francia ${ }^{11}$; diversos preceptos de la «Ley de Derechos de Empleo [Employment Rights Act]》 de 1996, en Gran Bretaña ${ }^{12}$; el Decreto Legislativo núm. 72, de 25 febrero 2000, en Italia ${ }^{13}$; y los artículos 6 a 8 del Código del Trabajo de 2009, en Portugal ${ }^{14}$.

§2. En materia de jornada, sí cabe hablar — desde 1993 — de la existencia de un verdadero Derecho europeo ad extra aplicable en todos los Estados miembros de la Unión, que está actualmente contenido en la Directiva 2003/88/CE del Parlamento Europeo y

8 Cfr. su considerando $3^{\circ}$.

9 Acerca de nuestra Ley 45/1999, de 29 noviembre, véase J. MARTÍNEZ GIRÓN, A. ARUFE VARELA y X.M. CARRIL VÁZQUEZ, Derecho del Trabajo, 2a ed., cit., págs. 118 y 290.

10 Véase J. MARTÍNEZ GIRÓN y A. ARUFE VARELA, El salario mínimo en Alemania. Un estudio comparado entre regímenes de salarios mínimos profesionales (alemanes) e interprofesionales legales (norteamericano y europeos), Netbiblo (A Coruña, 2009), págs. 25 y ss.

11 Véase J. PÉLISSIER, A. SUPIOT y A. JEAMMAUD, Droit du travail, 24ª ed., Dalloz (París, 2008), pág. 215.

12 Véase N.M. SELWYN, Law of Employment, 13 ed., Lexis Nexis-Butterworths (Londres, 2004), pág. 25 .

13 Véase A. TURSI y P.A. VARESI, Lineamenti di Diritto del Lavoro. Rapporti di lavoro e relazioni sindacali nel settore privato, $3^{\mathrm{a}}$ ed., Kluwer-Ipsoa (s.1., 2004), págs. 71 y ss.

14 Véase P. ROMANO MARTÍNEZ, L.M. MONTEIRO, J. VASCONCELOS, P. MADEIRA DE BRITO, G. DRAY y L. GONÇALVES DA SILVA, Código do Trabalho. Anotado, 4 ${ }^{\mathrm{a}}$ ed., Almedina (Coimbra, 2005), págs. 86 y ss. 
del Consejo, de 4 noviembre 2003, regulando determinados aspectos de la ordenación del tiempo de trabajo ${ }^{15}$. Hay que lamentar, sin embargo, que esta ordenación comunitaria no configure la jornada de trabajo como una verdadera condición mínima, sino más bien como una mer a condición orientativa -ideal, como es lógico, para desorientar y despistar a los Inspectores de Trabajo-, que el empresario puede estirar y encoger impunemente casi a voluntad. En efecto, la Directiva establece que «la duración media del trabajo no exceda de 48 horas, incluidas las horas extraordinarias, por cada período de 7 días» ${ }^{16}$, pero esto es sólo un promedio («duración media», recuérdese), cabiendo que los Estados miembros establezcan en su legislación «un período de referencia que no exceda de cuatro meses $\rangle^{17}$ —en que poder estirar y encoger dicha jornada semanal—, e incluso, que los interlocutores sociales estatales o regionales «establezcan períodos de referencia que en ningún caso excederán de 12 meses» ${ }^{18}$.

Formalmente hablando, esta Directiva — que refunde las Directivas 93/104/CE y 2000/34/CE - es una norma sobre seguridad y salud laboral. En efecto, afirma que «la presente Directiva se entenderá sin perjuicio de la facultad de los Estados miembros de aplicar o establecer disposiciones legales, reglamentarias o administrativas más favorables a la protección de la seguridad y la salud de los trabajadores, o de favorecer o permitir la aplicación de convenios colectivos o acuerdos celebrados entre interlocutores sociales que sean más favorables a la protección de la seguridad y la salud de los trabajadores» ${ }^{19}$. Siempre con un carácter relativista y «flexibilizador» ${ }^{20}$, también procede a regular el descanso diario $^{21}$, el descanso semanal ${ }^{22}$, las vacaciones ${ }^{23}$, el trabajo nocturno ${ }^{24}$, el trabajo a turnos ${ }^{25}$ o el ritmo de trabajo ${ }^{26}$.

En el plano ad intra del Derecho de la Unión Europea (recuérdese, el relativo al personal empleado por las instituciones de la propia Unión Europea), el «Estatuto de los Funcionarios» aprobado por el Reglamento núm. 31 (CEE), 11 (CEEA) de 1962, sienta la regla general de que «los funcionarios en activo estarán a disposición de su institución en

15 Véase M.A CASTRO ARGÜELLES, «Ordenación del tiempo de trabajo (Directiva 2003/88/CE y otras complementarias)», en J. GARCÍA MURCIA (Director), La transposición del Derecho social comunitario al ordenamiento español, Ministerio de Trabajo y Asuntos Sociales (Madrid, 2005), págs. 356 y ss.

16 Artículo 6.b).

17 Cfr. artículo 16.b).

18 Cfr. artículo 19, párrafo segundo.

19 Artículo 15.

20 Según ella, «habida cuenta de las posibles repercusiones de la ordenación del tiempo de trabajo en las empresas, parece oportuno prever cierta flexibilidad en la aplicación de determinadas disposiciones de la presente Directiva, al tiempo que se garantiza el cumplimiento de los principios de protección de la seguridad y la salud de los trabajadores» (considerando 15).

21 Artículo 3.

22 Artículos 5 y 6.a).

23 Artículo 7

24 Artículos 8 a 12.

25 Artículo 12.

26 Artículo 13. 
todo momento» ${ }^{27}$ —aplicable también al personal laboral en sentido estricto ${ }^{28}$-, aunque «sin embargo, la duración normal del trabajo no podrá exceder de 42 horas semanales según un horario diario establecido por la autoridad facultada para proceder a los nombramientos» ${ }^{29}$; además, «el total de horas extraordinarias exigidas a un funcionario no podrá exceder de 150 horas cumplidas por cada período de seis meses» ${ }^{30}$.

En la Carta de los Derechos Fundamentales de la Unión Europea se proclama que «todo trabajador tiene derecho a la limitación de la duración máxima del trabajo y a períodos de descanso diarios y semanales, así como a un período de vacaciones anuales retribuidas» ${ }^{31}$, aclarándose en las «explicaciones» relativas a este derecho que «se basa en la Directiva 93/104/CE relativa a determinados aspectos de la ordenación del tiempo de trabajo, así como en el artículo 2 de la Carta Social Europea y en el punto 8 de la Carta Comunitaria de los Derechos Sociales Fundamentales de los Trabajadores».

§3. Obligados a tan poco por la Directiva 2003/88/CE, los Estados miembros imponen sistemáticamente en sus legislaciones la posibilidad de promediar la jornada. Y así, refiriéndonos sólo a los Estados que consideramos de referencia, se afirma: 1) en Alemania $^{32}$, que «la jornada [Arbeitszeit] laborable de los trabajadores no puede sobrepasar ocho horas» ${ }^{33}$, que «sólo puede ser alargada en hasta diez horas cuando en promedio [im Durchschnitt] no se sobrepasen ocho horas laborales dentro de seis meses naturales o dentro de 24 semanas» ${ }^{34}$, y que estos límites pueden ser alterados «en un convenio colectivo o, con base en un convenio colectivo, en un acuerdo de empresa o acuerdo de empresa pública» ${ }^{35}$; 2) en Francia ${ }^{36}$, que «la duración legal del trabajo [durée légale $d u$ travail] efectivo de los asalariados se fija en treinta y cinco horas por

27 Artículo 55, párrafo primero.

28 Al respecto, véase artículo 16 del Anexo sobre «Régimen aplicable a los otros agentes de las Comunidades» del recién citado Reglamento, según el cual «las disposiciones de los artículos 42.bis y 42.ter y de los artículos 55 a 61 del Estatuto relativas a la duración y el horario de trabajo, horas extraordinarias, trabajo en servicio continuado, situación de disponibilidad en el lugar de trabajo o en el domicilio, vacaciones, licencias y días feriados se aplicarán por analogía» (párrafo primero, inciso primero).

29 Artículo 55, párrafo segundo, inciso primero.

30 Artículo 56, párrafo primero, inciso segundo.

31 Artículo 31, apartado 2.

32 Sobre el tema, véase K. DÖRNER, S. LUCZAK y M. WILDSCHÜTZ, Handbuch Arbeitsrecht, $4^{\mathrm{a}}$ ed., Luchterhand (Munich, 2004), págs. 306 ss.; W. DÄUBLER, Arbeitsrecht. Ratgeber für Beruf, Praxis und Studium, $6^{\mathrm{a}}$ ed., Bund-Verlag (Frankfurt am Main, 2006), págs. 180 y ss.; y A. JUNKER, Grundkurs Arbeitsrecht, $5^{\text {a }}$ ed., C.H. Beck (Munich, 2006), págs. 123 y ss.

33 Cfr. parágrafo 3, inciso primero, de la «Ley del Tiempo de Trabajo [Arbeitszeitgesetz]» de 1994. Sobre esta última, véase H. SCHLIEMANN, ArbZG. Kommentar zum Arbeitszeitgesetz mit Nebengesetzen, Luchterhand (Colonia, 2009), págs. 41 y ss. Nuestra traducción íntegra de la misma, en J. MARTÍNEZ GIRÓN y A. ARUFE VARELA, Leyes laborales alemanas. Estudio comparado y traducción castellana, Netbiblo (A Coruña, 2007), págs. 144 y ss.

34 Ibidem, inciso segundo.

35 Ibidem, parágrafo 7, apartado 1, número 1.

36 Véase E. MARTÍN PUEBLA, La reducción del tiempo de trabajo en Francia, Ministerio de Trabajo y Asuntos Sociales (Madrid, 2006), págs. 17 y ss; también, J. PÉLISSIER, A. SUPIOT, y A. JEAMMAUD, Droit du travail, $24^{\mathrm{a}}$ ed., cit., págs. 873 y ss. 
semana» ${ }^{37}$, aunque luego resulta que cabe la «ordenación [aménagement]» de la jornada por convenio colectivo o acuerdo de empresa ${ }^{38}$, en los que se prevea que la jornada semanal de trabajo puede «variar en todo o parte del año» ${ }^{39}$, a condición de que, en un año, esta jornada no exceda «más allá de 1607 horas» ${ }^{40}$; 3) en Gran Bretaña ${ }^{41}$, que «la jornada [working time] del trabajador, incluyendo horas extraordinarias,... no excederá una media [an average] de 48 horas por cada siete días» ${ }^{42}$, en un período de referencia «de 17 semanas» ${ }^{43}$, aunque por convenio o acuerdo colectivos cabe «la sustitución, por cada referencia a 17 semanas, de un período diferente, siendo un período que no exceda de 52 semanas» ${ }^{44}$; 4) en Italia ${ }^{45}$, que «la duración media [durata media] de la jornada de trabajo [orario di lavoro] no puede en todo caso superar, para todo período de siete días, las cuarenta y ocho horas, comprendidas las horas de trabajo extraordinario» ${ }^{46}$, aunque luego resulta - otra vez porque se trata de nuevo de un mero promedio, en un período de referencia de hasta doce meses - que los convenios colectivos pueden prever la «superación de las 48 horas de trabajo semanal» ${ }^{47}$; y 5) en Portugal ${ }^{48}$, que «el período normal de trabajo [período normal de trabalho] no puede exceder ocho horas por día ni cuarenta horas por semana» ${ }^{49}$, aunque «por instrumento de regulación colectiva del trabajo, el período normal de trabajo puede ser definido en términos medios [em termos médios]» ${ }^{50}$, en cuyo caso «el límite diario... puede ser aumentado hasta cuatro horas y la duración del trabajo semanal puede alcanzar sesenta horas» ${ }^{51}$. La prueba definitiva de que con semejante regulación «real» — tan «flexible» para el empresario — la jornada (diaria y semanal)

37 Artículo L. 3121-10, párrafo primero, del Código del Trabajo.

38 Cfr. artículo L. 3122-2 del Código del Trabajo.

39 Artículo L. 3122-3, párrafo segundo.

40 Ibidem.

41 Véase N.M. SELWYN, Law of Employment, 13ª ed., cit., págs. 353 y ss.

42 Sección 4(1) del «Reglamento de Jornada [Working Time Regulations]» de 1998.

43 Ibidem, sección 4(3).

44 Ibidem, sección 23(b).

45 Véase A. TURSI y P.A. VARESI, Lineamenti di Diritto del Lavoro. Rapporti di lavoro e relazioni sindacali nel settore privato, $3^{\text {a }}$ ed., cit., págs. 194 y ss.; y G. FAVALLI y F. ROTONDI, Manuale pratico di diritto del lavoro, $2^{\mathrm{a}}$ ed., CEDAM (Padua, 2005), págs. 219 y ss.

46 Artículo 4.2 del Decreto Legislativo núm. 66, de 8 abril 2003, de «transposición de las Directivas 93/104/CE y 2000/34/CE concernientes a algunos aspectos de organización de la jornada».

47 Ibidem, artículos 4.4 y 4.5 .

48 Véase A. MONTEIRO FERNANDES, Direito do Trabalho, 15 a ed., Almedina (Coimbra, 2010), págs. 353 y ss.

49 Artículo 203.1 del Código del Trabajo.

50 Ibidem, artículo 204.1.

51 Ibidem. 
ha dejado de ser en Europa una condición mínima de trabajo, pasando a convertirse con el consentimiento de los sindicatos en una mera referencia para el empresario, la suministran: 1) la legislación británica, en la que se afirma con todo desparpajo - aunque parezca increíble - que cabe el pacto individual entre trabajador y empresario (eso sí, "por escrito [in writing]»), incluso de vigencia indefinida (puede «referirse a un período especificado o aplicarse indefinidamente [relate to a specified period or apply indefinitely]»), para trabajar en exceso sobre la «jornada máxima semanal de trabajo» ${ }^{52}$; y 2) la legislación alemana, según la cual asimismo «sólo puede ser prolongada la jornada de trabajo cuando el trabajador ha consentido por escrito» ${ }^{53}$, aunque teniendo en cuenta que «el trabajador puede revocar por escrito el consentimiento con un plazo de seis meses» ${ }^{54}$, y que «el empresario no puede perjudicar al trabajador por causa de que éste no ha declarado el consentimiento para la prolongación de la jornada o ha revocado el consentimiento» ${ }^{55}$.

Estas normas británica y alemana se encuentran amparadas por la Directiva 2003/88/CE, a cuyo tenor «siempre que respete los principios generales de protección de la seguridad y la salud de los trabajadores, un Estado miembro podrá no aplicar el artículo 6 [sobre jornada semanal supuestamente máxima], a condición de que adopte las medidas necesarias para garantizar que... ningún empresario solicite a un trabajador que trabaje más de 48 horas en el transcurso de un período de siete días, calculado como promedio del período de referencia que se menciona en la letra b) del artículo 16, salvo que haya obtenido el consentimiento del trabajador para efectuar dicho trabajo» ${ }^{56}$.

Aunque el artículo 3 de la propia Directiva 2003/88/CE, respecto del descanso diario —en cuanto que institución de posible delimitación negativa de la jornada diaria—, afirma que «los Estados miembros adoptarán las medidas necesarias para que los trabajadores disfruten de un período mínimo de descanso diario de 11 horas consecutivas en el curso de cada período de 24 horas», resulta que la propia Directiva establece luego una insufrible lista de posibles excepciones al contenido de dicho precepto - a articular bien por los Estados miembros, bien por los acuerdos interprofesionales o los convenios colectivos-en su Capítulo V (rotulado precisamente «Excepciones»), relativizadas por el hecho de que

52 Cfr. secciones 4 y 5 del Reglamento de Jornada de 1998. La doctrina inglesa se refiere a este precepto calificándolo como la «cláusula de descuelgue [opt-out clause]»_legalmente se denomina «acuerdo para excluir el máximo [agreement to exclude the maximum]»-, afirmando que esta cláusula «ha tenido el efecto de convertir el Reglamento en prácticamente ineficaz para reducir la cultura de jornadas largas del Reino Unido» (cfr. S. HONEYBALL y J. BOWERS, Textbook on Labour Law, $8^{\mathrm{a}}$ ed., Oxford University Press [Oxford, 2004], pág. 317).

53 Cfr. parágrafo 7, apartado 7, inciso primero, de la citada Ley del Tiempo de Trabajo.

54 Ibidem, inciso segundo.

55 Ibidem, inciso tercero.

56 Artículo 22.1.a). Acerca de las tensiones entre el Derecho de la Unión Europea y la legislación interna británica, a propósito del tiempo de trabajo, véase J. CABEZA PEREIRO, «Sobre la compensación económica de las vacaciones no disfrutadas. El difícil diálogo entre la jurisprudencia británica y el Tribunal de Justicia de la Unión», Anuario Coruñés de Derecho Comparado del Trabajo-ACDCT, vol. II (2010), págs. 29 y ss. 
«sólo se admitirán a condición de que se conceda a los trabajadores de que se trate períodos equivalentes de descanso compensatorio, o bien una protección adecuada en los casos excepcionales en que, por razones objetivas, resulte imposible la concesión de dichos períodos equivalentes de descanso compensatorio» ${ }^{57}$.

De ahí la conclusión doctrinal de que en España no existe una jornada máxima diaria ni tampoco una jornada máxima semanal, sino sólo una jornada máxima «anual» de 1826 horas — que es el promedio anualizado de la jornada semanal de 40 horas-, de difícil control por la Inspección de Trabajo, que posee para el ciudadano común (cuyo día a día no se mide en años) un sentido equivalente al que tendría hablar — con o sin promedios-de «salario mínimo anual», pero que resulta — eso sí- extraordinariamente flexible para el empresario ${ }^{58}$.

§4. En materia de salario, el Derecho de la Unión Europea resulta totalmente desolador, puesto que el Tratado de Funcionamiento de la Unión Europea excluye la posibilidad de armonizar las legislaciones de los Estados miembros, vía Directivas, precisamente en lo tocante «a las remuneraciones» ${ }^{59}$. Esta renuncia al establecimiento de una condición mínima de trabajo tan crucial se explica quizá por causa del hecho de que - a diferencia de lo que ocurre en España, Francia, Gran Bretaña o Portugal - en Alemania e Italia no existe ningún salario mínimo interprofesional. Pero el mercado europeo es una cosa y los diversos mercados nacionales otra distinta, no quedando más remedio que concluir que si resultó posible la imposición del «euro» —y por tanto, impactar sobre los precios y, en consecuencia, sobre los gastos-, también debe resultar posible impactar sobre los ingresos - mediante la imposición de un salario mínimo interprofesional europeo-, a menos que se considere satisfactorio un mercado laboral sin regular, como los que existían en Europa - cuando campaban por sus respetos las «manos invisibles» de Adam SMITH - en el siglo XIX.

De ahí la posibilidad libre del fenómeno de las «deslocalizaciones» de empresas en el seno de la Unión Europea (buscando costes salariales más bajos), frente al que resulta inútil el denominado «Fondo Europeo de Adaptación a la Globalización», previsto para afrontar —como se verá- fenómenos externos a la Unión Europea (por ejemplo, «deslocalizaciones» de empresas a Estados terceros, distintos de los Estados miembros) ${ }^{60}$.

En Francia, el salario mínimo interprofesional (denominado «salario mínimo interprofesional de crecimiento [salaire minimum interprofessionnel de croissance]», corrientemente conocido desde 1970 por su acrónimo SMIC) ${ }^{61}$ está regulado en los artículos L. 3231-1 a

57 Artículo 18, párrafo tercero.

58 Al respecto, véase J. MARTÍNEZ GIRÓN, A. ARUFE VARELA y X.M. CARRIL VÁZQUEZ, Derecho del Trabajo, $2^{\mathrm{a}}$ ed., cit., pág. 198.

59 Cfr. artículo 153.5.

60 Al respecto, infra, Tema $18, \$ 4$.

61 Véase J. PÉLISSIER, A. SUPIOT y A. JEAMMAUD, Droit du travail, $24^{a}$ ed., cit., págs. 958 y ss. 
L. 3231-12 del Código del Trabajo. Se fija desde el año 2010 cada año con efectos de 1 de enero (antes, con efectos de 1 julio), por Decreto del Consejo de Ministros ${ }^{62}$. Hasta 31 diciembre 2010, su cuantía es de « 8,86 [euros] por hora», equivalentes — sobre la base de una jornada mensual de 35 horas - a 1343,77 euros brutos mensuales.

En Gran Bretaña, el salario mínimo interprofesional está regulado en la «Ley del Salario Mínimo Nacional [National Minimum Wage Act]» de $1998^{63}$. Se fija cada año por «reglamento [Regulations]» ${ }^{64}$, con efectos de 1 octubre, siendo su cuantía hasta 30 septiembre 2010 — para trabajadores de 22 ó más años de edad- de 5,80 libras esterlinas por hora (equivalentes a 6,42 euros por hora) ${ }^{65}$. En la Ley recién mencionada se contiene un notable precepto sobre inversión de la carga de la prueba, según el cual en procesos sobre reclamación de la cuantía del salario mínimo tramitados contra el empresario por el trabajador «se presumirá... que el trabajador en cuestión fue remunerado a un nivel inferior que el del salario mínimo nacional, salvo prueba en contrario [unless the contrary is established]» ${ }^{66}$.

En Portugal, su Código del Trabajo afirma que «a todos los trabajadores se les garantiza una retribución mínima mensual ..., cuyo valor se determina anualmente por legislación específica» ${ }^{67}$. Esta «retribución mínima mensual garantizada [retribuição mínima mensal garantida]» la fija cada año un Decreto-ley, con efectos de 1 enero ${ }^{68}$. Hasta 31 diciembre 2010, la cuantía de dicho salario mínimo interprofesional es de 475 euros mensuales brutos ${ }^{69}$.

El sitio en Internet del Observatorio Europeo de Relaciones Industriales —ubicado en www.eiro.eurofound.eu.int - contiene información útil sobre «salarios mínimos en Europa», aunque sólo en inglés y francés ${ }^{70}$. También, acerca de qué papel juegan en la fijación de salarios mínimos sectoriales (y por tanto, sólo salarios mínimos «profesionales») los convenios colectivos alemanes e italianos ${ }^{71}$. Según las «conclusiones» del Comité Europeo de Derechos Sociales del Consejo de Europa, correspondientes al año 2007 - obrantes en www.coe. int/socialcharter-, «aun reconociendo los esfuerzos realizados por el Gobierno [español] con el objeto de aumentar el salario mínimo, el Comité cree que todavía es muy bajo [it is still very low]»; y además, «el Comité concluye que la situación en España es de no conformidad [is not in conformity] con el artículo 4, apartado 1, de la Carta [Social Europea], dado que el salario mínimo neto es manifiestamente inadecuado [manifestly inadequate] ${ }^{72}$.

62 Cfr. artículo R. 3231-1.

63 Véase N.M. SELWYN, Law of Employment, 13ª ed., cit., págs. 226 y ss.

64 Cfr. la sección 2 de dicha Ley.

65 Muy útil al respecto, véase www.bis.gov.uk (vía «Policies», y luego «Policies by theme», «Employment matters» y «National Minimum Wage»).

66 Sección 28(3).

67 Artículo 273.1. Sobre el tema, véase A. MONTEIRO FERNANDES, Direito do Trabalho, $15^{\mathrm{a}}$ ed., cit., págs. 469-470.

68 Sobre su régimen jurídico, además, véanse los artículos 274 y 275 del Código del Trabajo.

69 Cfr. Decreto-ley núm. 5/2010, de 15 enero.

70 Vía «Comparative Information».

71 Respecto de Alemania, véase P. SENNE, Arbeitsrecht. Das Arbeitsverhältnis in der betrieblichen Praxis, $3^{\text {a }}$ ed., Luchterhand (Munich, 2004), pág. 88. Respecto de Italia, véase G. PERA y M. PAPALEONI, Diritto del Lavoro, $7^{\text {a }}$ ed., CEDAM (Padua, 2003), págs. 547 y ss. Acerca de ciertas consecuencias inadmisibles derivadas de la falta de existencia en Alemania del salario mínimo interprofesional, véase A. ARUFE VARELA, «La sentencia del Tribunal Federal alemán de Trabajo de 22 abril 2009, sobre usura salarial. Estudio contextualizador y comparado con el Derecho español, y traducción castellana», Anuario Coruñés de Derecho Comparado del Trabajo-ACDCT, vol. II (2010), págs. 13 y ss.

72 Sobre el tema, véase J. MARTÍNEZ GIRÓN y A. ARUFE VARELA, El salario mínimo en Alemania. Un estudio comparado entre regímenes de salarios mínimos profesionales (alemanes) e interprofesionales legales (norteamericano y europeos), cit., págs. 53 y ss. 
§5. En este punto, el Derecho de los Estados Unidos de Norteamérica es claramente superior al Derecho de la Unión Europea. En efecto, también allí existe un mercado federal (relativo al «comercio interestatal [interstate commerce]») y muy diversos mercados estatales (californiano, neoyorkino, tejano, etc.), pero con la diferencia de que en el mercado federal rigen condiciones de trabajo mínimas, que fueron impuestas por la «Ley de Condiciones de Trabajo Justas [Fair Labor Standards Act]》 de $1938^{73}$. Esta Ley regula, por supuesto, la «jornada máxima [Maximum hours]» federal, afirmando que «ningún empresario empleará a ninguno de sus trabajadores... por una semana laboral mayor de cuarenta horas [for a workweek longer than forty hours] $\gg{ }^{74}$, aunque con dos especificidades que resultan laboralmente antipáticas, dado que: 1) las «horas extraordinarias [overtime]» son libres, visto que la citada jornada de cuarenta horas no puede sobrepasarse «salvo que dicho trabajador reciba compensación por su trabajo en exceso sobre las horas recién especificadas a un nivel no menor de vez y media el nivel ordinario en que ha sido empleado [at a rate no less than one and one-half times the regular rate at which he is employed]» ${ }^{75}$; y 2) cabe asimismo promediar esta jornada máxima federal, «en cumplimiento de un convenio colectivo estipulado como resultado de la negociación colectiva con representantes de los trabajadores certificados como [representantes] de buena fe por la Oficina Nacional de Relaciones Laborales», en el que se disponga, por ejemplo, que «ningún trabajador será empleado más de mil cuarenta horas durante un período de veintiséis semanas consecutivas» ${ }^{76}$. Ahora bien, dicha Ley federal asimismo regula - y esto es lo verdaderamente significativo, desde el punto de vista europeo- el «salario mínimo [Minimum wage]» federal ${ }^{77}$, ordenando que el mismo será de «no menos de ... 7,25 dólares por hora [not less than ... \$7’25 an hour]» ${ }^{78}$. Evidentemente, cada concreto Estado federado también posee su propia regulación mínima del salario y la jornada, aunque estas otras

73 Recopilada en las secciones 201 a 219 del Título 29 del Código de los Estados Unidos. Sobre el tema, véase M.A. ROTHSTEIN, C.B. CRAVER, E.P. SCHROEDER, E.W. SHOBEN y L.S. VANDERVELDE, Employment Law, West Publ. Co. (St. Paul-Minn., 1994), págs. 194 y ss.

74 Sección 7(a)(1).

75 Ibidem.

76 Al respecto, véase sección 7(b).

77 Véase J. MARTÍNEZ GIRÓN y A. ARUFE VARELA, El salario mínimo en Alemania. Un estudio comparado entre regímenes de salarios mínimos profesionales (alemanes) e interprofesionales legales (norteamericano y europeos), cit., págs. 6 y ss.

78 Sección 6(a)(1). 
regulaciones sólo se aplican a aquellas empresas cuyas actividades no desbordan el marco del respectivo comercio intraestatal.

El sitio de Internet www.dol.gov/esa/minwage/america.htm, gestionado por el Ministerio de Trabajo de los Estados Unidos, contiene información exhaustiva y totalmente puesta al día, y muy gráfica, sobre los salarios mínimos vigentes en cada concreto Estado federado (además de en Puerto Rico, Guam y las Islas Vírgenes), oscilantes entre los 5,15 dólares por hora de los Estados de Georgia y Wyoming y los 8,55 dólares por hora del Estado de Washington.

Siempre según este mismo sitio de Internet, no existe salario mínimo en los Estados de Alabama, Carolina del Sur, Luisiana, Mississippi y Tennessee.

Curiosamente, la citada Ley federal de Condiciones de Trabajo Justas también regula el salario mínimo de los servidores domésticos (employees in domestic service), siempre y cuando trabajen «más de ocho horas» a la semana ${ }^{79}$.

79 Cfr. sección 6(f). 
TEMA 18

EL DERECHO A LA PROTECCIÓN DEL TRABAJADOR ANTE LAS SITUACIONES CRÍTICAS DE LA EMPRESA EN EL ORDENAMIENTO COMUNITARIO, EN LAS LEGISLACIONES Y PRÁCTICAS NACIONALES EUROPEAS, Y EN LA LEGISLACIÓN DE LOS ESTADOS UNIDOS

Sumario: §1. El Derecho de la Unión Europea en materia de protección del trabajador ante las situaciones críticas de la empresa. \$2. La Directiva comunitaria sobre despidos colectivos y su transposición a los ordenamientos nacionales europeos de referencia. §3. La Directiva comunitaria sobre traspasos de empresas y su transposición a los ordenamientos nacionales europeos de referencia. §4. La Directiva comunitaria sobre protección de los trabajadores en caso de insolvencia del empresario y su transposición a los ordenamientos nacionales europeos de referencia. §5. El reglamento comunitario sobre el Fondo Europeo de Adaptación a la Globalización. §6. El influjo de la legislación norteamericana en materia de protección del trabajador ante situaciones críticas de la empresa, sobre el Derecho de la Unión Europea. §7. El influjo del Derecho de la Unión Europea en materia de protección del trabajador ante situaciones críticas de la empresa, sobre la legislación norteamericana.

THEME 18

THE RIGHT TO PROTECTION OF THE EMPLOYEE BEFORE CRITICAL SITUATIONS OF THE ENTERPRISE IN THE EUROPEAN LAW, IN THE NATIONAL EUROPEAN LEGISLATIONS AND PRACTICES, AND IN THE LEGISLATION OF THE UNITED STATES

Contents: $\$ 1$. The Law of the European Union about protection of the employee before critical situations of the enterprise. \$2. The Community Directive about collective dismissals and its implementation by the European national reference legislations. \$3. The Community Directive about transfer of undertakings ant its implementation by the European national reference legislations. $\$ 4$. The Community Directive about protection of the employees in the case of employer insolvency ant its implementation by the European national reference legislations. \$5. The Community Regulation about the European Globalization Adjustment Fund. \$6. The influence of the USA legislation about protection of the employee before critical situations of the enterprise, on the Law of the European Union. \$7. The influence of the Law of the European Union about protection of the employee before critical situations of the enterprise, on the USA legislation. 
\$1. El Derecho de la Unión Europea en materia de protección del trabajador ante las situaciones críticas de la empresa tiene su origen en la Resolución del Consejo de 21 enero 1974, «relativa a un programa de acción social» ${ }^{1}$. En efecto, en esta Resolución - que encarnó en su día la reacción comunitaria ante la crisis económica mundial provocada por el alza del precio del petróleo, consecuencia de la guerra árabe-israelí de $1973^{2}$ — se afirma rotundamente que «los objetivos sociales deben constituir una preocupación constante de todas las políticas de la Comunidad», que esta preocupación debía traducirse en la «adopción de medidas concretas» para afrontar «las graves amenazas que puedan pesar sobre el empleo en razón de la situación existente en el momento en que se adopta la presente Resolución», y que entre tales medidas concretas debía figurar «una directiva relativa a la aproximación de las legislaciones de los Estados miembros referentes a los despidos colectivos», y también, «una directiva tendente a armonizar las legislaciones en lo que se refiere al mantenimiento de los derechos y ventajas en caso de cambio de propiedad de las empresas y principalmente en caso de fusión». En la actualidad, el Derecho de la Unión Europea sobre el tema aparece contenido en cuatro normas comunitarias (tres Directivas y un Reglamento) sucesivamente promulgadas en 1975, 1977, 1980 y 2006, dos de las cuales evidencian - luego se verá- las interacciones existentes entre esta concreta parcela del ordenamiento laboral comunitario y la legislación de los Estados Unidos de Norteamérica sobre el tema.

Al igual que las entonces Comunidades Europeas, los Estados Unidos también reaccionaron el propio año 1974 frente al impacto laboral adverso de la crisis del petróleo, mediante la promulgación de la Ley del Comercio (Trade Act) de dicho año, que tuvo que ser enmendada en 2002 por otra Ley federal homónima, para así poder hacer frente al impacto del fenómeno tan reciente de la globalización de la economía ${ }^{3}$.

El citado «programa de acción social» comunitario preveía expresamente asimismo la promulgación de otra Directiva («una directiva tendente a la aproximación de las legislaciones de los Estados miembros relativas a la aplicación del principio de igualdad

1 Sobre él, véase A. MONTOYA MELGAR, J.Mª GALIANA MORENO y A.V. SEMPERE NAVARRO, Instituciones de Derecho social europeo, Tecnos (Madrid, 1988), págs. 51 y ss.

2 Sobre la tercera década de vida del ordenamiento laboral comunitario, véase J. MARTÍNEZ GIRÓN, A. ARUFE VARELA y X.M. CARRIL VÁZQUEZ, Derecho del Trabajo, 2a ed., Netbiblo (A Coruña, 2006), pág. 100.

3 Acerca de esta segunda Ley norteamericana, véase infra, §6. Sobre el impacto de la globalización en nuestra disciplina, véase B. CARUSO, «Gli esiti della globalizzazione: disintegrazione o trasformazione del diritto del lavoro?», en S. SCARPONI (Coordinadora), Globalizzazione e diritto del lavoro. Il ruolo degli ordinamenti sovranazionali, Giuffrè (Milan, 2001), págs. 207 y ss. 
de retribuciones de hombres y mujeres») ${ }^{4}$, además de pretender reactivar el hasta entonces lánguido Fondo Social Europeo («para llevar a cabo las acciones propuestas, y sobre todo frente a los cambios y desequilibrios estructurales de la Comunidad, es importante prever los medios necesarios reforzando en particular la función del Fondo Social Europeo») $)^{5}$.

La Carta de los Derechos Fundamentales de la Unión Europea no menciona el derecho a la protección del trabajador ante las situaciones críticas de la empresa, aunque - visto el acervo comunitario citado en las «explicaciones» sobre tales derechos- debe considerarse embebido en el «derecho a la información y consulta de los trabajadores en la empresa» ${ }^{6} \mathrm{y}$ en el derecho a la «protección en caso de despido injustificado»?

\$2. La primera de dichas normas comunitarias fue la Directiva 75/129/CEE del Consejo, de 17 febrero 1975, que se ha transformado - tras sucesivas enmiendas - en la actualmente vigente Directiva 98/59/CE del Consejo, de 20 julio 1998, sobre «aproximación de las legislaciones de los Estados miembros que se refieren a los despidos colectivos ${ }^{8}$. Se trata de una norma articulada en lo esencial alrededor de dos piezas: 1) un concepto de «despido colectivo», que combina la motivación del despido (se trata de «despidos efectuados por un empresario, por uno o varios motivos no inherentes a la persona de los trabajadores») con el número de trabajadores afectados (variable, como regla, según el tamaño de los centros de trabajo afectados) en un concreto período de tiempo («para un período de 30 días», «para un período de 90 días») ${ }^{9}$; y 2) un «procedimiento», integrado por las obligaciones del empresario - a cumplir antes de la realización de los despidos- de «consultar, en tiempo hábil, a los representantes de los trabajadores con vistas a llegar a un acuerdo» ${ }^{10}$, y de «notificar por escrito cualquier proyecto de despido colectivo a la autoridad pública competente» ${ }^{11}$. Como se trata de una norma de mínimos —el ordenamiento español, por ejemplo, va mucho más allá, exigiendo autorización administrativa para poder

4 Sobre ella, véase M.A. CASTRO ARGÜELLES y P. MENÉNDEZ SEBASTIÁN, «Igualdad entre varón y mujer en materia de retribución (Directiva 75/117/CEE)», en J. GARCÍA MURCIA (Director), $L a$ transposición del Derecho social comunitario al ordenamiento español, Ministerio de Trabajo y Asuntos Sociales (Madrid, 2005), págs. 197 y ss. También, B. TEYSSIÉ, Droit Européen du Travail, Litec (Paris, 2001), págs. 213 y ss.

5 Sobre el tema, véase M. COLINA ROBLEDO, J.M. RAMÍREZ MARTÍNEZ y T. SALA FRANCO, Derecho social comunitario, $2^{\mathrm{a}}$ ed., Tirant lo blanch (Valencia, 1995), págs. 240 y ss.

6 Artículo 27.

7 Artículo 30.

8 Sobre el tema, exhaustivo desde el punto de vista del ordenamiento comunitario, véase X.M. CARRIL VÁZQUEZ, «Notas acerca de la Directiva 98/59/CE del Consejo, de 20 julio 1998, sobre despidos colectivos», Actualidad Laboral, núm. 19 (2004), págs. 2305 y ss.

9 Cfr. su artículo 1.1, letra a).

10 Cfr. su artículo 2.1.

11 Cfr. su artículo 3.1, párrafo primero. 
practicar un despido colectivo ${ }^{12}$, al igual que ocurría en el ordenamiento laboral francés hasta $1986^{13}$ - , su transposición a los diversos ordenamientos internos de los Estados miembros que consideramos de referencia no ha planteado problemas dignos de ser reseñados, salvo en los casos de Italia, Gran Bretaña y Portugal, condenadas respectivamente dos veces, una vez y una vez por el Tribunal de Luxemburgo, por transposición defectuosa del contenido de esta Directiva comunitaria ${ }^{14}$.

En la actualidad, las normas de transposición de la misma en dichos tres países son la Ley núm. 223, de 23 julio 1991, de «normas en materia de caja de integración, movilidad, tratamientos de desocupación, transposición de directivas de la Comunidad Europea, preparación para el trabajo y otras disposiciones en materia de mercado del trabajo [norme in materia di cassa integrazione, mobilità, trattamenti di disoccupazione, attuazione di direttive della Comunita Europea, avviamento al lavoro ed altre disposizioni in materia di mercato del lavoro]», en Italia ${ }^{15}$; el Capítulo II (rotulado "Procedimiento para el tratamiento de despidos colectivos [Procedure for handling of redundancies]» de la Parte IV de la «Ley Sindical y de Relaciones Laborales (Consolidada) [Trade Union and Labour Relations (Consolidation) Act]》 de 1992, secciones 188 a 198, en Gran Bretaña ${ }^{16}$; y por la División II (rotulada «Despido colectivo [Despedimento colectivo]») de la Subsección I de la Sección IV del Capítulo VII del Libro I del Código del Trabajo de 2009, artículos 359 a 366, en Portugal ${ }^{17}$.

En los restantes países europeos que consideramos de referencia, ha sido transpuesta por la Parte Tercera (rotulada «Despidos con deber de anuncio [Anzeigepflichtige Entlassungen]») de la «Ley de Protección contra el Despido [Kündigungsschutzgesetz]» de 10 agosto 1951, parágrafos 17 a 22, en Alemania ${ }^{18}$; y por el Capítulo III (rotulado «Despido

12 Al respecto, véase J. MARTÍNEZ GIRÓN, A. ARUFE VARELA y X.M. CARRIL VÁZQUEZ, Derecho del Trabajo, $2^{\mathrm{a}}$ ed., cit., pág. 339.

13 Véase J. PÉliSSIER, A. SUPIOT y A. JEAMMAUD, Droit du Travail, 24 a ed., Dalloz (París, 2008), pág. 603.

14 Para el caso de Italia, véanse Sentencias del Tribunal de Justicia de las Comunidades Europeas de 8 junio 1982 (asunto 91/81) y de 16 octubre 2003 (asunto C-33/02); para el caso de Gran Bretaña, Sentencia del Tribunal de Justicia de las Comunidades Europeas de 8 junio 1994 (asunto C-382/92); para el caso de Portugal, Sentencia del Tribunal de Justicia de las Comunidades Europeas de 12 octubre 2004 (asunto C-55/02). También fue condenada Bélgica, siempre por transposición defectuosa de la Directiva en cuestión, por Sentencia del Tribunal de Justicia de las Comunidades Europeas de 28 marzo 1985 (asunto 215/83).

15 Véase G. FAVALLI y F. ROTONDI, Manuale pratico di diritto del lavoro, $2^{\mathrm{a}}$ ed., CEDAM (Padua, 2005), págs. 447 y ss.

16 Véase N.M. SELWYN, Law of Employment, 13 ${ }^{\mathrm{a}}$ ed., LexisNexis-Butterworths (Londres y Edimburgo, 2004), pág. 440 y ss.

17 Véase A. MONTEIRO FERNANDES, Direito do Trabalho, 15 a ed., Almedina (Coimbra, 2010), págs. 636 y ss.

18 Véase J. MARTÍNEZ GIRÓN, «Las normas estructurales complementarias de la Ley actualmente vigente en Alemania en materia de protección contra el despido», Anuario da Facultade de Dereito da Universidade da Coruña. Revista Jurídica Interdisciplinar Internacional, vol. 10 (2006), págs. 717-718. Nuestra traducción íntegra de la Ley en cuestión, en J. MARTÍNEZ GIRÓN y A. ARUFE VARELA, Leyes laborales alemanas. Estudio comparado y traducción castellana, Netbiblo (A Coruña, 2007), págs. 168 y ss. 
por motivo económico [Licenciement pour motif économique]») del Título III del Libro II de la Parte I del Código del Trabajo de 2008, artículos L. 1233-1 a L. 1233-91, en Francia ${ }^{19}$.

La Directiva pone de relieve su naturaleza de norma mínima, al afirmar que «la presente Directiva no afectará a la facultad de los Estados miembros de aplicar o de introducir disposiciones legales, reglamentarias o administrativas más favorables para los trabajadores o de permitir o de fomentar la aplicación de disposiciones convencionales más favorables para los trabajadores» ${ }^{20}$.

§3. La segunda norma comunitaria, asimismo mencionada en el citado «programa de acción social» de 1974, es la Directiva 77/187/CEE del Consejo, de 14 febrero 1977, cuyo contenido - de nuevo tras sucesivas enmiendas - ha recalado en la actualmente vigente Directiva $2001 / 23 / \mathrm{CE}$ del Consejo, de 12 marzo 2001, sobre «aproximación de las legislaciones de los Estados miembros relativas al mantenimiento de los derechos de los trabajadores en caso de traspasos de empresas, de centros de actividad o de partes de empresas o de centros de actividad ${ }^{21}$. Se trata de una norma comunitaria que incide, al menos en el continente europeo, sobre un tema clásico del Derecho del contrato de trabajo ${ }^{22}$, lo que explica que en el caso de Alemania la transposición de la misma fuese operada por una Ley de modificación parcial del mismísimo Código Civil ${ }^{23}$. Pero es otra vez una Directiva de mínimos (su núcleo duro se refiere a que «los derechos y obligaciones que resulten para el cedente de un contrato de trabajo o de una relación laboral existente en la fecha del traspaso, serán transferidos al cesionario como consecuencia de tal traspaso» ${ }^{24}$, y a que «el traspaso de una empresa, de un centro de actividad o de una parte de éstos no constituirá en sí mismo un motivo de despido para el cedente o para el cesionario» ${ }^{25}$ ), aunque su transposición defectuosa provocó que el Tribunal de Luxemburgo tuviese que condenar en su día — dentro de los

19 Véase J. PÉLISSIER, A. SUPIOT y A. JEAMMAUD, Droit du Travail, $24^{a}$ ed., cit., págs. 605 y ss.

20 Artículo 5.

21 Véase C. MARTÍNEZ MORENO, «Los traspasos de empresas (Directiva 2001/23/CE y normas precedentes)», en en J. GARCÍA MURCIA (Director), La transposición del Derecho social comunitario al ordenamiento español, Ministerio de Trabajo y Asuntos Sociales (Madrid, 2005), págs. 443 y ss.

22 Acerca de la regulación del mismo ya en nuestra Ley de Contrato de Trabajo de 1931, véase J. MARTÍNEZ GIRÓN, A. ARUFE VARELA y X.M. CARRIL VÁZQUEZ, Derecho del Trabajo, $2^{a}$ ed., cit., pág. 281.

23 Véase E. HELML, Arbeitsrecht, $8^{\mathrm{a}}$ ed., C.H. Beck (Munich, 2004), págs. 68 ss.

24 Artículo 3.1, párrafo primero.

25 Artículo 4.1, párrafo primero, inciso primero. 


\section{Estados miembros que consideramos de referencia- de nuevo a Italia (por dos veces) y a Gran Bretaña ${ }^{26}$.}

En la actualidad, las normas de transposición de la misma en ambos países son el artículo 47 (rotulado «Traspasos de empresa [Transferimenti di azienda]») de la Ley núm. 428, de 29 diciembre 1990, de «disposiciones para el cumplimiento de obligaciones derivadas de la pertenencia de Italia a las Comunidades Europeas», en Italia ${ }^{27}$; y por «el Reglamento de Traspaso de Empresas (Protección del Empleo) [The Transfer of Undertakings (Protection of Employment) Regulations]» de 2006, en Gran Bretaña ${ }^{28}$.

En los restantes países europeos que consideramos de referencia, ha sido transpuesta por el parágrafo 613a (rotulado «Derechos y deberes en la transmisión de centro de trabajo [Rechte und Pflichten bei Betriebsübergang]») del Código Civil, en Alemania ${ }^{29}$; por el artículo L. 1224-1 a L. 1224-4 del Código del Trabajo de 2008, en Francia, bajo el rótulo genérico «Traspaso del contrato de trabajo [Transfert du contrat de travail] ] ${ }^{30}$; y por la Sección I (rotulada «Transmisión de la empresa o centro de trabajo [Transmissão da empresa ou estabelecimento]») del Capítulo V del Libro I del Código del Trabajo de 2009, artículos 285 a 287, en Portugal ${ }^{31}$.

Esta Directiva — que es, también, una norma de mínimos ${ }^{32}$ — viene suscitando una abundante jurisprudencia interpretativa de la misma a cargo del Tribunal de Luxemburgo ${ }^{33}$, que nuestros tribunales laborales tienen muy en cuenta a la hora de aplicar lo dispuesto en el artículo 44 del Estatuto de los Trabajadores ${ }^{34}$.

§4. La tercera norma comunitaria, referente ya a situaciones de verdadera agonía - más que meramente críticas - de las empresas, es la Dire c tiva $2008 / 94 / C E$ del Parlamento Europeo y del Consejo, de 22 octubre 2008, «relativa a la protección de los trabajadores asalariados

26 Para el caso de Italia, véase Sentencias del Tribunal de Justicia de las Comunidades Europeas de 10 julio 1986 (asunto 235/84) y de 11 junio 2009 (asunto C-561/07); para el caso de Gran Bretaña, la ya citada Sentencia del Tribunal de Justicia de las Comunidades Europeas de 8 junio 1994 (asunto C-382/92). También fue condenada Bélgica - al igual que en la hipótesis de la transposición de la Directiva sobre despidos colectivos, asimismo por transposición defectuosa de esta otra Directiva一, por Sentencia del Tribunal de Justicia de las Comunidades Europeas de 10 abril 1986 (asunto 237/84).

27 Véase G. FAVALLI y F. ROTONDI, Manuale pratico di diritto del lavoro, $2^{\mathrm{a}}$ ed., cit., págs. 375 y ss.

28 Véase N.M. SELWYN, Law of Employment, $13^{\mathrm{a}}$ ed., cit., págs. 230 y ss.

29 Véase J. MARTÍNEZ GIRÓN, «Las normas estructurales complementarias de la Ley actualmente vigente en Alemania en materia de protección contra el despido», cit., pág. 719.

30 Véase J. PÉLISSIER, A. SUPIOT y A. JEAMMAUD, Droit du Travail, $24^{\mathrm{a}}$ ed., cit., págs. 481 y ss.

31 Véase A. MONTEIRO FERNANDES, Direito do Trabalho, $15^{\mathrm{a}}$ ed., cit., págs. 265 y ss.

32 Su artículo 8 afirma que «la presente Directiva no afectará a la facultad de los Estados miembros de aplicar o adoptar disposiciones legales, reglamentarias o administrativas más favorables para los trabajadores o de promover o permitir la aplicación de convenios colectivos o acuerdos celebrados entre interlocutores sociales más favorables para los trabajadores».

33 Véase F.J. GÓMEZ ABELLEIRA, «Cambio de contratista y sucesión de empresa, en especial a la luz de la jurisprudencia del Tribunal de Justicia de las Comunidades Europeas», Actualidad Laboral, núm. 16 (2002), págs. 315 y ss.; y J.L. GOÑI SEIN, «El concepto de sucesión de empresa. Divergencias doctrinales entre el Tribunal de Justicia de la Unión Europea y el Tribunal Supremo Español», Anuario Coruñés de Derecho Comparado del Trabajo-ACDCT, vol. II (2010), págs. 37 y ss.

34 Véase J. MARTÍNEZ GIRÓN, A. ARUFE VARELA y X.M. CARRIL VÁZQUEZ, Derecho del Trabajo, $2^{\mathrm{a}}$ ed., cit., págs. 282-283. 
en caso de insolvencia del empresario (versión codificada)», que reemplaza la Directiva 80/987/CEE, varias veces enmendada ${ }^{35}$. Obliga a los Estados miembros a que existan en ellos «Instituciones de garantía» —en España y Portugal, el Fondo de Garantía Salarial ${ }^{36}$ _, que aseguren cuando el empresario es insolvente «el pago de los créditos impagados de los trabajadores asalariados que resulten de los contratos de trabajo o de relaciones laborales, incluidas las indemnizaciones debidas al término de la relación laboral, cuando así lo disponga el Derecho interno» ${ }^{37}$, aunque con límites, pues «los créditos tenidos en cuenta por la institución de garantía serán las remuneraciones impagadas correspondientes a un período situado antes o, en su caso, después de una fecha determinada por los Estados miembros, o antes y después de la misma» ${ }^{38}$. Su trans posición —dentro siempre de los Estados miembros que consideramos de referencia-sólo ha resultado problemática de momento otra vez en el caso de Italia, condenada por el Tribunal de Luxemburgo a causa de la defectuosa acomodación de su legislación interna a dicha Directiva en $1989^{39}$.

En la actualidad, dicha legislación interna italiana está contenida en el Decreto Legislativo núm. 80, de 27 enero 1992, de «transposición de la Directiva 80/987/CEE en materia de tutela de los trabajadores subordinados en caso de insolvencia del empresario [attuazione della Direttiva 80/987/CEE in materia di tutela dei lavoratori subordinati in caso di insolvenza del datore di lavoro]» ${ }^{40}$.

En Alemania, el tema se regula en el Libro Tercero del Código de Seguridad Social, parágrafos 183 a 189a (bajo el rótulo genérico «subsidio de insolvencia [Insolvenzgeld]») ${ }^{41}$; en Francia, en los artículos L. 3253-1 a L. 3253-23 del Código del Trabajo de 2008 42; y en Gran Bretaña, en la «Ley de Insolvencia [Insolvency Act]» de $1986^{43}$.

35 Sobre esta última, exhaustivo, véase A. ARUFE VARELA, «La Directiva 80/987/CEE del Consejo, de 20 de octubre de 1980, relativa a la protección de los trabajadores asalariados en caso de insolvencia del empresario», Actualidad Laboral, núm. 18 (2004), págs. 2160 y ss.

36 Para España, véase J. MARTÍNEZ GIRÓN, A. ARUFE VARELA y X.M. CARRIL VÁZQUEZ, Derecho del Trabajo, $2^{\mathrm{a}}$ ed., cit., págs. 222-223.

37 Artículo 3, párrafo primero.

38 Ibidem, párrafo segundo.

39 Véase Sentencia del Tribunal de Justicia de las Comunidades Europeas de 2 febrero de dicho año (asunto 22/87). Acerca de la condena de Grecia, asimismo por transposición defectuosa de la Directiva en cuestión, véase Sentencia del Tribunal de Justicia de las Comunidades Europeas de 8 noviembre 1990 (asunto C-53/88).

40 Véase A. TURSI y P.A. VARESI, Lineamenti di Diritto del Lavoro. Rapporti di lavoro e relazioni sindacali nel settore privato, $3^{\mathrm{a}}$ ed., Kluwer-Ipsoa (s.1., 2004), págs. 291 y ss.

41 Véase W. DÄUBLER, Arbeitsrecht. Ratgeber für Beruf, Praxis und Studium, $6^{\text {a }}$ ed., Bund-Verlag (Frankfurt a.M., 2006), págs. 291 y ss.

42 Véase J. PÉLISSIER, A. SUPIOT y A. JEAMMAUD, Droit du Travail, 24a ed., cit., págs. 997 y ss.

43 Véase N.M. SELWYN, Law of Employment, 13 ${ }^{\mathrm{a}}$ ed., cit., pág. 24. 
En Portugal, por excepción, la norma de transposición de la Directiva no es el Código del Trabajo de 2009 (que sólo menciona de pasada el «Fundo de Garantía Salarial») 44, sino el Reglamento del primer Código del Trabajo de 2003, artículos 317 a $326^{45}$.

§5. La cuarta norma - con vigencia directa e inmediata en todos los Estados miembros, desde 1 enero 2007- es el Reglamento (CE) núm. 1927/2006 del Parlamento Europeo y del Consejo, de 20 diciembre 2006, «por el que se crea el Fondo Europeo de Adaptación a la Globalización»o FEAG, modificado-porcausa del «crack» de 2008 - en 2009 ${ }^{46}$. Pretende hacer frente a despidos masivos, que sean «consecuencia de grandes cambios estructurales en los patrones del comercio mundial provocados por la globalización» ${ }^{47}$, y en particular, por «un incremento importante de las importaciones en la Unión Europea, una disminución acelerada de la cuota de mercado de la UE en un determinado sector o deslocalizaciones hacia terceros países» ${ }^{48}$, así como a aquellos despidos masivos que sean «resultado de la crisis financiera y económica mundial» ${ }^{49}$. Este Fondo - que estará operativo, en principio, hasta el 31 diciembre $2013^{50}$ - cofinancia hasta «el $50 \%$ », como regla, solicitudes de intervención presentadas por los Estados miembros ${ }^{51}$, teniendo en cuenta que sólo se consideran acciones subvencionables las encuadradas en políticas activas de empleo de los trabajadores despedidos - «el FEAG no financiará las medidas pasivas de protección social» ${ }^{52}$-, de las que este Reglamento menciona tres tipos distintos: 1) la «asistencia en la búsqueda de un empleo, orientación profesional, formación y reciclaje profesional a medida», incluida «la promoción del espíritu empresarial o asistencia con

44 Cfr. su artículo 336.

45 Véase A. MONTEIRO FERNANDES, Direito do Trabalho, $15^{\mathrm{a}}$ ed., cit., pág. 474.

46 Por el Reglamento (CE) núm. 546/2009 del Parlamento Europeo y del Consejo, de 18 junio 2009. Analizando las repercusiones laborales del «crack» en cuestión, desde sus respectivos puntos de vista nacionales, véanse S. BELLOMO, «Crisis económica, medidas de protección contra el desempleo, formas de ayuda al empleo y al empresariado: las medidas del legislador italiano en el período 2008-2009» (traducción castellana de J. GÁRATE CASTRO), Tribuna Social, núm. 227 (2009), págs. 27 y ss.; A.J. MOREIRA y J. GÁRATE CASTRO, «Las recientes medidas laborales anticrisis en Portugal» (traducción castellana de Y. MANEIRO VÁZQUEZ y J. GÁRATE CASTRO), Tribuna Social, núm. 228 (2009), págs. 14 y ss.; y H. BRECHT-HEITZMANN, «Medidas jurídicas laborales y de seguridad social para la lucha contra la crisis económica en Alemania» (traducción castellana de J. MARTÍNEZ GIRÓN), Tribuna Social, núm. 230 (2010), págs. 13 y ss.

\footnotetext{
47 Artículo 1, párrafo primero.

48 Artículo 2, párrafo primero.

49 Artículo 1, apartado 1bis.

50 Cfr. artículo 1, párrafo segundo.

51 Cfr. artículos 5 y 10.1, párrafo segundo.

52 Artículo 3, párrafo segundo.
} 
vistas al establecimiento por cuenta propia» ${ }^{53}$; 2) «medidas especiales de duración limitada», consistentes en asignaciones económicas compatibles incluso con el cobro de las prestaciones por desempleo, como «asignaciones de búsqueda de empleo, asignaciones de movilidad o asignaciones destinadas a las personas que participen en el aprendizaje permanente y en actividades de formación» ${ }^{54}$; y 3) «medidas para incentivar a los trabajadores con discapacidad o de más edad, para que permanezcan o se reintegren en el mercado laboral» ${ }^{55}$.

Entre las consecuencias negativas a que pretende hacer frente este Reglamento comunitario, se cuenta «el despido, durante un período de cuatro meses, de al menos quinientos trabajadores de una empresa en un Estado miembro, incluidos los asalariados despedidos por los proveedores o los transformadores de productos de dicha empresa» ${ }^{56}$; o también, «el despido, durante un período de nueve meses, de al menos quinientos trabajadores, en particular de pequeñas o medianas empresas, en una división del nivel 2 de la NACE en una región o dos regiones contiguas en el nivel NUTS $2{ }^{57}$.

Acerca de esta terminología insufriblemente tecnocrática, téngase en cuenta - por aplicación del Reglamento (CEE) núm. 3037/90 del Consejo, de 9 octubre 1990, relativo a la nomenclatura estadística de actividades económicas en la Comunidad Europea- que la expresión «nivel 2 de la NACE» se refiere a las actividades económicas «identificadas mediante un código alfabético de dos caracteres (divisiones)» ${ }^{58}$, precisamente en el Anexo único del propio Reglamento 3037/90 (por ejemplo, «industrias de productos alimenticios y bebidas», «industria textil»o «industria de la confección y de la peletería», todas relativas a actividades económicas aparentemente amenazadas de deslocalización en España) ${ }^{59}$; y además - pero ahora de conformidad con el Reglamento (CE) núm. 1059/2003 del Parlamento Europeo y del Consejo, de 26 mayo 2003, por el que se establece una nomenclatura común de unidades territoriales estadísticas (NUTS)—, que la expresión «nivel NUTS 2» alude - desde el punto de vista español - a cualquiera de nuestras diecisiete «Comunidades Autónomas», más las «Ciudades autónomas» de Ceuta y Melilla, mencionadas en el Anexo I del propio Reglamento 1059/2003.

En fin, el Reglamento del FEAG afirma asimismo que «la Comisión creará un sitio web en Internet, disponible en todas las lenguas comunitarias, para facilitar información sobre el FEAG y orientaciones para la preparación de solicitudes, así como información actualizada sobre las solicitudes admitidas y rechazadas, en la que se destacará el cometido de la Autoridad Presupuestaria» ${ }^{60}$. Por supuesto, la Comisión cumplió con su deber. Y este sitio se halla actualmente ubicado en http://ec.europa.eu/social/main.jsp?catId=326\&langId=es.

53 Cfr. artículo 3, párrafo primero, apartado a).

54 Ibidem, apartado b).

55 Ibidem, apartado c).

56 Artículo 2, apartado a).

57 Artículo 2, apartado b).

58 Cfr. su artículo 2.1.

59 Téngase en cuenta que a partir de 1 enero 2008 entró en vigor el nuevo Reglamento (CE) núm. 1893/2006 del Parlamento Europeo y del Consejo de 20 diciembre 2006, por el que se establece la nomenclatura estadística de actividades económicas NACE Revisión 2 y por el que se modifica el Reglamento (CEE) núm. 3037/90 del Consejo y determinados Reglamentos de la CE sobre aspectos estadísticos específicos.

60 Artículo 9, apartado 2. 
§6. Según reconoce el Comité Económico y Social de la Unión Europea, la fuente inspiradora de este Reglamento comunitario de creación del FEAG ha sido la Ley federal norteamericana de Comercio (Trade Act) de $2002{ }^{61}$ - y especialmente, la «División A» de su complejísimo contenido (rotulada "Apoyo a la Adaptación del Comercio [Trade Adjustment Assistance]»), más conocida por su acrónimo TAA - también promulgada para hacer frente a las consecuencias laborales negativas derivadas del fenómeno de la globalización de la economía, pero en los Estados Unidos. En efecto, esta Ley norteamericana - que entró en vigor el 1 octubre 2001 y hasta el 30 septiembre $2007^{62}$, aunque su vigencia fue luego prorrogada (con enmiendas), por causa del «crack» de 2008, últimamente en $2009^{63}$ — encara el hecho de que «un número o porcentaje significativos de trabajadores... han sido total o parcialmente despedidos [totally or partially separated] $\gg{ }^{64}$, como consecuencia — entre otras - de que «las ventas o la producción, o ambas, de... [su] empresa... han disminuido gravemente... [y] se han incrementado las importaciones de artículos parecidos o directamente competitivos con artículos producidos por dicha empresa» ${ }^{65}$, o porque «ha habido una deslocalización de la producción [shift in production] de la empresa de dichos trabajadores... a un país extranjero», supuesto que este país «sea [como ocurre, por ejemplo, con México o Canadá] parte de un acuerdo de libre comercio con los Estados Unidos» ${ }^{66}$. La tramitación de los diversos programas de apoyo regulados por esta Ley (también consistentes en «formación [training]», «subsidios de adaptación [adjustment allowances]», programas alternativos para trabajadores de «50 años de edad o más», etc., y que son financiados por la Administración laboral federal, aunque los gestionen las Administraciones laborales de los diversos Estados federados) ${ }^{67} \mathrm{resulta}$ infinitamente menos burocrática que la tramitación de los programas cubiertos en Europa por el FEAG, puesto que en los Estados Unidos los solicitantes son los propios trabajadores beneficiarios de los

61 Recopilada en el Subcapítulo II, del Capítulo 12 del Título 19 (rotulado «Deberes aduaneros [Customs Duties]») del Código de los Estados Unidos, secciones 2251 y ss.

62 Cfr. sección 111.

63 Mediante la «Ley de Recuperación y Reinversión Americanas [American Recovery and Reinvestment Act]», firmada por el Presidente OBAMA el 17 febrero 2009. Su texto íntegro y todos los materiales para su contextualización, en el sitio de Internet www.recovery.gov.

64 Cfr. sección 113(a)(1)(A)(a)(1).

65 Cfr. sección 113(a)(1)(A)(a)(2)(A).

66 Cfr. sección 113(a)(1)(A)(a)(2)(B).

67 Cfr. secciones 114 y ss. 
programas, actuando directamente por sí mismos o, también, a través de sus empresarios o de sus representantes sindicales ${ }^{68}$.

El sitio en Internet de la «Administración de Empleo y Formación [Employment \& Training Administration]» dependiente del Ministerio de Trabajo del Gobierno federal permite acceder a una completísima información normativa, estadística y de todo tipo sobre los programas en cuestión, vía www.doleta.gov/tradeact.

De acuerdo con la información suministrada por este sitio, hay Estados norteamericanos - tema a tener muy en cuenta para el reparto de los fondos federales - donde no parece haber impactado la globalización (por ejemplo, Dakota del Norte, Delaware, Hawaii o Wyoming), sectores económicos donde el impacto negativo de la globalización es muy intenso (por ejemplo, fabricación de productos textiles y metálicos, de maquinaria industrial y de equipos electrónicos e informáticos) y segmentos del empleo, dentro de estos sectores, también más intensamente sacudidos por la globalización (en especial, personas de raza blanca y con al menos estudios secundarios).

En el citado Dictamen del Comité Económico y Social de la Unión Europea, fechado en Bruselas el 13 septiembre 2006 y localizable en www.eesc.europa.eu, se afirma literalmente lo siguiente: «Hasta cierto punto, el programa ... de la Trade Adjustment Assistance ("ayuda a los ajustes comerciales") (TAA) de los EEUU ha servido de ejemplo. La TAA tenía por objeto corregir la asimetría entre las repercusiones negativas de la apertura de los mercados y la liberalización internacional de regiones o casos específicos e individuales y sus beneficios globales. No obstante, no es fácil comparar la TAA y el FEAG, debido a las diferencias culturales entre los EEUU y la UE y a los distintos criterios utilizados» ${ }^{69}$.

§7. El fenómeno inverso - esto es, la influencia del Derecho laboral de la Unión Europea sobre el Derecho laboral de los Estados Unidos de Norteamérica- cabe reconocerlo, a propósito siempre de la protección del trabajador ante las situaciones críticas de las empresas, en la Ley federal de Preaviso para el Reentrenamiento y la Adaptación del Trabajador (Worker Adjustment and Retraining Notification Act) de 1988 , más conocida (por causa de su acrónimo) como Ley WARN ${ }^{70}$. En este otro caso, asombroso - visto que en el otro lado del Atlántico la regla continúa siendo todavía la del despido libre ${ }^{71}$ - la fuente inspiradora ha sido la citada Directiva 70/129/CEE, sobre despidos colectivos ${ }^{72}$. Lo evidencia el hecho de que dicha Ley norteamericana — sólo aplicable a grandes empresas ${ }^{73}$-, que entró en

68 Cfr. sección 112.

69 Apartado 3.4.

70 Recopilada en las secciones 2101 y ss. del Título 29 del Código de los Estados Unidos. Sobre esta norma, véase W.Z. CARR JR, D.A. CATHCART y S.A. KRUSE, «United States of America», en International Handbook on Contracts of Employment, Kluwer Law International (La Haya, 2000), págs. 89 y ss.

71 Véase infra, Tema 19, \$5.

72 Véase supra, §2.

73 En principio, las de «100 ó más trabajadores, excluidos los trabajadores a tiempo parcial» [cfr. su sección 2(a)(1)(A)]. 
vigor el 4 febrero 1989: 1) se aplique al «cierre de factoría [plant closing]» $\mathrm{y}$ al «despido masivo por crisis [mass layoff] ]», que afecten a determinados números o porcentajes de trabajadores, bien en un «período de 30 días $\left[30\right.$-day period] ${ }^{74}$, bien en un "período de 90 días [90-day period] ${ }^{75}$; 2) obligue a abstenerse de cerrar o despedir «hasta el final del transcurso de un período de 60 días siguiente a que comunique preaviso escrito [serves written notice] el empresario» de su intención de cerrar o despedir, «a cada representante de los trabajadores afectados... o, si no existe dicho representante..., a cada trabajador afectado» ${ }^{76}$; y 3 ) obligue a efectuar esta misma comunicación, también, «al Estado [federado] o entidad designada por el Estado... y al funcionario jefe... de la unidad de Administración local en la que el cierre o despido vayan a ocurrir» ${ }^{77}$.

Los números y porcentajes de trabajadores afectados a que se refiere la Ley norteamericana son, como regla, los siguientes: en el caso de «cierre de factoría», «si el cierre [shutdown] provoca una pérdida de empleo... durante un período de 30 días para 50 ó más trabajadores excluyendo a los trabajadores a tiempo parcial»; en el caso de «despido masivo por crisis», si provoca «una pérdida de empleo durante un período de 30 días para... al menos el 33 por ciento de los trabajadores (excluyendo los trabajadores a tiempo parcial)» — que deben ser «al menos 50 trabajadores (excluyendo los trabajadores a tiempo parcial)» ${ }^{78}$ - o para «al menos 500 trabajadores (excluyendo trabajadores a tiempo parcial)» ${ }^{79}$.

La Ley norteamericana también prevé la posibilidad de multar al empresario incumplidor (con «500 dólares por cada día de dicho incumplimiento») y de que el trabajador reclame «salarios de tramitación [back pay]» y cualquier tipo de «mejoras [benefits]» que le correspondiesen durante el período de preaviso omitido, ejercitando demanda en una «corte de distrito de los Estados Unidos» ${ }^{80}$.

Los reglamentos de esta Ley federal aparecen recopilados en la Parte 639 del Capítulo V del Título 20 del Código de Reglamentos Federales, en la que se regula — entre otras cuestiones- «¿Quién debe dar el preaviso?», «¿Quién debe recibir el preaviso?», «¿Qué debe contener el preaviso?» y «¿Cómo debe comunicarse el preaviso?».

\footnotetext{
74 Cfr. sección 2(a)(2) y (3).

75 Cfr. sección 3(d).

76 Cfr. sección 3(a)(1).

77 Cfr. sección 3(a)(2).

78 Cfr. sección 2(a)(2).

79 Cfr. sección 2(a)(3)(B).

80 Cfr. su sección su sección 5 (rotulada «Administración y exigencia del cumplimiento de los requisitos [Administration and enforcement of requirements]»).
} 
TEMA 19

EL DERECHO A LA PROTECCIÓN DEL TRABAJADOR FRENTE AL DESPIDO INJUSTIFICADO EN EL ORDENAMIENTO COMUNITARIO, EN LAS LEGISLACIONES Y PRÁCTICAS NACIONALES EUROPEAS, Y EN LA LEGISLACIÓN DE LOS ESTADOS UNIDOS

Sumario: §1. El modelo de despido libre con preaviso aplicado por la Unión Europea al personal laboral a su servicio. \$2. La readmisión del trabajador, como regla, en el modelo alemán (y sus equivalentes italiano y portugués) de protección frente al despido injustificado. §3. La extinción indemnizada del contrato, como regla, en el modelo francés de protección frente al despido injustificado. \$4. El modelo británico de despido libre con preaviso, como regla, y sus excepciones. §5. El modelo norteamericano de despido libre, como regla, y sus excepciones.

THEME 19

THE RIGHT TO PROTECTION OF THE EMPLOYEE BEFORE WRONGFUL DISMISSAL IN THE EUROPEAN LAW, IN THE NATIONAL EUROPEAN LEGISLATIONS AND

PRACTICES, AND IN THE LEGISLATION OF THE UNITED STATES

Contents: \$1. The free termination with notice model applied by the European Union to the employment relationship personnel in its service. \$2. The reinstatement of the employee, as a general rule, in the German model (and its Italian and Portuguese variants) of protection before wrongful dismissal. \$3. The severance pay, as a general rule, in the French model of protection before wrongful dismissal. $\$ 4$. The British model of termination with notice, as a general rule, and its exceptions. \$5. The USA model of free discharge, as a general rule, and its exceptions.

\$1. Si por despido libre se entiende el hecho de que el empresario pueda extinguir lícitamente el contrato de trabajo sin precisar de ninguna justa causa ${ }^{1}$, la Unión Europea posee —en cuanto que empresario-el derecho de despedir libremente con preaviso a

1 Al respecto, véase J. MARTÍNEZ GIRÓN, A. ARUFE VARELA y X.M. CARRIL VÁZQUEZ, Derecho del Trabajo, 2a ed., Netbiblo (A Coruña, 2006), pág. 313. 
la parte más sustanciosa del personal laboral a su servi ci o. Como se sabe, el régimen jurídico básico aplicable a este personal laboral aparece contenido en el anexo sobre «Régimen aplicable a los otros agentes de las Comunidades» - distintos de los funcionarios- del Reglamento núm. 31 (CEE), 11 (CEEA) de 1962. Y de acuerdo con él: 1) cabe el despido libre con preaviso de los denominados «agentes temporales» ${ }^{2}$, dado que: a) si trabajan en virtud de un contrato «de duración determinada», resulta posible extinguirlo «al término del plazo de preaviso establecido en el contrato, si éste contiene una cláusula que otorgue al agente o a la institución la facultad de rescindir el contrato antes de su vencimiento» ${ }^{3}$; y b) si trabajan en virtud de un contrato «por tiempo indefinido», también resulta posible su extinción libre «al término del plazo de preaviso establecido en el contrato» ${ }^{4}$, teniendo en cuenta que «este plazo de preaviso no podrá ser inferior a un mes por año de servicio prestado, con un mínimo de tres y un máximo de diez meses» ${ }^{5}$; 2) asimismo cabe el despido libre con preaviso de los denominados «agentes contractuales» ${ }^{6}$, visto que el régimen jurídico de la extinción de sus contratos es idéntico al de los recién citados «agentes temporales» 7 ; y 3 ) en cambio, respecto de los denominados «agentes locales» — contratados para prestar servicios, recuérdese, en Estados no miembros ${ }^{8}$ - , puede caber o no despido libre con preaviso o sin él, visto que el tema de la «rescisión» de sus contratos se determinará «por cada institución sobre la base de la reglamentación y de las costumbres existentes en el lugar [esto es, el Estado tercero] donde el agente sea nombrado para ejercer sus funciones ${ }^{9}$, aunque teniendo en cuenta que «los litigios entre la institución y el agente local que preste sus servicios en un tercer país [por ejemplo, Bolivia, Nigeria o Arabia Saudita] serán sometidos a un arbitraje con arreglo a las condiciones establecidas en la cláusula compromisoria que figure en el contrato del agente» ${ }^{10}$.

Sólo respecto de la extinción ante tempus de los contratos de duración determinada de los agentes «temporales» y «contractuales» se prevé una compensación, pues en este caso

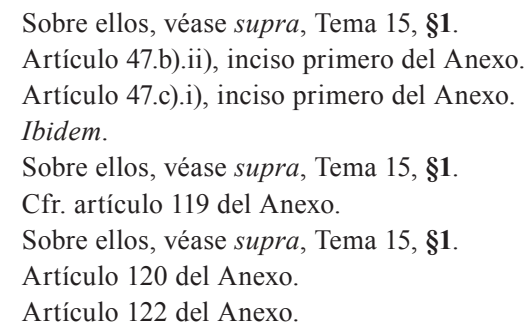


«el agente tendrá derecho a una indemnización igual a la tercera parte de su sueldo base durante el período comprendido entre la fecha en que cese en sus funciones y la fecha de expiración de su contrato» ${ }^{11}$.

La reciente Sentencia del Tribunal de la Función Pública de la Unión Europea (pleno) de 26 octubre $2006^{12}$, a propósito del despido de una «agente temporal» contratada «por tiempo indefinido», rectifica dentro de sus posibilidades esa lamentable regulación comunitaria ad intra ${ }^{13}$. En efecto, rechaza el argumento de la agencia comunitaria demandada («Fundación Europea para la Formación»), relativo a que «no existe... ninguna base legal que la hubiese obligado a motivar la decisión de despido», concluyendo lo siguiente: 1) que «la obligación de motivación constituye un principio esencial del derecho comunitario», que «tiene por objeto hacer posible el control jurisdiccional»; 2) que «el reconocimiento de dicha obligación de motivación a cargo de la autoridad competente no excluye que esta última disponga de un amplio poder de apreciación [del motivo para despedir] y que, por tanto, el poder del juez comunitario esté limitado a la verificación de la ausencia de un error manifiesto o de la desviación de poder»; y 3) en el caso de autos, que «la decisión de despido está viciada por un error manifiesto de apreciación y debe, en consecuencia, ser anulada», existiendo en este caso «en favor del trabajador, un eventual derecho a la readmisión» ${ }^{14}$. Dada la situación jurídica de estos «agentes temporales»—colocados durante la vigencia de su contrato en una situación análoga a la del período de prueba-, se comprende que el Tribunal también afirmase resultar «verdadero que la estabilidad en el empleo inherente a los contratos de duración indeterminada no es comparable a la garantizada por el Estatuto a los funcionarios».

Evidentemente, esta regulación comunitaria ad intra no casa bien con la afirmación de la Carta de los Derechos Fundamentales de la Unión Europea, a propósito de los derechos de solidaridad, previendo que «todo trabajador tiene derecho a protección en caso de despido injustificado, de conformidad con el Derecho de la Unión y con las legislaciones y prácticas nacionales» ${ }^{15}$, aunque en las «explicaciones» relativas a este derecho sólo se mencionaba acervo comunitario en relación con los despidos ante situaciones críticas de las empresas.

§2. En consecuencia, un trabajador alemán contratado como «agente temporal» o «agente contractual» para prestar servicios en la Unión Europea deja de gozar de la protección frente al despido injustificado que poseen los propios trabajadores alemanes. Esta protección está contenida en la «Ley de Protección contra el Despido [Kündigungsschutzgesetz]»

11 Artículo 47.b).ii), inciso último, del Anexo.

12 Asunto F-1/05.

13 La Sentencia declara expresamente aplicable su doctrina a los «agentes temporales... ligados por un contrato de duración determinada», que «son despedidos antes del vencimiento de este último».

14 En este caso, dada la voluntad contraria de la trabajadora a la readmisión, las partes fueron «invitadas... a fijar un acuerdo fijando una compensación pecuniaria equitativa del despido ilegal de la demandante y, a continuación, informar al Tribunal del montante así determinado, o, en defecto de acuerdo, a presentarle sus conclusiones cuantificadas con este propósito, en un plazo de tres meses a contar desde el pronunciamiento de esta sentencia».

15 Artículo 30 (rotulado «Protección en caso de despido injustificado»). Respecto de estas últimas, véase U. ZACHERT, Beendigungstatbestände im internationalen Vergleich. Eine normative und empirische Bestandsaufnahme, Nomos (Baden-Baden, 2004), págs. 9 y ss. 
de $1951^{16}$, que articula el modelo alemán sobre el tema alrededor de tres ideas clave: 1) el trabajador despedido debe accionar ante los Tribunales de Trabajo, siempre «dentro de las tres semanas siguientes a la notificación por escrito del despido» ${ }^{17}$; 2) si su demanda por despido injustificado - que en Alemania se denomina despido «socialmente injustificado»- prospera ${ }^{18}$, entonces el Tribunal de Trabajo siempre declarará que ha habido lo que en España denominaríamos un despido nulo - y en Alemania se denomina despido «jurídicamente ineficaz»—, pues «la extinción de la relación laboral de un trabajador... es jurídicamente ineficaz [rechtsunwirksam], si está socialmente injustificada [sozial ungerechtfertigt]» ${ }^{19}$; y 3) lógicamente, esta declaración de ineficacia del despido comporta la obligación de «readmisión [Weiterbeschäftigung]»del trabajador despedido, si hubiese sido solicitada por él ${ }^{20}$, con pago al mismo de lo que

16 Sobre ella, véase T. BACKMEISTER, W. TRITTIN y U. MAYER, Kündigungsschutzgesetz mit Nebengesetzen, $4^{\mathrm{a}}$ ed., Franz Vahlen (Múnich, 2008), págs. 1 y ss.; M. KITTNER, W. DÄUBLER y B. ZWANZIGER (Editores), KSchR. Kündigungsschutzrecht, $7^{\mathrm{a}}$ ed., Bund (Frankfurt a.M, 2008), págs. 41 y ss.; ROLFS, C., GIESEN, R., KREIKEBOHM, R. y UDSCHING, P. (Editores), Arbeitsrecht, C.H. Beck (Múnich, 2008), págs. 2543 y ss.; y F. BECKER y W. HILLEBRECHT (Fundadores), KR. Gemeinschaftskommentar zum Kündigungsschutzgesetz und zu sonstigen kündigungsschutzrechtlichen Vorschriften, $9^{\mathrm{a}}$ ed., Luchterhand (Colonia, 2009), págs. 1 y ss. Nuestra traducción íntegra de la misma, en J. MARTÍNEZ GIRÓN y A. ARUFE VARELA, Leyes laborales alemanas. Estudio comparado y traducción castellana, Netbiblo (A Coruña, 2007), págs. 168 y ss.

17 Cfr. parágrafo 4.

18 Respecto de lo que en España denominaríamos «causas justas» de despido, la Ley de Protección contra el Despido se limita a indicar casi telegráficamente —remitiendo su concreción a la casuística judicial, anclada para su valoración en el principio denominado de la «ultima ratio»— que «el despido es socialmente injustificado cuando no está condicionado por motivos que se basen en la persona o en la conducta del trabajador [in der Person oder in dem Verhalten des Arbeitsnehmers] o en necesidades empresariales urgentes [dringende betriebliche Erfordernisse], que impidan la recolocación del trabajador en esa empresa» (parágrafo 1, apartado 2, inciso primero). En efecto, esta norma alemana sólo contiene restricciones y matices a propósito de la causa relativa a las citadas «necesidades empresariales urgentes» — de algún modo equivalentes a nuestro despido objetivo económico u organizativo-, cuyo núcleo duro es la afirmación suya acerca de que «si un trabajador ha sido despedido por necesidades empresariales urgentes en el sentido del apartado 2, a pesar de ello el despido es entonces socialmente injustificado cuando el empresario no ha tomado en consideración o no ha tomado en consideración suficientemente en la selección del trabajador la duración de su pertenencia a la empresa, la edad, las cargas familiares y la incapacidad del trabajador» (parágrafo 1, apartado 3, inciso primero). Sobre esta "selección social [Sozialauswahl]», véase K. DÖRNER, S. LUCZAK y M. WILDSCHÜTZ, Handbuch Arbeitsrecht, $4^{\mathrm{a}}$ ed., Luchterhand (Munich, 2004), págs. 1317 y ss.

19 Cfr. parágrafo 1, apartado 1.

20 Sobre el tema, las decisiones judiciales claves y clásicas en Alemania son un Auto (Sala General) del Tribunal Federal de Trabajo de 27 febrero 1985 (referencia 2 AZR 426/04) y dos Sentencias del propio Tribunal de 19 diciembre 1985 (referencia 2 AZR 190/85) y de 8 abril 1988 (referencia 2 AZR 777/87). Nuestra traducción íntegra del recién citado Auto de Sala General, en U. ZACHERT, J. MARTÍNEZ GIRÓN y A. ARUFE VARELA, Los grandes casos judiciales del Derecho alemán del Trabajo. Estudio comparado con el Derecho español y traducción castellana, Netbiblo (A Coruña, 2008), págs. 213 y ss. 
en España llamaríamos salarios de tramitación ${ }^{21}$. Este modelo legal — tan integralmente protector del trabajador injustamente despedido ${ }^{22}$ - posee, sin embargo, una importante limitación de carácter subjetivo, puesto que la Ley alemana de Protección contra el Despido no se aplica — desde 1 enero 2004 - en empresas que tengan «diez o menos trabajadores» ${ }^{23}$. Por el mismo patrón está cortado el modelo italiano de protección contra el despido - construido alrededor del artículo 18 de la Ley núm. 300, de 20 mayo 1970, popularmente denominada «Estatuto de los Trabajadores [Statuto dei lavoratori]» ${ }^{24}$ _, pues en Italia procede la «tutela real [tutela reale]» del puesto de trabajo (y por tanto, la «readmisión [reintegrazione]») frente al «despido injustificado, ineficaz y nulo [licenziamento ingiustificato, inefficace e nullo]» ${ }^{25}$, aunque esta garantía integral sólo se imponga - como regla - al «empleador [no agrícola], empresario y no empresario, que en cualquier sede, establecimiento, filial, oficina o unidad autónoma en la cual ha tenido lugar el despido ocupa en sus dependencias más de quince trabajadores» ${ }^{26}$. Y lo mismo sucede en Portugal, donde la regla general —obrante en el Código del Trabajo de $2009^{27}$ _ es que el

21 Sobre el tema, véase parágrafo 11 (rotulado «Descuento de lo ganado durante la tramitación [Anrechnung auf entgangenen Zwischenverdienst]») de la Ley de Protección contra el Despido, y parágrafo 615 del Código Civil. Al respecto, véase J. MARTÍNEZ GIRÓN, «Las normas estructurales complementarias de la Ley actualmente vigente en Alemania en materia de protección contra el despido», Anuario da Facultade de Dereito da Universidade da Coruña. Revista Jurídica Interdisciplinar Internacional, vol. 10 (2006), pág. 722; y J. MARTÍNEZ GIRÓN, «La readmisión del trabajador despedido en el Derecho alemán del Trabajo», Revista Española de Derecho del Trabajo, núm. 135 (2007), págs. 557 y ss. Acerca de las fuentes alemanas en que se inspiró la originaria regulación española de los salarios de tramitación, véase J. GÁRATE CASTRO, Los salarios de tramitación. Un estudio de las percepciones salariales unidas a la declaración de improcedencia o nulidad del despido, ACARL (Madrid, 1994), págs. 85-86.

22 Aunque en la práctica, muchos despidos de trabajadores alemanes se concilian con el pago al trabajador de una indemnización compensatoria de la extinción, de donde que la doctrina científica alemana califique incluso la Ley de Protección contra el Despido como todo lo contrario de lo que formalmente es: la «Ley de la Indemnización [Abfindungsgesetz]» (cfr. al respecto, con datos estadísticos, A. JUNKER, Grundkurs Arbeitsrecht, $5^{\text {a }}$ ed., C.H. Beck [Múnich, 2006], pág. 224).

23 Cfr. su parágrafo 23, apartado 1.

24 Fundamental, véase L. NOGLER, La regulación de los despidos individuales en la época del equilibrio entre los "principios» constitucionales. Estudio a la luz del ordenamiento italiano (traducción castellana de A. ARUFE VARELA), Netbiblo (A Coruña, 2010), págs. 83 y ss.

25 Al respecto, Sentencia de la Corte Constitucional núm. 41/2003, de 30 enero 2003.

26 Artículo 18, párrafo primero, inciso primero, de la Ley núm. 300 de 1970. El propio artículo 18 continúa afirmando que la garantía en cuestión también se impone al «empleador, empresario y no empresario, que en el ámbito del mismo ayuntamiento ocupa más de quince dependientes..., también si ninguna unidad productiva, individualmente considerada, alcanza tales límites» (párrafo primero, inciso segundo); y «en todo caso, al empleador, empresario y no empresario, que ocupa en sus dependencias más de sesenta trabajadores» (párrafo segundo, inciso primero). Acerca de todo ello, véase G. FAVALLI y F. ROTONDI, Manuale pratico di diritto del lavoro, $2^{\mathrm{a}}$ ed., CEDAM (Padua, 2005), págs. 426 y ss.

27 El antecedente de este precepto, en el primer Código portugués del Trabajo de 2003, fue declarado conforme a la Constitución portuguesa por la Sentencia del Tribunal Constitucional núm. 306/2003, de 25 junio. 
«despido ilícito [despedimento ilícito]» lleva aparejada la «readmisión [reintegração]» del trabajador despedido ${ }^{28}$, aunque «en el caso de microempresa [que es la empresa "que emplea menos de 10 trabajadores"] o de trabajador que ocupe cargo de administración o dirección, el empleador puede requerir del tribunal que excluya la readmisión, con fundamento en hechos y circunstancias que conviertan el regreso del trabajador en gravemente perjudicial y perturbador del funcionamiento de la empresa» ${ }^{29}$.

En este último caso, aparte los salarios de tramitación (genéricamente denominados «compensación [compensação]») ${ }^{30}$, el trabajador portugués tiene derecho a percibir una indemnización compensatoria - fijada por los tribunales del trabajo- de «entre treinta y sesenta días» de retribución por año de antigüedad o fracción ${ }^{31}$, aunque su cuantía «no puede ser inferior a seis meses de retribución base y complementos» ${ }^{32}$.

En Italia, supuesto que no cupiese la citada «tutela real», operaría la denominada «tutela obligacional [tutela obbligatoria]» frente al despido injusto ${ }^{33}$, en cuyo caso - frente al trabajador - «el empresario está obligado... a resarcir el daño pagándole una indemnización [un'indemnità] de importe comprendido entre un mínimo de 2,5 y un máximo de 6 mensualidades de la última retribución global de hecho, teniendo en cuenta el número de dependientes ocupados, las dimensiones de la empresa, la antigüedad en el servicio del trabajador, el comportamiento y las condiciones de las partes» ${ }^{34}$.

En Alemania, respecto de los trabajadores empleados en empresas pequeñas, la protección contra su despido queda confiada por entero a la regulación del tema - muy genérica, todo hay que decirlo- efectuada por el Código Civil, pues — según una Sentencia del Tribunal Federal de Trabajo de 6 febrero $2003^{35}$, que reitera y resume la jurisprudencia alemana, incluso constitucional, sobre el asunto- «allí donde las disposiciones de la Ley de Protección contra el Despido no alcanzan, están protegidos los trabajadores a través de las cláusulas jurídico-civiles generales frente al ejercicio inmoral o de mala fe del derecho relativo al despido por parte del empresario (parágrafos 242 y 138 del BGB)», debiendo tenerse en cuenta que «en el marco de estas cláusulas generales, hay que observar también

28 Cfr. artículo 389.1.

29 Artículo 392.1. Véase A. MONTEIRO FERNANDES, Direito do Trabalho, $15^{\mathrm{a}}$ ed., Almedina (Coimbra, 2010), págs. 602 y ss. En relación con el precedente Código de 2003, P. ROMANO MARTÍNEZ, L.M. MONTEIRO, J. VASCONCELOS, P. MADEIRA DE BRITO, G. DRAY y L. GONÇALVES DA SILVA, Código do Trabalho. Anotado, $4^{\mathrm{a}}$ ed., Almedina (Coimbra, 2005), págs. 708 y ss.; y P. FURTADO MARTINS, «Consequências do Despedimento Ilícito: Indemnização / Reintegração», en el volumen Código do Trabalho. Alguns aspectos cruciais, Principia (Cascais, 2003), págs. 49 y ss.

30 Cfr. artículo 390.

31 Artículo 392.3.

32 Ibidem.

33 Cfr. Sentencia de la Corte Constitucional núm. 41 de 2003, ya citada; también, G. FAVALLI y F.

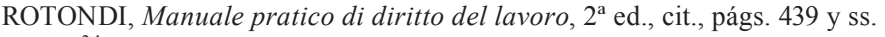

34 Cfr. artículo 8, inciso primero, de la Ley núm. 604, de 15 julio 1966, de «normas sobre los despidos individuales [norme sui licenziamenti individuali]». En este caso, el trabajador carece del derecho a cobrar salarios de tramitación, aunque sí — supuesto que lo extinguido hubiese sido un contrato de trabajo de duración indefinida - los salarios del preaviso extintivo que el empresario hubiese omitido (cfr. Sentencia de la Corte Suprema de Casación [Sección Trabajo] núm. 13380, de 8 junio 2006).

35 Referencia 2 AZR 627/01. 
el contenido objetivo del Derecho Constitucional, aquí ante todo el derivado del Artículo 12, apartado 1, de la Constitución Federal» ${ }^{36}$.

§3. Prosiguiendo con el argumento, si un trabajador francés resulta contratado como «agente temporal» o «agente contractual» al servicio de la Unión Europea, dejaría de gozar de la protección contra el despido que poseen los trabajadores franceses. A diferencia de lo que ocurre en Alemania, la regla general es en Francia que el despido injustificado - conocido doctrinal y jurisprudencialmente con la denominación genérica de «despido irregular [licenciement irregulier] ${ }^{37}$ provoca la extinción del contrato de trabajo con pago al trabajador de una indemnización compensatoria de los daños y perjuicios a él causados, cuyo régimen jurídico - contenido en el Código del Trabajo de 2008 — es distinto, según que lo irregularmente extinguido por el empresario hubiese sido un contrato de trabajo de duración determinada o un contrato de trabajo de duración indefinida. Sólo por excepción, en la hipótesis de lo que el propio Código del Trabajo denomina «despido nulo [licenciement nul] ${ }^{38}{ }^{38}-\mathrm{y}$ también, despido «nulo de pleno derecho [nul de plen droit $] \gg{ }^{39}$ o despido «nulo e ineficaz [nul et de $n u l$ effet $]{ }^{40}$-, lo jurídicamente procedente es decretar la readmisión del trabajador despedido («cuando el despido es nulo, el trabajador tiene derecho a la readmisión [réintegration] en su empleo o, en su defecto, en un empleo equivalente») ${ }^{41}$ y el cobro de salarios de tramitación, con deducción de todo lo que el trabajador hubiese percibido de otros tras su despido.

El «despido nulo» es una institución asistemáticamente regulada en preceptos múltiples del Código francés del Trabajo, respecto de la que la Corte de Casación ha declarado - sin desmentir nunca la regla general de extinción indemnizada del contrato de trabajo por «despido irregular»— que «el juez no puede, en ausencia de una disposición previéndolo

36 Acerca de todos estos preceptos, véase J. MARTÍNEZ GIRÓN, «Las normas estructurales complementarias de la Ley actualmente vigente en Alemania en materia de protección contra el despido», cit., pág. 720, nota 28; y sobre el artículo 12 de la Constitución Federal, M. SACHS (Editor), GG. Grundgesetz

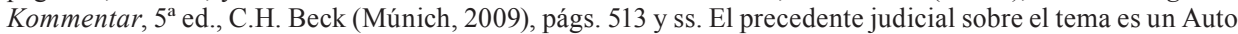
del Tribunal Federal Constitucional de 27 enero 1998 (referencia 1 BVL 15/87). Nuestra traducción íntegra del mismo, en U. ZACHERT, J. MARTÍNEZ GIRÓN y A. ARUFE VARELA, Los grandes casos judiciales del Derecho alemán del Trabajo. Estudio comparado con el Derecho español y traducción castellana, cit., págs. 202 y ss.

37 En la doctrina, por todos, véase J. PÉLISSIER, A. SUPIOT y A. JEAMMAUD, Droit du Travail, $24^{\mathrm{a}}$ ed., Dalloz (París, 2008), pág. 567 y ss. En la jurisprudencia laboral, también por todas, véase Sentencia de la Sala de lo Social de la Corte de Casación de 26 abril 2006 (núm. de recurso 04-44913).

38 Por todos, artículo L. 1225-71.

39 Por todos artículo L. 2511-1.

40 Por todos, artículos L. 1134-4 y L. 1144-3.

41 Por todas, Sentencia de la Sala de lo Social de la Corte de Casación de 30 abril 2003 (núm. de recurso 00-44811). 
[disposition le prévoyant], y en defecto de violación de una libertad fundamental [violation d'une liberté fondamentale], anular un despido» ${ }^{42}$. Los supuestos más típicos de nulidad por disposición legal se refieren al despido individual de «trabajadores protegidos [salariés protégés]» (por ejemplo, representantes legales o sindicales de los trabajadores, cuyo despido requiere de autorización de la Inspección de Trabajo) ${ }^{43}$ y a los despidos equivalentes del típico supuesto español de despido nulo por razones de fondo, que se hallan dispersos (incluso repetidos) en preceptos múltiples del propio Código del Trabajo (por ejemplo, a propósito de los despidos discriminatorios ${ }^{44}$, de los relacionados con el acoso ${ }^{45}$, de los de trabajadores con contrato de trabajo suspendido ${ }^{46}$, o también, a propósito de los despidos represalia por haber ejercitado el trabajador su derecho a la tutela judicial ${ }^{47}$ ). Por su parte, los «despidos nulos» por violación de una libertad fundamental suelen referirse a lo que en España denominaríamos violación de derechos constitucionales «inespecíficos» de los trabajadores, resultando ser el precedente judicial en Francia sobre el tema una Sentencia de la Sala de lo Social de la Corte de Casación de 28 abril $1988^{48}$, relativa a un despido que reprimía el ejercicio de la libertad de expresión del trabajador fuera de la empresa.

En la hipótesis de extinción irregular de un contrato de trabajo de duración determinada, la regla — según el artículo L. 1243-4 del Código del Trabajo — es que el incumplimiento empresarial «da derecho al trabajador a daños y perjuicios [dommages et intérêts] en cuantía al menos igual a las remuneraciones que habría percibido hasta el término del contrato [au moins égal aux rémunérations qu'il aurait perçues jusqu'au terme du contrat], sin perjuicio de la indemnización de fin de contrato prevista en el artículo L. 1243-8». Este último precepto se refiere, a su vez, a que «cuando, a la finalización de un contrato de duración determinada, las relaciones contractuales de trabajo no se continúen por un contrato de trabajo de duración indefinida, el trabajador tiene derecho, a título de complemento del salario, a una indemnización de fin de contrato destinada a compensar la precariedad de su situación [indemnité de fin de contrat destinée à compenser la précarieté de sa situation]». La Corte de Casación ha declarado la incompatibilidad entre la citada indemnización principal y la percepción por el trabajador precario irregularmente despedido de prestaciones por desempleo ${ }^{49}$.

Por lo que respecta al contrato de trabajo clásico de duración indefinida ${ }^{50}$, el artículo L. 1235-5 del Código del Trabajo obliga a distinguir dos supuestos de hecho. El primero se refiere al «despido irregular» de trabajadores fijos «que tengan menos de dos años de antigüedad en la empresa y a los despidos operados por los empresarios que ocupen habitualmente menos de once trabajadores», en cuyo caso los trabajadores irregularmente

42 Sentencia de la Sala de lo Social de la Corte de Casación de 22 febrero 2006 (núm. de recurso 03-46027).

43 Véase supra, Tema 7, §6.

44 Cfr., por ejemplo, artículos L. 1132-1 y L. 1142-1.

45 Cfr., por ejemplo, artículo L. 1152-2.

46 Cfr., por ejemplo, artículo L. 1226-13.

47 Cfr., por ejemplo, artículo L. 1134-4.

48 Núm. de recurso 87-41804.

49 Cfr. Sentencia de la Sala de lo Social de la Corte de Casación de 14 enero 1997 (núm. de recurso 95-13044).

50 Acerca de alguno no clásico (como el «contrato de trabajo de nuevas contrataciones [contrat du travail de nouvelles embauches]», con regulación que vaga fuera del Código del Trabajo, véase X.M. CARRIL VÁZQUEZ, «Breves consideraciones, a la luz del Derecho social de la Unión Europea, sobre las recientes y polémicas medidas de fomento de la contratación indefinida de jóvenes trabajadores en Francia», Anuario da Facultade de Dereito da Universidade da Coruña. Revista Jurídica Interdisciplinar Internacional, vol. 10 (2006), págs. 167 y ss. 
despedidos tienen derecho «a una indemnización correspondiente al perjuicio sufrido [indemnité correspondant au préjudice subi]», habiendo declarado la Corte de Casación — respecto de esta indemnización legalmente indeterminada - que «corresponde al juez apreciar [soberanamente] su extensión» ${ }^{51}$. El segundo se refiere - por contraposición - al caso de «despido irregular» de trabajador fijo con dos años o más de antigüedad en la empresa, o al servicio de empresa que ocupe habitualmente once o más trabajadores, en el que el despedido puede llegar a acumular hasta tres indemnizaciones distintas - minuciosamente fijadas las tres por el Código del Trabajo ${ }^{52}$-, que son: 1) según el artículo L. 1234-9, «una indemnización de despido [indemnité de licenciement]» ${ }^{53}$, cuyo «tope y modalidades se determinan por vía reglamentaria» ${ }^{54}$, habiéndose precisado por esa vía una indemnización variable «calculada por año de servicio en la empresa» ${ }^{55}$, que «no puede ser inferior a un quinto de mes de salario por año de antigüedad» ${ }^{56}$; 2) según el artículo L. 1235-3 —para el caso de que «el despido de un trabajador sobrevenga por una causa que no es ni real ni seria», y supuesto que el empresario «se niega [refuse]» a readmitir, como será normal一, una segunda indemnización ${ }^{57}$, teniendo en cuenta que «esta indemnización ... no puede ser inferior a los salarios de los seis últimos meses [ne peut être inférieure aux salaires des six derniers mois] $]{ }^{58}$, y además, que "se debe sin perjuicio, si es el caso, de la indemnización prevista en el artículo L. 1234-9» ${ }^{59}$, recién citado; y 3) según el artículo L. 1234-5 —para el caso ahora de que el empresario, al despedir irregularmente, también hubiese omitido el plazo de preaviso debido-, otra indemnización complementaria ulterior integrada por los «salarios y ventajas que el trabajador hubiera percibido de haber cumplido su trabajo hasta la expiración del preaviso, incluida la indemnización de permisos retribuidos» ${ }^{60}$, pues — de acuerdo con dicho tercer precepto- «esta indemnización compensatoria del preaviso se acumula con la indemnización de despido» ${ }^{61}$, del citado artículo L 1234-9.

§4. Un trabajador británico contratado como «agente temporal»o «agente contractual» de la Unión Europea tendría, en cambio, un régimen de protección frente al despido injustificado algo más parecido al de los trabajadores británicos, pues el modelo británico de despido es,

51 Cfr. Sentencia de la Sala de lo Social de la Corte de Casación de 25 septiembre 1991 (núm. de recurso $88-41251$ y $88-45660$ )

52 Las que libremente hubiesen podido convenir las partes del contrato de trabajo son rigurosamente acumulables a estas indemnizaciones legales, según una Sentencia de la Sala de lo Social de la Corte de Casación de 28 febrero 2006 (núm. de recurso 04-48280; localizable a través de www.legifrance.gouv.fr), a propósito de la ruptura de un contrato de trabajo que «contenía una cláusula, según cuyos términos, en caso de despido, cualquiera que fuese el motivo, el trabajador percibiría una indemnización igual a dieciocho meses de salario» (cfr. Considerando segundo).

53 Cfr. artículo L. 1234-9, párrafo primero.

54 Ibidem, párrafo segundo.

55 Cfr. artículo R. 1234-1.

56 Cfr. artículo R. 1234-2

57 Párrafo primero, inciso primero.

58 Ibidem, inciso segundo.

59 Ibidem, inciso tercero. Por eso mismo, la Corte de Casación viene afirmando tradicionalmente que «la readmisión de los trabajadores despedidos sin causa real y seria no es posible más que si el empresario no se niega a ello» (cfr. Sentencia de la Sala de lo Social de la Corte de Casación de 4 mayo 1984 [núm. de recurso 82-40001 y 82-40002; localizable a través de www.legifrance.gouv.fr], considerando segundo).

60 Párrafo segundo.

61 Párrafo tercero. 
también y en principio, un modelo de despido libre con preavi s o. En Gran Bretaña, a este modelo tradicional tan poco protector del trabajador (que se remonta a 1827) ${ }^{62}$ se le superpuso en 1971 otro modelo distinto, que dejó intactas las tradiciones británicas, pero que permite - mediante la creación de excepciones legales a la vieja regla tradicional de despido libre con preaviso - accionar al trabajador por «despido ilegal [unfair dismissal] ${ }^{63}$. Este último tipo de despido se encuentra actualmente regulado en la «Ley de Derechos del Empleo [Employment Rights Act]» de $1996^{64}$, según la cual el trabajador — si prosperase su demanda, a ejercitar ante un Tribunal de Empleo ${ }^{65}$ — podría llegar a obtener la condena del empresario: 1) a la «readmisión [reinstatement]» a su antiguo puesto de trabajo, discrecionalmente decretable por el tribunal sentenciador, teniendo en cuenta circunstancias tales como, por ejemplo, los deseos del trabajador actor, si éste contribuyó o no de algún modo a que ocurriese el despido, y si al empresario demandado le resulta o no posible («practicable») cumplir la orden de readmitirlo ${ }^{66}$; 2) a la "recolocación [re-engagement]», también discrecionalmente decretable por el tribunal sentenciador y teniendo en cuenta parecidas circunstancias, pero para que el trabajador ocupe un puesto de trabajo distinto en la misma empresa o para que sea contratado por el sucesor o por un asociado del empresario que lo empleaba ${ }^{67}$; 3) a una «indemnización adicional [additional award]), si el empresario rehusase cumplir las órdenes de readmitir o recolocar decretadas, consistente en el pago al trabajador - como regla — de una cantidad comprendida entre veintiséis y cincuenta y dos semanas de salario ${ }^{68}$; 4) a una «indemnización básica [basic award]», decretable en la misma hipótesis anterior y, en todo caso, si el tribunal no hubiese juzgado pertinente decretar la readmisión o recolocación, calculada sobre la base de la edad y la antigüedad del trabajador - esto es, semana y media de salarios por año de servicios, si el trabajador tuviese cuarenta y un años o más de edad; una semana por cada

62 Véase J. MARTÍNEZ GIRÓN, «El despido en los Estados Unidos e Inglaterra», en el vol. Estudios sobre el despido disciplinario, $2^{\mathrm{a}}$ ed., ACARL (Madrid, 1992), págs. 25-26.

63 Poniendo de relieve que se trata de un despido «contrario a la ley [contrary to statute]», con cita de jurisprudencia inglesa, véase S. HONEYBALL y J. BOWERS, Textbook on Labour Law, $8^{\mathrm{a}}$ ed., Oxford University Press (Oxford, 2004), pág. 146.

64 Más en concreto, en sus secciones 94 a 132.

65 «Antes de que finalice el período de tres meses a contar desde la fecha de efectividad de la extinción» (cfr. sección 111).

66 Cfr. secciones 114 y 116(1).

67 Cfr. secciones 115 y $116(2)$ y (3).

68 Cfr. sección 117. 
año de servicios, si tuviese entre veintidós y cuarenta; y media semana por cada año de servicios, si tuviese menos de veintidós-, todo ello sin que puedan computarse más de veinte años de servicios a la empresa ${ }^{69}$; y 5) a una «indemnización compensatoria [compensatory award]», que comprende «los gastos razonablemente efectuados por el demandante como consecuencia del despido»y, también, «la pérdida de toda ventaja a que el demandante razonablemente hubiera podido aspirar, de no haber sido por el despido» ${ }^{70}$.

La citada Ley de Derechos del Empleo confirma la vigencia del modelo tradicional británico, estableciendo tres plazos de preaviso para — en principio - poder despedir libremente, a saber: 1) «una semana, si el período de empleo continuo [del trabajador] es inferior a dos años»; 2) «una semana por cada año de empleo continuo, si el período de empleo continuo es de dos años o más, pero menos de doce años»; y 3) «doce semanas, si el período de empleo continuo es de doce años o más» ${ }^{71}$.

Sobre esta base, el despido es «legal», según la propia Ley, si el empresario logra probar un «motivo [reason]» para despedir «relacionado con la capacidad o las cualificaciones del trabajador para ejecutar el tipo de trabajo para el cual su empresario le haya contratado», «relacionado con la conducta del trabajador», si «es la jubilación de trabajador» o que el trabajador era personal «sobrante [redundant]», o basado en que «el trabajador no podía continuar trabajando en el puesto que ocupase sin contravención (suya o de su empresario) de una obligación o prohibición impuesta por disposición legal o en virtud de ella» ${ }^{72}$. En cambio, es presuntivamente «ilegal» el despido a que se refieren «las secciones $98 \mathrm{~A}$ a 107 de esta Ley» (esto es, despidos discriminatorios, despidos represalia, etc.) o, también, el «despido basado en la afiliación sindical o por actividades o en conexión con una acción industrial» (esto es, huelgas, etc. $)^{73}$.

Al trabajador británico despedido - pero no cubierto por la Ley de Derechos del Empleo, cosa que ocurre, por ejemplo, si no ha estado continuadamente al servicio de la empresa «por un período de no menos de un año» ${ }^{74}$ — también le cabe la posibilidad de accionar por «despido injusto [wrongful dismissal]» — pero no ante los Tribunales de Empleo, sino ante las Cortes ordinarias de Derecho común-, siempre y cuando hubiese mediado extinción ante tempus de un contrato de trabajo de duración determinada o, también, extinción sin preaviso de un contrato de trabajo de duración indefinida ${ }^{75}$.

§5. Siempre en materia de protección frente al despido injustificado, el Derecho de los Estados Unidos de Norteamérica resulta aparentemente

69 Cfr. sección 119.

70 Cfr. sección 123.

71 Acerca de todo esto, cfr. sección 86(1).

72 Cfr. sección 98(2).

73 Acerca de todo esto, cfr. sección 98(6).

74 Cfr. sección 108(1).

75 Sobre el tema, véase N.M. SELWYN, Law of Employment, $13^{\text {a }}$ ed., LexisNexis-Butterworths (Londres y Edimburgo, 2004), págs. 367 y ss.; y S. HONEYBALL y J. BOWERS, Textbook on Labour Law, 8 ed., cit, págs. 66 y ss. 
más odioso para el trabajador que el Derecho que la Unión Europea aplica a su propio personal laboral, puesto que el modelo norteamericano de despido es un modelo de despido libre puro, en el que el empresario ni siquiera está obligado a observar ningún tipo de preaviso ${ }^{76}$. Ahora bien, sobre esta base, es justo poner de relieve que en los Estados Unidos existen excepciones a la regla general del despido libre - la Administración federal norteamericana abolió incluso en 1978, respecto de sus trabajadores, la odiosa regla en cuestión ${ }^{77}$-, explicitadas en las leyes federales y estatales (y en la jurisprudencia federal y estatal), mientras que en el anexo del citado Reglamento núm. 31 (CEE), 11 (CEEA) de 1962, allí donde establece el estatuto jurídico de los «agentes temporales», «agentes contractuales» y demás, no aparece ni una sola referencia expresa a la prohibición de la discriminación (ni siquiera, aunque parezca increíble, a la prohibidísima en toda Europa discriminación por razón de sexo), limitándose a afirmar — se supone que, para guardar las apariencias de lo que hoy suele considerarse políticamente correcto- que «toda referencia contenida en el presente régimen [que consta de más de un centenar de artículos] a personas de sexo masculino se entenderá como hecha igualmente a personas de sexo femenino, y a la inversa [sic], salvo que el contexto indique claramente lo contrario» ${ }^{78}$. Y además, frente al entreguismo de la Unión Europea con sus «agentes locales» - dejados al albur en materia de despido, recuérdese, de «la reglamentación y de las costumbres existentes en el lugar donde el agente sea nombrado para ejercer sus funciones ${ }^{79}$-, que la legislación federal norteamericana antidiscriminatoria (orientada a impedir también en los Estados Unidos, como es lógico, la existencia de despidos discriminatorios y despidos represalia) tiene carácter extraterritorial (y obliga, en consecuencia, a los

76 Véase J. MARTÍNEZ GIRÓN, El despido en el Derecho de los Estados Unidos, Civitas (Madrid, 1988), págs. 33 y ss. Doctrinalmente, todavía se defiende con vigor este modelo, como en el caso, por ejemplo, de R.A. EPSTEIN, «In Defense of the Contract at Will», en D.L. GREGORY (Editor), Labour Law, Dartmouth (Aldershot, 1993), págs. 55 y ss.

77 Aunque en términos más light que propiamente hard o heavy, disponiendo en la actualidad la sección 7513(a) del Título 5 del Código de los Estados Unidos que «de acuerdo con los reglamentos emanados por la Oficina de Dirección de Personal, una agencia puede llevar a cabo una acción cubierta por este subcapítulo [sobre "Destitución, suspensión por más de 14 días, reducción del grado o sueldo, y permiso por 30 días o menos"] contra un trabajador sólo por una causa que mejore la eficiencia del servicio [only for such cause as will promote the efficiency of the service]».

78 Cfr. artículo 1. Respecto de los funcionarios, su «estatuto» reproduce esta misma regla (cfr. artículo 1 quater), pero completada — en términos jurídicamente irreprochables - con las antidiscriminatorias de sus artículos 1 quinquies y 12bis.

79 Véase supra, \$1. 


\section{empresarios norteamericanos a cumplirla, también fuera del territorio de los Estados Unidos) ${ }^{80}$.}

En los Estados Unidos, se habla de «contratación a voluntad [hiring at will]», pero no de «despido libre», para aludir a la situación - frecuentísima - en que se encuentran trabajador y empresario cuando no existe pacto que limite la duración del contrato de trabajo ${ }^{81}$. En este caso - que es justamente el del contrato de trabajo por tiempo «indefinido»-, cada parte puede rescindirlo lícitamente en cualquier momento, aunque no tenga ninguna justa causa para hacerlo. Se trata de una institución nacida cuando el país estaba empeñado en la colonización del Oeste, y que la Corte Suprema de los Estados Unidos juridificó en 1908 (caso Adair v. United States) y 1915 (caso Coppage v. Kansas), habiendo confirmado su vigencia - a propósito del empleo público estatal- en el caso Engquist v. Oregon Department of Agriculture et al. (2008) ${ }^{82}$.

Aparte sus excepciones legales (por ejemplo, despidos por causa de raza, edad o afiliación sindical) — sólo aplicables en empresas que no sean pequeñas ${ }^{83}$ - y jurisprudenciales (por ejemplo, despidos contrarios al orden público), la regla de la «contratación a voluntad» cuenta con importantes excepciones convencionales. Estas últimas están representadas especialmente por todos aquellos convenios colectivos en los que se pacta - cosa frecuente en los Estados Unidos - que el trabajador comprendido en su ámbito de aplicación sólo podrá ser despedido por «justa o buena causa [just or good cause]». En este caso, el trabajador despedido puede demandar al empresario por incumplimiento de convenio colectivo (al amparo, en el plano federal, de lo dispuesto en la sección 301 de la llamada Ley Taft

80 Sobre esto, véase J. MARTÍNEZ GIRÓN, «La regulación de la "defensa de "leyes extranjeras'” en la legislación laboral antidiscriminatoria de los Estados Unidos», Actualidad Laboral, núm. 10 (2007), págs. 1190 y ss.; y A. ARUFE VARELA, «La aplicación judicial de la "defensa de 'leyes extranjeras'" regulada en la legislación laboral antidiscriminatoria de los Estados Unidos», Actualidad Laboral, núm. 9 (2007), págs. 1075 y ss.

81 Véase supra, Tema 15, §5.

82 Acerca de todo esto, véase J. MARTÍNEZ GIRÓN, El despido en el Derecho de los Estados Unidos, cit., págs. 127 y ss.; A. ARUFE VARELA, «El voto particular del Juez Oliver Wendell Holmes, Jr. en el caso Coppage v. Kansas (1915). Un texto jurídico norteamericano clásico contra el despido libre», Anuario Coruñés de Derecho Comparado del Trabajo-ACDCT, vol. I (2009), págs. 13 y ss.; y J. MARTÍNEZ GIRÓN, «El caso Engquist v. Oregon Department of Agriculture et al. (2008). La última palabra de la Corte Suprema de los Estados Unidos en favor del despido libre», Anuario Coruñés de Derecho Comparado del Trabajo-ACDCT, vol. II (2010), págs. 59 y ss. El tema sigue de actualidad plena en la literatura jurídica norteamericana. Al respecto, véase P.J. STRELITZ, A.M. AVILES y D. WALTER, «Employment-at-will: has the death knell officially sounded», International HR Journal, núm. 17 (2008), págs. 3 y ss.; y K. R. SWIFT, «The public policy exception to employment at-will: time to retire a noble warrior», Mercer Law Review, núm. 61 (2010), págs. 551 y ss.

83 Véase R. CARLSON, «The small firm exemption and the single employer doctrine in employment discrimination Law», St. John's Law Review, vol. 80 (2006), págs. 1197 y ss. El tema se explica, de un lado, por la falta de ratificación por los Estados Unidos de los Convenios antidiscriminatorios de la OIT (cfr. S. CHARNOVITZ, «The ILO Convention on Freedom of Association and its future in the United States», American Journal of International Law, núm. 102 [2008], págs. 98 y ss.), a diferencia de la ratificación sistemática por España de todo el material normativo de la OIT (cfr. R.M ${ }^{a}$ RODRÍGUEZ MARTÍNRETORTILLO, «Convenio OIT núm. 187/2006, sobre el marco promocional para la seguridad y salud en el trabajo: razones de su previsible ratificación por España», Actualidad Laboral, núm. 5 [2009], págs. 2 y ss.); y de otro lado, por las reservas norteamericanas a la hora de ratificar los Pactos antidiscriminatorios de la ONU (cfr. J.H. STONE, «The International Covenant on Civil and Political Rights and the United States reservations: the American conception of International human rights», U.C. Davis Journal of International Law and Policy, núm. 7 [2001], págs. 1 y ss.; y K. ASH, «U.S. reservations to the International Covenant on Civil and Political Rights: credibility maximization and global influence», Northwestern University Journal of International Human Rights, núm. 3 [2005], págs. 7 y ss.). 
Hartley de 1947), cabiendo que pretenda la condena a su «readmisión [reinstatement]» en la empresa, con pago de «salarios de tramitación [backpay]» ${ }^{84}$.

El Estado noroccidental de Montana, con una extensión territorial idéntica a la de Alemania pero con una población que ni siquiera alcanza el millón de habitantes, abolió en 1987 la institución de la «contratación a voluntad». En el Código de este Estado (que contiene su Constitución y todas sus leyes), accesible en Internet a través de http://leg. mt.gov, el tema aparece regulado en la Parte 9 (rotulada «Despido injusto del empleo [Wrongful discharge from employment]» del Capítulo 2 (rotulado «La relación de empleo [The employment relationship]» de su Título 39 (rotulado «Trabajo [Labor]». Según esta regulación estatal, «un despido es injusto solamente si: (a) fue en represalia por la negativa del trabajador a violar el orden público [public policy] o por informar de una violación del orden público; (b) el despido no fue por buena causa [was not for good cause] y el trabajador había completado el período de prueba del empresario; o (c) el empresario violó disposiciones expresas de su propia política escrita de personal [own written personnel policy]» ${ }^{85}$.

84 Acerca de todo esto, J. MARTÍNEZ GIRÓN, El despido en el Derecho de los Estados Unidos, cit., págs. 103 y ss.

85 Sección 39-2-904, apartado (1). 


\section{TEMA 20 \\ LOS ACCIDENTES DE TRABAJO IN ITINERE EN EL ORDENAMIENTO COMUNITARIO, EN LAS LEGISLACIONES Y PRÁCTICAS NACIONALES EUROPEAS, Y EN LA LEGISLACIÓN DE LOS ESTADOS UNIDOS}

Sumario: §1. En las legislaciones española y comunitaria. §2. En las legislaciones continentales europeas. §3. En las legislaciones norteamericana y británica.

THEME 20

THE IN ITINERE ACCIDENTS AT WORK IN THE EUROPEAN LAW, IN THE NATIONAL EUROPEAN LEGISLATIONS AND PRACTICES, AND IN THE LEGISLATION OF THE UNITED STATES

Contents: $\$ 1$. In the Spanish and Community legislations. $\$ 2$. In the continental European legislations. $\$ 3$. In the USA and British legislations.

§1. Los accidentes de trabajo in itinere aparecen legalmente definidos, en España, con sólo muy pocas palabras, que son las catorce palabras siguientes: «los que sufra el trabajador al ir o al volver del lugar de trabajo» ${ }^{1}$. Se trata de una definición legal que se remonta al año 1966 - aunque su tenor actual sea el fruto de una ilegalidad flagrante, cometida en 1974-, pareciendo evidente hoy que las catorce palabras que utiliza han envejecido mal con el transcurso del tiempo - a pesar de resultar coincidentes, casi al pie de la letra, con las de la definición del ordenamiento comunitario,

1 Artículo 115, apartado 2.a), de la vigente Ley general de Seguridad Social de 1994. Esta misma Ley reputa igualmente accidentes de trabajo, en relación con los trabajadores que desempeñen cargos electivos de carácter sindical, «los ocurridos al ir o al volver del lugar en que ejerciten las funciones propias de dichos cargos» [artículo 115, apartado 2.c)]. En la misma línea lacónica, el Estatuto del Trabajo Autónomo (aprobado por la Ley 20/2007, de 11 julio) afirma — respecto de los trabajadores autónomos económicamente dependientes - que se considera «accidente de trabajo el que sufra el trabajador al ir o volver del lugar de la prestación de la actividad, o por causa o consecuencia de la misma» (artículo 26, apartado 3, párrafo segundo). 
contenida en el novísimo Reglamento (CE) núm. 987/2009 del Parlamento Europeo y del Consejo de 16 septiembre 2009, por el que se adoptan las normas de aplicación del Reglamento (CE) núm. 883/2004, sobre la coordinación de los sistemas de Seguridad Social («accidente ocurrido durante el desplazamiento hacia o desde el trabajo») ${ }^{2}$ - , pues la realidad social del siglo XXI es muy distinta de la que existía, en España y en Europa, a mediados del pasado siglo $\mathrm{XX}^{3}$. En efecto, se trata de una realidad social caracterizada, entre otras varias cosas, por la necesidad imperiosa de conciliar la vida laboral y familiar (¿es accidente de trabajo el ocurrido en el trayecto casa-guardería o colegio-lugar de trabajo?), por miramientos medioambientales y de ahorro energético ( $i \mathrm{y}$ si el accidente ocurre, por ejemplo, a varios trabajadores que se habían puesto de acuerdo para desplazarse, en un solo coche particular, al mismo lugar de trabajo?) y por la existencia de una nueva cultura prevencionista de riesgos laborales e, incluso, comunes ${ }^{4}$ (¿resulta verdaderamente imposible, como piensan tantos y tantos prevencionistas españoles, prevenir que ocurra este concretísimo tipo de accidentes de trabajo?). Nada de esto se tiene en cuenta por dicha telegráfica definición legal española — la comunitaria, en cambio, no tendría por qué esforzarse en afinar más-, a diferencia de lo que sucede en otros países de nuestro entorno más próximo, que consideramos iuscomparativamente significativos ${ }^{5}$. Y el hecho se agrava, por causa de la aparente incapacidad de la Sala de lo Social de nuestro Tribunal Supremo para adaptar el escueto concepto legal en cuestión a la nueva realidad social del tiempo en que tiene que ser aplicado.

Así, unificando doctrina, nuestro Tribunal Supremo - que antijurídicamente impone el «domicilio» como contrapunto del «lugar de trabajo», a pesar del completo silencio legal sobre dicha exigencia - no ha considerado accidentes de trabajo in itinere supuestos de hecho como los siguientes: 1) el relativo a un trabajador que «trabajó hasta el día 31-12-2001 y sobre las 5.20 horas del día 1-1-2002, cuando tras haber visitado a sus padres — quienes

Cfr. artículo 34.3.

Al respecto, véase A. ARUFE VARELA, «La regulación del accidente de trabajo en dos ordenamientos novísimos y codificados de seguridad social: Francia y Alemania», CEF. Trabajo y Seguridad Social, núms. 305-306 (2008), págs. 133-134 (Extracto y Sumario; texto íntegro en versión digital, disponible en www.ceflegal.com, al que remiten dichas páginas).

4 Respecto de esto último, véase J. MARTÍNEZ GIRÓN y A. ARUFE VARELA, «De la prevención de riesgos laborales a la emergente generalización de la prevención de riesgos comunes. A propósito del Reglamento de "Seguridad de la Prueba" de la Federación Inglesa de Orientación», Anuario da Facultade de Dereito da Universidade da Coruña. Revista Jurídica Interdisciplinar Internacional, vol. 13 (2009), págs. 415 y ss.

Fundamental desde la perspectiva del Derecho de la Seguridad Social, véase D. PIETERS, «Reflexiones sobre la metodología de la comparación en Derecho de la Seguridad Social» (traducción castellana de J. MARTÍNEZ GIRÓN), Anuario Coruñés de Derecho Comparado del Trabajo-ACDCT, vol. II (2010), págs. 103 y ss. 
residen en Valladolid...-... conducía el vehículo ... en dirección a Madrid para reincorporarse a las 7.00 horas a su puesto de trabajo, el vehículo se salió de forma suave y progresiva, por el margen derecho de la autovía ... donde chocó con el poste metálico de sujeción de una señal vertical ... volcando definitivamente ..., [a resultas de lo cual] se emitió dictamen propuesta por el EVI proponiendo la calificación del trabajador como incapacitado permanente en el grado de gran invalidez» ${ }^{6}$; ó 2) el referente a que «la actora volvía de la consulta de la matrona en el ambulatorio a la empresa», a que «había obtenido autorización para ello de la empresa», a que «se encontraba embarazada y tenía cita con la matrona para la vigilancia del desarrollo del embarazo», y por último, a que «colisiona con su moto contra un camión»?

La ilegalidad flagrante aludida se refiere al hecho de que «la primera Ley general de Seguridad Social de 1966, al proceder a definir los accidentes de trabajo in itinere, afirmaba que eran tales "los que sufra el trabajador al ir o al volver del lugar de trabajo, siempre que concurran las condiciones que reglamentariamente se determinen", pero esta remisión a normas reglamentarias fue suprimida [a pesar de tratarse de un mero texto refundido] por nuestra segunda Ley general de Seguridad Social de 1974»» ${ }^{8}$.

Lógicamente, el ordenamiento comunitario «ad extra» no puede ir más allá en este tema ${ }^{9}$, pues — aparte su naturaleza meramente coordinadora, pero no armonizadora, de las legislaciones nacionales sobre Seguridad Social - opera en un contexto caracterizado por el hecho de que no todos los Estados miembros ni siquiera prevén una protección social específica del accidente de trabajo ${ }^{10}$.

§2. En los países del continente europeo que consideramos iuscomparativamente más significativos, resultaría inconcebible trazar el régimen legal del accidente de trabajo in itinere con semejante penuria de palabras, supuesto que pretendiese tener en cuenta - como parece lógico - la realidad social del tiempo en que trabajamos, nos movemos y vivimos. Por ello, la legislación italiana ${ }^{11}$ se ve obligada a emplear — en su italiano original — varios cientos de palabras, aceptando que el accidente in itinere («infortunio in itinere») incluya, por ejemplo, el sufrido «durante el normal recorrido que une dos lugares de trabajo, si el trabajador mantiene varias relaciones laborales, y, cuando no exista un servicio de comedor de empresa, durante el normal recorrido de ida y regreso del lugar de trabajo al de consumo habitual de las comidas».

6 Cfr. Sentencia de la Sala de lo Social del Tribunal Supremo de 19 enero 2005 (recurso de casación para la unificación de doctrina núm. 6543/2003).

7 Cfr. Sentencia de la Sala de lo Social del Tribunal Supremo de 10 diciembre 2009 (recurso de casación para la unificación de doctrina núm. 3816/2008).

8 Véase J. MARTÍNEZ GIRÓN, A. ARUFE VARELA y X.M. CARRIL VÁZQUEZ, Derecho de la Seguridad Social, $2^{\mathrm{a}}$ ed., Netbiblo (A Coruña, 2008), pág. 60.

9 En su vertiente «ad intra», el «Estatuto de los Funcionarios» contenido en el Reglamento núm. 31 (CEE), núm. 11 (CEEA) de 1962, no hace ni una sola referencia al accidente de trabajo in itinere.

10 De ahí que el citado Reglamento (CE) núm. 883/2004 parta, en ocasiones, de la hipótesis de que «si en el Estado miembro donde el interesado resida o efectúe una estancia no existe un seguro contra los accidentes de trabajo o las enfermedades profesionales...» (cfr. artículo 40).

11 Sobre el tema, véase J. GÁRATE CASTRO, «Consideraciones, desde el Derecho español, sobre el daño producido con ocasión del trabajo como elemento del concepto italiano de accidente de trabajo», Anuario Coruñés de Derecho Comparado del Trabajo-ACDCT, vol. I (2009), págs. 60-63. 
Lo mismo ocurre en la novísima legislación portuguesa - que entró en vigor, respecto de este tema, el 1 enero 2010 - , pues además de en los dos supuestos italianos recién mencionados, también considera accidente de trabajo «en el trayecto [no trajecto] de ida para el lugar de trabajo o de regreso de éste», entre otros varios, el ocurrido al trabajador «entre su residencia habitual u ocasional [residência habitual ou ocasional] y las instalaciones que constituyen su lugar de trabajo». Por su parte, la legislación alemana constituye el paradigma de sensibilidad respecto de la necesidad de conciliar a estos concretos efectos la vida laboral y familiar ${ }^{12}$, al considerar actividades aseguradas $-\mathrm{y}$ por tanto, verdadero accidente de trabajo in itinere ( $($ Wegunfall $\gg)$ - entre otras varias (por ejemplo, la de «utilizar un vehículo conjuntamente con otros trabajadores o asegurados [gemeinsam ein Fahrzeug zu benutzen]»), también «el recorrido del trayecto distinto del trayecto directo hacia y desde el lugar de la actividad», con la finalidad de «confiar los hijos de los asegurados ... que viven en el hogar conjuntamente con ellos a custodia ajena [fremder Obhut], por causa de la actividad profesional suya, de su cónyuge o de su conviviente de hecho». En fin, la legislación francesa ${ }^{13}$-aparte su referencia expresa a algunos de los supuestos de hecho tenidos en cuenta expresamente en algunas de las legislaciones ya citadas («entre ... cualquier otro lugar [distinto de la residencia principal o de la residencia secundaria] donde el trabajador vuelva de manera habitual por motivos de orden familiar, y el lugar de trabajo»; «este trayecto puede no ser el más directo cuando el regreso efectuado se vuelva necesario en el marco de un vehículo regularmente compartido [d'un covoiturage regulier]») - constituye el paradigma prevencionista de los «accidentes de trayecto [accidents de trajet]», pues permite la denominada «rebaja [de cotizaciones] por trayecto [ristourne trajet]» ${ }^{14}$, supuesto que el empresario llegue a adoptar medidas preventivas de los mismos [tales como, por ejemplo, «el transporte colectivo del personal organizado o financiado por la empresa, la planificación de los horarios, eventualmente con separación de acuerdo con las empresas de los alrededores, la jornada continua con restaurante de empresa o refectorio, el acondicionamiento de los accesos a

12 Véase A. ARUFE VARELA, «La regulación del accidente de trabajo en dos ordenamientos novísimos y codificados de Seguridad Social: Francia y Alemania», cit.

13 Sobre ella, ibidem.

14 Los pormenores del tema fueron regulados, hace ya más de treinta años, en una Orden Ministerial (Arrêté) de 19 septiembre 1977 (al respecto, véase Code de la Sécurité Sociale, 30ª ed., Dalloz [París, 2006], págs. 317-318, a propósito del artículo L. 242-7 del propio Código). 
la empresa o la participación financiera en tales acondicionamientos (pasarelas, pasos subterráneos, luces de señalización, alumbrado, indicadores, etc), la verificación del estado mecánico de los vehículos de transporte del personal, acciones diversas de formación e información, principalmente a favor de la reducción de los accidentes de circulación»].

Esta información aparece pedagógicamente publicitada en los sitios web de las diversas Cajas Regionales francesas del Seguro de Enfermedad (por ejemplo, en la de Languedoc-Rousillon) ${ }^{15}$.

En Italia, el accidente de trabajo in itinere aparece regulado en el Decreto del Presidente de la República núm. 1124 de 30 junio 1965, aprobando el «Texto único de las disposiciones para el aseguramiento obligatorio contra los accidentes de trabajo y las enfermedades profesionales [Testo unico delle disposizioni per l'assicurazione obbligatoria contro gli infortuni sul lavoro e le malattie professionali]», artículos 2 y 210; en Portugal, en la Ley núm. 98/2009, de 4 septiembre, que «Reglamenta el régimen de reparación de accidentes de trabajo y de enfermedades profesionales [Regulamenta o regime de reparação de acidentes de trabalho e de doenças profissionais], incluyendo la rehabilitación y readmisión profesionales, en los términos del artículo 284 del Código del Trabajo, aprobado por la Ley núm. 7/2009, de 12 de febrero», artículos 9.1.a) y 9.2; en Alemania, en el Libro Séptimo de su Código de Seguridad Social (rotulado «Seguro legal del accidente [Gesetzliche Unfallversicherung]», parágrafo 8, apartado 2, números 1 a 4; y en Francia, en su Código de Seguridad Social, artículo L. 411-2.

En Francia, además, su Código de Seguridad Social establece dos regímenes de cotización distintos para los accidentes de trabajo en el tajo y para los accidentes de trabajo in itinere, aunque en el Título Cuarto (rotulado «Recursos [Ressources]») del Libro II de la Parte Reglamentaria secundaria del mismo ${ }^{16}$.

§3. En este concreto punto, la tradición anglosajona es rigurosamente antitética de la continental europea, pues se ajusta a la idea de que el empresario sólo debe seguridad a sus trabajadores dentro de lo que dominicalmente controla, que son única y exclusivamente las instalaciones de su empresa. Por eso, en los Estados Unidos de Norteamérica, la regla general (denominada «regla "de ir y volver" ["going and coming" rule]») es la de desprotección del accidente de trabajo in itinere, al considerarse que se trata de un accidente que no «ocurre con ocasión o por consecuencia del trabajo [arising out of, or in the course of, employment] ${ }^{17}$. Y lo mismo cabe afirmar de la legis lación británica, en la que el accidente in itinere sólo se protege a título de excepción, indicando en

15 Cfr. www.cram-lr.fr/static/telecharge/entreprises/ristourne_trajet.pdf.

16 Cfr., especialmente, los artículos D. 242-6-3 y D. 242-6-4.

17 Sobre el tema, véase J. MARTÍNEZ GIRÓN, «El accidente de trabajo en el Derecho de los Estados Unidos de Norteamérica y en el de la Unión Europea», en E. BORRAJO DACRUZ (Director), Accidentes de Trabajo y Mutuas, La Ley-FREMAP (Madrid, 2008), págs. 739 y ss. 
Gran Bretaña el precepto regulador de este tema (significativamente rotulado «Asalariado viajando en transporte del empresario [Earner travelling in employer's transport]»), con una redacción relativamente endiablada, que «el accidente ocurrido cuando el asalariado empleado está viajando como pasajero en un vehículo a, o desde, su lugar de trabajo, con permiso expreso o implícito de su empresario, con independencia de que no tenga el deber empresarial de viajar en ese vehículo, se considerará ocurrido con ocasión o por consecuencia de su trabajo», siempre y cuando «se considerase que el accidente habría ocurrido así, de haber estado sujeto a dicha obligación», o también, cuando «en el momento del accidente, el vehículo ... estaba siendo manejado por o en nombre de su empresario, o por otra persona a quien se hubiese designado en cumplimiento de acuerdos estipulados con su empresario ... y ... no estaba siendo manejado en el curso ordinario de un servicio público de transporte».

En los Estados Unidos, la legislación reparadora de accidentes de trabajo no se considera legislación de Seguridad Social, apareciendo contenida en Leyes de los diversos Estados federados, usualmente denominadas Leyes sobre «indemnización de trabajadores [workers' compensation]», cuyo conjunto resulta fácilmente accesible en Internet a través del portal del Ministerio de Trabajo de los Estados Unidos, ubicado en www.dol.gov ${ }^{18}$.

La Ley federal norteamericana de Salud y Seguridad en el Trabajo de 1970 —norma meramente prevencionista de los riesgos laborales ${ }^{19}$ — alude a toda esa legislación estatal, afirmando que «Nada será interpretado en esta Ley para derogar o afectar de cualquier modo a cualquier Ley de indemnización de trabajadores [any workmen's compensation law] o para ampliar o reducir, o afectar de cualquier otro modo, al Derecho común sobre derechos, deberes o responsabilidades legales de empresarios y trabajadores, al amparo de cualquier Ley relativa a lesiones, enfermedades o muerte de trabajadores por consecuencia, o con ocasión, del trabajo» ${ }^{20}$.

El precepto británico citado es la sección 99 de la «Ley de Cotizaciones y Prestaciones de Seguridad Social [Social Security Contributions and Benefits Act]» de 1992, incluido en la Parte V de la propia Ley (rotulada «Prestación por Lesiones Industriales [Benefit for Industrial Injuries]»).

18 Buscando el tópico «Workers Compensation» en «Find it! By Topic», y yendo luego a «state workers' compensation board».

19 Sobre ella, véase supra, Tema 16, §3.

20 Cfr. su sección 4(b)(4). 
TEMA 21

EL PRINCIPIO DE AUTOMATICIDAD DE LAS PRESTACIONES DE

SEGURIDAD SOCIAL EN EL ORDENAMIENTO COMUNITARIO, EN LAS LEGISLACIONES Y PRÁCTICAS NACIONALES

EUROPEAS, Y EN LA LEGISLACIÓN DE LOS ESTADOS UNIDOS

Sumario: §1. La automaticidad de las prestaciones de seguridad social, desde el punto de vista del ordenamiento español. \$2. Los modelos continentales europeos (italiano y portugués) de automaticidad de las prestaciones de seguridad social, basada en el principio de responsabilidad empresarial. §3. Los modelos continentales europeos (francés y alemán) de automaticidad de las prestaciones de seguridad social, no basada en el principio de responsabilidad empresarial. §4. Los modelos británico y norteamericano de falta de automaticidad de las prestaciones de seguridad social, aun en caso de responsabilidad empresarial. §5. El Derecho de la Unión Europea sobre el tema, en sus vertientes ad extra y ad intra.

\begin{abstract}
THEME 21
THE PRINCIPLE OF AUTOMATIC PAYMENT OF SOCIAL SECURITY BENEFITS IN THE EUROPEAN LAW, IN THE NATIONAL EUROPEAN LEGISLATIONS AND PRACTICES, AND IN THE LEGISLATION OF THE UNITED STATES

Contents: $\$ 1$. The automatic payment of social security benefits, from the viewpoint of the Spanish Law. \$2. The European continental (Italian and Portuguese) models of automatic payment of social security benefits, based on the principle of the employer liability. \$3. The European continental (French and German) models of automatic payment of social security benefits, not based on the principle of the employer liability. $\$ 4$. The British and USA models of lacking of automatic payment of social security benefits, even in the case of employer liability. \$5. The Law of the European Union about the subject-matter, in its ad extra and ad intra sides.
\end{abstract}

§1. En España, la expresión «automaticidad de las prestaciones de seguridad social»-que es incluso una expresión legal- se utiliza por nuestra jurisprudencia laboral para aludir a uno de los principios cardinales de ordenación de las responsabilidades relativas a las prestaciones de seguridad social, cuya mecánica — concebida para 
favorecer al beneficiario de prestaciones contributivas, evitándole tener que pleitear contra el empresario- es bien sencilla, a saber: 1) en caso de responsabilidad empresarial en orden a las prestaciones (por falta de cumplimiento de los deberes instrumentales de afiliar, dar de alta o cotizar), las entidades gestoras o colaboradoras en la gestión de las prestaciones de que se trate le anticipan al beneficiario el pago de las mismas; 2) tras esto, dichas entidades se subrogan en los derechos y acciones que pudiese tener el beneficiario afectado contra el empresario responsable; y 3) como consecuencia de tal subrogación y al efecto de poder resarcirse, las entidades subrogadas podrán utilizar frente al empresario las mismas vías procedimentales o procesales que hubiese debido seguir el beneficiario para la efectividad del derecho y de la acción objeto de subrogación ${ }^{1}$. Dada la importancia del principio - que acabamos de calificar, recuérdese, como principio «cardinal» del Derecho de la Seguridad Social ${ }^{2}$-, lo primero que a un español le sorprende es la inexistencia de equivalentes jurídicos de la expresión «automaticidad de las prestaciones» en los ordenamientos de los países que consideramos de referencia, salvo en Italia, de cuyo Derecho la tomó — por la vía doctrinal- el ordenamiento español en la década de los años sesenta del siglo pasado. Esta falta de equivalencia terminológica o formal no implica, sin embargo, falta de equivalencia real o material a pesar de todas las diferencias existentes entre los concretos sistemas nacionales de seguridad social $^{3}$, pues - salvo en los casos de Gran Bretaña y de los Estados Unidos, por paradójico que pueda resultar- se trata de un principio ordenador de la responsabilidad del pago de las prestaciones contributivas de seguridad social también en Italia, Portugal, Francia y Alemania, aunque en los casos francés y alemán sobre la base de un presupuesto distinto al que preside su operatividad en Italia, Portugal y España.

1 Acerca de todo ello, véase J. MARTÍNEZ GIRÓN, A. ARUFE VARELA y X.M. CARRIL VÁZQUEZ, Derecho de la Seguridad Social, $1^{\mathrm{a}}$ ed., Netbiblo (A Coruña, 2005), págs. 269 y ss.

2 A. BLASCO PELLICER, La responsabilidad empresarial en el pago de prestaciones de seguridad social, Thomson-Aranzadi (Cizur Menor-Navarra, 2005), pág. 153, critica la lógica de este principio - tal y como aparece positivizado en la legislación española-, afirmando lo siguiente: «a pesar de que su juego produzca, de hecho, el efecto propio de un régimen de protección público, en su configuración no responde plenamente al mismo. En efecto, para la ley la responsabilidad es del empresario, pero el Estado la adelanta, sin perjuicio de su derecho a exigírsela al empleador. Lo lógico sería operar de forma diferente: el Estado otorgaría la prestación debida cumpliendo su propia responsabilidad de protección; y posteriormente, sancionaría al empresario incumplidor».

3 Sobre estas diferencias -en relación con las pensiones-, véase A. PETRUCCI y V. SABATO, Il sistema pensionistico italiano, Cacucci (Bari, 2004), págs. 39 y ss. 
Como un verdadero trompe l'oeil, hay que calificar el hecho de que la jurisprudencia del Tribunal de Luxemburgo ofrezca versiones en todas las lenguas oficiales de la Unión de la expresión «automaticidad de las prestaciones» («automatischen Gewährung der Leistungen», en alemán; «automatic payment of benefits», en inglés; «automaticité des prestations», en francés; «automaticidade das prestações», en portugués; etc.), puesto que la expresión en cuestión sólo resulta inteligible — con sentido jurídico pleno- en las lenguas italiana y castellana ${ }^{4}$.

Respecto de la legislación española, recuérdese que el artículo 220 de nuestra vigente Ley General de Seguridad Social (rotulado «Automaticidad del derecho a las prestaciones») afirma que «la entidad gestora competente pagará las prestaciones por desempleo en los supuestos de incumplimiento de las obligaciones de afiliación, alta y cotización, sin perjuicio de las acciones que pueda adoptar contra la empresa infractora y la responsabilidad que corresponda a ésta por las prestaciones abonadas».

Resulta de justicia recordar que BORRAJO DACRUZ popularizó en España la expresión, comentando el artículo 7 de la Ley del Seguro de Desempleo de 1961, allí donde afirmaba este precepto que «en caso de no afiliación, o de afiliación sin cotización por causas no imputables al trabajador, tendrán derecho al Seguro» ${ }^{5}$.

§2. En efecto, al igual que en España, en Italia y Portugal la automaticidad de las prestaciones de seguridad social presupone la responsabilidad del empresario por incumplimiento de los citados deberes instrumentales de seguridad social (y especialmente, el de cotizar). En Italia, se trata de un tema regulado - en lo esencial - en el artículo 2116 del Código Civil de 1942, a cuyo tenor -en base al cual todo el mundo habla de «automaticità delle prestazioni» ${ }^{6}$, incluso el propio legislador italiano- «las prestaciones indicadas en el artículo 2114 [esto es, las «de previsión y de asistencia obligatorias»] son debidas al trabajador, incluso cuando el empresario no ha pagado regularmente las cotizaciones debidas [l'imprenditore non ha versato regolarmente $i$ contributi dovuti] a las instituciones de previsión y de asistencia, salvo disposiciones contrarias de las leyes especiales» ${ }^{7}$. Y en Portugal, aunque las fuentes no hablen expresamente de «automaticidad de las prestaciones», esta institución aparece actualmente regulada en el artículo 61 de la Ley núm. 4/2007,

4 Al respecto, por todas, véase la Sentencia del Tribunal de Justicia de las Comunidades Europeas de 22 enero 2002 (asunto C-218/00), y A. ARUFE VARELA, «Los equívocos de la jurisprudencia del Tribunal de Justicia de las Comunidades Europeas sobre el principio de automaticidad de las prestaciones. Su verificación a través del Derecho alemán de la Seguridad Social», Revista del Ministerio de Trabajo y Asuntos Sociales. Derecho social Internacional y Comunitario, núm. 77 (2008), págs. 197 y ss.

5 Véase E. BORRAJO DACRUZ, «El principio de la automaticidad de las prestaciones en el seguro nacional de desempleo», en sus Estudios jurídicos de previsión social, Aguilar (Madrid, 1962), págs. 209 y ss.

6 Véase F.P. ROSSI, La previdenza sociale, $7^{\mathrm{a}}$ ed., CEDAM (Padua, 2000), págs. 150-151; M. CINELli, Diritto della Previdenza Sociale, $5^{\text {a }}$ ed., Giapichelli (Turín, 2003), págs. 176 y ss.; y M. PERSIANI, Diritto de la previdenza sociale, $14^{\mathrm{a}}$ ed., CEDAM (Padua, 2005), págs. 59 y ss.

7 Párrafo primero. 
de 16 enero, que «aprueba las bases generales del sistema de seguridad social [aprova as bases gerais do sistema de segurança social] $\rangle^{8}$, según el cual «la falta de cumplimiento de la obligación de inscripción, incluyendo la falta de declaración del inicio de actividad profesional o a la falta de pago de cotizaciones [a falta de cumprimento da obrigação de inscripção, incluindo a falta de declaração do início de actividade profissional ou a falta do pagamento de contribuições] relativas a períodos de ejercicio de actividad profesional de los trabajadores por cuenta de otro, que no les sea imputable, no perjudica el derecho a las prestaciones» ${ }^{9}$.

Al respecto, una Sentencia de la Audiencia Territorial de Oporto de 25 noviembre $2002^{10}$, repasando los precedentes legislativos y jurisprudenciales del tema en Portugal, concluye que «hay que prestar atención a la especialidad de la relación jurídica contributiva de seguridad social en cuanto a los trabajadores por cuenta de otro, que es genéticamente tripartita, aun cuando en lo que respecta al régimen de cumplimiento lo sea en términos bilaterales - entidad patronal y seguridad social», resultando «de la Ley que la simple falta de entrega de las cotizaciones, aun cuando haga incurrir a la entidad empleadora en responsabilidad frente a la institución acreedora, no afecta a los derechos o garantías del trabajador (en calidad de beneficiarios), haciendo limitar los efectos de la falta de entrega a la relación bilateral de cumplimiento, quedando incólume la situación del trabajador en cuanto al sistema de "seguridad social"»).

Respecto de Italia, una de las leyes especiales aludidas por el precepto citado del Código Civil es, por ejemplo, la Ley núm. 493, de 3 diciembre 1999, de «normas para la tutela de la salud en las habitaciones e instituciones del aseguramiento contra los accidentes domésticos», en donde expresamente se afirma que «al aseguramiento no se aplica el principio de la automaticidad de las prestaciones [all'assicurazione non si applica il principio dell'automaticità delle prestazioni] $]{ }^{11}$.

La Sentencia de la Corte Constitucional italiana núm. 374, de 26 noviembre 1997, confirma la constitucionalidad de la legislación italiana reguladora del tema -efectuando incluso un examen de los precedentes legislativos anteriores al Código Civil—, incluida la Ley núm. 485, de 11 agosto 1972, que —-después de recordar el tradicional límite de diez años operante sobre las cotizaciones no pagadas («el requisito de cotización establecido para el derecho a las prestaciones de vejez, invalidez y supervivientes, se entiende cumplido aun cuando las cotizaciones no sean efectivamente pagadas, pero resulten debidas en los límites de la prescripción decenal [nei limite della prescrizione decennale]») - matiza asimismo, con claro sentido pro beneficiario, que «los períodos no cubiertos de cotización a los que se refiere el párrafo precedente se consideran útiles también a los fines de la determinación de la medida de las pensiones» ${ }^{12}$.

8 Sobre el tema, con referencias a la legislación precedente, véase I. DAS NEVES, Lei de Bases da Segurança Social: Comentada e Anotada, Coimbra Editora (Coimbra, 2003), págs. 11 y ss.

9 Apartado 3.

10 Núm. de proceso 0240745.

11 Artículo 9.3.

12 Cfr., al respecto de todo ello, su artículo 23.ter (este precepto vino a modificar el artículo 40 de la Ley núm. 153, de 30 abril 1969; precepto, éste último, a su vez modificador en su día del artículo 27 del Real Decreto-Ley núm. 636, de 14 abril 1939). 
§3. Frente a estos modelos, los modelos francés y alemán conciben la «automaticidad de las prestaciones»-sin utilizar en absoluto esta expresión- haciendo abstracción de la eventual responsabilidad del empresario por incumplimiento de sus deberes instrumentales de seguridad social, pues —quizá porque esta última se concibe como un verdadero servicio público- el beneficiario tiene derecho estricto al cobro de las prestaciones contributivas, aun cuando el empresario por dolo o negligencia no hubiese cotizado. De ahí que en estos casos se hable, en Francia, no de prestaciones anticipadas al beneficiario -como ocurre en España-, sino de prestaciones «servidas», con toda normalidad, previendo la legislación de seguridad social francesa el «reembolso» de tales prestaciones por el empresario incumplidor sólo en supuestos excepcionales ${ }^{13}$, como el del artículo L. 244-8 del Código de la Seguridad Social, según el cual «independientemente de las sanciones previstas en los artículos L. 244-1 a L. 244-7, las cajas primarias del seguro de enfermedad están legitimadas para perseguir, frente al empresario ..., el reembolso [remboursement] de las prestaciones de enfermedad de larga duración o de accidente de trabajo efectivamente servidas [servies] por ellas a los trabajadores» ${ }^{14}$. Y 10 mismo sucede en Alemania -en donde el Código de Seguridad Social, respecto de las prestaciones más clásicas, habla incluso de «prestaciones de oficio [Leistungen von Amts wegen]» ${ }^{15} \mathrm{y}$ de «aseguramiento por imperio de la Ley [Versicherung kraft Gesetzes]» ${ }^{16}$, dado que sólo se prevé legalmente el «reembolso» por el empresario de las prestaciones «satisfechas» al beneficiario también en supuestos muy extremosos, como el de radical impago del salario al trabajador, regulado en el parágrafo 115 del Libro Décimo del Código de Seguridad Social (rotulado «Derechos contra el empresario [Ansprüche gegen den Arbeitgeber]»), a cuyo tenor «supuesto que el empresario no cumpla el derecho del trabajador al salario y por eso una entidad gestora ha satisfecho prestaciones de seguridad social [ein Leistunsträger Sozialleistungen erbracht hat], el derecho del trabajador

13 Véase J.-J. DUPEYROUX, M. BORGETTO, R. LAFORE y R. RUELLAN, Droit de la sécurité sociale, $15^{\mathrm{a}}$ ed., Dalloz (París, 2005), págs. 678 y 900.

14 Párrafo primero, inciso primero.

15 En relación con los accidentes de trabajo, y contraponiéndolas a «prestaciones a instancia de parte [Leistungen auf Antrag]» (cfr. parágrafo 19 del Libro Cuarto).

16 Cfr. parágrafo 2 del Libro Séptimo (en relación con los accidentes de trabajo). 


\section{contra el empresario se traspasa a la entidad gestora hasta el tope de las prestaciones de seguridad social satisfechas» ${ }^{17}$.}

Este último precepto forma parte del «Capítulo [Abschnitt]» Tercero (rotulado «Derechos de reembolso y de indemnización de las entidades gestoras contra terceros [Erstattungs- und Ersatzansprüche der leistungsträger gegen Dritte]») de la «Parte [Kapitel]» Tercera del Libro Décimo del Código de Seguridad Social ${ }^{18}$, que también regula - entre otras cuestiones - los «derechos contra el obligado a indemnizar daños y perjuicios [Ansprüche gegen Schadenersatzpflichtige]» ${ }^{19}$ y los «derechos de indemnización de daños y perjuicios de varias entidades gestoras [Schadenersatzansprüche mehrerer Leistungsträger] $\gg^{20}$. Estos preceptos suelen estudiarse doctrinalmente en conjunción con el parágrafo 50 del propio Libro Décimo del Código de Seguridad Social, relativo a «reembolso [por el trabajador] de prestaciones injustamente satisfechas [Erstattung zu Unrecht erbrachter Leistungen]». Una concreción singular de esta última norma aparece contenida en la Ley para la Lucha contra el Trabajo Negro y la Ocupación Ilegal de 2004, según la cual «quien realiza una acción mencionada en el parágrafo 8, apartado 1, núm. 1, letras a), b) o c), y consigue mediante ella que le sea otorgada injustamente una prestación al amparo de alguna Ley allí mencionada, será castigado con pena de privación de libertad de hasta tres años o con multa penal, cuando la acción no resulte castigada con ninguna pena en el parágrafo 263 del Código Penal» ${ }^{21}$.

En el Código francés de la Seguridad Social, otros preceptos que también aluden al «reembolso» de las prestaciones «servidas» —supuesto siempre el incumplimiento por el empresario de sus deberes instrumentales - son los siguientes: 1) el artículo L. 374-1, a cuyo tenor «al empresario que ha ocupado un extranjero sometido al régimen establecido por los artículos L. 341-1 y siguientes del Código del Trabajo, se le obliga a reembolsar a los organismos de seguridad social el montante de las prestaciones del seguro de enfermedad, de maternidad, de muerte, de invalidez o de accidente de trabajo pagadas al interesado, si este último, antes de la realización del riesgo que hubiese entrañado el pago de las prestaciones, no se hubiese sometido al control médico previsto por dichos artículos» ${ }^{22}$; 2) el artículo L. 452-2 (a propósito del recargo de prestaciones de seguridad social por infracción de medidas de seguridad e higiene), según el cual «el recargo se paga por la caja, que recupera el montante del mismo por imposición de una cotización complementaria» ${ }^{23}$, teniendo en cuenta que «la cotización complementaria así prevista no puede ser percibida más allá de una cierta duración y su tasa exceder ni de una fracción de la cotización normal del empresario, ni de una fracción de los salarios que sirvan de base a esta cotización» ${ }^{24}$; y 3) el artículo L. 471-1, también a propósito de los accidentes de trabajo, relativo a que «la caja primaria

17 Apartado 1.

18 Sobre el tema, véase H. PLAGEMANN, «Ersatzpflichten Dritter», en B. BARON VON MAYDELL y F. RULAND (Editores), Sozialrechtshandbuch, $3^{\mathrm{a}}$ ed., Nomos (Baden-Baden, 2003), págs. $437 \mathrm{y}$ ss.

19 Cfr. parágrafo 116.

20 Cfr. parágrafo 117.

21 Cfr. parágrafo 9 (rotulado «Obtención fraudulenta de prestaciones de seguridad social en conexión con la realización de prestaciones de servicios o prestaciones de obra»).

22 Párrafo primero.

23 Párrafo sexto.

24 Párrafo séptimo. Sobre el tema, véase J. MARTÍNEZ GIRÓN, «¿Puede un empresario español asegurar su responsabilidad española por recargo de prestaciones de Seguridad Social en otro Estado de la Unión Europea distinto de España?», Actualidad Laboral, núm. (2005), pág. 1497. 
del seguro de enfermedad puede perseguir, frente a los empresarios o sus representantes que hayan incumplido estas disposiciones [esto es, las de los artículos L. 441-2 y L. 441-5], el reembolso de la totalidad de los gastos causados con ocasión del accidente» ${ }^{25}$.

Jurisprudencia constante de la Sala de lo Social de la Corte de Casación exige —para que resulte procedente el «reembolso» a que se refieren los preceptos recién citados- una actuación al menos culposa del empresario incumplidor, afirmando en este sentido una Sentencia de dicha Sala, de 21 marzo 2002 ${ }^{26}$, que «el artículo L. 244-8 del Código de la Seguridad Social se destina a sancionar la mala fe y la negligencia del empresario y no podría aplicarse ... sin que sea caracterizada por parte de este último una voluntad de eludir las obligaciones que la ley pone a su cargo» ${ }^{27}$.

§4. Frente a estos modelos continentales europeos -en los que prevalece, sobre al interés de la entidad gestora, el interés del beneficiario a percibir las prestaciones-, en los modelos británico y norte a merica no prevalece, en cambio, el interés de la Administración pública de seguridad social — respecto de las prestaciones contributivas- a satisfacer sólo prestaciones que cuenten con su correspondiente respaldo cotizatorio, lo que explica la completa falt a en ambos de algo similar a 1a «automaticidad de las prestaciones de seguridad social». En Gran Bretaña, lo establece la «Ley de Cotizaciones y Prestaciones de Seguridad Social [Social Security Contributions and Benefits Act]》 de 1992, al afirmar - haciendo abstracción de la existencia o no de posibles incumplimientos del empresario-que «el derecho a cualquiera de las prestaciones mencionadas en la sección 20(1)»-todas ellas prestaciones contributivas- «depende de que se hayan cumplido las condiciones de cotización [depends on contribution conditions being satisfied] ${ }^{28}$. Y en los Estados Unidos de Norteamérica — sobre la base de que la vida laboral (y por tanto, el historial de cotizaciones) del trabajador (asalariado o autónomo) consta en los «registros salariales [wage records]», individualizados por el «número de cuenta de Seguridad Social [Social Security account number]», que lleva el Comisionado de Seguridad Social ${ }^{29}$ - , lo confirma la sección 405(c)(3) del Título 42 del Código de los Estados Unidos, según la cual -recuérdese- «los registros del Comisionado harán prueb a a los efectos de plantear procedimientos ante el Comisionado de

25 Párrafo segundo.

26 Núm. de recurso de casación 00-15137.

27 Véanse además, de la propia Sala, Sentencias de 31 enero 1980 (núm. de recurso de casación 78-12868) y de 17 abril 1996 (núm. de recurso de casación 94-15553).

28 Sección 21(1). La disposición adicional (Schedule) 3 de la propia Ley regula las «condiciones de cotización para tener derecho a la prestación [contribution conditions for entitlement to benefit]».

29 Véase supra, Tema 9, \$5. 
Seguridad Social o ante cualquier Corte sobre la cuantía de los salarios pagados a una persona, y sobre las rentas autónomas ingresadas por una persona, y sobre los períodos en los cuales esos salarios se pagaron o esas rentas se ingresaron» ${ }^{30}$.

Evidentemente, en estos registros pueden introducirse correcciones o «cambios [changes] ${ }^{31}$, también a consecuencia de la actividad de investigación y persecución del fraude desarrollada por funcionarios al servicio del «Inspector General» de la Administración norteamericana de Seguridad Social ${ }^{32}$. Las faltas y delitos en relación con el tema aparecen descritos en la sección 408 del Título 42 del Código de los Estados Unidos (rotulada «Penas [Penalties]») ${ }^{33}$. Según el apartado (b)(4) de esta sección, se consideran «víctimas» de las faltas o delitos en cuestión, aparte el propio Comisionado de Seguridad Social, también «cualquier persona que sufra una pérdida financiera [financial loss] como resultado del incumplimiento del demandado» ${ }^{34}$.

En Gran Bretaña, la rígida ligazón existente entre cotizaciones y prestaciones contributivas, que tanto escandalizó en su día a P. DURAND ${ }^{35}$, se completa con un imponente aparato normativo - contenido en la «Ley de la Administración de la Seguridad Social [Social Security Administration Act]» de 1992- orientado a la «recuperación» de cotizaciones impagadas $^{36}$, en el que lógicamente juega un papel estelar la Inspección específica británica de Seguridad Social ${ }^{37}$.

Tanto en los Estados Unidos como en Gran Bretaña, aparte las prestaciones de seguridad social contributivas, existen otras no contributivas ${ }^{38}$, respectivamente reguladas en las secciones 1381 a 1385 del Título 42 del Código de los Estados Unidos (relativas a la «renta de seguridad complementaria [supplemental security income])») y en la Parte III (rotulada «Prestaciones no contributivas [Non-contributory benefits]»), secciones 63 a 79, de la Ley británica de Cotizaciones y Prestaciones de Seguridad Social de 1992.

§5. En fin, aunque a propósito de un supuesto de hecho muy concreto, el Derecho de la Unión Europea -en su vertiente ad 30 Ibidem.

31 Cfr. apartados (4) a (7) de la sección 405(c) del Título 42 del Código de los Estados Unidos. Sobre «evidence» en este contexto, exhaustivo, véase H.L. McCORMICK, Social Security. Claims and Procedures, vol. II, $4^{\text {a }}$ ed., West Publ. Co. (St. Paul-Minn., 1991), págs. 106 y ss.

32 A las «investigaciones» se refiere la sección 405(b) del Título 42 del Código de los Estados Unidos; al «Inspector General», la sección 902(e) del Título 42 del Código de los Estados Unidos.

33 Por su parte, el contencioso instrumental sobre el tema-que es contencioso de Derecho común- aparece regulado en la sección 405(c)(9) del Título 42 del Código de los Estados Unidos.

34 Cfr. subapartado (A).

35 Cfr. su La politique contemporaine de sécurité sociale, Dalloz (Paris, 1953), pág. 266.

36 Cfr. especialmente sus secciones 119 (rotulada «Recuperación de cotizaciones impagadas en con acción penal [Recovery of unpaid contributions on prosecution]») y 121 (rotulada «Cotizaciones impagadas - disposiciones complementarias [Unpaid contributions - supplementary]»).

37 Véase A. ARUFE VARELA, Estudio comparado de la carrera administrativa de los funcionarios del sistema de Inspección de Trabajo y Seguridad Social en Europa, Ministerio de Trabajo y Seguridad Social (Madrid, 2007), págs. 111-112.

38 Véase R. EAST, Social Security Law, Macmillan (Londres, 1999), págs. 15 y ss.; y N. HARRIS, "The Shape and Characteristics of Social Security Today (including Insurance, Pensions, and Means-tests)», en N. HARRIS (Editor), Social Security Law in context, Oxford University Press (Oxford, 2000), págs. 155 y ss. 
extra- también positiviza la «automaticidad de las prestaciones de seguridad social» ${ }^{39}$, visto que la Directiva 2008/94/CE del Parlamento Europeo y del Consejo, de 22 octubre 2008, relativa a la protección de los trabajadores asalariados en caso de insolvencia del empresario, ordena que «los Estados miembros adoptarán las medidas necesarias para garantizar que el impago de cotizaciones obligatorias adeudadas por el empresario a sus instituciones de seguros, antes de sobrevenir su insolvencia, en virtud de los regímenes legales nacionales de Seguridad Social, no tenga efectos perjudiciales en el derecho a prestaciones del trabajador asalariado respecto a tales instituciones de seguros, en la medida en que las cotizaciones salariales se hayan descontado previamente de los salarios abonados» ${ }^{40}$. Lo ha confirmado el Tribunal de Luxemburgo, con bastante contundencia, al ligar la transposición de este precepto comunitario a las normas internas - las italianas, en el caso- reguladoras de la «automaticidad de las prestaciones de seguridad social». Por supuesto, el tema ni se plantea en la vertiente ad intra del Derecho de la Unión Europea, en la medida en que la entidad gestora de la seguridad social del personal al servicio de la Unión Europea (denominada «Oficina de Gestión y Liquidación de los Derechos Individuales») forma parte de la Administración pública de la propia Unión Europea.

Esta «Oficina», más conocida por su acrónimo inglés «PMO» (esto es, PayMaster's Office), no es más que un mero servicio interno de la Comisión Europea ${ }^{41}$.

El caso que liga el precepto comunitario citado al principio de automaticidad de las prestaciones es la Sentencia del Tribunal de Justicia de las Comunidades Europeas de 2 febrero 1989 (asunto 22/87), en el que se concluyó —vista la limitación impuesta por la legislación interna italiana a la operatividad del principio, más allá de la prescripción decenal ${ }^{42}$ - que «el derecho de los trabajadores asalariados a prestaciones de vejez, de invalidez y a favor de los supervivientes, no se ve garantizado en caso de que prescriba la deuda del empresario insolvente ante la entidad gestora», y además, que «la disposición legal invocada por el Gobierno italiano no permite compensar las lagunas del principio del carácter automático de las prestaciones, en relación con lo dispuesto en el artículo 7 de la Directiva».

También desde la perspectiva ad extra, la normativa contenida en el Reglamento (CE) núm. 987/2009 del Parlamento Europeo y del Consejo, de 16 septiembre 2009, por el que se adoptan las normas de aplicación del Reglamento (CE) núm. 883/2004, sobre la

39 Véase J. MARTÍNEZ GIRÓN, «El Derecho de la Unión Europea y el principio de automaticidad de las prestaciones», Actualidad Laboral, núm. 3 (2009), págs. 285 y ss.

40 Artículo 7.

41 Aparece aludida, de modo hipergenérico, en el «Estatuto de los Funcionarios» aprobado por el Reglamento núm. 31 (CEE), 11 (CEEA) de 1962 (cfr. el artículo 45 de su Anexo VIII).

42 Véase supra, $\$ \mathbf{2}$, in fine. 
coordinación de los sistemas de seguridad social, presupone aparentemente una completa falta de automaticidad, puesto que la entidad gestora de cualquier Estado miembro lo que puede solicitar a su amparo - instada por un beneficiario nacional suyo- es sólo certificaciones de cotizaciones obrantes en los registros de seguridad social de cualquier otro Estado miembro de la Unión Europea ${ }^{43}$. 
TEMA 22

EL PRINCIPIO DEL RESPETO A LOS DERECHOS ADQUIRIDOS EN MATERIA DE SEGURIDAD SOCIAL COMPLEMENTARIA EN EL ORDENAMIENTO COMUNITARIO, EN LAS LEGISLACIONES Y PRÁCTICAS NACIONALES EUROPEAS, Y EN LA LEGISLACIÓN DE LOS ESTADOS UNIDOS

Sumario: §1. La precariedad general de la protección de los derechos adquiridos en el ordenamiento español. \$2. La protección otorgada por el ordenamiento comunitario a los derechos adquiridos, dispersa y todavía insuficiente, en materia de seguridad social complementaria. §3. La antijurídica interpretación por la Sala de lo Social de nuestro Tribunal Supremo del precepto tradicionalmente protector, en España, de los derechos adquiridos en materia de seguridad social complementaria. §4. La jurisprudencia de la Sala de lo Social de la Corte de Casación francesa sobre libre disponibilidad por convenio colectivo de los derechos adquiridos en materia de seguridad social complementaria. \$5. El respeto estricto a los derechos adquiridos en materia de seguridad social complementaria, según la jurisprudencia de la Sección Trabajo de la Corte de Casación italiana y del Tribunal Federal de Trabajo alemán. §6. La interpretación por la Corte Suprema de los Estados Unidos, protectora de los derechos adquiridos, de la «regla anti-recorte retroactivo» de pensiones complementarias de jubilación. §7. La Directiva 2003/41/CE, relativa a las actividades de supervisión de fondos de pensiones de empleo, y su defectuoso tratamiento de los derechos adquiridos.

\footnotetext{
THEME 22

THE PRINCIPLE OF RESPECTING TO VESTED RIGHTS ON COMPLEMENTARY SOCIAL SECURITY IN THE EUROPEAN LAW, IN THE NATIONAL EUROPEAN LEGISLATIONS AND PRACTICES, AND IN THE LEGISLATION OF THE UNITED STATES

Contents: \$1. The general precariousness of the protection of vested rights in Spanish Law. \$2. The dispersed and still short protection of vested rights by the European Law on the subject-matter of complementary social security. $\$ 3$. The against Law interpretation by the Social Chamber of our Supreme Court of the traditionally protecting norm, in Spain, of the vested rights on the subject-matter of complementary social security. $\$ 4$. The decision of the Social Chamber of the French Court of Cassation about free disposal by collective agreement of vested rights on the subject-matter of complementary social security. \$5. The strict respecting to vested rights on the subject-matter of complementary social security, according to the decisions of the Labor Section of the Italian Court of Cassation and the German Federal Labor Court. \$6. The protective interpretation of vested rights, by the United States Supreme Court, of "the anti-cutback rule» of complementary retirement pensions. $\$ 7$. The Directive 2003/41/EC, on the activities and supervision of institutions for occupational retirement provision, and its faulty treatment of vested rights.
} 
\$1. El tema magno y clásico del respeto que merecen los derechos adquiridos - los «iura quaesita» de que hablaban los viejos juristas europeos del Derecho común ${ }^{1}$ - parece haber acabado convirtiéndose en España en un tema jurídicamente menor, que desde luego no está en absoluto de moda entre nosotros, los españoles, y que resulta incluso perfectamente prescindible, aun a costa de atropellar - como luego comprobaremos- las más elementales exigencias de decencia y de Justicia material. Esta decadencia actual suya viene propiciada por dos razones principales, conectadas ambas a la precariedad general de la protección de los derechos adquiridos en España. Ante todo, por causa de la extravagante - nunca mejor dicho- ubicación de su regulación general en nuestro Código Civil de 1889, al aparecer contenida no en su articulado, sino entre las disposiciones extravagantes de dicho Código; y más en concreto, en sus disposiciones transitorias. Entre estas disposiciones arrinconadas de nuestro Código Civil, la clave es la usualmente denominada disposición transitoria preliminar ${ }^{2}$, en la que literalmente se afirma que «las variaciones introducidas por este Código, que perjudiquen derechos adquiridos según la legislación civil anterior, no tendrán efecto retroactivo». Ahora bien, lo que de verdad más ha dañado en España el principio general tradicional del respeto a los derechos adquiridos ha sido la doctrina elaborada sobre el tema por nuestro Tribunal Constitucional, resolviendo recursos o cuestiones de inconstitucionalidad, al hilo de la interpretación del artículo 9.3 de la vigente Constitución Española de 1978, allí donde este precepto afirma que «la Constitución garantiza... la irretroactividad de las disposiciones sancionadoras no favorables o restrictivas de los derechos individuales», dado que esta última expresión — siempre según el Tribunal Constitucional — se refiere sólo a derechos innatos (a la vida, al honor, a la intimidad personal, etc.), pero no a los derechos adquiridos ${ }^{3}$.

Esta doctrina arranca de la Sentencia del Tribunal Constitucional núm. 27/1981, de 20 julio - luego confirmada por otras muchas del propio Tribunal-, en la que se parte de la afirmación de que «desde el punto de vista de la constitucionalidad, debemos rehuir cualquier intento de aprehender la huidiza teoría de los derechos adquiridos, porque la Constitución no emplea la expresión "derechos adquiridos", y es de suponer que los constituyentes la

Comentando el canon 4 del viejo Código de Derecho Canónico de 1917, véase L. MIGUÉLEZ DOMÍNGUEZ, S. ALONSO MORÁN y M. CABEROS DE ANTA, Código de Derecho Canónico y Legislación Complementaria. Texto latino y versión castellana, con jurisprudencia y comentarios, BAC (Madrid, 1974), págs. 4-5.

2 Véase J. CASTÁN TOBEÑAS, Derecho Civil español, común y foral, Tomo $1^{\mathrm{o}}$, Volumen $1^{\mathrm{o}}, 11^{\mathrm{a}}$ ed., Reus (Madrid, 1975), pág. 601.

3 Véase L. DÍEZ-PICAZO y A. GULLÓN, Sistema de Derecho Civil, Volumen 1, $8^{\mathrm{a}}$ ed., Tecnos (Madrid, 1992), pág. 115. 
soslayaron, no por modo casual, sino porque la defensa a ultranza de los derechos adquiridos no casa con la filosofía de la Constitución, no responde a exigencias acordes con el Estado de Derecho que proclama el artículo $1^{\circ}$ de la Constitución»; a todo lo cual cabría razonablemente objetar, a nuestro juicio, que nuestra Constitución tampoco emplea, por ejemplo, la expresión jurídica «buena fe», lo que no ha impedido que el propio Tribunal Constitucional reconozca esta última — sin necesidad de ninguna defensa histérica («a ultranza») — como límite del ejercicio de cualesquiera derechos (incluidos los derechos constitucionales fundamentales) ${ }^{4}$, aparte el dato de que los derechos adquiridos no son ninguna «teoría» (y menos, «huidiza»), sino simplemente objeto de un principio general del Derecho, que se supone deberá estar protegido de algún modo en un verdadero Estado de Derecho.

Sobre esta base, la propia Sentencia continúa luego afirmando que «cuando se trata de la defensa del ordenamiento constitucional, hemos de tener en cuenta que el concepto de "derecho individual" no puede confundirse con el "ius quaesitum"; el 9.3 —en todo o en parte- alude a los derechos fundamentales del título I»; todo lo cual confirma, también a nuestro juicio, la desprotección constitucional de los derechos adquiridos, pues los derechos constitucionales aludidos por ese dictum resultan ser los derechos innatos.

Por eso, la Sentencia concluye que la protección de los derechos adquiridos queda reconducida al arbitrio de lo que llegue a decidir en cada caso sobre los mismos el legislador de turno, pues - siempre según ella- «el principio de irretroactividad del artículo 9.3, en cuanto a las Leyes, concierne sólo a las sancionadoras no favorables, y a las restrictivas de derechos individuales, en el sentido que hemos dado a esta expresión», de manera que «fuera de ello, nada impide, constitucionalmente, que el legislador dote a la Ley del ámbito de retroactividad que considere oportuno».

§2. En contraste con este estado de cosas, el Derecho derivado de la Unión Europea proclama con naturalidad, y con carácter general, que «el respeto de los derechos adquiridos constituye uno de los principios generales del Derecho protegidos por el ordenamiento jurídico comunitario» ${ }^{5}$. Y prueba ese respeto, incluso en relación con un tema extraordinariamente concreto - pero muy importante-, el hecho de que el ordenamiento comunitario ya desde 1977 manifestase su preocupación por la protección de los derechos adquiridos en materia de seguridad social complementaria, afirmando en la actualidad: 1) en la Directiva 98/49/CE del Consejo, de 29 junio 1998, relativa a la protección de los derechos de pensión complementaria de los trabajadores por cuenta ajena y los trabajadores por cuenta propia que se desplazan dentro de la Comunidad - norma muy generosa en sus alusiones expresas a los «derechos adquiridos»—, que «los Estados miembros

4 Véase J. MARTÍNEZ GIRÓN, A. ARUFE VARELA y X.M. CARRIL VÁZQUEZ, Derecho del

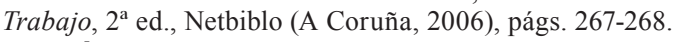

5 Véase, por ejemplo, Directiva 2006/116/CE del Parlamento Europeo y del Consejo, de 12 diciembre 2006, relativa al plazo de protección del derecho de autor y de determinados derechos afines, Considerando $10^{\circ}$; y en el ámbito laboral, por ejemplo, Directiva 2001/86/CE del Consejo, de 8 octubre 2001, por la que se completa el Estatuto de la Sociedad Anónima Europea en lo que respecta a la implicación de los trabajadores, Considerando $18^{\circ}$, inciso primero (calificándolo como «principio fundamental»). 
garantizarán que los regímenes complementarios de pensión paguen en otros Estados miembros... la totalidad de las prestaciones... debidas en virtud de estos regímenes, deducidos los posibles impuestos y gastos por transacciones» ${ }^{6}$; 2) en la Directiva 2001/23/CE del Consejo, de 12 marzo 2001, sobre traspasos de empresas, que «los Estados miembros... adoptarán... las medidas necesarias para proteger los intereses... de las personas que hayan dejado ya el centro de actividad del cedente en el momento del traspaso, en lo que se refiere a sus derechos adquiridos... a prestaciones de jubilación..., con arreglo a los regímenes complementarios ["profesionales o interprofesionales fuera de los regímenes legales de seguridad social de los Estados miembros"]) ${ }^{7}$; y 3) en la Directiva 2008/94/CE del Parlamento Europeo y del Consejo, de 22 octubre 2008, relativa a la protección de los trabajadores asalariados en caso de insolvencia del empresario (versión codificada), de nuevo que «los Estados miembros se asegurarán de que se adopten las medidas necesarias para proteger los intereses... de las personas que ya hayan dejado la empresa o el centro de actividad del empresario, en la fecha en que se produce la insolvencia de éste, en lo que se refiere a sus derechos adquiridos... a prestaciones de vejez..., en virtud de regímenes complementarios de previsión o interprofesionales que existan independientemente de los regímenes legales nacionales de seguridad social» ${ }^{8}$. Siempre en relación con este concreto tipo de derechos adquiridos - de que son titulares personas particularmente indefensas, como los ya jubilados-, la protección ofrecida por el ordenamiento comunitario se ha revelado insuficiente, precisamente cuando la agresión a los derechos de pensión complementaria adquiridos opera en un contexto distinto del expresamente previsto por el propio Derecho de la Unión Europea (insolvencia del empresario, desplazamiento del titular del derecho, traspaso de empresa).

La citada Directiva 98/49/CE llega incluso a definir los «derechos de pensión adquiridos», afirmando que son «todos los derechos a prestaciones obtenidos después de haber cumplido las condiciones requeridas por las normas de un régimen complementario de pensión y, en su caso, por la legislación nacional» ${ }^{9}$.

Artículo 5

Artículo 3.4.b).

8 Artículo 8.

9 Artículo 3.d). Además, según su artículo 3.b), «régimen complementario de pensión» es «todo régimen profesional de pensión establecido de conformidad con la legislación y la práctica nacional, como los contratos de seguros de grupo o los regímenes por reparto acordados por uno o más sectores o ramas, los regímenes por capitalización o los compromisos de pensión garantizados por provisiones en el balance de las empresas o cualquier dispositivo de carácter colectivo o dispositivo comparable destinados a abonar una pensión complementaria a trabajadores por cuenta ajena o por cuenta propia». 
§3. La completa desprotección en España de los derechos adquiridos en materia de seguridad social complementaria la ha certificado una Sentencia de la Sala de lo Social del Tribunal Supremo de 16 julio 2003, dictada en Sala General — con voto particular de tres Magistrados-y resolviendo un recurso de casación para la unificación de doctrina ${ }^{10}$, relativa al siguiente supuesto de hecho: 1) unos trabajadores habían sido anticipadamente jubilados por su empresa, en 1983, con el compromiso por parte de ésta - pactado en convenio colectivo - de que se les abonaría una pensión complementaria de jubilación de carácter vitalicio; 2) a partir de 1994, la empresa —que pretendía liquidar sus obligaciones «mediante el abono de un indemnización con pago único o su sustitución por la consignación de una renta vitalicia en una entidad aseguradora»— se negó a pagar los complementos vitalicios en cuestión, siendo repetidamente condenada a abonarlos por diversos tribunales laborales; y 3) en el año 2000, la empresa — que nunca había «exteriorizado» el cumplimiento de sus compromisos ${ }^{11}$ — logró acordar un nuevo convenio colectivo con los representantes de sus trabajadores, derogando el convenio colectivo que había dado lugar al percibo de los complementos de pensión y liquidando todos los compromisos jubilatorios asumidos en su día, mediante el pago a cada jubilado de una indemnización misérrima. Pues bien, esta injusta Sentencia — vista la imposibilidad de aplicar el ordenamiento laboral comunitario, puesto que la empresa no se encontraba en situación de insolvencia ${ }^{12}$ - confirmó la plena licitud de la actuación empresarial, mediante la utilización de tres argumentos. En primer lugar, que el Estatuto de los Trabajadores permitía a un convenio colectivo enmendar todo lo regulado en convenios colectivos anteriores del mismo ámbito, disponiendo libremente de los derechos creados por los mismos ${ }^{13}$. En segundo lugar, que ello resultaba posible porque el convenio colectivo no es fuente de derechos adquiridos a título individual (literalmente, «el beneficio suprimido no tiene su origen en pactos

10 Recurso núm. 862/2002.

11 Sobre el tema, véase A.L. DE VAL TENA, La exteriorización de los compromisos por pensiones: el régimen jurídico de la protección de los trabajadores, Thomson-Aranzadi (Cizur Menor-Navarra, 2004), págs. $47 \mathrm{y}$ ss.

12 Según ella, con cita de la Directiva 80/987/CEE (actualmente derogada por la citada Directiva 2008/94/CE), «no es precisamente éste el aspecto de la cuestión que debemos tener en cuenta para resolver el recurso» (Fundamento de Derecho $6^{\circ}$, párrafo segundo).

13 El precepto invocado era el artículo 82.4 del Estatuto de los Trabajadores. Para una crítica fundada y muy razonable de esta norma estatutaria, véase A. ARUFE VARELA, La denuncia del convenio colectivo, Civitas (Madrid, 2000), págs. 188 y ss. 
individuales celebrados entre los interesados y la empresa, sino en un convenio colectivo que reconoció la mejora con carácter de generalidad») ${ }^{14}$. $\mathrm{Y}$ en tercer lugar, puesto que el precepto legal específica y tradicionalmente protector de los derechos adquiridos en materia de seguridad social complementaria - que era el artículo 192 de la Ley General de la Seguridad Social—, ante la duda interpretativa, debía merecer una interpretación contraria al respeto de los derechos adquiridos.

Como se sabe, dicho artículo 192 establece una regla general protectora de los derechos adquiridos («no obstante el carácter voluntario, para los empresarios, de las mejoras a que este artículo se refiere, cuando al amparo de las mismas un trabajador haya causado el derecho a la mejora de una prestación periódica, ese derecho no podrá ser anulado o disminuido») y una salvedad o excepción a dicha regla general («si no es de acuerdo con las normas que regulan su reconocimiento»).

Evidentemente, la letra de esta excepción admitía dos interpretaciones posibles: 1) entender que si la norma reguladora del complemento (esto es, el originario convenio colectivo de 1983) nada había dispuesto sobre su futura anulación o disminución — como en este caso había ocurrido-, ello se debía a que había sido intención de las partes proscribir en el futuro todo intento de recorte; y 2) entender por el contrario, en cambio, que ese silencio convencional equivalía a otorgar por la tácita licencia en el futuro para anular o disminuir los compromisos en su día asumidos.

Pues bien, contra toda lógica hermenéutica (las excepciones, según se enseña en las Facultades de Derecho, parece que han de interpretarse en sentido estricto). Y contra lo impecablemente fallado por la Sentencia recurrida de la Sala de lo Social del Tribunal Superior de Justicia del País Vasco (según la cual, literalmente, el precepto en cuestión es «expresivo de una regla que protege al beneficiario..., con una sola excepción: que la merma o supresión del derecho estuviera ya prevista en las normas que regularon su reconocimiento») ${ }^{15}$, aquí el Tribunal Supremo acogió el sentido amplísimo de la salvedad citada y, por tanto, el más odioso de los sentidos posibles para los derechos adquiridos de que venían disfrutando pacíficamente los antiguos trabajadores de la empresa. Lo prueba su afirmación de que «en este caso concreto, la norma que reconoce y regula las mejoras cuestionadas es un convenio colectivo, que no contiene previsiones respecto de su permanencia en el tiempo o de su blindaje frente a pactos colectivos posteriores» ${ }^{16}$, por lo que - frente al claro blindaje que daba la interpretación estricta de la excepción, única jurídicamente admisible, de la letra de la ley - concluyó, por el contrario, que la doctrina de la Sentencia recurrida «supone el reconocimiento legal de una garantía reforzada para los derechos de los pasivos, hasta el punto de bloquear tales derechos frente a la negociación colectiva futura, pero no es ese el espíritu del artículo 192 de la Ley General de la Seguridad Social, como hemos venido diciendo» ${ }^{17}$.

\footnotetext{
14 Fundamento de Derecho séptimo, párrafo segundo.

15 Cfr. su Fundamento de Derecho segundo, apartado B), párrafo segundo.

16 Fundamento de Derecho séptimo, párrafo primero.

17 Fundamento de Derecho octavo, párrafo primero.
} 
§4. En la misma línea, pero ahora en Francia, una Sentencia de la Sala de lo Social de la Corte de Casación de 25 noviembre $2005^{18}$ también ha confirmado que las pensiones complementarias voluntarias de jubilación creadas por convenio colectivo, y ya causadas y disfrutadas por sus beneficiarios, podían e mpeorarse (impidiendo su revalorización) a través de un nuevo convenio colectivo ${ }^{19}$. En este caso, los jubilados afectados invocaban el precepto del Código francés del Trabajo entonces vigente, en el que se afirmaba - transponiendo el Derecho comunitario - que «ninguna disposición que entrañe la pérdida de los derechos adquiridos [droits acquis]... a prestaciones de retiro... de los... antiguos trabajadores en caso de insolvencia [insolvabilité] del empleador o de transmisión [transfert] de empresas, de centros de trabajo o de partes de centros de trabajo a otro empresario..., puede ser insertada bajo sanción de nulidad en los convenios colectivos» ${ }^{20}$. Pero la Corte de Casación — supuesto que no existía ni insolvencia del empleador ni traspaso de empresa - confirmó la legalidad del acuerdo colectivo en cuestión, afirmando lacónicamente que «los trabajadores jubilados... tenían derecho al mantenimiento del nivel de pensión alcanzado... hasta el acuerdo colectivo de sustitución..., sin poder prevalerse, más allá de esta fecha, de las modalidades de revalorización instituidas por el acuerdo colectivo denunciado, que constituyen una ventaja colectiva y no una ventaja individual» ${ }^{21}$.

Este caso francés se refería a unos antiguos trabajadores jubilados de cierta empresa, que venían disfrutando de pensiones complementarias voluntarias de jubilación reguladas en el convenio colectivo de la propia empresa ${ }^{22}$, las cuales dejaron de revalorizarse - contra lo originariamente previsto, desde 1950-, al estipularse «un acuerdo [colectivo] de sustitución de 19 diciembre $1997 \gg^{23}$.

§5. Ahora bien, la jurisprudencia de otros dos grandes países del continente europeo acredita, con toda rotundidad, que una conclusión distinta también resultaba jurídicamente defendible. Así, en Alemania ${ }^{24}$,

18 Núm. de recurso 02-46581.

19 Al respecto, véase J. PÉLISSIER, A. SUPIOT, y A. JEAMMAUD, Droit du travail, 24a ed., Dalloz (Paris, 2008), págs. 1362 y ss.

20 Cfr. artículo L. 913-2 del Código del Trabajo de 1973.

21 Cfr. Attendu tercero.

22 Acerca de la distinción típicamente francesa entre seguridad social complementaria «obligatoria» y «voluntaria», véase F. KESSLER, Droit de la Protection Sociale, 2ª ed., Dalloz (París, 2005), págs. 409 y ss.

23 Cfr. Attendu primero.

24 Al respecto, véase W. DÄUBLER, Arbeitsrecht. Ratgeber für Beruf, Praxis und Studium, $6^{\mathrm{a}}$ ed., Bund-Verlag (Frankfurt a.M., 2006), pág. 370. 
el Tribunal Federal de Trabajo en Sentencia de su Sala 3, de 25 octubre $1988^{25}$, a propósito de un supuesto de hecho del todo idéntico a los enjuiciados por las sentencias citadas del Tribunal Supremo español y de la Corte de Casación francesa - esto es, trabajadores jubilados perceptores de pensiones de jubilación complementarias creadas (y luego suprimidas o empeoradas) por convenio colectivo (en este caso alemán, por un «acuerdo de empresa [Betriebsvereinbarung]»)-, en cambio, sostuvo la intangibilidad del derecho adquirido por el pension ist a demandante (según el Tribunal Federal de Trabajo, aunque su «derecho era al principio un derecho derivado de un acuerdo de empresa», el mismo «se ha convertido en el momento del retiro del actor... en un derecho de crédito autónomo [einem selbständigen schuldrechtlichen Anspruch]») ${ }^{26}$, razonando lo siguiente: 1) que «la eficacia normativa de un acuerdo de empresa [como el acuerdo novatorio atacado]... sólo se despliega sobre los actualmente pertenecientes a la empresa» ${ }^{27}$; 2) que "falta el derecho del comité de empresa a representar a los trabajadores retirados» ${ }^{28}$, puesto que la empresa «no puede negar que los trabajadores retirados no participan en las elecciones al comité de empresa y que tampoco pueden activar ningún procedimiento de revocación o disolución» ${ }^{29}$; y 3) que «con esta solución no surgen... sospechas acerca de si el comité de empresa dejará de lado los intereses de los trabajadores respectivos, que no participan en la elección del comité de empresa ${ }^{30}$. Y en la hipótesis de Italia ${ }^{31}$, la Sentencia de la Sección Trabajo de la Corte de Casación núm. 2361, de 20 marzo 1996 ${ }^{32}$, sostuvo asimismo que «el trato de favor debido a los pensionistas... no se atribuye por la ley sobre aseguramiento obligatorio, ni se pone a cargo de ninguna de las gestoras comprendidas en él, sino que tiene un

25 Referencia 3 AZR 483/86.

26 Cfr. Fundamentos de la Decisión, marginal 15.

27 Ibidem, marginal 17.a).

28 Ibidem.

29 Ibidem, marginal 19.c), párrafo segundo.

30 Ibidem, marginal 21.

31 Desde el punto de vista doctrinal, véase L. GALANTINO, Diritto Sindacale, 4 ${ }^{\mathrm{a}}$ ed., G. Giappichelli (Turín, 1993), págs. 193 y ss.; M. PERSIANI, Diritto Sindacale, 7 7a ed., CEDAM (Padua, 2000), págs. 125 y ss.; TURSI, A. y VARESI, P.A., Lineamenti di Diritto del Lavoro. Rapporti di lavoro e relazioni sindacali nel settore privato, $3^{\mathrm{a}}$ ed., Kluwer-Ipsoa (s.1., 2004), págs. 325 y ss.; y R. PESSI, Lezioni di Diritto della Previdenza Sociale. III. Parte Speciale, $4^{a}$ ed., CEDAM (Padua, 2005), págs. 197 y ss.

32 Dada nuestra imposibilidad de acceder a www.italgiure.giustizia.it, el texto íntegro de esta Sentencia me fue facilitado por la Profesora Anna ALAIMO, de la Universidad de Catania, a quien quiero expresar mi agradecimiento. 
fundamento contractual, susceptible de constituir el resultado de un acto de previsión voluntario que tiene la naturaleza facultativa prevista por el artículo 2123 [del] C[]ódigo] C[ivil] y la finalidad de incrementar la cuantía de la pensión derivada del aseguramiento obligatorio» ${ }^{33}$, por lo que «de ello se sigue que, para las relaciones laborales extinguidas durante la vigencia de una determinada fuente colectiva, los derechos atribuidos por el convenio... no pueden ser influenciados por la estipulación de sucesivos convenios (cuyo objeto se limita a las relaciones laborales en curso), salvo que los trabajadores cesados hayan conferido específico mandato a las organizaciones sindicales negociadoras o ratificado la actividad negocial, o incluso, hayan prestado su aquiescencia a las nuevas normativas» ${ }^{34}$.

Esta misma Sentencia italiana rechazó igualmente «la tesis de que el trabajador cesado... consiente la eficacia de todas las sucesivas modificaciones de las fuentes colectivas de sus derechos» - lo que, según el consorcio demandado, «constituía aquiescencia a las modificaciones introducidas con la nueva reglamentación colectiva ${ }^{35}$ - pues «no es posible atribuir contenido negocial de renuncia al comportamiento [del trabajador jubilado]..., si no se acompaña de otros elementos que inequívocamente demuestren su voluntad de dimisión del derecho» ${ }^{36}$.

La «Ley de Organización de la Empresa [Betriebsverfassungsgesetz]» de 1972, al referirse a la actuación del «órgano arbitral» si «no se logra un acuerdo sobre el plan social», viene a reforzar la doctrina citada del Tribunal Federal de Trabajo, al mencionar única y exclusivamente los derechos en curso de adquisición - pero no los derechos adquiridos-, puesto que el órgano en cuestión «debe prever prestaciones para la compensación o la mitigación de perjuicios económicos, en especial a través de la disminución de ingresos, supresión de prestaciones especiales o pérdida de derechos en curso de adquisición [Anwartschaften] en seguros empresariales de jubilación, gastos de traslado o incrementos por gastos de viaje, que tengan en cuenta como regla las circunstancias del caso concreto» ${ }^{37}$.

En Portugal, aunque no conozcamos caso sobre el tema, la vigente Ley núm. 4/2007, de 16 enero, que «aprueba las bases generales del sistema de seguridad social [aprova as bases gerais do sistema de segurança social]», proclama con carácter general el «principio de la tutela de los derechos adquiridos y en formación [principio da tutela dos direitos adquiridos e em formação]» ${ }^{38}$, confirmando luego su respeto no sólo en relación con la seguridad social básica ${ }^{39}$, sino también en relación con la seguridad social complementaria ${ }^{40}$.

33 Fundamento de Derecho 2.

34 Fundamento de Derecho 3.

35 Ibidem.

36 Ibidem.

37 Parágrafo 112, apartado 5, número 1.

38 Cfr. artículo 20.

39 Cfr. artículo 66.

40 Cfr. artículo 86.2. 
§6. También en la misma línea, la Corte Suprema de los Estados Unidos, en el caso Central Laborers' Pension Fund v. Heinz et al. (fallado el 7 junio 2004) ${ }^{41}$, sostuvo la imposibilidad de que los derechos adquiridos de los beneficiarios de un plan multiempresarial de pensiones pudiesen ser recortados mediante una enmienda posterior de las especificaciones del plan (que ampliaba la lista de trabajos incompatibles susceptibles de poder ser realizados por los beneficiarios del propio plan). La médula del caso fue la interpretación que debía darse a la sección 204(g)(1) de la «Ley de Seguridad de los Ingresos por Retiro del Trabajador [Employee Retirement Income Security Act]》 de 1974 —más popularmente conocida, por su acrónimo en inglés, como ERISA-, a cuyo tenor «la prestación adquirida por un participante al amparo de un plan no puede ser disminuida por una modificación del plan [the accrued benefit of a participant under a plan may not be decreased by an amendment of the plan]» ${ }^{42}$. Pues bien, frente a la interpretación estricta de esta regla propuesta por los administradores del plan de pensiones (según ellos, «se aplica solamente a las modificaciones que alteren directamente la cantidad nominal en dólares de la pensión mensual del jubilado») ${ }^{43}$, la Corte Suprema norteamericana sostuvo que la regla en cuestión (que coloquialmente califica como "la regla "anti-recorte retroactivo" [the "anti-cutback" rule]») debía ser interpretada en sentido amplio (y en consecuencia, en favor de los derechos de los retirados), pues — según el Juez SOUTER — «nada en ERISA obliga a los empresarios a establecer planes de pensiones para los trabajadores» ${ }^{44}$, aunque «ERISA busca, sin embargo, asegurar que los trabajadores no serán dejados con las manos vacías [will not be left empty-handed] una vez que los empresarios les han garantizado ciertas prestaciones» ${ }^{45}$.

La Corte Suprema rechazó la «lectura estricta [constricted]» del precepto en cuestión, pues «las prestaciones del beneficiario no pueden ser entendidas sin referencia a las condiciones impuestas para recibir esas prestaciones», de modo que «una modificación imponiendo de hecho restricciones mayores en la recepción de la prestación la "reduce", seguramente de igual modo que una disminución de su importe mensual» ${ }^{46}$; y todo ello,

\footnotetext{
41 Referencia 541 US 739.

42 Esta regla aparece actualmente recopilada en la sección 1054(g)(1) del Título 29 del Código de los Estados Unidos.

43 Cfr. Apartado II-B, párrafo primero, inciso primero.

44 Cfr. Apartado II-A, párrafo primero.

45 Ibidem.

46 Cfr. Apartado II-A, párrafo tercero.
} 
a diferencia de lo que ocurriría si se hubiese litigado sobre meros derechos en curso de adquisición, pues el plan «puede ser enmendado para eliminar o reducir... prestaciones, con respecto a prestaciones aún no adquiridas [not yet accrued $] \gg{ }^{47}$.

§7. Como era previsible, el Derecho de la Unión Europea no ha tenido más remedio que acabar regulando los planes y fondos de pensiones, en cuanto que instrumentos llamados a suceder a la seguridad social complementaria empresarial, financiada - sin perspectivas de futuro- con cargo a fondos internos de las propias empresas ${ }^{48}$. Ahora bien, en lo tocante a la protección de los derechos adquiridos, la norma comunitaria sobre el tema - que es la Directiva $2003 / 41 / \mathrm{CE}$ del Parlamento Europeo y del Consejo, de 3 junio 2003, relativa a actividades de supervisión de fondos de pensiones de empleo-resulta decepcionante. En efecto, a diferencia de lo que ocurre en el Derecho federal norteamericano, su articulado no contiene ni una sola referencia expresa a los derechos adquiridos, estando obsesionada sólo por «garantizar un elevado grado de seguridad para los futuros pensionistas» ${ }^{49}$ - con olvido de dar seguridad a los pensionistas de presente-, lo que posibilita que incluso acabe primando en la transposición de esta norma a las legislaciones nacionales europeas la protección de los derechos en curso de adquisición (de titularidad de los «partícipes» del plan, o futuros pensionistas) sobre la que deberían merecer los «beneficiarios» del propio plan, o pensionistas actuales (únicos titulares de verdaderos derechos adquiridos) ${ }^{50}$.

El Real Decreto 304/2004, de 20 febrero, por el que se aprueba el Reglamento de Planes y Fondos de Pensiones - que es la norma que transpone a nuestra legislación interna la citada Directiva 2003/41/CE_, además de no contener ni una sola referencia expresa a los derechos adquiridos, prioriza sistemáticamente — respecto de los planes y fondos de pensiones de empleo- la posición de los «partícipes» (eventuales titulares de los que denomina «derechos consolidados») sobre la de los «beneficiarios» (titulares actuales de los por él asépticamente llamados «derechos económicos»).

En efecto, según este Reglamento español, téngase en cuenta: 1) que en la «comisión de control del plan» —órgano al que se asignan, entre otras importantes competencias, la de «proponer y, en su caso, acordar las modificaciones que estime pertinentes sobre

47 Cfr. Apartado II-C, párrafo segundo, inciso tercero.

48 Al respecto, véase J. MARTÍNEZ GIRÓN, A. ARUFE VARELA y X.M. CARRIL VÁZQUEZ, Derecho de la Seguridad Social, $2^{\text {a }}$ ed., Netbiblo (A Coruña, 2008), págs. 289 y ss.

49 Cfr., por ejemplo, su Considerando séptimo.

50 La única alusión expresa de esta norma a los derechos adquiridos aparece contenida en su Considerando $18^{\circ}$, pero se refiere, en realidad, a los derechos en curso de adquisición (literalmente, «en caso de quiebra de una empresa promotora, el partícipe puede perder su empleo y sus derechos de pensión adquiridos»). 
aportaciones, prestaciones $\mathrm{u}$ otras variables o aspectos del plan de pensiones» ${ }^{51}, \mathrm{y}$ también, la de «representar judicial y extrajudicialmente los intereses colectivos de los partícipes y beneficiarios en relación con el plan de pensiones» ${ }^{52}$ - la presencia de los «partícipes» tiene carácter necesario, mientras que la de los «beneficiarios» sólo resulta contingente, previéndose incluso que en tal comisión «la representación de los beneficiarios venga atribuida a la representación de los partícipes» ${ }^{53}$; 2) que los «derechos consolidados» de los partícipes están garantizados por el fondo correspondiente - pero no, en cambio, los «derechos económicos» de los beneficiarios ${ }^{54}$-, afirmándose incluso en relación con los planes de aportación definida, sin duda los más frecuentes, que «a partir del acaecimiento de la contingencia podrá garantizarse a los beneficiarios la cuantía de las prestaciones causadas, siempre que dicha garantía se instrumente a través de los correspondientes contratos previstos por el plan con entidades aseguradoras $u$ otras entidades financieras, el cual en ningún caso asumirá los riesgos inherentes a dichas prestaciones» ${ }^{55}$; y 3) frente a una cierta posibilidad de «movilización» de los «derechos consolidados» de los «partícipes» a otro plan - con la consiguiente «movilización de los recursos económicos» de un fondo a otro ${ }^{56}$ que los «beneficiarios» permanecen siempre cautivos, pues «los derechos económicos de los beneficiarios en los planes de empleo no podrán movilizarse salvo por terminación del plan de pensiones» ${ }^{57}$.

Añádase a todo esto la eventual contraposición e, incluso, contradicción de intereses de «partícipes» y «beneficiarios», para comprender — dada la eminente capacidad decisoria de los primeros - la situación de indefensión en que pueden llegar a quedar los derechos adquiridos de los segundos. La contraposición de intereses entre ambos no necesita de prueba ninguna, pues la declara este Reglamento español, al indicar que «con carácter general, no se podrá simultanear la condición de partícipe y la de beneficiario por una misma contingencia en un plan de pensiones o en razón de la pertenencia a varios planes de pensiones» ${ }^{58}$. La posible insolidaridad de los primeros respecto de los segundos ${ }^{59}$ — sólo neutralizable

51 Cfr., en relación con los planes de empleo, su artículo 29.c).

52 Siempre en relación con los planes de empleo, véase su artículo 29.f).

53 Cfr., en relación con los planes de empleo, su articulo 31.3.a), párrafo tercero; también, artículo 31.3.b), párrafo tercero.

54 Reforzando la garantía de los primeros, su artículo 22.7 sienta la regla general de que «los derechos consolidados del partícipe en un plan de pensiones no podrán ser objeto de embargo, traba judicial o administrativa, hasta el momento en el que se cause el derecho a la prestación».

55 Cfr. su artículo 16.a), párrafo cuarto. Por su parte, el artículo 34.3, párrafo primero, afirma que «producida y comunicada la contingencia, el beneficiario del plan de pensiones de empleo deberá recibir información apropiada sobre la prestación y sus posibles reversiones, sobre las opciones de cobro correspondientes, en su caso, y respecto del grado de garantía o del riesgo de cuenta del beneficiario». Además, el artículo 19.4, párrafo $3^{\circ}$, excluye la posibilidad de contratar, siempre respecto de los «beneficiarios», seguros o garantías «de carácter colectivo».

56 Cfr., en relación con los planes de pensiones de empleo, su artículo 35.3.

57 Cfr., siempre en relación con los planes de pensiones de empleo, su artículo 35.5.

58 Artículo 11.1, párrafo primero.

59 Eventualmente formalizada mediante la estipulación de un convenio colectivo, pues el Reglamento afirma que «en los planes de pensiones del sistema de empleo las especificaciones podrán prever que la modificación del régimen de prestaciones y aportaciones o cualesquiera otros extremos y, en su caso, la consiguiente adaptación de la base técnica pueda ser acordada, conforme a lo previsto en este Reglamento, mediante acuerdo colectivo entre la empresa y la representación de los trabajadores» (artículo 33.1, párrafo segundo; también, artículo 42.1, párrafo segundo). Sobre el tema, J. MARTINEZ GIRON, A. ARUFE VARELA y X.M. CARRIL VAZQUEZ, Derecho de la Seguridad Social, $2^{a}$ ed., cit, págs. 290-291; además, J.L. MONEREO PÉREZ y J.A. FERNÁNDEZ BERNAT, Las especificaciones de los planes de pensiones del sistema de empleo. Un estudio técnico de la experiencia negociadora, Comares (Granada, 2004), págs. 2 y ss. 
mediante una proclamación general de la necesidad de respetar los derechos adquiridos, al igual que ocurre en los Estados Unidos, que son al menos en esto todavía más grandes que nosotros, los europeos unidos - resultó evidenciada en la Sentencia de la Sala de lo Social del Tribunal Superior de Justicia del País Vasco luego revocada por la de nuestro Tribunal Supremo de 2003, que antes se criticó, pues en ella se afirma - a propósito de la supresión del complemento de pensión de jubilación, colectivamente acordada por los representantes en la empresa de los trabajadores en activo- que «hay que poner en cuarentena el carácter razonable y solidario de esa medida» ${ }^{60}$, pues «desde la perspectiva de los trabajadores en activo, la situación no es comparable, ya que éstos no han visto reducidos sus salarios en un porcentaje similar a lo que, para los demandantes, les supone el complemento litigioso» ${ }^{61}$, constando incluso «que tanto en el año 1999 como en el 2000 han tenido un incremento retributivo» ${ }^{62} ; \mathrm{y}$ además, porque «la supresión del complemento, para ellos, no es la pérdida de un derecho, sino de una simple expectativa, que podían o no causar e, incluso, que aún pueden llegar a causar (si, en el futuro, se vuelve a introducir [por convenio colectivo])» ${ }^{63}$.

\footnotetext{
60 Cfr. su Fundamento de Derecho segundo, apartado E), párrafo segundo.

61 Ibidem, párrafo cuarto, inciso primero.

62 Ibidem, inciso segundo.

63 Ibidem, inciso tercero.
} 


\section{ALEMANIA}

Accidente de trabajo in itinere: 20-2. Acuerdos de empresa: 11-3; 12-3; 13-2.

Acuerdos de empresa pública: 13-2.

Agencia Federal de Empleo: 6-2; 9-2.

Automaticidad de las prestaciones: 21-3.

Cajas sanitarias: 9-2.

Cierre patronal. 14-2.

Código Civil: 3-2.

Código de Seguridad Social: 2-3; 6-2; 7-5; 9-2; 21-3.

Código del Trabajo de la República

Democrática de Alemania: 2-3.

Cogestión en el centro de trabajo: 12-1.

Cogestión en la empresa: 12-1.

Comités de empresa: 12-3.

Contencioso de la seguridad social: 10-2.

Contencioso laboral: 8-1.

Contrato de trabajo:

A tiempo parcial: 15-3.

Cláusula de exclusión de jornada:

17-3.

Duración: 15-3.

Estabilidad en el empleo: 15-3.

Protección contra el despido: 19-2.

Relación laboral: 15-3.

Convenios colectivos:

Capacidad negocial: 11-3.

Eficacia general: 13-2.

Eficacia normativa limitada: 13-2.

Publicidad: 4-3.

Derecho del Trabajo: 3-2.

Despido colectivo: 18-2.

Despido individual: 19-2.
Escabinato:

En los Tribunales para materias de Seguridad Social: 10-2.

En los Tribunales para materias de

Trabajo: 8-1.

Fundación Hans Böckler: 4-3.

Gestoras de prestaciones: 9-2; 21-3.

Huelga:

Deber de paz: 14-2.

Luchas laborales: 14-2.

Paridad en la lucha: 14-2.

Servicios de mantenimiento: 14-2.

Subsidio de huelga: 14-2.

Insolvencia del empresario: 18-4.

Inspecciones de Trabajo: 7-3.

Jornada de trabajo: 17-3.

Ley de Enjuiciamiento Civil: 8-1.

Libertad sindical: 11-1.

Los «cinco pilares»: 9-2.

Mercado de trabajo: 3-2.

Ministerio federal de Justicia: 2-3.

Ministerio federal de Trabajo y de

Seguridad Social: 2-3; 3-2; 4-3; 6-2.

Modelo de difusión del Derecho a través de Internet: 1-3.

Mutuas patronales de accidentes de trabajo: 7-5; 9-2.

Paz laboral: 12-3; 14-2.

Políticas de empleo: 6-2.

Prestaciones de oficio: 2-3.

Prestaciones de servicios transnacionales: 17-1.

Protección [frente a los riesgos] del trabajo: 3-2.

Registros de convenios colectivos: 4-3.

El primer número remite al Tema y el segundo número al epígrafe dentro de dicho Tema, de manera que 3-3 significa Tema 3, §3. 
Salario mínimo interprofesional inexistente: 17-4.

Seguridad social complementaria:

Derechos adquiridos: 21-5.

Seguridad y salud laboral: 16-2.

Sindicatos reconocidos: 11-3.

Traspasos de empresas: 18-3.

Tratado de unificación de 1990: 2-3.

Tribunal Federal Constitucional: Jurisprudencia: 5-3.

Tribunal Federal de Seguridad Social: 10-2. Jurisprudencia: 5-3.

Tribunal Federal del Trabajo: 8-1. Jurisprudencia: 5-3.

Tribunal Federal Supremo: Jurisprudencia: 5-3.

Tribunales de Seguridad Social: 10-2.

Tribunales de Trabajo: 8-1.

Tribunales de Trabajo del Estado federado: 8-1.

Tribunales Estatales de Seguridad Social: $10-2$.

Unwissenheit schützt vor Strafe nicht: 1-1.

\section{AUSTRIA}

Modelo de difusión del Derecho a través de Internet: 1-3.

Seguridad y salud laboral: 16-2.

\section{BÉLGICA}

Despido colectivo: 18-2.

Traspasos de empresas: 18-3.

\section{ESPAÑA}

Accidente de trabajo in itinere: 20-1.

Administración de Seguridad Social: 3-4.

Agencia de la Seguridad Social: 9-1.

Automaticidad de las prestaciones: 21-1.

Código de Trabajo: 2-1.

Código del Trabajo de 1926: 2-1.

Comisión Consultiva Nacional de

Convenios Colectivos: 4-1.

Consejo Andaluz de Relaciones

Laborales: 4-1.
Consello Galego de Relacións Laborais: 4-1.

Contencioso de la seguridad social: 10-1.

Despido colectivo: 18-2.

Entidades gestoras: 9-1.

Insolvencia del empresario: 18-4.

Inspección de Trabajo y Seguridad Social: 7-3.

Jornada de trabajo: 17-3.

La ignorancia de las leyes no excusa de su cumplimiento: 1-1.

Ministerio de Trabajo y Asuntos Sociales: 3-4; 4-1.

Modelo de difusión del Derecho a través de Internet: 1-3.

Políticas de empleo: 6-4.

Portal del Poder Judicial: 5-2.

Portal del Tribunal Constitucional: 5-2.

Recopilaciones castellanas: 2-1.

Registros de convenios colectivos: 4-1.

Representantes unitarios: 12-3.

Salario mínimo interprofesional: 17-4.

Seguridad social complementaria:

Derechos adquiridos: 22-1; 22-3.

Seguridad y salud laboral: 16-2.

Servicio Público de Empleo Estatal: 6-4.

Servicios Públicos de Empleo de las Comunidades Autónomas: 6-4.

Sindicatos más representativos: 11-2.

Tesorería General de la Seguridad Social: 9-1.

Traspasos de empresas: 18-3.

«060»: 3-4.

\section{ESTADOS UNIDOS}

Abogados: 10-5.

Accidente de trabajo: 15-5; 16-3.

Accidente de trabajo in itinere: 20-3.

Adaptación a la globalización: 18-6.

Administración de Empleo y Formación: $6-5 ; 18-6$.

Administración de Seguridad Social: 9-5. Doctrina: 5-5.

Administración de Seguridad y Salud Laboral (OSHA): 7-7; 16-3.

Alabama:

Salario mínimo interprofesional inexistente: 17-5. 
Automaticidad de las prestaciones: 21-4.

California:

Código de Procedimiento Civil: 8-4.

Código del Seguro de Desempleo:

6-5.

Código del Trabajo: 2-5; 6-5; 7-7;

15-5.

Contratista de trabajo: $15-5$.

Cortes de Derecho Común: 8-4.

Despido libre: 15-5.

Inspección de Trabajo: 7-7.

Salario mínimo interprofesional: 17-5.

Carolina del Sur:

Salario mínimo interprofesional inexistente: 17-5.

Cierre patronal: 14-5.

Código de los Estados Unidos: 2-5.

Código de Reglamentos Federales: 2-5; $16-3 ; 18-7$.

Comisión de Revisión de Seguridad y

Salud Laboral: 8-4.

Doctrina: 5-5.

Comisión para la Oportunidad de un

Empleo Igual: 8-4.

Comisionado de Seguridad Social: 9-5; 10-5.

Contencioso de la seguridad social: 10-5.

Contratistas de trabajo: 15-5.

Contrato de trabajo:

A voluntad: 15-5.

Despido libre: $15-5$; 19-5.

Duración: 15-5.

Convenios colectivos:

Acciones por incumplimiento: 13-5.

Eficacia normativa general: 13-5.

Cortes Federales de Apelaciones: 8-4; 10-5.

Jurisprudencia: 5-5.

Reglas Federales del

Procedimiento de Apelación: 8-4.

Cortes Federales de Distrito: 8-4; 10-5; 13-5.

Jurisprudencia: 5-5.

Reglas Federales de

Procedimiento Civil: 8-4.

Corte Suprema de los Estados Unidos:

$8-4 ; 10-5$

Jurisprudencia: 5-5.

Reglas de la Corte Suprema de los

Estados Unidos: 8-4.
Departamento de Trabajo: 4-5; 6-5; 16-3; 18-6.

Deslocalizaciones: 18-6.

Despido colectivo: 18-7.

Despido individual: 19-5.

Empresas de trabajo temporal: 15-5.

Gestión de prestaciones: 9-5.

Gestión instrumental de la seguridad social: 9-5.

«Gobierno de la mayoría»: 11-5.

Huelga:

Empleados públicos: 14-5.

Esquiroles: 14-5.

Formalidades: 14-5.

Objetivos: 14-5.

Inspección de Trabajo: 7-7.

Jornada de trabajo: 17-5.

Mississippi:

Salario mínimo interprofesional inexistente: $17-5$.

Modelo de difusión del Derecho a través de Internet: 1-5.

Montana:

Abolición del despido libre: 15-5;

19-5.

Código laboral: 19-5.

Negociación colectiva de buena fe: 13-5.

Oficina de Condiciones Mínimas entre

Empresarios y Sindicatos: 4-5.

Oficina de Estadísticas Laborales: 4-5; 16-3.

Oficina de Gestión del Personal: 6-5.

Oficina de Mediación Nacional: 4-5.

Oficina Nacional de Relaciones

Laborales: 5-5; 8-4; 11-5; 12-5.

Oklahoma:

Ignorance of the law does not

excuse from punishment for its

violation: 1-1.

Pactos de seguridad sindical: 11-5.

Políticas de empleo: 6-5.

Programas de participación del trabajador: 12-5.

Registros de convenios colectivos: 4-5.

Salario mínimo federal: 17-5.

Seguridad social:

Programas federales: 21-4.

Seguridad social complementaria:

Derechos adquiridos: 22-6.

Seguridad y salud laboral: 16-3. 
Servicio de Empleo de los Estados Unidos: 6-5. Shop stewards: 12-5.

Sindicatos reconocidos: 11-5.

Tennessee:

Salario mínimo interprofesional inexistente: 17-5.

\section{FRANCIA}

Accidente de trabajo in tinere: 20-2.

Agencia Nacional para el Empleo

(ANPE): 6-3.

ASSEDIC: 6-3; 9-2.

Automaticidad de las prestaciones: 21-3.

Boletín Oficial de los convenios colectivos: 4-2.

Cierre patronal: $14-3$.

Codificación en Derecho constante: 2-2.

Código de la Acción Social y de las Familias: 2-2.

Código de la Organización Judicial: 5-2; 8-2.

Código de la Seguridad Social: 2-2; 9-2; 21-3.

Código de Procedimiento Civil: 8-2.

Código del Trabajo: 2-2; 6-3; 8-2; 9-2; $11-2 ; 13-3 ; 14-3 ; 15-3$.

Comisiones departamentales de asistencia social: 10-4.

Consejo de Hombres Prudentes: 8-2.

Contencioso de la seguridad social: 10-4.

Contrato de trabajo:

Duración: 15-3.

Estabilidad en el empleo: 15-3.

Precariedad: 15-3.

Protección contra el despido: 19-3.

Convenios colectivos:

Ampliación: 13-3.

Duración indefinida: 13-3.

Eficacia normativa limitada: 13-3.

Extensión: 13-3.

Corte de Casación: 8-2; 10-4.

Despido colectivo: $18-2$.

Despido individual: 19-3.

Diario Oficial de la República: 4-2.

Entidades gestoras del Régimen General: 9-2.
Escabinato:

En los Consejos de Hombres

Prudentes: 8-2.

Huelga:

Económico-política: 14-3.

Esquirolaje interno: 14-3.

Servicios mínimos: 14-3.

Insolvencia del empresario: 18-4.

Inspección de Trabajo: 7-6.

Jornada de trabajo: 17-3.

Jurisprudencia:

Del Consejo Constitucional: 5-2.

Del orden administrativo: 5-2.

Del orden judicial: 5-2.

Legifrance: 2-2.

Libertad sindical: 11-1.

Modelo de difusión del Derecho a través de Internet: 1-2.

Nuevo Código del Trabajo de 2007: 2-2.

Nul n'est censé ignorer la loi: 1-1.

Prestaciones de servicios transnacionales: 17-1.

Registros de convenios colectivos: 4-2.

Representantes unitarios:

Comités de empresa: 12-2.

Delegados del personal: 12-2.

Salario mínimo interprofesional: 17-4.

Seguridad social complementaria:

Derechos adquiridos: 22-3.

Seguridad y salud laboral: 16-2.

Sindicatos representativos a nivel nacional: 11-2.

Traspasos de empresas: 18-3.

Tribunales de asuntos de la seguridad social: 10-4.

Tribunales del contencioso de la incapacidad: 10-4.

\section{GRAN BRETAÑA}

Accidente de trabajo in itinere: 20-3.

Administración de Salud y Seguridad:

$$
\text { 3-5; 7-4. }
$$

Automaticidad de las prestaciones: 21-4.

Cámara de los Lores: 8-3; 10-2.

Jurisprudencia: 5-4.

Cierre patronal: 14-4. 
Códigos de Prácticas: 2-5.

Comisionados de Renta y Aduanas de $\mathrm{Su}$ Majestad: 9-3; 10-2.

Comisionados Generales: 10-2.

Comité central de arbitraje: 11-3.

Contencioso de la seguridad social: 10-2.

Contrato de trabajo:

Cláusula de exclusión de jornada:

17-3.

Duración: 15-4.

Falta de estabilidad en el empleo: 15-4.

Igualdad de trato de los precarios: 15-4.

Protección contra el despido: 19-4.

Convenios colectivos:

Falta de eficacia normativa: 13-4.

Corte Suprema del Reino Unido: 5-4; 8-3; 10-2.

Cortes de Derecho común: 8-3.

Jurisprudencia: 5-4.

Reglas de Procedimiento Civil: 8-3.

Departamento de Comercio e Industria: 3-5.

Departamento de Trabajo y Pensiones: $3-5 ; 6-2 ; 9-3$.

Despido colectivo: 18-2.

Despido individual: 19-4.

Discriminación en el empleo: 3-5.

Huelga:

Conflicto laboral: 14-4.

Emergencia: 14-4.

Libertad: 14-4.

Votaciones para la declaración: 14-4.

Insolvencia del empresario: 18-4.

Inspección de Trabajo: 7-4.

Instituto Británico e Irlandés de

Información Jurídica (BAILII): 5-4.

Jobcentre Plus: 6-2.

Jornada de trabajo: 17-3.

Modelo de difusión del Derecho a través de Internet: 1-3.

Negociación colectiva permanente: 13-4.

Pactos de seguridad sindical: 11-3.

Políticas de empleo: 6-2.

Prestaciones de servicios transnacionales:

17-1.
Registros de convenios colectivos: 4-3.

Salario mínimo interprofesional: 17-4.

Shop stewards: 12-5.

Seguridad y salud laboral: 16-2.

Sindicatos reconocidos: 11-3.

Traspasos de empresas: 18-3.

Tribunal de Apelación de Empleo: 8-3.

Doctrina: 5-4.

Tribunal Superior: 10-2.

Doctrina: 5-4.

Tribunales de Empleo: 3-5; 8-3.

GRAN DUCADO

DE LUXEMBURGO

Seguridad y salud laboral: 16-2.

\section{GRECIA}

Insolvencia del empresario: 18-4.

INDIA

Código electrónico de leyes: 2-5.

IRLANDA

Instituto Británico e Irlandés de

Información Jurídica (BAILII): 5-4.

Seguridad y salud laboral: 16-2.

\section{ITALIA}

Accidente de trabajo in itinere: 20-2.

Agencia Técnica Italia Lavoro: 6-4.

Automaticidad de las prestaciones: 21-2.

Carabinieri: 7-2.

Cierre patronal: 14-3.

Código Civil: 3-4; 21-2.

Código de Procedimiento Civil: 3-4; 8-2.

Consejo Nacional de la Economía y del

Trabajo: 4-3.

Contencioso de la seguridad social: 10-3.

Contrato de trabajo:

Duración: 15-4.

Estabilidad en el empleo: 15-4.

Protección contra el despido: 19-2. 
Convenios colectivos:

Eficacia normativa general: 13-3.

Eficacia normativa limitada: 13-3.

Corte Constitucional:

Jurisprudencia: 5-3.

Corte Suprema de Casación: 8-2.

Jurisprudencia: 5-3.

Despido colectivo: $18-2$.

Despido individual: 19-2.

Huelga:

Comisión de garantía: 14-3.

Esquirolaje interno: 14-3.

Servicios públicos esenciales: 14-3.

Insolvencia del empresario: 18-4.

Inspección de Trabajo: 7-2.

Instituto Nacional de la Previsión Social (INPS): 6-4; 9-2.

Instituto Nacional de Previsión para los

Dependientes de la Administración

Pública (INPDAP): 9-2.

Instituto Nacional para el Aseguramiento contra los Riesgos del Trabajo

(INAIL): 9-2.

Jornada de trabajo: 17-3.

Libertad sindical: 11-1.

Ministerio del Trabajo y de la Solidaridad Social: 3-4.

Modelo de difusión del Derecho a través de Internet: 1-3.

Nessuno può invocare a propria scusa l'ignoranza della legge penale: 1-1.

Ocupación y mercado de trabajo: 3-4.

Orientación y formación profesional: 3-4.

Políticas de empleo: 6-4.

Registros de convenios colectivos: 4-3.

Representantes de seguridad: 16-1.

Representaciones sindicales unitarias: 12-3.

Salario mínimo interprofesional inexistente: 17-4.

Seguridad social: 3-4.

Seguridad social complementaria:

Derechos adquiridos: 22-5.

Seguridad y salud laboral: $16-2$.

Servicios Regionales de Empleo: 6-4.

Sindicatos comparativamente más representativos: 11-2.

Traspasos de empresas: 18-3.
Tutela de las condiciones de trabajo: 3-4.

Vigilancia: 3-4.

\section{PORTUGAL}

A ignorância ou má interpretacão da lei não justifica a falta do seu cumprimento nem isenta as pessoas das sanções nela estabelecidas: 1-1.

Accidente de trabajo in itinere: 20-2.

Acción social: 3-3.

Automaticidad de las prestaciones: 21-2.

Boletín Oficial del Ministerio de Trabajo: 4-2.

Centro nacional de pensiones: 3-3.

Cierre patronal: $14-3$.

Código Civil: 5-2.

Código de Proceso de Trabajo: 2-4; 8-2.

Código del Proceso Civil: 5-2.

Código del Trabajo: 2-4; 13-2; 14-3; 15-3.

Contencioso de la seguridad social: 10-3.

Contrato de trabajo:

Duración: 15-3.

Estabilidad en el empleo: 15-3.

Protección contra el despido: 19-2.

Convenios colectivos:

Eficacia normativa limitada: 13-2.

Despido colectivo: 18-2.

Despido individual: 19-2.

Gabinete de Estudios y Planificación: 4-2.

Escabinato:

En los Tribunales del Trabajo: 8-2.

Huelga:

Servicios de mantenimiento: 14-3.

Servicios mínimos: 14-3.

Insolvencia del empresario: 18-4.

Inspección de Trabajo: 7-5.

Instituto de Gestión Financiera de la

Seguridad Social, I.P.: 9-3.

Instituto de la Seguridad Social, I.P.: 6-3; 9-3.

Instituto de las Tecnologías de Información en la Justicia: 5-2.

Instituto del Empleo y Formación

Profesional: 6-3.

Jornada de trabajo: 17-3.

Jurisprudencia: 5-2. 
Libertad sindical: 11-1.

Ministerio de Justicia: 5-2.

Ministerio del Trabajo y de la Solidaridad Social: 2-4; 3-3; 6-3.

Modelo de difusión del Derecho a través de Internet: 1-3.

Políticas de empleo: 6-3.

Portal del Ciudadano: 3-3.

Prestaciones de servicios transnacionales: 17-1.

Regímenes de seguridad social: 3-3.

Registros de convenios colectivos: 4-2.

Reglamento del Código del Trabajo: 2-4.

Representantes unitarios: 12-2.

Riesgos profesionales: 3-3.

Salario mínimo interprofesional: 17-4.

Seguridad social complementaria:

Derechos adquiridos: 22-5.

Seguridad y salud laboral: $16-2$.

Sindicatos reconocidos: 11-3.

Traspasos de empresas: 18-3.

Tribunales del Trabajo: 8-2; 10-3.

\section{UNIÓN EUROPEA}

Accidente de trabajo in itinere: 20-1.

Agencia Europea para la Seguridad y la

Salud en el Trabajo: 16-1.

Automaticidad de las prestaciones:

Vertiente ad extra: 21-5.

Vertiente ad intra: $21-5$.

Bolkenstein: 17-1.

«Codificación» de la legislación comunitaria: 3-1.

Comité de Altos Responsables de la Inspección de Trabajo: 7-1.

Comité Económico y Social: 3-1; 18-6.

Comités de empresa europeos: 12-1.

Condiciones de trabajo ad extra: 17-1.

Corte Europea de Derechos Humanos: $5-1 ; 8-5$.

Deslocalizaciones: 18-5.

Despido individual:

Libre con preaviso ad intra: 19-1.

Protección ad extra: 19-1.

Despido colectivo: 3-1; 18-2; 18-7.

Desplazamientos transnacionales: 17-1.
Diálogo social: 4-4.

Dirección General de la Competencia:

Doctrina: 5-1.

Empresas de trabajo temporal: 15-2.

Estabilidad en el empleo:

Ad extra: 14-1.

Falta ad intra: 14-1.

Perspectiva de género: 15-1.

EURES: 6-1.

Eurostat: 16-1.

Exportación de prestaciones: 9-4.

Flexiguridad: 15-2.

Fondo Europeo de Adaptación a la

Globalización: 18-5; 18-6.

Fondo Social Europeo: 18-1.

Huelga:

Doctrina Viking y Laval: 14-1.

Falta de regulación ad extra: 14-1.

Regulación ad intra: 14-1.

Insolvencia del empresario: 18-4.

Jornada de trabajo:

Ad extra: 17-2.

Ad intra: 17-2.

Libertad sindical:

Ad extra: 11-4.

Ad intra: 11-4.

Modelo de difusión del Derecho a través de Internet: 1-4.

NACE: $18-5$.

Negociación colectiva:

Ad extra: 4-4; 13-1.

Ad intra: 4-4; 13-1.

NUTS: $18-5$.

Observatorio Europeo de Relaciones

Laborales: 11-4.

Oficina Europea de Selección de Personal (EPSO): 6-1.

Participación de los trabajadores ad extra: 12-1.

Personal laboral:

Perspectiva de género: 15-1.

Régimen del despido: 19-1.

Tipos: 15-1.

Perspectiva de género:

Igualdad de retribuciones ad extra: 18-1.

Personal laboral ad intra: 15-1.

Programa de acción social: 18-1. 
Registros de convenios colectivos: 4-4.

Salario mínimo ad extra: 17-4.

Seguridad social complementaria:

Derechos adquiridos: 22-2; 22-7.

Seguridad y salud laboral:

Ad extra: 16-1.

Ad intra: 16-1.

Servicio Europeo de Empleo: 6-1.

Traspasos de empresas: 18-3.

Tribunal de Justicia de las Comunidades

Europeas:

Contencioso laboral: 8-5.

Jurisprudencia: 5-1.
Jurisprudencia sobre oficinas públicas de empleo: 6-1.

Jurisprudencia sobre seguridad y salud laboral: 16-2.

Tribunal de la Asociación Europea de Libre Comercio:

Jurisprudencia: 5-1.

Tribunal de la Función Pública:

Contencioso Laboral: 8-5.

Jurisprudencia: 5-1.

Tribunal de Primera Instancia:

Contencioso laboral: 8-5.

Jurisprudencia: 5-1. 


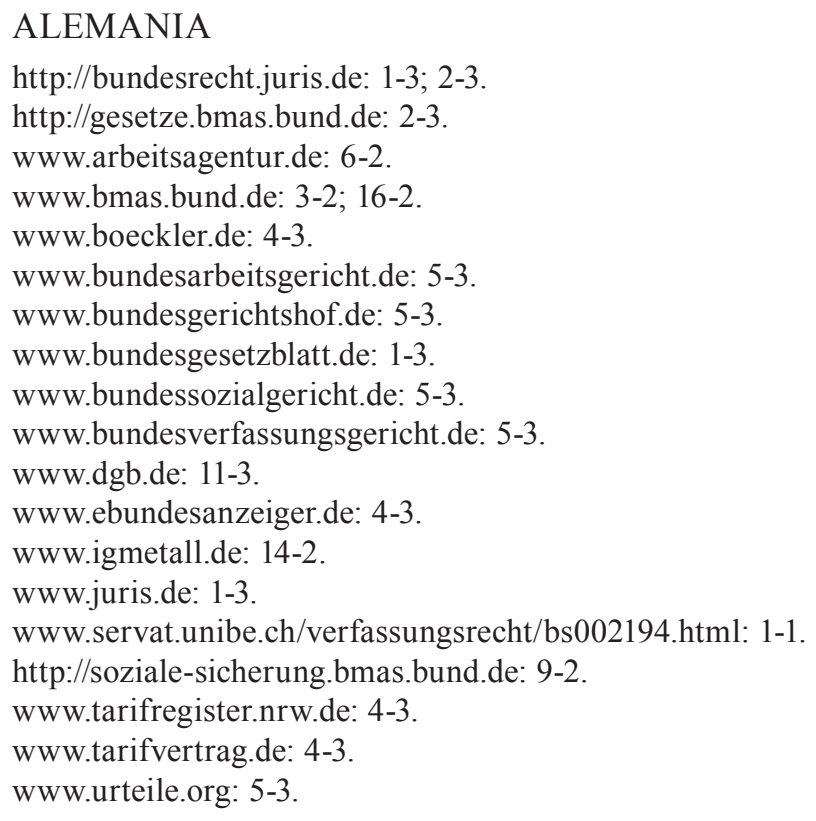

AUSTRIA

www.ris.bka.gv.at: 1-3.

\section{ESPAÑA}

http://cgrl.xunta.es: 4-1.

www.060.es: 1-3; 4-1.

www.boe.es: 1-3.

www.ceflegal.com: 20-1.

www.juntadeandalucia.es/empleo/carl: 4-1.

www.mtas.es/es/sec_trabajo/ccncc/index.htm: 4-1.

* El primer número remite al Tema y el segundo número al epígrafe dentro de dicho Tema, de manera que 3-3 significa Tema 3, §3. 
www.mtin.es: 3-4.

www.poderjudicial.es: 5-2.

www.seg-social.es: 3-4; 9-1.

www.tribunalconstitucional.es: 5-2.

\section{ESTADOS UNIDOS}

http://leg.mt.gov: 19-5.

www.aflcio.org: 11-5.

www.ca.gov: 8-4.

www.ca9.uscourts.gov: 5-5.

www.cacd.uscourts.gov: 5-5.

www.dol.gov: 20-3.

www.dol.gov/esa/minwage/america.htm: 17-5.

www.dol.gov/olms: 4-5.

www.doleta.gov: 6-5.

www.doleta.gov/tradeact: 18-6.

www.edd.ca.gov: 6-5.

www.eeoc.gov: 8-4.

www.findlaw.com/casecode: 5-5.

www.gpoaccess.gov: 1-5.

www.iir.berkeley.edu/library/contracts: 4-5.

www.ilr.cornell.edu/library/kheel/collections/descriptions.html: 4-5.

www.justia.com: 5-5.

www.law.cornell.edu/supct/index.html: 5-5.

www.law.cornell.edu/uscode: 1-5.

www.law.duke.edu/shell/cite.pl?48+Duke+L.+J.+341: 1-1.

www.leginfo.ca.gov: 2-5.

www.legis.state.la.us: 2-5.

www.llrx.com/columns/reference24.htm: 4-5.

www.1lsdc.org/statutes-code: 1-5.

www.nlrb.gov: 5-5.

www.nmb.gov: 4-5.

www.opm.gov: 6-5.

www.opm.gov/Strategic_Management_of_Human_Capital/documents/merit: 6-5.

www.osha.gov: 7-7; 16-3.

www.recovery.gov: 18-6.

www.socialsecurity.gov: 5-5; 9-5.

www.supremecourt.gov: 5-5; 8-4.

www.top100-law.com: 1-3.

www.usajobs.opm.gov: 6-5; 7-7.

www.uscourts.gov: 5-5.

\section{FRANCIA}

Www.courdecassation.fr: 5-2.

www.cram-lr.fr/static/telecharge/entreprises/ristourne_trajet.pdf: 20-2.

www.legifrance.gouv.fr:1-2; 2-2; 19-3. 
www.pole-emploi.fr: 6-3.

www.securite-sociale.fr: 9-2.

www.unedic.org: 6-3.

\section{GRAN BRETAÑA}

www.bailii.org: 5-4.

www.bis.gov.uk: 2-5; 3-5; 17-4.

www.csa.gov.uk: 9-3.

www.dwp.gov.uk: 3-5; 9-3.

www.employmentappeals.gov.uk: 8-3.

www.employmenttribunals.gov.uk: 8-3.

www.hmrc.gov.uk: 9-3.

www.hse.gov.uk: 16-2.

www.jobcentreplus.gov.uk: 6-2; 9-3.

www.justice.gov.uk/civil/procrules_fin/index.htm: 8-3.

www.lrd.org.uk: 4-3.

www.opsi.gov.uk: 1-3.

www.statutelaw.gov.uk: 1-3; 6-2.

\section{INDIA}

http://indiacode.nic.in: 2-5.

\section{INTERNACIONALES}

www.coe.int/socialcharter: 17-4.

www.echr.coe.int: 8-5.

www.eiro.eurofound.eu.int: 11-4; 17-4.

www.etuc.org: 4-4; 11-4.

www.ffpe-bxl.eu: 11-4.

www.ituc-csi.org: 11-4.

\section{ITALIA}

http://coordinamentorsu.it: 5-3; 12-4.

http://gazzettaufficiale.it: 1-3.

www.agenziapiemontelavoro.net: 6-4.

www.arifl.it: 6-4.

www.borsalavoro.it: 6-4.

www.commissionegaranziasciopero.it: 14-3.

www.cortecostituzionale.it: 1-1; 5-3.

www.cortedicassazione.it: 5-3.

www.giurcost.org: 5-3.

www.inail.it: 9-2.

www.inpdap.it: 9-2.

www.inps.it: 9-2.

www.ispesl.it: 16-2.

www.italgiure.giustizia.it: 1-3; 22-5. 
www.italialavoro.it: 6-4.

www.lavoro.gov.it: 3-4; 9-2.

www.normattiva.it: 1-3.

www.portalavoro.regione.lazio.it: 6-4.

www.portalecnel.it: 4-3.

www.regione.lazio.it: 6-4.

\section{PORTUGAL}

http://195.245.197.202: 9-3.

http://bte.gep.mtss.gov.pt: 4-2.

www.dgsi.pt: 5-2.

www.dre.pt: 1-3; 2-4; 4-2.

www.iefp.pt: 6-3.

www.ipq.pt: 16-2.

www.mtss.gov.pt: 2-4; 3-3.

www.netemprego.gov.pt: 6-3.

www.seg-social.pt: 3-3.

\section{UNIÓN EUROPEA}

http://ec.europa.eu/civil_service/about/figures/index_en.htm: 15-2.

http://ec.europa.eu/eures: 6-1.

http://ec.europa.eu/social/main.jsp?catId=326\&langId=es: 18-5.

http://ec.europa.eu/social/main.jsp?catId=329\&langId: 4-4.

http://epp.eurostat.ec.europa.eu: 16-1.

http://eur-lex.europa.eu: 1-4.

http://europa.eu/epso: 6-1.

http://osha.europa.eu: 16-1.

www.eesc.europa.eu: 18-6. 


\section{CITED BIBLIOGRAPHY}

ALONSO GARCÍA, M., La codificación del Derecho del Trabajo, CSIC (Madrid, 1957).

ALONSO OLEA, M., Leyes sindicales británicas. Estudio preliminar, traducción y notas, $2^{\mathrm{a}}$ ed., Instituto de Estudios Sindicales, Sociales y Cooperativos (Madrid, 1967).

ALONSO OLEA, M., La Ley sindical norteamericana de 1959. Traducción, introducción y notas, Consejo Social de la Organización Sindical Española (Madrid, 1960).

ARAGÓN BOMBÍN, «Campaña europea de inspecciones de trabajo sobre el riesgo de caída de altura en la construcción 2003», Prevención, trabajo y salud. Revista del Instituto Nacional de Seguridad e Higiene en el Trabajo, núm. 32 (2004).

ARNULL, A., The European Union and its Court of Justice, Oxford University Press (Oxford, 1999).

ARUFE VARELA, A., «La sentencia del Tribunal Federal alemán de Trabajo de 22 abril 2009, sobre usura salarial. Estudio contextualizador y comparado con el Derecho español, y traducción castellana», Anuario Coruñés de Derecho Comparado del Trabajo-ACDCT, vol. II (2010).

ARUFE VARELA, A., «Dos modelos contrastantes de codificación de la legislación de seguridad social: el continental europeo y el norteamericano», Revista de Derecho Social, núm. 44 (2009).

ARUFE VARELA, A., La igualdad de mujeres y hombres en Alemania. Estudio comparado de la legislación alemana con la legislación española, y traducción castellana, Netbiblo (A Coruña, 2009).

ARUFE VARELA, A., «La implicación de los trabajadores en la sociedad anónima europea: puntos críticos sobre la Ley 31/2006, de 18 de octubre», Actualidad Laboral, núm. (2009).

ARUFE VARELA, A., «El voto particular del Juez Oliver Wendell Holmes, Jr. en el caso Coppage v. Kansas (1915). Un texto jurídico norteamericano clásico contra el despido libre», Anuario Coruñés de Derecho Comparado del Trabajo-ACDCT, vol. I (2009).

ARUFE VARELA, A., «La jurisprudencia del Tribunal de Justicia de las Comunidades Europeas sobre incumplimientos por los Estados miembros de sus deberes de transposición de las Directivas marco y "específicas" en materia de seguridad y salud laboral», Tribuna Social, núm. 221 (2009). 
ARUFE VARELA, A., «El convenio colectivo verbal. Comentario histórico, sistemático y posibilista del artículo 90.1 del Estatuto de los Trabajadores», Revista Española de Derecho del Trabajo, núm. 142 (2009).

ARUFE VARELA, A., «Los equívocos de la jurisprudencia del Tribunal de Justicia de las Comunidades Europeas sobre el principio de automaticidad de las prestaciones. $\mathrm{Su}$ verificación a través del Derecho alemán de la Seguridad Social», Revista del Ministerio de Trabajo y Asuntos Sociales. Derecho social Internacional y Comunitario, núm. 77 (2008).

ARUFE VARELA, A., «El modelo alemán de gestión de las políticas de empleo», en el volumen Estrategia europea, Estado autonómico y política de empleo. XVIII Congreso Nacional de Derecho del Trabajo y de la Seguridad Social, Ministerio de Trabajo e Inmigración (Madrid, 2008).

ARUFE VARELA, A., «La regulación del accidente de trabajo en dos ordenamientos novísimos y codificados de seguridad social: Francia y Alemania», CEF. Trabajo y Seguridad Social, núms. 305-306 (2008).

ARUFE VARELA, A., «"Flexiguridad” laboral danesa y "rigiseguridad” laboral alemana. (La sesgada exigencia del cumplimiento de la directriz de la Unión Europea sobre "flexiguridad" laboral sólo a algunos Estados miembros)», Aranzadi Social, núms. 7/8 (2008).

ARUFE VARELA, A., Estudio comparado de la carrera administrativa de los funcionarios del sistema de Inspección de Trabajo y Seguridad Social en Europa, Servicio de Publicaciones del Ministerio de Trabajo y Asuntos Sociales (Madrid, 2007).

ARUFE VARELA, «La aplicación judicial de la "defensa de 'leyes extranjeras"” regulada en la legislación laboral antidiscriminatoria de los Estados Unidos», Actualidad Laboral, núm. 9 (2007).

ARUFE VARELA, A., «La problemática exigencia de responsabilidades laborales a los sindicatos por actividades huelguísticas de sus afiliados. Un análisis comparado de los ordenamientos español y norteamericano», Relaciones Laborales, núm. 9 (2006).

ARUFE VARELA, A., «El cumplimiento por Italia de las recomendaciones europeas sobre el empleo, a través de la "Reforma Biagi"»), Anuario de Facultade de Dereito da Universidade da Coruña. Revista jurídica interdisciplinar internacional, vol. 10 (2006).

ARUFE VARELA, A., «¿Por qué no se encuentran ni siquiera mencionados en el Estatuto de los Trabajadores los contratos de trabajo comunes y especiales de más rabiosa actualidad?», Foro Galego, núm. 195 (2006).

ARUFE VARELA, A., «Los representantes legales o unitarios "extraestatutarios" de los trabajadores», Revista Española de Derecho del Trabajo, núm. 127 (2005).

ARUFE VARELA, A., «La posición procesal de la Tesorería General de la Seguridad Social en pleitos sobre gestión de prestaciones, tras la Ley 52/2003, de 10 de diciembre», Tribuna Social, núm. 178 (2005).

ARUFE VARELA, A., «La Directiva 80/987/CEE del Consejo, de 20 de octubre de 1980, relativa a la protección de los trabajadores asalariados en caso de insolvencia del empresario», Actualidad Laboral, núm. 18 (2004). 
ARUFE VARELA, A., La denuncia del convenio colectivo, Civitas (Madrid, 2000).

ASH, K., «U.S. reservations to the International Covenant on Civil and Political Rights: credibility maximization and global influence», Northwestern University Journal of International Human Rights, núm. 3 (2005).

BACKMEISTER, T., TRITTIN, W. y MAYER, U., Kündigungsschutzgesetz mit Nebengesetzen, $4^{\mathrm{a}}$ ed., Franz Vahlen (Múnich, 2008).

BADER, P., CREUTZFELDT, M. y FRIEDRICH, H.-F., Kommentar zum Arbeitsgerichtsgesetz, $4^{\mathrm{a}}$ ed., Luchterhand (Munich, 2006).

BARNARD, C., EC Employment Law, Oxford University Press (Oxford, 2000).

BARREIRO GONZÁLEZ, G., «Análisis crítico», en O. VON GIERKE, Las raíces del contrato de servicios (Traducción y comentario crítico del propio G. BARREIRO GONZÁLEZ), Civitas (Madrid, 1989).

BECKER, F. y HILLEBRECHT, W. (Fundadores), KR. Gemeinschaftskommentar zum Kündigungsschutzgesetz undzu sonstigen kündigungsschutzrechtlichen Vorschriften, $9^{a}$ ed., Luchterhand (Colonia, 2009).

BELLOMO, S., «Crisis económica, medidas de protección contra el desempleo, formas de ayuda al empleo y al empresariado: las medidas del legislador italiano en el período 2008-2009» (traducción castellana de J. GÁRATE CASTRO), Tribuna Social, núm. 227 (2009).

BERGER, V., Jurisprudence de la Cour Européenne des Droits de l'Homme, $8^{\mathrm{a}}$ ed., Dalloz (París, 2002).

BISSETT, J., «Reference from coast to coast. Finding U.S. Collective Bargaining Agreements», en www.llrx.com/columns/reference24.htm.

BLANPAIN, R., «Temporary Work and the Law: the EC Directive and Proposals», en R. BLANPAIN (Editor), Temporary Work and Labour Law of the European Community and Member States, Kluwer (Deventer, 1993).

BLASCO PELLICER, A., La responsabilidad empresarial en el pago de prestaciones de seguridad social, Thomson-Aranzadi (Cizur Menor-Navarra, 2005).

BLEY, H., KREIKEBOHM, R. y MARSCHNER, A., Sozialrechr, $8^{\mathrm{a}}$ ed., Luchterhand (Neuwied y Kriftel, 2001).

BOECKEN, W. y JOUSSEN, J., Teilzeit- und Befristungsgesetz. Handkommentar, $2^{\mathrm{a}}$ ed., Nomos (Baden-Baden, 2010).

BORRAJO DACRUZ, E., «¿La ignorancia de la ley laboral excusa de su cumplimiento?», Actualidad Laboral, núm. 3 (1996).

BOWERS, J., A practical approach to Employment Law, $7^{\mathrm{a}}$ ed., Oxford University Press (Oxford, 2005).

BOWERS, J., BROWN, D. y GIBBONS, S., Trade Union Reform and Employment Rights Act 1993: A Practical Guide, Longman (Londres, 1993).

BOWERS, J., BROWN, D. y MANSFIELD, D., Employment Tribunal. Practice \& Procedure, vol. 2, 4⿳a ed., Sweet\&Maxwell (Londres, 2002). 
BRECHT-HEITZMANN, H., «Medidas jurídicas laborales y de seguridad social para la lucha contra la crisis económica en Alemania» (traducción castellana de J. MARTÍNEZ GIRÓN), Tribuna Social, núm. 230 (2010).

BRODIE, D., The employment contract. Legal principles, drafting and interpretation, Oxford University Press (Oxford, 2005).

BÚRCA, G. DE y WEILER, J.H.H. (Editores), The European Court of Justice, Oxford University Press (Oxford, 2001)

CABEZA PEREIRO, J., «Sobre la compensación económica de las vacaciones no disfrutadas. El difícil diálogo entre la jurisprudencia británica y el Tribunal de Justicia de la Unión», Anuario Coruñés de Derecho Comparado del Trabajo-ACDCT, vol. II (2010).

CABEZA PEREIRO, J., El descuento de la cuota sindical, Tirant lo blanch (Valencia, 2002).

CABEZA PEREIRO, J., La buena fe en la negociación colectiva, Escola Galega de Administración Pública (Santiago de Compostela, 1995).

CÁMARA LAPUENTE, S., «Protección jurídica de las bases de datos en Internet (Un ensayo de explicación de Internet desde la normativa sobre la propiedad intelectual de las bases de datos)», en J. CREMADES, M.A. FERNÁNDEZ-ORDÓÑEZ y R. ILLESCAS (Coordinadores), Régimen jurídico de Internet, La Ley (Madrid, 2002).

CARDOZO, B.N., The nature of the judicial process, Yale University Press (New Haven, 1949).

CARLSON, R., «The small firm exemption and the single employer doctrine in employment discrimination Law», St. John's Law Review, vol. 80 (2006).

CARR JR, W.Z., CATHCART, D.A. y KRUSE, S.A., «United States of America», en International Handbook on Contracts of Employment, Kluwer Law International (La Haya, 2000).

CARRIL VÁZQUEZ, X.M., «Breves consideraciones, a la luz del Derecho social de la Unión Europea, sobre las recientes y polémicas medidas de fomento de la contratación indefinida de jóvenes trabajadores en Francia», Anuario da Facultade de Dereito da Universidade da Coruña. Revista Jurídica Interdisciplinar Internacional, vol. 10 (2006).

CARRIL VÁZQUEZ, X.M., «Notas acerca de la Directiva 98/59/CE del Consejo, de 20 julio 1998, sobre despidos colectivos», Actualidad Laboral, núm. 19 (2004).

CARRIL VÁZQUEZ, X.M., Asociaciones sindicales y empresariales de carácter internacional, Comares (Granada, 2003).

CARUSO, B., «Gli esiti della globalizzazione: disintegrazione o trasformazione del diritto del lavoro?», en S. SCARPONI (Coordinadora), Globalizzazione e diritto del lavoro. Il ruolo degli ordinamenti sovranazionali, Giuffrè (Milan, 2001).

CASAS BAAMONDE, $\mathrm{M}^{\mathrm{a}}$.E., «La implicación de los trabajadores en la Sociedad Anónima Europea (Procedimiento de negociación colectiva y diferentes modelos de implicación convenida)», Revista Española de Derecho del Trabajo, núm. 117 (2003). 
CASAS BAAMONDE, Ma'.E., Los desplazamientos temporales de trabajadores en la Unión Europea y en el Espacio Económico Europeo, Civitas (Madrid, 2001).

CASTÁN TOBEÑAS, J., Derecho Civil español, común y foral, Tomo $1^{\circ}$, Volumen $1^{\circ}$, $11^{\mathrm{a}}$ ed., Reus (Madrid, 1975).

CASTRO ARGÜELLES, Ma ${ }^{a}$.A., «Ordenación del tiempo de trabajo (Directiva 2003/88/ CE y otras complementarias)» en J. GARCÍA MURCIA (Director), La transposición del Derecho social comunitario al ordenamiento español, Ministerio de Trabajo y Asuntos Sociales (Madrid, 2005).

CASTRO ARGÜELLES, M ${ }^{\text {a }}$.A., «Seguridad y salud en el trabajo (Directiva 89/391/ CEE y Directivas complementarias)», en J. GARCÍA MURCIA (Director), $L a$ transposición del Derecho social comunitario al ordenamiento español, Ministerio de Trabajo y Asuntos Sociales (Madrid, 2005).

CASTRO ARGÜELlES, Ma.A. y MENÉNDEZ SEBASTIÁN, P., «Igualdad entre varón y mujer en materia de retribución (Directiva 75/117/CEE)», en J. GARCÍA MURCIA (Director), La transposición del Derecho social comunitario al ordenamiento español, Ministerio de Trabajo y Asuntos Sociales (Madrid, 2005).

CATALDI, E., Studi di Diritto della Previdenza Sociale, Giuffré (Milan, 1958).

CHARNOVITZ, S., «The ILO Convention on Freedom of Association and its future in the United States», American Journal of International Law, núm. 102 (2008).

CHAUCHARD, J.-P., Droit de la Sécurité Sociale, $4^{\mathrm{a}}$ ed., LGDJ (Paris, 2005).

CHAUCHARD, J.-P., Manuel de Droit de la Sécurité Sociale, 2a ed., LGDJ (París, 1998).

CINELLI, M., Diritto della Previdenza Sociale, $5^{\text {a }}$ ed., G. Giappichelli (Turín, 2003).

CINELLI, M. y GIUBBONI, S., Il Diritto della sicurezza sociale in trasformazione, Giapichelli (Turín, 2005).

COLINA ROBLEDO, M., RAMÍREZ MARTÍNEZ, J.M. y SALA FRANCO, T., Derecho social comunitario, $2^{\mathrm{a}}$ ed., Tirant lo blanch (Valencia, 1995).

DAS NEVES, I., Lei de Bases da Segurança Social: Comentada e Anotada, Coimbra Editora (Coimbra, 2003).

DAS NEVES, I., Direito da Segurança Social: Principios Fundamentais numa Analise Prospectiva, Coimbra Editora (Coimbra, 1996).

DÄUBLER, W., Arbeitsrecht. Ratgeber für Beruf, Praxis und Studium, $6^{\mathrm{a}}$ ed., BundVerlag (Frankfurt a.M., 2006).

DAVIES, S.L., «The jurisprudente of willfulness: an evolving theory of excusable ignorance», 48 Duke L.J. 341 (a través de www.law.duke.edu/shell/cite. pl?48+Duke+L.+J.+341).

DE ANGELIS, L., Il processo del lavoro nella giurisprudenza e nella dottrina, $2^{\mathrm{a}}$ ed., CEDAM (Padua, 1986).

DE VAL TENA, A.L., La exteriorización de los compromisos por pensiones: el régimen jurídico de la protección de los trabajadores, Thomson-Aranzadi (Cizur Menor-Navarra, 2004).

DEAKIN, S. y MORRIS, G.S., Labour Law, $3^{\mathrm{a}}$ ed., Butterworths (Londres, 2001). 
DEL GIUDICE, F. y MARIANI, F., Diritto Sindacale, 10ª ed., Edizione Giuridiche Simone (Nápoles, 2001).

DELGADO KLOOS, C. y GARCÍA RUBIO, C., «Historia de Internet», en J. CREMADES, M.A. FERNÁNDEZ-ORDÓÑEZ y R. ILLESCAS (Coordinadores), Régimen jurídico de Internet, La Ley (Madrid, 2002).

DIÉGUEZ, G., «"Esquirolaje” interno y otras cuestiones (Comentario a la Sentencia de la Cassazione italiana n. 20164, de 26 septiembre 2007)», Anuario Coruñés de Derecho Comparado del Trabajo, vol. I (2009).

DIÉGUEZ, G., «Huelga y cierre patronal: una recapitulación», Revista del Ministerio de Trabajo y Asuntos Sociales. Derecho del Trabajo, núm. 13 (1998).

DÍEZ-PICAZO, L. y GULLÓN, A., Sistema de Derecho Civil, Volumen 1, 8 a ed., Tecnos (Madrid, 1992).

DÖRNER, K., LUCZAK, S. y WILDSCHÜTZ, M., Handbuch Arbeitsrecht, $4^{\mathrm{a}}$ ed., Luchterhand (Munich, 2004).

DUPEYROUX, J.-J., BORGETTO, M., LAFORE, R. y RUELlAN, R., Droit de la sécurité sociale, $15^{\mathrm{a}}$ ed., Dalloz (Paris, 2005).

EAST, E., Social Security Law, McMillan (Londres, 1999).

EICHENHOFER, E., Sozialrecht, $5^{\mathrm{a}}$ ed., Mohr Siebeck (Tubinga, 2004).

ENRICO, C., Diritto del Lavoro, $2^{\mathrm{a}}$ ed., Giapichelli (Turín, 2004).

EPSTEIN, R.A., «In Defense of the Contract at Will», en D.L. GREGORY (Editor), Labour Law, Dartmouth (Aldershot, 1993).

ESTREICHER, S. Y HARPER, M.C., Cases and Materials on the Law governing the Employment Relationship, $2^{a}$ ed., West Publi. Co. (St. Paul-Minn., 1992).

FAVALLI, G. (Coordinación), Codice di Diritto del Lavoro. Leggi, dottrina e giurisprudenza sul rapporto di lavoro subordinato, $2^{\mathrm{a}}$ ed., La Tribuna (Piacenza, 2004).

FAVALLI, G. y ROTONDI, F., Manuale pratico di diritto del lavoro, $2^{\mathrm{a}}$ ed., CEDAM (Padua, 2005).

FITTING, K., WLOTZKE, O. y WIßMANN, H. (Fundadores), Mitbestimmungsrecht. Mitbestimmungsgesetz, Drittelbeteiligungsgesetz, Wahlordnungen. Mitbestimmung auf europäischer Ebene. Kommentar, $3^{\mathrm{a}}$ ed., Franz Vahlen (Múnich, 2008).

FOSTER, N. y SULE, S. German Legal System and Laws, $3^{\mathrm{a}}$ ed., Oxford University Press (Oxford, 2002).

FURTADO MARTINS, P., «Consequências do Despedimento Ilícito: Indemnização/ Reintegração», en el volumen Código do Trabalho. Alguns aspectos cruciais, Principia (Cascais, 2003).

GALANTINO, L., Diritto del Lavoro, $10^{a}$ ed., G. Giappichelli (Turín, 2000).

GAlAnTINO, L., Diritto Sindacale, $4{ }^{\text {a }}$ ed., G. Giappichelli (Turín, 1993).

GAMILLSCHEG, F., «La cogestión de los trabajadores en el Derecho alemán. Balance a tenor de la Sentencia del Tribunal Constitucional Federal de 1 de marzo de 1979» (traducción castellana de C. MIÑAMBRES PUIG), Revista Española de Derecho del Trabajo, núm. 2 (1980). 
GÁRATE CASTRO, J., «Consideraciones, desde el Derecho español, sobre el daño producido con ocasión del trabajo como elemento del concepto italiano de accidente de trabajo», Anuario Coruñés de Derecho Comparado del Trabajo-ACDCT, vol. I (2009).

GÁRATE CASTRO, J., Los salarios de tramitación. Un estudio de las percepciones salariales unidas a la declaración de improcedencia o nulidad del despido, ACARL (Madrid, 1994).

GARCÍA MURCIA, J., «¿Huelga de un solo trabajador? A propósito de una Sentencia de la Sala de lo Social del Tribunal francés de Casación de 13 de noviembre de 1996», Anuario Coruñés de Derecho Comparado del Trabajo-ACDCT, vol. I (2009).

GARCÍA MURCIA, J., «Introducción», en J. GARCÍA MURCIA (Director), La transposición del Derecho social comunitario al ordenamiento español, Ministerio de Trabajo y Asuntos Sociales (Madrid, 2005).

GARCÍA RUBIO, Ma.A., La inspección de trabajo y Seguridad Social (Doctrina y Jurisprudencia), Tirant lo blanch (Valencia, 1999).

GASPARI, A. y GUADAGNINO, A., Le ispezioni in azienda: obblighi, poteri e tutele dopo il D.Lgs. 124/2004. Ministeri del Lavoro ed Enti Previdenziali: due sistema ispettivi a confronto, Iuridica Editrice (Roma, 2005).

GIUSSANI, A. (Coordinador), Il processo del lavoro. Commentario di giurisprudenza, IPSOA (Milán, 2001).

GÓMEZ ABELLEIRA, F.J., «Cambio de contratista y sucesión de empresa, en especial a la luz de la jurisprudencia del Tribunal de Justicia de las Comunidades Europeas», Actualidad Laboral, núm. 16 (2002).

GÓMEZ ABELLEIRA, F.J., El "Lockout” en el Derecho de los EE.UU. Su Contraste con el Cierre Patronal en el Derecho Español, Cedecs (Barcelona, 1998).

GÓMEZ ABELLEIRA, F., La adhesión al convenio colectivo, Escola Galega de Administración Pública (Santiago de Compostela, 1997).

GONZÁLEZ DEL REY RODRÍGUEZ, I., «Los contratos de trabajo de duración determinada (Directiva 1999/70/CE)», en J. GARCÍA MURCIA (Director), La transposición del Derecho social comunitario al ordenamiento español, Ministerio de Trabajo y Asuntos Sociales (Madrid, 2005).

GONZÁLEZ DEL REY RODRÍGUEZ, I., «Trabajo temporal y prevención de riesgos laborales (Directiva 91/383/CEE)», en J. GARCÍA MURCIA (Director), La transposición del Derecho social comunitario al ordenamiento español, Ministerio de Trabajo y Asuntos Sociales (Madrid, 2005).

GORMAN, R.A., Basic Text on Labor Law. Unionization and Collective Bargaining, West Publ. Co. (St. Paul-Minn., 1976).

GOÑI SEIN, J.L., «El concepto de sucesión de empresa. Divergencias doctrinales entre el Tribunal de Justicia de la Unión Europea y el Tribunal Supremo Español», Anuario Coruñés de Derecho Comparado del Trabajo-ACDCT, vol. II (2010).

GREENHALGH, R., Industrial Tribunals, Law and Employment Series (Londres, 1992). 
GREGORY, D.L., «The Right to Unionize as a Fundamental Human and Civil Right», en D.L. GREGORY (Editor), Labour Law, Dartmouth (Aldershot, 1993).

GUÉRINOT, S., Aller et gagner aux Prud'hommes, $2^{\mathrm{a}}$ ed., DELMAS (Paris, 2004).

HANAU, P. y ADOMEIT, K., Arbeitsrecht, 13 a ed., Luchterhand (Munich, 2005).

HARRIS, N., «The Shape and Characteristics of Social Security Today (including Insurance, Pensions and Means-tests)», en N. HARRIS, Social Security Law in Context, Oxford University Press (Oxford, 2000).

HEINSZ, T.J., NOLAN, D.R. y R. A. BALES, Labor Law. Collective Bargaining in a Free Society, $6^{\mathrm{a}}$ ed., Thomson-West (St. Paul-Minn., 2009).

HELML, E., Arbeitsrecht, 8 a ed., C.H. Beck (Munich, 2004).

HENNIG, W. y otros, Sozialgerichtsgesetz. Kommentar mit Nebenrecht, Tomo 1, Luchterhand (Neuwied, 2004).

HOLLAND, J. y BURNETT, S., Employment Law, Oxford University Press (Oxford, 2005).

HONEYBALL, S. y BOWERS, J., Textbook on Labour Law, $8^{\text {a }}$ ed., Oxford University Press (Oxford, 2004).

INNS OF COURT SCHOOL OF LAW (CITY UNIVERSITY, LONDON), Employment Law in Practice, $6^{\mathrm{a}}$ ed., Oxford University Press. (Oxford, 2004).

JENKINS, M., POORE, M., DOODS, H., BAIG, A., HAINSWORTH, K., BYERS, K., BRABBS, D., ABEYSEKERA, P. y DON, D., Blackstone's Guide to Pensions Act 2004, Oxford University Press (Oxford, 2005).

JONES JR., J.E., MURPHY, W.P. y BELTON, R., Discrimination in employment, $5^{\mathrm{a}}$ ed., West Publ. Co. (St. Paul-Minn., 1987).

JUNKER, A., Grundkurs Arbeitsrecht, $5^{\text {a }}$ ed., C.H. Beck (Munich, 2006).

KAHN-FREUND, O., Labour and the law, $2^{\mathrm{a}}$ ed., Stevens \& Sons (Londres, 1977).

KEMPEN, O.E. y ZACHERT, U. (Editores), Tarifvertragsgesetz, $4^{\mathrm{a}}$ ed., Bund-Verlag (Frankfurt am Maine, 2006).

KESSLER, F., Droit de la protection sociale, $2^{\mathrm{a}}$ ed., Dalloz (Paris, 2005).

KITTNER, M., DÄUBLER, W. y ZWANZIGER, B. (Editores), KSchR. Kündigungsschutzrecht, $7^{\mathrm{a}}$ ed., Bund (Frankfurt a.M, 2008).

KOCHER, E., «Requisitos de la demanda y objeto del litigio en el ejercicio de una pretensión de conflicto colectivo sobre cesación de negociaciones individuales en masa violadoras del convenio colectivo» (traducción al castellano de A. ARUFE VARELA), Anuario da Facultade de Dereito da Universidade da Coruña. Revista Jurídica Interdisciplinar Internacional, vol. 10 (2006).

KOKEMOOR, A. y KREISSL, S., Arbeitsrecht, $3^{\mathrm{a}}$ ed., Boorberg (Stuttgart, 2006).

KUMMER, P., Das Sozialgerichtliche Verfahren, $2^{\mathrm{a}}$ ed., Luchterhand (Munich, 2004).

LACHWITZ, K., SCHELLHORN, W. y WELTI, F., HK-SGB IX. Handkommentar zum Sozialgesetzbuch IX. Rehabilitation und Teilhabe behinderter Menschen, $3^{\mathrm{a}}$ ed., Luchterhand (Colonia, 2010). 
LESLIE, D.L., Labor Law. In a nutshell, 4ª ed., West Group (St. Paul-Minn., 2000).

LiTTLE, J.W., EATON, T.A. y SMITH, G.R., Workers' Compensation. Cases and materials, $3^{\text {a }}$ ed., West Publ. Co. (St. Paul-Minn., 1993).

MARIUCCI, L., Le fonti del Diritto del Lavoro. Quindici anni dopo, G. Giappichelli (Turín, 2003).

MARTÍN PUEBLA, E., La reducción del tiempo de trabajo en Francia, Ministerio de Trabajo y Asuntos Sociales (Madrid, 2006).

MARTÍN VALVERDE, A., «Huelga ilícita y despido en el Derecho del Trabajo alemán», Revista de Política Social, núm. 96 (1972).

MARTÍNEZ GIRÓN, «El caso Engquist v. Oregon Department of Agriculture et al. (2008). La última palabra de la Corte Suprema de los Estados Unidos en favor del despido libre», Anuario Coruñés de Derecho Comparado del Trabajo-ACDCT, vol. II (2010).

MARTÍNEZ GIRÓN, J., «Tipología y eficacia de los acuerdos marco negociados entre la Comisión Europea y las organizaciones sindicales y profesionales representativas de su personal», Aranzadi Social, núm. 6 (2009).

MARTÍNEZ GIRÓN, J., «El Derecho de la Unión Europea y el principio de automaticidad de las prestaciones», Actualidad Laboral, núm. 3 (2009).

MARTÍNEZ GIRÓN, J., «Las mutuas patronales alemanas de accidentes de trabajo y su gestión "especializada" de los riesgos profesionales», en el vol. La gestión del sistema de Seguridad Social, Laborum (Murcia, 2009).

MARTÍNEZ GIRÓN, J., «El género doctrinal “comentarios” en el Derecho alemán. A propósito del "Comentario Erfurtense" sobre Derecho alemán del Trabajo», Revista Española de Derecho del Trabajo, núm. 141 (2009).

MARTÍNEZ GIRÓN, J., «Los estatutos de la Federación Alemana de Sindicatos (Deutscher Gewerkchaftsbund). Comparación contextualizadora con los estatutos confederales de Comisiones Obreras y de la Unión General de Trabajadores, y traducción castellana», Anuario Coruñés de Derecho Comparado del TrabajoACDCT, vol. I (2009).

MARTÍNEZ GIRÓN, J., «La publicidad del convenio colectivo en el Derecho del Trabajo alemán», Revista de Derecho Social, núm. 42 (2008).

MARTÍNEZ GIRÓN, J., «El modelo norteamericano de codificación de la legislación de Seguridad Social», en el vol. V Congreso Nacional de la Asociación Española de Salud y Seguridad Social. La Seguridad Social en el siglo XXI, Laborum-AESSS (Murcia, 2008).

MARTÍNEZ GIRÓN, J., «El accidente de trabajo en el Derecho de los Estados Unidos de Norteamérica y en el de la Unión Europea», en E. BORRAJO DACRUZ (Director), Accidentes de Trabajo y Mutuas, La Ley-FREMAP (Madrid, 2008).

MARTÍNEZ GIRÓN, J., «La readmisión del trabajador despedido en el Derecho alemán del Trabajo», Revista Española de Derecho del Trabajo, núm. 135 (2007). 
MARTÍNEZ GIRÓN, J., «La negociación colectiva extraestatutaria», Revista del Ministerio de Trabajo y Asuntos Sociales-Derecho del Trabajo, núm. 68 (2007).

MARTÍNEZ GIRÓN, J., «La regulación de la "defensa de 'leyes extranjeras"” en la legislación laboral antidiscriminatoria de los Estados Unidos», Actualidad Laboral, núm. 10 (2007).

MARTÍNEZ GIRÓN, J., «Las normas estructurales complementarias de la Ley actualmente vigente en Alemania en materia de protección contra el despido», Anuario da Facultade de Dereito da Universidade da Coruña. Revista Jurídica Interdisciplinar Internacional, vol. 10 (2006).

MARTÍNEZ GIRÓN, J., «El contenido social del Tratado por el que se instituye una Constitución para Europa», Actualidad Laboral, núm. 18 (2004).

MARTÍNEZ GIRÓN, J., «Estudo Comparativo do Projecto Português de Código do Trabalho de 2002 e da Legislação Laboral Espanhola Vigente - Restrições à Celebração de Contratos de Trabalho a Termo», en el volumen Código do Trabalho. Alguns aspectos cruciais, Principia (Cascais, 2003).

MARTÍNEZ GIRÓN, J., Los pleitos de Derecho privado sobre esclavitud ultramarina en la jurisprudencia del Tribunal Supremo (1857-1891), Civitas (Madrid, 2002).

MARTÍNEZ GIRÓN, J., «La Directiva comunitaria sobre seguridad e higiene en el trabajo en las empresas de trabajo temporal», en el vol. IV Xornadas Galegas sobre Condicións de Traballo e Saúde, Fundación Caixa Galicia (Ferrol, 1994).

MARTÍNEZ GIRÓN, J., «La huelga laboral: experiencias inglesa y norteamericana», Actualidad Laboral, núm. 39 (1992).

MARTÍNEZ GIRÓN, J., «El despido en los Estados Unidos e Inglaterra», en el vol. Estudios sobre el despido disciplinario, 2a ed., ACARL (Madrid, 1992).

MARTÍNEZ GIRÓN, J., «La negociación colectiva en Inglaterra y en los Estados Unidos», Documentación Laboral, núm. 31 (1990).

MARTÍNEZ GIRÓN, J., El despido en el Derecho de los Estados Unidos, Civitas (Madrid, 1988).

MARTÍNEZ GIRÓN, J., «Las elecciones sindicales en los Estados Unidos», Revista de Política Social, núm. 148 (1985).

MARTÍNEZ GIRÓN, J., «El incumplimiento del convenio colectivo en la jurisprudencia federal norteamericana», Revista Española de Derecho del Trabajo, núm. 16 (1983).

MARTÍNEZ GIRÓN, J. y ARUFE VARELA, A., «The right to access of the nonemployee union organizers (das Zugangsrecht durch betriebsfremde Gewerkschaftsbeauftragte) to the premises of the enterprise. A comparative analysis of the German, Spanish and Federal North American case law», en T. DIETERICH, M. LE FRIANT, L. NOGLER y K. KEZUKA (Editores), Individuelle und kollektive Freiheit im Arbeitsrecht. Gedächtnisschrift für Ulrich Zachert, Nomos (Baden-Baden, 2010).

MARTÍNEZ GIRÓN, J. y ARUFE VARELA, A., «Federalismo y distribución de competencias normativas en materia de Prevención de Riesgos Laborales: los modelos Norteamericano, Alemán y Español», Aranzadi Social, núm. 21 (2010). 
MARTÍNEZ GIRÓN, J. y ARUFE VARELA, A., El salario mínimo en Alemania. Un estudio comparado entre regímenes de salarios mínimos profesionales (alemanes) e interprofesionales legales (norteamericano y europeos), Netbiblo (A Coruña, 2009).

MARTÍNEZ GIRÓN, J. y ARUFE VARELA, A., Leyes laborales alemanas. Estudio comparado y traducción castellana, Netbiblo (A Coruña, 2007).

MARTÍNEZ GIRÓN, J., ARUFE VARELA, A. y CARRIL VÁZQUEZ, X.M., Derecho del Trabajo, $2^{\mathrm{a}}$ ed., Netbiblo (A Coruña, 2006).

MARTÍNEZ GIRÓN, J., ARUFE VARELA, A. y CARRIL VÁZQUEZ, X.M., Derecho de la Seguridad Social, $2^{\text {a }}$ ed., Netbiblo (A Coruña, 2008).

MARTÍNEZ MORENO, C., «Los traspasos de empresas (Directiva 2001/23/CE y normas precedentes)», en J. GARCÍA MURCIA (Director), La transposición del Derecho social comunitario al ordenamiento español, Ministerio de Trabajo y Asuntos Sociales (Madrid, 2005).

MARTINON, A., Essai sur la stabilité du contrat de travail à durée indéterminée, Dalloz (Paris, 2005).

McKINNEY, R.J., «Basic overwiew on how federal laws are published, organized and cited», accesible a través de www.llsdc.org/sourcebook/statutes-code.htm.

McCORMICK, H.L., Social Security. Claims and Procedures, vol. I, $4^{\mathrm{a}}$ ed., West Publ. Co. (St. Paul-Minn., 1991).

McCORMICK, H.L., Social Security. Claims and Procedures, vol. II, $4^{\mathrm{a}}$ ed., West Publ. Co. (St. Paul-Minn., 1991).

MERRIFIELD, L.S., «La participación del trabajador en las decisiones de las empresas» (traducción castellana de J. MARTÍNEZ GIRÓN), Revista Española de Derecho del Trabajo, núm. 12 (1982).

MiGUÉLEZ DOMÍNGUEZ, L., ALONSO MORÁN, S. y CABEROS DE ANTA, M., Código de Derecho Canónico y Legislación Complementaria. Texto latino y versión castellana, con jurisprudencia y comentarios, BAC (Madrid, 1974).

MIRANDA BOTO, J.M., «El papel de la autonomía colectiva en la transposición de directivas», Aranzadi Social, núm. 21 (2003).

MINONDO SANZ, J., Fundamentos de la inspección de trabajo y seguridad social, Ministerio de Trabajo y Asuntos Sociales (Madrid, 2000).

MONEREO PÉREZ, J.L. y FERNÁNDEZ BERNAT, J.A., Las especificaciones de los planes de pensiones del sistema de empleo. Un estudio técnico de la experiencia negociadora, Comares (Granada, 2004).

MONEREO PÉREZ, J.L., FERNÁNDEZ AVILÉS, J.A., GARCÍA VALVERDE, M. ${ }^{\text {a D. }}$ y MALDONADO MOLINA, J.A., La Participación de los Trabajadores en las Sociedades Anónimas y Cooperativas Europeas. Estudio sistemático y crítico de la Ley 31/2006, de 18 de octubre, Thomson-Aranzadi (Cizur Menor-Navarra, 2007).

MONTANOS FERRÍN, E. y SÁNCHEZ-ARCILlA, J., Historia del Derecho y de las Instituciones, Tomo III, Dykinson (Madrid, 1991).

MONTEIRO FERNANDES, A., Direito do Trabalho, $15^{\mathrm{a}}$ ed., Almedina (Coimbra, 2010). 
MONTEIRO FERNANDES, A., «Notas sobre la jurisprudencia del trabajo en Portugal» (traducción castellana de J. MARTÍNEZ GIRÓN), Anuario Coruñés de Derecho Comparado del Trabajo-ACDCT, vol. II (2010).

MONTOYA MELGAR, A., «Introducción», Revista de la Facultad de Derecho de la Universidad Complutense, núm. 17 [monográfico sobre «El derecho de huelga. Seminario Hispano-Alemán en honor de los Profesores Manuel Alonso Olea y Franz Gamillscheg»] (1993).

MONTOYA MELGAR, A., Leyes sindicales francesas. Estudio preliminar, traducción y notas, Instituto de Estudios Sindicales, Sociales y Cooperativos (Madrid, 1968).

MONTOYA MELGAR, A., GALIANA MORENO, J.M ${ }^{\mathrm{a}}$. y SEMPERE NAVARRO, A.V., Instituciones de Derecho social europeo, Tecnos (Madrid, 1988).

MOREIRA, A.J. y GÁRATE CASTRO, J., «Las recientes medidas laborales anticrisis en Portugal» (traducción castellana de Y. MANEIRO VÁZQUEZ y J. GÁRATE CASTRO), Tribuna Social, núm. 228 (2009).

MORIN, M.-L., Le droit des salariés à la négociation collective principe général du droit, LGDJ (Paris, 1994).

MÜLLER-GLÖGE, R., PREIS, U. y SCHMIDT, I. (Editores), Erfurter Kommentar zum Arbeitsrecht, 10ª ed., C.H. Beck (Múnich, 2010).

NETTER, F., La Sécurité sociale et ses principes, Dalloz (Paris, 2005).

NOGLER, L., La regulación de los despidos individuales en la época del equilibrio entre los «principios» constitucionales. Estudio a la luz del ordenamiento italiano (traducción castellana de A. ARUFE VARELA), Netbiblo (A Coruña, 2010).

PANSIER, F.-J., Droit du Travail, $2^{\mathrm{a}}$ ed., Litec (Paris, 2000).

PANSIER, F.-J., Droit du travail. Relations individuelles et collectives, Litec (París, 2005).

PÉLISSIER, J., LYON-CAEN, A., JEAMMAUD, A. y DOCKÈS, E., Les grands arrêts du Droit du Travail, $3^{\mathrm{a}}$ ed., Dalloz (París, 2004).

PÉliSSIER, J., SUPIOT, A., y JEAMMAUD, A., Droit du travail, 24a ed., Dalloz (París, 2008).

PELLET, R., Leçons de droit social, Dalloz (Paris, 2005).

PERA, G. y PAPALEONI, M., Diritto del Lavoro, $7^{\mathrm{a}}$ ed., CEDAM (Padua, 2003).

PÉREZ DE LOS COBOS ORIHUEL, F., «Aporías de la negociación colectiva europea», en F. PÉREZ DE LOS COBOS y J.M. GOERLICH (Coordinadores), El régimen jurídico de la negociación colectiva en España, Tirant lo Blanch (Valencia, 2006).

PERSIANI, M., Diritto della Previdenza Sociale, 14ª ed., CEDAM (Padua, 2005).

PERSIANI, M., «Il problema della rappresentanza e della rappresentatività del sindacato in una democrazia neo-corporata», en su Diritto del Lavoro, CEDAM (Padua, 2004).

PERSIANI, M., Diritto Sindacale, $7^{\mathrm{a}}$ ed., CEDAM (Padua, 2000).

PESSI, R., Lezioni di Diritto della Previdenza Sociale. II. Profili Storici, $4^{\mathrm{a}}$ ed., CEDAM (Padua, 2005). 
PESSI, R., Lezioni di Diritto della Previdenza Sociale. III. Parte Speciale, $4^{\mathrm{a}}$ ed., CEDAM (Padua, 2005).

PESSI, R., Lezioni di Diritto della Previdenza Sociale. Parte Generale, $3^{\mathrm{a}}$ ed., CEDAM (Padua, 2004).

PETRUCCI, A. y SABATO, V., Il sistema pensionistico italiano, Cacucci (Bari, 2004).

PIC, P., Traité élémentaire de législation industrielle. Les lois ouvrières, $6^{\mathrm{a}}$ ed., Rousseau \& Cie. (París, 1931).

PIEPER, R., ArbSchR. Arbeitsschutzrecht. Arbeitsschutzgesetz, Arbeitssicherheitsgesetz und andere Arbeitsschutzvorschriften, $4^{\mathrm{a}}$ ed., Bund Verlag (Frankfurt a.M., 2009).

PIETERS, D., «Reflexiones sobre la metodología de la comparación en Derecho de la Seguridad Social» (traducción castellana de J. MARTÍNEZ GIRÓN), Anuario Coruñés de Derecho Comparado del Trabajo-ACDCT, vol. II (2010).

PLAYER, M.A., Employment discrimination Law, West Publ. Co. (St. Paul-Minn., 1988).

PRÉTOT, X., Les grands arrêts du Droit de la Sécurité Sociale, 2a ed., Dalloz (París, 1998).

REICHOLD, H., Arbeitsrecht, $2^{\mathrm{a}}$ ed., C.H. Beck (Munich, 2006).

RICHARDI, R. (Editor), Betriebsverfassungsgesetz mit Wahlordnung, 11 ${ }^{\mathrm{a}}$ ed., C.H. Beck (Múnich, 2008).

RICHTHOFEN, W. VON, Labour Inspection. A Guide to the Profession, OIT (Ginebra, 2002)

RODRÍGUEZ MARTÍN-RETORTILLO, R.Mª, «Convenio OIT núm. 187/2006, sobre el marco promocional para la seguridad y salud en el trabajo: razones de su previsible ratificación por España», Actualidad Laboral, núm. 5 (2009).

ROLFS, C., GIESEN, R., KREIKEBOHM, R. y UDSCHING, P. (Editores), Arbeitsrecht, C.H. Beck (Múnich, 2008).

ROMANO MARTÍNEZ, P., Direito do Trabalho, Almedina (Coimbra, 2002).

ROMANO MARTÍNEZ, P., MONTEIRO, L.M., VASCONCELOS, J., MADEIRA DE BRITO, P., DRAY, G. y GONÇALVES DA SILVA, L., Código do Trabalho. Anotado, $4^{\mathrm{a}}$ ed., Almedina (Coimbra, 2005).

RON LATAS, R.P., Los sindicatos horizontales, Comares (Granada, 2003).

ROSSI, F.P., La previdenza sociale, $7^{\mathrm{a}}$ ed., CEDAM (Padua, 2000).

ROTHSTEIN, M.A., Occupational Safety and Health Law, $3^{\mathrm{a}}$ ed., West Publ. (St. Paul- Minn., 1990).

ROTHSTEIN, M.A., CRAVER, C.B., SCHROEDER, E.P., SHOBEN, E.W. y VANDERVELDE, L.S., Employment Law, West Publ. Co. (St. Paul-Minn., 1994).

SACHS, M. (Editor), GG. Grundgesetz Kommentar, $5^{\text {a }}$ ed., C.H. Beck (Múnich, 2009).

SÄCKER, F.J. (Editor), Kollektives Arbeitsrecht. Case by case, Recht und Wirtschaft (Frankfurt am Maine, 2006).

SAINSBURY, R., «Social Security Decision Making and Appeals», en N. HARRIS, Social Security Law in Context, Oxford University Press (Oxford-Nueva York, 2000). 
SANTORO, C., I Contratti "Erga Omnes", Gruppo Cooperativistico Editoriale (Salerno, 1994).

SANTORO-PASSARELLI, G., Diritto dei Lavori, G. Giappichelli (Turín, 2004).

SAVATIER, J., «Contentieux de l'assurance chômage», Droit Social, núm. 12 (2000).

SCHELLHORN, H., SGB XI - Pflegeversicherung. Textausgabe des Sozialgesetzbuches -Elftes Buch -. Soziale Pflegeversicherung mit einer systematischen Einführung, $4^{\mathrm{a}}$ ed., Luchterhand (Munich, 2005).

SCHELLHORN, W., SGB XII - Sozialhilfe. Textausgabe des SozialgesetzbuchesZwölftes Buch - (SGB XII). Sozialhilfe mit einer systematischen Einführung, 12a ed., Luchterhand (Munich, 2005).

SCHERMERS, H.G. y WAELBROECK, D.F., Judicial Protection in the European Union, $6^{\text {a }}$ ed., Kluwer Law International (La Haya, 2001).

SCHLIEMANN, H., ArbZG. Kommentar zum Arbeitszeitgesetz mit Nebengesetzen, Luchterhand (Colonia, 2009).

SCHULIN, B., «Introducción», en el volumen Sozialgeseztbuch, 33ª ed., Beck (Munich, 2006).

SCHULIN, B., e IGL, G., Sozialrecht, 6ª ed., Werner Verlag (Düsseldorf, 1999).

SELWYN, N.M., Law of Employment, 13 ${ }^{\mathrm{a}}$ ed., LexisNexis-Butterworths (Londres, 2004).

SEMPERE NAVARRO, A.V. y CARDENAL CARRO, M., Transposición de la Directiva Marco de Seguridad Laboral en diferentes países de Europa, Fundación Mapfre (Madrid, 2000).

SENNE, P., Arbeitsrecht. Das Arbeitsverhältnis in der betrieblichen Praxis, $3^{\mathrm{a}}$ ed., Luchterhand (Munich, 2004).

SERRANO CARVAJAL, J., «La codificación del Derecho del Trabajo en España», Revista de Política Social, núm. 135 (1982).

STONE, J.H., «The International Covenant on Civil and Political Rights and the United States reservations: the American conception of International human rights», U.C. Davis Journal of International Law and Policy, núm. 7 (2001).

STRELITZ, P.J., AVILES, A.M. y WALTER, D., «Employment-at-will: has the death knell officially sounded», International HR Journal, núm. 17 (2008).

SUPPIEJ, G., DE CRISTOFARO, M. y CESTER, C., Diritto del Lavoro. Il rapporto individuale, $2^{\mathrm{a}}$ ed., CEDAM (Padua, 2003).

SWIFT, K.R., «The public policy exception to employment at-will: time to retire a noble warrior», Mercer Law Review, núm. 61 (2010).

TAYLOR, B.J. y WITNEY, F., Labor Relations Law, $6^{\mathrm{a}}$ ed., Prentice Hall (Englewood Cliffs-New Jersey, 1992).

TEYSSIÉ, B., Droit Européen du Travail, Litec (Paris, 2001).

TURSI, A. y VARESI, P.A., Lineamenti di Diritto del Lavoro. Rapporti di lavoro e relazioni sindacali nel settore privato, $3^{\mathrm{a}}$ ed., Kluwer-Ipsoa (s.1., 2004). 
UPEX, R., BENNY, R. y HARDY, S., Labour Law, $1^{\text {a }}$ ed., Oxford University Press (Oxford, 2004).

VALlEBONA, A., Istituzioni di Diritto del Lavoro. II. Il rapporto di lavoro, $4^{\mathrm{a}}$ ed., CEDAM (Padua, 2004).

VÁZQUEZ GONZÁLEZ (Coordinador), I., La Inspección de Trabajo y Seguridad Social, Aranzadi (Pamplona, 1999).

VERKINDT, P.-Y., Le Droit du Travail, Dalloz (Paris, 2005).

VILLEBRUN, J. y QUÉTANT, G.-P., Traité de la jurisdiction prud'homale, $3^{\mathrm{a}}$ ed., LGDJ (Paris, 1998).

VILLEBRUN, J. y QUÉTANT, G.-P., Les jurisdictions du Travail en Europe, LGDJ (Paris, 1992).

WALTERMAN, R., Sozialrecht, $5^{\text {a }}$ ed., C.F. Müller (Heidelberg, 2005).

WEBER, J.-F., «Comprendre un arrêt de la Cour de Cassation rendu en matière civile», Bulletin d'Information de la Cour de Cassation, núm. 702 (2009).

WIEDEMANN, H., Tarifvertragsgesetz mit Durchfürungs- und Nebenvorschriften, $7^{\mathrm{a}}$ ed., C.H. Beck (Múnich, 2007).

WITTERSTÄTTER, K., Soziale Sicherung. Eine Einführung für Sozialarbeiter/ Sozialpädagogen mit Fallbeispielen, $6^{\mathrm{a}}$ ed., Luchterhand (Munich, 2003).

WOLLET, D.H., GRODIN, J.R. y WEISBERGER, J.M., Collective bargaining in public employment, West Publ. Co. (St. Paul-Minn., 1993).

WRIGHT, C.A., Law of Federal Courts, West Publ. Co. (St. Paul-Minn., 1983).

XAVIER, B.G.L., Curso de Direito do Trabalho. I. Introdução, quadros organizacionais e fontes, $3^{\mathrm{a}}$ ed., Verbo (Lisboa, 2004).

XAVIER, B.G.L., Direito do Trabalho. Ensinar e investigar, Universidade Católica Editora (Lisboa, 2005).

XAVIER, B.G.L., "Collective Bargaining in Portugal», en el vol. Collective Bargaining in Europe, Ministerio de Trabajo y Asuntos Sociales (Madrid, 2004).

ZACHERT, U., «La eficacia de los convenios colectivos en Alemania» (traducción castellana de A. ARUFE VARELA), Anuario Coruñés de Derecho Comparado del Trabajo-ACDCT, vol. II (2010).

ZACHERT, U., «La jurisprudencia laboral en Alemania», Anuario Coruñés de Derecho Comparado del Trabajo-ACDCT, vol. I (2009).

ZACHERT, U., Beendigungstatbestände im internationalen Vergleich. Eine normative und empirische Bestandsaufnahme, Nomos (Baden-Baden, 2004).

ZACHERT, U., "Collective bargaining in Germany», en el vol. Collective bargaining in Europe, Ministerio de Trabajo y Asuntos Sociales (Madrid, 2004).

ZACHERT, U., «Los derechos fundamentales de los trabajadores en la Carta Europea de Derechos Fundamentales», Temas Laborales, núm. 65 (2002). 
ZACHERT, U., Lecciones de Derecho del Trabajo alemán (traducción castellana de F. MARTÍN RODRÍGUEZ y N. MENDOZA NAVAS), Ministerio de Trabajo y Asuntos Sociales (Madrid, 1998).

ZACHERT, U., MARTÍNEZ GIRÓN, J. y ARUFE VARELA, A., Los grandes casos judiciales del Derecho alemán del Trabajo. Estudio comparado con el Derecho español y traducción castellana, Netbiblo (A Coruña, 2008). 
